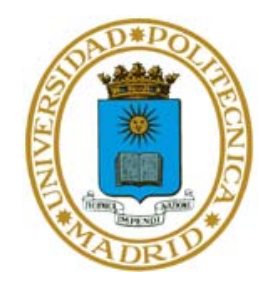

\author{
UNIVERSIDAD POLITÉCNICA DE MADRID \\ ESCUELA TÉCNICA SUPERIOR DE INGENIEROS DE \\ CAMINOS, CANALES Y PUERTOS
}

\title{
REQUISITOS DE SEGURIDAD ESTRUCTURAL BASADOS EN LOS RIESGOS PARA LAS PERSONAS
}

TESIS DOCTORAL

\section{Peter TANNER}

Master of Science ETH Zürich, Suiza 

DOCTORADO EN INGENIERÍA DE ESTRUCTURAS, CIMENTACIONES Y MATERIALES

ESCUELA TÉCNICA SUPERIOR DE INGENIEROS DE CAMINOS, CANALES Y PUERTOS

\title{
REQUISITOS DE SEGURIDAD ESTRUCTURAL BASADOS EN LOS RIESGOS PARA LAS PERSONAS
}

TESIS DOCTORAL

\author{
Autor \\ Peter TANNER \\ Master of Science ETH Zürich, Suiza
}

Director

Luis ALBAJAR MOLERA

Doctor Ingeniero de Caminos, Canales y Puertos 


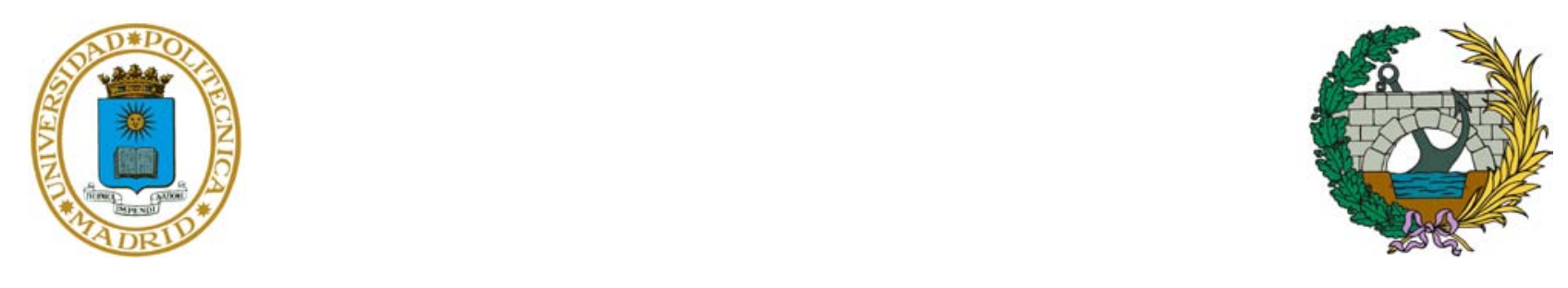

TESIS DOCTORAL

\section{REQUISITOS DE SEGURIDAD ESTRUCTURAL BASADOS EN LOS RIESGOS PARA LAS PERSONAS}

\section{Peter TANNER}

Master of Science ETH Zürich, Suiza

Tribunal nombrado por el Magnífico y Excelentísimo Sr. Rector de la Universidad Politécnica de Madrid, el día de de 2016 para juzgar la Tesis Doctoral arriba citada, compuesto de la siguiente manera:

Presidente/a:

Vocal:

Vocal:

Vocal:

Vocal Secretario/a:

Acuerda otorgarle la calificación de: 



\section{A mis padres y a Elena}





\section{RESUMEN}

Según los procedimientos habituales de la ingeniería, en el marco del dimensionado de las estructuras nuevas o la evaluación de las existentes, la verificación del cumplimiento de los requisitos de seguridad estructural se lleva a cabo mediante unos métodos que no permiten cuantificar los riesgos asociados con los sistemas analizados. Además, los riesgos implícitamente aceptados a través de la aplicación de estos métodos y requisitos pueden estar afectados por grandes dispersiones. En este contexto, los métodos explícitos de análisis de riesgos presentan importantes ventajas para abordar los problemas relacionados con la seguridad estructural. No obstante, todavía existen impedimentos técnicos y administrativos que dificultan su implementación.

El presente estudio aborda el desarrollo de herramientas y criterios racionales para la aplicación práctica de los métodos explícitos. Se establece un procedimiento para cuantificar los riesgos para las personas, asociados con las estructuras. Está basado en la determinación de las probabilidades de fallo de los elementos resistentes del sistema analizado y de las pérdidas esperadas de vidas humanas en caso de producirse estos eventos. El procedimiento se aplica a un conjunto representativo de estructuras de edificación que se ajustan a la mejor práctica actual. A partir de los resultados obtenidos, se deducen unos criterios de aceptación de los riesgos para las personas, asociados con las estructuras de edificación. Estos criterios constituyen una base racional para la adopción de decisiones en la ingeniería estructural. Pueden emplearse a efectos de un análisis de riesgos explicito, o como base para la calibración consistente de los modelos usados en la práctica diaria para la verificación de la seguridad estructural, en el marco del denominado método de los coeficientes parciales adoptado por la mayoría de las normas actuales.

\section{SUMMARY}

In routine engineering practice, the risks associated with safety considerations addressed when designing new or assessing existing structures are not quantified and the corresponding acceptance criteria may diverge widely. While the use of explicit risk analysis methods to quantify structural safety would therefore deliver significant benefits, the implementation of such methods is hindered by a series of technical and administrative obstacles.

The present study explores tools and rational criteria for the practical application of explicit risk analysis methods. Structure-related risks to persons are established on the grounds of the probability of structural failure and its consequences in terms of loss of human life. The procedure adopted is applied to a representative set of building structures which are in compliance with current best practice. Acceptance criteria for risks to persons associated with such structures are deduced from the findings. These criteria provide a rational basis for decision-making in structural engineering. They may be used in explicit risk analysis or as a basis for the consistent calibration of simplified models for determining partial factors in the design of new or the assessment of existing structures.

\section{RÉSUMÉ}

Les méthodes utilisées dans la pratique de l'ingénierie pour vérifier par le calcul la sécurité structurale, lors du dimensionnement d'une structure porteuse nouvelle ou de l'évaluation d'une 
structure existante, ne permettent pas de quantifier les risques associés avec le système analysé. En outre, par l'utilisation de ces méthodes et critères de vérification, les risques implicitement acceptés peuvent varier largement. Tandis que les méthodes explicites d'analyse de risques apporteraient des avantages importants dans la prise de décision concernant la sécurité structurale, leur mise en œuvre est entravée par une série d'obstacles techniques et administratifs.

La présente étude traite le développement des outils et critères rationnels en vue de faciliter l'application des méthodes explicites d'analyse de risques dans le domaine de l'ingénierie structurelle. La procédure établie permet de quantifier les risques pour les personnes, inhérents aux structures de génie civil. Elle est basée sur le calcul des probabilités de ruine des éléments porteurs du système analysé ainsi que des conséquences associées, dans le cas où se produisent ces évènements, en termes de la perte en vies humaines attendue. Cette procédure est appliquée à un ensemble représentatif de structures de bâtiments en conformité avec les meilleures pratiques actuelles. Les résultats obtenus permettent de déduire des critères d'acceptation des risques pour les personnes dans le domaine des structures. À leur tour, ces critères fournissent une base rationnelle pour la prise de décision dans l'ingénierie structurelle. Ils peuvent être utilisés dans le cadre d'une analyse des risques explicite ou comme base pour la calibration cohérente des modèles destinés à la pratique courante de l'ingénieur qui, selon la plupart des normes actuelles, emploie la méthode dite des facteurs partiels pour la vérification de la sécurité structurale.

\section{ZUSAMMENFASSUNG}

Die im konstruktiven Ingenieurbau, bei der Bemessung neuer oder der Erhaltung bestehender Tragwerke, üblichen Methoden zum Nachweis der Tragsicherheit erlauben es nicht, die mit dem untersuchten System verbundenen Risiken zu quantifizieren. Zudem können die durch die Benutzung besagter Methoden und Anforderungen implizit akzeptierten Risiken grossen Streuungen unterworfen sein. Obwohl die Durchführung von expliziten Risikoanalysen im Rahmen der Lösung von Tragsicherheitsproblemen bedeutende Vorteile mit sich bringen würde, stehen ihrer Einführung in der Praxis immer noch grosse, sowohl technische als auch administrative, Hindernisse im Wege.

In der vorliegenden Studie wird die Entwicklung eines Instrumentariums und objektiver Anforderungen für die praktische Anwendung von expliziten Risikoanalysen in Angriff genommen. Ein Verfahren wird eingeführt, welches es erlaubt, die mit Tragwerken verbundenen Todesfallrisiken zu quantifizieren. Es basiert auf der Bestimmung der Versagenswahrscheinlichkeiten der Tragelemente des untersuchten Systems und der Erwartungswerte der Anzahl Opfer bei Eintritt der entsprechenden Ereignisse. Das Verfahren wird auf einen repräsentativen Satz von Gebäudetragwerken, welche der besten gegenwärtigen Praxis entsprechen, angewendet. Ausgehend von den dabei erhaltenen Resultaten werden die mit solchen Tragwerken verbundenen zulässigen Personenrisiken abgeleitet. Diese Kriterien bilden eine rationale Basis für die Entscheidungsfindung im Rahmen der Planung und Erhaltung von Tragwerken. Sie können sowohl für explizite Risikoanalysen eingesetzt werden, als auch zur Kalibrierung von Teilsicherheitsbeiwerten für die Last und Widerstandsmodelle, welche laut den meisten gültigen Normen in der gängigen Ingenieurpraxis zur Durchführung von Tragsicherheitsnachweisen Anwendung finden. 


\section{AGRADECIMIENTOS}

El éxito de un proyecto de ingeniería depende decisivamente de la estrecha colaboración entre múltiples equipos y profesionales. Aunque una tesis doctoral, por lo menos a primera vista, no tenga demasiados aspectos en común con el proyecto de un puente o una estructura de edificación, su realización tampoco es, de ninguna manera, obra de un lobo solitario. Desde luego, esta tesis nunca hubiera visto la luz sin la contribución de muchas personas, bien a través de su colaboración o consejos específicos, bien por su apoyo indirecto, también decisivo. Así, en primer lugar, quisiera darles las gracias a todos los familiares, amigos y compañeros que, durante el desarrollo de este trabajo, me hayan apoyado moral-, técnica- o científicamente, pero cuyos nombres no aparecen en el siguiente relato.

Si tuviera algo de un Querdenker, se lo debería a mis padres. Ellos nos transmitieron que una pizca de pensamiento lateral es un ingrediente imprescindible para encontrar la mejor solución a un problema de cualquier tipo. Ciertamente es el caso de la ingeniería estructural para cuyo ejercicio, además de los conocimientos técnicos y la experiencia, resulta clave la capacidad de vislumbrar, proponer y materializar soluciones innovadoras, alternativas a las convencionales. Les agradezco enormemente esta enseñanza, como todo lo demás.

Un agradecimiento muy especial va dirigido a Elena, por caminar junto a mí y por su apoyo continuo. Sin ella esta tesis no existiría. Y no solamente porque no estaría aquí si no nos hubiéramos conocido, sino también, aunque ella no lo crea, porque fue quien me dio un importante impulso para avanzar en esta línea de trabajo. Sus explicaciones pacientes de algunos conceptos básicos del Derecho, sobre todo el hecho de que el denominado "Paraguas de las Instrucciones", tan invocado en la profesión, tiene un alcance muy limitado, por muy obligatorias que sean las reglas normalizadas en algunos países, han tenido un efecto catalizador para el presente estudio. También constituyen la base para librarnos de las ataduras de las normas prescriptivas y pensar de manera más creativa, o lateral, en el marco de los proyectos que realizamos como ingenieros estructurales en Cesma. En definitiva, este razonamiento nos permite dormir relativamente tranquilos, incluso cuando las soluciones que ideamos y desarrollamos dejan atrás la fase de proyecto para ser construidas. Esta tesis ya es muy larga, por lo que debo renunciar a la enumeración de las otras cosas que le agradezco a Elena. Se las comentaré en privado.

Espero, y creo, que el hecho de haber simultaneado, durante casi 20 años, la actividad de proyectista con mis investigaciones en el Instituto Torroja, contribuya a que éstas tengan un enfoque práctico. A mi socio durante todo este tiempo, Juan Luis Bellod, así como a los otros compañeros de Cesma Ingenieros, les doy las gracias por comprender que en los últimos tiempos no me haya podido dedicar de la manera habitual a los trabajos de la oficina, con el fin de terminar este estudio, y por otras circunstancias.

Siendo directora del Instituto Eduardo Torroja, IETcc, fue la Dra. Carmen Andrade quien me ofreció incorporarme a este centro, lo que le agradezco. En el Torroja he podido dedicarme, aunque sea a tiempo parcial, a aquellos temas que, según algunos compañeros de profesión, son cosa de una especie de secta, pero cuyas ventajas potenciales ya había percibido en mis tiempos de estudiante en la Eidgenössische Technische Hochschule Zürich, ETHZ, y de colaborador científico en el Instituto de la Construcción Metálica, ICOM, de la École Polytechnique Fédérale de Lausanne, EPFL: los métodos de fiabilidad estructural y análisis de riesgo, así como sus múltiples aplicaciones. Mi intención no era realizar una tesis doctoral, ya que mi segunda actividad no me dejaba tiempo para ello y también por considerar que lo realmente importante en la vida profesional debería ser lo que uno sepa hacer, no los títulos académicos. Desde un principio y durante mucho tiempo, Carmen Andrade me instaba a que me retractase de esta convicción. Con el paso de los años y de manera 
paulatina, aprovechando sus periódicas visitas de trabajo al Instituto, el Dr. Luis Albajar, profesor titular de la ETS de Ingenieros de Caminos, Canales y Puertos de la UPM, empezó a administrarme las mismas píldoras persuasivas en unas dosis homeopáticas. Nunca he sabido si detrás de este relevo había una intención. En cualquier caso, finalmente lo han conseguido y a los dos les agradezco su tenacidad.

No quisiera dejar de hacer extensivo este agradecimiento también a aquel estudiante a quien hace más de 20 años, mientras él estaba realizando prácticas en el extranjero, al llegar al país le quité, dice, su sillón en la oficina de proyectos en la que luego trabajaríamos juntos durante unos años. Gracias, Miguel, convertido hace tiempo en Dr. Miguel Gómez, Director de la Escuela de Arquitectura, Ingeniería y Diseño de la Universidad Europea de Madrid, por recordarme periódicamente que tenía una tesis por hacer, las siempre enriquecedoras conversaciones, no necesariamente sobre ingeniería, los buenos ratos y el apoyo en los que lo eran menos. Y todo ello a pesar de aquel primer encuentro.

Al Dr. Carlos Siegrist, profesor titular de la ETSICCP de la UPM, le agradezco que haya desempeñado la función de tutor académico durante la fase de reconocimiento de la suficiencia investigadora. Que se quedara en eso se debió a que su proceso de jubilación como profesor le ganó la carrera al mío de decisión de desarrollar una tesis.

Nuevamente fue Luis Albajar quien tomó el relevo, asumiendo la dirección de esta tesis ciertamente ardua, lo que también le agradezco. Es un privilegio haberle tenido como interlocutor. Su fiscalización de mis hipótesis y desarrollos, crítica y constructiva a la vez, así como sus propuestas y sugerencias, siempre inspiradas en su profundo conocimiento de las estructuras, experiencia y sentido común, han contribuido decisivamente a mejorar la tesis.

Durante la última década he tenido la inmensa suerte de tener al lado a unos compañeros que, antes que participar como ingenieros en el boom de la construcción, han preferido dedicarse al mundo del $L Q I$, los índices beta y otros coeficientes que a la mayoría de los ingenieros les parecen esotéricos y que, quizás por ello, no cuentan con grupos de presión ni patrocinadores en el sector. Juntos hemos explorado, y seguimos explorando, el amplio campo del análisis de riesgo y la fiabilidad estructural, tanto en el marco de investigaciones fundamentales y aplicadas, como en peritajes o trabajos de asistencia técnica. Estos últimos no solamente han permitido financiar, en gran parte, las tesis doctorales del grupo, las que están terminadas y las que falten por terminar, sino además actúan como importante catalizador de ideas para nuevas investigaciones y ayudan en la selección y priorización de los temas a desarrollar. Todo ello les agradezco a Ramon Hingorani, Carlos Lara y Dr. Miguel Prieto. Además, a Ramon le agradezco su inmensa ayuda en el manejo de los, literalmente, millones de datos en los que se basa esta investigación y a los tres les doy las gracias por todas las ideas, consejos y críticas constructivas que han surgido en las incontables reuniones y conversaciones a lo largo de los años, en el marco de todos los trabajos que hemos realizado. Como último, y no porque sea de menor importancia, aparte del permanente apoyo y dedicación, también quisiera destacar y agradecerles nuestra excelente relación personal que va más allá de lo estrictamente profesional y lo hace todo muy fácil.

A Carlos Almarza, anterior Jefe del Servicio de Desarrollos Climatológicos, y la Dra. Ana Morata de la Agencia Estatal de Meteorología, AEMET, les agradezco su disponibilidad y colaboración en el modelado de los fenómenos meteorológicos extremos. Sin su ayuda seguramente me hubiera ahogado en el mar de datos de las estaciones climatológicas de la red de AEMET. Al matemático Dr. Andrés Jiménez, profesor titular de la ETS de Ingeniería de la Universidad de Sevilla, le agradezco su ayuda y colaboración para transformar unos datos difusos sobre las consecuencias de los colapsos estructurales en unos modelos de utilidad práctica. 
Aparte del apoyo de terceros, su vocación, voluntarismo y talento, también hacen falta otros ingredientes para poder realizar una tesis doctoral. En particular, aunque quizás sea más prosaico, es necesario contar con un apoyo económico suficiente. Agradezco la financiación proporcionada por los Ministerios de Fomento y de Ciencia e Innovación, a través de los proyectos de investigación FOM-741 (Modelos para la evaluación y la mitigación de los riesgos técnicos en el marco de los proyectos de las estructuras de edificación) y Habitat 2030 (Materiales y componentes), respectivamente, al igual que el apoyo económico del Ministerio de Vivienda, primero, y del Ministerio de Fomento, después, por los trabajos que hemos tenido la oportunidad de realizar en el marco del desarrollo del Código Técnico de la Edificación. Finalmente, también agradezco la confianza de los peticionarios de los distintos peritajes y trabajos de asistencia técnica, anteriormente mencionados. Sin estos encargos no sería posible mantener un grupo de investigación como el nuestro y, por tanto, tampoco existiría esta tesis. 

"If a builder build a house for some one, and does not construct it properly, and the house which he built fall in and kill its owner, then that builder shall be put to death."

Law 229, Code of Hammurabi, $6^{\text {th }}$ king of the Amorite First Dynasty of Babylon, 1792 - 1750 BCE. 



\section{ÍNDICE}

RESUMEN

AGRADECIMIENTOS

ÍNDICE

NOTACIÓN

1 INTRODUCCIÓN 35

1.1 ANTECEDENTES Y MOTIVACIÓN 35

$\begin{array}{lll}1.1 .1 & \text { Contexto } & 35\end{array}$

1.1.2 Situación actual 36

$\begin{array}{lll}1.1 .3 & \text { Enfoques prestacionales } & 40\end{array}$

1.1.4 Contribución al desarrollo de herramientas prácticas 42

1.2 ALCANCE 43

1.3 OBJETIVO

1.4 ORGANIZACIÓN DE LA TESIS 45

2 PRINCIPIOS BÁSICOS 49

$\begin{array}{ll}2.1 \text { INTRODUCCIÓN } & 49\end{array}$

2.2 PROCESO DE DECISIÓN BASADO EN RIESGOS 50

2.2.1 Procedimiento genérico 50

2.2.2 Evaluación cualitativa 51

2.2.3 Evaluación cuantitativa 53

2.2.4 Tratamiento de los riesgos $\quad 55$

2.3 CRITERIOS DE ACEPTACIÓN 56

2.3.1 Visión general $\quad 56$

2.3.2 Riesgo individual $\quad 58$

$\begin{array}{lll}2.3 .3 & \text { Riesgo colectivo } & 59\end{array}$

2.3.4 Criterios económicos 62

2.3.5 Índice de calidad de vida 63

2.4 OBSERVACIONES FINALES $\quad 64$

3 SEGURIDAD Y FIABILIDAD EN LA INGENIERÍA ESTRUCTURAL 67

$\begin{array}{ll}3.1 \text { INTRODUCCIÓN } & 67\end{array}$

3.2 INCERTIDUMBRES ASOCIADAS CON LAS VARIABLES BÁSICAS 68

3.2.1 Fuentes de incertidumbre 68 
$\begin{array}{lll}3.2 .2 & \text { Obtención de datos } & 69\end{array}$

3.2.3 Selección de funciones de distribución 70

3.3 CRITERIOS PARA EL FALLO ESTRUCTURAL 70

$\begin{array}{lll}\text { 3.3.1 Conceptos básicos } & 70\end{array}$

$\begin{array}{lll}\text { 3.3.2 } & \text { Estados límite últimos } & 74\end{array}$

$\begin{array}{lll}\text { 3.3.3 Estados límite de servicio } & 76\end{array}$

3.4 MÉTODOS BASADOS EN LA DETERMINACIÓN DE LOS VALORES DE CÁLCULO 76

3.4.1 Valores de cálculo según el método FORM 76

$\begin{array}{lll}\text { 3.4.2 Factores de sensibilidad según el método FORM } & 77\end{array}$

3.5 EL MÉTODO DE LOS COEFICIENTES PARCIALES 78

$\begin{array}{lll}3.5 .1 & \text { Coeficientes parciales basados en valores de cálculo } & 78\end{array}$

$\begin{array}{lll}3.5 .2 & \text { Coeficientes parciales calibrados } & 80\end{array}$

3.6 NIVELES DE FIABILIDAD $\quad 81$

$\begin{array}{lll}3.6 .1 & \text { Generalidades } & 81\end{array}$

$\begin{array}{lll}3.6 .2 & \text { Valores numéricos } & 82\end{array}$

3.6.3 Observaciones finales $\quad 83$

3.7 FIABILIDAD DE SISTEMAS $\quad 84$

$\begin{array}{lll}3.7 .1 & \text { Generalidades } & 84\end{array}$

3.7.2 Idealizaciones $\quad 85$

$\begin{array}{ll}3.8 \text { OBSERVACIONES FINALES } & 88\end{array}$

4 METODOLOGÍA $\quad 91$

$\begin{array}{ll}4.1 \text { INTRODUCCIÓN } & 91\end{array}$

$\begin{array}{lll}4.1 .1 & \text { Situación } & 91\end{array}$

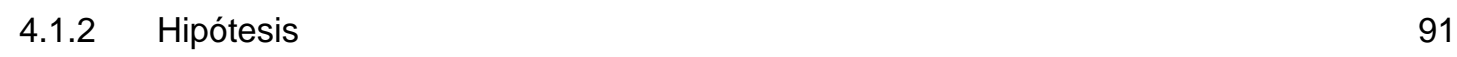

$\begin{array}{ll}4.1 .3 & \text { Dificultades }\end{array}$

$\begin{array}{ll}4.1 .4 & \text { Desarrollos necesarios }\end{array}$

$\begin{array}{lll}4.1 .5 & \text { Organización del capítulo } & 92\end{array}$

4.2 ANÁLISIS CUANTITATIVO DE LOS RIESGOS 93

4.2.1 Planteamiento global 93

4.2.2 Probabilidad de fallo de sistemas estructurales $\quad 94$

$\begin{array}{lll}\text { 4.2.3 Consecuencias para las personas } & 95\end{array}$

4.3 REPRESENTACIÓN DE LOS RIESGOS PARA LAS PERSONAS 96

4.4 DEDUCCIÓN DE CRITERIOS DE ACEPTACIÓN 98

$\begin{array}{lr}4.5 \text { PROCEDIMIENTO } & 99\end{array}$

$\begin{array}{lr}\text { 4.6 OBSERVACIONES FINALES } & 101\end{array}$

5 ANÁLISIS DE LOS RIESGOS ASOCIADOS CON LAS ESTRUCTURAS DE EDIFICACIÓN

$\begin{array}{lll}5.1 & 1 & 103\end{array}$ 
$\begin{array}{ll}5.2 \text { ALCANCE } & 104\end{array}$

5.2.1 Visión de conjunto 104

5.2.2 Consideraciones sobre la influencia del sistema estructural en la probabilidad de fallo

5.3 SELECCIÓN DE ESTRUCTURAS Y ELEMENTOS 110

$\begin{array}{lll}\text { 5.3.1 Edificios con estructuras de acero } & 110\end{array}$

$\begin{array}{ll}\text { 5.3.2 Edificios con estructuras de hormigón armado } & 116\end{array}$

$\begin{array}{lll}\text { 5.3.3 Edificios con estructuras mixtas de acero y hormigón } & 119\end{array}$

5.3.4 Edificios con estructuras de madera laminada encolada 123

5.4 MECANISMOS DE FALLO Y FUNCIONES DE ESTADO LÍMITE 128

$\begin{array}{lll}5.4 .1 & \text { Generalidades } & 128\end{array}$

$\begin{array}{lll}\text { 5.4.2 } & \text { Elementos de acero } & 129\end{array}$

5.4.3 Elementos de hormigón armado 130

$\begin{array}{ll}\text { 5.4.4 Elementos mixtos de acero y hormigón } & 131\end{array}$

5.4.5 Elementos de madera laminada encolada 132

5.5 OBSERVACIONES FINALES 133

6 DEDUCCIÓN DE MODELOS PROBABILISTAS 135

6.1 INTRODUCCIÓN 135

6.2 VARIABLES ALEATORIAS 135

$\begin{array}{lll}\text { 6.2.1 } & \text { Representación de las incertidumbres } & 135\end{array}$

6.2.2 Requisitos para los modelos 136

6.3 VERIFICACIÓN DE LA SEGURIDAD ESTRUCTURAL 136

$\begin{array}{lll}\text { 6.3.1 Formato de los coeficientes parciales } & 136\end{array}$

6.3.2 Resistencia de los elementos de acero 140

$\begin{array}{lll}\text { 6.3.3 Resistencia de los elementos de hormigón armado } & 141\end{array}$

6.3.4 Resistencia de los elementos mixtos de acero y hormigón 143

6.3.5 Resistencia de los elementos de madera laminada encolada 144

6.4 CARGAS DE NIEVE 146

$\begin{array}{lll}\text { 6.4.1 Introducción } & 146\end{array}$

$\begin{array}{lll}\text { 6.4.2 Modelo } & 148\end{array}$

$\begin{array}{lll}\text { 6.4.3 Verificación y ajuste de los parámetros } & 160\end{array}$

6.5 LÍMITE ELÁSTICO DEL ACERO ESTRUCTURAL 166

$\begin{array}{lll}6.5 .1 & \text { Introducción } & 166\end{array}$

$\begin{array}{lll}6.5 .2 & \text { Modelo } & 169\end{array}$

6.5.3 Valor de cálculo y coeficiente parcial 172

6.6 INCERTIDUMBRES DE LOS MODELOS PARA LA RESISTENCIA DE LOS ELEMENTOS DE ACERO 173

$\begin{array}{lll}\text { 6.6.1 Introducción } & 173\end{array}$

$\begin{array}{lll}\text { 6.6.2 Identificación de parámetros } & 177\end{array}$

$\begin{array}{lll}\text { 6.6.3 Estudio de verosimilitud } & 178\end{array}$

$\begin{array}{ll}\text { 6.6.4 Verificación de los parámetros } & 183\end{array}$

6.7 RESUMEN DE LOS RESULTADOS OBTENIDOS 186 
$\begin{array}{lll}\text { 6.7.1 Introducción } & 186\end{array}$

$\begin{array}{lll}\text { 6.7.2 } & \text { Estructuras de acero } & 187\end{array}$

$\begin{array}{ll}\text { 6.7.3 Estructuras de hormigón armado } & 191\end{array}$

$\begin{array}{lll}\text { 6.7.4 Estructuras mixtas de acero y hormigón } & 193\end{array}$

$\begin{array}{ll}\text { 6.7.5 Estructuras de madera laminada encolada } & 195\end{array}$

$\begin{array}{ll}\text { 6.7.6 Conclusiones } & 197\end{array}$

6.8 OBSERVACIONES FINALES 198

7 MODELOS DE CONSECUENCIAS $\quad 201$

$\begin{array}{ll}7.1 \text { INTRODUCCIÓN } & 201\end{array}$

7.2 BASE DE DATOS SOBRE COLAPSOS ESTRUCTURALES 202

$\begin{array}{lll}7.2 .1 & 202\end{array}$

$\begin{array}{lll}7.2 .2 & \text { Edificio } & 203\end{array}$

$\begin{array}{lll}7.2 .3 & \text { Colapso } & 204\end{array}$

$\begin{array}{lll}7.2 .4 & \text { Consecuencias } & 205\end{array}$

$\begin{array}{lll}7.2 .5 & \text { Información adicional } & 206\end{array}$

$\begin{array}{ll}\text { 7.2.6 Evaluación estadística de los datos } & 207\end{array}$

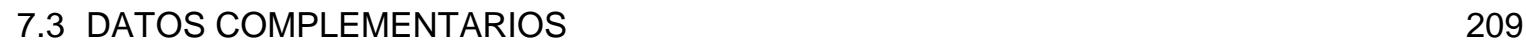

$\begin{array}{lll}\text { 7.3.1 Generalidades } & 209\end{array}$

$\begin{array}{lll}\text { 7.3.2 Edificios residenciales } & 210\end{array}$

$\begin{array}{lll}\text { 7.3.3 Centros educativos } & 212\end{array}$

$\begin{array}{lll}\text { 7.3.4 Base de datos complementada } & 214\end{array}$

7.4 ANÁLISIS DE REGRESIÓN 218

$\begin{array}{lll}7.4 .1 & \text { Criterios } & 218\end{array}$

$\begin{array}{lll}7.4 .2 & \text { Resultados } & 219\end{array}$

$\begin{array}{ll}7.5 & \text { OBSERVACIONES FINALES } \\ & 221\end{array}$

8 CRITERIOS DE ACEPTACIÓN 223

8.1 INTRODUCCIÓN 223

8.2 NIVEL DE FIABILIDAD REQUERIDO 224

$\begin{array}{lll}\text { 8.2.1 Generalidades } & 224\end{array}$

$\begin{array}{ll}\text { 8.2.2 Elementos de acero } & 227\end{array}$

8.2.3 Elementos de hormigón armado 234

8.2.4 Elementos mixtos de acero y hormigón 239

8.2.5 Elementos de madera laminada encolada 240

$\begin{array}{lll}\text { 8.2.6 Observaciones finales } & 242\end{array}$

8.3 RIESGOS ADMISIBLES PARA LAS PERSONAS 243

$\begin{array}{lll}\text { 8.3.1 Generalidades } & 243\end{array}$

$\begin{array}{lll}\text { 8.3.2 Riesgos nominales } & 244\end{array}$

8.3.3 Criterios de aceptación de los riesgos individuales 248

8.3.4 Criterios de aceptación de los riesgos colectivos 250

$\begin{array}{lll}\text { 8.3.5 Observaciones finales } & 256\end{array}$

8.4 CONCLUSIONES 257 
9 OBSERVACIONES FINALES

$\begin{array}{ll}9.1 \text { INTRODUCCIÓN } & 261\end{array}$

9.2 DESARROLLOS Y RESULTADOS 262

$\begin{array}{ll}9.3 \text { CONCLUSIONES } & 271\end{array}$

9.4 TRABAJOS FUTUROS 274

$\begin{array}{ll}\text { REFERENCIAS } & 277\end{array}$ 



\section{NOTACIÓN}

\section{MAYÚSCULAS LATINAS}

A : área de influencia de un elemento horizontal; área de la sección transversal de un elemento; altitud sobre el nivel del mar; superficie útil total de un edificio

$A_{a} \quad$ : área de la sección de acero estructural

$A_{c} \quad$ : área de la sección de hormigón

$A_{c o l} \quad: \quad$ superficie afectada por un colapso

$A_{c o l, j} \quad: \quad$ superficie afectada por el colapso en el escenario $j$

$A_{i, m} \quad$ : valor medio de la superficie útil disponible por persona

$A_{s} \quad$ : área de la sección del acero de armar

$A_{s w} \quad: \quad$ área por unidad de longitud de la sección de la armadura de cortante

$A_{V} \quad$ : área de cortante de la sección transversal de la viga de acero

$A_{0} \quad$ : área de referencia

$B \quad$ : anchura de la estructura de un edificio

C $\quad$ : consecuencias esperadas de un determinado evento no deseado

$C_{e} \quad: \quad$ coeficiente de exposición

$C_{f} \quad: \quad$ coste económico asociado al fallo de un sistema

$C_{f, t o t} \quad$ : coste económico asociado al fallo de un sistema, incluido el costo equivalente para evitar daños personales

$C_{t} \quad$ : coeficiente térmico

$C_{\text {tot }} \quad: \quad$ coste total en términos económicos

$C(x) \quad$ : consecuencias de un evento no deseado en función de las variables básicas $\boldsymbol{X}$

$C_{i j, k} \quad: \quad$ consecuencias del tipo $k$ asociadas con el evento $j$ causado por la amenaza $i$

$D \quad$ : desviación agregada

$E(. .$.$) \quad : efecto de las acciones e influencias en función de (...)$

$E(N) \quad$ : número esperado de víctimas mortales

$E_{d} \quad: \quad$ valor de cálculo de los efectos de las acciones e influencias

$E_{i j} \quad: \quad$ evento $j$ causado por la amenaza $i$

$E_{k, G+Q} \quad: \quad$ valor característico de los efectos de las acciones permanentes y variables

$E_{k, Q} \quad$ : valor característico de los efectos de las acciones variables

$E_{0} \quad$ : valor de los efectos de las acciones que delimita las condiciones satisfactorias de las insatisfactorias en una definición nítida de los estados límite

$E_{1} \quad$ : valor de los efectos de las acciones a partir del cual una estructura pierde paulatinamente su aptitud para cumplir con los requisitos en una definición difusa de los estados límite

$E_{2} \quad$ : valor de los efectos de las acciones a partir del cual una estructura se considera completamente insatisfactoria en una definición difusa de los estados límite

F $\quad$ : fallo de un sistema técnico o de uno de sus componentes

$F_{d} \quad: \quad$ valor de cálculo de una acción o influencia

$\boldsymbol{F}_{\boldsymbol{d}} \quad$ : vector de valores de cálculo de las acciones e influencias

$F_{k} \quad: \quad$ valor característico de una acción o influencia 
$F_{k j} \quad: \quad$ valor característico de la acción o influencia $j$

$F(\ldots) \quad$ : función de distribución de (...)

$F(n) \quad$ : frecuencia anual de los eventos con $n$ o más víctimas mortales

F(1) : frecuencia anual de los eventos con una o más víctimas mortales

$G_{k, j} \quad: \quad$ valor característico de la acción permanente $j$

$H \quad$ : altura de la estructura de un edificio

$H_{i} \quad$ : amenaza $i$ relacionada con un determinado sistema

I $\quad$ : inversión en términos económicos

ICAF : costo equivalente para evitar una víctima mortal

$L \quad$ : índice de calidad de vida; longitud de la estructura de un edificio; número de mecanismos de fallo considerados

$M_{a} \quad: \quad$ momento flector debido al peso propio de la viga de acero

$M_{c} \quad$ : momento flector debido al peso propio de la viga de hormigón armado; momento flector debido al peso propio de la losa superior de hormigón de la viga mixta

$M_{\text {cub }} \quad$ : momento flector debido a los elementos resistentes y no resistentes de la cubrición

$M_{E} \quad$ : momento flector

$M_{E d} \quad$ : valor de cálculo del momento flector

$M_{g} \quad$ : momento flector debido al peso propio de la viga de madera laminada encolada

$M_{i} \quad$ : elemento $i$ de un sistema

$M_{j} \quad$ : elemento $j$ de un sistema

$M_{M} \quad$ : variable auxiliar

$M_{M, F O R M, d}$ : valor de cálculo de la variable auxiliar, obtenido mediante el método FORM normalizado

$M_{M, k} \quad$ : $\quad$ valor característico de la variable auxiliar

$M_{p, 1} \quad$ : $\quad$ momento flector debido a las cargas permanentes actuando sobre las vigas de planta

$M_{p, 2} \quad$ : momento flector debido a las cargas permanentes actuando sobre las vigas de cubierta (falsos techos, instalaciones, etcétera, pero sin cubrición)

$M_{Q, 1} \quad$ : momento flector debido a la carga concentrada del modelo para la acción variable dominante

$M_{q, 1} \quad$ : momento flector debido a la carga distribuida del modelo para la acción variable dominante

$M_{R d} \quad: \quad$ valor de cálculo de la resistencia frente a momentos flectores

$N \quad$ : número; número esperado de víctimas; número de víctimas mortales en un evento

$N_{a p} \quad$ : esfuerzo axil debido al peso propio del pilar de acero; esfuerzo axil debido al peso propio del acero del pilar mixto

$N_{a v} \quad$ : esfuerzo axil debido al peso propio de las vigas de acero de los forjados y de la cubierta; esfuerzo axil debido al peso propio del acero de las vigas mixtas de los forjados y de la cubierta

$N_{c p} \quad$ : esfuerzo axil debido al peso propio del pilar de hormigón armado; esfuerzo axil debido al peso propio del hormigón del pilar mixto

$N_{\text {cub }} \quad$ : esfuerzo axil debido a los elementos resistentes y no resistentes de la cubrición 
$N_{c v} \quad$ : esfuerzo axil debido al peso propio de las vigas de hormigón armado de los forjados y de la cubierta; esfuerzo axil debido al peso propio del hormigón de las vigas mixtas de los forjados y de la cubierta

$N_{E} \quad$ : esfuerzo axil

$N_{E d} \quad$ : valor de cálculo del esfuerzo axil

$N_{g p} \quad$ : esfuerzo axil debido al peso propio del pilar de madera laminada encolada

$N_{g v} \quad$ : esfuerzo axil debido al peso propio de las vigas de madera laminada encolada de los forjados y de la cubierta

$N_{j} \quad: \quad$ consecuencias del escenario $j$ en términos del número de víctimas mortales

$N_{p} \quad$ : número de personas expuestas a un sistema o participantes en una actividad

$N_{p, 1} \quad: \quad$ esfuerzo axil debido a las cargas permanentes actuando sobre las vigas de planta

$N_{p, 2} \quad$ : esfuerzo axil debido a las cargas permanentes actuando sobre las vigas de cubierta (falsos techos, instalaciones, etcétera, pero sin cubrición)

$N_{q, 1} \quad$ : esfuerzo axil debido a la acción variable dominante

$N_{q, 2} \quad$ : esfuerzo axil debido a la acción variable concomitante

$N_{R d} \quad$ : valor de cálculo de la resistencia frente a esfuerzos axiles

$P \quad$ : probabilidad; probabilidad de ocurrencia de un evento no deseado; valor representativo de la acción del pretensado

$P_{f} \quad:$ probabilidad de fallo

$P_{f, A-B-C} \quad:$ probabilidad de fallo del sistema $A-B-C$

$P_{f, a d m} \quad:$ probabilidad de fallo admisible

$P_{s} \quad:$ probabilidad de supervivencia; fiabilidad

$Q_{k, 1} \quad$ : valor característico de la acción variable dominante

$Q_{k, i} \quad$ : valor característico de la acción variable concomitante $i$

$R \quad$ : riesgo; riesgo colectivo asociado con el sistema analizado; capacidad portante real de un elemento o sistema estructural

$R(\ldots) \quad$ : resistencia en función de (...)

$R_{d} \quad: \quad$ valor de cálculo de la resistencia

$R_{j} \quad$ : riesgo colectivo del escenario $j$

$R_{k} \quad$ : riesgo total asociado con las consecuencias adversas del tipo $k$; valor característico de la resistencia

$R_{k, a d m} \quad$ : nivel admisible del riesgo total asociado con las consecuencias adversas del tipo $k$

$R_{k, 95,1 y} \quad$ : cuantil del 95\% del riesgo colectivo para las personas, asociado con el sistema analizado, para un período de referencia de un año

$R_{m, 1 y} \quad: \quad$ valor medio del riesgo colectivo para las personas, asociado con el sistema analizado, para un período de referencia de un año

$R_{n y} \quad$ : riesgo colectivo para las personas, asociado con el sistema analizado, para un período de referencia de $n$ años

$R_{t} \quad$ : capacidad portante teórica de un elemento o sistema estructural

$(R / A)_{n y}$ : riesgo colectivo para las personas, normalizado con la superficie útil total de los edificios, para un período de referencia de $n$ años

$\left(R / n_{s c}\right)_{n y}$ : riesgo colectivo para las personas, normalizado con el número total de escenarios relevantes para la estructura del edificio, para un período de referencia de $n$ años 
$S_{f y} \quad$ : coeficiente de sesgo del límite elástico del acero estructural

$S_{q} \quad$ : coeficiente de sesgo de la carga de nieve máxima sobre una cubierta para un período de referencia de 50 años

$S_{W, p l} \quad: \quad$ coeficiente de sesgo del módulo plástico de la sección transversal

$S_{x i} \quad$ : coeficiente de sesgo de la variable básica $X_{i}$

$S_{\xi E, M} \quad$ : coeficiente de sesgo de la variable del modelo para la determinación de los momentos flectores

$S_{\xi R, M} \quad$ : coeficiente de sesgo de la variable del modelo de resistencia frente a momentos flectores

$T_{a} \quad$ : período de un año

$T_{d} \quad$ : período de servicio previsto

$V \quad$ : valor actual del riesgo en términos económicos

$V_{a} \quad$ : esfuerzo cortante debido al peso propio de la viga de acero

$V_{c} \quad$ : esfuerzo cortante debido al peso propio de la viga de hormigón armado; esfuerzo cortante debido al peso propio de la losa superior de hormigón de la viga mixta

$V_{c u b} \quad$ : esfuerzo cortante debido a los elementos resistentes y no resistentes de la cubrición

$V_{E} \quad$ : esfuerzo cortante

$V_{E d} \quad: \quad$ valor de cálculo del esfuerzo cortante

$V_{f y} \quad: \quad$ coeficiente de variación del límite elástico del acero estructural

$V_{g} \quad$ : esfuerzo cortante debido al peso propio de la viga de madera laminada encolada

$V_{M, M} \quad$ : coeficiente de variación de la variable auxiliar

$V_{p, 1} \quad$ : esfuerzo cortante debido a las cargas permanentes actuando sobre las vigas de planta

$V_{p, 2} \quad$ : esfuerzo cortante debido a las cargas permanentes actuando sobre las vigas de cubierta (falsos techos, instalaciones, etcétera, pero sin cubrición)

$V_{q} \quad$ : coeficiente de variación de la carga de nieve máxima sobre una cubierta para un período de referencia de 50 años

$V_{Q, 1} \quad$ : esfuerzo cortante debido a la carga concentrada del modelo para la acción variable dominante

$V_{q, 1} \quad$ : esfuerzo cortante debido a la carga distribuida del modelo para la acción variable dominante

$V_{R d} \quad: \quad$ valor de cálculo de la resistencia frente a esfuerzos cortantes

$V_{R d, c} \quad$ : valor de cálculo de la resistencia frente a compresión oblicua en el alma de una viga de hormigón armado

$V_{R d, s} \quad: \quad$ valor de cálculo de la resistencia frente a tracción en el alma de una viga de hormigón armado

$V_{W, p l} \quad: \quad$ coeficiente de variación del módulo plástico de la sección transversal

$V_{x i} \quad$ : coeficiente de variación de la variable básica $X_{i}$

$V_{\xi E, M} \quad$ : coeficiente de variación de la variable del modelo para la determinación de los momentos flectores

$V_{\xi R} \quad: \quad$ coeficiente de variación del coeficiente para las incertidumbres del modelo de resistencia

$V_{\xi R, M} \quad$ : coeficiente de variación de la variable del modelo de resistencia frente a momentos flectores

W $\quad$ : módulo de la sección transversal

$W_{e l} \quad$ : módulo elástico de la sección transversal

UPM-ETSICCP. Doctorado en Ingeniería de Estructuras, Cimentaciones y Materiales 


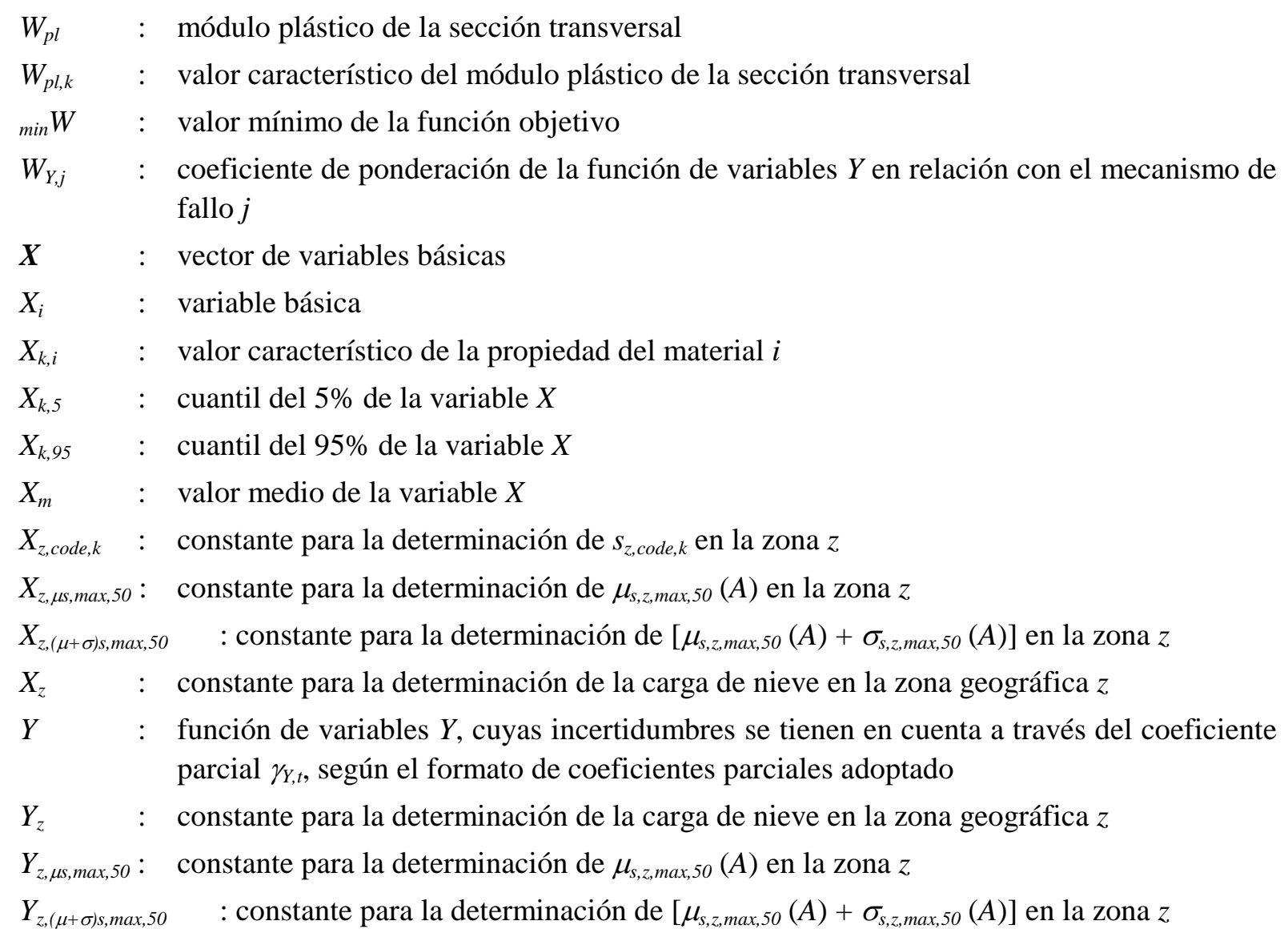

\section{MINÚSCULAS LATINAS}

a $\quad$ : dimensión de un lado de la sección transversal del pilar

$a_{d} \quad: \quad$ valor de cálculo de una dimensión geométrica

$\boldsymbol{a}_{\boldsymbol{d}} \quad: \quad$ vector de valores de cálculo de las dimensiones geométricas

$a_{\text {nom }} \quad:$ valor nominal de una dimensión geométrica

$b \quad$ : distancia entre ejes de los pilares en sentido transversal de un edificio; ancho de la sección transversal

$b_{A} \quad: \quad$ espesor del alma de la sección transversal en apoyo

$b_{c} \quad: \quad$ ancho de la sección transversal

$b_{\text {eff }} \quad: \quad$ ancho eficaz de la losa de hormigón

c : factor; víctimas mortales

$d \quad: \quad$ canto útil de la sección transversal

$e \quad$ : esperanza de vida al nacer

$f_{c} \quad: \quad$ resistencia a compresión del hormigón

$f_{c e} \quad:$ resistencia plástica efectiva del hormigón

$f_{c k} \quad: \quad$ valor característico de la resistencia a compresión del hormigón

$f_{c, 0, g} \quad: \quad$ resistencia a compresión paralela a la fibra de la madera laminada encolada

$f_{c, 0, g, k}$ : valor característico de la resistencia a compresión paralela a la fibra de la madera laminada encolada

$f_{d} \quad$ : valor de cálculo de una propiedad de un material 


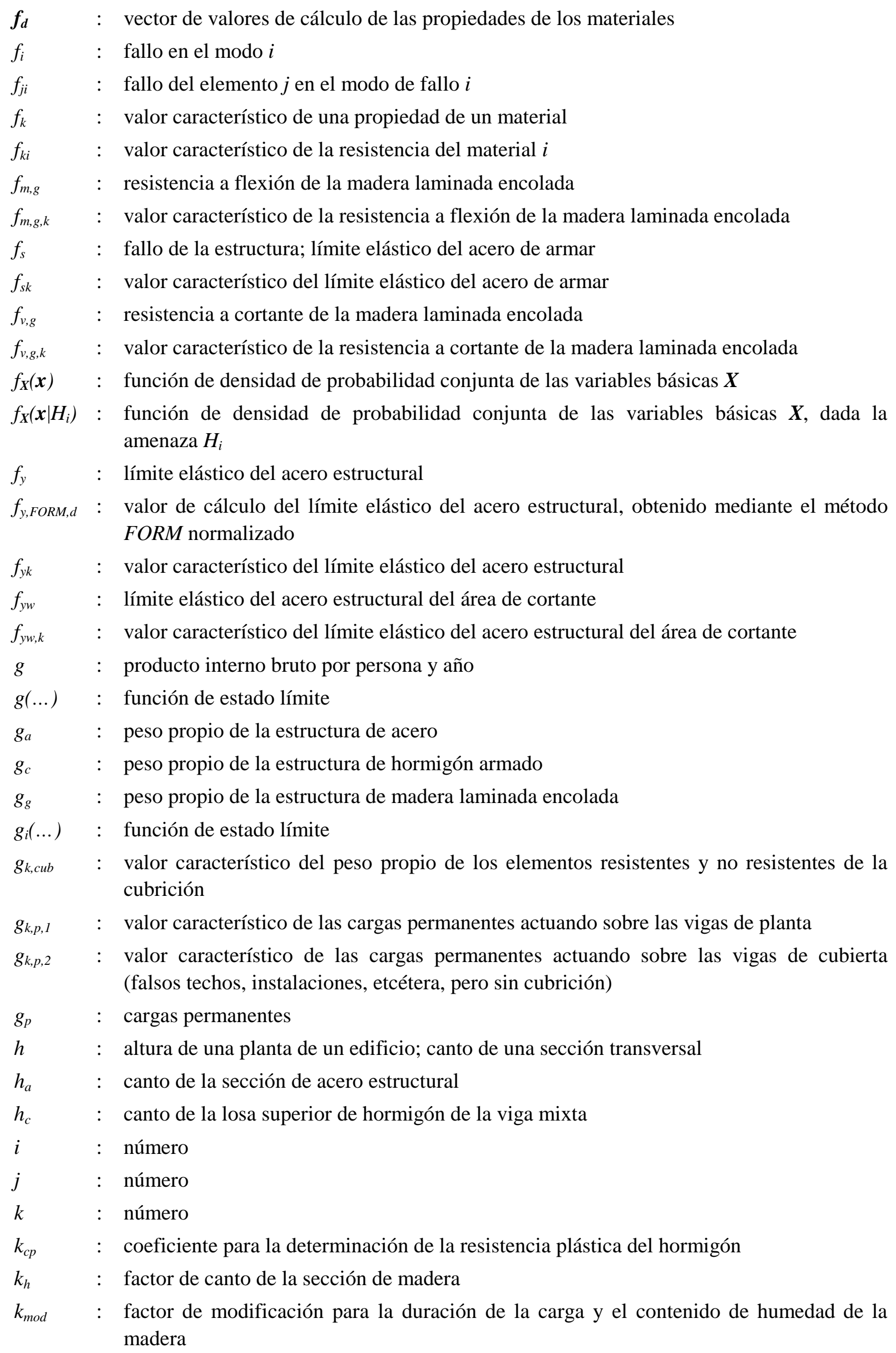


l $\quad$ : distancia entre ejes de los pilares en sentido longitudinal de un edificio; luz de una viga

$l_{i j} \quad: \quad$ letalidad del escenario $j$ para la persona $i$

m : número

n : número; consecuencia de un evento no deseado en términos del número de víctimas mortales; número; número de plantas de la misma categoría de uso, situadas por encima de un pilar; período de referencia en años

$n_{\text {col }} \quad: \quad$ número de plantas afectadas por un colapso

$n_{i} \quad$ : número de elementos cuyo fallo es necesario para la formación del modo o mecanismo de fallo $i$

$n_{s} \quad: \quad$ número de plantas de un edificio, sin planta baja ni cubierta

$n_{s c} \quad: \quad$ número de escenarios de riesgo

$p(\ldots) \quad$ : probabilidad anual de (...)

$p_{c \mid f} \quad$ : probabilidad condicional de fallecimiento de una persona, presente en el área de influencia de la estructura, dado el colapso

$p_{F} \quad:$ probabilidad de fallo

$p_{f} \quad:$ probabilidad de fallo

$p_{f i} \quad$ : probabilidad de fallo del elemento $i$

$p_{f, A M-B M}:$ probabilidad de fallo debida al mecanismo iniciado por la rotura a flexión de la sección $A$ y seguido por la rotura a flexión de la sección $B$

$p_{f, A M V} \quad:$ probabilidad de fallo debida a la rotura de la sección $A$ por la interacción de flexión y cortante

$p_{f, B M-A M}:$ probabilidad de fallo debida al mecanismo iniciado por la rotura a flexión de la sección $B$ y seguido por la rotura a flexión de la sección $A$

$p_{f, C V-A M}:$ probabilidad de fallo debida al mecanismo iniciado por la rotura a cortante de la sección $C$ y seguido por la rotura a flexión de la sección $A$

$p_{f, \max } \quad: \quad$ valor máximo de la probabilidad de fallo

$p_{f, \min } \quad: \quad$ valor mínimo de la probabilidad de fallo

$p_{f, \text { opt }} \quad$ : valor óptimo de la probabilidad de fallo

$p_{f t, I R} \quad$ : probabilidad de fallo objetivo, basada en el valor admisible para el riesgo individual

$p_{f t, S R} \quad:$ probabilidad de fallo objetivo, basada en el valor admisible para el riesgo colectivo

$p_{j} \quad: \quad$ probabilidad de ocurrencia del escenario $j$

$p_{N \mid f} \quad:$ probabilidad condicional de que, dado el colapso, se produzcan $N$ víctimas mortales, siendo $N$ igual o superior a $n$

$p_{s} \quad:$ probabilidad de supervivencia; fiabilidad

$p_{t} \quad:$ probabilidad de fallo admisible

$q \quad$ : carga de nieve sobre la cubierta

$q_{c o d e, k} \quad: \quad$ valor característico normalizado de la carga de nieve sobre la cubierta

$q_{F O R M, d}:$ valor de cálculo de la carga de nieve sobre la cubierta, obtenido mediante el método FORM normalizado

$q_{i} \quad:$ acción variable $i$

$q_{k, 1} \quad$ : valor característico de la carga distribuida del modelo para la acción variable dominante

$q_{k, i} \quad$ : valor característico de la carga distribuida del modelo para la acción variable $i$ 


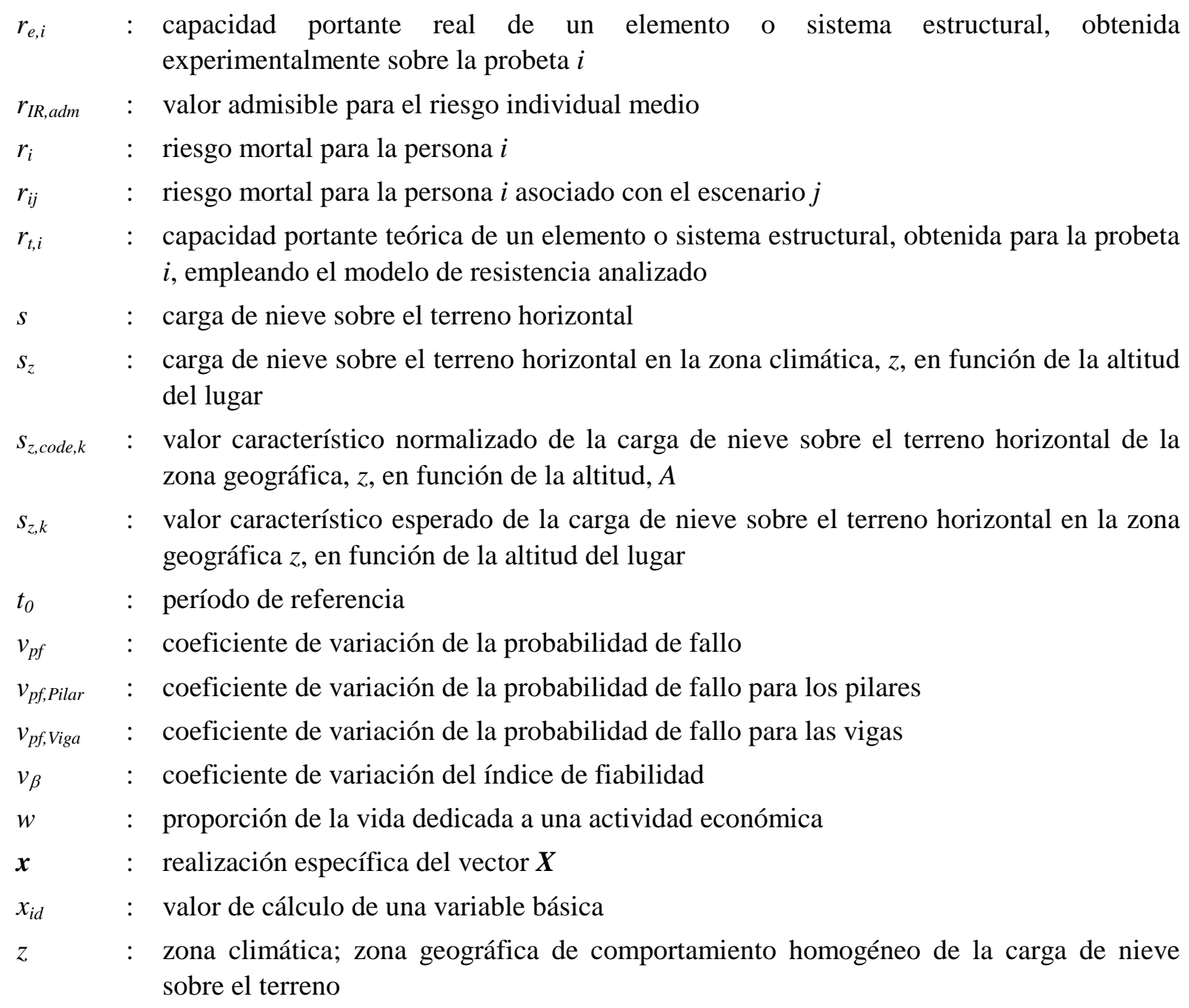

\section{MAYÚSCULAS GRIEGAS}

$\begin{array}{lll}\Delta a & : & \text { desviación de una dimensión geométrica de su valor nominal } \\ \Delta e & : & \text { variación de la esperanza de vida al nacer } \\ \Delta L & : & \text { variación del índice de calidad de vida } \\ \Delta g & : & \text { variación del producto interno bruto por persona y año } \\ \Phi & : & \text { función de distribución normal }\end{array}$

\section{MINÚSCULAS GRIEGAS}

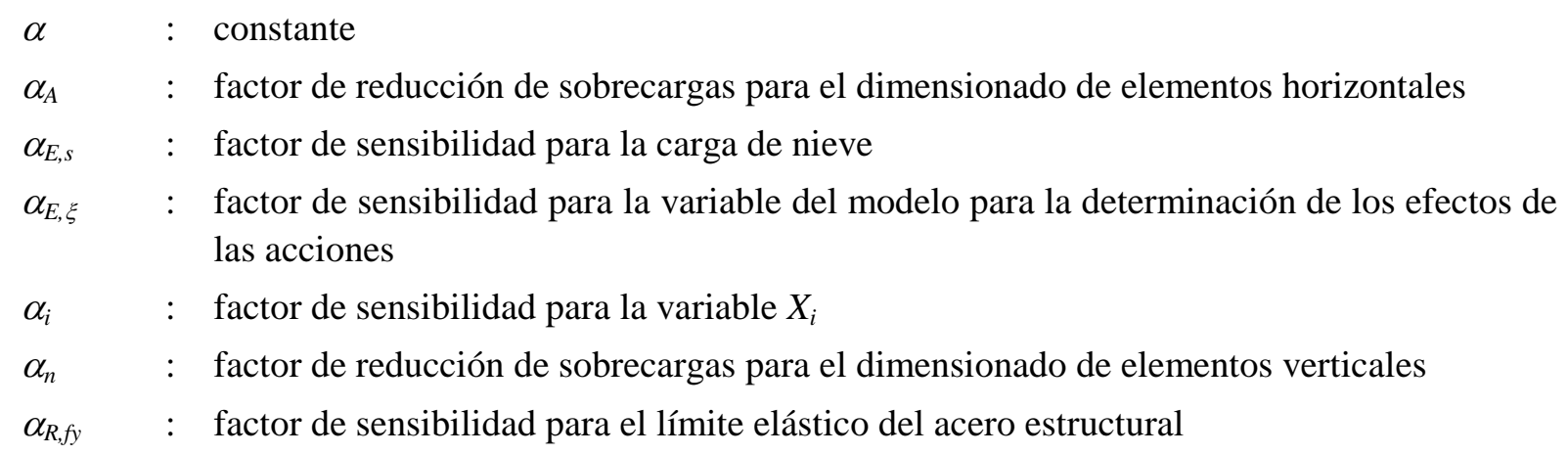




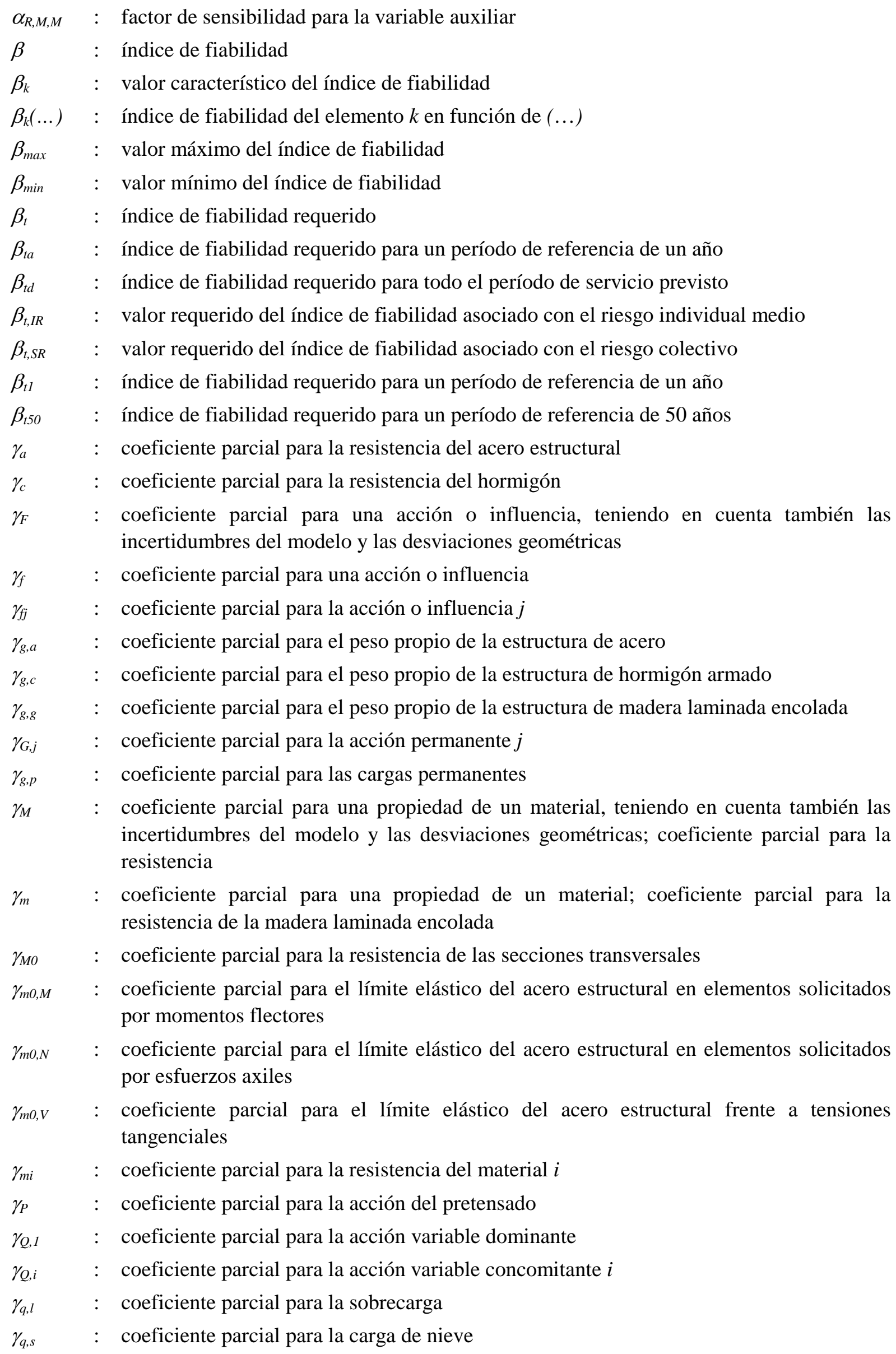


$\gamma_{R} \quad:$ coeficiente parcial para la resistencia, teniendo en cuenta las incertidumbres asociadas con las propiedades de los materiales y el modelo, así como las desviaciones geométricas

$\gamma_{R d} \quad:$ coeficiente parcial para el modelo de resistencia

$\gamma_{R d, M} \quad: \quad$ coeficiente parcial para el modelo de resistencia frente a momentos flectores

$\gamma_{R d, N} \quad: \quad$ coeficiente parcial para el modelo de resistencia frente a esfuerzos axiles

$\gamma_{R d, V} \quad: \quad$ coeficiente parcial para el modelo de resistencia frente a esfuerzos cortantes

$\gamma_{R d, V c} \quad$ : coeficiente parcial para el modelo de resistencia frente a esfuerzos de compresión oblicua en el alma

$\gamma_{R d, V s} \quad: \quad$ coeficiente parcial para el modelo de resistencia frente a esfuerzos de tracción en el alma

$\gamma_{s} \quad:$ coeficiente parcial para la resistencia de la armadura

$\gamma_{S d} \quad: \quad$ coeficiente parcial para el modelo de los efectos de las acciones e influencias

$\gamma_{S d, M} \quad$ : coeficiente parcial para el modelo empleado en la determinación de los momentos flectores

$\gamma_{S d, N} \quad: \quad$ coeficiente parcial para el modelo empleado en la determinación de los esfuerzos axiles

$\gamma_{s d, V} \quad$ : coeficiente parcial para el modelo empleado en la determinación de los esfuerzos cortantes

$\gamma_{Y, j} \quad$ : coeficiente parcial para la función de variables $Y$, que depende del formato de coeficientes parciales adoptado, obtenido mediante el método FORM para el mecanismo de fallo $j$ y utilizando los modelos probabilistas adoptados para las variables

$\gamma_{Y, t} \quad: \quad$ valor requerido del coeficiente parcial para la función de variables $Y$

$\delta \quad: \quad$ factor de contribución del acero estructural a la resistencia de un pilar mixto

$\varepsilon_{1} \quad:$ deformación unitaria en sentido transversal

$\eta_{c} \quad: \quad$ factor de conversión de la resistencia a compresión del hormigón

$\eta_{f c} \quad:$ factor de corrección que tiene en cuenta el comportamiento frágil de los hormigones de alta resistencia

$\eta_{i} \quad: \quad$ valor medio del factor de conversión de la propiedad del material $i$

$\theta_{d} \quad: \quad$ valor de cálculo del coeficiente de incertidumbre de un modelo

$\theta_{d} \quad: \quad$ vector de valores de cálculo de los coeficientes de incertidumbre de los modelos

$\boldsymbol{\mu} \quad$ : valores medio de las variables del vector $\boldsymbol{X}$

$\mu_{f y} \quad: \quad$ valor medio del límite elástico del acero estructural

$\mu_{i} \quad: \quad$ coeficiente de forma de la cubierta

$\mu_{M, M} \quad: \quad$ valor medio de la variable auxiliar

$\mu_{p f} \quad: \quad$ valor medio de la probabilidad de fallo

$\mu_{p f, P i l a r} \quad: \quad$ valor medio de la probabilidad de fallo para los pilares

$\mu_{p f \text { Viga }} \quad: \quad$ valor medio de la probabilidad de fallo para las vigas

$\mu_{q} \quad$ : valor medio de la carga de nieve máxima sobre una cubierta para un período de referencia de 50 años

$\mu_{5, \text { max,1 }} \quad$ : valor medio de la carga de nieve máxima anual sobre el terreno horizontal

$\mu_{s, \max , n} \quad$ : valor medio de la carga de nieve máxima sobre el terreno horizontal para un período de referencia de $n$ años

$\mu_{5, z, \max , 50}$ : valor medio de la carga de nieve máxima sobre el terreno horizontal de la zona geográfica, $z$, en función de la altitud, $A$, para un período de referencia de 50 años 


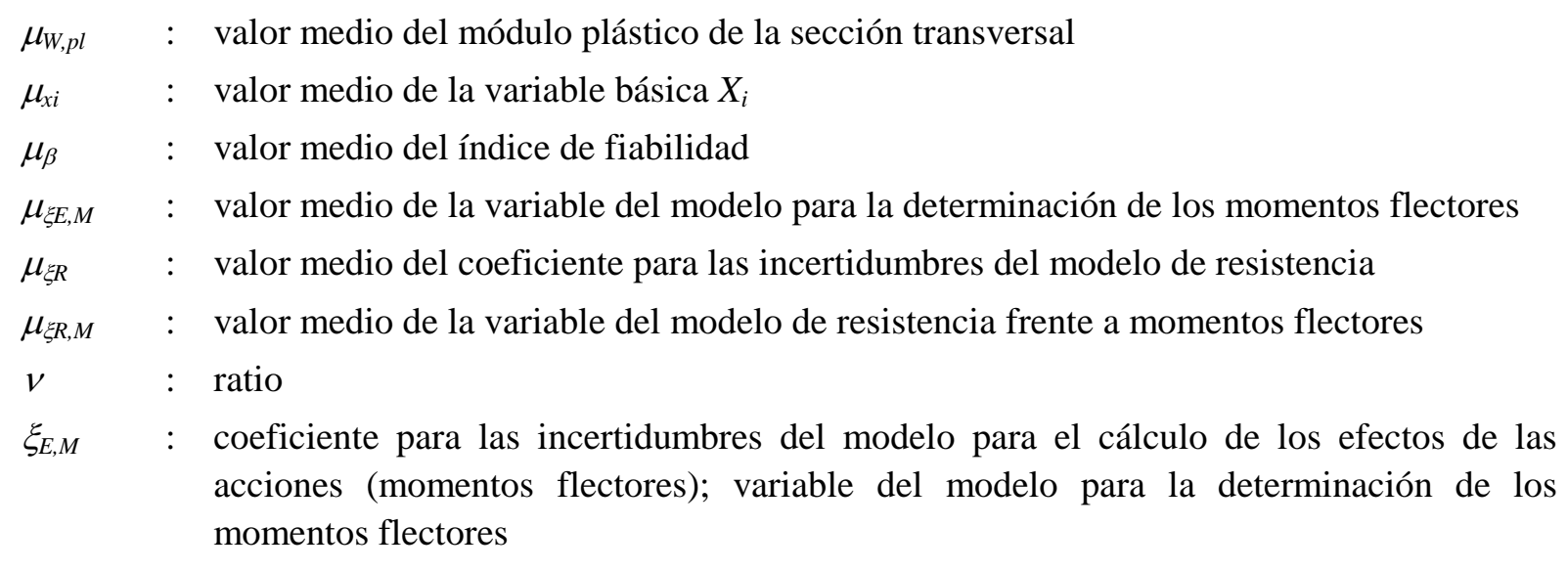

$\xi_{E, M, F O R M, d} \quad: \quad$ valor de cálculo, obtenido mediante el método FORM normalizado, del coeficiente para las incertidumbres del modelo para el cálculo de los efectos de las acciones (momentos flectores)

$\xi_{E, M, k} \quad$ : valor característico del coeficiente para las incertidumbres del modelo para el cálculo de los efectos de las acciones (momentos flectores)

$\xi_{E, N} \quad$ : coeficiente para las incertidumbres del modelo para el cálculo de los efectos de las acciones (esfuerzos axiles)

$\xi_{E, V} \quad$ : coeficiente para las incertidumbres del modelo para el cálculo de los efectos de las acciones (esfuerzos cortantes)

$\xi_{q} \quad: \quad$ coeficiente de incertidumbre del modelo de la carga de nieve sobre la cubierta

$\xi_{R} \quad: \quad$ coeficiente para las incertidumbres del modelo de resistencia

$\xi_{R, i} \quad: \quad$ ratio entre las capacidades portantes real y teórica para la probeta $i$

$\xi_{R, M} \quad$ : coeficiente para las incertidumbres del modelo de resistencia frente a momentos flectores

$\xi_{R, M, k} \quad$ : valor característico de la variable del modelo de resistencia frente a momentos flectores

$\xi_{R, N} \quad: \quad$ coeficiente para las incertidumbres del modelo de resistencia frente a esfuerzos axiles

$\xi_{R, V} \quad$ : coeficiente para las incertidumbres del modelo de resistencia frente a esfuerzos cortantes

$\xi_{R, V c} \quad$ : coeficiente para las incertidumbres del modelo de resistencia frente a la compresión oblicua en el alma

$\xi_{R, V s} \quad: \quad$ coeficiente para las incertidumbres del modelo de resistencia frente a la tracción en el alma

$\xi_{s} \quad$ : coeficiente de incertidumbre del método empleado en la determinación de la carga de nieve sobre el terreno horizontal

$\xi_{z} \quad$ : coeficiente de incertidumbre del modelo para la carga de nieve sobre el terreno horizontal de la zona $z$

$\rho \quad$ : cuantía del acero de armar

$\boldsymbol{\sigma} \quad$ : desviaciones típicas de las variables del vector $\boldsymbol{X}$

$\sigma_{E 1} \quad$ : desviación típica de la variable de la acción o influencia dominante

$\sigma_{f y} \quad: \quad$ desviación típica del límite elástico del acero estructural

$\sigma_{p f} \quad:$ desviación típica de la probabilidad de fallo

$\sigma_{q} \quad$ : desviación típica de la carga de nieve máxima sobre una cubierta para un período de referencia de 50 años

$\sigma_{R 1} \quad$ : desviación típica de la variable de resistencia dominante 
$\sigma_{s, \max , 1} \quad: \quad$ desviación típica de la carga de nieve máxima anual sobre el terreno horizontal

$\sigma_{s, m a x, n} \quad$ : desviación típica de la carga de nieve máxima sobre el terreno horizontal para un período de referencia de $n$ años

$\sigma_{s, z, m a x, 50}:$ desviación típica de la carga de nieve máxima sobre el terreno horizontal de la zona geográfica, z, en función de la altitud, $A$, para un período de referencia de 50 años

$\sigma_{W, p l} \quad: \quad$ desviación típica del módulo plástico de la sección transversal

$\sigma_{x i} \quad$ : desviación típica de la variable básica $X_{i}$

$\sigma_{\beta} \quad:$ desviación típica del índice de fiabilidad

$\sigma_{\xi E, M} \quad$ : desviación típica de la variable del modelo para la determinación de los momentos flectores

$\sigma_{\xi R} \quad:$ desviación típica del coeficiente para las incertidumbres del modelo de resistencia

$\sigma_{\xi R, M} \quad$ : desviación típica de la variable del modelo de resistencia frente a momentos flectores

$\psi_{0} \quad$ : coeficiente para el valor de combinación de una acción variable

$\psi_{0, i} \quad$ : coeficiente para el valor de combinación de la acción variable $i$ 


\section{INTRODUCCIÓN}

\subsection{ANTECEDENTES Y MOTIVACIÓN}

\subsubsection{Contexto}

Terremotos, inundaciones, tempestades, riadas, pero también incendios en túneles o en edificios, desastres industriales, accidentes de tráfico, accidentes aéreos y, por supuesto, colapsos de puentes y de edificios nos recuerdan, con cierta frecuencia, nuestra vulnerabilidad en un entorno natural y tecnológico. Estos eventos no deseados conllevan consecuencias adversas entre las que se pueden mencionar:

- daños personales (víctimas mortales, heridos);

- daños medioambientales;

- alarma social;

- pérdidas económicas, incluidos los costes de reparación y de reconstrucción o la posible interrupción de una actividad económica;

- disminución del bienestar de las personas.

Uno de los retos más importantes para las sociedades modernas consiste en responder mediante actuaciones adecuadas a todas las amenazas, tanto las debidas a las fuerzas de la naturaleza como las generadas por las actividades humanas, que puedan tener consecuencias del tipo mencionado. Es por ello que el proyecto, la realización y la posterior utilización de los sistemas técnicos en general, y de las estructuras de ingeniería civil en particular, siempre implican la consideración de aspectos relacionados con la seguridad, el medio ambiente, así como la economía, con el objetivo de alcanzar un nivel de riesgo aceptable.

En este contexto, una amenaza puede ser cualquier circunstancia con el potencial para causar eventos con consecuencias no deseadas [Schneider 1994, CIB 259 2001]. El término riesgo, por otro lado, se entiende como una función de la frecuencia de ocurrencia de un evento no deseado y de las consecuencias potenciales en caso de producirse este evento. Un riesgo se puede cuantificar, por lo que permite determinar la magnitud de una amenaza. Si los riesgos asociados con un determinado sistema técnico se consideran inaceptables, se deben mitigar mediante medidas que permitan reducir bien la frecuencia de ocurrencia de los eventos no deseados, bien sus consecuencias. También se pueden adoptar diferentes combinaciones de medidas.

Seguridad frente a una amenaza existe si esta, a través de unas medidas adecuadas, se mantiene bajo control o se limita el riesgo correspondiente a un nivel suficientemente pequeño. Todas las posibles medidas tienen un coste mientras que, por otro lado, los recursos necesarios para ponerlas en práctica están limitados, tanto los naturales como los económicos, por lo que se trata de asignarlos de manera óptima buscando un nivel de riesgo mínimo. Este proceso de gestión de los riesgos en el fondo debe responder a dos preguntas fundamentales [Schneider 1994]: ¿qué es suficientemente seguro? y ¿qué precio estamos, como sociedad, dispuestos a pagar para reducir los niveles de riesgo?

Respuestas o actuaciones inadecuadas frente a estas preguntas se manifiestan en sobrerreacciones, tanto por parte del público como de las autoridades. Puede ocurrir, por ejemplo, después de determinados accidentes mediatizados, a través de la adopción de medidas irracionales que conducen a un uso subóptimo de los recursos disponibles, realizando de la mejor manera posible actividades que en realidad no deberían llevarse a cabo. Para evitar el despilfarro de los recursos, es necesario disponer de criterios racionales para adoptar decisiones sobre el nivel aceptable de los riesgos asociados con un determinado sistema o actividad. Por todo ello, en el marco del proyecto de 
cualquier sistema técnico, por ejemplo un puente o la estructura de un edificio, se debe abordar el tema de los riesgos, bien implícitamente, bien explícitamente [CIB 259 2001]:

- En el caso de un tratamiento implícito, los riesgos se mantienen en unos niveles aceptables mediante unas reglas prescriptivas que, sobre la base de la experiencia del pasado y la práctica habitual, se consideran adecuadas para proyectar, construir, utilizar y mantener el sistema objeto del proyecto. Las reglas de esta naturaleza no permiten cuantificar los riesgos asociados con un determinado sistema, por ejemplo una estructura de ingeniería civil.

- Un tratamiento explícito requiere la realización de un análisis de riesgo, tanto cualitativo como cuantitativo, así como la comparación de los resultados obtenidos con unos criterios de aceptación, o requisitos, en términos de los riesgos aceptables.

\subsubsection{Situación actual}

Según la práctica habitual, en la ingeniería estructural los riesgos siempre se han tratado de manera implícita. En este contexto, los objetivos que se persiguen al proyectar, construir, utilizar y mantener una estructura son básicamente dos. Por un lado, la resistencia y la estabilidad de la estructura deben resultar adecuadas para no generar riesgos inaceptables, suponiendo que el umbral entre los riesgos aceptables e inaceptables sea conocido. Por otro lado, el comportamiento estructural en servicio debe responder a las necesidades de los usuarios, en función de la utilización prevista de la obra. Estos objetivos se deben cumplir, con una fiabilidad adecuada y durante un periodo de tiempo establecido, para todas las acciones e influencias a las que la estructura previsiblemente pueda estar sometida [EN 1990 2002, CTE DB SE 2006].

Los anteriores objetivos se consideran alcanzados si una estructura cumple una serie de exigencias. Tradicionalmente, la definición de estas exigencias ha estado y está a cargo de los colectivos profesionales dedicados al proyecto y a la realización de las estructuras. En otras palabras, la ingeniería estructural ha sido, y sigue siendo una disciplina autorregulada [Faber 2002]. A efectos prácticos, esta autorregulación se materializa en normas para el proyecto, la ejecución y, más recientemente, también para la inspección y el mantenimiento de las estructuras. Por definición, la correcta aplicación de las normas que estén en vigor produce estructuras que cumplen con los dos objetivos arriba mencionados [Schneider 1994]. Los resultados obtenidos a través de la mencionada autorregulación mediante normas prescriptivas se describen a continuación.

Aunque poco frecuentes, fallos estructurales, en particular colapsos parciales o totales de las estructuras de ingeniería civil, se producen con cierta regularidad. En Suiza se realizó un estudio de 800 casos en los que se habían producido daños estructurales [Matousek 1976]. A pesar de su antigüedad mantiene toda la validez y aporta información extremadamente útil. Aparte de las causas de los incidentes o accidentes, los autores también analizaron las medidas que hubieran sido necesarias para evitarlos. Los resultados obtenidos constituyen un punto de partida apropiado para mejorar las disposiciones que inciden en la seguridad de las estructuras [Schneider 1994]. No es objeto del presente trabajo analizar en detalle los resultados obtenidos en el citado estudio que, por otro lado, están resumidos en una publicación anterior [Tanner 1999]. Por el interés que tienen en el presente contexto, se reproducen únicamente las causas reales que están en el origen de los 800 fallos analizados (los porcentajes indicados se refieren al número de casos analizados):

- $37 \% \quad$ ignorancia, descuido y negligencia;

- $27 \%$ falta de conocimiento;

- $14 \%$ infravaloración de influencias;

- $10 \%$ olvido y equivocaciones;

- $6 \%$ confianza injustificada en otras personas;

- $6 \%$ influencias objetivamente desconocidas. 
A pesar de que según los autores el $13 \%$ de estos fallos se deben clasificar como prácticamente inevitables [Matousek 1976], las anteriores cifras caracterizan en cierto modo el nivel de calidad de la práctica habitual en el proyecto, la ejecución, la utilización y el mantenimiento de las estructuras, y sugieren la existencia de un potencial para mejorar la situación actual. Ésta se representa de manera más abstracta en la Figura 1.1. A cada sistema técnico se le puede asignar un determinado potencial objetivo de amenazas, aunque resulte imposible conocer su alcance real ya que en la práctica es materialmente imposible identificar la totalidad de las circunstancias que puedan causar daños. De todas las circunstancias que constituyen el potencial objetivo de amenazas, es razonable asumir que resulten detectables aquellas de las que se disponga de alguna experiencia previa, es decir las circunstancias que se hayan producido con anterioridad en algún sistema equiparable, o que se conozcan a través de estudios empíricos o teóricos, disponibles en la literatura. Las restantes circunstancias conforman el conjunto de las amenazas objetivamente desconocidas.

En principio, las amenazas objetivamente conocidas se pueden aceptar conscientemente, o bien contrarrestar a través de las medidas necesarias para que el sistema alcance el nivel de prestaciones requerido. Sin embargo, en la práctica existe una tercera categoría de amenazas: tanto en la identificación de las circunstancias con un potencial para causar daños, como en la adopción de medidas para contrarrestar las amenazas, las personas involucradas en estas actividades pueden cometer errores. De hecho, los riesgos asociados con los errores humanos constituyen la contribución más significativa a los denominados riesgos residuales. La estructura de estos últimos se explica a continuación.

La Figura 1.1 pone de manifiesto que en el marco de la identificación de las circunstancias con el potencial de causar daños, las amenazas objetivamente desconocidas proporcionan una primera contribución a los riesgos residuales. Una segunda contribución corresponde a las amenazas que, aunque objetivamente conocidas, pueden subjetivamente quedarse sin identificar. Las amenazas que se ignoren por el motivo que sea, aportan una tercera contribución.

\begin{tabular}{|c|c|c|c|c|c|c|}
\hline \multicolumn{7}{|c|}{ Potencial objetivo de amenazas } \\
\hline \multicolumn{6}{|l|}{ Objetivamente conocidas } & \\
\hline \multicolumn{5}{|c|}{ Subjetivamente identificadas } & \multirow{5}{*}{ 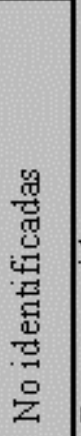 } & \\
\hline \multicolumn{4}{|l|}{ Consideradas } & \multirow{4}{*}{ 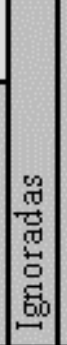 } & & \\
\hline \multicolumn{3}{|c|}{ Medidas de reducción de riesgos } & \multirow{3}{*}{$\begin{array}{l}+3 \\
\mathbb{8} \\
8 \\
0 \\
0 \\
0 \\
0 \\
0 \\
0 \\
0\end{array}$} & & & 10 \\
\hline \multicolumn{2}{|l|}{ Medidas adecuadas } & \multirow{2}{*}{ 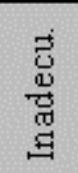 } & & & & 吉 \\
\hline Aplicación correcta & 窂 & & & & & $\stackrel{\bar{a}}{\circ}$ \\
\hline $\begin{array}{c}\text { Seguridad } \\
\text { mediante tratamiento } \\
\text { de riesgos }\end{array}$ & & & & & & \\
\hline
\end{tabular}

Figura 1.1 - Potencial de amenazas, seguridad y riesgos residuales (figura adaptada de [Schneider 1994]). 
Como ya se ha mencionado, las amenazas conocidas que no se consideren aceptables, se suelen contrarrestar a través de medidas de diferente naturaleza. No todas las medidas son adecuadas para mitigar un determinado riesgo. Además, también se puede producir una puesta en práctica errónea de una medida que a priori resultaría apropiada. La adopción de medidas inadecuadas y la aplicación errónea de medidas teóricamente adecuadas, representan dos contribuciones adicionales a los riesgos residuales.

En definitiva, los riesgos residuales se componen por un lado de los riesgos aceptados conscientemente y, por otro lado, de los riesgos debidos a los errores humanos cuyos orígenes son muy variados: son por tanto los riesgos remanentes después de la realización de todas las medidas previstas para el tratamiento y la mitigación de las amenazas. Los riesgos residuales no se pueden eliminar completamente, aunque su reducción a un nivel óptimo debe ser un objetivo a perseguir en el proyecto, la realización, el uso y el mantenimiento de los sistemas técnicos. El hecho de que el 75\% del número total de los fallos estructurales, el $90 \%$ de los daños materiales y el $85 \%$ de los daños personales tengan su origen en algún error humano constituye un poderoso indicio sobre cuáles son los problemas que se deberían abordar de manera prioritaria en vista de una reducción de los riesgos relacionados con las estructuras [Schneider 1994].

A través de un número importante de trabajos significativos en el campo de la fiabilidad estructural, realizados sobre todo durante el último medio siglo en Norteamérica [Freudenthal 1947, Cornell 1969, Turkstra 1972, Hasofer 1974, Ditlevsen 1977] y diferentes países europeos [Mayer 1926, Basler 1961, Ferry-Borges 1971, Rackwitz 1977, Thoft-Christensen 1982, Melchers 1987, Ditlevsen 1989], destacando también las contribuciones españolas [Torroja 1957], se han conseguido importantes avances en la racionalización del tratamiento implícito de los riesgos en las reglas para el dimensionado estructural. En este contexto merecen una mención especial los desarrollos realizados en el seno del Joint Committee on Structural Safety, [JCSS 2001], a los que han contribuido la mayoría de los más destacados investigadores en el campo de la fiabilidad estructural, desde su creación en el año 1971 por parte del Liaison Committee de las asociaciones internacionales de ingeniería estructural (CEB y FIP, ahora fib; CIB; ECCS; IABSE; IASS; RILEM). Estos desarrollos, tanto en el campo de la teoría como en los procedimientos de aplicación, han influido decisivamente en el tratamiento de los riesgos en las normas estructurales internacionales como los Eurocódigos [EN 1990 2002] y, a través de estas, también en la mayoría de las normas nacionales, por ejemplo en España [CTE DB SE 2006, EHE-08 2008, EAE 2011, IAP-11 2012].

A pesar de todos los avances teóricos y prácticos, que se han producido en paralelo con el desarrollo de los métodos de cálculo numérico que finalmente son los que hacen viable la aplicación de la teoría de la fiabilidad estructural [Schneider 1997], las reglas normalizadas están dominadas por un enfoque implícito para el tratamiento de los riesgos. El carácter prescriptivo de estas reglas, anteriormente mencionado, hace que su aplicación práctica conduce a una serie de problemas. El primero de ellos se pone de manifiesto a través del anterior resumen de la situación actual: en el proyecto, la construcción, la utilización y el mantenimiento de las estructuras, con cierta frecuencia no se tienen en cuenta todas las amenazas objetivamente conocidas, lo que explica en parte la abrumadora importancia relativa de los errores humanos en los incidentes y accidentes.

Debido a que los criterios de aceptación para la mayoría de los requisitos estructurales se basan sobre todo en la experiencia del pasado, un segundo conjunto de problemas estriba en que se desconoce la probabilidad de fallo real de las estructuras proyectadas y construidas según las reglas normalizadas. A su vez, esta probabilidad real depende fuertemente de los errores humanos anteriormente mencionados [Ditlevsen 1980]. Por la combinación de estas circunstancias (al estar las probabilidades de fallo afectadas por grandes dispersiones, no solamente las reales sino también las nominales, y al basarse los valores admisibles de estas probabilidades en la experiencia del pasado), también los 
criterios de aceptación para las estructuras están afectados por importantes dispersiones [Tanner 2010]. Finalmente, mientras algunas normas establecen diferentes criterios de aceptación en función de la gravedad de las consecuencias de un posible fallo [EN 1990 2002] otras, particularmente también las normas españolas que están en vigor [CTE DB SE 2006, EHE-08 2008, EAE 2011, IAP11 2012], no hacen esta distinción.

La falta de un enfoque totalmente racional en los criterios de aceptación de los riesgos que se manifiesta en la situación anteriormente descrita no es exclusiva de la ingeniería estructural. Una situación análoga se produce también en otros campos de la técnica y de la salud pública, lo que se traduce en una gran dispersión de los riesgos asociados con diferentes actividades de la vida diaria, tal y como reflejan los números de la Tabla 1.1.

Tabla 1.1 - Riesgo mortal individual relativo para diferentes actividades (valores para Reino Unido, deducidos de [Hambly 1994]).

\begin{tabular}{|l|c|}
\hline Actividad & $\begin{array}{c}\text { Muertos por 100 millones de } \\
\text { horas de exposición }\end{array}$ \\
\hline Viajar en helicóptero & 500 \\
Andar por un arcén & 20 \\
Viajar en coche & 15 \\
Construcción & 5 \\
Colapso de edificios & 0,002 \\
Colapso de puentes & 0,000002 \\
\hline
\end{tabular}

Debido a que la puesta en práctica de cualquier medida de seguridad adecuada conduce a una reducción de los riesgos (Figura 1.1), y debido a que estas medidas tienen un coste económico, resulta interesante expresar la eficacia de diferentes medidas en términos de la ratio entre su coste y la reducción del riesgo que conlleva. Si esta reducción se expresa en términos de la disminución de los casos de muerte prematura, se obtiene el coste por vida salvada, asociado a una determinada medida. La Tabla 1.2 representa la eficacia de diferentes medidas de seguridad [Schneider 1994]. Las cifras dejan entrever que, aparte de medidas de seguridad que resultan muy económicas, y otras que subjetivamente parecen razonables, también hay algunas difícilmente justificables. El hecho de que en muchos casos se adopten medidas poco eficaces sugiere que la aversión social a ciertos riesgos podría tener un peso excesivo en la adopción de las decisiones [CIB 259 2001]. Eso a su vez permitiría explicar, por lo menos parcialmente, el gasto subóptimo de los recursos disponibles y, en cualquier caso, comparaciones de este tipo son un indicio de que en muchos campos de la técnica y la salud pública las decisiones sobre el nivel aceptable de los riesgos no obedecen a criterios racionales.

Un tercer tipo de problemas asociados con la mayoría de las normas actuales en el campo de las estructuras de ingeniería civil es intrínseco a su carácter básicamente prescriptivo. Las normas y los reglamentos técnicos se tienen que basar siempre en el estado del arte consolidado del sector que deben regular. Existe por tanto un desfase entre los desarrollos más novedosos y los textos normativos que estén en vigor. Este desfase es inevitable y su alcance depende de múltiples factores, por ejemplo la dinámica innovadora en el sector en cuestión o la periodicidad de la renovación de las normas. Debido a este desfase, los métodos prescriptivos para el tratamiento de los requisitos estructurales no son suficientes para abordar problemas relacionados con tecnologías novedosas y complejas. Consecuentemente, las normas basadas en este enfoque pueden retrasar o incluso imposibilitar la implementación de ciertos avances innovadores. Esta problemática resulta particularmente acusada si las normas no solamente son prescriptivas sino, además, de obligado 
cumplimiento, como por ejemplo en España [CTE DB SE 2006, EHE-08 2008, EAE 2011, IAP-11 2012].

Tabla 1.2 - Eficacia de diferentes medidas de seguridad (valores según [Schneider 1994] para, respectivamente, paises en vías de desarrollo, Suiza (CH) y Reino Unido (GB)).

\begin{tabular}{|l|c|}
\hline Medida & $\begin{array}{c}\text { Coste por vida salvada } \\
{[\mathbf{1 0} \boldsymbol{\mathbf { \epsilon }} / \text { vida salvada] }}\end{array}$ \\
\hline Vacuna múltiple (países en vías de desarrollo) & 0,06 \\
Equipo de rayos X (CH) & 1,3 \\
Helicóptero de emergencias (CH) & 33,3 \\
Reordenación cruce de carreteras $(\mathrm{CH})$ & 200 \\
Medidas de seguridad en túnel ferroviario $(\mathrm{CH})$ & 3.300 \\
Norma sismorresistente $(\mathrm{CH})$ & 6.600 \\
Prescripciones para rascacielos $(\mathrm{GB})$ & 66.000 \\
Eliminación amianto en edificio escolar $(\mathrm{CH})$ & 660.000 \\
\hline
\end{tabular}

\subsubsection{Enfoques prestacionales}

Los efectos potencialmente inhibidores de las reglas implícitas de las normas actuales, igual que los otros problemas anteriormente descritos (amenazas objetivamente conocidas que, con una cierta frecuencia, se quedan sin contemplar; las probabilidades de fallo reales y nominales de las estructuras dimensionadas según las citadas reglas están afectadas por incertidumbres; los requisitos que deben cumplir las estructuras a menudo no dependen de las consecuencias esperadas de un posible fallo), así como las desventajas que se derivan de todos ellos, se han reconocido hace tiempo. Por la relevancia de toda esta problemática, ciertas normas estructurales recientes permiten aplicar los métodos explícitos de análisis de riesgo en los proyectos estructurales [ISO 2394 1998, EN 1990 2002]. Algunas administraciones también han promovido el desarrollo de directrices y reglamentos relativos a la evaluación y la gestión de los riesgos tecnológicos y naturales en general [BUWAL 1991a, BUWAL 1991b, AS/NZS 4360 1999]. Los métodos y procedimientos contenidos en este tipo de documentos son aplicables, directamente o por analogía, a cualquier sistema técnico, por tanto también a las estructuras de ingeniería civil. En la misma línea, pero más recientemente, en foros internacionales como la Organización para la Cooperación y el Desarrollo Económico (OECD, en sus siglas en inglés) se están debatiendo posibles enfoques integrales que permitan adoptar, de manera racional y transparente, decisiones acerca de la evaluación, el tratamiento y la aceptación de los riesgos en todos los campos, a escala global, abarcando la gestión de los riesgos relacionados con amenazas del entorno natural, accidentes industriales, desastres nucleares, seguridad vial, salud pública o ayuda al desarrollo [Faber 2012].

Volviendo al campo de los sistemas técnicos en general, y en particular las estructuras de ingeniería civil, la tarea última de los técnicos involucrados en su proyecto, realización, uso y mantenimiento consiste en adoptar las decisiones necesarias para asegurar que los sistemas cumplan con todos los requisitos establecidos. Estos están relacionados con la seguridad de las personas expuestas al sistema, los efectos de éste sobre el ambiente, así como su eficacia económica para servir al fin previsto [Faber 2002]. En este contexto, el empleo de los métodos explícitos para la evaluación y la gestión de los riesgos asociados con las estructuras conllevan una serie de ventajas frente a los enfoques tradicionales, basados en un tratamiento implícito [Tanner 2005]: 
- La realización sistemática de un análisis cualitativo de los riesgos puede contribuir al objetivo de la identificación de todas las amenazas objetivamente conocidas. Una vez identificadas, es posible adoptar las medidas necesarias para mitigar los riesgos asociados, reduciendo por tanto los riesgos residuales (Figura 1.1).

- Un análisis explícito de los riesgos asociados con diferentes conjuntos representativos de sistemas técnicos permite una comparación objetiva de los resultados obtenidos. A su vez, estudios comparativos de este tipo permiten extraer conclusiones sobre los niveles aceptables de los riesgos asociados con distintos sistemas técnicos: contribuyen al establecimiento de una base racional para la adopción de decisiones acerca de la aceptación de determinados sistemas técnicos.

- En general, la disponibilidad de una base racional para tomar decisiones permite abordar tareas relevantes, por ejemplo: calibración de los modelos implícitos para las acciones y la resistencia de modo que su empleo en el marco de un dimensionado estructural mediante un método como el de los coeficientes parciales, recogido por la mayoría de las normas actuales, conduzca a resultados comparables a los que resultarían de un análisis explícito; optimización de determinadas soluciones; justificación de soluciones innovadoras; evaluación de la fiabilidad de las estructuras existentes para las condiciones de uso actuales y futuras; investigación de los mecanismos y las causas de colapsos estructurales en el marco de investigaciones periciales [Tanner 2013a]; etcétera.

- Mediante un análisis explícito también es posible cuantificar la influencia de diferentes medidas -tales como la puesta en práctica de procedimientos de aseguramiento de la calidad; inspección y mantenimiento; instalación de sistemas de alarma; etcétera- en los riesgos asociados con un determinado sistema técnico. Los métodos explícitos constituyen por tanto una herramienta para establecer un concepto global de seguridad.

- La aplicación de los métodos explícitos de análisis de riesgo conlleva una representación transparente de las prestaciones de las estructuras, lo que a su vez facilita la comunicación entre expertos y público. Una buena comunicación es importante en muchos casos, por ejemplo cuando los expertos sólo participan en la determinación de las bases de decisión (niveles de fiabilidad exigibles a los sistemas y los costes asociados), mientras que las decisiones finales están siendo adoptadas por personas no especializadas [CIB 259 2001].

En la actualidad existen todavía lagunas que dificultan la implementación práctica de los métodos explícitos en los proyectos estructurales. Aunque formalmente admitidos por determinadas normas, como se ha mencionado [ISO 2394 1998, EN 1990 2002, CTE DB SE 2006], éstas definen básicamente un marco y unos procedimientos genéricos para los análisis de riesgo, pero no contienen los modelos necesarios para facilitar su aplicación práctica. Por otro lado, las presiones económicas y de tiempo que rigen las actividades de ingeniería, imposibilitan normalmente la elaboración de las bases necesarias para llevar a cabo un análisis explícito en el marco de un proyecto estructural.

Pero estos aspectos técnicos y circunstanciales no son los únicos motivos por los que en la práctica diaria los métodos explícitos de análisis de riesgo están muy poco extendidos. También existen motivos administrativos y legales. En comparación con los métodos implícitos, de carácter prescriptivo, los explícitos o prestacionales le brindan al técnico que los aplique un mayor grado de libertad en el momento de adoptar una determinada solución, o de justificar que ésta cumpla con los requisitos relevantes. Por otro lado, un mayor grado de libertad normalmente también implica más responsabilidad ya que, por lo menos aparentemente, el técnico que aplique un documento normativo con reglas implícitas delega una parte de la suya en los comités de redacción de estas normas o en los organismos de normalización [Jiménez Losada 2005, Tanner 2007a]. Resulta extremadamente difícil calibrar los efectos de la aplicación de los métodos explícitos de análisis de riesgo sobre la 
responsabilidad de los técnicos [Jiménez Losada 2005] por lo que éstos, para evitar posibles problemas, en la práctica ni siquiera suelen considerar la posibilidad de usarlos.

\subsubsection{Contribución al desarrollo de herramientas prácticas}

A la vista de la situación anteriormente expuesta, existe la necesidad de desarrollar métodos y modelos pragmáticos, aptos para aplicaciones prácticas en el campo del análisis de los riesgos inherentes a las estructuras de ingeniería civil. Además, también se requiere una base racional para la adopción de decisiones sobre la aceptación de estos riesgos.

Como ya se ha mencionado, riesgo es un término cuantitativo que, en un contexto técnico, se entiende como una previsión matemática de las consecuencias de un evento no deseado. En su forma más sencilla, el riesgo $R$ se representa como el producto de la probabilidad de ocurrencia de un evento no deseado, por ejemplo la probabilidad de fallo de una estructura, y del valor esperado del daño en caso de producirse el citado evento, por ejemplo las consecuencias esperadas de un determinado fallo estructural. Considerando un sólo evento no deseado, el riesgo se puede expresar a través de la ecuación (1.1). $R$ tiene la misma unidad que el valor esperado del daño, por ejemplo una unidad monetaria o el número de víctimas:

$R=P \cdot C$

$P \quad:$ : probabilidad de ocurrencia de un evento no deseado

C : valor esperado del daño en caso de producirse un determinado evento no deseado; consecuencias esperadas de un determinado evento no deseado

Para elementos tales como los componentes de sistemas eléctricos, por ejemplo las bombillas, existe una enorme cantidad de datos sobre fallos. Su probabilidad o frecuencia de fallo se puede evaluar sobre la base de un análisis estadístico de los eventos de fallo observados. En estructuras de ingeniería civil u otros sistemas que se caractericen por la demanda de una determinada capacidad (capacity-demand systems), los fallos son poco frecuentes por lo que no existe información estadísticamente relevante al respecto. En estos casos, la previsión de las frecuencias o probabilidades de fallo requiere la aplicación de métodos de fiabilidad. Estos métodos se pueden aplicar a efectos de la evaluación de la probabilidad de fallo de las estructuras de ingeniería civil, para lo que se deben conocer los modelos probabilistas de las variables relevantes.

Por otro lado, la estimación del segundo factor de la ecuación (1.1), las consecuencias de un evento no deseado del tipo de un colapso estructural, constituye posiblemente una de las tareas más difíciles en el marco de un análisis de riesgo, tal y como apuntan algunos investigadores [Rackwitz 2002]. De todas las posibles consecuencias adversas de unos eventos no deseados (Apartado 1.1.1), incluyendo daños personales, daños medioambientales y pérdidas económicas, directas e indirectas, en ingeniería en general, y en la ingeniería civil en particular, los riesgos para las personas suelen ser dominantes. Eso es debido tanto a motivos éticos como a razones legales. Consecuentemente, se puede simplificar la representación de las consecuencias de los fallos estructurales teniendo en cuenta únicamente las víctimas mortales.

A través de esta hipótesis, el riesgo mortal no solamente se considera como siendo representativo para los posibles daños personales en general (víctimas mortales, heridos de diferente gravedad) sino, en un sentido más amplio, se considera representativo de los riesgos inherentes a un sistema técnico, como puede ser la estructura portante de una obra de ingeniería. Ante este trasfondo, el presente estudio se centra en el desarrollo de unas herramientas prácticas para la evaluación y la aceptación de los riesgos para las personas, asociados con las estructuras portantes de ingeniería civil. 


\subsection{ALCANCE}

De acuerdo con la ecuación (1.1), cualquier análisis de riesgo requiere un estudio tanto de la frecuencia de ocurrencia de los eventos no deseados como de sus consecuencias potenciales. Debido a que el presente estudio se refiere a las estructuras de ingeniería civil, una adecuada estimación de los riesgos inherentes a estos sistemas requeriría, en principio, el estudio sistemático de todo tipo de estructuras, materiales constitutivos y fallos:

- las estructuras de edificación y de las obras públicas tales como puentes, túneles, obras portuarias, etcétera;

- estructuras constituidas por los materiales de construcción más relevantes como acero estructural, hormigón armado y pretensado, mixtas de acero y hormigón, madera, fábrica e incluso materiales compuestos del tipo CFRP (Carbon Fibre Reinforced Plastic), poco extendidos en la actualidad;

- fallos estructurales que conducen a, respectivamente, un comportamiento inadecuado en servicio, problemas de durabilidad, el colapso parcial o total del sistema.

Por su variedad y amplitud, no es posible abarcar todos los anteriores aspectos en el marco de un único trabajo. Es necesario, por tanto, limitar el alcance del presente estudio, con una primera restricción en relación al tipo de obras a contemplar. Se consideran únicamente las estructuras de edificación, lo que no solamente por su número e importancia parece una selección razonable, sino también por la coincidencia de las siguientes circunstancias. Por un lado, el riesgo para las personas asociado con un determinado sistema depende, entre otros muchos parámetros, de la duración de la exposición. Resulta que el tiempo que las personas pasan dentro de un edificio, ya sea su vivienda, un edificio de oficinas, un edificio industrial, etcétera, supera ampliamente al tiempo que puedan encontrarse dentro de un túnel o sobre un puente, para mencionar solo estos ejemplos. Pero no solamente el tiempo de exposición resulta mayor, sino también el riesgo mortal individual asociado con los edificios, en comparación con el relativo a los puentes (Tabla 1.1).

La siguiente limitación se refiere a los materiales constitutivos de las estructuras. Con la excepción de algún prototipo, en la práctica los materiales compuestos (CFRP o similar) no se han empleado en elementos resistentes de estructuras de edificación. Y tampoco parece verosímil que esta situación vaya a cambiar en un futuro próximo, básicamente por motivos económicos. Consecuentemente, en el marco del presente estudio no se tienen en cuenta las estructuras constituidas por elementos de materiales compuestos.

En el otro extremo de la modernidad de los materiales de construcción, tampoco se contemplan las estructuras constituidas por uno de los más tradicionales de todos los materiales que todavía estén en uso, las estructuras de fábrica. En este caso, el motivo se debe a que en la actualidad el empleo de los sistemas resistentes de fábrica se limita normalmente a los edificios de dimensiones reducidas, o a elementos secundarios (tabiques, etcétera) en edificios de mayor envergadura. En este tipo de aplicaciones, el nivel de solicitaciones suele estar muy por debajo de la capacidad resistente de las fábricas. Por ello se estima subjetivamente que su contribución a los riesgos inherentes a las estructuras de ingeniería civil sea pequeña, motivo por el que no se tienen en cuenta en el presente estudio.

La tercera limitación se refiere al tipo de fallos estructurales. Solamente se tienen en cuenta aquellos que se traducen en un colapso parcial o total de la estructura afectada. Otras formas de fallos, tales como un inadecuado comportamiento estructural en servicio, o problemas de durabilidad, también constituyen una fuente de preocupación para la propiedad de una obra. No obstante, debido a que las consecuencias de un colapso de una estructura predominan sobre las consecuencias de otros posibles modos de fallo, en el marco del presente trabajo se asocia un evento no deseado al colapso, total o parcial, de una estructura. Esta limitación es consistente con lo manifestado en el Apartado 1.1.4, en 
el sentido de que las consecuencias de los fallos estructurales se representan a través del número de víctimas mortales.

Excluyendo como posible causa los errores humanos graves (Apartado 1.1.2), un colapso estructural puede tener su origen en desviaciones desfavorables de los valores previstos para los efectos de las acciones o las resistencias correspondientes. En cuanto a las primeras, se consideran únicamente las posibles desviaciones relacionadas con las condiciones normales de uso de los edificios: las correspondientes a los valores extremos de las sobrecargas de uso, las acciones climáticas, etcétera. No se tienen en cuenta, por tanto, las denominadas situaciones accidentales [EN 1990 2002, CTE DB SE 2006] que por falta de datos a menudo no se pueden caracterizar estadísticamente.

De acuerdo con lo anterior, en el marco del presente trabajo se desarrollan métodos, modelos y requisitos que permitan, por un lado, analizar los riesgos asociados con las estructuras de edificación $\mathrm{y}$, por otro, decidir de manera racional sobre su aceptación. El alcance del estudio está caracterizado por las siguientes limitaciones:

- se estudian estructuras de edificación constituidas por los materiales de construcción más habituales, respectivamente acero estructural, hormigón armado, mixtas de acero y hormigón, así como madera laminada encolada;

- como eventos no deseados se consideran únicamente los colapsos parciales y totales de los sistemas estructurales;

- se considera que el origen de estos colapsos se encuentre en las posibles desviaciones desfavorables de los valores previstos para los efectos de las acciones o las resistencias correspondientes, relacionadas con las condiciones normales de uso (situaciones persistentes según la terminología de las normas actuales [EN 1990 2002, CTE DB SE 2006]); eso implica asumir que los colapsos no se deben a situaciones accidentales ni a posibles errores humanos graves;

- la frecuencia de ocurrencia de los eventos no deseados (colapsos estructurales) se cuantifica en términos de su probabilidad de fallo asociada a un determinado periodo de tiempo;

- las consecuencias de estos eventos no deseados se representan exclusivamente a través de la pérdida de vidas humanas.

Consecuentemente, los análisis de riesgo y la definición de los criterios de aceptación se realizan, en el presente estudio, en términos de los riesgos para las personas.

\subsection{OBJETIVO}

El objetivo del presente trabajo consiste en el desarrollo de métodos, modelos y requisitos que contribuyan a establecer una base racional para la adopción de decisiones en relación con los riesgos para las personas asociados con las estructuras de edificación, en vista de facilitar no solamente el dimensionado estructural basado en prestaciones, sino también la evaluación de la fiabilidad de las estructuras existentes. Se han identificado cinco temas de estudio que es necesario abordar para alcanzar el objetivo del trabajo:

- Estudio de los principios básicos de los métodos explícitos de análisis de riesgo, así como su relación con el tratamiento implícito de los riesgos asociados con las estructuras, de acuerdo con la práctica habitual.

- Definición de un procedimiento sencillo para el análisis cualitativo y cuantitativo de los riesgos para las personas asociados con las estructuras de edificación. Este procedimiento debe ser compatible con los métodos actualmente disponibles y generalmente aceptados, tanto explícitos como implícitos. 
- Desarrollo de modelos probabilistas, tanto para las acciones sobre las estructuras de edificación como para la resistencia de éstas, aptos para ser empleados en un análisis de riesgo explícito.

- Desarrollo de modelos matemáticos sencillos para la estimación de las consecuencias de los colapsos estructurales, en términos del número esperado de víctimas mortales.

- Determinación de las prestaciones requeridas de las estructuras de edificación en términos de su probabilidad de fallo admisible o, lo que es equivalente, el nivel de fiabilidad requerido, así como los riesgos aceptables para las personas.

El dimensionado de las estructuras de edificación mediante métodos explícitos sólo es posible en el marco de un concepto para la evaluación y la gestión de los riesgos asociados con los sistemas técnicos que sea pragmático y de fácil aplicación. Consecuentemente, en el presente trabajo se propone un procedimiento específico para la evaluación de los riesgos asociados con las estructuras de edificación, en cuya elaboración se tienen en cuenta reconocidos trabajos de investigación sobre el análisis de los riesgos tecnológicos y naturales [AS/NZS 4360 1999, CIB 259 2001, Faber 2002, JCSS 2008]. Los análisis de riesgo se efectúan necesariamente sobre la base de la información acerca de las acciones, sus efectos y las resistencias correspondientes, que está sujeta a incertidumbres cuyo modelado resulta fundamental en este contexto. Por este motivo, en el presente trabajo se desarrollan unos modelos probabilistas para las acciones, sus efectos y la resistencia estructural que tienen en cuenta todas las incertidumbres relevantes. También resulta imprescindible, en el marco de un análisis de riesgo, estimar las consecuencias de un posible fallo estructural. Se desarrollan por ello unos modelos de consecuencias sencillos, pero suficientemente precisos, a efectos de su aplicación práctica. Posteriormente, los modelos probabilistas para las acciones, sus efectos y la resistencia estructural se emplean para deducir la probabilidad de fallo admisible y el nivel de fiabilidad requerido para los elementos estructurales. Los mismos modelos, en combinación con los de las consecuencias, se utilizan también para deducir los riesgos admisibles para las personas, asociados con las estructuras de edificación. El conocimiento de estos datos es fundamental en el presente contexto ya que los resultados de los análisis de riesgo se deben comparar siempre con unos criterios de aceptación, o requisitos, con el fin de tomar decisiones sobre el sistema analizado.

\subsection{ORGANIZACIÓN DE LA TESIS}

El presente apartado contiene una visión de conjunto del procedimiento empleado en este trabajo, así como su relación con los temas de estudio identificados y los capítulos de la tesis. El examen de los métodos de análisis de riesgo explícitos e implícitos, así como la relación entre ambos enfoques, está basado en un amplio estudio de la literatura especializada (Capítulos 2 y 3), con el fin de aplicar las conclusiones de los trabajos provenientes de diferentes campos de la técnica a las estructuras de edificación. Las conclusiones extraídas se reflejan en la metodología y las hipótesis adoptadas para el desarrollo de unos modelos y requisitos destinados al análisis explícito de los riesgos asociados con estas estructuras (Capítulos 4 y 5). Uno de los aspectos centrales de la tesis consiste en el desarrollo de los modelos necesarios para la determinación de las probabilidades de fallo estructural (Capítulo 6) y de las consecuencias correspondientes en caso de producirse un fallo (Capítulo 7). Estos modelos se utilizan a continuación para deducir unos requisitos consistentes para la seguridad estructural (Capítulo 8).

\section{Introducción}

- Partiendo de la necesidad de mantener los riesgos asociados con los sistemas técnicos en general dentro de unos límites aceptables, la tesis se inicia en el Capítulo 1 con un resumen de la situación actual en la ingeniería estructural y en otros campos de la técnica. Este breve análisis permite observar que la práctica actual dista de ser óptima desde el punto de vista de la 
asignación de los recursos disponibles para la reducción de los riesgos, existiendo un considerable potencial de mejora a través de la aplicación de métodos explícitos de análisis de riesgo. Se presentan los desarrollos necesarios a estos efectos, así como las ventajas inherentes a un enfoque de este tipo. Este repaso permite fijar el objetivo, el alcance y los límites, así como los temas de estudio de la tesis.

\section{Métodos de análisis de riesgo explícitos e implícitos}

- Los principios del análisis de los riesgos tecnológicos y naturales en general y, en particular, su aplicación al tratamiento de los riesgos en el campo de la ingeniería civil son objeto del Capítulo 2. Se introducen los planteamientos más habituales para realizar este tipo de análisis, así como diferentes criterios de aceptación de los riesgos inherentes a un determinado sistema.

- En el Capítulo 3 se introducen los métodos probabilistas disponibles para determinar la fiabilidad de las estructuras de ingeniería civil. También se tratan los niveles habitualmente requeridos para la fiabilidad nominal de las estructuras. A continuación, se presentan los denominados métodos implícitos, basados en el formato de los coeficientes parciales, que se emplean normalmente en la práctica diaria a efectos de la verificación de la seguridad de las estructuras. Se analiza un aspecto relevante en el contexto del presente trabajo, la relación existente entre ambos tipos de métodos, respectivamente los explícitos y los implícitos. Finalmente, según las normas y la práctica actuales, la seguridad suele tratarse a nivel de las secciones transversales de los elementos resistentes, motivo por el que se abordan los aspectos básicos de la fiabilidad de los sistemas estructurales.

\section{Metodología e hipótesis}

- En el marco de la presente tesis se adopta un concepto específico para la evaluación de los riesgos, ajustado al caso de las estructuras de edificación y a la vez compatible con los métodos genéricos del análisis de los riesgos tecnológicos y naturales. Este concepto integra métodos de análisis cualitativo y cuantitativo de los riesgos, permite una representación intuitiva de los riesgos para las personas, tanto los individuales como los colectivos, y es apto para la adopción de decisiones sobre la aceptación de los riesgos, así como para la valoración, en su caso, de la influencia de las medidas adoptadas para la reducción de los riesgos. En este concepto, que se explica en el Capítulo 4, se basa el procedimiento adoptado para el posterior desarrollo de las herramientas prácticas, según el objetivo de esta tesis.

- En el Capítulo 5 se presentan las bases para la elaboración de los modelos necesarios para la evaluación de los riesgos para las personas, asociados con las estructuras de edificación, y de los criterios para su aceptación. Se definen los diferentes tipos de estructuras a estudiar, los sistemas resistentes, así como los elementos y materiales constitutivos, de modo que su análisis conduzca a unos resultados representativos para los edificios. Se describen los mecanismos de fallo considerados en los análisis y se formulan las correspondientes funciones de estado límite.

\section{Incertidumbres}

- Las incertidumbres asociadas con las diferentes variables que intervienen en un análisis estructural, y de las que dependen las probabilidades de fallo y finalmente los riesgos, se analizan en el Capítulo 6. Para cuantificar estas incertidumbres, de origen variado, se desarrollan unos modelos probabilistas para las acciones, sus efectos y la resistencia correspondiente de las estructuras. Estos modelos cumplen con una serie de requisitos previamente establecidos, siendo uno de ellos su aptitud para ser utilizados en la práctica, a efectos de un análisis de riesgo. 


\section{Consecuencias}

- El modelado de las consecuencias de los colapsos de las estructuras de edificación es objeto del Capítulo 7. Los datos recopilados sobre accidentes reales se complementan con la información proveniente de otras fuentes y se introducen en una base de datos. Mediante análisis estadísticos se desarrollan unos modelos de consecuencias para las personas, en términos del número esperado de víctimas mortales en caso de producirse un colapso estructural.

\section{Requisitos}

- Siguiendo los procedimientos establecidos y utilizando los modelos desarrollados en los Capítulos 4 a 7, el Capítulo 8 está dedicado al establecimiento de los requisitos de seguridad estructural. Estos se representan en términos de la probabilidad de fallo admisible y la fiabilidad requerida para los elementos estructurales, así como los riesgos admisibles para las personas, tanto a nivel individual como colectivo.

\section{Observaciones finales}

- La tesis finaliza en el Capítulo 9 con una serie de observaciones que incluyen los logros alcanzados, las principales conclusiones, así como algunas propuestas para los desarrollos y trabajos futuros. 


\section{PRINCIPIOS BÁSICOS}

\subsection{INTRODUCCIÓN}

Según lo especificado en el Apartado 1.1, en un contexto técnico y por tanto en el marco de la ingeniería estructural, el término riesgo se refiere a una previsión matemática de las consecuencias de un evento no deseado. La representación del riesgo a través de la ecuación (1.1), para el caso más sencillo de una única actividad con un posible evento no deseado, deja entrever una de las grandes dificultades que surgen en este contexto. Se debe a las probabilidades de ocurrencia muy pequeñas de los eventos no deseados, en combinación con valores elevados para el daño esperado, por lo que la consideración del riesgo como el producto de dos factores según la citada ecuación (1.1) llega a sus límites de validez. Se produce lo que se podría llamar el dilema "cero multiplicado por infinito" que con frecuencia lleva a abstenerse de una determinada actividad o solución ya que el daño máximo imaginable, que es el parámetro decisivo, no se puede o no se quiere asumir [Schneider 1994].

Un análisis de riesgo se puede realizar con diferentes grados de detalle, aunque en la actualidad no existe ningún sistema de clasificación generalmente aceptado. En el campo de la industria nuclear, por ejemplo, es frecuente distinguir entre tres niveles de análisis [Faber 2002]:

- Nivel 1: análisis de la probabilidad de ocurrencia de determinados eventos críticos que se pueden producir en una central nuclear.

- Nivel 2: análisis de la probabilidad de ocurrencia de determinados eventos críticos y de sus consecuencias en caso de que se produzcan.

- Nivel 3: análisis de la probabilidad de ocurrencia de determinados eventos críticos y de sus consecuencias, incluidos los efectos sobre las personas y la pérdida de vidas humanas.

Tanto las dificultades asociadas con el tratamiento de las probabilidades pequeñas en combinación con grandes consecuencias, como los múltiples grados de detalle para la realización de los análisis, hacen necesario establecer unos principios claros como punto de partida y base para la continuación del presente trabajo. Los propósitos de esta parte del estudio son por ello:

- revisión de los procedimientos más relevantes para el análisis de los riesgos tecnológicos y naturales;

- evaluación de los criterios de aceptación de los riesgos asociados con los sistemas técnicos;

- adquisición de la información necesaria para el posterior desarrollo de un concepto adecuado para el análisis de los riesgos asociados con las estructuras de edificación.

En el Apartado 2.2 se presenta un proceso genérico de decisión basado en los riesgos relacionados con los sistemas técnicos. El proceso es compatible con el marco global para la gestión de los riesgos relacionados con los sistemas técnicos, propuesto en la literatura especializada más relevante. Se trata por tanto de un proceso generalmente aceptado que engloba todas las actividades necesarias para tomar decisiones basadas en riesgos.

Un resumen del estudio de los criterios de aceptación de los riesgos se encuentra en el Apartado 2.3. Se recopilan los requisitos más relevantes en relación con los riesgos para las personas, tanto a nivel individual como colectivo, así como los criterios económicos que brindan la posibilidad de tratar el nivel aceptable de los riesgos en términos de un problema de optimización monetaria. Finalmente, también se abordan los criterios de aceptación basados en indicadores sociales.

El Apartado 2.4 contiene una serie de observaciones finales que destacan particularmente aquellos aspectos del capítulo que resulten relevantes para la continuación de la tesis. 


\subsection{PROCESO DE DECISIÓN BASADO EN RIESGOS}

\subsubsection{Procedimiento genérico}

El marco global para la gestión de los riesgos asociados con un sistema técnico se ilustra en la Figura 2.1, adaptada del código de Australia y Nueva Zelanda sobre la materia [AS/NZS 4360 1999]. La parte central constituye el núcleo del procedimiento, englobando respectivamente los análisis cualitativo y cuantitativo de los riesgos. La adopción de decisiones basadas en la consideración de los riesgos asociados con un determinado sistema afecta a numerosos agentes e intereses, por lo que es necesario establecer mecanismos de comunicación y consulta con las partes interesadas. Sobre todo en grandes proyectos, la gestión de los riesgos es un proceso dinámico, con la incorporación continua de nueva información, por lo que también deben ser continuos los mecanismos de control y revisión de las decisiones acerca de las prestaciones del sistema analizado. Tal y como lo pone de manifiesto la Figura 2.1, están interrelacionados todos los elementos que constituyen el proceso de gestión de riesgos.

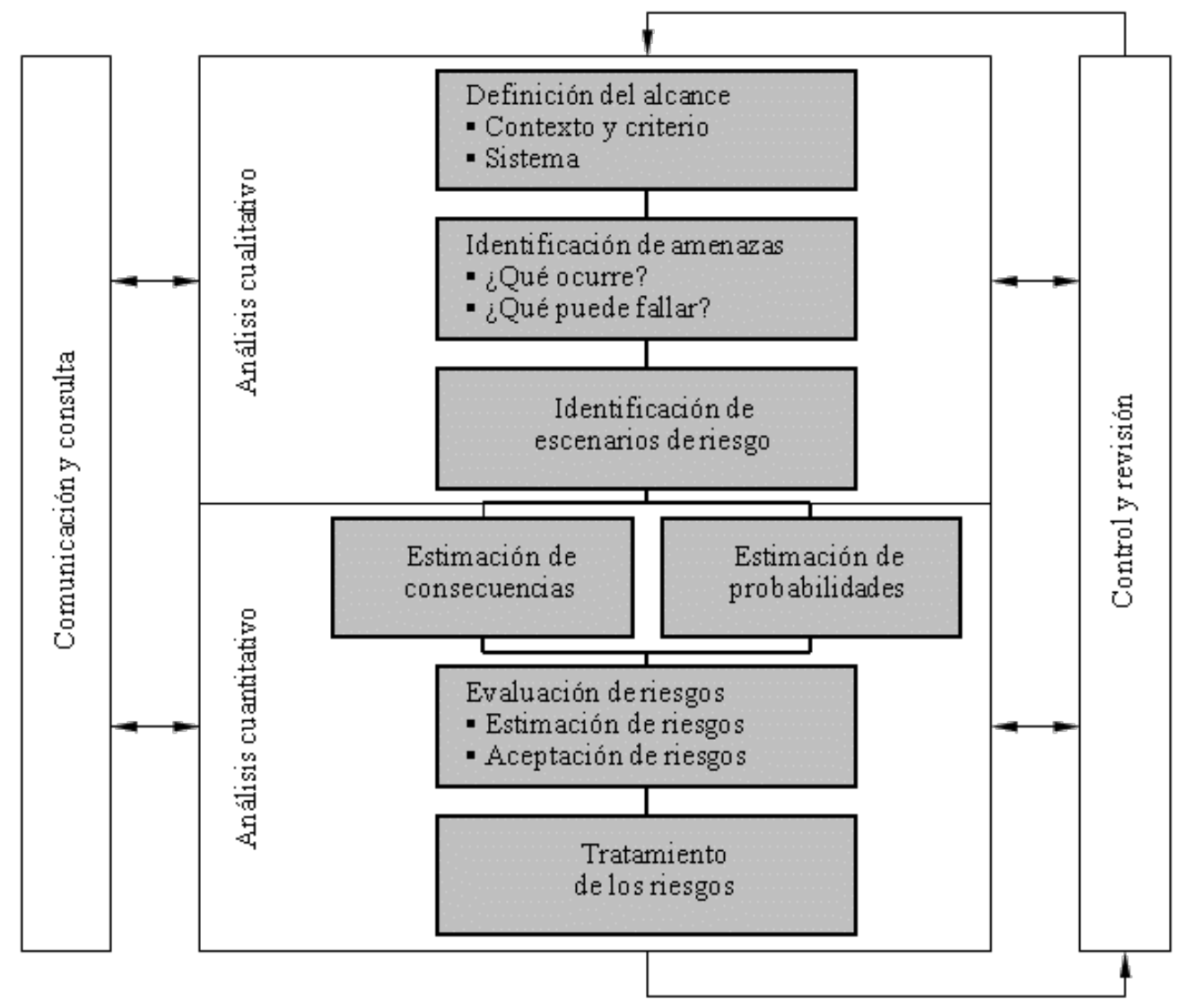

Figura 2.1 - Marco global para la gestión de riesgos (figura adaptada de [AS/NZS 4360 1999]).

En la primera fase del procedimiento, el análisis cualitativo de los riesgos, resulta imprescindible concretar el alcance del estudio, definiendo el contexto, incluida la identificación de los agentes involucrados, y los criterios de decisión a considerar. Un aspecto importante es la definición de los límites del sistema a tener en cuenta ya que tiene consecuencias importantes sobre las posibles amenazas, las consecuencias en caso de producirse un evento no deseado o los criterios de aceptación de los riesgos, y también sobre el grado de detalle del posterior análisis a efectuar. Más importante todavía es el siguiente paso, la identificación de todas las posibles amenazas (Apartado 1.1.1), debido 
a que aquellas que no se identifiquen probablemente quedan excluidas de los posteriores análisis y toma de decisiones. A continuación se establecen combinaciones, lógicas y físicamente posibles, de las relevantes amenazas. Cada una de estas combinaciones constituye un denominado escenario de riesgo. El posterior análisis cuantitativo se lleva a cabo para los escenarios identificados.

Tal y como se desprende de la ecuación (1.1), un análisis cuantitativo de los riesgos implica la determinación de las frecuencias o probabilidades de ocurrencia de los diferentes escenarios, así como de sus consecuencias en caso de que se produzcan. Los riesgos asociados con el sistema analizado son una función de los riesgos correspondientes a todos los escenarios relevantes. Una vez determinados los riesgos, se comparan con un requisito o criterio de aceptación en términos de un nivel aceptable para los riesgos. En caso de incumplimiento, se deben reducir los riesgos asociados con el sistema, a través de la adopción de unas medidas adecuadas.

Los Apartados 2.2.2 a 2.2.4 contienen más información, respectivamente sobre los análisis cualitativo y cuantitativo de los riesgos, así como su reducción a niveles aceptables.

\subsubsection{Evaluación cualitativa}

\section{Definición del alcance}

El primer paso de un análisis cualitativo de los riesgos, asociados con un determinado sistema, consiste en clarificar el contexto del problema a resolver y de las decisiones a tomar. Es necesario identificar a los agentes involucrados, las partes con intereses e influencias en las decisiones, así como los responsables de estas decisiones. También se deben identificar posibles influencias recíprocas entre el proceso de decisión adoptado y los resultados esperados [Faber 2002]. Además, es necesario establecer los criterios que sean determinantes para la aceptación de los riesgos en relación con las personas, el medio ambiente y los aspectos económicos. En el nivel aceptable de los riesgos, en cuya determinación han de tenerse en cuenta los relevantes reglamentos nacionales e internacionales, influye entre otros muchos factores el sistema analizado ya que de este depende por ejemplo el número de personas expuestas a las amenazas, pero también el origen y la naturaleza de las mismas. Consecuentemente, la definición del alcance de un determinado estudio implica establecer los límites del sistema, objeto de análisis. Se deben señalar las hipótesis y simplificaciones adoptadas para la representación del sistema que, por otro lado, tiene que estar en concordancia con el grado de detalle del análisis de riesgo a efectuar.

\section{Identificación de amenazas}

En términos generales, se puede distinguir entre dos grandes grupos de circunstancias con el potencial para causar eventos con unas consecuencias no deseadas en relación con los sistemas técnicos tales como las estructuras de ingeniería civil: las amenazas que tienen su origen en, respectivamente, las fuerzas de la naturaleza y el entorno artificial, creado a través de la actividad humana. Amenazas pertenecientes a este segundo grupo serían por ejemplo las sobrecargas en un edificio o las explosiones de gas, pero también las desviaciones excesivas de las dimensiones previstas de un elemento estructural o de la resistencia de un material. Además, las amenazas que tienen su origen en el entorno natural casi siempre están relacionadas, de manera dominante o concomitante, con la actividad humana o, más concretamente, con equivocaciones y errores de las personas involucradas (Apartado 1.1.2). Constituye una amenaza, por ejemplo, la posible desviación entre los valores admitidos en un proyecto estructural para el viento, la nieve o el sismo y la intensidad real de estas $u$ otras acciones del entorno natural.

En el Apartado 2.2.1 se menciona la importancia de la identificación de las amenazas, $H_{i}$, en relación con un determinado sistema. Para ello existen diferentes técnicas cuya aplicación requiere imaginación y creatividad, además de los conocimientos técnicos necesarios, para asegurar la 
detección de todas las amenazas que podrían causar eventos con consecuencias no deseadas. Algunas técnicas conocidas son, por ejemplo, Hazard and Operability Study (HAZOP), What-if-analysis, o Failure Mode and Effect Análisis (FMEA), cuyas estrategias tienen en común el hecho de estar basadas en la formulación de unas preguntas pertinentes [Schneider 1994, CIB 259 2001]. Una vez planteadas estas preguntas, encontrar las respuestas adecuadas resulta relativamente fácil:

- Análisis cronológico: ¿qué podría ocurrir, dónde, cuándo y en qué circunstancias?

- Análisis de utilización: ¿qué equipos o máquinas se van a utilizar?; ¿qué influencia tienen?; ¿qué puede fallar?

- Análisis energético: ¿dónde y en qué circunstancias se pueden producir situaciones críticas por la existencia de potenciales energéticos (gravitatorio, cinético, químico, térmico, eléctrico, etcétera)?; ¿puede un posible fallo del suministro energético causar un evento no deseado?

- Análisis del material: ¿conlleva la capacidad de combustión, la toxicidad, el carácter explosivo o la falta de durabilidad de los materiales constitutivos empleados o de los productos finales un potencial para causar eventos no deseados?

- Análisis de interfaces: muchas amenazas están relacionadas con la transferencia de materiales, fuerzas, información o responsabilidades [Schneider 1994, Tanner 2013b], por lo que la pregunta adecuada versa sobre ¿cómo se salva una determinada interfaz?

La identificación de amenazas no se debe basar exclusivamente en encontrar respuestas acertadas a unas preguntas bien planteadas. La experiencia propia o de otros técnicos constituye una fuente de información de gran importancia [Schneider 1994]. En este contexto también se debe tener en cuenta la literatura especializada, así como prescripciones técnicas, recomendaciones o normas, que suelen estar basadas en la experiencia del pasado. Todos estos conocimientos previos resultan fundamentales para la identificación de las amenazas objetivamente conocidas (Apartado 1.1.2).

Debido al estado avanzado de la técnica, el porcentaje de los fallos asociados con influencias objetivamente desconocidas representa hoy en día una pequeña minoría [Rackwitz 2006]. Un caso conocido es el colapso del puente Takoma Narrows en Estados Unidos que en el fondo se produjo por el desconocimiento, en el campo de la ingeniería civil, de los efectos aeroelásticos en ciertas estructuras expuestas a la acción del viento. La gran mayoría de los fallos se deben asignar a circunstancias objetivamente conocidas, lo que subraya más aun la importancia de la tarea de la identificación de las amenazas.

\section{Identificación de escenarios}

Diferentes circunstancias con el potencial para causar eventos con consecuencias no deseadas pueden coincidir en el espacio y en el tiempo. Esta coincidencia puede conducir a situaciones cuyos riesgos asociados superan la suma de los riesgos correspondientes a las amenazas individuales, $H_{i}$. En el campo de la ingeniería estructural esto es la regla y no la excepción [Schneider 1997], por lo que resulta fundamental identificar las denominadas situaciones o escenarios de riesgo que describen la posible coincidencia de diferentes amenazas. Son estas situaciones o escenarios que se tienen en cuenta para la continuación del análisis y, en su caso, para la adopción de las medidas destinadas a reducir los riesgos a unos niveles aceptables.

La identificación de los escenarios de riesgo que resulten relevantes es el objetivo principal del análisis cualitativo de los riesgos. A estos efectos se emplean diferentes técnicas, como las ya mencionadas en el apartado anterior para la identificación de las amenazas, pero también los denominados árboles lógicos. La aplicación de árboles de fallo o de evento, así como de diagramas causa-consecuencia permite introducir orden, claridad y consistencia en un análisis cualitativo de los riesgos [Schneider 1997]. Por ejemplo, mediante un árbol de fallo se pueden identificar las posibles causas de un determinado evento, por lo que permite detectar combinaciones de circunstancias con el potencial de conducir a eventos no deseados, antes de que estos se produzcan. Mediante un árbol de 
evento, al contrario, se identifican las posibles consecuencias, o eventos posteriores, desencadenados por un evento inicial. Más información sobre estos métodos se encuentra en la literatura especializada [Schneider 1994, CIB 259 2001].

\subsubsection{Evaluación cuantitativa}

\section{Estimación de probabilidades}

En términos generales, la probabilidad se puede interpretar como el grado de certeza de la ocurrencia de un determinado evento en un período de tiempo establecido. Si se asume que un sistema técnico esté expuesto a diferentes amenazas mutuamente excluyentes, $H_{i}$, y que bajo alguna de estas circunstancias el fallo, $F$, del sistema o de alguno de sus componentes se produzca con una probabilidad condicional $P\left\{F \mid H_{i}\right\}$, entonces la probabilidad de fallo del sistema o del componente, $p_{F}$, se obtiene a partir de la ecuación (2.1) [CIB 259 2001]:

$$
p_{F}=\sum_{i} P\left\{H_{i}\right\} \cdot P\left\{F \mid H_{i}\right\}
$$

$P\left\{H_{i}\right\} \quad$ : probabilidad de ocurrencia de la amenaza $H_{i}$

$P\left\{F \mid H_{i}\right\} \quad$ : probabilidad condicional de que se produzca el fallo $F$ dada la amenaza $H_{i}$

$p_{F} \quad:$ probabilidad de fallo

Las probabilidades condicionales, $P\left\{F \mid H_{i}\right\}$, deben determinarse mediante un análisis probabilista detallado de las respectivas amenazas, $H_{i}$, o circunstancias con el potencial para causar eventos no deseados. Los métodos clásicos de fiabilidad estructural asumen que el fallo, $F$, de un sistema o uno de sus componentes puede definirse en el dominio del vector de variables básicas, $\boldsymbol{X}$ [Ellingwood 1999]. Según esta hipótesis, el dominio de fallo de un sistema o un componente puede definirse a través de la inecuación $g(\boldsymbol{x})<0$, donde $g(\boldsymbol{x})$ es la denominada función de estado límite, mientras que $\boldsymbol{x}$ es una realización específica del vector $\boldsymbol{X}$. Cabe señalar que la inecuación $g(\boldsymbol{x})>0$, describe el dominio de no fallo del sistema y la ecuación $g(\boldsymbol{x})=0$ el límite entre los dominios de fallo y ausencia de fallo, respectivamente.

Si se conoce la función de densidad de probabilidad conjunta, $f_{\boldsymbol{X}}\left(\boldsymbol{x} \mid H_{i}\right)$, de las variables básicas, $\boldsymbol{X}$, dadas las circunstancias $H_{i}$, la probabilidad de fallo condicional, $P\left\{F \mid H_{i}\right\}$, puede ser determinada utilizando la siguiente integral [Ellingwood 1999]:

$$
P\left\{F \mid H_{i}\right\}=\int_{g(x)<0} f_{X}\left(\boldsymbol{x} \mid H_{i}\right) \cdot d \boldsymbol{x}
$$

$f_{\boldsymbol{X}}\left(\boldsymbol{x} \mid H_{i}\right)$ : función de densidad de probabilidad conjunta de las variables básicas $\boldsymbol{X}$, dada la amenaza $H_{i}$

$g(\boldsymbol{x}) \quad$ : función de estado límite

$\boldsymbol{X} \quad:$ vector de variables básicas

$\boldsymbol{x} \quad$ : realización específica del vector $\boldsymbol{X}$

Cabe mencionar que la probabilidad $P\left\{F \mid H_{i}\right\}$, calculada mediante la ecuación (2.2), generalmente implica incertidumbres asociadas con:

- la definición de la función de estado límite, $g(\boldsymbol{x})$;

- el modelo teórico de la función de densidad de probabilidad conjunta, $f_{\boldsymbol{X}}\left(\boldsymbol{x} \mid H_{i}\right)$, de las variables básicas $\boldsymbol{X}$ [Ellingwood 1999].

Sin contar la influencia de los errores humanos (Apartado 1.1.2), las anteriores deficiencias constituyen muy probablemente algunas de las causas más significativas de las discrepancias observadas entre las probabilidades de fallo calculadas y la frecuencia real de los fallos de los sistemas técnicos, por ejemplo de las estructuras de ingeniería civil. Por este motivo, los valores $p_{F}$ calculados se suelen considerar como probabilidades nominales, lo que en casos prácticos puede 
dificultar su interpretación [CIB 259 2001]. Aun así, generalmente se aceptan los requisitos de fiabilidad estructural basados en probabilidades de fallo, $p_{F}<p_{t}$, donde $p_{t}$ representa la probabilidad de fallo admisible que se puede determinar por ejemplo sobre la base de los riesgos para las personas o mediante una optimización económica (Apartado 2.3).

Por la importancia de las posibles consecuencias, en el campo de la ingeniería civil, y más particularmente en la ingeniería estructural, el fallo, $F$, de un sistema o de un componente se refiere en primer lugar a su colapso. No obstante, en un análisis de riesgo se deben conocer las probabilidades de todos los eventos con consecuencias no deseadas. Además de un colapso, una amenaza, $H_{i}$, puede causar diferentes eventos, $E_{i j}$ (por ejemplo, deformaciones excesivas, vibraciones, etcétera). Las correspondientes probabilidades condicionales, $P\left\{E_{i j} \mid H_{i}\right\}$, se deben estimar mediante un análisis específico, por ejemplo aplicando árboles de fallo o redes neuronales [CIB 259 2001].

\section{Estimación de consecuencias}

Las consecuencias esperadas de un determinado evento no deseado se suelen expresar verbalmente o numéricamente para definir el alcance de, por ejemplo, los daños personales, medioambientales o las pérdidas económicas [CIB 259 2001]. Las consecuencias consideradas en un análisis deben estar en concordancia con la especificación de los criterios de aceptación. A pesar de que las consecuencias obviamente suelen ser multidimensionales, en muchos casos, se simplifica su representación considerando solo algunas de sus componentes.

Por ejemplo, en ingeniería civil los daños personales son dominantes y se expresan en términos del número de muertos o heridos (Apartado 1.1.4). Por otro lado, las posibles consecuencias medioambientales abarcan la contaminación de suelo, agua o aire, mientras que las consecuencias económicas se pueden dividir en pérdidas directas e indirectas. Los costes relacionados con los daños inducidos por el colapso parcial o total de una estructura, así como su rehabilitación o reconstrucción, se clasifican como pérdidas directas. Otros costes, como los derivados del tratamiento médico de heridos, su hospitalización, los costes de evacuación o aquellos que se deben a la inutilización temporal de los servicios o las instalaciones de un sistema técnico, se consideran cómo pérdidas indirectas.

Un análisis de consecuencias requiere un conocimiento detallado del sistema estudiado, así como de sus interrelaciones con el entorno. En un procedimiento sistemático, las consecuencias adversas de los eventos, $E_{i j}$, se pueden expresar a través de diferentes componentes, $C_{i j, k}$, donde el subíndice $k$ indica un determinado tipo de consecuencias. En la práctica, una estimación se puede llevar a cabo mediante un análisis estadístico de la información disponible en una base de datos. Si esta información resulta insuficiente, también se puede realizar una estimación subjetiva, en cuyo caso es especialmente importante especificar el nivel de confianza correspondiente.

\section{Evaluación de los riesgos}

Tal y como se menciona en los Apartados 1.1.4 y 2.1, salvo en los casos más sencillos, normalmente no es posible representar los riesgos asociados con un determinado sistema en los términos de la ecuación (1.1), a través del producto de dos factores describiendo un evento no deseado (probabilidad, consecuencias). Una interpretación más amplia del término riesgo implica representar probabilidades y consecuencias de forma alternativa a un simple producto, considerando por ejemplo un espectro de diferentes consecuencias, cada una con una probabilidad de ocurrencia distinta [CAN/CSA Q634 1991].

Según los pasos representados en la Figura 2.1 y descritos en los apartados anteriores, en un contexto específico, la estimación de los riesgos asociados con un determinado sistema está basada en la identificación de las amenazas y los escenarios relevantes, y consiste en el análisis de las 
correspondientes probabilidades y consecuencias, así como en su integración [ISO 13824 2009]. En caso de correspondencia (mapeo inyectivo) entre las consecuencias, $C_{i j, k}$, y los eventos, $E_{i j}$, para las amenazas, $H_{i}$, y los escenarios considerados, el riesgo total asociado con un determinado tipo de consecuencias, $R_{k}$, se obtiene mediante la siguiente suma [CIB 259 2001]:

$R_{k}=\sum_{i j} C_{i j, k} \cdot P\left\{E_{i j} \mid H_{i}\right\} \cdot P\left\{H_{i}\right\}$

$C_{i j, k} \quad$ : consecuencias del tipo $k$ asociadas con el evento $j$ causado por la amenaza $i$

$P\left\{E_{i j} \mid H_{i}\right\} \quad$ : probabilidad condicional de que se produzca el evento $E_{i j}$ dada la amenaza $H_{i}$

$R_{k} \quad$ : riesgo total asociado con las consecuencias adversas del tipo $k$

Si la relación entre consecuencias y eventos no es inyectiva, el análisis es más complejo y la ecuación (2.3) debe modificarse. Al contrario, si es suficiente considerar unas consecuencias unidimensionales, la ecuación (2.3) se simplifica al desaparecer la distinción entre diferentes tipos de consecuencias. Si en estos casos la probabilidad de ocurrencia de los eventos no deseados depende del vector de variables básicas, $\boldsymbol{X}$, el riesgo total puede expresarse formalmente a través de la siguiente integral [CIB 259 2001]:

$R=\int_{g(x)<0} C(x) \cdot f_{X}(x) \cdot d x$

$C(\boldsymbol{x}) \quad$ : consecuencias de un evento no deseado en función de las variables básicas $\boldsymbol{X}$

$f_{X}(x) \quad$ : función de densidad de probabilidad conjunta de las variables básicas $\boldsymbol{X}$

Forma parte de la evaluación de los riesgos asociados con un determinado sistema la decisión sobre su aceptación. A estos efectos se deben comparar los riesgos estimados mediante relaciones como las reflejadas en las ecuaciones (2.3) o (2.4) con los correspondientes niveles de aceptación, previamente establecidos (Apartado 2.2.1):

$R_{k} \leq R_{k, a d m}$

$R_{k, a d m} \quad$ : nivel admisible del riesgo total asociado con las consecuencias adversas del tipo $k$

Aunque una verificación de este tipo, por lo menos en apariencia, pueda parecer una comparación meramente formal, las decisiones sobre la aceptación de los riesgos basadas en la inecuación (2.5) esconden una gran complejidad. No solamente pueden existir varios criterios para diferentes tipos de consecuencias, sino también distintos niveles de aceptación. Se suele distinguir, por ejemplo, entre riesgos objetivos, aceptables o tolerables. Además, en su determinación han de considerarse múltiples aspectos, entre ellos los culturales, sociales, psicológicos, económicos y otros. Es interesante constatar que el público en general parece estar preparado para aceptar ciertos niveles de riesgo, mientras que causan rechazo los requisitos expresados en términos de probabilidades de fallo aunque sean equivalentes a los anteriores [CIB 259 2001].

En el caso de que un determinado sistema no cumpla con los requisitos expresados a través de la condición (2.5), es necesario adoptar medidas para mitigar o reducir los riesgos. Estas medidas se abordan de manera genérica en el siguiente apartado. Si al contrario los riesgos estimados están por debajo del umbral de aceptación, el sistema técnico objeto del análisis es apto para ser realizado o, si ya existe, para seguir en uso.

\subsubsection{Tratamiento de los riesgos}

\section{Adopción de medidas}

En la planificación de las medidas necesarias para mitigar o reducir los riesgos asociados con un determinado sistema que superen los umbrales establecidos para su aceptación (Apartado 2.2.3), a 
menudo se revelan de gran utilidad los análisis cualitativos, realizados previamente para identificar las amenazas y los escenarios relevantes (Apartado 2.2.2). Efectivamente, el conocimiento de la naturaleza y las características de las amenazas ayuda a establecer aquellos casos donde, con un pequeño esfuerzo, resulta posible obtener un gran efecto sobre los riesgos. El objetivo consiste en la optimización de la ratio entre el coste de las medidas adoptadas y la reducción de los riesgos obtenidos. Las mencionadas medidas pueden ser técnicas o administrativas y normalmente están basadas en alguna de las siguientes estrategias [Schneider 1994, CIB 259 2001]:

- eliminar la amenaza a través de una intervención en su origen;

- evitar el riesgo cambiando los objetivos o el concepto de la solución;

- controlar el riesgo mediante procedimientos de inspección y monitorización, o a través de sistemas de alarma;

- dominar el riesgo dotando al sistema con una capacidad adecuada;

- transferir ciertos riesgos, básicamente los económicos, por ejemplo a una compañía aseguradora;

- aceptar conscientemente los riesgos suficientemente pequeños o inevitables.

Las medidas previstas para mitigar o reducir los riesgos pueden referirse a todas las etapas que atraviesa un sistema técnico, desde su planificación, realización, puesta en servicio, uso, hasta su desmantelamiento. En muchos casos resulta interesante adoptar una combinación de diferentes medidas que permitan reducir simultáneamente, $\mathrm{y}$ en las proporciones necesarias, tanto la probabilidad de fallo del sistema como las consecuencias en caso de que éste se produzca. En otros casos puede ser útil o necesario cambiar la estrategia durante el período de servicio del sistema técnico, por ejemplo debido a una variación en las amenazas relevantes, la aparición de nuevas soluciones técnicas para tratarlas, o porque algunas medidas adoptadas inicialmente se revelen como ineficaces.

\section{Control y revisión}

Un análisis de riesgo se puede llevar a cabo por diferentes motivos, todos ellos con el denominador común de que siempre se trata de establecer una base racional para la adopción de algún tipo de decisiones (Apartado 2.2.1). En muchas aplicaciones pertenecientes a diferentes campos de la ingeniería, el análisis de riesgo es un proceso dinámico cuyas hipótesis se retroalimentan continuamente con nueva información [Faber 2002]. Siempre cuando se obtienen nuevos datos sobre el sistema técnico objeto de estudio, es posible actualizar las bases del análisis, lo que a su vez conduce a nuevos resultados. De esta manera, un análisis de riesgo constituye una potente herramienta para la optimización de un determinado sistema y sus prestaciones, con respecto a los criterios de aceptación especificados.

\subsection{CRITERIOS DE ACEPTACIÓN}

\subsubsection{Visión general}

La determinación de los criterios de aceptación de los riesgos constituye una tarea a la vez decisiva y compleja, tal y como se ha mencionado con anterioridad. Teniendo en cuenta que los riesgos asociados con un sistema se entienden como una función de la frecuencia o probabilidad de ocurrencia de un evento no deseado y de las consecuencias en caso de producirse este evento (Apartado 1.1.1), y asumiendo que se puedan establecer los niveles aceptables para estos riesgos (Apartado 2.2.3), se deduce que las probabilidades aceptadas disminuyen con el aumento de las consecuencias esperadas. Esta afirmación resulta subjetivamente plausible y se puede deducir sustituyendo la ecuación (2.3) en la (2.5). Como también se ha mencionado ya, en general es necesario distinguir entre diferentes tipos de consecuencias, particularmente daños personales, 
medioambientales y económicos, aunque por los motivos recogidos en el Apartado 1.1.4, en ingeniería civil los riesgos para las personas suelen ser dominantes.

Un problema central en relación con los niveles admisibles de los riesgos para las personas reside en los posibles conflictos de intereses entre la sociedad en su conjunto y determinadas personas individuales o grupos de personas [CIB 259 2001, Faber 2002]. Los riesgos que la sociedad en su conjunto estaría dispuesta a aceptar con el fin de obtener determinados beneficios, expresados a través de la frecuencia con la que se admite que se produzcan unos eventos causando un determinado número de víctimas, podrían resultar inaceptables para las personas directamente expuestas a las correspondientes amenazas. Para los gestores de sistemas técnicos tales como, por ejemplo, una red de transporte ferroviario o una planta química, así como para la sociedad en su conjunto, resulta primordial limitar los riesgos colectivos a un nivel aceptable, suponiendo que éste pueda ser conocido. No obstante, siempre se deberán preservar los derechos de todos los individuos, en concordancia con el artículo 3 de la Declaración Universal de Derechos Humanos que establece que "todo individuo tiene derecho a la vida, a la libertad y a la seguridad de su persona" [ONU 1948]. Consecuentemente, en relación con los riesgos para las personas, es necesario formular diferentes criterios de aceptación, respectivamente para la sociedad y para los individuos. El sistema técnico en cuestión debe cumplir con el más restrictivo de ambos requisitos, a través de la adopción de unas medidas cuyo coste resulte proporcional con respecto a los beneficios obtenidos [CIB 259 2001, SIA 269 2011].

Partiendo de las anteriores premisas, en el presente apartado se recopilan los criterios de aceptación más habituales en términos de los riesgos admisibles, teniendo en cuenta parámetros tales como las probabilidades de fallo, las pérdidas esperadas, así como las inversiones necesarias para incrementar la fiabilidad. Criterios de aceptación de este tipo han sido desarrollados para diferentes campos y actividades industriales, entre ellos también para las estructuras de ingeniería civil. A efectos de la determinación de los límites de aceptación para estructuras de nueva construcción existen diversas opciones [JCSS 2001, Diamantidis 2007, Diamantidis 2012]:

- deducción a partir de las tasas de mortalidad observadas y las pérdidas económicas documentadas;

- calibración con la práctica actual, basada en el postulado de que los niveles de fiabilidad implícitos en las reglas y los procedimientos aplicados en la actualidad sean aceptables y conduzcan a soluciones óptimas desde un punto de vista económico;

- optimización teniendo en cuenta tanto los beneficios asociados con una determinada realización como su coste, incluidos los costes directos e indirectos de un posible fallo estructural (Apartado 2.2.3);

- procesos de normalización o legislación.

Los límites de aceptación no necesariamente son los mismos para todas las estructuras ya que dependen de múltiples parámetros. Una diversificación es particularmente importante en relación con las estructuras existentes donde una reducción de los requisitos puede resultar inevitable por motivos económicos y legales [Vrouwenvelder 2011]. Factores de influencia son, por ejemplo:

- el período de servicio previsto de la obra;

- las consecuencias esperadas de un posible fallo estructural;

- la eficacia de las medidas de reducción de los riesgos;

- las posibles limitaciones de tiempo y otros condicionantes relacionados con la planificación o la realización de una obra;

- grado de detalle de la información disponible sobre estructuras existentes;

- preferencias socioeconómicas y políticas. 


\subsubsection{Riesgo individual}

Los datos estadísticos disponibles sobre el riesgo mortal de las personas proporcionan indicios a efectos de establecer un valor objetivo para el riesgo individual admisible. En los denominados países desarrollados, el riesgo mortal global por accidentes y otros efectos adversos, incluidos incendios o colapsos estructurales tanto en el lugar de trabajo como de residencia, oscila entre $10^{-4}$ por año y más de $5 \times 10^{-4}$ por año, con tendencia decreciente a largo plazo. En cuanto a los riesgos asociados con los colapsos estructurales, normalmente inducidos por eventos extremos tales como sismos, tempestades, riadas o corrimientos de tierras, las estadísticas disponibles a nivel mundial son poco concluyentes. No obstante, para el riesgo mortal se puede estimar muy aproximadamente un valor medio de $10^{-6} \mathrm{a}$ $10^{-7}$ por año, mientras que para el riesgo de sufrir una herida grave por un colapso estructural se debe contar con un valor medio de un orden de magnitud superior [Diamantidis 2012].

Desde el punto de vista de una persona individual, la aceptación de un determinado riesgo depende del tipo de actividad y, más concretamente, si esta es voluntaria o no. El hecho de que la tolerancia frente al riesgo crece con el grado de voluntariedad de la actividad constituye la base para establecer unos criterios de aceptación del riesgo individual. Además, se deben tener en cuenta los efectos del beneficio obtenido a través de la actividad [CIB 259 2001], así como el grado de la influencia personal en la reducción de los riesgos [Schneider 1994]. "Viajar en coche", con un riesgo individual medio del orden de $10^{-4}$ por año, se emplea a menudo a efectos comparativos. Se presta para ello por la combinación de las siguientes circunstancias:

- se trata de una actividad neutra en cuanto al grado de voluntariedad, ya que con frecuencia existen medios de transporte alternativos;

- la mayoría de las personas suele desplazarse en coche, por el beneficio objetivo o subjetivo que aporta esta forma de viajar, aceptando implícitamente los riesgos asociados;

- la influencia personal en la reducción de los riesgos se puede clasificar como mediana.

Para una actividad completamente voluntaria como la escalada extrema, los riesgos aceptados son significativamente superiores a los correspondientes al desplazarse en coche, del orden de una o dos magnitudes [CIB 259 2001]. Incluso en el caso de las actividades voluntarias de este tipo, parece existir un límite superior para el riesgo individual medio, del orden de $10^{-2}$ a $10^{-3}$ al año [Diamantidis 2012]. Por otro lado, en relación con las actividades involuntarias, y en función de los beneficios esperados, los riesgos aceptados se sitúan una o dos órdenes de magnitud por debajo de los riesgos asumidos al viajar en coche.

Según lo anterior, es posible distinguir entre diferentes niveles de aceptación de los riesgos individuales. Existen riesgos inaceptables en cualquier circunstancia, los aceptables en caso de que la actividad correspondiente aporte algún tipo de compensación, así como los aceptables sin compensación. En este contexto cabe destacar que los riesgos debidos a los colapsos estructurales siempre se asumen involuntariamente y en algunas recomendaciones se establecen valores admisibles para ellos. Por ejemplo, en la norma internacional [ISO 2394 1998], dedicada a la fiabilidad estructural, se admite un riesgo individual medio asociado con los colapsos estructurales, $r_{I R, a d m}$, de $10^{-6}$ por año, y según la norma suiza sobre la evaluación de las estructuras existentes [SIA 269 2011] el valor admisible es de $10^{-5}$ por año. Sobre esta base, se puede deducir el valor admisible de la probabilidad anual de fallo estructural, $p_{f t, I R}$, en función de la probabilidad condicional de fallecimiento de una persona expuesta al colapso considerado, $p_{c j} j$

$p_{f t, I R} \leq \frac{r_{I R, a d m}}{p_{c \mid f}}$

$p_{c f f} \quad$ : probabilidad condicional de fallecimiento de una persona, presente en el área de influencia de la estructura, dado el colapso 
$p_{f t, I R} \quad:$ probabilidad de fallo objetivo, basada en el valor admisible para el riesgo individual

$r_{I R, a d m} \quad$ : valor admisible para el riesgo individual medio

La probabilidad condicional de fallecimiento de un ocupante de la obra en el caso de un colapso se puede estimar, por ejemplo, mediante la evaluación de una base de datos sobre colapsos estructurales [Eldukair 1991]. Valores obtenidos de esta u otra forma están afectados por grandes incertidumbres y probablemente constituyen un límite superior de las probabilidades reales [Diamantidis 2012]. También cabe mencionar que los valores admisibles de la probabilidad de fallo anual, $p_{f t, I R}$, deducidos a partir de la inecuación (2.6), no cubren la influencia del posible desconocimiento de algunos de los parámetros que intervienen en los análisis ni de los errores humanos graves [JCSS 2001, Diamantidis 2012].

\subsubsection{Riesgo colectivo}

La inecuación (2.6) permite, por lo menos en teoría, establecer unos requisitos de fiabilidad estructural sobre la base de los riesgos para las personas desde un punto de vista individual. Tal y como se menciona en el Apartado 2.3.1, el objetivo tanto de los gestores de sistemas técnicos como de las autoridades, en representación de la sociedad en su conjunto, consiste en evitar eventos con un gran número de víctimas, por lo que es necesario definir un requisito diferente a (2.6). El riesgo colectivo para las personas, asociado con un determinado sistema y representado en términos del número esperado de víctimas por año, se puede estimar según la ecuación (2.3), dependiendo de las probabilidades de ocurrencia de los eventos relevantes así como de sus consecuencias. El riesgo colectivo equivale a la suma de los riesgos individuales correspondientes a todas las personas expuestas al mismo sistema. Por este motivo, los requisitos para los riesgos individuales y colectivos, respectivamente, necesariamente están interrelacionados. Por otro lado, esta interrelación pone de manifiesto que el nivel de los riesgos colectivos depende fuertemente de los límites del sistema analizado, definidos previamente en el marco de la evaluación cualitativa (Apartado 2.2.2).

En la mayoría de los estudios prácticos, los riesgos colectivos asociados con un determinado sistema se representan numéricamente, a través de las denominadas curvas frecuencia - consecuencias, $F-n$, en las que $n$ refleja el número de víctimas mortales y $F(n)$ la frecuencia anual de los eventos con $n$ o más víctimas mortales [CIB 259 2001]. Para el sistema considerado, estas curvas ponen de manifiesto la relación entre los eventos con unas consecuencias de un determinado alcance y su frecuencia o probabilidad de ocurrencia. A efectos de la representación de los diagramas $F$ - $n$ se suele emplear una escala logarítmica para ambos ejes, con las consecuencias en el eje de abscisas y la frecuencia en el de ordenadas, según la Figura 2.2. El desarrollo original de este tipo de representaciones se adscribe al campo de la energía nuclear [Reid 2002], con el fin de reflejar los umbrales de aceptación de los riesgos asociados con este tipo de producción energética, teniendo en cuenta la aversión social frente a eventos catastróficos con un gran número de víctimas. Herramientas similares también se utilizan para adoptar decisiones relativas a los riesgos asociados con infraestructuras singulares de ingeniería civil, por ejemplo el túnel del Great Belt Link en Dinamarca [Faber 2002].

Cuanto mayor el alcance de las consecuencias esperadas o, en otras palabras, cuantas más víctimas se esperan en caso de producirse un evento no deseado, menor es el grado de aceptación por parte de la sociedad. Esta relación se pone de manifiesto a través de la pendiente de las curvas $F-n$ que se emplean para decidir si un sistema es aceptable o no desde un punto de vista de los riesgos colectivos. Como queda reflejado en la Figura 2.2, es habitual introducir dos curvas dividiendo el diagrama en tres zonas [CIB 259 2001]. No son aceptables los sistemas cuyos riesgos colectivos se sitúan por encima de la curva superior. En el otro extremo, los sistemas con riesgos por debajo de la línea inferior son aceptables sin necesidad de adoptar medidas adicionales. Los riesgos correspondientes a la zona intermedia son tolerables, pero se deben reducir en la medida de lo posible, de acuerdo con el principio conocido como ALARP (As Low As Reasonably Practicable). Las correspondientes 
medidas de reducción o mitigación de los riesgos se pueden optimizar de acuerdo con criterios económicos (Apartado 2.3.4). Las curvas de aceptación a menudo se truncan en la región correspondiente a probabilidades de ocurrencia muy pequeñas pero con consecuencias muy importantes en cuanto al número de víctimas potenciales (Figura 2.2). Por otro lado, las curvas del tipo $F-n$ no son de aplicación para tomar decisiones acerca de eventos relativamente frecuentes con consecuencias comparativamente menores, como por ejemplo los accidentes de tráfico [CIB 259 2001]. A estos efectos se emplea el criterio de aceptación para el riesgo individual (Apartado 2.3.2) y a menudo se considera que las curvas para el riesgo colectivo solo son válidas a partir de un número mínimo de víctimas esperadas, por ejemplo $n=5$ ó 10 .

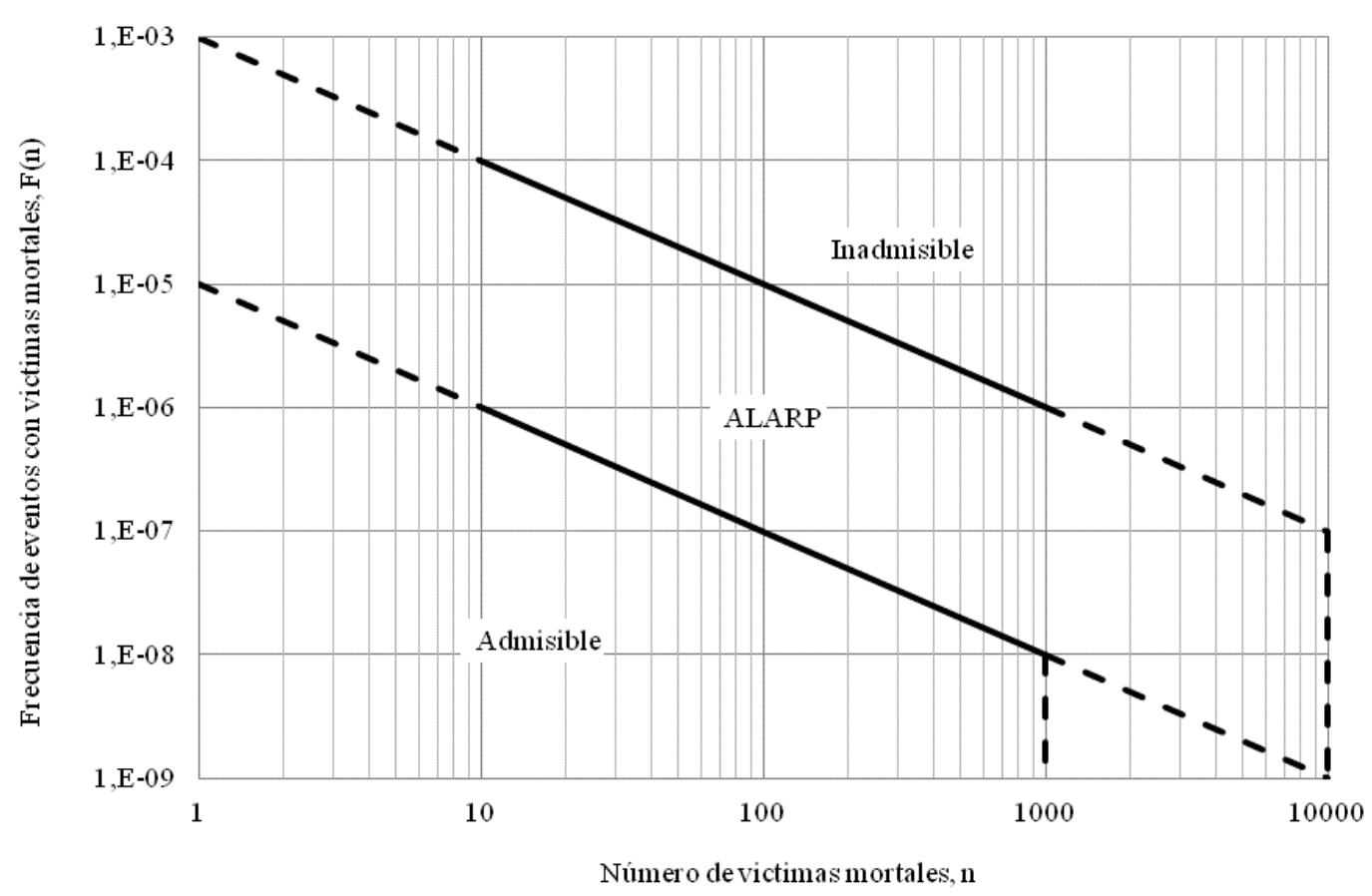

Figura 2.2 - Diagrama frecuencia - consecuencias y representación de los criterios de aceptación de los riesgos colectivos (figura adaptada de [Diamantidis 2012]).

Matemáticamente, el criterio de aceptación para los riesgos colectivos asociados con un determinado sistema, estimados mediante la ecuación (2.3) o similar, se puede expresar a través de la siguiente condición, de carácter general [CIB 259 2001]:

$F(n)=p(N \geq n) \leq F(1) \cdot n^{-\alpha}$

$F(n) \quad$ : frecuencia anual de los eventos con $n$ o más víctimas mortales

$F(1) \quad:$ frecuencia anual de los eventos con una o más víctimas mortales

$N \quad:$ número de víctimas mortales en un evento

$n \quad:$ consecuencia de un evento no deseado en términos del número de víctimas mortales

$p(\ldots) \quad:$ probabilidad anual de (...)

$\alpha \quad$ : constante

La constante $\alpha$ define la pendiente de las curvas frecuencia - consecuencias por lo que permite tener en cuenta la aversión de la sociedad frente a los riesgos. Así, valores $\alpha<1$ reflejarían una predisposición hacia la aceptación de los riesgos, lo que parece estar en contradicción con el comportamiento de la mayoría de las personas. En cualquier caso, valores inferiores a uno llevarían a un número infinito de víctimas mortales esperados con lo que esta opción queda descartada por absurda, si no se impone alguna limitación alternativa para las consecuencias. Un valor $\alpha=1$ significaría una actitud neutra frente a los riesgos, mientras que valores $\alpha>1$ reflejarían la aversión 
de la sociedad frente a los eventos con consecuencias importantes. Efectivamente, 100 accidentes de coche con una víctima por accidente en un determinado período de tiempo resultan claramente menos impactantes para la sociedad que un solo accidente de cualquier tipo con 100 muertos. Partiendo de este tipo de consideraciones, por ejemplo la norma internacional sobre la fiabilidad estructural [ISO 2394 1998] sugiere un valor de $\alpha=2$.

Por otro lado, la frecuencia anual de los eventos con una o más víctimas, $F(1)$, corresponde al valor de la ordenada para $n=1$ en el diagrama frecuencia - consecuencias, $F-n$. En el manual sobre métodos innovadores para la evaluación de las estructuras existentes [Diamantidis 2012], se menciona que los valores tanto de $F(1)$ como de la constante $\alpha$, anteriormente descrita, están sometidos a grandes dispersiones dependiendo de la actividad técnica considerada, así como del tipo de amenazas involucradas. Se sugiere adoptar unos valores numéricos de forma que las correspondientes curvas de aceptación constituyan unas envolventes para la mayoría de los desastres naturales y algunos creados por la actividad humana.

También el informe sobre el análisis y la comunicación de los riesgos en el campo de la ingeniería civil [CIB 259 2001] contiene algunas consideraciones sobre la determinación de $F(1)$. Toma como punto de partida la situación según la cual muchas de las actividades que se llevan a cabo en un país contribuyen a la probabilidad de que se produzca un evento no deseado con consecuencias de gran alcance. Por ello, la discusión sobre el nivel aceptable del riesgo colectivo debería iniciarse a nivel del conjunto de un país, teniendo en cuenta todas las actividades y sistemas que impliquen riesgos. Para cada uno de ellos se debería deducir a continuación una determinada cuota, equivalente al límite de aceptación del sistema o la actividad correspondiente. También se pueden deducir cuotas para diferentes regiones geográficas donde se practica una determinada actividad o un conjunto de actividades. Además, la asignación de cuotas puede incluir el establecimiento de algún criterio destinado a evitar una distribución desigual de los riesgos entre diferentes regiones. Por todo ello, la elección de los criterios de aceptación del riesgo colectivo relacionado con un determinado sistema o actividad, y por tanto la elección del valor de $F(1)$, y también de $\alpha$, debe reflejar la política nacional de seguridad. En países grandes o densamente poblados el valor de $F(1)$ es mayor que en países pequeños considerando el mismo tipo de actividad o sistemas. Este efecto escala es consistente con la interrelación arriba mencionada entre los riesgos individuales y colectivos, según la cual el nivel admisible de estos últimos no puede ser representado por un valor absoluto sino depende del sistema analizado o de la actividad considerada. En concordancia con todo ello debe ser seleccionado el valor de la frecuencia anual de los eventos con una o más víctimas mortales, $F(1)$.

En combinación con el criterio mencionado para tener en cuenta la aversión frente al riesgo $(\alpha=2)$, la norma internacional [ISO 2394 1998] indica dos valores, respectivamente $F(1)=0,01$ y 0,1 (en [ISO 2394 1998] se emplea en lugar de $F(1)$ la notación $A$ que en el presente trabajo está reservada para el área de una superficie). No obstante, estos valores orientativos no están asociados con un determinado sistema o actividad, lo que complica la interpretación de los criterios de aceptación de los riesgos colectivos establecidos en la norma [ISO 2394 1998], por ejemplo a efectos de su aplicación práctica en el campo de la ingeniería estructural.

La falta de asociación del criterio de aceptación con un sistema de referencia no es la única dificultad a la hora de emplear en la práctica la inecuación (2.7). Por ejemplo, si se pretende utilizar los riesgos colectivos admisibles como base para deducir unos requisitos de fiabilidad estructural racionales, también se debe tener en cuenta que la frecuencia anual de los eventos con $n$ o más víctimas mortales, $F(n)$, reflejada en las curvas frecuencia - consecuencias (Figura 2.2), no equivale a la probabilidad de fallo, total o parcial, de un sistema estructural. Efectivamente, la frecuencia $F(n)$ o probabilidad anual de que en un colapso estructural se produzcan $N$ víctimas mortales, siendo $N$ igual o superior a $n$, depende de la probabilidad de fallo total o parcial del sistema considerado, y de todos los parámetros 
que determinan el número de víctimas en el caso de que se produzca el fallo [CIB 259 2001]. Someramente, este conjunto de parámetros se podría expresar a través de la probabilidad condicional de que, dado el colapso, se produzcan $N$ víctimas mortales, siendo $N$ igual o superior a $n, p_{N f}$. Partiendo de estas consideraciones, el valor objetivo de la probabilidad de fallo anual, basado en el riesgo colectivo admisible, $p_{f t, S R}$, se puede deducir introduciendo $p_{N f f}$ en la inecuación (2.7):

$p_{f t, S R} \leq \frac{F(1) \cdot n^{-\alpha}}{p_{N \mid f}}$

$p_{f t, S R} \quad:$ probabilidad de fallo objetivo, basada en el valor admisible para el riesgo colectivo

$p_{N f} \quad:$ probabilidad condicional de que, dado el colapso, se produzcan $N$ víctimas mortales, siendo $N$ igual o superior a $n$

Al igual que en el caso del valor objetivo de la probabilidad de fallo anual basado en el riesgo individual admisible (Apartado 2.3.2), la inecuación (2.8) resulta formalmente muy sencilla. Pero en este caso tampoco es posible aplicarla directamente a efectos prácticos. A los problemas relacionados con la influencia de la escala del sistema y de la aversión frente al riesgo en los criterios de aceptación, se les añade la falta de modelos consistentes para estimar el número de víctimas mortales en caso de un colapso estructural. Finalmente, también se desconoce la relación entre un valor objetivo de la probabilidad de fallo, deducido de la inecuación (2.8), y las incertidumbres asociadas con las variables que intervienen en un análisis estructural.

\subsubsection{Criterios económicos}

La determinación del nivel aceptable de los riesgos asociados con un sistema o una actividad, también se puede expresar en términos de un problema de decisión de tipo económico. La inversión necesaria, I, compuesta por el coste inicial así como los costes de mantenimiento y deconstrucción [ISO 2394 1998], para que la probabilidad de fallo del sistema analizado en el período de servicio previsto no supere un determinado valor, $p_{f}$, se equipara con la reducción del valor actual del riesgo en términos económicos, $V$ [JCSS 2000]. El nivel óptimo de la fiabilidad estructural, representada en términos de la probabilidad de fallo óptima referida al período de servicio de la estructura, $p_{f, o p t}$, corresponde al punto del coste total mínimo, $\min \left(C_{t o t}\right)$. Este se establece en función de la inversión, $I, \mathrm{y}$ del valor actual del riesgo, $V$, teniendo en cuenta la probabilidad de fallo de la estructura, $p_{f}$, y el coste asociado al fallo, $C_{f}$. La determinación de la probabilidad óptima se representa esquemáticamente en la Figura 2.3 y analíticamente mediante la ecuación (2.9). Se trata de una representación simplificada ya que no solamente $I$ se subdivide en diferentes inversiones, realizadas en distintos momentos a lo largo del período de servicio de una estructura, sino también el riesgo se compone de diferentes sumandos correspondientes a varios tipos de consecuencias, asociadas con distintos eventos y amenazas (Apartado 2.2.3):

$$
\begin{array}{ll}
\min \left(C_{t o t}\right)= & \min \left(I\left(p_{f}\right)+V\left(p_{f} \cdot C_{f}\right)\right) \\
C_{f} & : \text { coste económico asociado al fallo de un sistema } \\
C_{t o t} & : \text { coste total en términos económicos } \\
I & : \text { inversión en términos económicos } \\
p_{f} & : \text { probabilidad de fallo } \\
V & : \text { valor actual del riesgo en términos económicos }
\end{array}
$$

Si además de los costes asociados con los daños materiales causados por un fallo estructural se tiene en cuenta el costo equivalente para evitar víctimas mortales, ICAF (Implied Cost for Averting a Fatality), la cantidad del daño se incrementa hasta:

$C_{f, t o t}=p_{c \mid f} \cdot N_{p} \cdot I C A F+C_{f}$ 
$C_{f, t o t} \quad$ : coste económico asociado al fallo de un sistema, incluido el costo equivalente para evitar daños personales

ICAF : costo equivalente para evitar una víctima mortal

$N_{p} \quad$ : número de personas expuestas a un sistema o participantes en una actividad

La asociación de una vida humana con un valor económico podría causar objeciones éticas. No obstante, el denominado ICAF no pretende asignarle un precio a la vida de las personas. Lo que refleja es un valor monetario que la sociedad debería estar dispuesta a invertir para evitar la muerte prematura de una persona. La ventaja de este enfoque consiste en que las medidas de reducción o mitigación de los riesgos (Apartado 2.2.4) se pueden abordar en el contexto de la renta nacional [Diamantidis 2012].

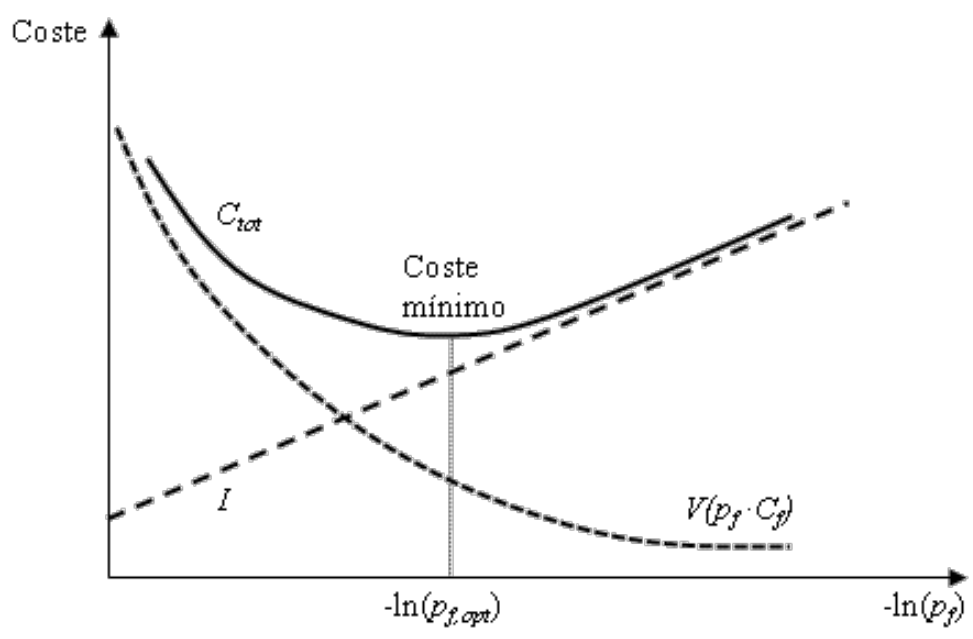

Figura 2.3 - Representación esquemática del valor óptimo, desde un punto de vista económico, de la probabilidad de fallo de una estructura.

\subsection{5 Índice de calidad de vida}

En un análisis del tipo coste - beneficio, todos los daños y pérdidas se traducen a unidades monetarias, también las víctimas mortales. Para tener en cuenta a estas últimas, se emplea un enfoque específico basado en un indicador social, el denominado índice de calidad de vida, L (Life Quality Index), que relaciona las inversiones de la sociedad con los beneficios obtenidos por las personas. Se trata de un indicador social compuesto [Nathwani 1997, Rackwitz 1999], en términos de una función monótonamente creciente con el producto interno bruto y la esperanza de vida, dependiendo del tiempo dedicado al trabajo:

$$
L=g^{w} \cdot e^{1-w}
$$

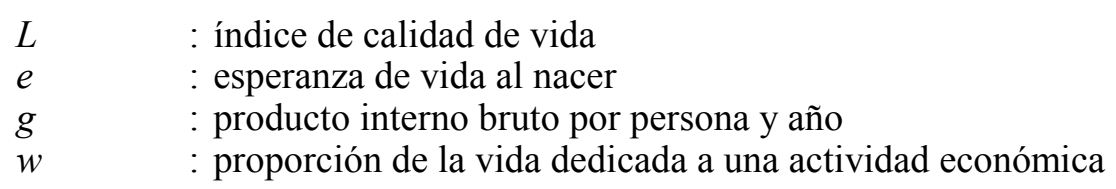

En países con economías avanzadas se puede suponer un valor de aproximadamente $w=0,125$ para la proporción de la vida dedicada al trabajo.

Las decisiones relativas a la aceptación de los riesgos mediante el enfoque del índice de calidad de vida implican que una determinada opción o medida resulta apropiada si conduce a una variación positiva de $L$. La reducción de los riesgos a través de la implementación de una determinada medida conduce a un incremento, $\Delta e$, de la esperanza de vida, $e$. El coste asociado con la medida considerada 
se puede expresar a través de la variación, $\Delta g$, del producto interno bruto, $g$. Según el criterio del índice de calidad de vida, la medida se debería implementar si se cumple la siguiente condición:

$\frac{\Delta e}{e}>-\frac{\Delta g}{g} \cdot \frac{w}{1-w}$

La inecuación (2.12) se obtiene mediante la diferenciación de la expresión para el índice de calidad de vida, en combinación con la mencionada condición $\Delta L>0$. Bajo la hipótesis de que la vida remanente de una persona media corresponda a la mitad de la esperanza de vida al nacer, e/2, el número medio de años salvados al evitar la muerte prematura de una persona se puede estimar en $\Delta e$ $=e / 2$. Sustituyendo este valor en la inecuación (2.12) y transformando el criterio del índice de calidad de vida, se puede estimar el límite superior de la variación del producto interno bruto por persona y año:

$|\Delta g|_{\max }=\frac{g}{e} \cdot \frac{1-w}{w} \cdot \Delta e=\frac{g}{2} \cdot \frac{1-w}{w}$

El valor obtenido mediante la ecuación (2.13) se puede interpretar como siendo la inversión óptima por año de vida salvada [Diamantidis 2012]. Consecuentemente, el valor óptimo del costo equivalente para evitar una víctima mortal, ICAF, se obtiene a partir de la siguiente ecuación:

$I C A F=|\Delta g|_{\max } \cdot \Delta e=\frac{g \cdot e}{4} \cdot \frac{1-w}{w}$

Igual que en el Apartado 2.3.4, conviene resaltar que la ecuación (2.14) no asigna un valor económico a la vida humana. Ésta no tiene precio. Tampoco representa el importe de una posible compensación monetaria de los familiares de las víctimas de un accidente. Es simplemente una estimación de la inversión óptima para evitar la muerte prematura de una persona.

\subsection{OBSERVACIONES FINALES}

Este capítulo presenta los principios de los procesos de decisión basados en un análisis cualitativo y cuantitativo de los riesgos tecnológicos y naturales, para lo que existen distintos enfoques que se distinguen por el grado de detalle de los análisis. Todos los procedimientos deben abordar los problemas que surgen inevitablemente al tratar con unos eventos de frecuencias o probabilidades de ocurrencia muy pequeñas, en combinación con unas consecuencias esperadas que pueden tener un alcance importante. Los principios reflejados en el capítulo son de aplicación general y se ajustan al marco global para la gestión de riesgos comúnmente aceptado en la literatura especializada. A lo largo del capítulo se introducen referencias específicas a la ingeniería estructural, en vista de la aplicación de los principios genéricos al desarrollo de la tesis.

Un aspecto crucial y especialmente delicado consiste en la determinación de los criterios de aceptación de los riesgos, en concordancia con las características del sistema o de la actividad objeto del análisis. Siendo el riesgo una función de la frecuencia o probabilidad de ocurrencia de un evento no deseado y de sus consecuencias, los criterios de aceptación deben tener las mismas unidades que estas últimas. El presente capítulo incluye algunas consideraciones sobre el establecimiento de los niveles aceptables de los riesgos, respectivamente desde el punto de vista de las personas, en términos económicos, y mediante un indicador social, el denominado índice de calidad de vida.

Los riesgos para las personas son dominantes en ingeniería civil (Apartado 1.1.4) y es precisamente este tema que se aborda en el marco del presente trabajo, según el alcance (Apartado 1.2) y el objetivo (Apartado 1.3) establecidos. En el presente capítulo se expone la necesidad de distinguir entre dos criterios de aceptación de los riesgos para las personas, respectivamente desde los puntos de 
vista de los individuos y la sociedad en su conjunto. Se recopilan los criterios disponibles en la literatura especializada y se identifican los problemas relacionados con ellos. Estas dudas, que se deben tener en cuenta en la continuación del trabajo, están resumidas a continuación.

Problemas relacionados con los criterios de aceptación del riesgo individual:

- De manera simplificada, el riesgo individual asociado con los colapsos estructurales depende de la probabilidad de fallo estructural y la probabilidad condicional de fallecimiento de una persona presente en el momento del colapso, dado el fallo. Existen pocos modelos para estimar esta probabilidad condicional y los resultados que proporcionan están afectados por grandes incertidumbres.

- Estas incertidumbres se reflejan en los valores objetivo de la probabilidad de fallo estructural: estos no solamente dependen del valor establecido para el riesgo individual admisible, sino también de la probabilidad condicional de fallecimiento de una persona en caso de producirse un colapso estructural.

- Los valores objetivo de la probabilidad de fallo estructural, basados en el riesgo individual admisible, no tienen en cuenta la influencia de los errores humanos graves y se desconoce su relación con las incertidumbres asociadas con las variables que intervienen en un análisis estructural.

Problemas relacionados con los criterios de aceptación del riesgo colectivo:

- El campo de aplicación de la mayoría de los criterios de aceptación del riesgo colectivo para las personas, contenidos en normas y recomendaciones internacionales, se refiere a sistemas técnicos muy diversos y actividades de todo tipo. No obstante, en los citados documentos los criterios de aceptación no están asociados con un sistema de referencia determinado, con unos límites claramente establecidos. Esta falta de información dificulta la interpretación de los criterios de aceptación, pudiendo conducir a problemas de escala, con los correspondientes efectos en las decisiones sobre la aceptación de un determinado sistema o actividad.

- La aversión de la sociedad frente a los riesgos depende de múltiples parámetros, algunos de carácter subjetivo, por lo que los criterios de aceptación están afectados por grandes dispersiones. Estas a su vez dificultan la definición de unos requisitos racionales para el riesgo colectivo.

- No existen modelos fiables para estimar las consecuencias, en términos del número de víctimas, de los colapsos estructurales.

- Igual que en el caso del riesgo individual, se desconoce la relación entre los valores objetivo de la probabilidad de fallo estructural, basados en el riesgo colectivo admisible, y las incertidumbres asociadas con las variables que intervienen en un análisis estructural. 


\section{SEGURIDAD Y FIABILIDAD EN LA INGENIERÍA ESTRUCTURAL}

\subsection{INTRODUCCIÓN}

En el campo de la ingeniería es normal que no se disponga de toda la información que sería deseable para adoptar decisiones informadas en relación con los requisitos que debe cumplir un determinado sistema. Por este motivo, en cualquier tarea de la ingeniería estructural se deben considerar las incertidumbres asociadas con los datos en los que se basan los análisis de las posibles soluciones [Bailey 1996]. El origen de estas incertidumbres se encuentra en el carácter aleatorio de la mayoría de las variables básicas a tener en cuenta. Así, la información en la que se basa el análisis de una estructura, o de cualquier otro sistema de ingeniería, no es determinista y los cálculos estructurales deberían efectuarse mediante métodos probabilistas que permitan tener en cuenta la aleatoriedad de las variables. A estos efectos, resultaría especialmente adecuada la aplicación de los métodos explícitos de análisis de riesgos, presentados en el Capítulo 2, ya que implican la determinación de la probabilidad de fallo de los sistemas analizados teniendo en cuenta las incertidumbres asociadas con los parámetros a considerar (Apartado 2.2.3). No obstante, con la excepción de contadas infraestructuras singulares (Apartado 2.3.3), en la práctica diaria se suelen emplear métodos implícitos para tomar decisiones en relación con los requisitos que deben cumplir las estructuras de ingeniería civil (Apartado 1.1.2).

Partiendo de esta situación, los objetivos de este capítulo se pueden resumir de la siguiente manera:

- repaso de los métodos implícitos empleados en la práctica habitual para asegurar que las estructuras cumplan, con una fiabilidad adecuada, los objetivos de la seguridad estructural y también de la aptitud al servicio;

- recopilación de los requisitos de fiabilidad estructural según los métodos implícitos;

- análisis de la relación entre ambos tipos de métodos, respectivamente los explícitos según el Capítulo 2 y los implícitos que se emplean en la práctica diaria;

- discernimiento de las limitaciones de los métodos de fiabilidad estructural, contenidos en la normativa en vigor y por tanto aplicados en la práctica habitual, a la vista del posterior desarrollo de un concepto para la evaluación de los riesgos asociados con el sistema estructural de los edificios.

En el Apartado 3.2 se abordan los aspectos relevantes, a efectos prácticos, en relación con las incertidumbres asociadas con las variables que intervienen en un análisis estructural. Se distingue entre diferentes tipos de incertidumbres según su origen. También se trata la manera de caracterizarlas, a través de la obtención de los datos necesarios por distintas vías, así como la selección de una adecuada función de distribución estadística.

Los criterios para el fallo de una estructura se introducen conceptualmente en el Apartado 3.3, a través del método de los estados límite. Con respecto a estos, se determinan las probabilidades de fallo, teniendo en cuenta el carácter aleatorio de las variables.

Diferentes métodos permiten estimar la probabilidad de fallo de una estructura con respecto a un determinado estado límite. En el Apartado 3.4 se menciona un método analítico aproximado [Hasofer 1974], denominado según sus siglas en inglés FOSM (First Order Second Moment Method) o FORM (First Order Reliability Method), al que se recurre en la continuación del trabajo. Mediante la determinación de los así llamados valores de cálculo de las variables, que tienen en cuenta su carácter aleatorio, este método permite asegurar la condición de ausencia de fallo estructural con respecto a los estados límite a considerar.

La mayoría de las normas y recomendaciones para el proyecto de las estructuras de ingeniería civil introducen de manera indirecta los valores de cálculo de las variables aleatorias. Estas se describen a 
través de sus valores representativos, particularmente los denominados valores característicos, a los que se les aplica un conjunto de coeficientes parciales y de combinación de las acciones para obtener los valores de cálculo que posteriormente se emplean para verificar la fiabilidad estructural. Este método de los coeficientes parciales se presenta en el Apartado 3.5.

Los coeficientes parciales se pueden calibrar de forma que su aplicación en el dimensionado estructural conduzca a un nivel de fiabilidad lo más próximo posible a un valor objetivo seleccionado. El Apartado 3.6 contiene información sobre los niveles de fiabilidad requeridos en diferentes documentos normativos. Valores requeridos para la fiabilidad estructural se pueden determinar mediante un análisis de riesgo, relacionando de esta manera los denominados métodos explícitos e implícitos (Apartado 1.1.1).

De acuerdo con los criterios establecidos en las normas actuales, la fiabilidad estructural se considera a nivel de las secciones transversales o de los elementos estructurales. Como base para el posterior desarrollo de un concepto de evaluación de los riesgos asociados con las estructuras de los edificios, el Apartado 3.7 contiene algunos aspectos fundamentales sobre la fiabilidad de los sistemas.

El Apartado 3.8 contiene un resumen de los aspectos principales del presente capítulo para la continuación del trabajo.

\subsection{INCERTIDUMBRES ASOCIADAS CON LAS VARIABLES BÁSICAS}

\subsubsection{Fuentes de incertidumbre}

La determinación de las prestaciones de una estructura de ingeniería civil, por ejemplo en términos de su probabilidad de fallo con respecto a un determinado estado límite, requiere la consideración de un importante número de variables básicas. Se trata de variables estocásticas cuyos valores no se pueden determinar de manera determinista ya que están asociadas con distintos niveles de incertidumbres, de las que depende la probabilidad de fallo. Por ejemplo, si se efectuara un determinado número de ensayos de tracción sobre probetas extraídas de diferentes secciones de varios perfiles nominalmente idénticos, laminados a partir del mismo tipo de acero, el límite elástico obtenido sería distinto para cada caso. Las diferencias serían mayores aún si se efectuaran ensayos sobre probetas extraídas de distintos elementos, aunque se hayan fabricado del mismo tipo de acero. Por este motivo, no es posible atribuir un valor determinista al límite elástico de todos los aceros de un mismo tipo. No obstante, disponiendo de un número suficiente de resultados experimentales, la dispersión del límite elástico se puede describir mediante métodos estadísticos. A título de ejemplo se supone que sobre la base de un determinado número de resultados experimentales se estime una probabilidad del $93 \%$ de que el límite elástico supere un determinado valor, digamos $360 \mathrm{~N} / \mathrm{mm}^{2}$. Es importante destacar que una probabilidad siempre está asociada con un determinado evento. En este caso, el evento sería el hecho de que el límite elástico supere los $360 \mathrm{~N} / \mathrm{mm}^{2}$.

Además de la dispersión natural, ilustrada mediante el anterior ejemplo, las incertidumbres relacionadas con las variables básicas pueden tener otros orígenes. En general, se suele distinguir entre tres tipos de incertidumbres [ISO 2394 1998]:

- la variabilidad aleatoria inherente, o dispersión natural;

- las incertidumbres debidas a la falta de conocimientos;

- las incertidumbres estadísticas.

Cada uno de estos tipos de incertidumbres se puede subdividir. En el caso de la variabilidad aleatoria inherente se distingue entre incertidumbres afectadas o no afectadas, respectivamente, por actividades humanas de cualquier tipo. Muchos parámetros relativos a las acciones e influencias pertenecen al 
segundo tipo. Ejemplos son la velocidad del viento o la carga de nieve sobre el terreno. También existen parámetros de resistencia pertenecientes a este segundo tipo, por ejemplo los relativos a la resistencia de un terreno natural. Ejemplos correspondientes al primer tipo de incertidumbres son la resistencia de los materiales constructivos (hormigón; acero; etcétera) o las dimensiones de los elementos estructurales. Estas incertidumbres se pueden reducir a través de métodos de fabricación o de producción más avanzados, o mediante métodos de control más adecuados, lo que por otro lado puede incrementar los costes de una construcción. Por este motivo, el nivel de incertidumbre se puede elegir hasta un cierto límite y la diferenciación entre los dos tipos, según estén o no afectados por las actividades humanas, puede ser importante en el marco de una optimización económica.

Descartando los errores humanos graves, por su diversidad y la subsiguiente dificultad de caracterizarlos, como es habitual en el campo de la teoría de la fiabilidad estructural (Apartado 1.2), las incertidumbres debidas a la falta de conocimientos se pueden subdividir en dos categorías, respectivamente las asociadas con los modelos y las que dependen de la evolución futura de ciertos parámetros. Las primeras se pueden referir tanto a los modelos de las acciones y sus efectos como a los modelos de resistencia. Las incertidumbres relativas a los modelos se pueden reducir a través de la mejora de los conocimientos mediante ensayos o investigaciones teóricas. A la segunda categoría pertenecen, entre otras y a título de ejemplo, las incertidumbres sobre la evolución futura de las sobrecargas de uso o de las acciones ambientales, afectadas por el cambio climático. Las posibilidades de reducción de estas incertidumbres son más reducidas.

Las incertidumbres estadísticas están asociadas con la evaluación estadística de los resultados de ensayos, mediciones u otras observaciones. Entre las posibles causas de estas incertidumbres se pueden nombrar:

- la falta de identificación y de distinción entre diferentes poblaciones estadísticas;

- un número limitado de resultados que conduce a incertidumbres en la estimación de los parámetros estadísticos (por ejemplo del valor medio o de la desviación típica);

- la no consideración de las variaciones sistemáticas de las variables analizadas (por ejemplo de parámetros climáticos);

- una extrapolación excesiva de la información estadística;

- la no consideración de posibles correlaciones;

- el empleo de distribuciones estadísticas para la descripción de incertidumbres cuyo origen solo en parte es estadístico.

Normalmente, las incertidumbres estadísticas se pueden reducir a través de un mayor número de ensayos u observaciones.

\subsubsection{Obtención de datos}

Los valores numéricos de los parámetros que caracterizan un modelo y sus incertidumbres se pueden obtener por diferentes vías, por ejemplo [ISO 2394 1998]:

- mediciones u observaciones;

- análisis;

- decisiones subjetivas;

- consideraciones o criterios de ingeniería.

Los parámetros empleados para describir una variable básica son, por ejemplo, el valor medio, la desviación típica, las correlaciones con otras variables y el tipo de distribución estadística. Con frecuencia, los valores numéricos de estos parámetros se deducen mediante la combinación de datos obtenidos por diferentes de las vías anteriormente mencionadas. 
En el caso de las mediciones u observaciones, el procedimiento suele incluir un análisis estadístico para deducir los parámetros buscados a partir de los datos adquiridos. Incertidumbres asociadas con posibles errores de medición o los efectos escala, se deben evitar a través de la adopción de medidas adecuadas, por ejemplo una eficaz gestión de la calidad del proceso de obtención de los datos básicos.

Una representación en términos estadísticos resulta más difícil si los parámetros se deben determinar mediante decisiones subjetivas o a través de consideraciones ingenieriles. No obstante, a efectos de la aplicación de los métodos probabilistas, también a estas variables se les deben asignar unos parámetros estadísticos. Por ejemplo, la carga útil en un almacén se podría caracterizar adoptando el valor nominal como valor medio y un hipotético exceso de carga como desviación típica. Esta manera de proceder obviamente implica adoptar una serie de decisiones subjetivas. No obstante, los modelos así obtenidos son perfectamente útiles si estas decisiones se ajustan a criterios avalados por la buena práctica.

\subsubsection{Selección de funciones de distribución}

Normalmente se dispone de un número limitado de datos para deducir los parámetros de una determinada variable. Esta situación dificulta el establecimiento inequívoco de la función de distribución estadística más adecuada. En la mayoría de los casos es por ello necesario seleccionar, entre los conocidos tipos de distribución, una función cuyas características se ajusten a las propiedades de la variable básica considerada.

Para las acciones permanentes se suele adoptar una distribución Normal, siempre y cuando el hecho de que se puedan producir valores negativos no resulte contradictorio con otras hipótesis ni pueda ser la causa de resultados erróneos. De lo contrario, una distribución del tipo Lognormal, Weibull o Gamma resultaría más adecuada. Para las acciones variables es conveniente adoptar una distribución del tipo Lognormal, Weibull o Gamma, particularmente si la función debe representar un valor máximo en un determinado período de tiempo.

Para las propiedades de los materiales y para las dimensiones de una estructura o de sus elementos, suele ser adecuada una distribución del tipo Normal o Lognormal. Una distribución Lognormal resulta preferible si, debido a motivos físicos u otras circunstancias, no se pueden producir valores negativos. Eso suele ser el caso, por ejemplo, de la resistencia de los materiales.

\subsection{CRITERIOS PARA EL FALLO ESTRUCTURAL}

\subsubsection{Conceptos básicos}

\section{Período de servicio}

Se denomina período de servicio el tiempo previsto para el uso de una estructura, destinada a la función para la que se proyecta y realiza, poniendo en práctica las actividades de mantenimiento previstas, pero sin necesidad de acometer reparaciones importantes. La Tabla 3.1 establece diferentes categorías para el período de servicio y recoge los correspondientes valores indicativos, establecidos en el Eurocódigo para las estructuras de nueva construcción [EN 1990 2002]. Además, refleja algunos ejemplos ilustrativos para cada una de las categorías.

Según el estado actual de los conocimientos, no es posible predecir con precisión el período de tiempo durante el que una determinada estructura vaya a cumplir unos requisitos predefinidos (Apartado 1.1.1), de modo que pueda mantenerse en servicio. El comportamiento a largo plazo de las estructuras y sus materiales constitutivos solo puede ser estimado de manera aproximada. No 
obstante, es posible adoptar unos intervalos verosímiles para las tareas de mantenimiento previstas o para la sustitución de determinados elementos o componentes de una estructura.

Tabla 3.1 - Valores indicativos para el periodo de servicio de diferentes tipos de estructuras de ingeniería civil [EN 1990 2002].

\begin{tabular}{|c|c|l|}
\hline $\begin{array}{c}\text { Categoría para el } \\
\text { período de servicio }\end{array}$ & $\begin{array}{c}\text { Período de servicio } \\
\text { [años] }\end{array}$ & \multicolumn{1}{|c|}{ Ejemplos } \\
\hline 1 & 10 & Estructuras temporales. \\
2 & 10 a 25 & Elementos sustituibles (por ejemplo, apoyos). \\
3 & 15 a 30 & Construcciones agrícolas. \\
4 & 50 & Estructuras de edificación. \\
5 & 100 & Estructuras monumentales; puentes. \\
\hline
\end{tabular}

Partiendo de estas circunstancias, el concepto del período de servicio resulta útil para:

- la selección de las acciones e influencias a tener en cuenta en el dimensionado de una estructura, así como la determinación de su magnitud;

- la consideración de las propiedades de los materiales, incluidos su comportamiento a largo plazo y los relevantes mecanismos de deterioro;

- la comparación, en términos económicos, de diferentes soluciones en lo relativo a sistema estructural, materiales constitutivos, etcétera, conduciendo cada una de ellas a distintos costes totales y distintas proporciones entre la inversión inicial y las inversiones a lo largo del tiempo (Apartado 2.3.4);

- el establecimiento de estrategias para la gestión de las estructuras mediante procedimientos racionales de inspección, mantenimiento y renovación.

\section{Situaciones de proyecto}

En la ingeniería estructural, las situaciones o escenarios de riesgo (Apartado 2.2.2) relevantes para el dimensionado de una estructura, se denominan situaciones de proyecto. Su identificación corresponde al objetivo principal del proceso de análisis cualitativo de los riesgos, descrito en el Apartado 2.2.2. Las situaciones de proyecto deben englobar todas las condiciones y circunstancias previsibles durante la realización de una obra y su posterior utilización, teniendo en cuenta las características tanto de la propia obra y su entorno, como de la solución estructural adoptada, así como las medidas previstas para mitigar o reducir los riesgos asociados con la estructura (Apartado 2.2.4). Se suele distinguir entre las siguientes clases de situaciones de proyecto [EN 1990 2002, CTE DB SE 2006]:

- Las situaciones persistentes, referidas a las condiciones normales de uso. Normalmente, estas situaciones están relacionadas con el período de servicio de la estructura.

- Las situaciones transitorias que se refieren a unas condiciones en las que la estructura se puede encontrar temporalmente, en términos de su utilización o la exposición. Ejemplos típicos son las fases de construcción o reparación.

- Las situaciones accidentales conciernen a unas condiciones excepcionales en las que se puede encontrar la estructura o a las que puede estar expuesta. Ejemplos son incendios, explosiones, impactos, fallos locales de elementos estructurales, etcétera. Normalmente, estas situaciones están relacionadas con períodos cortos de tiempo.

- Las situaciones sísmicas se refieren a las condiciones excepcionales a las que una estructura está expuesta en caso de eventos sísmicos. 


\section{Estados límite}

Tradicionalmente se considera que los estados de cualquier estructura se pueden clasificar como satisfactorios (estructura segura, apta para el servicio) o insatisfactorios (estructura insegura, no apta para el servicio), respectivamente. Existen diferentes condiciones, denominadas estados límite, que separan ambos dominios. En otras palabras, un estado para el que una estructura cumple exactamente las exigencias establecidas, se conoce como estado límite. Cada uno de estos estados está asociado con un determinado requisito, referido a la estructura o su comportamiento. Así, de ser superado un estado límite, la estructura no cumple con el correspondiente requisito. Sin embargo, a menudo la definición de estos requisitos carece de la precisión necesaria para establecer unos estados límite nítidos [Diamantidis 2012].

En los casos en los que resulte difícil cuantificar un determinado requisito estructural y, por tanto, definir de manera inequívoca el correspondiente estado límite, es necesario recurrir a una adecuada aproximación. La Figura 3.1 representa esquemáticamente las incertidumbres asociadas con el concepto de los estados límite. Una definición nítida de este concepto conduce a que una determinada estructura se clasifique como satisfactoria hasta que los efectos de las acciones alcancen un determinado valor, $E_{0}$. Para valores que superen este límite, la estructura se considera completamente insatisfactoria (Figura 3.1a). En los casos en los que resulte imposible establecer un valor que separe con precisión las condiciones satisfactorias de las insatisfactorias, el establecimiento de una zona de transición, delimitada por los valores $E_{1}$ y $E_{2}$ en la Figura $3.1 \mathrm{~b}$ ), en la que la estructura pierde paulatinamente su aptitud para cumplir con los requisitos, proporciona una definición difusa, pero más realista, de los estados límite. Las incertidumbres correspondientes a un criterio difuso de este tipo únicamente se pueden tener en cuenta en el marco de un análisis probabilista, utilizando técnicas matemáticas específicas [Diamantidis 2012]. Estos aspectos no están cubiertos en la generación actual de los Eurocódigos [EN 1990 2002].

En el campo de la ingeniería estructural, los estados límite se dividen normalmente en dos clases [Melchers 1987]: los estados límite últimos (ELU) y los estados límite de servicio (ELS), respectivamente. La naturaleza de ambos es fundamentalmente diferente. Las principales razones de esta distinción se pueden resumir de la siguiente manera [Diamantidis 2012]:

- El incumplimiento de un estado límite último conlleva normalmente la pérdida de la integridad de la estructura afectada, con las correspondientes consecuencias para las personas que se encuentren en su área de influencia. Además, esta situación se suele traducir finalmente en la necesidad de reparar o incluso sustituir la obra. El incumplimiento de un estado límite de servicio, al contrario, tiene normalmente unas consecuencias de menor alcance. Por regla general, la estructura se puede seguir usando después de la desaparición de las acciones o influencias que estén en el origen del incumplimiento.

- Mientras que los requisitos asociados con los estados límite últimos dependen exclusivamente de una serie de parámetros que caracterizan a la estructura y las acciones e influencias, en los criterios de estados límite de servicio intervienen adicionalmente las exigencias, a menudo muy subjetivas, de la propiedad o de los usuarios, así como las características de los elementos no estructurales y de los equipos instalados en la obra. 
a)

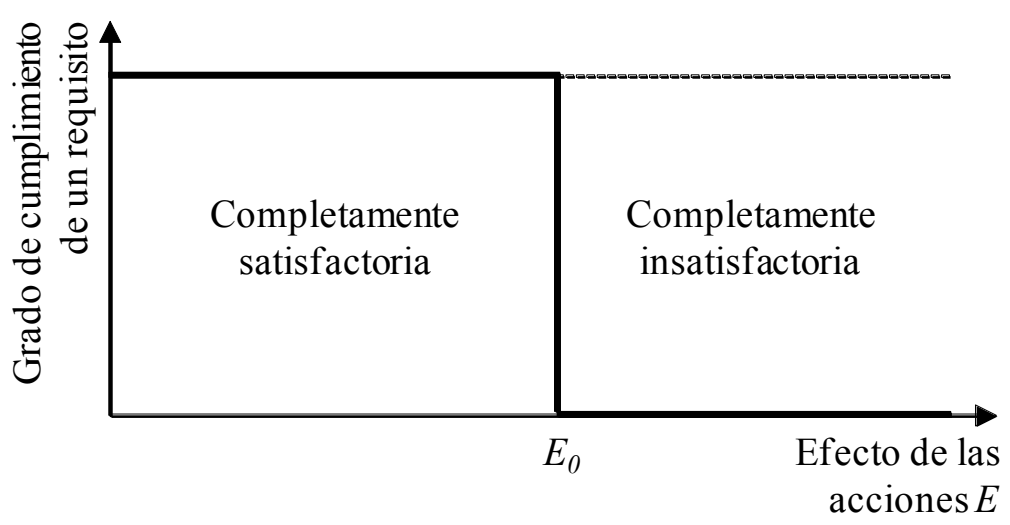

b)

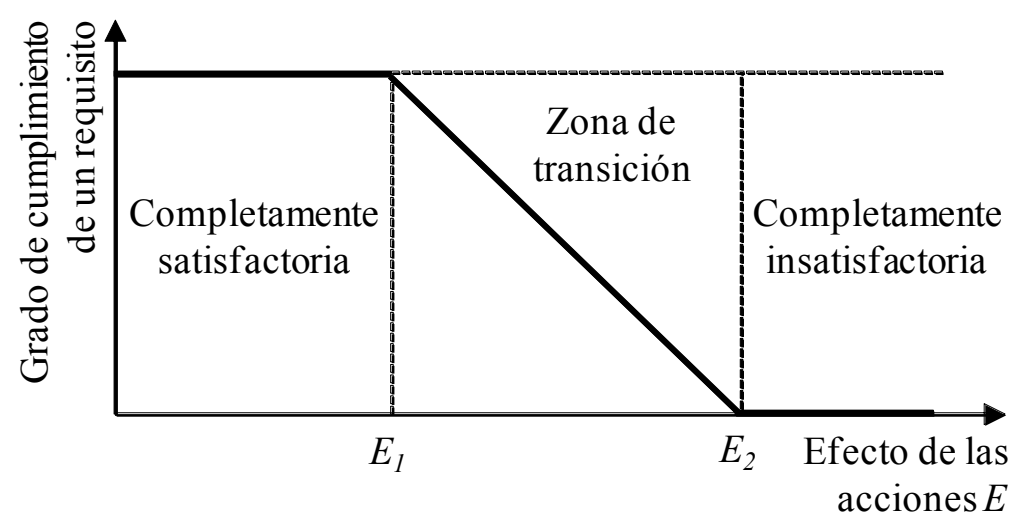

Figura 3.1 - Definición de un estado límite: a) nítida; b) difusa (figura adaptada de [Diamantidis 2012]).

De acuerdo con lo anterior, el Eurocódigo y otras normas estructurales [EN 1990 2002, CTE DB SE 2006] definen los estados límite últimos como aquellos que están asociados con el colapso, u otras formas similares de fallo estructural, y afectan a:

- la seguridad de las personas;

- la integridad de las estructuras.

La verificación de los estados límite últimos engloba comprobaciones relativas a:

- la pérdida del equilibrio estático del conjunto de la estructura, o de parte de ella, considerada como un cuerpo rígido;

- la rotura o las deformaciones excesivas de la estructura o de cualquier elemento estructural;

- el fallo o la deformación excesiva del terreno;

- los fallos inducidos por mecanismos de deterioro (fatiga; corrosión; etcétera).

Se clasifican como estados límite de servicio aquellos estados que, de ser superados, afectan a [EN 1990 2002, CTE DB SE 2006]:

- el confort y el bienestar de los usuarios de la obra o de terceras personas;

- el correcto funcionamiento de los elementos estructurales y no estructurales, así como de las instalaciones y los equipos;

- la apariencia de la obra.

En términos generales, la verificación de los estados límite de servicio se basa en criterios referentes a los siguientes aspectos:

- las deformaciones que afecten a la apariencia o la funcionalidad de la obra; 
- las vibraciones que afecten negativamente al bienestar de las personas o al funcionamiento de la estructura, las instalaciones o los equipos;

- los daños o los mecanismos de deterioro que influyan en la apariencia, la durabilidad o el funcionamiento de la obra.

El dimensionado de una estructura debe englobar las verificaciones relevantes tanto para la seguridad estructural como la aptitud al servicio, incluyendo en ambos casos los aspectos de la durabilidad [Diamantidis 2012]. Este enfoque es razonable debido a que los requisitos relacionados con ambas clases de estados límite deben cumplirse durante todo el período de servicio de una obra y los procesos de deterioro pueden afectar tanto al adecuado comportamiento en servicio de la estructura como a su seguridad. La durabilidad se contempla por ello a través de los relevantes estados límite de servicio y últimos.

\subsubsection{Estados límite últimos}

De acuerdo con la norma internacional sobre la fiabilidad estructural [ISO 2394 1998] se asume que el criterio de fallo de una estructura se rige según una función, $g(\boldsymbol{X})$, del vector de las variables básicas, $\boldsymbol{X}$, de manera que (Apartado 2.2.3):

- Para el estado deseado

$g(X)>0$

- Para el estado límite

$g(X)=0$

- Para el estado no deseado

$g(X)<0$

Esta situación queda ilustrada en la Figura 3.2 para un vector con dos variables básicas, $\boldsymbol{X}=\left(X_{1}, X_{2}\right)$.

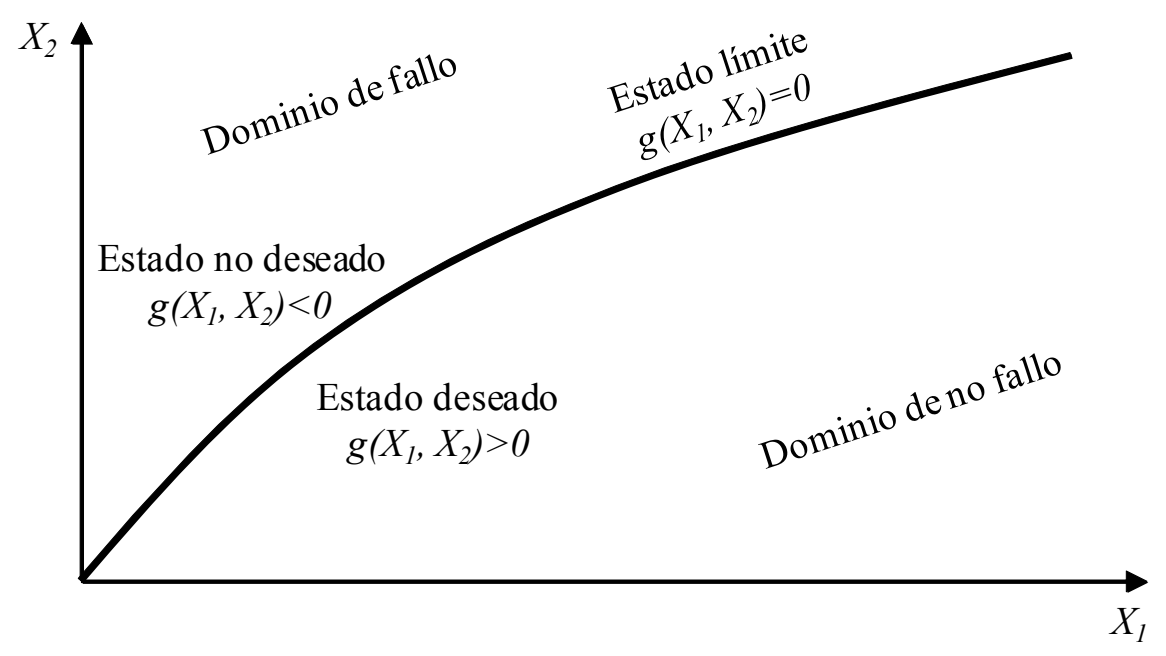

Figura 3.2 - Ilustración de la función g(X) (figura adaptada de [ISO 2394 1998]).

Muchas variables básicas dependen del factor tiempo. Por ejemplo: las acciones ambientales extremas pueden variar a lo largo del tiempo, lo que es un aspecto de gran actualidad en el contexto de los fenómenos asociados con el cambio climático; los materiales constitutivos pueden estar afectados por mecanismos de deterioro en función del tiempo; la resistencia de los elementos 
solicitados por cargas variables repetidas puede disminuir con el tiempo debido a mecanismos de fatiga; etcétera. En general, algunas de las variables de un vector $\boldsymbol{X}$ se deben representar mediante procesos estocásticos. La variabilidad con el tiempo significa que los máximos o mínimos de las componentes de $\boldsymbol{X}$ no se producen simultáneamente. La dependencia del factor tiempo implica que la probabilidad de fallo siempre debe estar asociada con un determinado período de referencia, $t_{0}$, que es objeto de elección.

El fallo de una estructura o de un elemento estructural se asocia con su transición de un estado deseado a un estado no deseado (Figura 3.2). Para la mayoría de los estados límite últimos, la probabilidad de fallo, $P_{f}$, se puede representar a través de la siguiente relación:

$P_{f}=P[g(\boldsymbol{X})<0]$

Algunos aspectos genéricos sobre la determinación de las probabilidades de fallo se encuentran en el Apartado 2.2.3. Por otro lado, el complemento de la probabilidad de fallo de una estructura se entiende como su fiabilidad o probabilidad de supervivencia, $P_{s}$ :

$P_{s}=1-P_{f}$

Si se analiza la fiabilidad de un elemento estructural, o de una de sus secciones transversales, con respecto a un determinado mecanismo de fallo y una situación de proyecto específica, normalmente es posible describir la función de estado límite, $g(\boldsymbol{X})$, a través de una expresión única derivada del comportamiento mecánico (Apartado 2.2.3). Un análisis de este tipo se puede entender como el análisis de un elemento, no en el sentido estructural de la palabra sino en el sentido probabilista.

Si se considera más de un mecanismo de fallo para un elemento estructural, o si se estudian simultáneamente varios de estos elementos, $g(\boldsymbol{X})$ puede representarse en términos de una función compuesta por varias funciones $g_{1}(\boldsymbol{X}), g_{2}(\boldsymbol{X}), \ldots$. La consideración simultánea de varias condiciones $g_{i}(\boldsymbol{X})<0$, se entiende como el análisis de un sistema. La definición de la función de estado límite, $g(\boldsymbol{X})$, depende fuertemente de las características del sistema. Por ejemplo, en un sistema estructural en serie el fallo de una sección conduce al fallo total. En este caso, el dominio de fallo (estado no deseado) quedaría determinado por las siguientes condiciones [ISO 2394 1998]:

$g_{1}\left(X_{1}, X_{2}\right)<0$ ó $g_{2}\left(X_{1}, X_{2}\right)<0$

Por otro lado, si el sistema estructural es redundante en el sentido de que el agotamiento de una sección o de un elemento no conduce al colapso total de la estructura ya que dispone de una cierta capacidad de redistribución de los esfuerzos, las condiciones que rigen el dominio de fallo son:

$g_{1}\left(X_{1}, X_{2}\right)<0$ y $g_{2}\left(X_{1}, X_{2}\right)<0$

En realidad, las estructuras de ingeniería civil a menudo no se pueden clasificar claramente como sistemas en serie o redundantes, respectivamente. Se trata de sistemas combinados cuyo comportamiento se sitúa entre los dos casos extremos mencionados (Apartado 3.7.2).

En una aplicación directa de los métodos probabilistas explícitos, una vez determinada la probabilidad de fallo de la estructura o del elemento estructural, $P_{f}$, para el período de referencia, $t_{0}$, se debe comprobar que no supere la probabilidad de fallo admisible, $P_{f, a d m}$. Esta última se determina en concordancia con lo especificado en el Apartado 2.3:

$P_{f} \leq P_{f, a d m}$ 


\subsubsection{Estados límite de servicio}

Según lo especificado en el Apartado 3.3.1, existen estados límite de servicio para los que puede ser acotada claramente la transición de unas condiciones satisfactorias a otras insatisfactorias al estar asociadas con criterios objetivos. Para otros estados límite de servicio, esta transición es difusa, produciéndose una disminución paulatina del grado de cumplimiento de los requisitos. La Figura 3.1b) representa una relación lineal pero, según la norma internacional [ISO 2394 1998], la transición puede ser más o menos rápida. En términos genéricos puede definirse un grado de cumplimiento de los requisitos, en función de un determinado efecto de las acciones o un parámetro relacionado con el comportamiento en servicio de la estructura, como por ejemplo la deformación de una viga, o la intensidad de las vibraciones de un forjado. A efectos de optimización, el grado de cumplimiento también se puede expresar en términos económicos [ISO 2394 1998].

\subsection{MÉTODOS BASADOS EN LA DETERMINACIÓN DE LOS VALORES DE CÁLCULO}

\subsubsection{Valores de cálculo según el método FORM}

Según lo especificado en los Apartados 2.2.3 y 3.3.2, un determinado estado límite se puede describir en términos de un modelo de cálculo con una (o varias) función(es) $g(.$.$) de un conjunto de variables$ $X_{1}, X_{2}, \ldots, X_{n}$, relativas a las acciones sobre la estructura para una determinada situación de proyecto, los parámetros geométricos, las características de los materiales, etcétera. La condición de ausencia del fallo estructural asociado con el estado límite considerado, se expresa formalmente de la siguiente manera, en concordancia con las ecuaciones (3.1) y (3.2):

$$
g\left(X_{1}, X_{2}, \ldots, X_{n}\right) \geq 0
$$

A efectos de la verificación del estado límite considerado, la condición (3.9) se suele expresar en términos de los denominados valores de cálculo de las variables:

$g\left(x_{1 d}, x_{2 d}, \ldots, x_{n d}\right) \geq 0$

siendo $x_{1 d}, x_{2 d}, \ldots, x_{n d}$ los valores de cálculo de las variables $X_{1}, X_{2}, \ldots, X_{n}$.

De acuerdo con el método FOSM (First Order Second Moment Method) o FORM (First Order Reliability Method), mencionado en el Apartado 3.1, el valor de cálculo, $x_{i d}$, de una variable, $X_{i}$, depende de:

- los parámetros de la variable $X_{i}$;

- el tipo de distribución probabilista asumida;

- el valor requerido, $\beta_{\mathrm{t}}$, del denominado índice de fiabilidad, $\beta$, que para el estado límite y la situación de proyecto considerados está relacionado con la correspondiente probabilidad de fallo (Apartado 3.6.1);

- un factor $\alpha_{i}$ que describe la sensibilidad de la probabilidad de fallo, asociada con el estado límite y la situación de proyecto considerados, con respecto a la variación de $X_{i}$ (Apartado 3.4.2).

Para una distribución arbitraria de la variable, $F\left(x_{i}\right)$, los valores de cálculo se pueden expresar mediante la siguiente ecuación:

$F\left(x_{i d}\right)=\Phi\left(-\alpha_{i} \cdot \beta_{t}\right)$

$F(\ldots) \quad$ : función de distribución de (...)

$\Phi \quad$ : función de distribución normal

$\alpha_{i} \quad$ : factor de sensibilidad para la variable $X_{i}$ 
$\beta_{t} \quad$ : índice de fiabilidad requerido

\subsubsection{Factores de sensibilidad según el método FORM}

Asumiendo que las variables aleatorias de la función $g(\boldsymbol{X})$ sean estadísticamente independientes, los factores de sensibilidad, $\alpha_{i}$, a emplear en un análisis mediante el método FORM (First Order Reliability Method), tienen las siguientes propiedades [ISO 2394 1998]:

$-1 \leq \alpha_{i} \leq 1$

$\sum \alpha_{i}^{2}=1$

En principio, los valores $\alpha_{i}$ se deberían determinar a partir de un análisis, mediante el método FORM [Hasofer 1974], de un conjunto representativo de estructuras. No obstante, en primera aproximación se puede adoptar un conjunto de valores normalizados para los factores de sensibilidad, $\alpha_{i}$, basados en la experiencia y reflejados en la Tabla 3.2, según la norma internacional [ISO 2394 1998]. Los mismos valores también han sido adoptados en los Eurocódigos [EN 1990 2002].

Los valores indicados en la Tabla 3.2 no cumplen la condición correspondiente a la ecuación (3.13). Debido a que la suma de los cuadrados de los factores de sensibilidad es superior a la unidad, la aplicación de los valores numéricos indicados conduce a resultados conservadores. Con el fin de limitar los errores cometidos, estos valores solo deben aplicarse si se cumple la siguiente condición [ISO 2394 1998]:

$0,16<\frac{\sigma_{E 1}}{\sigma_{R 1}}<6,6$

$\sigma_{E I} \quad:$ desviación típica de la variable de la acción o influencia dominante

$\sigma_{R 1} \quad$ : desviación típica de la variable de resistencia dominante

Tabla 3.2 - Valores normalizados para los factores de sensibilidad $\alpha_{i}$ [ISO 2394 1998, EN 1990 2002].

\begin{tabular}{|l|l|c|}
\hline & \multicolumn{1}{|c|}{ Variable $\boldsymbol{X}_{\boldsymbol{i}}$} & Factor de sensibilidad $\boldsymbol{\alpha}_{\boldsymbol{i}}$ \\
\hline \multirow{2}{*}{ Resistencia } & Variable dominante de resistencia & 0,8 \\
& Otras variables de resistencia & $0,4 \cdot 0,8=0,32$ \\
\hline \multirow{2}{*}{ Acciones e influencias } & Acción o influencia dominante & $-0,7$ \\
& Otras acciones e influencias & $-0,4 \cdot 0,7=-0,28$ \\
\hline
\end{tabular}

Al efectuar un análisis estructural se desconoce, a priori, cuáles de las variables se deben considerar como siendo dominantes. Por este motivo, en el análisis se deben adoptar como variables dominantes simultáneamente una de resistencia y una de las acciones, y las restantes como no dominantes, probando todas las posibles combinaciones con el fin de deducir cuáles de ellas gobiernen el problema estudiado. 


\subsection{EL MÉTODO DE LOS COEFICIENTES PARCIALES}

\subsubsection{Coeficientes parciales basados en valores de cálculo}

Los métodos probabilistas implícitos, en los que se suele basar en la práctica el dimensionado de las estructuras, no emplean directamente los valores de cálculo, $x_{d}$, para las variables que intervienen en la verificación de un determinado estado límite. Las variables aleatorias se introducen mediante sus valores representativos (valor característico, nominal, de combinación, etcétera, según el caso) que se emplean con un conjunto de coeficientes parciales para las acciones e influencias, así como para la resistencia. Los valores numéricos de estos coeficientes parciales dependen de una serie de factores, en consonancia con lo establecido en el Apartado 3.4.1:

- el modelo probabilista de la variable considerada;

- la probabilidad de fallo aceptable, expresada a menudo en términos del índice de fiabilidad requerido;

- la sensibilidad de la probabilidad de fallo, asociada con el estado límite y la situación de proyecto considerados, con respecto a la variación de la variable;

- el valor representativo de la variable.

En la mayoría de los casos, la condición (3.10), que se debe cumplir en el marco de una verificación basada en el formato de los coeficientes parciales, se puede expresar de la siguiente manera:

$g\left(x_{d}\right)=R_{d}-E_{d} \geq 0$

$E_{d} \quad:$ valor de cálculo de los efectos de las acciones e influencias

$R_{d} \quad$ : valor de cálculo de la resistencia correspondiente

Los valores de cálculo de los efectos de las acciones e influencias por un lado, y de la resistencia frente a estos efectos por otro lado, se pueden expresar a través de:

$E_{d}=E\left(\boldsymbol{F}_{\boldsymbol{d}}, \boldsymbol{a}_{\boldsymbol{d}}, \boldsymbol{\theta}_{\boldsymbol{d}}, \ldots\right)$

$R_{d}=R\left(\boldsymbol{f}_{\boldsymbol{d}}, \boldsymbol{a}_{\boldsymbol{d}}, \boldsymbol{\theta}_{\boldsymbol{d}}, \ldots\right)$

$E(\ldots) \quad$ : efecto de las acciones e influencias en función de (...)

$\boldsymbol{F}_{\boldsymbol{d}} \quad:$ vector de valores de cálculo de las acciones e influencias

$R(\ldots) \quad$ : resistencia (correspondiente al efecto considerado) en función de (...)

$\boldsymbol{a}_{\boldsymbol{d}} \quad:$ vector de valores de cálculo de las dimensiones geométricas

$\boldsymbol{f}_{\boldsymbol{d}} \quad:$ vector de valores de cálculo de las propiedades de los materiales

$\boldsymbol{\theta}_{\boldsymbol{d}} \quad:$ vector de valores de cálculo de los coeficientes de incertidumbre de los modelos

Los valores de cálculo de las diferentes variables se determinan a partir de las relaciones enumeradas a continuación.

- Valor de cálculo de una acción o influencia, $F_{d}$, distinguiendo para las acciones variables entre los casos en los que sean dominantes o no, respectivamente

$F_{d}=\gamma_{f} \cdot F_{k}$

$F_{d}=\gamma_{f} \cdot \psi_{0} \cdot F_{k}$

$F_{k} \quad:$ valor característico de una acción o influencia

$\gamma_{f} \quad:$ coeficiente parcial para una acción o influencia

$\psi_{0} \quad$ : coeficiente para el valor de combinación de una acción variable

- Valor de cálculo de una propiedad de un material, $f_{d}$ 


$$
f_{d}=\frac{f_{k}}{\gamma_{m}}
$$

$f_{k} \quad:$ valor característico de una propiedad de un material

$\gamma_{m} \quad$ : coeficiente parcial para una propiedad de un material

- Valor de cálculo de una dimensión geométrica, $a_{d}$

$a_{d}=a_{\text {nom }} \pm \Delta a$

$a_{\text {nom }} \quad:$ valor nominal de una dimensión geométrica

$\Delta a \quad$ : desviación de una dimensión geométrica de su valor nominal

- Valor de cálculo del coeficiente de incertidumbre de un modelo, $\theta_{d}$

Normalmente, los valores de cálculo de los coeficientes de incertidumbre de los modelos, $\theta_{d}$, se introducen en los cálculos a través de los coeficientes parciales, respectivamente para el modelo de los efectos de las acciones e influencias, $\gamma_{S d}$, y para el modelo de resistencia, $\gamma_{R d}$ :

$E_{d}=\gamma_{S d} \cdot E\left(\gamma_{f} \cdot F_{k} ; \gamma_{f} \cdot \psi_{0} \cdot F_{k} ; a_{\text {nom }} \pm \Delta a ; \ldots\right)$

$R_{d}=\frac{1}{\gamma_{R d}} \cdot R\left(\frac{f_{k}}{\gamma_{m}} ; a_{\text {nom }} \pm \Delta a ; \ldots\right)$

$\gamma_{R d} \quad:$ coeficiente parcial para el modelo de resistencia

$\gamma_{S d} \quad$ : coeficiente parcial para el modelo de los efectos de las acciones e influencias

Los coeficientes parciales se pueden deducir a partir de los valores de cálculo de las variables, determinados por ejemplo según el método FORM (Apartado 3.4), de acuerdo con las relaciones:

$\gamma_{f}=\frac{F_{d}}{F_{k}}$

$\gamma_{m}=\frac{f_{k}}{f_{d}}$

Muchas normas estructurales no emplean exactamente el formato según las ecuaciones (3.22) y (3.23) para la determinación de los valores de cálculo de los efectos de las acciones e influencias y de la resistencia, respectivamente. Desde un punto de vista práctico, este formato se considera a menudo como siendo innecesariamente complicado y laborioso. Por este motivo, algunas normas como [CTE DB SE 2006, EHE-08 2008, EAE 2011] adoptan un formato simplificado, del estilo que se representa a continuación.

- Efectos de las acciones e influencias

$E_{d}=E\left(\gamma_{F} \cdot F_{k} ; a_{\text {nom }}\right)$

- Resistencia

$R_{d}=R\left(\frac{f_{k}}{\gamma_{M}} ; a_{\text {nom }}\right)$

o alternativamente

$R_{d}=\frac{1}{\gamma_{R}} \cdot R\left(f_{k} ; a_{\text {nom }}\right)$ 
$\gamma_{F} \quad:$ coeficiente parcial para una acción o influencia, teniendo en cuenta también las incertidumbres del modelo y las desviaciones geométricas

$\gamma_{M} \quad$ : coeficiente parcial para una propiedad de un material, teniendo en cuenta también las incertidumbres del modelo y las desviaciones geométricas

$\gamma_{R} \quad$ : coeficiente parcial para la resistencia, teniendo en cuenta las incertidumbres asociadas con las propiedades de los materiales y el modelo, así como las desviaciones geométricas

En estos casos, los coeficientes parciales $\gamma_{F}, \gamma_{M}$ o $\gamma_{R}$ deben calibrarse de modo que las ecuaciones (3.26), (3.27) y (3.28) conduzcan a los mismos resultados que las ecuaciones originales (3.22) y (3.23), respectivamente.

\subsubsection{Coeficientes parciales calibrados}

En la literatura especializada se encuentra información sobre los procedimientos de calibración de los coeficientes parciales [Thoft-Christensen 1982]. Tomando como punto de partida un formato arbitrario de coeficientes parciales, el objetivo de la calibración consiste en la deducción de unos coeficientes de modo que la fiabilidad de las estructuras, en cuyo dimensionado se aplican, se aproxime al máximo al nivel de fiabilidad requerido y predefinido. El proceso de calibración consta de los pasos mencionados a continuación [ISO 2394 1998].

1. Definición de un formato de coeficientes parciales

$$
g\left(\frac{f_{k 1}}{\gamma_{m 1}} ; \frac{f_{k 2}}{\gamma_{m 2}} ; \ldots ; \gamma_{f 1} \cdot F_{k 1} ; \gamma_{f 2} \cdot F_{k 2} ; \ldots\right) \geq 0
$$

$F_{k j} \quad:$ valor característico de la acción o influencia $j$

$f_{k i} \quad:$ valor característico de la resistencia del material $i$

$\gamma_{f j} \quad:$ coeficiente parcial para la acción o influencia $j$

$\gamma_{m i} \quad$ : coeficiente parcial para la resistencia del material $i$

2. Selección de elementos estructurales

Selección de un conjunto de $n$ elementos estructurales representativos que cubran adecuadamente el campo de aplicación de los modelos a calibrar en relación con:

- los tipos de acciones e influencias;

- las dimensiones de las estructuras;

- los materiales constitutivos;

- los estados límite considerados.

3. Dimensionado estructural

Dimensionado de los $n$ elementos estructurales representativos, aplicando un conjunto de coeficientes parciales $\left(\gamma_{m l} ; \gamma_{m 2} ; \ldots ; \gamma_{f 1} ; \gamma_{f 2} ; \ldots\right)$. A cada uno de los elementos así dimensionados le corresponde un nivel de fiabilidad, expresado por ejemplo en términos del índice $\beta$, que se desvía más o menos de la fiabilidad requerida y predefinida, $\beta_{t}$ (Apartado 3.4.1).

4. Función de agregado

La desviación entre el nivel de fiabilidad de los $n$ elementos y la fiabilidad requerida, $\beta_{t}$, se puede expresar en los siguientes términos:

$D=\sum_{k=1}^{n}\left[\beta_{k}\left(\gamma_{m i} ; \gamma_{f j}\right)-\beta_{t}\right]^{2}$

$D \quad$ : desviación agregada

$\beta_{k}(\ldots) \quad$ : índice de fiabilidad del elemento $k$, en cuyo dimensionado se emplean los coeficientes parciales $\left(\gamma_{m 1} ; \gamma_{m 2} ; \ldots ; \gamma_{f 1} ; \gamma_{f 2} ; \ldots\right)$ 


\section{Optimización}

Selección del conjunto de coeficientes parciales que conduzca al valor mínimo de la desviación agregada, $D$.

Alternativamente, el nivel de fiabilidad se puede expresar en términos de la probabilidad de fallo. En los casos en los que los $n$ elementos estructurales tengan importancias relativas desiguales, $D$ se puede determinar introduciendo unos factores de ponderación. Los valores que excedan el nivel admisible de la probabilidad de fallo deberían penalizarse más que los valores que se queden por debajo de la probabilidad de fallo admisible [ISO 2394 1998].

\subsection{NIVELES DE FIABILIDAD}

\subsubsection{Generalidades}

Los criterios de aceptación de los riesgos (Apartado 2.3) se reflejan de manera implícita o explícita en las normas estructurales (Apartado 1.1). Por ejemplo, en el Eurocódigo [EN 1990 2002] y en otras normas y recomendaciones [ISO 2394 1998, JCSS 2001] se definen unos valores requeridos, $\beta_{t}$, para el índice de fiabilidad, $\beta$ (Apartado 3.4.1). Este índice se suele usar para cuantificar la fiabilidad estructural debido a que sus valores numéricos resultan más prácticos que las probabilidades de fallo, muy pequeñas. En cualquier caso, el índice de fiabilidad está relacionado con la probabilidad de fallo a través de la función de distribución normal, $\beta=-\Phi^{-1}\left(P_{f}\right)$, relación que se ilustra en la Tabla 3.3 por medio de algunos ejemplos numéricos, por lo que los valores aceptables para la probabilidad de fallo están definidos a través de $\beta_{t}$. Los índices de fiabilidad requeridos, establecidos en las normas mencionadas, son el resultado de una serie de estudios laboriosos, combinando algunos de los enfoques mencionados en el Apartado 2.3. Estos índices $\beta_{t}$ se emplean a su vez para la obtención de los coeficientes parciales para el dimensionado de las estructuras de nueva construcción.

Las probabilidades de fallo admisibles y los índices de fiabilidad requeridos están asociados con un determinado período de referencia, reflejan las consecuencias esperadas en caso de producirse un fallo y también el coste relativo de las medidas necesarias para evitarlo (Apartado 2.2.4). Su validez se limita a los elementos estructurales individuales, por lo que requieren una atención particular los casos en los que se puede producir un colapso total [Diamantidis 2012]. Además, al estar basadas en los criterios de aceptación del Apartado 2.3, las probabilidades admisibles también están afectadas por los problemas recopilados en el Apartado 2.4.

En los siguientes subapartados se recogen los índices de fiabilidad requeridos, de acuerdo con algunas normas estructurales modernas. A estos efectos se adopta un orden cronológico según el año de su publicación.

Tabla 3.3 - Relación entre probabilidad de fallo, $P_{f}$, e indice de fiabilidad, $\beta$ [ISO 2394 1998, EN 1990 2002].

\begin{tabular}{|c|c|c|c|c|c|c|c|}
\hline $\boldsymbol{P}_{\boldsymbol{f}}$ & $10^{-1}$ & $10^{-2}$ & $10^{-3}$ & $10^{-4}$ & $10^{-5}$ & $10^{-6}$ & $10^{-7}$ \\
\hline $\boldsymbol{\beta}$ & 1,3 & 2,3 & 3,1 & 3,7 & 4,2 & 4,7 & 5,2 \\
\hline
\end{tabular}




\subsubsection{Valores numéricos}

\section{ISO 23941998}

La norma internacional [ISO 2394 1998] proporciona valores numéricos para el índice de fiabilidad requerido, $\beta_{t d}$, referido a todo el período de servicio previsto, $T_{d}$. No obstante, este documento no contiene ninguna especificación sobre el período $T_{d}$ a considerar. Por lo demás, tal y como se deduce de la Tabla 3.4, la citada norma [ISO 2394 1998] establece dos parámetros para la diferenciación de los índices de fiabilidad requeridos: el coste relativo de las medidas necesarias para prevenir un fallo estructural, así como las consecuencias esperadas de un posible fallo.

Tabla 3.4 - Índice de fiabilidad requerido, $\beta_{t d}$, para todo el periodo de servicio previsto, $T_{d}$ [ISO $23941998]$.

\begin{tabular}{|l|c|c|c|c|}
\hline Coste relativo de las medidas & \multicolumn{4}{|c|}{ Consecuencias esperadas en caso de un fallo estructural } \\
de seguridad & Pequeñas & Algunas & Moderadas & Grandes \\
\hline Alto & 0 & 1,5 & 2,3 & 3,1 \\
Moderado & 1,3 & 2,3 & 3,1 & 3,8 \\
Bajo & 2,3 & 3,1 & 3,8 & 4,3 \\
\hline
\end{tabular}

\section{JCSS 2001}

El Joint Committee on Structural Safety establece unos índices de fiabilidad requeridos, $\beta_{t a}$, asociados con los estados límite últimos para un período de referencia de un año, $T_{a}$. Los valores recomendados se encuentran en la Tabla 3.5 [JCSS 2001], en función del coste relativo de las medidas que es necesario adoptar para alcanzar un nivel adecuado de fiabilidad y las consecuencias esperadas en el caso de producirse un fallo. El código modelo probabilista [JCSS 2001] contiene más información sobre la deducción de estos valores.

Tabla 3.5 - Índice de fiabilidad requerido, $\beta_{t a}$ para un periodo de referencia de un año, $T_{a}$ [JCSS 2001].

\begin{tabular}{|l|c|c|c|}
\hline Coste relativo de las medidas & \multicolumn{3}{|c|}{ Consecuencias esperadas } \\
de seguridad & Menores & Moderadas & Grandes \\
\hline Grande & 3,1 & 3,3 & 3,7 \\
Normal & 3,7 & 4,2 & 4,4 \\
Pequeño & 4,2 & 4,4 & 4,7 \\
\hline
\end{tabular}

\section{EN 19902002}

La Tabla 3.6 contiene los índices de fiabilidad requeridos para los estados límite últimos, según el Eurocódigo [EN 1990 2002]. Esta norma establece dos conjuntos de valores, para períodos de referencia de 1 y 50 años, respectivamente, pero sin establecer una relación explícita con el período de servicio previsto, $T_{d}$. Los valores requeridos están definidos en función de las consecuencias esperadas de un posible fallo, desde los puntos de vista de las personas, el medio ambiente y la economía. A efectos prácticos, las consecuencias esperadas se dividen cualitativamente en tres clases, asociadas con las correspondientes clases de fiabilidad. Cada una de ellas está ilustrada a través de diferentes tipos de edificios y obras de ingeniería civil. 
Tabla 3.6 - Índice de fiabilidad requerido, $\beta_{t}$ [EN 1990 2002].

\begin{tabular}{|l|l|c|c|l|}
\hline Clase de & Consecuencias & \multicolumn{2}{|c|}{ Período de referencia } & \multirow{2}{*}{ Ejemplos } \\
fiabilidad & esperadas & $\mathbf{1}$ año & $\mathbf{5 0}$ años & \\
\hline RC3 Alta & Grandes & $\beta_{t l}=5,2$ & $\beta_{t 50}=4,3$ & Puentes; edificios públicos. \\
RC2 Normal & Medianas & $\beta_{t l}=4,7$ & $\beta_{t 50}=3,8$ & Edificios de viviendas/oficinas. \\
RC1 Baja & Pequeñas & $\beta_{t l}=4,2$ & $\beta_{t 50}=3,3$ & Construcciones agrícolas. \\
\hline
\end{tabular}

Conviene destacar que el par de índices de fiabilidad, $\beta_{t l}$ y $\beta_{t 50}$, correspondientes a una determinada clase de fiabilidad y asociados con un período de referencia de 1 y 50 años, respectivamente, representan el mismo nivel de fiabilidad. La aplicación práctica de uno u otro de estos valores depende del período de tiempo considerado en las verificaciones de la fiabilidad estructural. Este a su vez puede estar relacionado con la información estadística disponible sobre las acciones variables en el tiempo, tales como las acciones climáticas, sismo, etcétera, y el correspondiente vector de variables básicas $\boldsymbol{X}=\left(X_{1}, X_{2}, \ldots, X_{n}\right)$. Si se considera por ejemplo la clase de fiabilidad RC2 y un periodo de referencia de 50 años, en las verificaciones de la fiabilidad estructural se debería tener en cuenta un índice de fiabilidad requerido de $\beta_{t 50}=3,8$. El mismo nivel de fiabilidad estructural es alcanzado al considerar un período de referencia de 1 año y un índice de fiabilidad requerido de $\beta_{t l}=4,7$. Todo ello en el caso de una situación de proyecto con una acción variable en el tiempo como acción dominante.

Finalmente, el Eurocódigo [EN 1990 2002] también define índices de fiabilidad requeridos para los estados límite de servicio irreversibles: $\beta_{t 50}=1,5$ para un período de referencia de 50 años y $\beta_{t l}=2,9$ para un año.

\subsubsection{Observaciones finales}

Diferentes normas y recomendaciones internacionales tales como el Eurocódigo [EN 1990 2002] o [ISO 2394 1998] definen unos índices de fiabilidad requeridos, $\beta_{t}$, asociados con determinados períodos de referencia específicos. No obstante, estos documentos no contienen reglas explícitas sobre el ajuste de los índices $\beta_{t}$ a diferentes períodos de servicio previstos, $T_{d}$, recomendados para distintos tipos de estructuras de ingeniería civil (Apartado 3.3.1). Según el código modelo probabilista [JCSS 2001], la probabilidad de fallo admisible, asociada con el período de servicio previsto, $T_{d}$, se puede estimar multiplicando el valor admisible de la probabilidad de fallo anual por $T_{d}$ y un factor $c$ que tiene en cuenta la dependencia entre los diferentes eventos de fallo que pueden ocurrir en el período de un año. En muchos casos, estos eventos son independientes por lo que $c$ adopta un valor de uno [Diamantidis 2012].

El campo de aplicación de los requisitos de fiabilidad estructural, del tipo de los anteriormente citados, se limita a los elementos estructurales (Apartado 3.6.1). Si el posible colapso afecta a una parte considerable de una estructura, por ejemplo del orden del $15 \%$ al $20 \%$ de la superficie útil [Diamantidis 2012], el comportamiento del sistema en su conjunto cobra especial importancia y los aspectos relacionados con la fiabilidad estructural se deberían abordar mediante métodos basados en prestaciones. Se trata de un enfoque relativamente novedoso según el que se establecen unos objetivos específicos para las prestaciones de un sistema en relación con un determinado nivel de las amenazas. El intento de introducir estos conceptos en normas o recomendaciones de carácter práctico tiene su origen en la observación de que los terremotos más importantes ocurridos en California en los últimos 25 años, Loma Prieta en 1989 y Northridge en 1994, tenían unas consecuencias económicas desproporcionadas e inaceptables [Diamantidis 2012]. 


\subsection{FIABILIDAD DE SISTEMAS}

\subsubsection{Generalidades}

\section{Situación}

Las probabilidades de fallo y los índices de fiabilidad a los que se hace referencia en apartados anteriores caracterizan normalmente solo la fiabilidad de un elemento integrado en un sistema. Además, se refieren a una determinada situación de proyecto y un estado límite específico. No obstante, cada sistema está compuesto por diferentes elementos cuyo fallo, aislado o en combinación con el fallo de otros elementos, puede conducir al fallo global del sistema. Todo ello sin olvidar que diferentes mecanismos pueden estar en el origen del fallo de un determinado elemento y que la mayoría de los sistemas pueden estar sometidos a diferentes situaciones de proyecto con distintas disposiciones de cargas. En las estructuras hiperestáticas, es necesario que diferentes elementos fallen simultáneamente para que se produzca el fallo parcial o total del sistema.

Por estas circunstancias, resulta imprescindible extender a los sistemas estructurales las especificaciones de los apartados anteriores sobre la fiabilidad de los elementos. La evaluación de la fiabilidad de los sistemas requiere la consideración de unos modos de fallo múltiples, representados por los correspondientes estados límite que, además, pueden estar relacionados entre ellos.

\section{Definiciones}

Un sistema se puede representar gráficamente mediante esquemas del tipo de las Figuras 3.3 y 3.4. Los elementos $M_{j}$ están simbolizados por medio de recuadros, unidos entre ellos por líneas. No se trata de modelos físicos, sino de diagramas lógicos cuyas entradas y salidas están marcadas mediante flechas. Para la probabilidad de fallo de los elementos aislados se emplea la notación con letras minúsculas, $p_{f}$, igual que para su complemento, la probabilidad de supervivencia o fiabilidad, $p_{s}$. Por otro lado, las probabilidades de fallo y de supervivencia de un sistema se representan mediante letras mayúsculas, $P_{f}$ y $P_{s}$, respectivamente. Probabilidad de fallo y fiabilidad están relacionadas de la siguiente manera:

- Elemento

$p_{s}+p_{f}=1$

- Sistema

$P_{s}+P_{f}=1$

Existen diferentes definiciones para el fallo de una estructura, considerándola en términos de un sistema:

- alcance de una tensión determinada (tensión admisible);

- alcance de una rigidez estructural mínima;

- alcance de una deformación máxima;

- formación de un mecanismo (plástico);

- alcance de un determinado límite de daño (por ejemplo en procesos de deterioro por fatiga).

En el marco del presente trabajo, se entiende como fallo de un sistema estructural la formación de un mecanismo. En el caso de las estructuras hiperestáticas, eso significa que dos o más elementos deben fallar simultáneamente para que se produzca el colapso del sistema. 


\section{Métodos}

Para el análisis estructural de sistemas con múltiples elementos se pueden adoptar básicamente dos métodos complementarios:

- método de los modos de fallo;

- método de los modos de supervivencia.

El segundo de estos métodos tradicionalmente ha recibido poca atención debido a las dificultades inherentes a la formulación de las ecuaciones de los estados límite. Consecuentemente, este método no se contempla en el presente trabajo.

El primero de los dos métodos está basado en la identificación de todos los posibles modos de fallo de una estructura, por ejemplo a través de la consideración de los mecanismos de colapso. Cada modo de fallo está caracterizado por una secuencia de fallos de distintos elementos, de manera que la estructura en su conjunto alcance el estado límite previamente definido, normalmente la formación de un mecanismo. Las posibles vías que conducen al colapso de una determinada estructura se pueden representar gráficamente en árboles lógicos, por ejemplo en un árbol de eventos (Apartado 2.2.2).

Debido a que cada una de las secuencias identificadas contribuye a la probabilidad de fallo, el evento denominado como fallo estructural, $f_{s}$, corresponde a la unión de los $m$ posibles modos de fallo. Como ya se ha mencionado, algunos modos implican el fallo simultáneo de un determinado número de elementos para que se forme un mecanismo. La probabilidad de fallo se determina aplicando la regla de la adición:

$$
P_{f}=P\left[f_{s}\right]=P\left[f_{1} \cup f_{2} \cup \ldots \cup f_{m}\right]
$$

$$
\begin{array}{ll}
f_{i} & : \text { fallo en el modo } i \\
f_{s} & : \text { fallo de la estructura }
\end{array}
$$

Por otro lado, la probabilidad de fallo del elemento $j$ en el modo $i$ se obtiene mediante la regla de la multiplicación, siendo $n_{i}$ el número de elementos cuyo fallo es necesario para la formación del mecanismo considerado (modo $i$ ):

$$
P\left[f_{i}\right]=P\left[f_{1 i} \cap f_{2 i} \cap \ldots \cap f_{n i}\right]
$$

$f_{j i} \quad:$ fallo del elemento $j$ en el modo de fallo $i$

$n_{i} \quad$ : número de elementos cuyo fallo es necesario para la formación del modo o mecanismo de fallo $i$

De lo anterior se deduce inmediatamente que la determinación de la probabilidad de fallo, $P_{f}$, basada en el método de los modos de fallo subestima esta probabilidad. Esta situación sólo se podría evitar si en el análisis se tuvieran en cuenta todos los posibles modos de fallo lo que, por su número, resulta inabordable en la práctica.

\subsubsection{Idealizaciones}

\section{Sistemas en serie}

En los casos en los que, desde un punto de vista funcional, los elementos constitutivos de un sistema están dispuestos en cadena, se le denomina un sistema en serie (Figura 3.3). En un sistema de este tipo, el fallo de un elemento conduce al fallo del sistema. El elemento menos fiable es predominante desde el punto de vista de la fiabilidad del sistema. En el campo de las estructuras, una viga isostática conforma un ejemplo sencillo de un sistema en serie cuyos elementos son las secciones transversales y los apoyos: el fallo de cualquiera de ellos conduce al fallo de todo el sistema. 
La determinación de la probabilidad de fallo de un sistema según la ecuación (3.33) presenta algunas dificultades, incluso cuando se trata de un sistema en serie. Por este motivo, a continuación se presenta una manera pragmática para su acotación [Melchers 1987].

La fiabilidad de un sistema en serie equivale a la probabilidad de que no falle ninguno de sus $n$ elementos. Suponiendo independencia estadística entre los elementos, la probabilidad de supervivencia del sistema se puede estimar mediante la ecuación:

$P_{s}=\left(1-p_{f 1}\right) \cdot\left(1-p_{f 2}\right) \cdot \ldots \cdot\left(1-p_{f n}\right)=\prod_{i=1}^{n}\left(1-p_{f i}\right)$

$p_{f i} \quad:$ probabilidad de fallo del elemento $i$

Debido a que la probabilidad de fallo, $P_{f}$, es complementaria a la fiabilidad, en caso de valores pequeños de $p_{f i}$ e independencia estadística entre los elementos del sistema, la siguiente ecuación constituye una estimación aceptable de $P_{f}$ :

$P_{f}=1-\prod_{i=1}^{n}\left(1-p_{f i}\right) \approx \sum_{i=1}^{n} p_{f i}$

Obviamente, la probabilidad de fallo de un sistema en serie crece con el número de elementos que lo constituyen y suele ser superior a la probabilidad de fallo del elemento menos fiable. Solo si existe una correlación perfecta entre los elementos de un sistema en serie, lo que puede ocurrir, aproximadamente, si los realiza el mismo fabricante utilizando el mismo material, la probabilidad de fallo del sistema equivale a la probabilidad de fallo del elemento menos fiable:

$P_{f}=\left\lfloor p_{f i}\right\rfloor_{\max }$

Según lo anterior, la ecuación (3.36) proporciona una estimación conservadora de la probabilidad de fallo de un sistema en serie y esta se puede acotar de acuerdo con la ecuación (3.38):

$\left[p_{f i}\right]_{\max } \leq P_{f}<\sum_{i=1}^{n} p_{f i}$

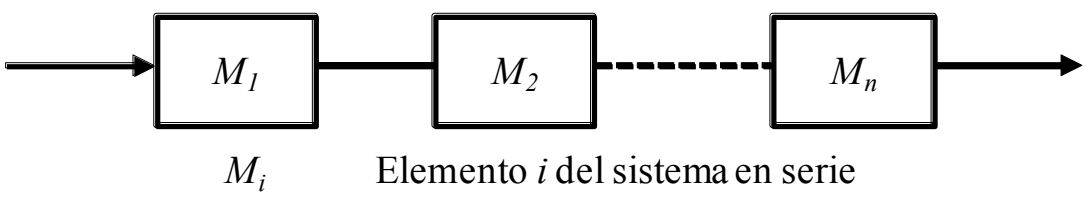

Figura 3.3 - Representación esquemática de un sistema en serie.

\section{Sistemas en paralelo}

Sistemas en los que alguno o algunos de sus elementos pueden fallar sin que se produzca su colapso total, se denominan sistemas en paralelo. El paralelismo al que hace referencia el nombre se debe entender como un aspecto referido al esquema lógico empleado (Figura 3.4), no como una propiedad mecánica del sistema estructural representado. El fallo total de un sistema en paralelo requiere el fallo simultáneo de todos sus elementos.

También en este caso se elige un enfoque pragmático para estimar los límites superior e inferior de la probabilidad de fallo [Melchers 1987]. El hecho de que todos los elementos tienen que fallar para que se produzca el colapso del sistema permite estimar la probabilidad de fallo mediante la ecuación:

$P_{f}=p_{f 1} \cdot p_{f 2} \cdot \ldots \cdot p_{f n}=\prod_{i=1}^{n} p_{f i}$ 
La validez de la anterior ecuación queda supeditada a la independencia estadística entre los elementos constitutivos del sistema. Por otro lado, en caso de correlación completa entre los elementos, la probabilidad de fallo de un sistema en paralelo no puede ser mayor que la probabilidad de fallo del elemento más fiable:

$$
P_{f}=\left\lfloor p_{f i}\right\rfloor_{\min }
$$

De lo anterior se puede deducir que la probabilidad de fallo de un sistema en paralelo está comprendida entre los límites indicados en la ecuación (3.41), y la relación (3.40) proporciona una estimación conservadora de la probabilidad de fallo:

$$
\prod_{i=1}^{n} p_{f i} \leq P_{f} \leq\left[p_{f i}\right]_{\min }
$$

\section{Sistemas mixtos}

En la realidad, los sistemas suelen estar constituidos por subsistemas en paralelo y en serie. Se trata de sistemas mixtos con ramificaciones en serie y conteniendo elementos en paralelo. La probabilidad de fallo de sistemas mixtos se obtiene, en la práctica, mediante una reducción paso a paso del sistema total a subsistemas compuestos por elementos en serie o en paralelo. A estos efectos, también se debe tener en cuenta que el fallo de un elemento independiente puede afectar a la probabilidad de fallo de otros elementos o de grupos de elementos. Se trata por tanto de eventos y probabilidades condicionales.

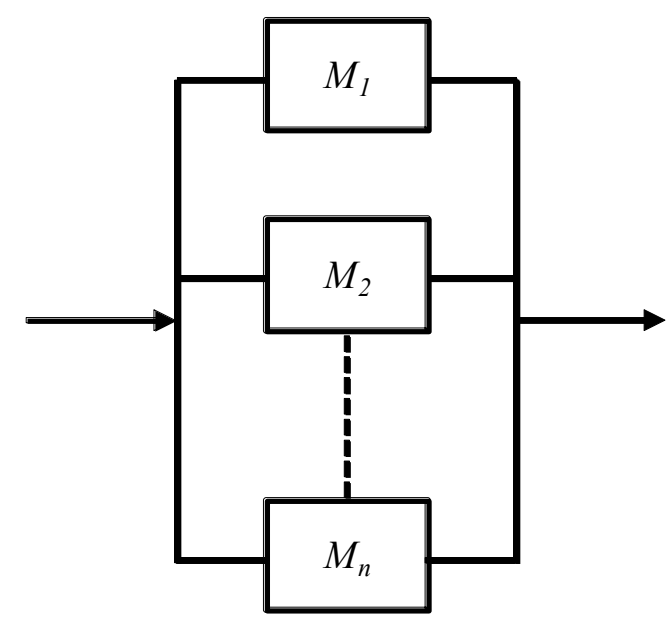

$M_{i} \quad$ Elemento $i$ del sistema en paralelo

Figura 3.4 - Representación esquemática de un sistema en paralelo.

\section{Sistemas estructurales}

Las estructuras de ingeniería civil pueden fallar debido a unos mecanismos muy variados. Por este motivo, una estructura se puede entender como un sistema lógico con elementos en serie, representando cada uno de ellos a un posible mecanismo de fallo. En sistemas hiperestáticos, algunos de estos mecanismos pueden tener el carácter de un sistema en paralelo (Apartado 5.2.2). Además, los elementos que intervienen en un determinado mecanismo de fallo pueden presentar una mayor o menor dependencia estadística, por tener algunas características (variables) en común. Por todos estos motivos, la determinación de las probabilidades de fallo de las estructuras de ingeniería civil resulta todo menos fácil y, generalmente, sólo se pueden estimar valores aproximados. 
En relación con los sistemas estructurales conviene destacar una problemática que resulta fundamental para el desarrollo del presente trabajo. Debido a que un sistema en paralelo solo puede fallar totalmente si se produce el fallo simultáneo de todos sus elementos, el comportamiento estructural de estos últimos resulta particularmente importante desde el punto de vista de la fiabilidad del sistema. Eso en contraste con los sistemas en serie. Si la denominada redundancia del sistema, que se manifiesta en su capacidad de redistribución de las cargas, es pequeña y sus elementos estructurales tienen un comportamiento frágil, el fallo de un elemento normalmente es suficiente para causar el colapso de todo el sistema. Sistemas de este tipo tienden a fallar progresivamente, tal y como se puede observar con frecuencia en colapsos de estructuras reales [Tanner 2001, Tanner 2013a]: el fallo de un elemento conduce a una redistribución de los esfuerzos, un segundo elemento presenta una resistencia insuficiente para estos nuevos esfuerzos y falla inmediatamente, y así sucesivamente hasta que se produce el colapso de todo el sistema. Por este motivo, en caso de un comportamiento frágil, el fallo del primer elemento se puede asociar, a efectos prácticos, al colapso del sistema. En el caso de un comportamiento dúctil, al contrario, la situación cambia radicalmente: una vez alcanzada la capacidad resistente de un elemento, éste sigue activo contribuyendo a la resistencia del sistema en su conjunto.

\subsection{OBSERVACIONES FINALES}

Mientras que el capítulo anterior, más conceptual, contiene unos principios generalmente aplicables para la gestión de los riesgos tecnológicos y naturales, el presente se centra en los métodos más habituales que se emplean en el campo de la ingeniería civil para asegurar que los riesgos asociados con los sistemas estructurales se mantengan en unos niveles considerados como aceptables. El punto de partida es el hecho de que los datos que intervienen en las tareas de la ingeniería estructural están afectados por incertidumbres. El tratamiento de estas incertidumbres constituye el hilo conductor del capítulo cuyos aspectos más relevantes se resumen a continuación:

- Las incertidumbres asociadas con las variables que intervienen en un análisis estructural se pueden representar mediante distribuciones de probabilidad.

- Se denomina fallo estructural el incumplimiento de cualquier requisito establecido en relación con una estructura o su comportamiento. Con respecto a un determinado requisito, una estructura se suele clasificar de manera simplificada como satisfactoria o insatisfactoria, respectivamente. La separación entre ambos dominios se denomina estado límite.

- Las prestaciones de una estructura se pueden representar a través de las probabilidades de fallo, con respecto a las relevantes funciones de estado límite y para un determinado período de referencia, teniendo en cuenta las incertidumbres asociadas con las variables.

- La determinación de las probabilidades de fallo no es trivial si las funciones de estado límite no son lineales, o si las variables tienen funciones de distribución diferentes a la normal. En estos casos, los métodos analíticos aproximados FOSM o FORM permiten una estimación con suficiente precisión.

- En una aplicación directa de los métodos probabilistas, el cumplimiento de los requisitos estructurales se verifica comparando las probabilidades de fallo con los correspondientes valores admisibles.

- Los valores admisibles de la probabilidad de fallo para un determinado período de referencia se pueden establecer mediante métodos de análisis de riesgo. Estos valores también se pueden expresar a través de los denominados índices de fiabilidad requeridos.

- Algunas normas y recomendaciones actuales definen los índices de fiabilidad requeridos, para un determinado período de tiempo, en función de las consecuencias esperadas en caso de producirse un fallo estructural. En ocasiones, también se tiene en cuenta el coste relativo de las medidas de seguridad que son necesarias para evitar el fallo. El nivel requerido de la fiabilidad 
crece con el alcance de las consecuencias esperadas y la disminución del coste de las medidas de seguridad.

- Para obviar las dificultades asociadas con la aplicación directa de los métodos probabilistas, el carácter aleatorio de las variables se puede tener en cuenta mediante sus valores de cálculo. En su determinación interviene el índice de fiabilidad requerido, entre otros parámetros.

- En la mayoría de las normas y recomendaciones actuales, los valores de cálculo se introducen de manera indirecta, a través de los valores representativos de las variables, aplicándoles los correspondientes coeficientes parciales. Por ello, este método destinado a tener en cuenta las incertidumbres asociadas con las variables se denomina el método de los coeficientes parciales. Entre otros parámetros, los coeficientes parciales también dependen del índice de fiabilidad requerido.

- El método de los coeficientes parciales proporciona un tratamiento implícito de los riesgos (Apartado 1.1.1). La relación entre los métodos implícitos y explícitos se puede establecer a través de los índices de fiabilidad requeridos, equivalentes a los valores admisibles de la probabilidad de fallo, que a su vez se pueden determinar a partir de los riesgos admisibles para las personas, tal y como lo ponen de manifiesto las inecuaciones (2.6) y (2.8).

- El campo de aplicación de los métodos habituales para la determinación de las probabilidades de fallo y de los índices de fiabilidad se limita a los elementos estructurales individuales. Lo mismo cabe decir de los correspondientes criterios de aceptación.

- En el marco de la teoría de la fiabilidad de sistemas existen procedimientos simplificados que permiten estimar con suficiente precisión la probabilidad de fallo de un sistema estructural.

Los conceptos y métodos contenidos en el presente capítulo, igual que las interacciones existentes entre ellos, se emplean para la continuación del trabajo. A estos efectos también se tienen en cuenta los aspectos que en la actualidad no están resueltos de manera satisfactoria. En particular, los requisitos de fiabilidad estructural en los casos en los que un posible colapso no solamente afecta a un elemento aislado, sino a una parte o la totalidad de una estructura. 


\section{METOdOLOGÍA}

\subsection{INTRODUCCIÓN}

\subsubsection{Situación}

A pesar de las ventajas inherentes a los métodos explícitos para la evaluación y la gestión de los riesgos tecnológicos y naturales, su difusión en el campo de la ingeniería estructural resulta insignificante. Aunque algunas normas modernas en principio permiten su aplicación [ISO 2394 1998, EN 1990 2002, CTE DB SE 2006], estos métodos no se suelen emplear en la práctica diaria, con la excepción de pocas infraestructuras singulares (Apartado 2.3.3). En el Apartado 1.1.3 se enumeran las principales causas de esta situación, tanto de carácter técnico y práctico, como administrativo y legal. Entre ellas se puede mencionar el hecho de que las citadas normas no contienen modelos pragmáticos, aptos para aplicaciones prácticas, a efectos de la determinación tanto de la probabilidad de ocurrencia de un fallo estructural como de las correspondientes consecuencias. Además, existen incertidumbres acerca de la determinación de los criterios de aceptación de los riesgos en función del sistema analizado (Apartados 1.1.2, 1.1.3 y 2.4).

Como consecuencia directa de la situación anteriormente resumida, se establece el objetivo para este trabajo: el desarrollo de métodos, modelos y requisitos que posibiliten un tratamiento explícito de los riesgos para las personas, asociados con las estructuras de edificación (Apartado 1.3). El desarrollo de estas herramientas prácticas debe basarse en un procedimiento sencillo para el análisis de riesgo, incluido un modelo matemático para su cuantificación, aplicable a las estructuras de edificación. Ambos, el procedimiento y el modelo, no solamente tienen que ser consistentes con los métodos explícitos, de validez general, para el análisis y la gestión de los riesgos tecnológicos y naturales (Capítulo 2), sino también con los métodos que tratan los riesgos de manera implícita y que se emplean habitualmente en la ingeniería estructural (Capítulo 3). Además, deben servir para establecer una relación entre los dos tipos de métodos, explícitos e implícitos (Apartado 1.3).

Los riesgos asociados con una estructura, cuantificados mediante un procedimiento del tipo arriba mencionado, deben cumplir unos determinados criterios de aceptación (Apartado 2.2.3). Riesgos y requisitos se expresan en los mismos términos, por ejemplo como riesgos para las personas, en concordancia con el alcance del presente estudio (Apartado 1.2). Teniendo en cuenta las dificultades para encontrar una respuesta a la pregunta fundamental ¿qué es suficientemente seguro? (Apartado 1.1), la determinación de los riesgos aceptables para las personas se basa en las premisas resumidas a continuación.

\subsubsection{Hipótesis}

Parece verosímil asumir que en términos generales el nivel de los riesgos asociados con la mejor práctica actual (Best Current Practice, BCP) de la ingeniería estructural resulte aceptable. Efectivamente, la práctica cambiaría rápidamente si los fallos estructurales fueran demasiado frecuentes [Schneider 1997]. Por otro lado, la mejor práctica actual podría conducir a márgenes de seguridad ocultos, es decir a soluciones innecesariamente fiables. En caso de ser cierto, significaría que se podrían aceptar unos riesgos superiores a los actuales. Para averiguar la posible desviación de la situación óptima, desconocida, sería necesario cambiar la práctica actual, relajando el nivel de exigencia para las estructuras. No obstante, eso sería difícil en muchos casos ya que, en el marco de las normas empleadas, las soluciones proyectadas a menudo se aproximan a un dimensionado estricto que, además, no está gobernado por el posible colapso parcial o total del sistema, sino por la necesidad de cumplir otros requisitos tales como los relacionados con el comportamiento estructural 
en servicio, por ejemplo para asegurar el correcto funcionamiento de instalaciones y equipos (Apartado 3.3.1), o por criterios de tipo constructivo.

La combinación de las anteriores circunstancias hace que la mejor práctica actual en la ingeniería estructural se aproxime a un óptimo. El enfoque más lógico para determinar los riesgos aceptables consiste por ello en fijarlos en los niveles de riesgo aceptados según la citada práctica, que a su vez está reflejada, por lo menos en parte, en la normativa en vigor. Los riesgos aceptables dependen por ello del nivel de fiabilidad requerido implícitamente por estas normas, que a su vez depende del nivel de incertidumbre asociado con las reglas de la normativa empleada (Apartado 3.2.1). Este enfoque está en consonancia con la nueva edición de la norma internacional sobre la fiabilidad estructural [ISO/FDIS 2394 2014], en el sentido de que en su Anejo G queda establecido que una actividad aceptable de acuerdo con un análisis del tipo coste - beneficio (Apartado 2.3.5), también requiere una evaluación del nivel asociado de los riesgos para las personas.

\subsubsection{Dificultades}

En relación con este enfoque, en apariencia sencillo, se plantean algunas dificultades. La primera reside en el hecho de que con frecuencia no se han establecido explícitamente los modelos probabilistas para las variables de las acciones y la resistencia en los que se basan las reglas normalizadas para el dimensionado estructural. Eso se traduce en que a menudo se desconoce el nivel de incertidumbre correspondiente a las reglas de dimensionado y, por tanto, se desconocen las incertidumbres asociadas con las estructuras dimensionadas de acuerdo con estas reglas [Tanner 2006]. Además, tampoco se conoce la relación entre estas incertidumbres y los riesgos admisibles según la misma normativa (Apartado 2.4). A todo ello se suman las dudas ya mencionadas sobre el propio nivel aceptable de los riesgos (Apartados 1.1.2 y 4.1.1).

\subsubsection{Desarrollos necesarios}

Sobre el trasfondo de las diferentes tareas en las que se divide la cuantificación de los riesgos asociados con un sistema técnico (Figura 2.1), y tomando como punto de partida las hipótesis establecidas para la inferencia de los riesgos aceptables para las personas así como las dificultades que conlleva el enfoque adoptado (Apartados 4.1.2 y 4.1.3, respectivamente), resulta fácil identificar los aspectos que se deben abordar con el fin de alcanzar el objetivo de este trabajo (Apartado 1.3): el desarrollo de herramientas prácticas destinadas al análisis de los riesgos para las personas, asociados con las estructuras de edificación. Las tareas a realizar, resumidas a continuación, obviamente están estrechamente relacionadas con los temas de estudio, identificados en el Apartado 1.3:

- Definición de un modelo matemático para el análisis y la cuantificación de los riesgos para las personas, asociados con las estructuras de edificación.

- Desarrollo de unos modelos matemáticos para la estimación de las consecuencias de los fallos estructurales.

- Determinación del estado de incertidumbre asociado con las reglas de las normas para el dimensionado estructural que estén en vigor.

- Deducción del nivel de fiabilidad requerido implícitamente por estas normas.

- Determinación del nivel aceptable de los riesgos para las personas, asociados con las estructuras de edificación.

- Interpretación de los resultados.

\subsubsection{Organización del capítulo}

El objetivo del presente capítulo consiste en la elaboración de un procedimiento detallado para el desarrollo de las herramientas que permitan evaluar y gestionar los riesgos para las personas en 
relación con las estructuras de edificación. Todo ello al hilo de las tareas, definidas de manera genérica en el Apartado 4.1.4, que a su vez emanan de las reflexiones resumidas en el Apartado 4.1.2 sobre la determinación de los riesgos aceptables para las personas. Según las consideraciones e hipótesis del citado apartado, los riesgos inherentes a las estructuras que cumplan estrictamente los requisitos de seguridad según un conjunto consistente de normas que estén en vigor, no solamente son aceptables por definición sino, además, constituyen soluciones óptimas. Este axioma es la base para los desarrollos reflejados en los siguientes capítulos de la tesis.

En el Apartado 4.2 se presentan el modelo matemático y, de manera implícita, el procedimiento para la cuantificación de los riesgos para las personas, adoptados en el marco del presente trabajo. El modelo constituye una particularización de los métodos explícitos para el análisis de los riesgos tecnológicos y naturales, presentados en el Capítulo 2, para las estructuras de edificación. Además, a través de las probabilidades de fallo y su relación con los índices de fiabilidad, el modelo adoptado está vinculado con los métodos de fiabilidad habituales en ingeniería estructural, según el Capítulo 3.

El Apartado 4.3 se centra en la representación práctica de los riesgos para las personas, en vista de su tratamiento posterior. Para ello se opta por diagramas del tipo frecuencia - consecuencias, $F-n$, introducidos en el Capítulo 2.

Teniendo en cuenta el procedimiento y el modelo previamente establecidos para la cuantificación de los riesgos, así como su representación en términos de diagramas F-n, en el Apartado 4.4 se definen las tareas necesarias para la deducción de los riesgos aceptables para las personas. Estas tareas se basan en el axioma arriba mencionado según el que una estructura estrictamente dimensionada es aceptable desde el punto de vista de los riesgos para las personas y representa una solución óptima.

Las hipótesis y los desarrollos de los anteriores apartados permiten establecer, en el Apartado 4.5, el procedimiento detallado para la deducción de los pretendidos métodos, modelos y requisitos, destinados a la adopción de decisiones racionales en el campo de las estructuras de edificación.

El Apartado 4.6 cierra este capítulo, relacionando los diferentes pasos del procedimiento establecido con los desarrollos contenidos en la continuación de la tesis.

\subsection{ANÁLISIS CUANTITATIVO DE LOS RIESGOS}

\subsubsection{Planteamiento global}

\section{Riesgo mortal individual}

La probabilidad de que un determinado escenario de riesgo relacionado con un determinado sistema conduzca a la muerte de una determinada persona, se denomina el riesgo mortal individual de esta persona para el escenario considerado. Igual que la cuantificación de cualquier riesgo, también este riesgo individual se refiere a un determinado período de tiempo. Formalmente se puede expresar en los siguientes términos:

$r_{i j}=p_{j} \cdot l_{i j}$

$l_{i j} \quad$ : letalidad del escenario $j$ para la persona $i$

$p_{j} \quad$ : probabilidad de ocurrencia del escenario $j$

$r_{i j} \quad$ : riesgo mortal para la persona $i$ asociado con el escenario $j$

En el presente contexto, el sistema considerado es la estructura de un edificio. Un escenario de riesgo es un conjunto de circunstancias, que pueden producirse simultáneamente dentro de este sistema, con el potencial de causar eventos no deseados (Apartado 2.2.2). Un ejemplo sería el colapso total o parcial de una estructura. 
Según la ecuación (4.1), la probabilidad de que la persona $i$ muera en el escenario $j$ depende de la probabilidad de ocurrencia de este escenario para el período de referencia establecido, $p_{j}$, así como de la probabilidad condicional de que la persona $i$ muera suponiendo que se produzca el escenario $j$. En la referencia [BUWAL 1991a], esta probabilidad condicional se denomina la letalidad del escenario $j$ para la persona $i, l_{i j}$.

Normalmente, diferentes escenarios contribuyen al riesgo mortal de un individuo debido a un determinado sistema. En el caso de independencia estadística entre los $n$ escenarios que pueden ser relevantes, y para valores pequeños del riesgo mortal individual correspondiente a cada uno de ellos, $r_{i j}$, el riesgo mortal individual para la persona $i$ debido al sistema analizado y para el período de referencia establecido, $r_{i}$, se puede estimar mediante la ecuación (4.2):

$$
\begin{aligned}
& r_{i}=\sum_{j=1}^{n} r_{i j}= \\
& r_{i} \quad \sum_{j=1}^{n} p_{j} \cdot l_{i j} \\
& : \text { riesgo mortal para la persona } i
\end{aligned}
$$

\section{Riesgo colectivo de un escenario}

El riesgo colectivo para las personas en el caso de que se produce un determinado escenario $j, R_{j}$, se obtiene sumando los riesgos mortales individuales correspondientes a todas las $m$ personas que estén expuestas al sistema:

$$
\begin{aligned}
& R_{j}=\sum_{i=1}^{m} r_{i j}=p_{j} \cdot \sum_{i=1}^{m} l_{i j} \\
& R_{j} \quad: \text { riesgo colectivo del escenario } j
\end{aligned}
$$

\section{Riesgo colectivo asociado con una estructura}

Igual que en el caso del riesgo individual, para la determinación del riesgo colectivo se asume independencia estadística entre los escenarios relevantes. Entonces, el riesgo colectivo para las personas debido al sistema analizado, $R$, se obtiene sumando los riesgos colectivos correspondientes a cada uno de los $n$ escenarios:

$R=\sum_{j=1}^{n} R_{j}=\sum_{j=1}^{n} \sum_{i=1}^{m} p_{j} \cdot l_{i j}$

$R \quad$ : riesgo colectivo asociado con el sistema analizado

\subsubsection{Probabilidad de fallo de sistemas estructurales}

A efectos del presente estudio sobre estructuras de edificación, un escenario de riesgo se caracteriza por un determinado mecanismo de fallo de un determinado elemento estructural con unas propiedades establecidas, para una determinada combinación y disposición de las acciones e influencias. Sin entrar en aspectos tales como las posibles redistribuciones de los esfuerzos u otros efectos que pudieran ser desencadenados por este mecanismo de fallo (Apartado 3.7.2), la probabilidad de ocurrencia del escenario de riesgo considerado (Apartado 4.2.1) equivale aproximadamente a la probabilidad de fallo del elemento estructural en cuestión, para la combinación de acciones e influencias y el mecanismo de fallo contemplados. Consecuentemente, en el marco del presente trabajo se asume que en una estructura la probabilidad de ocurrencia de un escenario $j, p_{j}$, se pueda aproximar a través de una probabilidad de fallo de un elemento. Por otro lado, una probabilidad de fallo se puede representar, para un determinado estado límite último (Apartado 3.3.2), a través de una relación del tipo de la ecuación (3.4), que a su vez se puede resolver mediante métodos analíticos o 
numéricos [Schneider 1997], siempre y cuando se disponga de datos para caracterizar las variables que intervienen en el problema (Capítulo 3).

Por regla general, una estructura está compuesta por varios elementos cuyo fallo, aislado o en combinación con el fallo de otros elementos, puede conducir al colapso parcial o total del sistema (Apartado 3.7). Además, diferentes mecanismos de fallo pueden inducir el colapso de un determinado elemento estructural y la mayoría de las estructuras pueden estar sometidas a múltiples combinaciones y disposiciones de acciones e influencias. Por todos estos motivos, un número importante de diferentes escenarios de riesgo pueden conducir al colapso de un sistema estructural. Consecuentemente, la probabilidad de ocurrencia de todos los escenarios relevantes influye en la probabilidad de fallo acumulada del sistema en su conjunto.

Según lo especificado en el Apartado 3.7.2 para los sistemas estructurales, una estructura de ingeniería civil se puede asimilar a un sistema lógico compuesto por elementos en serie. En este contexto, la palabra no se refiere a elementos estructurales sino a procesos lógicos. Cada uno de estos elementos representa uno de los posibles mecanismos de fallo. Como también se menciona en el Apartado 3.7, en estructuras hiperestáticas, algunos de estos elementos pueden estar formados por sub-sistemas en paralelo ya que un colapso parcial o total del sistema requiere que se produzca una combinación de fallos de distintos elementos estructurales.

Para valores pequeños de las probabilidades de ocurrencia de los escenarios, $p_{j}$, lo que suele ser el caso en estructuras, y suponiendo independencia estadística entre los elementos estructurales que componen el sistema considerado, la probabilidad de fallo acumulada para este sistema, $P_{f}$, puede estimarse en analogía con la ecuación (3.36), siendo $n$ el número de escenarios a considerar:

$P_{f} \approx \sum_{j=1}^{n} p_{j}$

Como ya se ha mencionado, la probabilidad de fallo acumulada de un sistema de este tipo crece con el número de escenarios de riesgo relevantes para el análisis. Para las estructuras, la ecuación (4.5) significa que la probabilidad de fallo acumulada crece, en general, con el número de posibles mecanismos de fallo y por tanto con el número de elementos estructurales. Esta observación resulta intuitivamente plausible y deja prever que los riesgos asociados con las estructuras están afectados por un importante efecto escala [Tanner 2010].

\subsubsection{Consecuencias para las personas}

En concordancia con el Apartado 2.3, donde se establece la necesidad de contemplar los riesgos tanto desde el punto de vista de los individuos como de la sociedad, en el Apartado 4.2.1 se hace esta distinción en el contexto de la cuantificación de los riesgos relacionados con las estructuras de edificación. Consecuentemente, para cuantificar las consecuencias de un colapso estructural se requiere por un lado un modelo para estimar la probabilidad condicional de que una determinada persona $i$ muera, suponiendo que se produzca un determinado escenario $j$. En la ecuación (4.1) esta probabilidad condicional se denomina letalidad, $l_{i j}$. Por otro lado, también es necesario disponer de un modelo para estimar el número total de víctimas mortales causadas por el mismo colapso, $N_{j}$. De la ecuación (4.3) se puede deducir que las consecuencias de un determinado escenario $j$ en términos del número de víctimas corresponde a la suma de las probabilidades condicionales $l_{i j}$ para todas las $m$ personas que puedan estar expuestas al sistema en el momento del colapso:

$$
N_{j}=\sum_{i=1}^{m} l_{i j}
$$

$N_{j} \quad$ : consecuencias del escenario $j$ en términos del número de víctimas mortales 
Aunque en el desarrollo de los modelos se debe distinguir entre las consecuencias de los colapsos estructurales para los individuos y la sociedad, respectivamente, la ecuación (4.6) pone de manifiesto la estrecha relación que existe entre ambos. Por otro lado, de cara a la continuación del trabajo conviene destacar que la letalidad de un escenario para una persona, $l_{i j}$, o la probabilidad condicional de que una determinada persona muera en un colapso, también se encuentra en la condición (2.6) que establece de manera genérica los requisitos estructurales en relación con los riesgos para los individuos. Finalmente, el número de víctimas mortales que se pueden producir en un colapso, $N_{j}$, está relacionado con la probabilidad condicional de que las consecuencias para la sociedad alcancen un determinado nivel. Esta última aparece en la condición (2.8) para los requisitos estructurales en relación con los riesgos colectivos.

\subsection{REPRESENTACIÓN DE LOS RIESGOS PARA LAS PERSONAS}

Con el fin de facilitar la interpretación posterior de los resultados que se obtengan con los modelos establecidos en el Apartado 4.2.1 para cuantificar los riesgos individual y colectivo para las personas, es necesario desarrollar una representación práctica de los datos. A estos efectos se tienen en cuenta las especificaciones de los Apartados 4.2.2 y 4.2.3, respectivamente sobre la probabilidad de ocurrencia y las consecuencias de los escenarios de riesgo relacionados con las estructuras de edificación.

Cada uno de estos escenarios de riesgo se puede caracterizar a través de los parámetros relevantes en el contexto de un análisis explícito: su frecuencia de ocurrencia y las consecuencias en caso de producirse el escenario. Para representar el riesgo colectivo de un determinado escenario de riesgo, $j$, su frecuencia de ocurrencia se expresa a través de su probabilidad de ocurrencia en el período de referencia establecido, $p_{j}$, y las consecuencias en términos del número esperado de víctimas mortales en caso de ocurrencia, $N_{j}$. A estos efectos se sustituye la ecuación (4.6) en la ecuación (4.3):

$$
R_{j}=p_{j} \cdot N_{j}
$$

Según lo especificado en el Apartado 4.2.2, en el marco del presente estudio se denomina escenario de riesgo cualquier mecanismo de fallo que pueda conducir a un colapso parcial o total de una estructura, en unas determinadas circunstancias. Por este motivo, en una estructura de edificación la probabilidad de ocurrencia de un escenario $j$, $p_{j}$, se aproxima mediante la probabilidad de fallo de un elemento estructural, $p_{f}$, como también se expone en el Apartado 4.2.2. Considerando la estructura mixta de acero y hormigón del edificio representado en la Figura 4.1a), un escenario de riesgo sería, por ejemplo, el fallo por flexión de la sección del centro del vano de la viga biapoyada en el borde del forjado de la segunda planta para la combinación más desfavorable de las acciones e influencias. La probabilidad de ocurrencia, $p_{k}$, de este escenario, $k$, equivaldría a la probabilidad de fallo de la viga considerada para el mecanismo de fallo por flexión, $p_{f, M, f l, e d}(f$ : fallo; $M$ : momento flector; fl: planta; ed: borde). Según las hipótesis del presente trabajo, el número de víctimas mortales, $N_{k}$, representaría las consecuencias en caso de producirse el escenario, $k$.

Para la misma u otra combinación de las acciones, en la misma viga también se podría producir un mecanismo de fallo diferente, por ejemplo por esfuerzos cortantes en cualquiera de las dos secciones de apoyo. En comparación con el anterior, relacionado con la flexión, se trata de un escenario de riesgo distinto, caracterizado por su probabilidad de ocurrencia específica y las consecuencias asociadas. Para diferentes disposiciones o combinaciones de las acciones también podría producirse el fallo de las vigas de borde de otros forjados, o de la cubierta, inducido por cualquiera de los posibles mecanismos. Igualmente podrían fallar las vigas interiores de los diferentes forjados o de la cubierta, así como los pilares de borde e interiores en cualquiera de las plantas. Según la definición adoptada (Apartado 4.2.2), cada uno de estos casos representa un escenario de riesgo.

UPM-ETSICCP. Doctorado en Ingeniería de Estructuras, Cimentaciones y Materiales 
Si existe independencia estadística entre los distintos escenarios de riesgo, éstos se pueden representar en un denominado diagrama frecuencia - consecuencias, por orden decreciente de las consecuencias (Figura 4.1b). Las situaciones con consecuencias de mayor alcance aparecen en la parte inferior del diagrama, y las situaciones con consecuencias menores en la parte superior. Una representación de este tipo se denomina perfil de riesgo y es característica de un determinado sistema técnico, por ejemplo una estructura de edificación. Resulta evidente la similitud con los diagramas frecuencia - consecuencias, descritos en el Apartado 2.3.3. No obstante, entre ambas representaciones existe una diferencia que no se puede obviar: en el diagrama de la Figura 2.2 se representa en el eje de ordenadas, para un determinado período de referencia, la frecuencia de los eventos con un determinado número de víctimas mortales, $F(n)$, mientras que en la representación de la Figura 4.1 se reflejan en el mismo eje las probabilidades de ocurrencia de los diferentes escenarios, $p_{j}$, también para un determinado período de referencia. La suma de estas probabilidades de ocurrencia corresponde a la probabilidad de fallo acumulada del sistema considerado, en concordancia con la ecuación (4.5). Finalmente, cabe mencionar que mediante integración del perfil de riesgo se obtiene el mismo resultado que también proporciona la ecuación (4.4), el riesgo colectivo para las personas debido al sistema analizado, $R$ :

$R=\sum_{j=1}^{n} p_{j} \cdot N_{j}$

a)

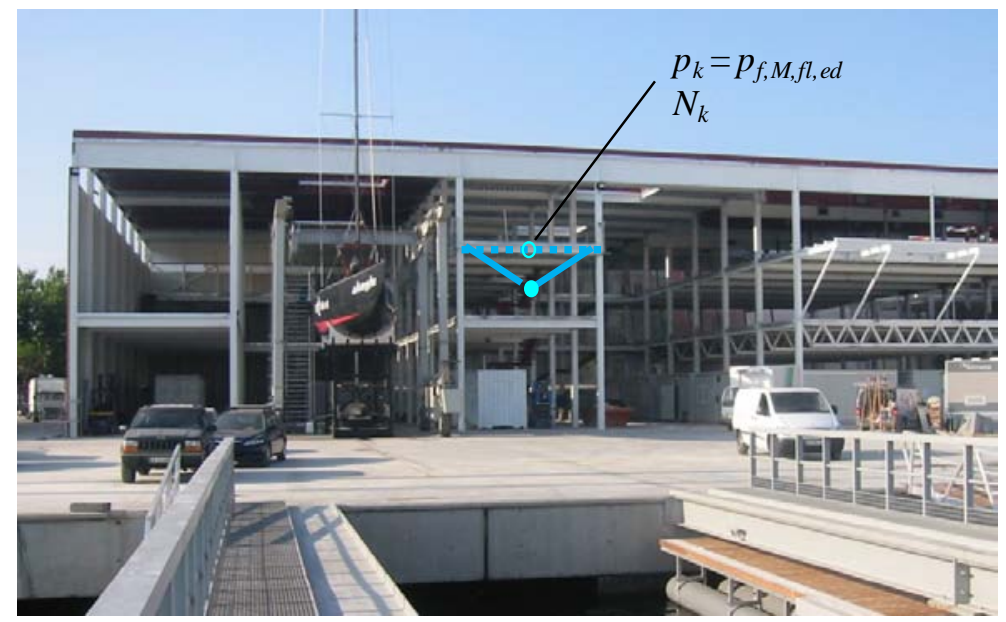

b)

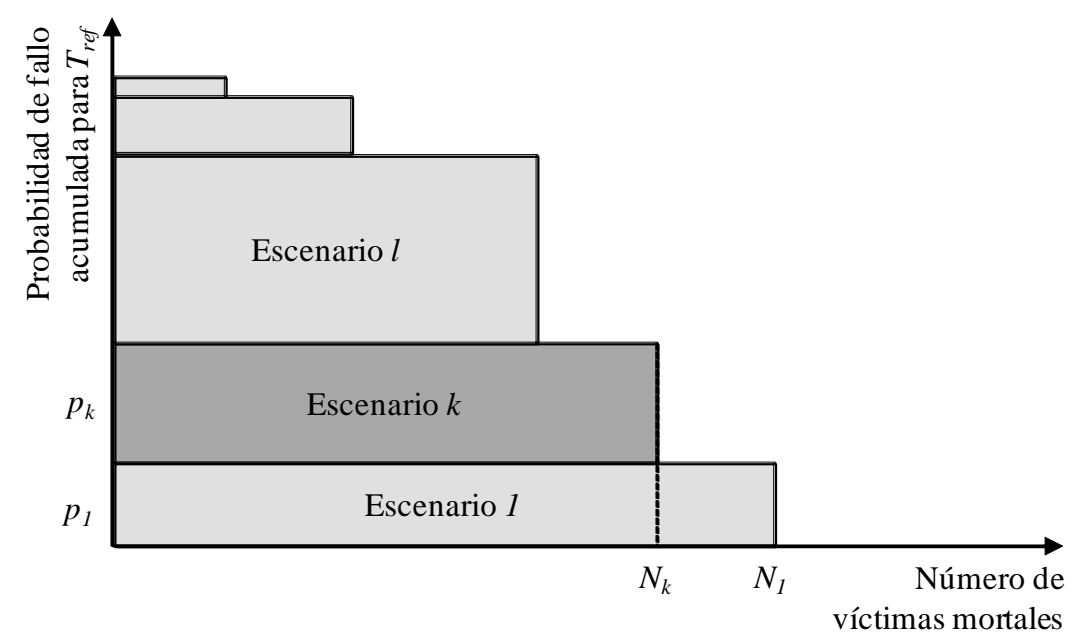

Figura 4.1 - Estructura de edificación constituida por vigas y pilares mixtos de acero y hormigón: a) escenario de riesgo $k$; b) representación esquemática del perfil de riesgo de la estructura, incluyendo el riesgo colectivo del escenario $k$. 


\subsection{DEDUCCIÓN DE CRITERIOS DE ACEPTACIÓN}

De acuerdo con el axioma establecido en el Apartado 4.1.2, los criterios de aceptación para los riesgos asociados con las estructuras de edificación se deducen en el marco del presente trabajo a partir de los riesgos inherentes a las estructuras que cumplan estrictamente los requisitos de seguridad según un conjunto de normas, consistentes desde el punto de vista del tratamiento de las incertidumbres relativas a las variables relevantes en la ingeniería estructural. A estos efectos, una familia adecuada de normas serían por ejemplo los Eurocódigos, respectivamente para las bases de proyecto [EN 1990 2002], las acciones [EN 1991-1-1 2002, EN 1991-1-3 2003] y la resistencia de los elementos estructurales constituidos por diferentes materiales [EN 1992-1-1 2004, EN 1993-1-1 2005, EN 1994-1-1 2004, EN 1995-1-1 2004]. En principio, también los Documentos Básicos relativos a la Seguridad Estructural del Código Técnico de la Edificación, así como las Instrucciones asociadas, sobre las bases de proyecto [CTE DB SE 2006], las acciones [CTE DB SE-AE 2006] y la resistencia [EHE-08 2008, EAE 2011, CTE DB SE-M 2006], podrían considerarse como un conjunto consistente de normas para el dimensionado estructural. El Capítulo 6 contiene más información sobre las normas empleadas y su compatibilidad, mientras que en el presente contexto el interés se centra en los aspectos procedimentales.

Sobre la anterior base se establecen las tareas genéricas a realizar para la deducción de los criterios de aceptación, tanto en términos de la fiabilidad requerida como de los riesgos aceptables para las personas (Apartado 4.1.4). Para ello se tiene en cuenta la definición adoptada del término escenario de riesgo (Apartado 4.2.2), así como la subsiguiente equivalencia aproximada entre la probabilidad de ocurrencia de un escenario de riesgo y la probabilidad de fallo del elemento estructural considerado, caracterizado por unas condiciones determinadas. El procedimiento se resume en los siguientes puntos:

- Selección de un conjunto representativo de estructuras de edificación. Se eligen estructuras hipotéticas aunque realistas, comparables con la representada en la Figura 4.2, constituidas por vigas y pilares de diferentes materiales de construcción.

- Dimensionado de todos los elementos de las estructuras seleccionadas de manera que cumplan exactamente los requisitos de seguridad estructural definidas en el conjunto de normas empleadas. Este dimensionado se denomina estricto ya que para las combinaciones de acciones e influencias relevantes, todos los elementos estructurales de un determinado edificio cumplen, para todos los posibles mecanismos de fallo, la condición de igualdad de los valores de cálculo de los efectos de las acciones e influencias por un lado y de las resistencias correspondientes por otro (Apartado 3.5): $E_{d}=R_{d}$.

- Establecimiento de las probabilidades de ocurrencia de los escenarios de riesgo relevantes, $p_{j}$, que equivalen a las probabilidades de fallo de los diferentes elementos estructurales para las combinaciones de acciones e influencias y los mecanismos de fallo relevantes (Apartado 4.2.2). La determinación de estas probabilidades se efectúa mediante métodos analíticos o numéricos (Capítulo 3). Es importante que los parámetros de las variables, empleados a estos efectos, reflejen adecuadamente las incertidumbres asociadas con las reglas aplicadas en el dimensionado estricto de los elementos estructurales. Si eso es el caso, las probabilidades de fallo obtenidas se pueden utilizar para deducir el nivel de fiabilidad requerido implícitamente por el conjunto de normas empleadas en el dimensionado estricto de los elementos estructurales, bien en términos de la probabilidad de fallo admisible, $p_{t}$, o del índice de fiabilidad requerido, $\beta_{t}$. Efectivamente, si un elemento cumple exactamente los requisitos de seguridad estructural normalizados, la probabilidad de fallo asociada y el correspondiente nivel de fiabilidad son aceptables por definición. 
- Determinación de las consecuencias asociadas a cada uno de los escenarios relevantes, caracterizados por el colapso parcial o total de la estructura analizada. Las consecuencias se representan en términos del número esperado de víctimas mortales, $N_{j}$, y se calculan mediante un modelo cuyo desarrollo es objeto del Capítulo 7 del presente trabajo. La relación entre esta representación, destinada en primer lugar a la determinación de los riesgos colectivos, y las consecuencias de un colapso para los individuos queda establecida en el Apartado 4.2.3.

- Establecimiento del perfil de riesgo para cada una de las estructuras seleccionadas. Para ello se procede según las especificaciones del Apartado 4.3.

- Determinación del riesgo colectivo para las personas, $R$, correspondiente a cada una de las estructuras del conjunto representativo seleccionado. También este paso se ajusta a lo establecido en el Apartado 4.3.

- Análisis e interpretación de los resultados obtenidos, desde los puntos de vista tanto de los riesgos individuales como de los colectivos para las personas. Todo ello sobre el trasfondo del axioma en el que se basa este estudio (Apartado 4.1.2), según el cual los riesgos asociados con las estructuras cuyos elementos cumplen exactamente los requisitos modernos de seguridad estructural, no solamente son aceptables en el marco de las normas empleadas, sino también se aproximan a un nivel óptimo.

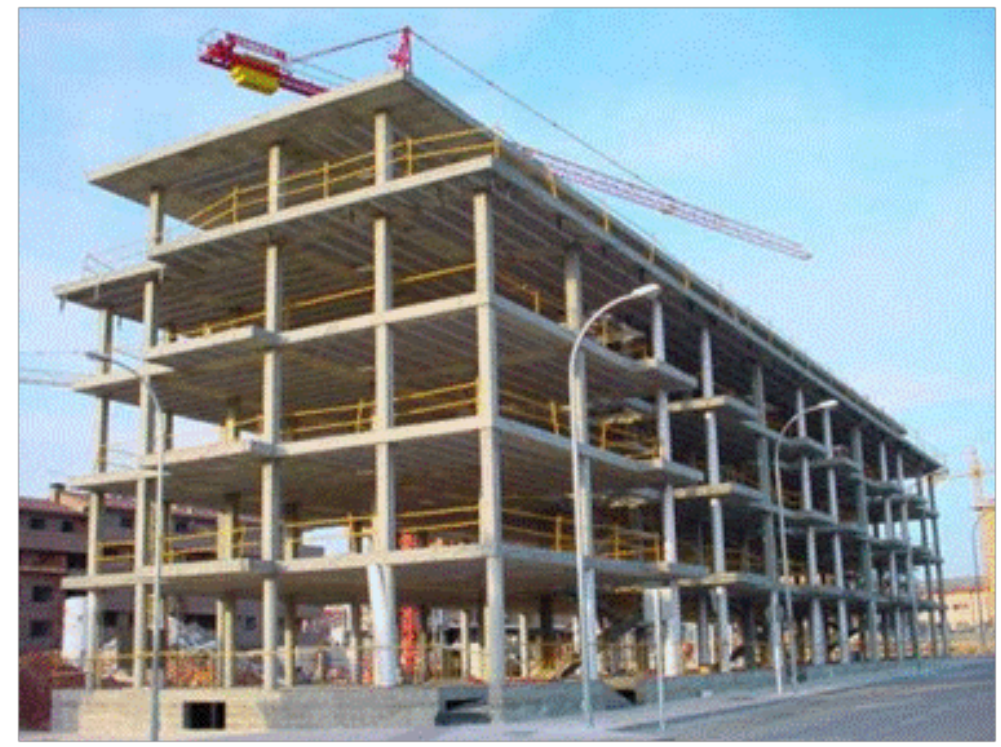

Figura 4.2 - Estructura de edificación representativa con elementos de hormigón armado.

\subsection{PROCEDIMIENTO}

Sobre la base de las hipótesis y los desarrollos anteriores, en el presente apartado se define el procedimiento detallado para la elaboración de las herramientas necesarias a efectos de la cuantificación y el posterior tratamiento de los riesgos para las personas en el campo de las estructuras de edificación. Se trata de concretar las tareas identificadas previamente, de manera genérica para el desarrollo de las pretendidas herramientas (Apartado 4.1.4), y más específicamente para la deducción de los criterios de aceptación de los riesgos (Apartado 4.4). Bajo estas premisas, el procedimiento adoptado se divide en los pasos enumerados a continuación.

1. Definición del alcance del estudio:

- Tipos de estructuras a estudiar. 
- Tipos de fallo a considerar (por ejemplo, colapso de la estructura o de un elemento estructural; comportamiento inadecuado en servicio; rotura por fatiga).

2. Selección de un conjunto representativo de estructuras y elementos estructurales.

3. Identificación de los mecanismos de fallo más representativos para los elementos seleccionados. Formulación de estos mecanismos en términos de las correspondientes funciones de estado límite (FEL).

4. Deducción de los modelos probabilistas para las variables que intervienen en las funciones de estado límite:

- Formulación de los requisitos para los modelos.

- Representación consistente del formato de verificación empleado en el conjunto de normas analizadas:

- coeficientes parciales para las acciones y para la resistencia;

- coeficientes de combinación para las acciones;

- $\quad$ uso de los coeficientes parciales en las verificaciones de la seguridad estructural.

- Identificación de modelos probabilistas para las variables relevantes en el marco de los mecanismos de fallo considerados.

- Determinación de los valores de cálculo de las variables, aplicando el método FORM normalizado (Apartado 3.4), para los diferentes mecanismos de fallo.

- Determinación de los coeficientes parciales, $\gamma_{Y, j}(\mu, \sigma)$, en función del mecanismo de fallo y la correspondiente FEL, el formato de coeficientes parciales, los valores representativos de las variables y los modelos probabilistas adoptados.

- Definición de la función objetivo para el ajuste de los modelos [Tanner 2007b], de modo que representen adecuadamente el estado de incertidumbre asociado con las reglas normalizadas, pero sin vulnerar los otros requisitos establecidos (Apartado 6.2.2):

$$
{ }_{\min } W(\boldsymbol{\mu}, \boldsymbol{\sigma})=\sum_{j=1}^{L} W_{Y, j}\left(\gamma_{Y, j}(\boldsymbol{\mu}, \boldsymbol{\sigma})-\gamma_{Y, t}\right)^{2}
$$

$L \quad$ : número de mecanismos de fallo considerados

${ }_{\min } W \quad$ : valor mínimo de la función objetivo

$W_{Y, j} \quad$ : coeficiente de ponderación de la función de variables $Y$ en relación con el mecanismo de fallo $j$

$Y \quad$ : función de variables $Y$, cuyas incertidumbres se tienen en cuenta a través del coeficiente parcial $\gamma_{Y, t}$, según el formato de coeficientes parciales adoptado

$\gamma_{Y, j} \quad$ : coeficiente parcial para la función de variables $Y$, que depende del formato de coeficientes parciales adoptado, obtenido mediante el método FORM para el mecanismo de fallo $j$ y utilizando los modelos probabilistas adoptados para las variables

$\gamma_{Y, t} \quad:$ valor requerido del coeficiente parcial para la función de variables $Y$

$\boldsymbol{\mu} \quad$ : valores medio de las variables del vector $\boldsymbol{X}$

$\boldsymbol{\sigma} \quad$ : desviaciones típicas de las variables del vector $\boldsymbol{X}$

- Determinación de los modelos probabilistas óptimos para la función objetivo establecida.

- Verificación de los resultados.

5. Desarrollo de modelos de consecuencias.

6. Determinación del nivel de fiabilidad implícito en las normas analizadas y del nivel de riesgo asociado (Apartado 4.4):

- Dimensionado estricto de los elementos seleccionados (Paso 2), según el formato de verificación de las normas analizadas (Paso 4). 
- Cálculo de la probabilidad de ocurrencia para cada escenario relevante, equivalente a la probabilidad de fallo para cada mecanismo representativo (Paso 3), en todos los elementos dimensionados de manera estricta (Apartados 4.2.2 y 4.3). A estos efectos se emplean los modelos probabilistas desarrollados en el Paso 4.

- Determinación del número esperado de víctimas mortales para cada escenario, utilizando los modelos de consecuencias según el Paso 5 (Apartados 4.2 .3 y 4.3).

- Determinación del perfil de riesgo para la estructura de cada edificio considerado (Apartado 4.3).

- Análisis, evaluación estadística e interpretación de los resultados obtenidos.

\subsection{OBSERVACIONES FINALES}

Este capítulo establece, de manera detallada, el procedimiento a seguir para el desarrollo de unas herramientas prácticas destinadas al tratamiento explícito de los riesgos para las personas, asociados con las estructuras de edificación. Todo ello al hilo de un modelo matemático para la cuantificación de estos riesgos, caracterizado por su sencillez y por lo tanto su viabilidad práctica, establecido específicamente para este trabajo (Apartado 4.2). Este modelo es compatible tanto con los métodos explícitos para el tratamiento de los riesgos, según el Capítulo 2, como con los métodos de fiabilidad estructural, presentados en el Capítulo 3, que tratan los riesgos de manera implícita. El modelo constituye por ello un vínculo entre ambos tipos de métodos, explícitos e implícitos, un rasgo imprescindible en el presente contexto. Para establecer este vínculo resultan clave las reflexiones según las que la mejor práctica actual (Best Current Practice, $B C P$ ) de la ingeniería estructural no solamente conduce a un nivel aceptable de los riesgos sino, además, a soluciones próximas a un óptimo. Esta hipótesis, argumentada en el apartado 4.1.2, conduce de manera natural al enfoque para determinar los riesgos aceptables, fijándolos en los niveles de riesgo aceptados según la mejor práctica actual de la que a su vez se puede asumir que esté reflejada en la normativa en vigor. Sencillo en apariencia, este enfoque plantea una serie de dificultades que se identifican en el Apartado 4.1.3, con el fin de deducir a continuación, en el Apartado 4.1.4, las tareas que necesariamente se deben abordar para alcanzar el objetivo del trabajo (Apartado 1.3).

Según la ecuación (4.2), el modelo matemático establecido en el Apartado 4.2.1 permite cuantificar, para una determinada estructura, el riesgo mortal individual en términos de las probabilidades de ocurrencia de los relevantes escenarios de riesgo y la letalidad de cada uno de estos escenarios para una persona. Además, también permite cuantificar el riesgo colectivo, a través de la ecuación (4.4) que tiene en cuenta que diferentes personas suelen estar expuestas a la misma estructura. Según las hipótesis adoptadas (Apartado 4.2.2), cualquier mecanismo de fallo con el potencial de conducir a un colapso parcial o total de una estructura es un escenario de riesgo, por lo que su probabilidad de ocurrencia se puede cuantificar, aproximándola a través de la probabilidad de fallo del correspondiente elemento estructural. Se justifica, además, que la ecuación (4.5) permite estimar con suficiente precisión la probabilidad de fallo acumulada para la estructura en su conjunto, considerada como un sistema, lo que es importante a efectos de la determinación de los riesgos colectivos de este sistema. Por el mismo motivo, también es necesario relacionar la letalidad de un escenario de riesgo para una persona con las consecuencias del mismo escenario en términos del número de víctimas mortales (Apartado 4.2.3). Este vínculo entre las consecuencias de un colapso estructural para los individuos y la sociedad, respectivamente, establecido a través de la ecuación (4.6), es la clave para relacionar el riesgo mortal individual asociado con un sistema y el correspondiente riesgo colectivo. Teniendo en cuenta las anteriores especificaciones sobre la probabilidad de ocurrencia y las consecuencias de los escenarios de riesgo relacionados con una determinada estructura de edificación, el Apartado 4.3 contiene una propuesta para la representación práctica de los riesgos para las personas, en términos de un perfil de riesgo, destacando también sus 
diferencias con los diagramas frecuencia - consecuencias descritos en el Apartado 2.3.3. Para cada estructura se puede establecer un perfil de riesgo específico, cuya integración proporciona el riesgo colectivo para las personas debido al sistema analizado, de acuerdo con la ecuación (4.8).

Según las consideraciones e hipótesis razonadas de este capítulo, los criterios de aceptación se deducen a partir de los riesgos inherentes a las estructuras que se ajustan exactamente a los requisitos de seguridad estructural definidos en un conjunto consistente de normas (Apartado 4.4). Los puntos clave del procedimiento establecido a estos efectos consisten, por un lado, en el dimensionado estricto según las normas adoptadas de todos los elementos estructurales de un conjunto representativo de edificios y, por otro lado, en la determinación de las probabilidades de fallo de los elementos así dimensionados utilizando modelos probabilistas para las variables relevantes que reflejan las incertidumbres asociadas con las reglas de las normas empleadas. Al utilizar estas probabilidades en el establecimiento de los perfiles de riesgo para cada una de las estructuras seleccionadas, los riesgos asociados representan el nivel óptimo y son aceptables. Consecuentemente, los resultados así obtenidos sirven para extraer los riesgos aceptables para las personas, desde los puntos de vista individual y colectivo, respectivamente.

En concordancia con las tareas genéricas establecidas en el Apartado 4.4, y teniendo en cuenta todo su trasfondo según los Apartados 4.1 a 4.3, en el Apartado 4.5 se define el procedimiento detallado para la elaboración de las herramientas necesarias a efectos de la cuantificación y el posterior tratamiento de los riesgos para las personas en el campo de las estructuras de edificación. Los pasos establecidos sirven de guión para la continuación del trabajo y están relacionados con los restantes capítulos de la tesis (Apartado 1.4):

- Los Pasos 1 a 3 del procedimiento establecido en el Apartado 4.5 se abarcan en el Capítulo 5. Este contiene por tanto la definición detallada de las bases de los análisis posteriores.

- El Paso 4 del mismo procedimiento, la cuantificación de las incertidumbres a tener en cuenta en los análisis estructurales, es objeto del Capítulo 6.

- El Paso 5, el desarrollo de los modelos de consecuencias de los colapsos estructurales para las personas, se aborda en el Capítulo 7.

- El Paso 6, el establecimiento de los requisitos de seguridad estructural, se presenta en el Capítulo 8. 


\section{ANÁLISIS DE LOS RIESGOS ASOCIADOS CON LAS ESTRUCTURAS DE EDIFICACIÓN}

\subsection{INTRODUCCIÓN}

En concordancia con la metodología establecida en el Capítulo 4, el desarrollo de las herramientas necesarias para un tratamiento racional de los riesgos individuales y colectivos se basa en el análisis de los riesgos asociados con unas estructuras representativas que cumplen exactamente los requisitos de seguridad según un conjunto consistente de normas. De acuerdo con los Pasos 1 a 3 del procedimiento establecido en el Apartado 4.5, en primer lugar es necesario definir detalladamente las bases para los análisis destinados a la elaboración de las pretendidas herramientas:

- definición de los tipos de estructuras a estudiar en cuanto a sus sistemas estáticos, elementos constitutivos y materiales de construcción;

- selección de un conjunto de estructuras, siguiendo los criterios definidos en el desarrollo del punto anterior, de modo que su posterior análisis permita extraer conclusiones representativas en relación con los riesgos para las personas;

- determinación de los tipos de fallo estructural a considerar, de acuerdo con el alcance del estudio que se refiere a los riesgos mortales para las personas;

- identificación de los mecanismos de fallo relevantes, en consonancia con las estructuras, los elementos y los materiales constitutivos considerados;

- formulación de las funciones de estado límite para los mecanismos identificados.

Todas estas tareas son objeto del presente capítulo. Para llevarlas a cabo, éste se divide en los apartados descritos a continuación.

En el Apartado 5.2 se define el alcance de los análisis en cuanto a los tipos de estructuras y fallos a considerar, así como los criterios genéricos para la obtención de un conjunto representativo de estructuras. En este contexto, también se tiene en cuenta la influencia de las características del sistema estático, isostático o hiperestático, y del comportamiento estructural, frágil o dúctil, en las probabilidades de fallo de las estructuras y, por tanto, en los riesgos asociados con ellas. Se trata de una ampliación de las consideraciones del Apartado 3.7.2, sobre la fiabilidad de los sistemas estructurales, que resulta fundamental para la definición de los tipos de estructuras a tener en cuenta en el presente estudio.

La selección de un conjunto representativo de estructuras y de los elementos que las constituyen se aborda en el Apartado 5.3. Para los diferentes materiales constitutivos analizados en el estudio, se definen por separado los parámetros a variar. Para cada uno de estos parámetros se establecen los valores numéricos a considerar. La combinación de todos ellos resulta en los conjuntos de estructuras y elementos, respectivamente, objeto de análisis.

El Apartado 5.4 contiene los mecanismos de fallo más representativos para los diferentes tipos de elementos estructurales seleccionados. Además, se establecen las correspondientes funciones de estado límite. La identificación de los mecanismos y la formulación de las funciones de estado límite se llevan a cabo por separado para cada uno de los materiales constitutivos objeto del estudio.

Una serie de observaciones finales, relacionadas con el presente capítulo y centradas en la continuación del trabajo, se encuentran en el Apartado 5.5. 


\subsection{ALCANCE}

\subsubsection{Visión de conjunto}

El Apartado 1.2 contiene una serie de hipótesis relevantes en relación con el alcance del presente trabajo. El estudio se limita a las estructuras de edificación, constituidas por elementos de acero estructural, hormigón armado, mixtos y madera laminada encolada, respectivamente, y expuestas a situaciones persistentes. Como eventos no deseados se analizan los colapsos parciales o totales de las estructuras, cuyas frecuencias de ocurrencia se expresan en términos de probabilidades de fallo referidas a un determinado período de tiempo, mientras que las consecuencias se representan a través del número de víctimas mortales. En las mencionadas hipótesis acerca de los tipos de fallo y sus consecuencias a considerar están basados el modelo matemático para la cuantificación de los riesgos (Apartado 4.2), la representación práctica de los riesgos para las personas (Apartado 4.3), así como el enfoque para la deducción de los criterios de aceptación (Apartado 4.4). Otras hipótesis afectan tanto al tipo de los sistemas estáticos de las estructuras estudiadas, como a las características de los colapsos a considerar. Se trata de simplificaciones, necesarias para hacer viable el estudio planteado (Apartado 4.5), que se exponen a continuación.

En primer lugar, se considera que las estructuras analizadas, semejantes al tipo representado en la Figura 4.2, estén constituidas por vigas y pilares isostáticos. Esta hipótesis se debe a dos motivos. Por un lado, el uso de elementos isostáticos es muy extendido en las estructuras habituales de edificación, por ejemplo en soluciones con elementos prefabricados de cualquiera de los materiales contemplados, con lo que se trata de una elección realista. Además, la probabilidad de fallo acumulada (Apartado 4.2.2) es superior para sistemas isostáticos, expuestos a situaciones persistentes, en comparación con la de los sistemas equivalentes hiperestáticos, particularmente si el comportamiento de éstos es dúctil [Tanner 2002]. Este aspecto se analiza más en detalle en el Apartado 5.2.2. En cualquier caso, aunque el sistema estático y el comportamiento estructural también influyen en las consecuencias de un colapso, se puede asumir que esta dependencia sea menor que para la probabilidad de fallo acumulada. Consecuentemente, según la ecuación (4.8), los riesgos asociados con las estructuras isostáticas son mayores que para las estructuras hiperestáticas comparables. Por todo lo anterior, según el enfoque adoptado para la deducción de los criterios de aceptación (Apartado 4.4), el análisis de estructuras hiperestáticas con un comportamiento dúctil conduciría a una estimación poco realista de los riesgos para las personas asociados con las estructuras de edificación, y por tanto a una subestimación del nivel aceptable de los mismos.

En relación con los sistemas estáticos de las estructuras analizadas se asume, además, que sean intraslacionales. También esta hipótesis es realista ya que mediante la integración en el sistema global de elementos tales como escaleras, cajas de ascensores o arriostramientos de fachada y cubierta, la mitigación de los efectos de las acciones horizontales resulta fácil y económica. Además, la adopción de este tipo de medidas resulta imprescindible para asegurar la estabilidad de las estructuras constituidas por elementos isostáticos. Asumiendo que estas medidas se pongan correctamente en práctica, resulta que, con la excepción de los edificios de gran altura que no se contemplan en el marco del presente trabajo, las acciones horizontales no contribuyen significativamente a la probabilidad de fallo acumulada para el conjunto de un sistema estructural del tipo considerado. Por tanto, estas acciones no se tienen en cuenta en la determinación de los riesgos asociados con las estructuras analizadas.

En relación con los colapsos parciales de las estructuras, debido a que los elementos estructurales se asumen isostáticos, se adopta la hipótesis que la rotura de un determinado pilar o viga no conduzca a un fallo en cadena de otros elementos. Por ejemplo, el colapso de una viga de planta afectaría a los elementos secundarios o forjados apoyados en ella, ya que estos perderían el equilibrio por tratarse 
también de elementos isostáticos, según las hipótesis adoptadas. No obstante, se supone que la caída de estos elementos no arrastre a las vigas ni a los forjados de las crujías adyacentes, y que su impacto en la planta inferior no induzca el fallo de los elementos afectados, ni de las vigas ni tampoco de los pilares. Por otro lado, el fallo de un pilar de una determinada planta conllevaría el colapso de los pilares de la misma alineación situados en las plantas superiores, así como de las vigas apoyadas en todos ellos, y de los correspondientes elementos secundarios o forjados. También en este caso se asume que el impacto por la caída no cause el colapso de las plantas inferiores, lo que de todas las hipótesis mencionadas quizás sea la más discutible.

Para la obtención del conjunto representativo de estructuras y elementos constitutivos, objeto de análisis, se varían los parámetros más relevantes para el dimensionado estructural, dentro de unos límites suficientemente amplios que permitan cubrir la gran mayoría de los casos prácticos, en concordancia con las anteriores hipótesis sobre el alcance del trabajo. Los parámetros a variar se refieren a los aspectos enumerados a continuación.

- Geometría:

- proporciones del edificio;

- longitud, anchura y altura del edificio;

- número de plantas;

- distancia entre ejes de los pilares y, por tanto, luz y separación de las vigas.

- Categoría de uso de los edificios, sin considerar la posibilidad de usos mixtos:

- residencia, oficina;

- concentración de personas;

- tienda, almacén.

- Acciones, representadas por cargas gravitatorias:

- cargas permanentes;

- sobrecargas en función de la categoría de uso;

- carga de nieve en función del clima regional.

- Material constitutivo:

- acero estructural, hormigón armado, mixto de acero y hormigón, madera laminada encolada;

- tipo del material constitutivo considerado, que en la mayoría de los casos está asociado al valor característico de su resistencia (Apartado 3.5).

Los valores numéricos a considerar para cada uno de estos parámetros se establecen en el Apartado 5.3, por separado para los diferentes materiales constitutivos analizados en el estudio. El peso propio de la estructura no es un parámetro de elección sino el resultado del dimensionado estricto (Apartado 4.4), a efectuar en función de los valores adoptados para los parámetros restantes. Las posibles combinaciones de todos estos valores permiten establecer los pretendidos conjuntos de estructuras y elementos estructurales.

\subsubsection{Consideraciones sobre la influencia del sistema estructural en la probabilidad de fallo}

\section{Generalidades}

Las ventajas que, desde el punto de vista de la fiabilidad estructural, normalmente presentan los elementos hiperestáticos frente a los isostáticos son bien conocidos cualitativamente [Tanner 2002]. No obstante, no abundan las investigaciones sistemáticas sobre la influencia del sistema estático de una estructura y de su comportamiento en la fiabilidad estructural, y en la práctica habitual esta influencia no suele tenerse en cuenta. Los métodos de verificación de la seguridad estructural están basados en un análisis independiente de los efectos de las acciones y de la respuesta estructural [Muttoni 1997, Tanner 2002]. El fallo de una estructura se asimila al fallo de una sección transversal. 
Esta manera de proceder no permite tener en cuenta explícitamente la interacción entre los efectos de las acciones y la respuesta de una estructura. En otras palabras, la influencia de las posibles redistribuciones de los esfuerzos en la fiabilidad estructural no se tiene adecuadamente en cuenta, simplificación que se debe a la complejidad del problema (Apartado 3.7.2).

\section{Ejemplo}

La fiabilidad de un sistema depende fuertemente de su comportamiento, dúctil o frágil. Considerando la viga continua sobre dos vanos simétricos de la Figura 5.1, se asume en primer lugar un comportamiento frágil de la sección de apoyo intermedio, $A$. Suponiendo además que se produzca el fallo de la sección, ésta se convierte en inactiva ya que la resistencia frente al momento desaparece con el incremento de las deformaciones según el diagrama momento - curvatura, $M-\chi$, lo que conduce a un cambio sustancial del sistema estático. Consecuentemente, se produce una redistribución de los momentos flectores hacia los vanos, particularmente el vano $A-C$, más cargado que el vano simétrico, $A-C$ ', donde solamente actúan el peso propio y las cargas permanentes. Normalmente, la sección $B$ no tendrá una resistencia suficiente para la solicitación resultante, por lo que fallará inmediatamente. Se habla de un colapso progresivo, característico para los sistemas con comportamientos frágiles. Por este motivo, la hipótesis arriba mencionada de los métodos habituales de verificación de la seguridad estructural, según la cual el fallo de una sección equivale al fallo del sistema, parece razonable en el caso de estructuras frágiles, y por supuesto que lo es para las estructuras isostáticas que desde el punto de vista de la fiabilidad se pueden considerar como casos extremos de las estructuras hiperestáticas con un comportamiento frágil. Volviendo a la viga continua de la Figura 5.1, la situación cambia radicalmente si la sección $A$ tiene la misma resistencia última que en el supuesto anterior, pero con un comportamiento dúctil. Después del alcance de esta resistencia última, la sección se mantiene activa y el colapso de la estructura no se produce hasta que no falle alguna de las secciones del vano.

En términos generales, el colapso de una estructura depende del sistema estático, la disposición y la intensidad de las cargas para una determinada situación de riesgo (Apartado 3.3), así como la capacidad resistente y el comportamiento de las secciones transversales. Intuitivamente parece evidente que la fiabilidad de un sistema con un comportamiento frágil es significativamente inferior a la fiabilidad de un sistema análogo, pero con un comportamiento dúctil. La incidencia del modo de fallo es aún mayor, teniendo en cuenta que el comportamiento de estructuras frágiles puede resultar muy sensible frente a las incertidumbres de las deformaciones impuestas, debidas a las acciones e influencias tales como la fluencia, la retracción, la variación térmica o los asientos diferenciales, así como de las aceleraciones sísmicas u otras acciones accidentales, de forma que su colapso se puede producir repentinamente, sin aviso previo.

\section{Hipótesis}

Sin considerar acciones e influencias tales como deformaciones impuestas o sismo, arriba mencionados, a través de la viga de la Figura 5.1 se reflexiona a continuación sobre la relevancia del comportamiento estructural en la fiabilidad de un sistema. A estos efectos se compara el caso de la viga continua de comportamiento dúctil con el de dos vigas isostáticas que, como se apunta con anterioridad, constituye un caso extremo de una viga hiperestática de comportamiento frágil. Por ello, y por las consideraciones contenidas en el Apartado 5.2.1 sobre la conveniencia de analizar estructuras constituidas por elementos isostáticos, se trata de la comparación que resulta relevante en el marco del presente estudio. Además, se adoptan las siguientes hipótesis:

- Se consideran únicamente cargas gravitatorias: peso propio; cargas permanentes; sobrecargas.

- La sobrecarga es uniforme y a efectos del dimensionado estructural se aplica en las zonas más desfavorables.

- Teniendo en cuenta la simetría del sistema, se considera el sistema parcial A-B-C. 
- En el caso de un fallo estructural, las deformaciones se concentran en secciones o zonas determinadas, formando rótulas. Por este motivo, para el desarrollo del ejemplo se contemplan la sección de apoyo intermedio, $A$, la sección de vano, $B$, y la sección de apoyo lateral, $C$. La ubicación de la sección $B$ en la Figura 5.1 corresponde a la del máximo momento flector en el sistema hiperestático. En el caso del sistema isostático, la sección $B$ se encuentra en el centro del vano.

- El dimensionado de estas secciones sea estricto para todos los mecanismos de fallo considerados (Apartado 4.4), con lo que la ratio entre los valores de cálculo de la resistencia, $R_{d}$, y de las solicitaciones, $E_{d}$, es la unidad en todos los casos.

- Se asume una calibración perfecta de los modelos y coeficientes parciales aplicados en el dimensionado estructural. Según esta hipótesis, que no cumplen las normas actuales (Apartado 1.1.2), para la disposición relevante de las sobrecargas a efectos del dimensionado estricto de todas las secciones, la probabilidad de fallo asociada corresponde exactamente al valor admisible, $p_{t}$.

- Las probabilidades de fallo de los dos sistemas parciales, respectivamente el vano de la viga hiperestática de comportamiento dúctil y la viga isostática, se determina para la disposición antimétrica de la sobrecarga según la Figura 5.1.

\section{Viga hiperestática}

Bajo las anteriores hipótesis, se identifican los mecanismos de colapso que teóricamente se pueden producir en el sistema parcial considerado de la viga hiperestática, $A-B-C$ :

1. Fallo por flexión de la sección de apoyo intermedio, $A_{M}$. Dada la rotura de la sección $A$, fallo por flexión de la sección de vano, $B_{M}$.

2. Fallo por flexión de la sección de vano, $B_{M}$. Dada la rotura de la sección $B$, fallo por flexión de la sección de apoyo intermedio, $A_{M}$.

3. Fallo por interacción de flexión y cortante de la sección de apoyo intermedio, $A_{M V}$.

4. Fallo por cortante de la sección de apoyo lateral, $C_{V}$. Dada la rotura de la sección $C$, fallo por flexión de la sección de apoyo intermedio, $A_{M}$.

Para otras situaciones que no se contemplan en el presente análisis, por ejemplo en presencia de importantes cargas concentradas, sería necesario tener en cuenta también el posible fallo por cortante de la sección de apoyo intermedio, $A_{V}$. Al considerar únicamente una sobrecarga uniforme, su disposición relevante para la determinación del esfuerzo cortante máximo en la sección $A$ conduce a momentos flectores que no son despreciables, por lo que el mecanismo de fallo es de interacción entre flexión y cortante, $A_{M V}$.

Los mecanismos de fallo identificados están representados esquemáticamente en la Figura 5.1, formando un sistema lógico mixto según la descripción del Apartado 3.7.2. La probabilidad de fallo del sistema estructural parcial, $A-B-C$, se puede estimar adoptando las siguientes hipótesis conservadoras:

- la probabilidad de fallo de los subsistemas lógicos en paralelo, representando los correspondientes mecanismos de colapso, se determina según la ecuación (3.40);

- la probabilidad de fallo del sistema estructural parcial, $A-B-C$, equivalente a un sistema lógico en serie constituido por los posibles mecanismos de colapso, se determina según la ecuación (3.36).

En concordancia con estas hipótesis, que no tienen en cuenta el grado de correlación existente entre los elementos formando el sistema, simplificación justificada debido a que las probabilidades de fallo se emplean a efectos comparativos y no se interpretan como valores absolutos, la probabilidad de fallo del sistema parcial $A-B-C, P_{f, A-B-C}$, se obtiene a partir de la siguiente ecuación: 
$P_{f, A-B-C}=p_{f, A_{M}-B_{M}}+p_{f, B_{M}-A_{M}}+p_{f, A_{M V}}+p_{f, C_{V}-A_{M}}$

$P_{f, A-B-C} \quad:$ probabilidad de fallo del sistema parcial $A-B-C$

$p_{f, A M-B M} \quad$ : probabilidad de fallo debida al mecanismo iniciado por la rotura a flexión de la sección $A$ y seguido por la rotura a flexión de la sección $B$

$p_{f, A M V} \quad$ : probabilidad de fallo debida a la rotura de la sección $A$ por la interacción de flexión y cortante

$p_{f, B M-A M} \quad$ : probabilidad de fallo debida al mecanismo iniciado por la rotura a flexión de la sección $B$ y seguido por la rotura a flexión de la sección $A$

$p_{f, C V-A M} \quad$ : probabilidad de fallo debida al mecanismo iniciado por la rotura a cortante de la sección $C$ y seguido por la rotura a flexión de la sección $A$

Según la ecuación (3.40), la probabilidad de que se produzca el mecanismo $A_{M}-B_{M}, p_{f, A M-B M}$, no puede ser mayor que la menor de las probabilidades de fallo asociadas con los dos elementos lógicos del mecanismo. Para la disposición considerada de la sobrecarga (Figura 5.1) y las hipótesis adoptadas, el momento flector en la sección $A$ es claramente inferior al valor relevante para el dimensionado estricto de la misma sección, mientras que el momento flector en la sección $B$ corresponde al valor del dimensionado estricto, incluso después del fallo de la sección $A$ cuyo comportamiento se supone dúctil. Consecuentemente, la probabilidad de fallo de la sección $A$ es muy inferior a la probabilidad de fallo de la sección $B$, dado el fallo de la sección $A$, y determina la probabilidad de ocurrencia del mecanismo $A_{M}-B_{M}$. Debido a que la capacidad resistente de la sección A supera claramente a la solicitación, la probabilidad de ocurrencia del mecanismo considerado está muy por debajo de la probabilidad de fallo admisible, $p_{f, A M-B M}<<p_{t}$. La contribución de $p_{f, A M-B M}$ a la probabilidad de fallo del sistema parcial, $P_{f, A-B-C}$, resulta despreciable a efectos prácticos, tal y como se demuestra en un trabajo anterior a través del análisis de la fiabilidad del tablero de un puente mixto de carretera [Tanner 2002], cuyas conclusiones se pueden hacer extensivas al presente ejemplo.

Por los mismos motivos -comportamiento dúctil de las secciones transversales; momento flector inferior al valor considerado para el dimensionado estricto de la sección $A$ - la probabilidad de fallo de la sección $A$, dado el fallo de la sección $B$, determina la probabilidad de ocurrencia del mecanismo $B_{M}-A_{M}$. También la probabilidad de este mecanismo queda muy por debajo de la probabilidad de fallo admisible, $p_{f, B M-A M}<<p_{t}$.

Lo mismo no se puede decir de los mecanismos de fallo iniciados por, respectivamente, la rotura a cortante de la sección de apoyo lateral, $C$, y la rotura de la sección de apoyo intermedio, $A$, por la interacción de flexión y cortante. En ambos casos, la disposición considerada de la sobrecarga conduce a los esfuerzos cortantes relevantes para el dimensionado estricto de las secciones de apoyo. Debido a que la rotura de la sección $A$ por la interacción de flexión y cortante conduce inmediatamente al colapso del sistema parcial considerado, la probabilidad de fallo correspondiente equivale, según las hipótesis adoptadas, al valor admisible: $p_{f, A M V}=p_{t}$. En el caso del mecanismo $C_{V}$ $A_{M}$, después de la rotura por cortante de la sección $C$, el vano $A-C$ se convierte en un voladizo, situación para la que la sección $A$ no está dimensionada. Ésta falla inmediatamente, con una probabilidad elevada. Aplicando la ecuación (3.40), la probabilidad de ocurrencia del mecanismo $C_{V}$ $A_{M}$ corresponde a la probabilidad de fallo a cortante de la sección $C$ que, según las hipótesis adoptadas, tiene el valor de la probabilidad de fallo admisible: $p_{f, C V-A M}=p_{t}$.

Según todo lo anterior, para la disposición considerada de la sobrecarga, el sistema parcial $A-B-C$ de la viga continua, dimensionada de manera estricta y con un comportamiento dúctil, tiene una probabilidad de fallo de:

$P_{f, A-B-C, \text { duct }} \approx 2 \cdot p_{t}$ 


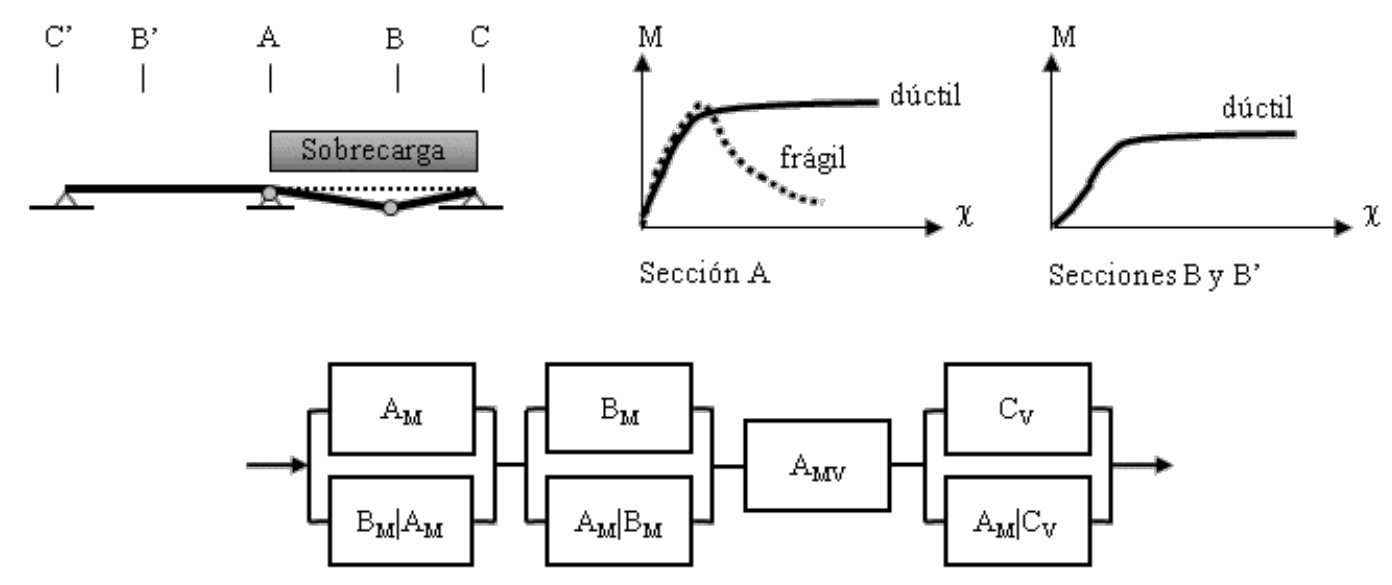

Figura 5.1 - Viga hiperestática de dos vanos simétricos con la representación esquemática de los principales mecanismos de fallo.

\section{Viga isostática}

Si cada uno de los dos vanos, respectivamente $C^{\prime}-A$ y $A-C$, se salva con una viga isostática, la disposición de la sobrecarga según la Figura 5.1 conlleva unos esfuerzos que, según las hipótesis adoptadas, son relevantes para el dimensionado estricto tanto de las dos secciones de apoyo de la viga A-C como de la sección del centro del vano. La rotura de cualquiera de estas tres secciones, a cortante en el caso de los apoyos y a flexión en el caso del centro del vano, conduce al colapso de la viga isostática. Cada uno de los mecanismos de fallo a considerar queda por ello caracterizado por la rotura de una determinada sección. Como están dimensionadas de manera estricta, la probabilidad de ocurrencia de cada mecanismo equivale a la probabilidad de fallo admisible para una sección, $p_{t}$. Siempre en el marco de las hipótesis de este ejemplo, para la disposición considerada de la sobrecarga, el sistema parcial isostático $A-B-C$ tiene una probabilidad de fallo de:

$P_{f, A-B-C, \text { isost }}=3 \cdot p_{t}$

\section{Conclusiones}

Las anteriores consideraciones ponen de manifiesto que la probabilidad de fallo de un vano que forma parte de una viga continua, dimensionada de manera estricta y con un comportamiento dúctil, es menor que la probabilidad de fallo de una viga isostática equivalente. Eso no solamente para la disposición considerada de la sobrecarga, sino también para la sobrecarga aplicada en el vano $C^{\prime}$ - $A$, lo que resulta obvio por motivos de simetría, o para una sobrecarga simétrica actuando sobre ambos vanos. En este último caso, los motivos son equivalentes a los anteriormente expuestos: el momento flector en la sección $A$ corresponde al considerado en el dimensionado estricto, mientras que en la sección $B$ se queda por debajo de este valor, con las consecuencias que ello supone para la probabilidad de ocurrencia de los diferentes mecanismos de fallo del sistema, siempre y cuando su comportamiento sea dúctil.

Reflexiones análogas también se pueden realizar para otros tipos de cargas, como por ejemplo las concentradas [Tanner 2002], o para otros sistemas estáticos constituidos por vigas o pórticos, observando tendencias similares: la probabilidad de fallo de los sistemas hiperestáticos con un comportamiento dúctil es menor que la de los sistemas equivalentes con un comportamiento frágil, o de los isostáticos. La proporción entre las probabilidades de fallo de los sistemas analizados a efectos comparativos depende de cada caso. Los valores aquí obtenidos, $P_{f, A-B-C, \text { isost }}=1,5$ x $P_{f, A-B-C, \text { duct }}$, sólo son válidos para este ejemplo y en el marco de las hipótesis adoptadas. 


\subsection{SELECCIÓN DE ESTRUCTURAS Y ELEMENTOS}

\subsubsection{Edificios con estructuras de acero}

\section{Variación de parámetros}

En el Apartado 5.2.1 se establecen, de manera genérica, los parámetros a variar y combinar para la obtención de un conjunto representativo de estructuras y de sus elementos constitutivos. Se trata de los parámetros más relevantes que determinan las características de las estructuras y que condicionan su dimensionado. Se pueden dividir en tres categorías, respectivamente los relacionados con la geometría, las cargas y los materiales constitutivos de los elementos estructurales. En el presente apartado se recopilan, para los edificios con estructuras de acero, los parámetros específicos estudiados, los valores numéricos adoptados y las hipótesis que están en el origen de esta selección.

En este contexto se debe mencionar que para la deducción de las probabilidades de fallo admisibles de los elementos estructurales (Apartado 4.4), considerados separadamente por tipos (vigas de cubierta; vigas de planta; pilares), se tiene en cuenta un mayor número de valores numéricos para los diferentes parámetros que para los elementos equivalentes, integrados en las estructuras cuyos riesgos asociados se determinan según el procedimiento del Apartado 4.5. Para el análisis de las estructuras completas se reduce básicamente el número de categorías de uso y tipos de materiales. Esta reducción permite asegurar que el número de distintos edificios se mantenga dentro de unos límites razonables para los análisis a efectuar en el Capítulo 8. Y eso sin afectar a los resultados finales ya que la mencionada reducción no incide en el valor medio ni la desviación típica de la probabilidad de fallo de los elementos dimensionados de manera estricta, tal y como lo pone de manifiesto la comparación con un estudio anterior [Tanner 2008].

En línea con las anteriores especificaciones, los parámetros y valores numéricos considerados se agrupan a continuación de acuerdo con el siguiente esquema:

- geometría de la estructura;

- elementos estructurales, distinguiendo entre vigas de cubierta, vigas de planta y pilares, respectivamente.

En el caso de los elementos estructurales, se indica también cuáles de los valores numéricos de los diferentes parámetros se tienen en cuenta para la deducción de los riesgos asociados con las estructuras de edificación.

\section{Geometría de las estructuras}

Con el fin de obtener un conjunto representativo de estructuras de edificación con elementos de acero, se varían los parámetros geométricos mencionados en el Apartado 5.2.1, utilizando la siguiente notación:

- proporciones de la estructura, $H: B: L$;

- altura, $H$, anchura, $B$, y longitud, $L$, de la estructura del edificio;

- número de plantas, $n_{s}$, sin planta baja ni cubierta;

- altura de una planta, $h$, (según se especifica a continuación, este parámetro no varía);

- distancia entre ejes de los pilares en sentido transversal del edificio, $b$;

- distancia entre ejes de los pilares en sentido longitudinal del edificio, $l$.

En el marco de las hipótesis adoptadas para las estructuras objeto de análisis (Apartado 5.2.1), la altura de una planta, $h$, no es un parámetro especialmente relevante. No obstante, a través del número de plantas, $n_{s}$, y las proporciones, está relacionada con las otras dimensiones de la estructura. Para poder considerar edificios de hasta 30 plantas sin que para ciertas proporciones resulten valores poco 
realistas para las dimensiones $L$ y $B$, se adopta una altura de planta constante de $h=3 \mathrm{~m}$, un valor relativamente pequeño para estructuras modernas.

Tabla 5.1 - Variación de parámetros geométricos para la selección de dos conjuntos representativos de estructuras de edificación, constituidas por elementos de acero y de hormigón armado (Apartado 5.3.2), respectivamente.

\begin{tabular}{|c|c|c|c|c|c|}
\hline H:B:L (aprox.) & $\boldsymbol{n}_{s}$ & $H[\mathrm{~m}]$ & $B[\mathrm{~m}]$ & $L[\mathrm{~m}]$ & $I[\mathrm{~m}]$ \\
\hline \multirow{3}{*}{ 1:1:1 } & 1 & 6 & 10 & 10 & $5 ; 10$ \\
\hline & 10 & 33 & 40 & 40 & $5 ; 10 ; 20$ \\
\hline & 20 & 63 & 60 & 60 & $10 ; 15$ \\
\hline \multirow{6}{*}{ 1:10:10 } & 0 & 3 & 20 & 20 & $10 ; 20$ \\
\hline & 0 & 3 & 40 & 40 & $5 ; 10 ; 20$ \\
\hline & 3 & 12 & 120 & 120 & $5 ; 10 ; 20 ; 40$ \\
\hline & 5 & 18 & 200 & 200 & $5 ; 10 ; 20 ; 40$ \\
\hline & 10 & 33 & 300 & 240 & 10; 15; 30 \\
\hline & 10 & 33 & 300 & 300 & $10 ; 15 ; 30$ \\
\hline \multirow{3}{*}{$10: 1: 1$} & 10 & 33 & 5 & 5 & 5 \\
\hline & 20 & 63 & 10 & 10 & $5 ; 10$ \\
\hline & 30 & 93 & 15 & 15 & $5 ; 15$ \\
\hline \multirow{4}{*}{$1: 2: 2$} & 3 & 12 & 30 & 30 & $5 ; 15 ; 30$ \\
\hline & 5 & 18 & 40 & 40 & $5 ; 40$ \\
\hline & 10 & 33 & 60 & 60 & $5 ; 10 ; 20 ; 30$ \\
\hline & 15 & 48 & 80 & 80 & $10 ; 20$ \\
\hline \multirow{3}{*}{$2: 2: 1$} & 5 & 18 & 20 & 10 & $5 ; 10$ \\
\hline & 10 & 33 & 30 & 15 & $5 ; 15$ \\
\hline & 20 & 63 & 60 & 30 & $10 ; 15$ \\
\hline \multirow{3}{*}{ 2:1:2 } & 5 & 18 & 10 & 20 & $5 ; 10 ; 20$ \\
\hline & 10 & 33 & 15 & 30 & $5 ; 15 ; 30$ \\
\hline & 20 & 63 & 30 & 60 & $5 ; 15$ \\
\hline $1: 3: 2$ & 1 & 6 & 20 & 10 & 5 \\
\hline 1:3:3 & 1 & 6 & 20 & 20 & 20 \\
\hline \multirow{3}{*}{ 1:4:1 } & 1 & 6 & 40 & 10 & $5 ; 10$ \\
\hline & 5 & 18 & 80 & 20 & $10 ; 20$ \\
\hline & 15 & 48 & 180 & 45 & $5 ; 15$ \\
\hline \multirow{3}{*}{ 1:1:4 } & 1 & 6 & 10 & 40 & $5 ; 10$ \\
\hline & 5 & 18 & 20 & 80 & $10 ; 20$ \\
\hline & 15 & 48 & 45 & 180 & $5 ; 15$ \\
\hline \multirow{3}{*}{$1: 5: 10$} & 0 & 3 & 10 & 20 & 20 \\
\hline & 5 & 18 & 100 & 200 & $5 ; 10 ; 20 ; 40$ \\
\hline & 10 & 33 & 180 & 300 & 10; 15; 30 \\
\hline
\end{tabular}




\begin{tabular}{|c|c|c|c|c|c|}
\hline & 10 & 33 & 60 & 10 & $5 ; 10$ \\
$5: 10: 1$ & 20 & 63 & 120 & 15 & $5 ; 15$ \\
& 30 & 93 & 200 & 20 & $10 ; 20$ \\
\hline \multirow{3}{*}{$5: 1: 10$} & 10 & 33 & 10 & 60 & $5 ; 10 ; 20$ \\
& 20 & 63 & 15 & 120 & $10 ; 15$ \\
& 30 & 93 & 20 & 200 & $10 ; 20$ \\
\hline $1: 10: 5$ & 10 & 33 & 300 & 120 & $10 ; 15 ; 30$ \\
\hline
\end{tabular}

Para determinar la distancia entre ejes de los pilares en sentido transversal del edificio, $b$, se adopta la hipótesis de que la separación entre pórticos, paralelos a las fachadas de la dimensión $L$, sea la mitad de la distancia entre ejes de los pilares en sentido longitudinal del edificio, $l$. Consecuentemente, se adopta una proporción constante de $b=0,5 \times l$. Las vigas principales forman parte de los mencionados pórticos, por lo que se disponen paralelas a las fachadas de la dimensión $L$, salvando una luz $l$. En estas vigas se apoyan unos forjados o elementos secundarios que salvan la luz entre pórticos, $b$. Se supone que el posible colapso de estos elementos secundarios afecte únicamente una zona localizada (Apartado 5.2.1), con consecuencias despreciables en comparación con las asociadas con el colapso de un elemento principal. Por este motivo, con la excepción de su peso propio, en los posteriores análisis no se tiene en cuenta la influencia de estos elementos secundarios. En particular, no se considera su contribución a los riesgos asociados con las estructuras de edificación.

$\mathrm{Al}$ adoptar un valor constante para la altura de una planta, $h$, así como una relación constante entre la luz de las vigas, $l$, y la separación de los pórticos, $b$, la altura, $H$, la anchura, $B$, y la longitud, $L$, de la estructura no siempre se ajustan exactamente a las proporciones asumidas, $H: B: L$. A pesar de ello, está justificada la consideración de esta proporción como punto de partida para la definición de los parámetros geométricos (Tabla 5.1), ya que ayuda a establecer un conjunto hipotético de estructuras de edificación que englobe a la mayoría de las estructuras que se podrían construir en la realidad.

Finalmente, para los edificios tales como los de viviendas u oficinas, pertenecientes a la clase de consecuencias CC2 según el Eurocódigo [EN 1990 2002], asociada a su vez a la clase de fiabilidad RC2 (Apartado 3.6.2), se considera un número máximo de $n_{s}=30$ plantas. Esta elección se justifica por el hecho de que en España son muy poco frecuentes los edificios con un mayor número de plantas. Para los edificios de la clase de consecuencias CC3, asociada a la clase de fiabilidad RC3, el número se limita a $n_{s}=10$ plantas. Pertenecen a esta clase por ejemplo los edificios públicos o, en general, los edificios donde se pueden producir concentraciones de personas.

La Tabla 5.1 contiene los valores numéricos de los parámetros geométricos que caracterizan el conjunto representativo de las estructuras de edificación con elementos de acero, objeto del posterior análisis. Estos valores están en concordancia con las consideraciones arriba mencionadas. Además, aunque hipotéticas, las estructuras seleccionadas son suficientemente realistas como para asumir que representen a la gran mayoría de las construidas en el pasado y de las que se puedan construir en el futuro.

\section{Vigas de cubierta}

En este apartado se refleja, para las vigas de cubierta, la variación de los parámetros distintos a los de la geometría de las estructuras, destinada a la obtención de los conjuntos representativos de estructuras y elementos estructurales de acero, respectivamente. En cursiva se reflejan los valores que se tienen en cuenta únicamente para la deducción del nivel de fiabilidad implícito en las normas analizadas para las vigas de cubierta consideradas como elementos aislados. Los valores restantes se 
tienen en cuenta tanto para el análisis de estos elementos estructurales como para la deducción de los riesgos admisibles, asociados con las estructuras en su conjunto.

Las vigas de cubierta estudiadas engloban a los siguientes casos:

- Vigas en edificios expuestos a diferentes climas regionales con valores característicos para la carga de nieve de, respectivamente: $q_{k, 1}=1,5 \mathrm{kN} / \mathrm{m}^{2} ; 2 \mathrm{kN} / \mathrm{m}^{2} ; 2,5 \mathrm{kN} / \mathrm{m}^{2}$ y $3,0 \mathrm{kN} / \mathrm{m}^{2}$.

- Vigas con luces de, respectivamente: 5 m; 10 m; 15 m; 20 m; 30 m y 40 m.

- Aceros estructurales con valores característicos del límite elástico de, respectivamente: $f_{y k}=235$ $\mathrm{N} / \mathrm{mm}^{2} ; 275 \mathrm{~N} / \mathrm{mm}^{2}$ y $355 \mathrm{~N} / \mathrm{mm}^{2}$.

- Peso específico aparente del acero estructural de $78,5 \mathrm{kN} / \mathrm{m}^{3}$.

- Cargas permanentes comprendidas entre $1,0 \mathrm{kN} / \mathrm{m}^{2}$ y $10,0 \mathrm{kN} / \mathrm{m}^{2}$, de acuerdo con los criterios recopilados a continuación. Además, en la Tabla 5.2 se reflejan en detalle los valores numéricos adoptados.

Las cargas permanentes engloban tanto el peso propio de los elementos resistentes y no resistentes de la cubrición que salva la luz entre las vigas principales de la cubierta, $g_{k, \text { cub }}$, como el peso de los falsos techos, las instalaciones, etcétera, $g_{k, p, 2}$. Para cada viga de cubierta se consideran dos valores para el peso de los elementos secundarios, $g_{k, c u b}$, correspondientes a soluciones de cubiertas ligeras y pesadas, respectivamente. Además, estos valores se varían en función de la luz de las vigas principales, considerando tres rangos de luces, respectivamente de $5 \mathrm{~m}$ a $10 \mathrm{~m}$, de $15 \mathrm{~m}$ a $20 \mathrm{~m}$, y de $30 \mathrm{~m}$ a $40 \mathrm{~m}$. Esta hipótesis se adopta debido a que el peso propio de los elementos secundarios depende de la luz que deben salvar. Y en muchos casos, particularmente en el presente estudio según las hipótesis adoptadas, esta depende a su vez de la luz de las vigas principales.

Las vigas de cubierta están constituidas por perfiles armados con secciones en doble T. En teoría, también se podrían disponer perfiles laminados. No obstante, el dimensionado estricto de los elementos (Apartado 4.4) conduce normalmente a unas secciones que no están disponibles entre los perfiles laminados comerciales. Además, las normas empleadas para este dimensionado estricto, no distinguen entre elementos armados y laminados en cuanto a la determinación de los valores de cálculo de la resistencia en los casos en los que se eviten fenómenos de inestabilidad. Eso es relativamente fácil de conseguir: el pandeo lateral de las vigas se impide utilizando los elementos resistentes de la cubrición para arriostrar al ala comprimida de las vigas de cubierta, mientras que la abolladura de las chapas delgadas de las vigas se evita respetando unas condiciones mínimas para la esbeltez de las alas comprimidas y disponiendo los rigidizadores necesarios en las almas [EN 1993-11 2005, EAE 2011].

Tabla 5.2 - Variación de las cargas permanentes actuando sobre las vigas de planta, $g_{k, p, 1}, y$ de cubierta, $g_{k, p, 2}$, así como del peso propio de los elementos resistentes y no resistentes de la cubrición, $g_{k, c u b}$, en edificios con estructuras de acero y de hormigón armado (Apartado 5.3.2).

\begin{tabular}{|c|c|c|c|}
\hline \multirow[b]{2}{*}{$\begin{array}{l}\text { Luz de las vigas principales } \\
\qquad I[\mathrm{~m}]\end{array}$} & \multirow{2}{*}{$\begin{array}{c}\text { Planta } \\
g_{k, p, 1} \\
{\left[\mathbf{k N} / \mathbf{m}^{2}\right]}\end{array}$} & \multicolumn{2}{|c|}{ Cubierta } \\
\hline & & $\begin{array}{c}g_{k, p, 2} \\
{\left[\mathbf{k N} / \mathbf{m}^{2}\right]}\end{array}$ & $\begin{array}{c}g_{k, c u b} \\
{\left[\mathbf{k N} / \mathbf{m}^{2}\right]}\end{array}$ \\
\hline $5 ; 10$ & 0,$5 ; 5,0 ; 8,0$ & 0,5 & 0,$5 ; 4,5$ \\
\hline $15 ; 20$ & 4,$0 ; 9,0 ; 13,0$ & 0,5 & 0,$6 ; 8,5$ \\
\hline $30 ; 40$ & 6,$0 ; 10,0 ; 13,0$ & 0,5 & 0,$65 ; 9,5$ \\
\hline
\end{tabular}




\section{Vigas de planta}

En analogía con el apartado anterior para las vigas de cubierta, éste contiene una recopilación de la variación de los parámetros para las vigas de planta, con la excepción de los geométricos que se encuentran en la Tabla 5.1. En cursiva se reflejan los valores que se tienen en cuenta únicamente para la deducción del nivel de fiabilidad implícito en las normas analizadas para las vigas de planta consideradas como elementos aislados. Los valores restantes se tienen en cuenta para la deducción tanto del citado nivel de fiabilidad, como de los riesgos admisibles para las estructuras en su conjunto:

- Vigas de edificios destinados a los siguientes usos (entre paréntesis se indica la categoría de uso según [CTE DB SE-AE 2006]): residencia (A1); oficina (B); tienda (D); concentración de personas (C5); almacén (E1). A efectos del dimensionado estricto de las vigas de planta (Apartado 4.4), se utilizan los modelos de las normas europea [EN 1991-1-1 2002] o española [CTE DB SE-AE 2006], asociados a las diferentes categorías de uso y representados por cargas uniformemente distribuidas o concentradas que, normalmente, no se consideran simultáneamente. Según las dos normas citadas, las sobrecargas uniformes, correspondientes a una determinada categoría, se pueden reducir en función del área de influencia de la viga. A estos efectos definen un factor de reducción de sobrecargas, $\alpha_{A}$, para las cargas uniformemente distribuidas correspondientes a las categorías A a E:

$$
\alpha_{A}=\frac{5}{7} \cdot \psi_{0}+\frac{A_{0}}{A} \leq 1,0
$$

$\begin{array}{ll}A & : \text { área de influencia de un elemento horizontal } \\ A_{0} & : \text { área de referencia } \\ \psi_{0} & : \text { coeficiente para el valor de combinación de una acción variable }\end{array}$

Las dos normas [EN 1991-1-1 2002] y [CTE DB SE-AE 2006] adoptan un valor de $A_{0}=10 \mathrm{~m}^{2}$ para el área de referencia e indican un límite inferior de 0,6 para el factor de reducción de sobrecargas, $\alpha_{\mathrm{A}}$, en el caso de las categorías de uso C y D.

- Vigas con luces de, respectivamente: 5 m; 10 m; 15 m; 20 m; 30 m y 40 m.

- Aceros estructurales con valores característicos del límite elástico de $f_{y k}=235 \mathrm{~N} / \mathrm{mm}^{2} ; 275$ $\mathrm{N} / \mathrm{mm}^{2}$ y $355 \mathrm{~N} / \mathrm{mm}^{2}$, respectivamente.

- Peso específico aparente del acero estructural de 78,5 kN/m³.

- Cargas permanentes comprendidas entre $0,5 \mathrm{kN} / \mathrm{m}^{2}$ y $13,0 \mathrm{kN} / \mathrm{m}^{2}$ (Tabla 5.2). Las consideraciones que justifican esta selección están resumidas a continuación.

Se supone que las cargas permanentes dependen de la luz de las vigas principales de un forjado. Esta hipótesis está justificada por la combinación de las siguientes circunstancias. Por un lado, las cargas permanentes que actúan sobre las vigas de una estructura de edificación dependen en gran medida del peso propio de la estructura secundaria (forjado) que se apoya en ellas, y no tanto del peso de las instalaciones, los acabados o los falsos techos. Por otro lado, la tipología y por tanto el peso de los forjados depende normalmente de la luz que deben salvar y esta, a su vez, a menudo es función de la disposición y de la luz de las vigas principales. Los valores de las cargas permanentes se varían por ello en función de la luz de las vigas principales, considerando los mismos tres rangos arriba mencionadas para las vigas de cubierta. Dentro de cada uno de estos rangos se consideran para cada viga de planta tres valores de las cargas permanentes: un valor mínimo correspondiente a una solución ligera para el forjado, un valor máximo representando una solución pesada, así como un valor intermedio para una solución tipo.

Igual que las vigas de cubierta, también las de planta están constituidas por perfiles armados con secciones en doble T. A efectos de su dimensionado estricto según el procedimiento establecido en el Capítulo 4, se supone que el pandeo lateral de las vigas esté impedido, estabilizando su ala 
comprimida a través de la estructura secundaria, o forjado, que se utiliza a modo de arriostramiento. Y con las mismas medidas descritas en el contexto de las vigas de cubierta, también en las de planta se evita la abolladura de las chapas delgadas.

\section{Pilares}

El presente apartado contiene los detalles de la variación de los parámetros para los pilares, con la excepción de los geométricos de la estructura global que están reflejados en la Tabla 5.1. Por este motivo, en relación con la geometría se mencionan únicamente los datos más relevantes a modo de recordatorio. En cursiva se indican los valores de los parámetros que se consideran solamente para la deducción del nivel de fiabilidad implícito en las normas analizadas para los pilares como elementos aislados. Los valores restantes se tienen en cuenta para la deducción tanto del nivel de fiabilidad implícito, como de los riesgos admisibles para las estructuras en su conjunto:

- Pilares de edificios expuestos a climas regionales con valores característicos para la carga de nieve de, respectivamente: $q_{k, i}=1,5 \mathrm{kN} / \mathrm{m}^{2} ; 2 \mathrm{kN} / \mathrm{m}^{2} ; 2,5 \mathrm{kN} / \mathrm{m}^{2}$ y $3,0 \mathrm{kN} / \mathrm{m}^{2}$.

- Pilares de edificios destinados a los siguientes usos (entre paréntesis se indica la categoría de uso según [CTE DB SE-AE 2006]): residencia (A1); oficina (B); tienda (D); concentración de personas (C5); almacén (E1). Para el dimensionado estricto de los pilares, se utilizan los mismos modelos para las sobrecargas, asociados a las diferentes categorías de uso, que se mencionan en el apartado anterior, relativo a las vigas de planta. Según las normas [EN 1991-1-1 2002] y [CTE DB SE-AE 2006], si las sobrecargas de diferentes plantas actúan sobre un determinado pilar, su intensidad se puede reducir en función del número de plantas de la misma categoría de uso situadas por encima del pilar considerado. Para ello definen un factor de reducción, $\alpha_{n}$, para las cargas uniformemente distribuidas, correspondientes a las categorías A a D:

$\alpha_{n}=\frac{2+(n-2) \cdot \psi_{0}}{n}$

$n$

: número de plantas (> 2) de la misma categoría de uso, situadas por encima del pilar considerado

En el dimensionado de los pilares se pueden aplicar simultáneamente los factores de reducción de las sobrecargas para elementos verticales, $\alpha_{n}$, y horizontales, $\alpha_{A}$, respectivamente, siempre y cuando las plantas situadas por encima del pilar considerado estén destinadas al mismo uso y estén siendo explotadas por diferentes usuarios.

- Pilares con áreas de influencia por planta comprendidas entre $12,5 \mathrm{~m}^{2}$ y $800 \mathrm{~m}^{2}$, según la geometría de la estructura del edificio (Tabla 5.1).

- Pilares de edificios con una altura por planta de $3 \mathrm{~m}$.

- Pilares de edificios residenciales y de oficinas con un máximo de 30 plantas, sin contar ni planta baja ni cubierta. En los edificios destinados a usos donde se pueden producir concentraciones de personas o almacén, se considera un máximo de 10 plantas, además de la planta baja y de la cubierta.

- Aceros estructurales con valores característicos del límite elástico de $f_{y k}=235 \mathrm{~N} / \mathrm{mm}^{2} ; 275$ $\mathrm{N} / \mathrm{mm}^{2}$ y $355 \mathrm{~N} / \mathrm{mm}^{2}$, respectivamente.

- Peso específico aparente del acero estructural de $78,5 \mathrm{kN} / \mathrm{m}^{3}$.

- Cargas permanentes comprendidas entre $1,0 \mathrm{kN} / \mathrm{m}^{2}$ y $10,0 \mathrm{kN} / \mathrm{m}^{2}$ en cubierta, así como entre 0,5 $\mathrm{kN} / \mathrm{m}^{2}$ y $13,0 \mathrm{kN} / \mathrm{m}^{2}$ en los forjados de planta.

Debido a que la introducción de las cargas en los pilares se realiza a través de las vigas, respectivamente de cubierta y de planta, los valores indicados en la Tabla 5.2 para la variación de las cargas permanentes también se tienen en cuenta en el análisis de los pilares, bien como elementos aislados, bien dentro de las estructuras en su conjunto. Las hipótesis que están en el origen de la selección de estos valores lógicamente mantienen su validez. 
Por motivos equivalentes a los enunciados en relación con las vigas, los pilares están constituidos por perfiles armados. Su sección es cerrada, de geometría rectangular, formada por cuatro chapas idénticas. Esta hipótesis facilita el dimensionado estricto (Apartado 4.4), a cuyos efectos se suponen impedidos los mecanismos de inestabilidad: el pandeo de los pilares esbeltos se puede evitar mediante la disposición de arriostramientos, mientras que la abolladura de las chapas comprimidas se impide respetando unas condiciones mínimas para su esbeltez [EN 1993-1-1 2005, EAE 2011].

\section{Resumen}

La combinación de los valores anteriormente mencionados de los parámetros más relevantes para el dimensionado estructural permite definir los conjuntos representativos de, respectivamente, estructuras y elementos de acero. Ambos se utilizan para el posterior análisis según el procedimiento establecido en el Capítulo 4.

El primero de estos conjuntos está constituido por 2.256 estructuras de edificios correspondientes a la clase de consecuencias CC2 [EN 1990 2002] y 1.680 estructuras de la clase CC3. La superficie útil por edificio oscila entre $200 \mathrm{~m}^{2}$ y $990.000 \mathrm{~m}^{2}$. En la clase CC3 se consideran edificios con un máximo de 10 plantas, además de la planta baja y la cubierta, y en la clase CC2 un máximo de 30 plantas. El número de elementos estructurales por estructura oscila entre 6 y 40.931 en las estructuras de ambas clases.

Por otro lado, el conjunto representativo de elementos estructurales de acero está constituido por 144 diferentes vigas de cubierta, 270 diferentes vigas de planta y 12.168 pilares distintos. Igual que ocurre con las estructuras, teniendo en cuenta los rangos de variación de los distintos parámetros, el conjunto de elementos estructurales cubre la gran mayoría de los casos que se pueden encontrar en la práctica.

\subsubsection{Edificios con estructuras de hormigón armado}

\section{Variación de parámetros}

Igual que en el caso de los edificios con estructuras de acero (Apartado 5.3.1), los conjuntos representativos de, respectivamente, sistemas y elementos estructurales de hormigón armado se obtienen variando y combinando los parámetros más relevantes que determinan las características de las estructuras o que condicionan su dimensionado. Estos parámetros están relacionados con la geometría, las cargas y los materiales constitutivos. Para la adopción de los valores numéricos de estos parámetros se sigue una línea argumental equivalente a la expuesta en el apartado sobre las estructuras de acero. También para la representación de los parámetros y valores adoptados se respeta el mismo esquema del Apartado 5.3.1.

\section{Geometría de las estructuras}

Para la selección de un conjunto representativo de estructuras de edificación con elementos de hormigón armado, se adoptan los mismos parámetros geométricos a variar como en el caso de las estructuras de acero. Además, para estos parámetros se adoptan valores numéricos idénticos. En consecuencia, la Tabla 5.1 también es válida para las estructuras de hormigón armado y contiene la información necesaria para su definición geométrica en vista del posterior análisis.

\section{Vigas de cubierta}

Con la excepción de los parámetros geométricos de las estructuras, en este apartado se representa la variación de los parámetros relativos a las vigas de cubierta, construidas con hormigón armado. Los valores en cursiva solamente se tienen en cuenta para deducir el nivel de fiabilidad de las vigas de cubierta consideradas aisladamente, mientras que los otros valores también se utilizan para la deducción de los riesgos admisibles para las estructuras de los edificios: 
- Vigas en edificios expuestos a diferentes climas regionales con valores característicos para la carga de nieve de, respectivamente: $q_{k, 1}=1,5 \mathrm{kN} / \mathrm{m}^{2} ; 2 \mathrm{kN} / \mathrm{m}^{2} ; 2,5 \mathrm{kN} / \mathrm{m}^{2}$ y $3,0 \mathrm{kN} / \mathrm{m}^{2}$.

- Vigas con luces de, respectivamente: 5 m; 10 m; 15 m; 20 m; 30 m y 40 m.

- Hormigones con resistencias características a compresión de, respectivamente: $f_{c k}=25 \mathrm{~N} / \mathrm{mm}^{2}$; $30 \mathrm{~N} / \mathrm{mm}^{2} ; 35 \mathrm{~N} / \mathrm{mm}^{2} ; 40 \mathrm{~N} / \mathrm{mm}^{2}$ y $50 \mathrm{~N} / \mathrm{mm}^{2}$.

- Acero de armar con un valor característico del límite elástico de $f_{s k}=500 \mathrm{~N} / \mathrm{mm}^{2}$.

- Peso específico aparente del hormigón armado de $25 \mathrm{kN} / \mathrm{m}^{3}$.

- Cargas permanentes, $g_{k, p, 2}+g_{k, c u b}$, comprendidas entre $1,0 \mathrm{kN} / \mathrm{m}^{2}$ y $10,0 \mathrm{kN} / \mathrm{m}^{2}$, de acuerdo con los criterios recopilados en el Apartado 5.3.1. Los valores numéricos adoptados están reflejados en la Tabla 5.2.

Las vigas de cubierta tienen una sección rectangular, para facilitar el dimensionado estricto según el procedimiento del Apartado 4.4. Además, para el canto y el ancho de las secciones se elige una ratio constante de dos. El canto a su vez depende de la luz de la viga y se elige respetando las reglas de la buena práctica para obtener un conjunto realista de estructuras y elementos.

\section{Vigas de planta}

El presente apartado contiene la variación de los parámetros relativos a las vigas de planta, construidas con hormigón armado. No se reflejan los parámetros geométricos de las estructuras que se encuentran en la Tabla 5.1. Igual que en los apartados anteriores, los valores en cursiva solamente se tienen en cuenta para deducir el nivel de fiabilidad de las vigas de planta consideradas como elementos aislados, mientras que los valores restantes también se utilizan para la deducción de los riesgos admisibles para las estructuras:

- Vigas de edificios destinados a los siguientes usos (entre paréntesis se indica la categoría de uso según [CTE DB SE-AE 2006]): residencia (A1); oficina (B); tienda (D); concentración de personas (C5); almacén (E1). Para el dimensionado estricto de las vigas (Apartado 4.4), se utilizan los modelos para las sobrecargas de las normas [EN 1991-1-1 2002, CTE DB SE-AE 2006], tal y como se menciona en el Apartado 5.3.1 para las vigas de acero. Y también en este caso, las sobrecargas uniformes correspondientes a una determinada categoría de uso del edificio se pueden reducir en función del área de influencia de la viga, utilizando el factor de reducción, $\alpha_{A}$.

- Vigas con luces de, respectivamente: 5 m; 10 m; 15 m; 20 m; 30 m y 40 m.

- Hormigones con resistencias características a compresión de, respectivamente: $f_{c k}=25 \mathrm{~N} / \mathrm{mm}^{2}$; $30 \mathrm{~N} / \mathrm{mm}^{2} ; 35 \mathrm{~N} / \mathrm{mm}^{2} ; 40 \mathrm{~N} / \mathrm{mm}^{2}$ y $50 \mathrm{~N} / \mathrm{mm}^{2}$.

- Acero de armar con un valor característico del límite elástico de $f_{s k}=500 \mathrm{~N} / \mathrm{mm}^{2}$.

- Peso específico aparente del hormigón armado de $25 \mathrm{kN} / \mathrm{m}^{3}$.

- Cargas permanentes, $g_{k, p, 1}$, comprendidas entre $0,5 \mathrm{kN} / \mathrm{m}^{2}$ y $13,0 \mathrm{kN} / \mathrm{m}^{2}$. Los criterios para esta selección se encuentran en el Apartado 5.3.1, y los valores numéricos en la Tabla 5.2.

Igual que las de cubierta, las vigas de planta tienen una sección rectangular, con un canto que duplica al ancho y que depende de la luz a salvar.

\section{Pilares}

A continuación se resume la variación de los parámetros de los que depende el dimensionado de los pilares de hormigón. En relación con la geometría de las estructuras se mencionan algunos datos, únicamente a modo de recordatorio. Los parámetros correspondientes están reflejados en la Tabla 5.1. En cuanto a la representación de los valores, se sigue el mismo esquema de los apartados anteriores: los valores en cursiva solamente se tienen en cuenta para deducir el nivel de fiabilidad de los pilares de hormigón armado; los otros valores se usan tanto a estos efectos como para la deducción de los riesgos admisibles para las estructuras: 
- Pilares de edificios expuestos a climas regionales con valores característicos para la carga de nieve de, respectivamente: $q_{k, i}=1,5 \mathrm{kN} / \mathrm{m}^{2} ; 2 \mathrm{kN} / \mathrm{m}^{2} ; 2,5 \mathrm{kN} / \mathrm{m}^{2}$ y $3,0 \mathrm{kN} / \mathrm{m}^{2}$.

- Pilares de edificios destinados a los siguientes usos (entre paréntesis se indica la categoría de uso según [CTE DB SE-AE 2006]): residencia (A1); oficina (B); tienda (D); concentración de personas (C5); almacén (E1). Para el dimensionado estricto de los pilares se utilizan los modelos para las sobrecargas definidos en las normas en vigor [EN 1991-1-1 2002, CTE DB SE-AE 2006]. Igual que en el dimensionado de los pilares de acero se pueden aplicar simultáneamente los factores de reducción de las sobrecargas para elementos verticales, $\alpha_{n}$, y horizontales, $\alpha_{A}$, respectivamente, siempre y cuando las plantas situadas por encima del pilar considerado estén destinadas al mismo uso y siendo explotadas por diferentes usuarios.

- Pilares con áreas de influencia por planta comprendidas entre $12,5 \mathrm{~m}^{2}$ y $800 \mathrm{~m}^{2}$, según la geometría de la estructura del edificio (Tabla 5.1).

- Pilares de edificios con una altura por planta de $3 \mathrm{~m}$.

- Pilares de edificios con un máximo de 30 plantas, sin contar ni planta baja ni cubierta, si están destinados a uso residencial o de oficina, y un máximo de 10 plantas en los edificios destinados a usos donde se pueden producir concentraciones de personas o almacén.

- Hormigones con resistencias características a compresión de, respectivamente: $f_{c k}=25 \mathrm{~N} / \mathrm{mm}^{2}$; $30 \mathrm{~N} / \mathrm{mm}^{2} ; 35 \mathrm{~N} / \mathrm{mm}^{2} ; 40 \mathrm{~N} / \mathrm{mm}^{2}$ y $50 \mathrm{~N} / \mathrm{mm}^{2}$.

- Acero de armar con un valor característico del límite elástico de $f_{s k}=500 \mathrm{~N} / \mathrm{mm}^{2}$.

- Peso específico aparente del hormigón armado de $25 \mathrm{kN} / \mathrm{m}^{3}$.

- Cargas permanentes comprendidas entre $1,0 \mathrm{kN} / \mathrm{m}^{2}$ y $10,0 \mathrm{kN} / \mathrm{m}^{2}$ en cubierta $\left(g_{k, p, 2}+g_{k, c u b}\right)$, así como entre $0,5 \mathrm{kN} / \mathrm{m}^{2}$ y $13,0 \mathrm{kN} / \mathrm{m}^{2}$ en los forjados de planta $\left(g_{k, p, 1}\right)$. Los valores numéricos adoptados se encuentran en la Tabla 5.2 y los criterios en los que se basan en el Apartado 5.3.1.

Para facilitar el dimensionado estricto según el procedimiento del Apartado 4.4, la sección transversal de los pilares es cuadrada con una disposición simétrica de la armadura para la que se respetan las condiciones de cuantía mínima, según las normas europea y nacional [EN 1992-1-1 2004, EHE-08 2008]. Igual que para los pilares de acero, se supone que se dispongan suficientes arriostramientos para impedir el pandeo de los pilares esbeltos, por lo que están solicitados por esfuerzos de compresión simple.

\section{Resumen}

Los conjuntos representativos de estructuras y elementos de hormigón armado, respectivamente, se obtienen combinando los valores mencionados para los parámetros más importantes que intervienen en su dimensionado. El número de estructuras de hormigón armado pertenecientes a la clase de consecuencias CC2 [EN 1990 2002] se eleva a 2.256, mientras que otras 1.680 forman parte de la clase CC3. Es decir, el número de diferentes estructuras es igual que en el caso de las de acero, anteriormente descritas (Apartado 5.3.1). Debido a que se consideran edificios con las mismas geometrías como en el contexto de las estructuras de acero, existen más coincidencias entre los dos conjuntos, por ejemplo en cuanto a la superficie útil por edificio (entre $200 \mathrm{~m}^{2}$ y $990.000 \mathrm{~m}^{2}$ ), número de plantas (un máximo de 30 y 10 en los edificios de las clases CC2 y CC3, respectivamente), o el número de elementos estructurales por estructura (entre 6 y 40.931, en las estructuras de ambas clases).

En cuanto al conjunto representativo de elementos estructurales de hormigón armado, los números son distintos de los correspondientes a los elementos de acero. En el presente caso se obtienen 240 vigas de cubierta, 450 vigas de planta y 22.320 pilares.

Los dos conjuntos, respectivamente de estructuras y de elementos constitutivos, engloban a la mayoría de los casos prácticos. Consecuentemente se emplean para la continuación del trabajo, según el procedimiento establecido en el Capítulo 4. 


\subsubsection{Edificios con estructuras mixtas de acero y hormigón}

\section{Variación de parámetros}

Para la obtención de los conjuntos representativos de, respectivamente, sistemas y elementos estructurales mixtos de acero y hormigón, se varían los parámetros más relevantes en relación con la geometría, las cargas así como los materiales, y se combinan las diferentes opciones, en analogía con los Apartados 5.3.1 y 5.3.2. No obstante, para las estructuras mixtas existen más parámetros a variar que para los casos de los otros materiales constitutivos, por lo que para algunos de ellos se reduce el número de los diferentes valores numéricos a considerar. De esta manera, el volumen de los cálculos a efectuar en el marco del Capítulo 8 se mantiene dentro de unos límites abarcables. A estos efectos, en comparación con los sistemas estructurales de acero o de hormigón armado, se reduce sobre todo el número de las diferentes geometrías a estudiar.

\section{Geometría de las estructuras}

El conjunto representativo de estructuras de edificación con elementos mixtos se determina variando los parámetros geométricos mencionados en el Apartado 5.2.1. Para ello se utiliza la notación del Apartado 5.3.1. También mantienen su validez las consideraciones de carácter general del mismo apartado (número máximo de plantas en función de la clase de consecuencias; altura de planta; distancia entre ejes de los pilares en sentido transversal del edificio; etcétera). La Tabla 5.3 refleja los valores numéricos seleccionados para los parámetros geométricos de las estructuras mixtas.

Tabla 5.3 - Variación de parámetros geométricos para la selección de un conjunto representativo de estructuras de edificación, constituidas por elementos mixtos de acero y hormigón.

\begin{tabular}{|c|c|c|c|c|c|}
\hline H:B:L (aprox.) & $\boldsymbol{n}_{s}$ & $H[\mathrm{~m}]$ & $B$ [m] & $L[\mathrm{~m}]$ & $I[\mathrm{~m}]$ \\
\hline \multirow{2}{*}{ 1:1:1 } & 1 & 6 & 10 & 10 & 5 \\
\hline & 10 & 33 & 40 & 40 & $5 ; 20$ \\
\hline \multirow{5}{*}{ 1:10:10 } & 0 & 3 & 20 & 20 & 20 \\
\hline & 0 & 3 & 40 & 40 & $5 ; 20$ \\
\hline & 3 & 12 & 120 & 120 & $5 ; 20 ; 40$ \\
\hline & 5 & 18 & 200 & 200 & $5 ; 20 ; 40$ \\
\hline & 10 & 33 & 300 & 300 & 20 \\
\hline \multirow{3}{*}{ 10:1:1 } & 10 & 33 & 5 & 5 & 5 \\
\hline & 20 & 63 & 10 & 10 & 5 \\
\hline & 30 & 93 & 15 & 15 & 5 \\
\hline \multirow{4}{*}{$1: 2: 2$} & 3 & 12 & 30 & 30 & 5 \\
\hline & 5 & 18 & 40 & 40 & $5 ; 40$ \\
\hline & 10 & 33 & 60 & 60 & $5 ; 20$ \\
\hline & 15 & 48 & 80 & 80 & 20 \\
\hline \multirow{2}{*}{$2: 2: 1$} & 5 & 18 & 20 & 10 & 5 \\
\hline & 10 & 33 & 30 & 15 & 5 \\
\hline \multirow{3}{*}{$2: 1: 2$} & 5 & 18 & 10 & 20 & $5 ; 20$ \\
\hline & 10 & 33 & 15 & 30 & 5 \\
\hline & 20 & 63 & 30 & 60 & 5 \\
\hline
\end{tabular}




\begin{tabular}{|c|c|c|c|c|c|}
\hline $1: 3: 2$ & 1 & 6 & 20 & 10 & 5 \\
\hline $1: 3: 3$ & 1 & 6 & 20 & 20 & 20 \\
\hline & 1 & 6 & 40 & 10 & 5 \\
$1: 4: 1$ & 5 & 18 & 80 & 20 & 20 \\
& 15 & 48 & 180 & 45 & 5 \\
\hline & 1 & 6 & 10 & 40 & 5 \\
$1: 1: 4$ & 5 & 18 & 20 & 80 & $20 ; 40$ \\
& 15 & 48 & 45 & 180 & 5 \\
\hline \multirow{3}{*}{$1: 5: 10$} & 0 & 3 & 10 & 20 & 20 \\
& 5 & 18 & 100 & 200 & $5 ; 20 ; 40$ \\
\hline & 10 & 33 & 60 & 10 & 5 \\
$5: 10: 1$ & 20 & 63 & 120 & 15 & 5 \\
& 30 & 93 & 200 & 20 & 20 \\
\hline \multirow{2}{*}{$5: 1: 10$} & 10 & 33 & 10 & 60 & $5 ; 20$ \\
& 30 & 93 & 20 & 200 & 20 \\
\hline $1: 10: 5$ & 10 & 33 & 360 & 120 & $20 ; 40$ \\
\hline
\end{tabular}

\section{Vigas de cubierta}

A continuación se resume la variación de los parámetros relativos a las vigas mixtas de cubierta. No se reflejan los parámetros que definen la geometría de las estructuras en su conjunto, objeto de la Tabla 5.3. Los valores en cursiva solamente se tienen en cuenta para deducir el nivel de fiabilidad de las vigas de cubierta consideradas aisladamente. Los valores restantes se utilizan para el mismo fin, y también para la deducción de los riesgos admisibles para las estructuras de los edificios:

- Vigas en edificios expuestos a diferentes climas regionales con valores característicos para la carga de nieve de, respectivamente: $q_{k, 1}=1,5 \mathrm{kN} / \mathrm{m}^{2} ; 2 \mathrm{kN} / \mathrm{m}^{2} ; 2,5 \mathrm{kN} / \mathrm{m}^{2}$ y $3,0 \mathrm{kN} / \mathrm{m}^{2}$.

- Vigas con luces de, respectivamente: 5 m; 10 m; 15 m; 20 m; 30 m y 40 m.

- Aceros estructurales con valores característicos del límite elástico de, respectivamente: $f_{y k}=235$ $\mathrm{N} / \mathrm{mm}^{2} ; 275 \mathrm{~N} / \mathrm{mm}^{2}$ y $355 \mathrm{~N} / \mathrm{mm}^{2}$.

- Hormigones con resistencias características a compresión de, respectivamente: $f_{c k}=25 \mathrm{~N} / \mathrm{mm}^{2}$; $30 \mathrm{~N} / \mathrm{mm}^{2} ; 40 \mathrm{~N} / \mathrm{mm}^{2}$ y $50 \mathrm{~N} / \mathrm{mm}^{2}$. Para las vigas con una luz de $40 \mathrm{~m}$ se emplean hormigones con $f_{c k}=40 \mathrm{~N} / \mathrm{mm}^{2}$. En todos los demás casos, los hormigones tienen una resistencia de $f_{c k}=25$ $\mathrm{N} / \mathrm{mm}^{2}$.

- Peso específico aparente del acero estructural de $78,5 \mathrm{kN} / \mathrm{m}^{3}$.

- Peso específico aparente del hormigón armado de $25 \mathrm{kN} / \mathrm{m}^{3}$.

- Cargas permanentes, $g_{k, p, 2}+g_{k, c u b}$, de $0,85 \mathrm{kN} / \mathrm{m}^{2}$ y $2,2 \mathrm{kN} / \mathrm{m}^{2}$, de acuerdo con las consideraciones resumidas a continuación.

Por definición, las estructuras y por tanto las vigas de cubierta son mixtas, por lo que existe una conexión de esfuerzos rasantes entre los perfiles de acero y la losa de hormigón, para asegurar el trabajo conjunto de ambos. Simultáneamente, la losa de hormigón forma el elemento resistente de la cubrición, salvando la luz entre las vigas principales, en su caso conjuntamente con un entramado de vigas secundarias de acero con las que también estaría conectada. Por este motivo, a efectos de cálculo, el peso propio de la losa corresponde al peso propio de las vigas mixtas. Eso en contraste con las vigas de los otros materiales para las que el peso propio de la cubrición constituye una carga permanente (Apartados 5.3.1, 5.3.2 y 5.3.4). Consecuentemente, en el caso de las vigas mixtas de cubierta, las cargas permanentes engloban solamente el peso de los elementos no resistentes de la 
cubrición (chapa exterior; impermeabilización; aislante; barrera de vapor; etcétera), $g_{k, c u b}$, así como el peso de los falsos techos, las instalaciones, etcétera, $g_{k, p, 2}$. Ninguno de los dos, $g_{k, c u b}$ y $g_{k, p, 2}$, depende de la luz de la losa, es decir de la separación de las vigas de cubierta. Para el primero se adoptan por ello dos valores, correspondientes a una cubrición ligera, $g_{k, c u b}=0,35 \mathrm{kN} / \mathrm{m}^{2}$, y una solución tipo, $g_{k, \text { cub }}=1,7 \mathrm{kN} / \mathrm{m}^{2}$, respectivamente. Para el peso de los falsos techos, las instalaciones, etcétera, se selecciona un único valor, $g_{k, p, 2}=0,5 \mathrm{kN} / \mathrm{m}^{2}$, igual que el adoptado para las vigas de cubierta de otros materiales (Tabla 5.2).

Las vigas de cubierta están constituidas por perfiles armados con secciones en doble $\mathrm{T}$ y una losa superior. Para los perfiles de acero se eligen secciones doblemente simétricas con un canto que depende de la luz de la viga, según las reglas de la buena práctica, lo que facilita el dimensionado estricto. Por el mismo motivo, los espesores de losa se adoptan de tal forma que el eje neutro plástico se encuentre en la sección de hormigón, y se toman medidas destinadas a evitar los posibles fenómenos de inestabilidad. El pandeo lateral de las vigas de acero se impide disponiendo un número suficiente de apeos durante la fase de construcción y, en el estado final, a través de la conexión con la losa de hormigón, de modo que ésta arriostra al ala comprimida de acero. Por otro lado, la abolladura de las chapas delgadas de acero se evita respetando unas condiciones mínimas para la esbeltez de las alas comprimidas y disponiendo los rigidizadores necesarios en las almas [EN 1994-1-1 2004].

Finalmente, enlazando con los anteriores aspectos relacionados con los condicionantes para las vigas de cubierta y sus mecanismos de fallo, conviene mencionar los motivos por los que, entre los parámetros a variar, no se encuentra ninguno sobre los pernos conectadores ni la armadura de la losa. En estructuras mixtas es práctica habitual dimensionar la conexión de modo que no se pueda producir su fallo prematuro. Por ello resulta pequeña la contribución de la posible rotura de la conexión a la probabilidad de fallo acumulada para un sistema mixto (Apartado 4.2.2). Consecuentemente, no se tiene en cuenta este mecanismo en la continuación de los trabajos según el procedimiento del Apartado 4.5. Tampoco se tiene en cuenta la influencia de la armadura ya que no interviene en la determinación de la resistencia frente a momentos flectores y esfuerzos cortantes, respectivamente, de las vigas mixtas biapoyadas con losa superior.

\section{Vigas de planta}

Las anteriores indicaciones sobre la variación de los parámetros relativos a las vigas mixtas de cubierta también son válidas para las vigas mixtas de planta, con la excepción de las relativas a las cargas variables y permanentes. Igualmente, se hacen extensivas a las vigas de planta las consideraciones sobre la geometría de la sección transversal de las vigas mixtas de cubierta, los condicionantes que intervienen en su dimensionado, así como los mecanismos de fallo relevantes. A continuación no se repiten todos estos aspectos en común entre las vigas mixtas de cubierta y de planta.

En relación con las cargas variables, se consideran vigas de edificios destinados a los mismos usos como en los casos de las estructuras con elementos de acero y de hormigón, respectivamente, por lo que la información de los Apartados 5.3.1 y 5.3.2 acerca de las sobrecargas a considerar es de aplicación también en el presente caso. Por otro lado, igual que para las vigas mixtas de cubierta, la losa de hormigón salva la luz entre las vigas mixtas de planta por lo que, a efectos de cálculo, el peso propio de la losa corresponde al peso propio de las vigas mixtas. Consecuentemente, las cargas permanentes no dependen de la luz de la losa. Se adoptan por ello tres valores para estas cargas, independientes de la geometría de la estructura. Una solución ligera correspondería a una carga permanente prácticamente despreciable, mientras que para estimar un valor máximo se asume que incluso los revestimientos de mármol, incluidos los morteros de nivelación, no suelen superar los 3 $\mathrm{kN} / \mathrm{m}^{2}$. Teniendo en cuenta también la contribución de instalaciones, falsos techos y aislamientos, 
además de los revestimientos, los valores característicos deducidos se elevan a $g_{k, p, 1}=0,1 \mathrm{kN} / \mathrm{m}^{2}$ para la solución ligera, $g_{k, p, 1}=2,25 \mathrm{kN} / \mathrm{m}^{2}$ para la solución tipo y $g_{k, p, 1}=3,5 \mathrm{kN} / \mathrm{m}^{2}$ para la solución pesada.

\section{Pilares}

Por la función de los elementos verticales, asegurando el descenso de las cargas de los forjados hasta la cimentación, muchas de las anteriores especificaciones sobre la variación de los parámetros relativos a las vigas mixtas de cubierta y de planta también afectan a los pilares mixtos, tal y como se pone de manifiesto en los Apartados 5.3.1, para las estructuras de acero, y 5.3.2, para las de hormigón. Por ello no es necesario repetir en detalle la variación de los parámetros en cuestión. Concretamente, se trata de los geométricos que definen las estructuras en su conjunto según la Tabla 5.3 (área de influencia por planta; altura por planta; número de plantas por encima del pilar considerado, etcétera), así como los parámetros relativos a:

- clima regional y altitud sobre el nivel del mar, a través de la carga de nieve asociada;

- categoría de uso y sobrecarga asociada;

- peso propio de los forjados;

- cargas permanentes en cubierta y en los forjados de planta.

A continuación, se resume la variación de los restantes parámetros de los que depende el dimensionado de los pilares mixtos. Igual que en los apartados anteriores, los valores en cursiva solamente se tienen en cuenta para deducir el nivel de fiabilidad de los pilares considerados aisladamente. Los valores restantes se utilizan adicionalmente también para la deducción de los riesgos admisibles para las estructuras mixtas de edificación:

- Aceros estructurales con valores característicos del límite elástico de, respectivamente: $f_{y k}=235$ $\mathrm{N} / \mathrm{mm}^{2} ; 275 \mathrm{~N} / \mathrm{mm}^{2}$ y $355 \mathrm{~N} / \mathrm{mm}^{2}$.

- Hormigones con resistencias características a compresión de, respectivamente: $f_{c k}=25 \mathrm{~N} / \mathrm{mm}^{2}$; $30 \mathrm{~N} / \mathrm{mm}^{2} ; 40 \mathrm{~N} / \mathrm{mm}^{2}$ y $50 \mathrm{~N} / \mathrm{mm}^{2}$. Para los pilares y las vigas de una determinada estructura se emplea el mismo tipo de hormigón: si las vigas tienen una luz de $40 \mathrm{~m}$ se emplean hormigones con $f_{c k}=40 \mathrm{~N} / \mathrm{mm}^{2}$, mientras que en todos los demás casos, los hormigones tienen una resistencia de $f_{c k}=25 \mathrm{~N} / \mathrm{mm}^{2}$.

- Acero de armar con un valor característico del límite elástico de $f_{s k}=500 \mathrm{~N} / \mathrm{mm}^{2}$.

- Factor de contribución del acero estructural a la resistencia última de, respectivamente: $\delta=0,2$; 0,6 y 0,9 .

- Cuantía de acero de armar de, respectivamente: $\rho=0,003$ y 0,04 .

Los dos últimos parámetros están relacionados con la sección transversal de los pilares mixtos y los valores seleccionados son compatibles con las reglas de la buena práctica, así como con las condiciones mínimas establecidas en la normativa europea [EN 1994-1-1 2004]. El cumplimiento de estas últimas es necesario para poder aplicar los procedimientos general y simplificado, respectivamente, para el dimensionado de los pilares mixtos según el citado Eurocódigo [EN 1994-11 2004]. Para el factor de contribución del acero estructural a la resistencia última, $\delta$, se adoptan los valores mínimo, $\delta=0,2$, y máximo según la norma, $\delta=0$,9, así como un valor intermedio, $\delta=0,6$. De manera similar, para la cuantía de acero de armar se adopta en primer lugar el valor mínimo establecido, $\rho=0,003$. Valores reducidos de este orden de magnitud son habituales en pilares mixtos constituidos por perfiles cerrados, rellenos de hormigón. Por otro lado, también se adopta el valor máximo establecido de $\rho=0,04$. El interés práctico de cuantías de armadura tan elevadas en pilares mixtos reside por ejemplo en el incremento de su resistencia en caso de incendio. Para limitar el número de casos a estudiar en el marco del Capítulo 8, no se adopta ningún valor intermedio para la cuantía de armadura.

Igual que en los casos de los pilares de acero (Apartado 5.3.1) y de hormigón (Apartado 5.3.2), se asume que se adopten las medidas necesarias para evitar los posibles mecanismos de inestabilidad en 
los pilares mixtos. Como también se menciona con anterioridad, la adopción de medidas de este tipo resulta relativamente sencilla. Bajo estas premisas, no es necesario definir un determinado tipo de sección transversal para efectuar el dimensionado estricto. A estos efectos se pueden emplear directamente las diferentes combinaciones de los valores indicados para el factor de contribución del acero estructural a la resistencia última, $\delta$, y la cuantía de acero de armar, $\rho$.

\section{Resumen}

La combinación de los valores numéricos adoptados para los diferentes parámetros relativos a la geometría, las cargas y los materiales constitutivos, proporciona los dos conjuntos representativos, respectivamente para los sistemas estructurales y los elementos mixtos de acero y hormigón. El primero está constituido por 4.704 estructuras de la clase de consecuencias CC2 y 3.840 estructuras pertenecientes a la clase CC3 [EN 1990 2002]. Los edificios correspondientes tienen superficies útiles que oscilan entre $200 \mathrm{~m}^{2}$ y $990.000 \mathrm{~m}^{2}$. El número máximo de plantas, sin contar planta baja ni cubierta, es de 10 en los edificios de la clase CC3 y de 30 en los de la clase CC2. Finalmente, el número de elementos estructurales por sistema considerado varía entre un mínimo de 6 y un máximo de 39.366, independientemente de la clase de consecuencias del edificio correspondiente.

El conjunto de diferentes elementos mixtos, por otro lado, engloba 480 vigas de cubierta, 900 vigas de planta y 76.464 pilares. La gran mayoría de los elementos que se pueden encontrar en las estructuras mixtas de la práctica están cubiertos por este conjunto, teniendo en cuenta los valores considerados para los distintos parámetros. Por ello, este conjunto de elementos mixtos es adecuado para la continuación del trabajo según el procedimiento del Capítulo 4, igual que el conjunto de sistemas estructurales obtenido.

\subsubsection{Edificios con estructuras de madera laminada encolada}

\section{Variación de parámetros}

En analogía con los apartados anteriores, los conjuntos representativos de, respectivamente, sistemas y elementos estructurales de madera laminada encolada se determinan variando, dentro de unos límites realistas, los principales parámetros relativos a la geometría, las cargas, así como los materiales, y combinando las diferentes opciones. No obstante, en comparación con los elementos y las estructuras de otros materiales constitutivos existen algunas limitaciones, intrínsecas a las estructuras de madera, que en la mayoría de los casos afectan a la geometría. Por ejemplo, en los edificios con estructuras de madera el número máximo de plantas es menor que en los casos anteriores. También lo suele ser la luz máxima de las vigas. Eso a pesar de que existen numerosos ejemplos con luces considerables, sobre todo en cubiertas de madera. Pero estas se suelen resolver con soluciones y sistemas estáticos tales como por ejemplo vigas o arcos con tirantes inferiores, estructuras espaciales, etcétera, que están fuera del alcance del presente estudio. Otras limitaciones o diferencias con respecto a los apartados anteriores se explican a continuación. Todas ellas se tienen debidamente en cuenta en la selección de los sistemas y elementos.

\section{Geometría de las estructuras}

Para la obtención del conjunto representativo de estructuras de edificación con elementos de madera laminada encolada se varían los parámetros geométricos mencionados en el Apartado 5.2.1, utilizando la notación del Apartado 5.3.1. También son de aplicación las consideraciones de carácter general del mismo apartado sobre la altura de planta o la distancia entre ejes de los pilares en sentido transversal del edificio. En cuanto al número máximo de plantas, en la clase de consecuencias CC3 se consideran edificios con un máximo de 5 plantas, además de planta baja y cubierta, mientras que en la clase CC2 este máximo es de 10 plantas. La Tabla 5.4 refleja los valores numéricos seleccionados para los parámetros geométricos de las estructuras de madera laminada encolada. 
Tabla 5.4 - Variación de parámetros geométricos para la selección de un conjunto representativo de estructuras de edificación, constituidas por elementos de madera laminada encolada.

\begin{tabular}{|c|c|c|c|c|c|}
\hline H:B:L (aprox.) & $\boldsymbol{n}_{s}$ & $H[\mathrm{~m}]$ & $B[\mathrm{~m}]$ & $L[\mathrm{~m}]$ & $l[\mathrm{~m}]$ \\
\hline \multirow{2}{*}{ 1:1:1 } & 1 & 6 & 10 & 10 & $5 ; 10$ \\
\hline & 10 & 33 & 40 & 40 & $5 ; 10 ; 20$ \\
\hline \multirow{6}{*}{ 1:10:10 } & 0 & 3 & 20 & 20 & $10 ; 20$ \\
\hline & 0 & 3 & 40 & 40 & $5 ; 10 ; 20$ \\
\hline & 3 & 12 & 120 & 120 & $5 ; 10 ; 20$ \\
\hline & 5 & 18 & 200 & 200 & $5 ; 10 ; 20$ \\
\hline & 10 & 33 & 300 & 240 & $10 ; 15 ; 30$ \\
\hline & 10 & 33 & 300 & 300 & $10 ; 15 ; 30$ \\
\hline $10: 1: 1$ & 10 & 33 & 5 & 5 & 5 \\
\hline \multirow{3}{*}{$1: 2: 2$} & 3 & 12 & 30 & 30 & $5 ; 15 ; 30$ \\
\hline & 5 & 18 & 40 & 40 & 5 \\
\hline & 10 & 33 & 60 & 60 & $5 ; 10 ; 20 ; 30$ \\
\hline \multirow{2}{*}{$2: 2: 1$} & 5 & 18 & 20 & 10 & $5 ; 10$ \\
\hline & 10 & 33 & 30 & 15 & $5 ; 15$ \\
\hline \multirow{2}{*}{$2: 1: 2$} & 5 & 18 & 10 & 20 & $5 ; 10 ; 20$ \\
\hline & 10 & 33 & 15 & 30 & $5 ; 15 ; 30$ \\
\hline 1:3:2 & 1 & 6 & 20 & 10 & 5 \\
\hline \multirow{2}{*}{ 1:3:3 } & 1 & 6 & 20 & 20 & 20 \\
\hline & 5 & 18 & 60 & 80 & $5 ; 10 ; 20$ \\
\hline \multirow{2}{*}{ 1:4:1 } & 1 & 6 & 40 & 10 & $5 ; 10$ \\
\hline & 5 & 18 & 80 & 20 & $10 ; 20$ \\
\hline \multirow{2}{*}{ 1:1:4 } & 1 & 6 & 10 & 40 & $5 ; 10$ \\
\hline & 5 & 18 & 20 & 80 & $10 ; 20$ \\
\hline \multirow{3}{*}{$1: 5: 10$} & 0 & 3 & 10 & 20 & 20 \\
\hline & 5 & 18 & 100 & 200 & $5 ; 10 ; 20$ \\
\hline & 10 & 33 & 180 & 300 & $10 ; 15 ; 30$ \\
\hline $5: 10: 1$ & 10 & 33 & 60 & 10 & $5 ; 10$ \\
\hline $5: 1: 10$ & 10 & 33 & 10 & 60 & $5 ; 10 ; 20$ \\
\hline $1: 10: 5$ & 10 & 33 & 300 & 120 & $10 ; 15 ; 30$ \\
\hline
\end{tabular}

\section{Vigas de cubierta}

La variación de los parámetros relativos a las vigas de cubierta de madera laminada encolada se representa a continuación, en analogía con los apartados anteriores. En consecuencia, no se repiten los parámetros geométricos de la estructura, que se encuentran en la Tabla 5.4, y se representan en cursiva aquellos valores de los distintos parámetros que solamente se tienen en cuenta para deducir el nivel de fiabilidad de las vigas de cubierta consideradas aisladamente:

- Vigas en edificios expuestos a diferentes climas regionales con valores característicos para la carga de nieve de, respectivamente: $q_{k, 1}=1,5 \mathrm{kN} / \mathrm{m}^{2} ; 2 \mathrm{kN} / \mathrm{m}^{2} ; 2,5 \mathrm{kN} / \mathrm{m}^{2}$ y $3,0 \mathrm{kN} / \mathrm{m}^{2}$. 
- Vigas con luces de, respectivamente: 5 m; 10 m; 15 m; 20 m y 30 m.

- Madera laminada encolada homogénea de las clases resistentes GL24h y GL28h, según el Eurocódigo [EN 1995-1-1 2004] y el Código Técnico de la Edificación [CTE DB SE-M 2006], con valores característicos de la resistencia a flexión de, respectivamente: $f_{m, g, k}=24 \mathrm{~N} / \mathrm{mm}^{2}$ y 28 $\mathrm{N} / \mathrm{mm}^{2}$. Los valores característicos de la resistencia a cortante de las maderas de estas clases se elevan a $f_{v, g, k}=2,7 \mathrm{~N} / \mathrm{mm}^{2}$ y $3,2 \mathrm{~N} / \mathrm{mm}^{2}$, respectivamente.

- Peso específico aparente de la madera laminada encolada de $4,4 \mathrm{kN} / \mathrm{m}^{3}$, según las hipótesis establecidas a continuación.

- Cargas permanentes, $g_{k, p, 2}+g_{k, c u b}$, comprendidas entre $1,0 \mathrm{kN} / \mathrm{m}^{2}$ y $9,0 \mathrm{kN} / \mathrm{m}^{2}$, de acuerdo con las consideraciones resumidas a continuación. Los valores numéricos adoptados están reflejados en la Tabla 5.5.

Para la fabricación de los elementos de las clases resistentes consideradas (GL24h y GL28h) se emplean láminas de pino. Para una humedad de esta madera del 12\%, el código modelo probabilista establece una densidad media de $4,4 \mathrm{kN} / \mathrm{m}^{3}$ [JCSS 2001]. Por estos motivos, se considera un único valor nominal para el peso específico aparente, obviando que en un sentido estricto depende tanto de la clase resistente como de la humedad de la madera laminada encolada.

Igual que en las estructuras de acero (Apartado 5.3.1) y de hormigón armado (Apartado 5.3.2), y contrariamente a las mixtas (Apartado 5.3.3), no existe ninguna conexión entre las vigas de madera y los elementos resistentes de la cubrición. Las cargas permanentes engloban por tanto el peso propio de estos elementos (puede tratarse de chapas o paneles resistentes apoyados en las vigas principales si su separación es suficientemente pequeña, o una estructura secundaria si la luz a salvar es mayor) y de los no resistentes (chapa exterior; impermeabilización; aislante; barrera de vapor; chapa interior) de la cubrición, $g_{k, c u b}$, así como el peso de los falsos techos y las instalaciones, $g_{k, p, 2}$. Para el peso propio de la cubrición, $g_{k, c u b}$, se consideran dos valores, correspondientes a soluciones ligeras y pesadas, respectivamente. Estos valores dependen, además, de la luz que debe salvar el sistema de cubrición, es decir de la separación de las vigas principales que, según las hipótesis adoptadas, a su vez depende de la luz de estas mismas vigas (Apartado 5.3.1). Por otro lado, para el peso de los falsos techos y las instalaciones se adopta un único valor de $0,5 \mathrm{kN} / \mathrm{m}^{2}$ (Tabla 5.5).

Para las vigas se adopta una sección rectangular con un canto que se elige en función de la luz a salvar, según las reglas de la buena práctica, y un ancho correspondiente a la quinta parte del canto. Por motivos de fabricación, el ancho de la sección no debería superar los 250 mm. No obstante, con las proporciones geométricas habituales no es posible respetar esta condición en las vigas de $30 \mathrm{~m}$ de luz, lo que en cualquier caso no es estrictamente necesario ya que en el presente estudio se analizan elementos hipotéticos. Las anteriores hipótesis facilitan el dimensionado estricto de las vigas según el procedimiento del Apartado 4.4, para las que se admite, además, que no se produzcan fenómenos de inestabilidad. En particular, el pandeo lateral se evita utilizando los elementos resistentes de la cubrición para arriostrar la cabeza comprimida de las vigas de cubierta.

Para el dimensionado estricto se deben adoptar algunas hipótesis adicionales sobre la influencia de la duración de las cargas, las clases de servicio, así como las dimensiones de las secciones transversales. A estos efectos, tanto el Eurocódigo [EN 1995-1-1 2004] como el Código Técnico de la Edificación [CTE DB SE-M 2006] introducen una serie de factores de corrección o modificación de las propiedades del material. En el presente contexto, resulta relevante el factor de modificación que tiene en cuenta el efecto de la duración de la carga y el contenido de humedad, $k_{\text {mod. }}$ Para la geometría de la sección adoptada también se debe considerar la influencia del canto de la sección solicitada por momentos flectores, a través del factor de canto, $k_{h}$.

En la mayoría de las regiones de la península ibérica, la capa de nieve suele desaparecer entre dos sistemas meteorológicos con nevadas. La carga de nieve es por ello de corta duración (menor que una 
semana). Además, según las hipótesis adoptadas en el presente trabajo, los edificios analizados están protegidos por un sistema de cubrición, por lo que las vigas de madera no están expuestas a la intemperie: las condiciones de exposición corresponden por ello en buena aproximación a la clase de servicio 1 según la normativa en vigor [EN 1995-1-1 2004, CTE DB SE-M 2006]. Para elementos de madera laminada encolada expuestos a esta clase de servicio y solicitados por acciones de corta duración, el factor de modificación tiene un valor de $k_{\text {mod }}=0,9$.

En piezas de madera laminada encolada de sección rectangular, el valor de referencia del canto de la sección solicitada por momentos flectores es de $600 \mathrm{~mm}$. Para cantos inferiores, el valor característico de la resistencia a flexión, $f_{m, g, k}$, puede incrementarse por el factor $k_{h}$ :

$k_{h}=\min \left\{\left(\frac{600}{h}\right)^{0,1} ; 1,1\right\}$

$h \quad$ : canto de la sección transversal

$k_{h} \quad$ : factor de canto de la sección de madera

Tabla 5.5 - Variación de las cargas permanentes actuando sobre las vigas de planta, $g_{k, p, 1}, y$ de cubierta, $g_{k, p, 2}$, así como del peso propio de los elementos resistentes y no resistentes de la cubrición, $g_{k, c u b}$, en edificios con estructuras de madera laminada encolada.

\begin{tabular}{|c|c|c|c|}
\hline \multirow[b]{2}{*}{$\begin{array}{l}\text { Luz de las vigas principales } \\
\qquad I[\mathrm{~m}]\end{array}$} & \multirow{2}{*}{$\begin{array}{c}\text { Planta } \\
g_{k, p, 1} \\
{\left[\mathbf{k N} / \mathbf{m}^{2}\right]}\end{array}$} & \multicolumn{2}{|c|}{ Cubierta } \\
\hline & & $\begin{array}{c}g_{k, p, 2} \\
{\left[\mathbf{k N} / \mathbf{m}^{2}\right]}\end{array}$ & $\begin{array}{c}g_{k, c u b} \\
{\left[\mathbf{k N} / \mathbf{m}^{2}\right]}\end{array}$ \\
\hline $5 ; 10$ & 0,$5 ; 3,5 ; 6,0$ & 0,5 & 0,$5 ; 4,5$ \\
\hline $15 ; 20$ & 2,$5 ; 5,0 ; 7,0$ & 0,5 & 0,$6 ; 8,5$ \\
\hline 30 & 4,$0 ; 6,5 ; 8,0$ & 0,5 & 0,$65 ; 8,5$ \\
\hline
\end{tabular}

\section{Vigas de planta}

Las anteriores consideraciones sobre algunos de los parámetros relativos a las vigas de cubierta y su variación también son de aplicación a las vigas de planta. Además de los parámetros geométricos de las estructuras (Tabla 5.4), incluidas las luces de las vigas, se trata de las clases resistentes de la madera laminada encolada, el peso específico aparente, así como la geometría de las secciones transversales. En parte, también son válidos los aspectos que determinan los mecanismos de fallo e intervienen en el dimensionado de las vigas. Es el caso de la adopción de medidas para evitar los posibles fenómenos de inestabilidad, así como de la influencia del canto de una sección rectangular en la resistencia a flexión de la viga que se tiene en cuenta a través del factor de canto, $k_{h}$, según la ecuación (5.6). A continuación no se repiten todos estos aspectos en común entre las vigas de cubierta y de planta, pero si se abordan las diferencias. En particular, en comparación con las vigas de cubierta tanto las cargas variables como las permanentes son diferentes en las vigas de planta.

Los edificios con estructuras de madera laminada encolada están destinados a los mismos usos que los edificios con estructuras de acero, hormigón y mixtas, respectivamente. Consecuentemente, la información contenida en los Apartados 5.3.1 a 5.3.3 en relación con las sobrecargas a tener en cuenta mantiene su validez para el estudio de las vigas de madera. El único aspecto que requiere una consideración especial es la influencia, en el dimensionado estructural, de la duración de las sobrecargas en combinación con las relevantes clases de servicio [EN 1995-1-1 2004, CTE DB SE-M 2006]. Las cargas de uso que conducen al valor máximo de las sobrecargas se añaden a las cargas sostenidas y suelen ser de corta duración. Como además las vigas de planta se encuentran en el 
interior de los edificios, las condiciones de exposición pertenecen a la clase de servicio 1 y el factor de modificación tiene un valor de $k_{\text {mod }}=0,9$, igual que en el caso de las vigas de cubierta.

Por último, las cargas permanentes, $g_{k, p, 1}$, están comprendidas entre $0,5 \mathrm{kN} / \mathrm{m}^{2}$ y $8,0 \mathrm{kN} / \mathrm{m}^{2}$. Siguiendo la argumentación del Apartado 5.3.1, se consideran tres diferentes valores para las cargas permanentes que actúan sobre las vigas de madera de los forjados de planta: un valor mínimo, intermedio y máximo, respectivamente. Las cargas permanentes dependen igualmente de la luz de las vigas principales, ya que la luz de la estructura secundaria (forjado), y por tanto su tipología y peso propio, dependen de la separación de los pórticos que, según las hipótesis adoptadas, es función de la luz de las vigas principales. Los valores numéricos para las cargas permanentes, $g_{k, p, 1}$, obtenidos sobre esta base, se encuentran en la Tabla 5.5 para los tres rangos de luces considerados para las vigas principales.

\section{Pilares}

Gran parte de las consideraciones sobre los parámetros a variar en relación con las vigas de cubierta y de planta también afectan a los pilares de madera laminada encolada, debido a su función de asegurar el descenso de las cargas de los forjados a la cimentación. Consecuentemente, no se van a repetir las consideraciones relativas a los siguientes parámetros:

- geometría de las estructuras en su conjunto (área de influencia por planta; altura por planta; número de plantas por encima del pilar analizado; etcétera), datos que se pueden deducir de la Tabla 5.4;

- clima regional y altitud sobre el nivel del mar, a través de la carga de nieve asociada;

- categoría de uso y sobrecarga asociada;

- peso propio de los forjados;

- cargas permanentes en cubierta y en los forjados de planta.

A continuación, se resume la variación de los restantes parámetros de los que depende el dimensionado de los pilares de madera laminada encolada. Todos los valores mencionados se tienen en cuenta para deducir tanto el nivel de fiabilidad de los pilares considerados aisladamente como los riesgos admisibles para las estructuras de edificación con elementos de madera:

- Madera laminada encolada homogénea de las clases resistentes GL24h y GL28h, con valores característicos de la resistencia a compresión paralela a la fibra de, respectivamente: $f_{c, 0, g, k}=24$ $\mathrm{N} / \mathrm{mm}^{2}$ y 26,5 N/mm² [EN 1995-1-1 2004, CTE DB SE-M 2006].

- Peso específico aparente de la madera laminada encolada de los pilares de $4,4 \mathrm{kN} / \mathrm{m}^{3}$.

Para los pilares se elige una sección cuadrada que, a efectos del presente estudio, no tiene que cumplir ninguna condición mínima según la normativa en vigor ya que se analizan elementos hipotéticos. Según las disposiciones adoptadas para el sistema estructural, los pilares están solicitados por esfuerzos de compresión centrada. Igual que para los pilares de los otros materiales constitutivos, se supone que se proporcionen suficientes apoyos laterales como para impedir fenómenos de inestabilidad. Todas estas hipótesis facilitan el dimensionado estricto según el procedimiento del Apartado 4.4.

A efectos de este dimensionado también se debe tener en cuenta la influencia de la duración de las cargas, así como de las clases de servicio. Como los pilares se encuentran en el interior de los edificios se puede asumir que estén protegidos de la intemperie. Por otro lado, tanto la carga de nieve como los valores extremos de las sobrecargas son de corta duración, como se menciona en relación con las vigas de cubierta y de planta, respectivamente. Por todo ello, igual que en el caso de las vigas, para los pilares de madera laminada encolada se adopta un valor de modificación de $k_{\text {mod }}=0,9$. 


\section{Resumen}

Para la obtención de los conjuntos de, respectivamente, las estructuras y los elementos de madera laminada encolada se combinan los valores numéricos adoptados para los diferentes parámetros, en analogía con los otros materiales constitutivos. Los dos conjuntos son aptos para ser utilizados en la continuación del trabajo, de acuerdo con el procedimiento del Capítulo 4.

El conjunto de sistemas estructurales engloba 1.656 estructuras de edificios pertenecientes a la clase de consecuencias CC2, definida en el Eurocódigo [EN 1990 2002], y 936 de la clase CC3. Los edificios pertenecientes a la clase CC2 tienen superficies útiles que varían entre $200 \mathrm{~m}^{2}$ y $990.000 \mathrm{~m}^{2}$. En el caso de los edificios que integran la clase CC3, la superficie mínima es la misma, mientras que la máxima es de $240.000 \mathrm{~m}^{2}$. En la clase CC3 se consideran edificios con un máximo de 5 plantas, sin contar planta baja ni cubierta, mientras que en la clase CC2 los edificios tienen un máximo de 10 plantas, además de planta baja y cubierta. El número mínimo de elementos estructurales por sistema considerado es de 6, en los edificios de ambas clases de consecuencias, mientras que el número máximo es de 40.931 en las estructuras de los edificios de la clase CC2 y de 39.366 en el caso de la clase CC3.

Por otro lado, el conjunto representativo de diferentes elementos estructurales de madera laminada encolada engloba 80 vigas de cubierta, 150 vigas de planta y 5.280 pilares.

\subsection{MECANISMOS DE FALLO Y FUNCIONES DE ESTADO LÍMITE}

\subsubsection{Generalidades}

En el Apartado 5.2 se justifica la conveniencia de considerar, en el marco del presente estudio, estructuras de edificación constituidas por vigas y pilares isostáticos. Se asume también que estos sistemas sean intraslacionales y, según lo especificado en el Apartado 5.3, que se adopten las medidas necesarias para evitar posibles fenómenos de inestabilidad en las vigas y los pilares de cualquiera de los materiales constitutivos considerados. Aparte de que la puesta en práctica de este tipo de medidas resulta relativamente sencilla (Apartado 5.3.1), es verosímil que la no consideración de los diferentes fenómenos de inestabilidad (pandeo, pandeo lateral, abolladura, etcétera) no distorsione los resultados finales de este estudio. Efectivamente, los índices de fiabilidad obtenidos para un conjunto representativo de pilares de hormigón armado sometidos a la interacción de esfuerzos axiles de compresión y momentos flectores [Hingorani 2011], no se distingue significativamente del nivel de fiabilidad determinado en un estudio similar para pilares solicitados por esfuerzos axiles de compresión centrada [Tanner 2007b]. En pilares que fallan por pandeo, la rotura se produce por la interacción de esfuerzos axiles y momentos flectores a nivel de las secciones transversales más solicitadas. Aunque en estos casos la dispersión de los resultados presumiblemente aumentaría, se puede suponer que los índices de fiabilidad y las probabilidades de fallo serían sensiblemente comparables con los obtenidos en los dos estudios citados que no consideran los fenómenos de inestabilidad por pandeo. Las hipótesis adoptadas en el presente estudio tienen la ventaja adicional de que los índices de fiabilidad obtenidos para los mecanismos de fallo analizados se pueden comparar con los de otros estudios, por ejemplo [SAKO 1999], mucho menos amplios pero basados en premisas similares.

Según todas estas consideraciones, los fallos por flexión, esfuerzo cortante y esfuerzo axil de compresión, respectivamente, son los mecanismos más representativos para las vigas y los pilares de las estructuras de edificación seleccionadas. A continuación se formulan por ello las respectivas funciones de estado límite para las vigas y los pilares de acero estructural (Apartado 5.4.2), hormigón armado (Apartado 5.4.3), mixtos (Apartado 5.4.4) y madera laminada encolada (Apartado 5.4.5), 
expuestas a situaciones persistentes [EN 1990 2002]. Teniendo en cuenta las especificaciones del Apartado 5.3 sobre las vigas y los pilares, sus secciones transversales, así como algunos aspectos que afectan a su dimensionado, estas funciones se establecen a partir de la representación de los diferentes efectos de las acciones según los Eurocódigos [EN 1990 2002, EN 1991-1-1 2002, 1991-13 2003], y las correspondientes resistencias últimas de los elementos, también según los relevantes Eurocódigos, dependiendo de los materiales constitutivos [EN 1990 2002, EN 1992-1-1 2004, EN 1993-1-1 2005, EN 1994-1-1 2004, EN 1995-1-1 2004]. En este contexto conviene destacar que, para los mecanismos de fallo considerados y las hipótesis adoptadas, las normas españolas equivalentes, [CTE DB SE 2006, CTE DB SE-AE 2006, EHE-08 2008, EAE 2011, CTE DB SE-M 2006], conducen a las mismas funciones de estado límite.

\subsubsection{Elementos de acero}

\section{Vigas de planta}

La función de estado límite para la sección del centro del vano de una viga de planta de acero estructural se expresa en los siguientes términos:

$$
\xi_{R, M} \cdot W_{p l} \cdot f_{y}-\xi_{E, M} \cdot\left(M_{a}+M_{p, 1}+\left(M_{q, 1}+M_{Q, 1}\right)\right)=0
$$

$M_{a} \quad:$ momento flector debido al peso propio de la viga de acero

$M_{p, 1} \quad:$ momento flector debido a las cargas permanentes actuando sobre las vigas de planta

$M_{q, 1} \quad$ : momento flector debido a la carga distribuida del modelo para la acción variable dominante (por ejemplo la sobrecarga)

$M_{Q, 1} \quad$ : momento flector debido a la carga concentrada del modelo para la acción variable dominante (por ejemplo la sobrecarga; normalmente no se considera simultáneamente con la carga distribuida, según Apartado 5.3.1)

$W_{p l} \quad$ : módulo plástico de la sección transversal en el centro del vano

$f_{y} \quad$ : límite elástico del acero estructural

$\xi_{E, M} \quad$ : coeficiente para las incertidumbres del modelo para el cálculo de los efectos de las acciones (momentos flectores)

$\xi_{R, M} \quad$ : coeficiente para las incertidumbres del modelo de resistencia frente a momentos flectores

Para la sección de apoyo de una viga de planta se considera la siguiente función de estado límite:

$$
\xi_{R, V} \cdot A_{V} \cdot \frac{f_{y w}}{\sqrt{3}}-\xi_{E, V} \cdot\left(V_{a}+V_{p, 1}+\left(V_{q, 1}+V_{Q, 1}\right)\right)=0
$$

$V_{a} \quad:$ esfuerzo cortante debido al peso propio de la viga de acero

$V_{p, 1} \quad$ : esfuerzo cortante debido a las cargas permanentes actuando sobre las vigas de planta

$V_{q, 1} \quad$ : esfuerzo cortante debido a la carga distribuida del modelo para la acción variable dominante (por ejemplo la sobrecarga)

$V_{Q, 1} \quad$ : esfuerzo cortante debido a la carga concentrada del modelo para la acción variable dominante (por ejemplo la sobrecarga; normalmente no se considera simultáneamente con la carga distribuida, según Apartado 5.3.1)

$A_{V} \quad$ : área de cortante de la sección transversal en apoyo

$f_{y w} \quad$ : límite elástico del acero estructural del área de cortante

$\xi_{E, V} \quad$ : coeficiente para las incertidumbres del modelo para el cálculo de los efectos de las acciones (esfuerzos cortantes)

$\xi_{R, V} \quad$ : coeficiente para las incertidumbres del modelo de resistencia frente a esfuerzos cortantes

\section{Vigas de cubierta}

Para las vigas de cubierta, las funciones de estado límite son análogas a las de las vigas de planta, teniendo en cuenta las solicitaciones debidas a las diferentes acciones sobre la cubierta. Estas acciones engloban al peso propio de la viga, el peso propio de los elementos resistentes y no 
resistentes de la cubrición, los falsos techos e instalaciones, así como la nieve como acción variable dominante:

$$
\begin{aligned}
& \xi_{R, M} \cdot W_{p l} \cdot f_{y}-\xi_{E, M} \cdot\left(M_{a}+M_{c u b}+M_{p, 2}+M_{q, 1}\right)=0 \\
& \xi_{R, V} \cdot A_{V} \cdot \frac{f_{y w}}{\sqrt{3}}-\xi_{E, V} \cdot\left(V_{a}+V_{c u b}+V_{p, 2}+V_{q, 1}\right)=0
\end{aligned}
$$

$M_{\text {cub }} \quad$ : momento flector debido a los elementos resistentes y no resistentes de la cubrición

$M_{p, 2} \quad$ : momento flector debido a las cargas permanentes actuando sobre las vigas de cubierta (falsos techos, instalaciones, etcétera, pero sin cubrición)

$M_{q, 1} \quad$ : momento flector debido a la acción variable dominante (por ejemplo la nieve)

$V_{\text {cub }} \quad$ : esfuerzo cortante debido a los elementos resistentes y no resistentes de la cubrición

$V_{p, 2} \quad$ : esfuerzo cortante debido a las cargas permanentes actuando sobre las vigas de cubierta (falsos techos, instalaciones, etcétera, pero sin cubrición)

$V_{q, 1} \quad$ : esfuerzo cortante debido a la acción variable dominante (por ejemplo la nieve)

\section{Pilares}

La función de estado límite para la sección transversal en la base de un pilar de acero estructural, solicitado por un esfuerzo axil de compresión simple, se representa mediante la siguiente relación:

$$
\xi_{R, N} \cdot A \cdot f_{y}-\xi_{E, N}\left(N_{a v}+N_{a p}+N_{p, 1}+N_{c u b}+N_{p, 2}+N_{q, 1}+\psi_{o} \cdot N_{q, 2}\right)=0
$$

$N_{a v} \quad: \quad$ : esfuerzo axil debido al peso propio de las vigas de los forjados y de la cubierta

$N_{a p} \quad:$ : esfuerzo axil debido al peso propio del pilar

$N_{p, 1} \quad$ : esfuerzo axil debido a las cargas permanentes actuando sobre las vigas de planta

$N_{p, 2} \quad$ : esfuerzo axil debido a las cargas permanentes actuando sobre las vigas de cubierta (falsos techos, instalaciones, etcétera, pero sin cubrición)

$N_{\text {cub }} \quad$ : esfuerzo axil debido a los elementos resistentes y no resistentes de la cubrición

$N_{q, 1} \quad$ : esfuerzo axil debido a la acción variable dominante

$N_{q, 2} \quad$ : esfuerzo axil debido a la acción variable concomitante

A $\quad$ : área de la sección transversal del pilar

$\psi_{0} \quad$ : coeficiente para el valor de combinación de la acción variable concomitante

$\xi_{E, N} \quad$ : coeficiente para las incertidumbres del modelo para el cálculo de los efectos de las acciones (esfuerzos axiles)

$\xi_{R, N} \quad$ : coeficiente para las incertidumbres del modelo de resistencia frente a esfuerzos axiles

\subsubsection{Elementos de hormigón armado}

\section{Vigas}

Por la similitud de las funciones de estado límite para, respectivamente, las vigas de cubierta y planta (Apartado 5.4.2), a continuación se representan únicamente las correspondientes a las vigas de planta de hormigón armado. Las primeras se distinguen de las segundas por las acciones a tener en cuenta. Las acciones sobre las vigas de cubierta son equivalentes a las que actúan sobre las vigas de cubierta de acero (Apartado 5.4.2): el peso propio de las vigas, el peso propio de los elementos resistentes y no resistentes de la cubrición, las cargas permanentes (falsos techos e instalaciones), y la nieve como acción variable dominante.

Las acciones sobre las vigas de planta también son equivalentes a lo establecido en el Apartado 5.4.2. Los momentos flectores inducidos por estas acciones aparecen en la ecuación (5.12) que representa la función de estado límite para la sección del centro de vano:

$$
\xi_{R, M} \cdot\left(A_{s} \cdot f_{s} \cdot d-0,5 \cdot \frac{\left(A_{s} \cdot f_{s}\right)^{2}}{b_{c} \cdot \eta_{c} \cdot f_{c}}\right)-\xi_{E, M} \cdot\left(M_{c}+M_{p, 1}+\left(M_{q, 1}+M_{Q, 1}\right)\right)=0
$$


$M_{c} \quad:$ momento flector debido al peso propio de la viga de hormigón armado

$b_{c} \quad:$ : ancho de la sección transversal

$d \quad$ : canto útil de la sección transversal

$A_{s} \quad$ : área de la sección del acero de armar

$f_{s} \quad$ : límite elástico del acero de armar

$f_{c} \quad:$ resistencia a compresión del hormigón

$\eta_{c} \quad$ : factor de conversión de la resistencia a compresión del hormigón

Para la sección de apoyo de una viga de hormigón armado se consideran dos funciones de estado límite, la ecuación (5.13) para la tracción en el alma y la ecuación (5.14) para la compresión oblicua en el alma:

$$
\begin{aligned}
& \xi_{R, V_{s}} \cdot\left(A_{s w} \cdot f_{s} \cdot 0,9 \cdot d\right)-\xi_{E, V} \cdot\left(V_{c}+V_{p, 1}+\left(V_{q, 1}+V_{Q, 1}\right)\right)=0 \\
& \xi_{R, V_{c}} \cdot\left(b_{A} \cdot d \cdot 0,5 \cdot \eta_{c} \cdot f_{c}\right)-\xi_{E, V} \cdot\left(V_{c}+V_{p, 1}+\left(V_{q, 1}+V_{Q, 1}\right)\right)=0
\end{aligned}
$$

$V_{c} \quad:$ esfuerzo cortante debido al peso propio de la viga de hormigón armado

$b_{A} \quad$ : espesor del alma de la sección transversal en apoyo

$A_{s w} \quad$ : área por unidad de longitud de la sección de la armadura de cortante

$\xi_{R, V s} \quad$ : coeficiente para las incertidumbres del modelo de resistencia frente a la tracción en el alma

$\xi_{R, V c} \quad$ : coeficiente para las incertidumbres del modelo de resistencia frente a la compresión oblicua en el alma

\section{Pilares}

La función de estado límite para la sección transversal en la base de un pilar de hormigón armado, solicitado por un esfuerzo axil de compresión simple, se expresa en los siguientes términos:

$$
\xi_{R, N}\left(a^{2} \cdot \eta_{c} \cdot f_{c}+A_{s} \cdot f_{s}\right)-\xi_{E, N}\left(N_{c v}+N_{c p}+N_{p, 1}+N_{c u b}+N_{p, 2}+N_{q, 1}+\psi_{o} \cdot N_{q, 2}\right)=0
$$

$N_{c v} \quad$ : esfuerzo axil debido al peso propio de las vigas de los forjados y de la cubierta

$N_{c p} \quad$ : esfuerzo axil debido al peso propio del pilar

$a \quad$ : dimensión de un lado de la sección transversal del pilar

\subsubsection{Elementos mixtos de acero y hormigón}

\section{Vigas}

Igual que para las vigas de hormigón armado (Apartado 5.4.3), también en el caso de las vigas mixtas de acero y hormigón, se representan las funciones de estado límite únicamente para las vigas de planta sobre las que actúan el peso propio del perfil de acero y de la losa de hormigón, las cargas permanentes y las sobrecargas de uso. Para las vigas de cubierta, las funciones son equivalentes, diferenciándose solamente por las acciones a considerar: el peso propio de acero y hormigón, el peso propio de los elementos no resistentes de la cubrición (en este caso, los elementos resistentes de la cubrición están formados por la estructura mixta), las cargas permanentes debidas a falsos techos e instalaciones, y la carga de nieve como acción variable dominante (Apartado 5.3.3).

Para la sección del centro de vano de una viga mixta de planta, la función de estado límite se expresa en los términos de la ecuación (5.16):

$$
\begin{aligned}
& \xi_{R, M} \cdot\left(A_{a} \cdot f_{y} \cdot\left(\frac{h_{a}}{2}+h_{c}\right)-0,5 \cdot \frac{\left(A_{a} \cdot f_{y}\right)^{2}}{b_{e f f} \cdot \eta_{c} \cdot f_{c}}\right)- \\
& -\xi_{E, M} \cdot\left(M_{a}+M_{c}+M_{p, 1}+\left(M_{q, 1}+M_{Q, 1}\right)\right)=0
\end{aligned}
$$

$M_{c} \quad:$ momento flector debido al peso propio de la losa superior de hormigón 
$A_{a} \quad$ : área de la sección de acero estructural

$b_{\text {eff }} \quad:$ ancho eficaz de la losa de hormigón

$h_{a} \quad$ : canto de la sección de acero estructural

$h_{c} \quad$ : canto de la losa superior de hormigón

Para la sección de apoyo de una viga mixta de planta se considera la siguiente función de estado límite, teniendo en cuenta únicamente la contribución de la viga de acero estructural a la resistencia frente a esfuerzos cortantes [EN 1994-1-1 2004]:

$\xi_{R, V} \cdot A_{V} \cdot \frac{f_{y w}}{\sqrt{3}}-\xi_{E, V} \cdot\left(V_{a}+V_{c}+V_{p, 1}+\left(V_{q, 1}+V_{Q, 1}\right)\right)=0$

$V_{c} \quad$ : esfuerzo cortante debido al peso propio de la losa superior de hormigón

\section{Pilares}

La función de estado límite para la sección transversal en la base de un pilar mixto de acero y hormigón, solicitado por un esfuerzo axil de compresión simple, se representa a través de la siguiente relación:

$$
\begin{aligned}
& \xi_{R, N}\left(A_{a} \cdot f_{y}+A_{c} \cdot \eta_{c} \cdot f_{c}+A_{s} \cdot f_{s}\right)- \\
& -\xi_{E, N}\left(N_{a v}+N_{c v}+N_{a p}+N_{c p}+N_{p, 1}+N_{c u b}+N_{p, 2}+N_{q, 1}+\psi_{o} \cdot N_{q, 2}\right)=0
\end{aligned}
$$

$N_{a v} \quad$ : esfuerzo axil debido al peso propio del acero de las vigas mixtas de los forjados y de la cubierta

$N_{c v} \quad$ : esfuerzo axil debido al peso propio del hormigón de las vigas mixtas de los forjados y de la cubierta

$N_{a p} \quad$ : esfuerzo axil debido al peso propio del acero del pilar mixto

$N_{c p} \quad$ : esfuerzo axil debido al peso propio del hormigón del pilar mixto

$A_{c} \quad$ : área de la sección de hormigón del pilar mixto

\subsubsection{Elementos de madera laminada encolada}

\section{Vigas}

Las funciones de estado límite para las vigas de madera laminada encolada, en principio, deberían representarse distinguiendo entre vigas de planta y cubierta, como en el caso de las vigas de acero estructural (Apartado 5.4.2). No obstante, igual que en los Apartados 5.4.3 y 5.4.4, relativos a los elementos de hormigón y mixtos, respectivamente, para aligerar el texto se reflejan únicamente las funciones de estado límite para las vigas de planta de madera. De ellas se pueden deducir inmediatamente las funciones para las vigas de cubierta, teniendo en cuenta los efectos de las acciones relevantes (Apartado 5.3.4): su peso propio, el peso propio de los elementos resistentes y no resistentes de la cubrición, las cargas permanentes debidas a falsos techos e instalaciones, y la carga de nieve.

La función de estado límite para la sección del centro de vano de una viga de planta de madera laminada encolada se representa mediante la ecuación (5.19):

$$
\xi_{R, M} \cdot W_{e l} \cdot k_{h} \cdot k_{\text {mod }} \cdot f_{m, g}-\xi_{E, M} \cdot\left(M_{g}+M_{p, 1}+\left(M_{q, 1}+M_{Q, 1}\right)\right)=0
$$

$M_{g} \quad$ : momento flector debido al peso propio de la viga de madera laminada encolada

$W_{e l} \quad:$ módulo elástico de la sección transversal en el centro del vano

$f_{m, g} \quad$ : resistencia a flexión de la madera laminada encolada

Para la sección de apoyo de una viga de planta de madera laminada encolada se considera la siguiente función de estado límite: 


$$
\xi_{R, V} \cdot A \cdot \frac{1}{1,5} \cdot k_{\mathrm{mod}} \cdot f_{v, g}-\xi_{E, V} \cdot\left(V_{g}+V_{p, 1}+\left(V_{q, 1}+V_{Q, 1}\right)\right)=0
$$

$V_{g} \quad$ : esfuerzo cortante debido al peso propio de la viga de madera laminada encolada

$f_{v, g} \quad$ : resistencia a cortante de la madera laminada encolada

\section{Pilares}

La función de estado límite para la sección transversal en la base de un pilar de madera laminada encolada, solicitado por un esfuerzo axil de compresión simple, se expresa en los términos de la ecuación (5.21):

$$
\xi_{R, N} \cdot A \cdot k_{\text {mod }} \cdot f_{c, 0, g}-\xi_{E, N}\left(N_{g v}+N_{g p}+N_{p, 1}+N_{c u b}+N_{p, 2}+N_{q, 1}+\psi_{o} \cdot N_{q, 2}\right)=0
$$

$N_{g v} \quad$ : esfuerzo axil debido al peso propio de las vigas de madera laminada encolada de los

forjados y de la cubierta

$N_{g p} \quad$ : esfuerzo axil debido al peso propio del pilar de madera laminada encolada

$f_{c, 0, g} \quad$ : resistencia a compresión paralela a la fibra de la madera laminada encolada

\subsection{OBSERVACIONES FINALES}

Es objeto del presente capítulo la elaboración de las bases e hipótesis para el desarrollo tanto de los modelos destinados a la evaluación de los riesgos para las personas, asociados con las estructuras de edificación, como de los correspondientes criterios de aceptación. Siguiendo el procedimiento establecido previamente (Apartado 4.5), en el Apartado 5.2 se definen los tipos de estructuras a estudiar en cuanto a sus sistemas estáticos, elementos resistentes y materiales de construcción. Se consideran estructuras constituidas por vigas y pilares isostáticos, hipótesis que se justifica por tratarse de una elección realista a la vista de la práctica habitual, por ejemplo en soluciones con elementos prefabricados, y por el hecho de que la consideración de estructuras hiperestáticas conduciría a una subestimación del nivel aceptable de los riesgos, sobre todo si su comportamiento es dúctil, tal y como se demuestra en el Apartado 5.2.2. Se asume, además, que estos sistemas sean intraslacionales, lo que en la práctica se puede asegurar a través de medidas conceptuales sencillas, por lo que también esta hipótesis es realista (Apartado 5.2.1).

Los conjuntos representativos de sistemas y elementos estructurales, respectivamente, se determinan variando, dentro de unos límites realistas y suficientemente amplios, y combinando los parámetros más relevantes, tanto para el dimensionado como desde el punto de vista de las características de las estructuras (Apartado 5.2.1). Estos parámetros se refieren a la geometría del edificio (proporciones; longitud; anchura; altura; número de plantas; luz de las vigas; separación de los pórticos), las acciones (cargas permanentes; sobrecargas; cargas de nieve), así como el material constitutivo (acero estructural; hormigón armado; mixto de acero y hormigón; madera laminada encolada) y su tipo (que en muchos casos está asociado con un determinado valor de la resistencia). Por otro lado, el peso propio de las estructuras resulta del dimensionado estricto (Apartado 4.4), no es un parámetro de elección.

En el Apartado 5.3 se seleccionan los valores numéricos a considerar para cada uno de los parámetros sometidos a variación. Estos valores y su justificación se representan por separado para los diferentes materiales constitutivos. Su combinación conduce a un conjunto representativo de $\mathbf{1 0 . 8 7 2}$ diferentes sistemas estructurales de edificios pertenecientes a la clase de consecuencias CC2, según la definición del Eurocódigo [EN 1990 2002], y 8.136 de la clase CC3. La Tabla 5.6 refleja el reparto de estos sistemas entre los diferentes materiales constitutivos considerados. Los edificios tienen superficies útiles que oscilan entre $200 \mathrm{~m}^{2}$ y $990.000 \mathrm{~m}^{2}$. En la clase CC3 se consideran edificios con un máximo de 10 plantas (5 para las estructuras de madera laminada encolada), sin 
contar planta baja ni cubierta, mientras que en la clase CC2 los edificios tienen un máximo de 30 plantas (10 para estructuras de madera), además de planta baja y cubierta. El número mínimo de elementos estructurales por sistema es de 6, mientras que el número máximo alcanza los 40.931 elementos.

Por otro lado, el conjunto representativo de diferentes elementos estructurales engloba 944 vigas de cubierta, 1.770 vigas de planta y 116.232 pilares. También para este conjunto, la Tabla 5.6 contiene el reparto entre los diferentes materiales constitutivos.

Tabla 5.6 - Número de estructuras y de elementos estructurales seleccionados.

\begin{tabular}{|l|c|c|c|c|c|}
\hline \multirow{2}{*}{ Material constitutivo } & \multicolumn{3}{|c|}{$\mathbf{N}^{\mathbf{0}}$ de elementos } & \multicolumn{2}{c|}{$\mathbf{N}^{\mathbf{0}}$ de estructuras } \\
& Vigas & Pilares & Clase CC2 & Clase CC3 \\
\hline Acero estructural & 144 & 270 & 12.168 & 2.256 & 1.680 \\
\hline Hormigón armado & 240 & 450 & 22.320 & 2.256 & 1.680 \\
\hline Mixto de acero y hormigón & 480 & 900 & 76.464 & 4.704 & 3.840 \\
\hline Madera laminada encolada & 80 & 150 & 5.280 & 1.656 & 936 \\
\hline Total & $\mathbf{9 4 4}$ & $\mathbf{1 . 7 7 0}$ & $\mathbf{1 1 6 . 2 3 2}$ & $\mathbf{1 0 . 8 7 2}$ & $\mathbf{8 . 1 3 6}$ \\
\hline
\end{tabular}

En el Apartado 5.3 se explican también las medidas necesarias para evitar los posibles mecanismos de inestabilidad en las vigas y los pilares de los diferentes materiales constitutivos. Estas medidas suelen ser de carácter conceptual y de fácil puesta en obra, por lo que es razonable asumir que en la práctica se adopten con frecuencia. Además, no hay indicios de que la no consideración de casos en los que se puedan producir los diferentes fenómenos de inestabilidad conduzca a un sesgo en los resultados finales de este estudio (Apartado 5.4.1). Y en cualquier caso, si se produjera, se trataría de una subestimación de los riesgos admisibles, ya que las incertidumbres asociadas con los modelos de resistencia en caso de inestabilidad tendencialmente son mayores que para los modelos de resistencia de las secciones, por lo que conllevan mayores probabilidades de fallo.

Según las especificaciones anteriores, los fallos de las secciones más solicitadas por momentos flectores, esfuerzos cortantes y esfuerzos axiles de compresión, respectivamente, son los mecanismos de colapso más representativos para las vigas y los pilares de las estructuras seleccionadas. Las correspondientes funciones de estado límite se establecen teniendo en cuenta los respectivos Eurocódigos para las bases de proyecto, las acciones y la resistencia de los elementos estructurales constituidos por diferentes materiales. Se recuerda que para los mecanismos de fallo considerados y las hipótesis adoptadas, las normas españolas equivalentes a los Eurocódigos conducen a las mismas funciones de estado límite. Estas funciones están representadas por las ecuaciones (5.7) a (5.21), agrupadas según el material constitutivo de los elementos estructurales (Apartado 5.4). 


\section{DEDUCCIÓN DE MODELOS PROBABILISTAS}

\subsection{INTRODUCCIÓN}

Según el enfoque adoptado en el marco del presente estudio (Capítulo 4), los riesgos aceptables para las personas dependen del nivel de fiabilidad implícito en las normas empleadas en el dimensionado de las estructuras de edificación, que a su vez depende del nivel de incertidumbre asociado con las reglas de estas normas. En el Apartado 4.1 se argumenta que una de las principales dificultades planteadas por este enfoque reside en el hecho de que las normas actuales para el dimensionado estructural no establecen explícitamente estas incertidumbres. Por ello se identifica como uno de los desarrollos necesarios la cuantificación de las incertidumbres asociadas con las reglas normalizadas. Concretamente, se trata del Paso 4 del procedimiento establecido en el Apartado 4.5. Este paso consiste en la deducción de los modelos probabilistas para las variables que intervienen en las funciones de estado límite establecidas en el Apartado 5.4. En el presente capítulo, cuya estructura está resumida a continuación, se describen las tareas abordadas en este contexto.

En el Apartado 6.2 se establecen, a efectos del presente estudio, las características más adecuadas para los modelos probabilistas destinados a cuantificar las incertidumbres asociadas con las variables básicas. Para que estos modelos sean aptos para aplicaciones prácticas y conduzcan a resultados racionales, deben cumplir unos requisitos específicos que se definen en el mismo apartado.

La cuantificación de las incertidumbres asociadas con las reglas de las normas actuales para el dimensionado estructural implica comparar las incertidumbres representadas por los modelos probabilistas para las distintas variables básicas con las implícitamente cubiertas mediante el método de los coeficientes parciales empleado en las mismas normas. Esta comparación, a su vez, requiere una representación consistente del formato de coeficientes parciales empleado en el conjunto de las normas analizadas. En el Apartado 6.3 se adopta un formato de coeficientes parciales que facilita esta comparación y que es compatible con los formatos adoptados tanto en los Eurocódigos para las bases de proyecto, las acciones y la resistencia de los elementos estructurales constituidos por diferentes materiales, como en las normas españolas equivalentes.

A través de tres ejemplos se ilustra la deducción de los modelos probabilistas según el procedimiento establecido (Apartado 4.5). Se trata de los modelos para, respectivamente, las cargas de nieve (Apartado 6.4), el límite elástico del acero estructural (Apartado 6.5) y los coeficientes para las incertidumbres de los modelos de resistencia de los elementos de acero (Apartado 6.6). Los ejemplos cubren por tanto todo el abanico de diferentes variables, respectivamente las relativas a las acciones, la resistencia y las imprecisiones de los modelos.

Procediendo de la misma manera, se deducen los modelos probabilistas para todas las variables que intervienen en las funciones de estado límite, necesarios para la continuación del trabajo. Los resultados obtenidos se resumen en el Apartado 6.7.

Finalmente, el Apartado 6.8 contiene una serie de observaciones finales acerca del presente capítulo, dentro del contexto de todo el estudio.

\subsection{VARIABLES ALEATORIAS}

\subsubsection{Representación de las incertidumbres}

Una estructura de ingeniería civil se suele modelar en términos matemático-físicos, en combinación con unas relaciones empíricas. Mediante modelos de este tipo se pueden estimar las prestaciones del 
sistema considerado para un determinado conjunto de los parámetros que intervienen en el problema. Estos parámetros o variables deben tener en cuenta todos los tipos de incertidumbres, asociadas con los datos de entrada de los modelos, que puedan influir en el análisis (Apartado 3.2). Son estas incertidumbres que es necesario cuantificar a efectos del presente estudio (Apartado 4.1).

Los métodos modernos de fiabilidad estructural y de análisis de riesgos permiten representaciones muy variadas de las incertidumbres asociadas con las variables básicas que abarcan desde procesos estocásticos no estacionarios hasta variables aleatorias consideradas invariables en el tiempo. En la mayoría de los casos, es suficiente modelar las cantidades inciertas a través de variables aleatorias, caracterizadas por unas determinadas funciones de distribución, así como los denominados parámetros de la distribución. Por este motivo, para cada variable, $X_{i}$, se debe determinar, en el marco del presente trabajo, un modelo probabilista, definido por una función de distribución estadística, su valor medio, $\mu_{x i}$, y su desviación típica, $\sigma_{x i}$.

\subsubsection{Requisitos para los modelos}

Para la determinación sistemática de los modelos probabilistas requeridos, se procede según lo especificado en el Apartado 4.5. En términos generales, los modelos probabilistas a deducir para las acciones y sus efectos, así como las resistencias correspondientes de los elementos estructurales, deben cumplir con los siguientes requisitos:

- aptitud para aplicaciones prácticas, representando las incertidumbres mediante variables aleatorias;

- representación de las características físicas de la variable correspondiente;

- consistencia con los modelos probabilistas del código modelo probabilista [JCSS 2001];

- representación del estado de incertidumbre asociado con las reglas de la normativa en vigor.

A efectos de la representación de una variable se emplea la siguiente notación: $X_{i}=$ Tipo $\left(\mu_{x i} ; \sigma_{x i}\right)$. De manera equivalente, el valor medio y la desviación típica también pueden representarse a través de los denominados coeficientes de sesgo y de variación, respectivamente, de modo que la notación sería: $X_{i}$ $=$ Tipo $($ Sesgo; $\mathrm{CoV})$. El coeficiente de sesgo es la ratio entre el valor medio y el valor representativo de una variable, mientras que el coeficiente de variación es la ratio entre su desviación típica y su valor medio. En comparación con la primera notación, la segunda tiene la ventaja de ser adimensional, por lo que se emplea con frecuencia a efectos prácticos.

Para las distribuciones de las diferentes variables se adoptan, en general, los tipos sugeridos en el código modelo probabilista [JCSS 2001]. Esta elección se debe a la circunstancia de que resulta recomendable utilizar siempre las mismas distribuciones para las variables. Efectivamente, en ingeniería civil suelen interesar probabilidades muy pequeñas, y éstas se deberían interpretar comparativamente. Obviamente, las comparaciones requieren que las hipótesis básicas se mantengan sin variar.

\subsection{VERIFICACIÓN DE LA SEGURIDAD ESTRUCTURAL}

\subsubsection{Formato de los coeficientes parciales}

\section{Generalidades}

El Capítulo 3 recoge los principios del método de los coeficientes parciales, así como su relación con los métodos probabilistas, que son necesarios para llevar a cabo el presente estudio y, en particular, para la deducción de los modelos probabilistas para las variables relevantes que cumplan con los requisitos establecidos (Apartado 6.2.2). En el mismo capítulo también se recopilan las hipótesis 
relativas a la aplicación de los métodos de los coeficientes parciales en el marco del Eurocódigo [EN 1990 2002] y, por extensión, la normativa española [CTE DB SE 2006]: los índices de fiabilidad requeridos y los valores numéricos para los factores de sensibilidad.

Según los Eurocódigos y las normas españolas equivalentes, una estructura, un elemento o una unión entre elementos se considera fiable si cumple la siguiente condición para todas las situaciones relevantes:

$$
E_{d} \leq R_{d}
$$

$E_{d} \quad:$ valor de cálculo de los efectos de las acciones e influencias

$R_{d} \quad$ : valor de cálculo de la resistencia correspondiente

A continuación, se representa el formato de los coeficientes parciales adoptado por la norma española [CTE DB SE 2006] para la determinación de los valores de cálculo de los efectos de las acciones y de la resistencia. Se trata de uno de los varios formatos propuestos en el Eurocódigo [EN 1990 2002]. Además, se establece un formato alternativo, equivalente al anterior, que tiene en cuenta los diferentes orígenes de las incertidumbres cubiertas por un determinado coeficiente parcial. Este desglose facilita la deducción de los modelos probabilistas requeridos, por lo que se emplea a efectos del presente estudio.

\section{Valor de cálculo de los efectos de las acciones e influencias}

De acuerdo con la norma [CTE DB SE 2006] el valor de cálculo de los efectos de las acciones correspondientes a una situación persistente o transitoria se determina según la siguiente relación:

$$
E_{d}=E\left\{\sum_{j \geq 1} \gamma_{G, j} \cdot G_{k, j} "+" \gamma_{P} \cdot P^{\prime \prime}+" \gamma_{Q, 1} \cdot Q_{k, 1} "+" \sum_{i>1} \gamma_{Q, i} \cdot \psi_{0, i} \cdot Q_{k, i}\right\}
$$

$G_{k, j} \quad$ : valor característico de la acción permanente $j$

$P \quad:$ valor representativo de la acción del pretensado

$Q_{k, 1} \quad:$ valor característico de la acción variable dominante

$Q_{k, i} \quad$ : valor característico de la acción variable concomitante $i$

$\gamma_{G, j} \quad$ : coeficiente parcial para la acción permanente $j$

$\gamma_{P} \quad:$ coeficiente parcial para la acción del pretensado

$\gamma_{Q, 1} \quad:$ coeficiente parcial para la acción variable dominante

$\gamma_{Q, i} \quad$ : coeficiente parcial para la acción variable concomitante $i$

$\psi_{0, i} \quad:$ coeficiente para el valor de combinación de la acción variable $i$

"+" : implica "a ser combinado con"

$\Sigma \quad$ : implica "el efecto combinado de"

De acuerdo con [EN 1990 2002], la ecuación (6.2) equivale a:

$$
E_{d}=\gamma_{S d} \cdot E\left\{\sum_{j \geq 1} \gamma_{g, j} \cdot G_{k, j} "+" \gamma_{p} \cdot P^{\prime \prime}+" \gamma_{q, 1} \cdot Q_{k, 1} "+" \sum_{i>1} \gamma_{q, i} \cdot \psi_{0, i} \cdot Q_{k, i}\right\}
$$

Esta representación es similar a la reflejada en la ecuación (3.22) y para los coeficientes parciales se puede escribir, en términos generales:

$\gamma_{F, i}=\gamma_{S d} \cdot \gamma_{f, i}$

Para la acción, $i$, el coeficiente parcial, $\gamma_{f, i}$, tiene en cuenta la variación estadística de su valor. En otras palabras, el coeficiente tiene en cuenta la posibilidad de desviaciones desfavorables entre el valor de la acción y su valor representativo. 
El coeficiente parcial para los modelos, $\gamma_{S d}$, tiene en cuenta las incertidumbres asociadas con el modelo empleado para la determinación de los efectos de las acciones. En algunos casos también tiene en cuenta las incertidumbres asociadas con el modelo de las acciones.

Debido a que las incertidumbres del modelo varían en función de los efectos de las acciones a determinar, su valor de cálculo se establece en el marco del presente estudio según las ecuaciones (6.5), (6.6) y (6.7), respectivamente para momentos flectores, esfuerzos cortantes y esfuerzos axiles. Esta distinción difiere del formato del Eurocódigo [EN 1990 2002] y del Código Técnico de la Edificación [CTE DB SE 2006], pero permite una mayor precisión en la deducción de los modelos probabilistas de las variables, objeto del presente capítulo, sin entrar en conflicto con estas normas:

$$
\begin{aligned}
& M_{E d}=\gamma_{S d, M} \cdot M_{E}\left\{\sum_{j \geq 1} \gamma_{g, j} \cdot G_{k, j} "+" \gamma_{p} \cdot P^{\prime \prime}+" \gamma_{q, 1} \cdot Q_{k, 1} "+\sum_{i>1} \gamma_{q, i} \cdot \psi_{0, i} \cdot Q_{k, i}\right\} \\
& V_{E d}=\gamma_{S d, V} \cdot V_{E}\left\{\sum_{j \geq 1} \gamma_{g, j} \cdot G_{k, j} "+" \gamma_{p} \cdot P^{\prime \prime}+" \gamma_{q, 1} \cdot Q_{k, 1} "+" \sum_{i>1} \gamma_{q, i} \cdot \psi_{0, i} \cdot Q_{k, i}\right\} \\
& N_{E d}=\gamma_{S d, N} \cdot N_{E}\left\{\sum_{j \geq 1} \gamma_{g, j} \cdot G_{k, j} "+" \gamma_{p} \cdot P^{\prime \prime}+" \gamma_{q, 1} \cdot Q_{k, 1} "+" \sum_{i>1} \gamma_{q, i} \cdot \psi_{0, i} \cdot Q_{k, i}\right\}
\end{aligned}
$$

$M_{E} \quad:$ momento flector

$N_{E} \quad$ : esfuerzo axil

$V_{E} \quad$ : esfuerzo cortante

$M_{E d} \quad:$ valor de cálculo del momento flector

$N_{E d} \quad:$ valor de cálculo del esfuerzo axil

$V_{E d} \quad:$ valor de cálculo del esfuerzo cortante

$\gamma_{S d, M} \quad$ : coeficiente parcial para el modelo empleado en la determinación de los momentos flectores

$\gamma_{S d, N} \quad:$ coeficiente parcial para el modelo empleado en la determinación de los esfuerzos axiles

$\gamma_{S d, V} \quad$ : coeficiente parcial para el modelo empleado en la determinación de los esfuerzos cortantes

\section{Valor de cálculo de la resistencia}

En la notación del Eurocódigo [EN 1990 2002] y de la normativa española [CTE DB SE 2006], el formato de los coeficientes parciales para la determinación del valor de cálculo de la resistencia de los elementos estructurales se puede representar de la siguiente manera:

$$
R_{d}=\frac{R_{k}}{\gamma_{M}}
$$

$R_{k} \quad$ : valor característico de la resistencia

$\gamma_{M} \quad:$ coeficiente parcial para la resistencia

El coeficiente parcial para la resistencia, $\gamma_{M}$, debe tener en cuenta las siguientes incertidumbres:

- variación estadística de la propiedad del material;

- la parte aleatoria del factor de conversión de la propiedad del material;

- las desviaciones de las dimensiones geométricas;

- las incertidumbres asociadas con el modelo de resistencia.

Según las mismas normas [EN 1990 2002] y [CTE DB SE 2006], y en analogía con la ecuación (3.23), el coeficiente parcial, $\gamma_{M}$, se puede desglosar:

$\gamma_{M}=\gamma_{R d} \cdot \gamma_{m}$ 
Por otro lado, el factor de conversión de una propiedad de un material, $\eta_{i}$, tiene en cuenta las diferencias entre las condiciones de los ensayos empleados para determinar esta propiedad y las condiciones de la estructura real. A título de ejemplo se pueden mencionar influencias tales como los efectos de volumen, escala, humedad o temperatura [EN 1990 2002]. Este factor, $\eta_{i}$, incluido implícitamente en $R_{k}$ o $\gamma_{M}$ según la ecuación (6.8), se puede tener en cuenta explícitamente. Consecuentemente, en términos generales, el valor de cálculo de la resistencia de un elemento estructural se escribe:

$$
R_{d}=\frac{1}{\gamma_{R d}} \cdot R\left\{\eta_{i} \cdot \frac{X_{k, i}}{\gamma_{m, i}} ; a_{d}\right\} i \geq 1
$$

$X_{k, i} \quad:$ valor característico de la propiedad del material $i$

$a_{d} \quad:$ valor de cálculo de una dimensión geométrica

$\eta_{i} \quad:$ valor medio del factor de conversión de la propiedad del material $i$

Para la propiedad del material, $i$, el coeficiente parcial, $\gamma_{m, i}$, tiene en cuenta las siguientes incertidumbres:

- variación estadística de la propiedad del material;

- en su caso, la parte aleatoria del factor de conversión de la misma propiedad.

El factor de conversión se considera a menudo como siendo determinista. Eso es particularmente el caso si la propiedad considerada es la resistencia del material frente a tensiones normales o tangenciales, respectivamente. Por este motivo, en el presente estudio $\gamma_{m, i}$ no tiene en cuenta ninguna parte aleatoria correspondiente a $\eta_{i}$.

Por lo demás, el coeficiente parcial para el modelo de resistencia, $\gamma_{R d}$, tiene en cuenta:

- incertidumbres asociadas con el modelo de resistencia;

- desviaciones de las dimensiones geométricas, en caso de que éstas no se consideren de manera explícita.

Para los elementos estructurales constituidos por un determinado material, las incertidumbres del modelo y las desviaciones geométricas dependen del mecanismo de resistencia contemplado. Por este motivo, se establecen unas expresiones específicas para la determinación del valor de cálculo de la resistencia de las secciones frente a, respectivamente, momentos flectores, esfuerzos cortantes y esfuerzos axiles de compresión. En analogía con los diferentes tipos de esfuerzos (ecuaciones (6.5) a (6.7)), en estas expresiones se introducen diferentes coeficientes parciales para los modelos de resistencia específicos (Apartados 6.3.2 a 6.3.5). También en este caso, la mencionada distinción difiere del formato adoptado en los Eurocódigos y las normas españolas equivalentes para la resistencia de los elementos estructurales, sin que se produzca una pérdida de compatibilidad.

\section{Observaciones finales}

Las ecuaciones (6.5) a (6.7) para el valor de cálculo de los efectos de las acciones, y la (6.10) para el valor de cálculo de la resistencia, representan de manera consistente el formato de verificación empleado en el conjunto de las normas analizadas: los Eurocódigos para las bases de proyecto, las acciones y la resistencia de los elementos estructurales, así como las normas españolas correspondientes. Formalmente, la representación de los efectos de las acciones es de aplicación para cualquier tipo de material constitutivo, con la salvedad de que este conducirá a diferentes notaciones para el peso propio de los elementos estructurales. Para los valores de cálculo de la resistencia, aunque la ecuación (6.10) sea de carácter general, son necesarias diferentes ecuaciones en función del material constitutivo de los elementos estructurales y del mecanismo de resistencia considerados. Estas ecuaciones, basadas en las reglas de los relevantes Eurocódigos y las normas españolas correspondientes, se representan en los Apartados 6.3.2 a 6.3.5 para los elementos de, 
respectivamente, acero estructural, hormigón armado, mixtos de acero y hormigón, así como madera laminada encolada. Son estas ecuaciones que se usan después, en combinación con las ecuaciones (6.5) a (6.7) para el valor de cálculo de los correspondientes efectos de las acciones, con el fin de deducir los modelos probabilistas para las diferentes variables, siguiendo el procedimiento del Apartado 4.5.

\subsubsection{Resistencia de los elementos de acero}

\section{Momentos flectores}

El valor de cálculo de la resistencia frente a momentos flectores de la sección transversal de una viga de acero estructural se puede expresar en los siguientes términos:

$$
M_{R d}=\frac{1}{\gamma_{R d, M}} \cdot W_{p l} \cdot \frac{f_{y k}}{\gamma_{m 0, M}}
$$

$\gamma_{m 0, M} \quad$ : coeficiente parcial para el límite elástico del acero estructural en elementos solicitados por momentos flectores

$\gamma_{R d, M}$

: coeficiente parcial para el modelo de resistencia frente a momentos flectores

En función de la clase de la sección transversal [EN 1993-1-1 2005, EAE 2011], el módulo se debería determinar según la teoría plástica, elástica o para una sección reducida. No obstante, en concordancia con las consideraciones del Apartado 5.3.1, se adoptan las medidas necesarias para evitar los posibles mecanismos de inestabilidad, por lo que se considera el módulo plástico de la sección transversal, $W_{p l}$.

El coeficiente parcial para la resistencia del material, $\gamma_{m 0, M}$, tiene en cuenta la variación estadística del límite elástico del acero estructural en elementos solicitados por momentos flectores. Por otro lado, el coeficiente parcial para el modelo de resistencia, $\gamma_{R d, M}$, tiene en cuenta las incertidumbres asociadas con el modelo de resistencia frente a momentos flectores, así como las imprecisiones relativas al módulo de la sección.

\section{Esfuerzos cortantes}

Asumiendo que se adopten las medidas necesarias para poder excluir posibles fenómenos de inestabilidad por abolladura (Apartado 5.3.1), el valor de cálculo de la resistencia frente a esfuerzos cortantes de la sección transversal de una viga se obtiene mediante la expresión:

$V_{R d}=\frac{1}{\gamma_{R d, V}} \cdot A_{V} \cdot \frac{f_{y w, k} / \sqrt{3}}{\gamma_{m 0, V}}$

$f_{y w, k} \quad:$ valor característico del límite elástico del acero estructural del área de cortante

$\gamma_{m 0, V} \quad:$ coeficiente parcial para el límite elástico del acero estructural frente a tensiones tangenciales

$\gamma_{R d, V} \quad$ : coeficiente parcial para el modelo de resistencia frente a esfuerzos cortantes

En las vigas con una sección transversal en doble $\mathrm{T}$ en la que se evite la abolladura, el área de cortante corresponde al área del alma de la sección, $A_{V}$. El coeficiente parcial para la resistencia del material, $\gamma_{m 0, V}$, tiene en cuenta la variación estadística del límite elástico del acero estructural frente a tensiones tangenciales. El coeficiente parcial para el modelo de resistencia, $\gamma_{R d, V}$, cubre las incertidumbres asociadas con el modelo de resistencia frente a esfuerzos cortantes, así como las imprecisiones relativas al área de cortante de la sección transversal. 


\section{Esfuerzos axiles de compresión}

Como en los casos anteriores, según las hipótesis del Apartado 5.3.1 están excluidos los fenómenos de inestabilidad. El valor de cálculo de la resistencia frente a esfuerzos axiles de compresión de la sección transversal de un pilar se determina por ello según la expresión:

$N_{R d}=\frac{1}{\gamma_{R d, N}} \cdot A \cdot \frac{f_{y k}}{\gamma_{m 0, N}}$

$\gamma_{m 0, N} \quad$ : coeficiente parcial para el límite elástico del acero estructural en elementos solicitados por esfuerzos axiles

$\gamma_{R d, N} \quad$ : coeficiente parcial para el modelo de resistencia frente a esfuerzos axiles

Debido a que no se producen fenómenos de inestabilidad, se puede tener en cuenta el área bruta de la sección transversal, $A$. El coeficiente parcial para la resistencia del material, $\gamma_{m 0, N}$, tiene en cuenta la variación estadística del límite elástico del acero estructural en elementos solicitados por esfuerzos axiles. Por otro lado, el coeficiente parcial para el modelo de resistencia, $\gamma_{R d, N}$, tiene en cuenta las incertidumbres asociadas con el modelo de resistencia frente a esfuerzos axiles, y las imprecisiones relativas al área de la sección transversal.

\subsubsection{Resistencia de los elementos de hormigón armado}

\section{Momentos flectores}

Asumiendo un diagrama rectangular para la resistencia a compresión del hormigón, el valor de cálculo de la resistencia frente a momentos flectores de la sección transversal de una viga de hormigón armado se puede expresar en los siguientes términos:

$$
M_{R d}=\frac{1}{\gamma_{R d, M}} \cdot\left(\frac{A_{s} \cdot f_{s k}}{\gamma_{s}} \cdot d-0,5 \cdot\left(\frac{A_{s} \cdot f_{s k}}{\gamma_{s}}\right)^{2} \cdot \frac{\gamma_{c}}{\eta_{c} \cdot f_{c k}} \cdot \frac{1}{b_{c}}\right)
$$

$\gamma_{s} \quad:$ coeficiente parcial para la resistencia de la armadura

$\gamma_{c} \quad:$ coeficiente parcial para la resistencia del hormigón

El coeficiente parcial para la resistencia de la armadura, $\gamma_{s}$, tiene en cuenta las incertidumbres relativas al límite elástico del material y las relativas al área de la sección de acero. Por el contrario, el coeficiente parcial para la resistencia del hormigón, $\gamma_{c}$, solo tiene en cuenta las incertidumbres relativas a la propiedad del material.

Aparte de las incertidumbres asociadas con el modelo de resistencia empleado, el coeficiente parcial para el modelo de resistencia frente a momentos flectores, $\gamma_{R d, M}$, también tiene en cuenta las desviaciones en las dimensiones geométricas. Concretamente, las relativas a canto útil y ancho de la sección.

Para vigas con las características consideradas en el marco del presente estudio (Apartado 5.3.2), se puede asumir un valor de $\eta_{c}=1,0$ para el factor de conversión de la resistencia del hormigón en las bielas con un estado de compresión uniaxial. Esta hipótesis está en concordancia con las recomendaciones tanto del Eurocódigo [EN 1992-1-1 2004] como de la normativa española [EHE-08 2008].

\section{Esfuerzos cortantes}

En el caso de los esfuerzos cortantes, se distingue entre la resistencia frente a, respectivamente, tracción y compresión oblicua en el alma. A efectos de la deducción de los modelos probabilistas requeridos, se contempla el caso de los elementos con armadura de cortante. De esta manera, el 
análisis engloba todas las variables para las que se deben determinar los modelos probabilistas. Adicionalmente, se adoptan las siguientes simplificaciones:

- La armadura de cortante se dispone perpendicularmente al eje del elemento.

- La armadura de cortante se determina sobre la base de la teoría de los campos de tensiones [Muttoni 1997], sin tener en cuenta la contribución del hormigón a la resistencia frente a los esfuerzos cortantes. Por los siguientes motivos, esta hipótesis es razonable. En primer lugar, para determinar las probabilidades de fallo asociadas con las reglas normalizadas, así como los riesgos admisibles para las estructuras de los edificios, fin último del presente trabajo, es necesario analizar elementos representativos dimensionados de manera estricta $\left(E_{d}=R_{d}\right)$. Por ello, la cuantía de armadura longitudinal es mínima y la contribución del hormigón escasa. En segundo lugar, para situaciones próximas a un colapso y, por tanto, para deformaciones unitarias avanzadas, la contribución del hormigón también es reducida.

- Para los campos de tensión en el hormigón se admite una inclinación de $45^{\circ}$ con respecto al eje del elemento.

De acuerdo con estas simplificaciones, los valores de cálculo de la resistencia frente a tracción en el alma, $V_{R d, s}$, y compresión oblicua en el alma, $V_{R d, c}$, se pueden expresar de acuerdo con las ecuaciones (6.15) y (6.16), respectivamente:

$$
V_{R d, s}=\frac{1}{\gamma_{R d, V_{s}}} \cdot\left(\frac{A_{s w} \cdot f_{s k}}{\gamma_{s}} \cdot 0,9 \cdot d\right)
$$

$\gamma_{R d, V s} \quad:$ coeficiente parcial para el modelo de resistencia frente a esfuerzos de tracción en el alma

$$
V_{R d, c}=\frac{1}{\gamma_{R d, V_{c}}} \cdot\left(b_{A} \cdot d \cdot \frac{\eta_{c} \cdot f_{c k}}{\gamma_{c}} \cdot 0,5\right)
$$

$\gamma_{R d, V c} \quad$ : coeficiente parcial para el modelo de resistencia frente a esfuerzos de compresión oblicua en el alma

El coeficiente parcial para la resistencia de la armadura pasiva, $\gamma_{s}$, tiene en cuenta las incertidumbres relativas al límite elástico del acero y el área de la sección de la armadura de cortante. Por otro lado, el coeficiente parcial para la resistencia del hormigón, $\gamma_{c}$, tiene en cuenta las incertidumbres relativas a la propiedad del material.

El coeficiente parcial para el modelo de resistencia frente a esfuerzos de tracción en el alma, $\gamma_{R d, V s}$, cubre las incertidumbres asociadas con el modelo de resistencia empleado, así como las desviaciones relativas a la geometría, particularmente el brazo, para el que se admite un valor de $0,9 \cdot d$. En analogía, el coeficiente parcial para el modelo de resistencia frente a esfuerzos de compresión oblicua en el alma, $\gamma_{R d, V c}$, tiene en cuenta tanto las incertidumbres del modelo de resistencia como las desviaciones en las dimensiones geométricas. Estas últimas se refieren al canto útil y el espesor del alma. Por los siguientes motivos se consideran distintos coeficientes parciales para el modelo de resistencia:

- Los coeficientes $\gamma_{R d, V s}$ y $\gamma_{R d, V c}$ se refieren a, respectivamente, la plastificación de la armadura de cortante y el agotamiento de la biela de compresión. Eso significa que están asociados con diferentes mecanismos de rotura.

- Para deformaciones unitarias avanzadas, próximas a un colapso, las incertidumbres asociadas con los dos mecanismos de rotura pueden ser diferentes. Suelen ser mayores para el modelo de resistencia de un campo de compresión atravesado por fisuras oblicuas que para el modelo de resistencia a tracción de la armadura. 
Para las vigas consideradas en el marco del presente estudio (Apartado 5.3.2), el factor de conversión de la resistencia del hormigón en los campos de compresión con una armadura oblicua con respecto al sentido de la compresión adopta un valor de $\eta_{c}=0,6$. Se trata del valor recomendado para las almas de las vigas de hormigón armado que se encuentra tanto en la literatura especializada [Muttoni 1997], como en la normativa actual [EN 1992-1-1 2004, EHE-08 2008].

\section{Esfuerzos axiles de compresión}

Teniendo en cuenta las hipótesis adoptadas en el Apartado 5.3.2 para los pilares, el valor de cálculo de su resistencia frente a esfuerzos axiles de compresión se puede expresar en los siguientes términos:

$$
N_{R d}=\frac{1}{\gamma_{R d, N}} \cdot\left(A_{c} \cdot \frac{\eta_{c} \cdot f_{c k}}{\gamma_{c}}+\frac{A_{s} \cdot f_{s k}}{\gamma_{s}}\right)
$$

El coeficiente parcial para la resistencia de la armadura pasiva, $\gamma_{s}$, tiene en cuenta las incertidumbres relativas al límite elástico del acero y el área de la sección de la armadura comprimida. Mientras, el coeficiente parcial para la resistencia del hormigón, $\gamma_{c}$, tiene en cuenta las incertidumbres relativas a la propiedad del material.

El coeficiente parcial para el modelo de resistencia frente a esfuerzos axiles de compresión, $\gamma_{R d, N}$, cubre las incertidumbres asociadas con el modelo de resistencia empleado. También tiene en cuenta las desviaciones en las dimensiones geométricas de la sección transversal, particularmente las relativas al área de la sección de hormigón.

Para los pilares con las características consideradas en el presente estudio (Apartado 5.3.2), el factor de conversión de la resistencia a compresión del hormigón tiene un valor de $\eta_{c}=1,0$ [EN 1992-1-1 2004, EHE-08 2008].

\subsubsection{Resistencia de los elementos mixtos de acero y hormigón}

\section{Momentos flectores}

El valor de cálculo de la resistencia frente a momentos flectores de la sección transversal de una viga mixta de acero y hormigón se expresa en los siguientes términos:

$$
M_{R d}=\frac{1}{\gamma_{R d, M}} \cdot\left(A_{a} \cdot \frac{f_{y k}}{\gamma_{a}} \cdot\left(\frac{h_{a}}{2}+h_{c}\right)-0,5 \cdot\left(A_{a} \cdot \frac{f_{y k}}{\gamma_{a}}\right)^{2} \cdot \frac{\gamma_{c}}{\eta_{c} \cdot f_{c k}} \cdot \frac{1}{b_{e f f}}\right)
$$

$\gamma_{a} \quad$ : coeficiente parcial para la resistencia del acero estructural

El coeficiente parcial para la resistencia del acero estructural, $\gamma_{a}$, tiene en cuenta la variación estadística del límite elástico del acero. De manera análoga, el coeficiente parcial para la resistencia del hormigón, $\gamma_{c}$, cubre la variación estadística de la resistencia a compresión del hormigón. Finalmente, el coeficiente parcial para el modelo de resistencia, $\gamma_{R d, M}$, tiene en cuenta las incertidumbres asociadas con el modelo de resistencia frente a momentos flectores, así como las desviaciones en las dimensiones geométricas. Estas últimas se refieren al área de la sección de acero y el brazo de palanca.

Para el factor de conversión de la resistencia a compresión del hormigón en vigas mixtas de las características consideradas en el presente estudio (Apartado 5.3.3), se adopta un valor de $\eta_{c}=0,85$ según el Eurocódigo relativo a las estructuras mixtas [EN 1994-1-1 2004]. 


\section{Esfuerzos cortantes}

La contribución de la losa de hormigón a la resistencia de una viga mixta frente a los esfuerzos cortantes suele ser despreciable. Por este motivo, el valor de cálculo correspondiente a este mecanismo de resistencia se determina para el perfil metálico [EN 1994-1-1 2004], en analogía con el Apartado 6.3.2 para las vigas de acero. La única diferencia con la ecuación (6.12) consiste en la notación empleada para el coeficiente parcial para la resistencia del acero estructural, al utilizar la equivalente a la que se usa también para los valores de cálculo de la resistencia de los elementos mixtos frente a otras solicitaciones:

$V_{R d}=\frac{1}{\gamma_{R d, V}} \cdot A_{V} \cdot \frac{f_{y w, k} / \sqrt{3}}{\gamma_{a}}$

El coeficiente parcial para la resistencia del acero estructural, $\gamma_{a}$, tiene en cuenta la variación estadística del límite elástico frente a tensiones tangenciales. El coeficiente parcial para el modelo de resistencia, $\gamma_{R d, V}$, también cubre las mismas incertidumbres que en el caso de las vigas de acero: las asociadas con el modelo de resistencia y las relativas al área de cortante.

\section{Esfuerzos axiles de compresión}

Al estar impedidos los fenómenos de inestabilidad según las hipótesis adoptadas (Apartado 5.3.3), el valor de cálculo de la resistencia frente a esfuerzos axiles de compresión de la sección transversal de un pilar mixto se determina mediante la expresión:

$$
N_{R d}=\frac{1}{\gamma_{R d, N}} \cdot\left(A_{a} \cdot \frac{f_{y k}}{\gamma_{a}}+A_{c} \cdot \frac{\eta_{c} \cdot f_{c k}}{\gamma_{c}}+A_{s} \cdot \frac{f_{s k}}{\gamma_{s}}\right)
$$

Los coeficientes parciales para la resistencia de los materiales, $\gamma_{a}, \gamma_{c}$ y $\gamma_{s}$, tienen en cuenta las variaciones estadísticas de, respectivamente, el límite elástico del acero estructural, la resistencia a compresión del hormigón y el límite elástico del acero de armar. El coeficiente parcial para el modelo de resistencia, $\gamma_{R d, N}$, tiene en cuenta las incertidumbres asociadas con el modelo de resistencia frente a esfuerzos axiles de compresión, así como las imprecisiones relativas a las áreas de las secciones transversales del acero estructural, hormigón y acero de armar.

Para los pilares mixtos con las características consideradas en el presente estudio (Apartado 5.3.3), el factor de conversión de la resistencia a compresión del hormigón tiene un valor de $\eta_{c}=0,85$ si están constituidos a partir de perfiles embebidos o parcialmente embebidos [EN 1994-1-1 2004]. Este valor se puede incrementar hasta $\eta_{c}=1,0$ en los casos en los que los pilares están constituidos por perfiles de sección cerrada, rellenos de hormigón. Aunque en el Apartado 5.3.3 no se adopta ninguna hipótesis sobre el tipo de la sección transversal de los pilares mixtos, en el marco del presente estudio se utiliza este último valor a efectos de cálculo.

\subsubsection{Resistencia de los elementos de madera laminada encolada}

\section{Momentos flectores}

En ausencia de fenómenos de inestabilidad tales como el pandeo lateral (Apartado 5.3.4), el valor de cálculo de la resistencia frente a momentos flectores de la sección transversal de una viga de madera laminada encolada se puede expresar en los siguientes términos:

$M_{R d}=\frac{1}{\gamma_{R d, M}} \cdot W_{e l} \cdot \frac{k_{h} \cdot k_{\mathrm{mod}} \cdot f_{m, g, k}}{\gamma_{m}}$ 
$\gamma_{m} \quad$ : coeficiente parcial para la resistencia de la madera laminada encolada

El coeficiente parcial para la resistencia de la madera laminada encolada, $\gamma_{m}$, tiene en cuenta la variación estadística de la resistencia de la madera en elementos solicitados por momentos flectores, así como la parte aleatoria de los factores de canto y de modificación, $k_{h}$ y $k_{m o d}$, respectivamente. El coeficiente parcial para el modelo de resistencia, $\gamma_{R d, M}$, tiene en cuenta las incertidumbres asociadas con el modelo de resistencia frente a momentos flectores, así como las imprecisiones relativas al módulo de la sección.

\section{Esfuerzos cortantes}

Teniendo en cuenta las hipótesis adoptadas en el Apartado 5.3.4 para las vigas de madera laminada encolada, el valor de cálculo de su resistencia frente a esfuerzos cortantes se obtiene mediante la expresión:

$$
V_{R d}=\frac{1}{\gamma_{R d, V}} \cdot \frac{A}{1,5} \cdot \frac{k_{\mathrm{mod}} \cdot f_{v, g, k}}{\gamma_{m}}
$$

Esta ecuación es el resultado de una interpretación del criterio del dimensionado estricto en términos de la teoría elástica, lo que es razonable para los elementos de madera. Según este enfoque, el valor de cálculo de la resistencia de la sección se determina igualando el valor de cálculo de las tensiones tangenciales en secciones rectangulares, $\tau_{E d}=1,5 \cdot \mathrm{V}_{\mathrm{Ed}} / A$, siendo $V_{E d}=V_{R d}$ para el caso del dimensionado estricto, con el valor de cálculo de la resistencia correspondiente de la madera laminada encolada, $k_{\text {mod }} f_{v, g, k} / \gamma_{m}$.

El coeficiente parcial para la resistencia de la madera laminada encolada, $\gamma_{m}$, tiene en cuenta la variación estadística de la resistencia de la madera en elementos solicitados por esfuerzos cortantes, así como la parte aleatoria del factor de modificación, $k_{\text {mod }}$. El coeficiente parcial para el modelo de resistencia, $\gamma_{R d, V}$, tiene en cuenta las incertidumbres asociadas con el modelo de resistencia frente a esfuerzos cortantes, así como las imprecisiones relativas al área de la sección.

\section{Esfuerzos axiles de compresión}

Asumiendo que los mecanismos de inestabilidad estén excluidos, particularmente el pandeo (Apartado 5.3.4), el valor de cálculo de la resistencia frente a esfuerzos axiles de compresión de la sección transversal de un pilar se obtiene mediante la siguiente expresión:

$$
N_{R d}=\frac{1}{\gamma_{R d, N}} \cdot A \cdot \frac{k_{\mathrm{mod}} \cdot f_{c, 0, g, k}}{\gamma_{m}}
$$

En analogía con los casos anteriores, el coeficiente parcial para la resistencia de la madera laminada encolada, $\gamma_{m}$, tiene en cuenta la variación estadística de la resistencia del material frente a la compresión paralela a la fibra, así como la parte aleatoria del factor de modificación, $k_{\text {mod }}$. El coeficiente parcial para el modelo de resistencia, $\gamma_{R d, N}$, tiene en cuenta las incertidumbres asociadas con el modelo de resistencia frente a esfuerzos axiles de compresión, así como las imprecisiones relativas al área de la sección. 


\subsection{CARGAS DE NIEVE}

\subsubsection{Introducción}

\section{Generalidades}

La distribución y la intensidad de la carga de nieve sobre una estructura en general y, en particular, sobre la cubierta de un edificio dependen de factores climatológicos, la topografía del terreno colindante, la cercanía de otros edificios u obstáculos, la forma y el emplazamiento de la obra, los efectos del viento, las características de la cubierta y los intercambios térmicos en su superficie. En la determinación de la carga de nieve sobre una cubierta, a efectos de su análisis estructural, se debe tener en cuenta de manera explícita por lo menos la influencia de la altitud del lugar, el clima regional, la forma de la cubierta y la exposición de la obra. También se les debe prestar la necesaria atención a los efectos locales, así como las condiciones particulares que faciliten la acumulación de nieve.

La nieve depositada sobre una estructura o cubierta puede ser el resultado de una nevada única o corresponder a la acumulación de diferentes nevadas. En casos particulares, por ejemplo cuando la carga de nieve es fruto de un evento extremadamente poco probable, también puede tratarse de una situación extraordinaria o accidental, en la terminología del Eurocódigo [EN 1990 2002]. En cubiertas accesibles para personas o vehículos existe la posibilidad de que se produzcan acumulaciones de la nieve debidas a su redistribución artificial. Finalmente, en edificios situados en zonas donde se pueden producir precipitaciones de lluvia sobre la capa de nieve, con sucesivos procesos de hielo y deshielo, también cabe la posibilidad de situaciones extremas desde el punto de vista de la carga de nieve sobre la cubierta, particularmente si la nieve o el hielo pueden bloquear el sistema de desagüe.

Los modelos disponibles para la determinación de la carga de nieve normalmente no son de aplicación a las obras en las que se pueda producir alguna de las circunstancias particulares arriba mencionadas. Tampoco son de aplicación a las obras situadas en lugares expuestas a unas condiciones extremas de nevadas o de vientos, ni a las que se encuentren situadas en altitudes extremas. En todos estos casos, la determinación de un modelo para la carga de nieve requiere un estudio específico, por lo que están fuera del alcance del presente trabajo. Por otro lado, en cubiertas expuestas a unas condiciones normales de viento, con un depósito natural de la nieve, la carga correspondiente se puede determinar según la siguiente ecuación [EN 1991-1-3 2003, CTE DB SEAE 2006]:

$q=\mu_{i} \cdot C_{e} \cdot C_{t} \cdot s$

$s \quad$ : carga de nieve sobre el terreno horizontal

$\mu_{i} \quad$ : coeficiente de forma de la cubierta

$C_{e} \quad$ : coeficiente de exposición

$C_{t} \quad$ : coeficiente térmico

A través de la carga de nieve sobre un terreno horizontal, protegido del viento y situado en las cercanías de la obra, $s$, se tiene en cuenta la influencia del clima regional y la altitud del lugar. Según la mayoría de las normas, incluido el Eurocódigo [EN 1991-1-3 2003] y la norma española equivalente [CTE DB SE-AE 2006], esta carga se debe tener en cuenta a través de su valor característico, basado en un período de retorno de 50 años o, en otras palabras, el valor cuya probabilidad anual de ser sobrepasado es del $2 \%$.

El coeficiente de forma de una determinada cubierta, $\mu_{i}$, tiene en cuenta la relación entre las cargas de nieve sobre, respectivamente, la cubierta y el terreno horizontal cercano a la obra. Debido a que una nevada puede estar acompañada o seguida de la acción del viento, el depósito de la nieve sobre la 
cubierta puede ser irregular. La nieve se suele acumular en zonas protegidas del viento, bien por la presencia de otras zonas más altas de la propia cubierta en caso de que ésta sea de aguas múltiples, bien por árboles o edificios colindantes. El espesor de la capa de nieve sobre estas cubiertas o zonas de cubiertas puede superar al espesor de la capa de nieve sobre el terreno colindante. Por este motivo, normas como las anteriormente mencionadas [EN 1991-1-3 2003, CTE DB SE-AE 2006], introducen dos diferentes familias de coeficientes de forma para las cubiertas expuestas a unas condiciones normales de viento, permitiendo tener en cuenta las siguientes disposiciones de la carga de nieve:

- depósito uniforme, sin transporte por el viento;

- depósito irregular, debido al transporte por el viento.

En edificios con cubiertas múltiples de diferentes niveles se debe considerar, además, el posible deslizamiento de la nieve desde las zonas superiores hacia las inferiores. Y en cubiertas con voladizos puede producirse una acumulación de nieve colgada, cuyo efecto corresponde a una carga lineal en el borde que puede alcanzar valores importantes.

El coeficiente de exposición, $C_{e}$, tiene en cuenta la influencia de diferentes factores sobre la carga de nieve, como son los relacionados con la topografía, la cercanía de otras estructuras u obstáculos, las condiciones de viento y la radiación solar. Según las normas europea y española [EN 1991-1-3 2003, CTE DB SE-AE 2006], los valores numéricos para el coeficiente de exposición oscilan entre 0,8 para obras fuertemente expuestas al viento y 1,2 para obras ubicadas en emplazamientos protegidos del viento.

Por otro lado, el coeficiente térmico, $C_{t}$, tiene en cuenta tanto la influencia de las propiedades térmicas de la cubierta sobre la carga de nieve, como el régimen térmico en el interior del edificio. Sólo en casos excepcionales, cuando se produce una transmisión importante de calor desde el interior del edificio hacia la superficie de la cubierta $\left(>1 \mathrm{~W} / \mathrm{m}^{2} \mathrm{~K}\right.$, según las normas actuales [EN 1991-1-3 2003, CTE DB SE-AE 2006]), se puede tener en cuenta una reducción de la carga de nieve sobre la cubierta por efectos térmicos.

\section{Estructuración del apartado}

El presente apartado está dedicado al desarrollo de un modelo probabilista para las cargas de nieve sobre cubiertas que cumpla con los requisitos establecidos en el Apartado 6.2.2. En la literatura especializada se encuentran modelos probabilistas para la carga de nieve, por ejemplo en el código modelo probabilista [JCSS 2001] o en el estudio escandinavo [SAKO 1999]. El primero está basado sobre todo en datos meteorológicos del centro y norte de Europa, mientras que el segundo se desarrolló para los países escandinavos, como indica su nombre. En todas estas zonas geográficas se suelen producir nevadas con regularidad, todos los inviernos, y también es habitual que se acumule la nieve de diferentes sistemas meteorológicos. En amplias zonas de la península ibérica no se produce ninguna de estas dos circunstancias: existen inviernos sin nevadas y la nieve suele desaparecer entre sucesivos sistemas meteorológicos con nevadas. Consecuentemente, los modelos probabilistas para las cargas de nieve disponibles en la literatura, no son de aplicación al caso español, motivo que justifica el desarrollo de un modelo específico en el marco de este trabajo.

El apartado no incluye resumen alguno de los dos modelos probabilistas mencionados [SAKO 1999, JCSS 2001]. No obstante, estos se utilizan con fines orientativos y comparativos a lo largo del desarrollo del modelo específico. Para ello es necesario abordar los siguientes aspectos:

- formulación general del modelo para la carga de nieve sobre una cubierta, compatible simultáneamente con los modelos disponibles en la literatura especializada y los datos que proporciona la Agencia Estatal de Meteorología, AEMET (Apartado 6.4.2);

- a partir de los datos de AEMET, determinación de las precipitaciones de nieve (Apartado 6.4.2); 
- determinación de los parámetros de las variables que definen la carga de nieve sobre el terreno horizontal (Apartado 6.4.2);

- partiendo de la carga de nieve sobre el terreno, y utilizando datos de la literatura para las otras variables que definen el modelo, deducción de un modelo probabilista para las cargas de nieve sobre las cubiertas (Apartado 6.4.2);

- ajuste de los parámetros de las variables según el procedimiento establecido en el Apartado 4.5 (Apartado 6.4.3).

\subsubsection{Modelo}

\section{Formulación general}

En analogía con los estudios y modelos citados [JCSS 2001, SAKO 1999], en el presente trabajo la carga de nieve sobre una cubierta, $q$, se obtiene a partir de la carga de nieve sobre el terreno horizontal, teniendo en cuenta la influencia de la forma de la cubierta, los intercambios térmicos en su superficie, así como las condiciones de exposición de la obra. Para el desarrollo de un modelo probabilista de la carga de nieve sobre una cubierta, no solamente se deben tener en cuenta las incertidumbres asociadas con los diferentes parámetros arriba mencionados, sino también las correspondientes a los propios modelos, tanto para la carga de nieve sobre el terreno como para su transformación en carga sobre la cubierta.

De acuerdo con lo anterior, a efectos del presente estudio la carga de nieve sobre una cubierta, $q$, se determina según la ecuación [Tanner 2011b]:

$q=\mu_{i} \cdot C_{e} \cdot C_{t} \cdot \xi_{q} \cdot s_{z} \cdot \xi_{s} \cdot \xi_{z}$

$s_{z} \quad:$ carga de nieve sobre el terreno horizontal en la zona climática, $z$, en función de la altitud del lugar

$\xi_{q} \quad$ : coeficiente de incertidumbre del modelo de la carga de nieve sobre la cubierta

$\xi_{s} \quad$ : coeficiente de incertidumbre del método empleado en la determinación de la carga de nieve sobre el terreno horizontal

$\xi_{z} \quad$ : coeficiente de incertidumbre del modelo para la carga de nieve sobre el terreno horizontal de la zona $z$

La carga de nieve sobre el terreno depende de factores climatológicos (clima regional y local) y de la altitud del lugar de la obra, por lo que se requiere un modelo específico para la carga de nieve en el lugar considerado o, en su defecto, para la región en la que se ubica. En contraste, los otros parámetros relevantes (exposición; forma; características térmicas; incertidumbres del modelo de la carga sobre la cubierta) se pueden tratar de manera independiente de las regiones climáticas. Los modelos existentes en la literatura especializada para estos parámetros resultan por ello suficientemente precisos para edificios situados en la península ibérica.

La mayoría de las normas modernas definen los requisitos de seguridad estructural en términos de una probabilidad de fallo admisible o de un índice de fiabilidad requerido, referidos a todo el período de servicio de la obra (Apartado 3.6). Consecuentemente, la probabilidad de fallo de los elementos estructurales se debe referir al mismo período de tiempo que, en el caso de las estructuras de edificación, normalmente es de 50 años (Apartado 3.3). Es necesario tener en cuenta esta circunstancia en la determinación de los modelos probabilistas para las variables que intervienen en los cálculos. En el caso de la nieve, eso afecta básicamente al modelo para la carga sobre el terreno horizontal.

Igual que en los estudios mencionados [SAKO 1999, JCSS 2001], los coeficientes térmico y de exposición se tratan como si fueran deterministas, adoptando $C_{t}=C_{e}=1,0$. También en el caso del coeficiente de forma de la cubierta se siguen las recomendaciones del código modelo probabilista 
[JCSS 2001], igualmente respetadas en el estudio escandinavo [SAKO 1999]. Para el coeficiente de variación de esta variable se adopta por ello un valor de $V_{\mu i}=0,15$. Las incertidumbres del modelo de la carga de nieve sobre la cubierta, finalmente, se tienen en cuenta mediante el coeficiente de variación propuesto en el estudio escandinavo [SAKO 1999], $V_{\xi q}=0,1$. Esta variable cubre las imprecisiones del modelo de la carga de nieve sobre la cubierta que no tiene explícitamente en cuenta influencias como, entre otras, las debidas a posibles distribuciones irregulares de la capa de nieve, ciertas redistribuciones por el viento, la variación del peso específico de la nieve en función del espesor de la capa o en función del tiempo.

Los parámetros de la carga de nieve sobre el terreno horizontal, $s_{z}$, y del coeficiente de incertidumbre asociado al modelo para esta carga, $\xi_{z}$, se deducen de un estudio específico [Morata 2004a], realizado en una colaboración entre el Instituto de Ciencias de la Construcción Eduardo Torroja dependiente de la Agencia Estatal Consejo Superior de Investigaciones Científicas, IETcc-CSIC, y la Agencia Estatal de Meteorología, AEMET, para paliar la falta de datos fiables sobre las cargas de nieve en el país, en el marco de la elaboración del Código Técnico de la Edificación [CTE DB SE-AE 2006]. Por otro lado, los parámetros del coeficiente de incertidumbre $\xi_{s}$ dependen del método empleado para la determinación de la carga de nieve sobre el terreno horizontal, según el citado estudio [Morata 2004a], descrito en un artículo divulgativo [Morata 2004b]. La escasez de datos dificulta su cuantificación, por lo que los parámetros que se deduzcan para esta variable tienen un marcado carácter subjetivo.

\section{Determinación de las precipitaciones de nieve}

Las estaciones climatológicas de la red de la Agencia Estatal de Meteorología, AEMET, no registran directamente ni el espesor ni la densidad de las precipitaciones acumuladas en forma de nieve, por lo que el estudio está basado en un método indirecto de evaluación del equivalente en agua de la capa de nieve [Morata 2004a]. En función de los datos meteorológicos disponibles en las estaciones, se determina la precipitación acumulada en las rachas de días sucesivos con temperaturas mínimas iguales o inferiores a cero grados (Figura 6.1). Una vez computada la precipitación en cada una de las rachas que cumplan con esta condición, y asumiendo que la nieve desaparezca por fusión en el intervalo entre dos rachas sucesivas, se identifica para cada mes y cada estación el valor de la precipitación máxima mensual en forma de nieve. Al tratarse de la medida equivalente en agua de la cantidad de nieve acumulada, la conversión a una carga gravitatoria de nieve no requiere consideración alguna sobre la densidad de la nieve en función de la altitud.

Siguiendo el procedimiento mencionado, se construye una base de datos que consiste en 1.936 series con registros de valores de la precipitación máxima mensual en forma de nieve, abarcando períodos temporales diferentes, según la disponibilidad de la información. De los valores máximos mensuales se deducen los correspondientes valores máximos anuales. Después de un exhaustivo control de calidad de los datos se descarta más del $40 \%$ de las series, contando finalmente con 1.024 series de valores de la carga de nieve máxima anual, correspondientes a otros tantos observatorios distribuidos de manera no uniforme en todo el país [Morata 2004a]. La influencia de la mencionada falta de homogeneidad en los períodos de tiempo que abarcan las diferentes series se mitiga sometiendo los datos a una evaluación individualizada. La metodología empleada a estos efectos se divide en dos fases. En primer lugar, se determina para cada estación el valor esperado de la carga de nieve sobre el terreno horizontal para un período de retorno de 50 años, equivalente al valor cuya probabilidad anual de ocurrencia es del 2\%. A continuación, se definen diferentes zonas geográficas (Figura 6.2), caracterizada cada una de ellas por la semejanza del comportamiento de los valores extremos en baja frecuencia (períodos de retorno de 50 años), previamente determinados para las estaciones analizadas, en función de la altitud sobre el nivel del mar. 


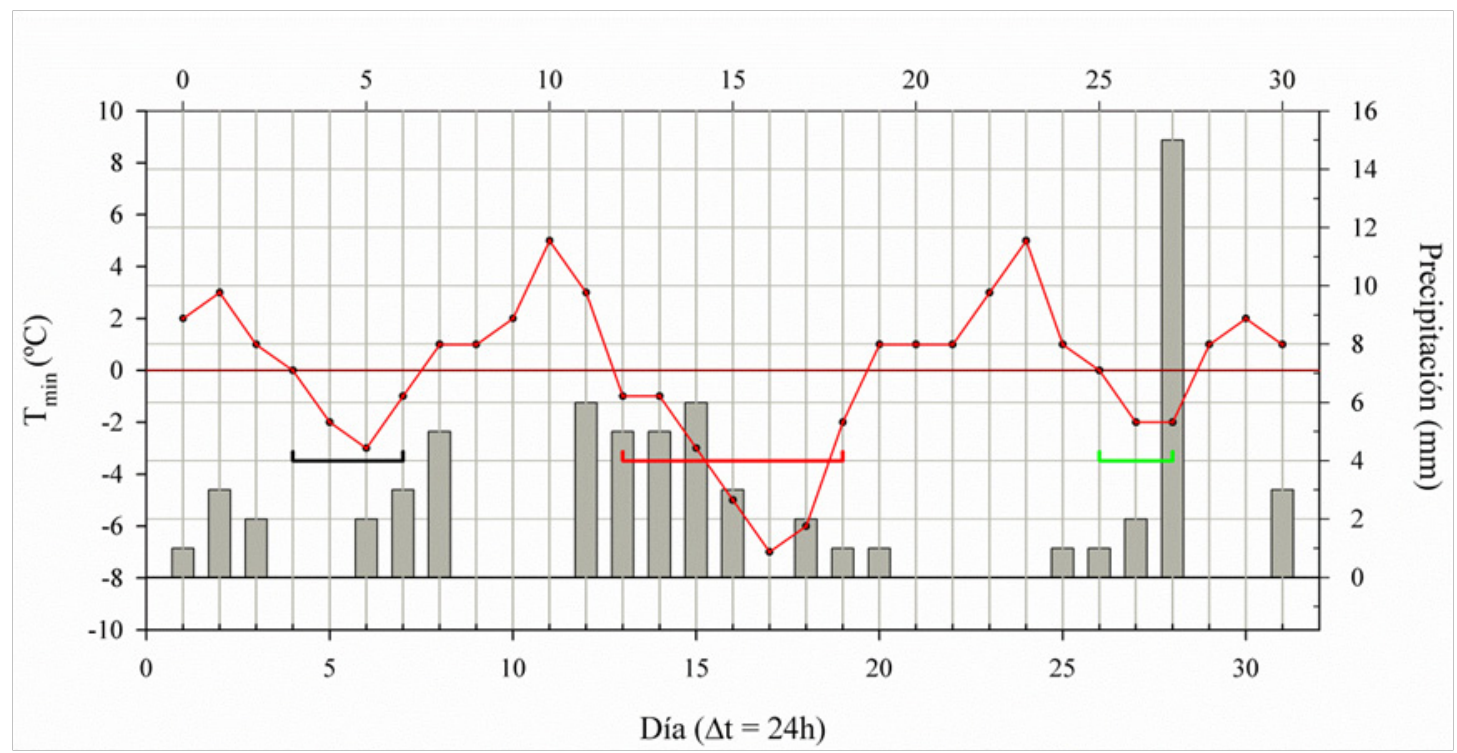

Figura 6.1 - Representación esquemática del procedimiento adoptado para la determinación de la precipitación máxima mensual en forma de nieve.

El comportamiento de la variable en función de la altitud en cada zona se ajusta a una función exponencial. Consecuentemente, el valor característico esperado de la carga de nieve sobre el terreno horizontal, $s_{z, k}$, en función de la altitud sobre el nivel del mar, $A$, en cada zona, $z$, se obtiene mediante la ecuación:

$$
S_{z, k}(A)=X_{z} \cdot Y_{z}^{A}
$$

A : altitud sobre el nivel del mar

$X_{z} \quad:$ : constante para la determinación de la carga de nieve en la zona geográfica $z$

$Y_{z} \quad$ : constante para la determinación de la carga de nieve en la zona geográfica $z$

$s_{z, k} \quad$ : valor característico esperado de la carga de nieve sobre el terreno horizontal en la zona geográfica $z$, en función de la altitud del lugar

$z \quad$ : zona geográfica de comportamiento homogéneo de la carga de nieve sobre el terreno

La denominación de $s_{z, k}$, valor característico esperado, se adopta para distinguirlo del valor

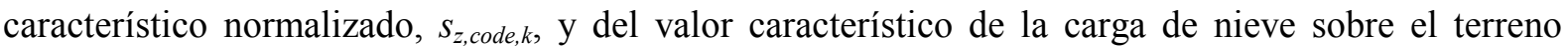
horizontal en una estación climatológica, $s_{k, \text { Gumbel }}$. Las constantes $X_{z}$ y $Y_{z}$ se determinan mediante un ajuste por el método de los mínimos cuadrados, a partir de los valores característicos de la carga de nieve sobre el terreno horizontal en las estaciones pertenecientes a la zona considerada, $z$, en función de su altitud en metros, $A$. La Tabla 6.1 refleja los resultados obtenidos para las diferentes zonas geográficas, con la excepción del Archipiélago Canario (Zona 7) donde no se han registrado precipitaciones en forma de nieve en las estaciones analizadas. Las funciones obtenidas sólo son válidas para valores de $A$ inferiores a una altitud máxima ya que para altitudes geográficas extremas la precipitación en forma de nieve no sigue un comportamiento exponencial. Por este motivo, las funciones obtenidas se truncan en la altitud máxima de cada zona para la que se dispone de un registro, $A_{\max }$. Este límite superior para la validez de las funciones también se indica en la Tabla 6.1, igual que el coeficiente de variación, $\mathrm{CoV}$, que cuantifica la dispersión de los valores característicos de la carga de nieve sobre el terreno horizontal en las diferentes estaciones consideradas, relativa al valor característico esperado. 


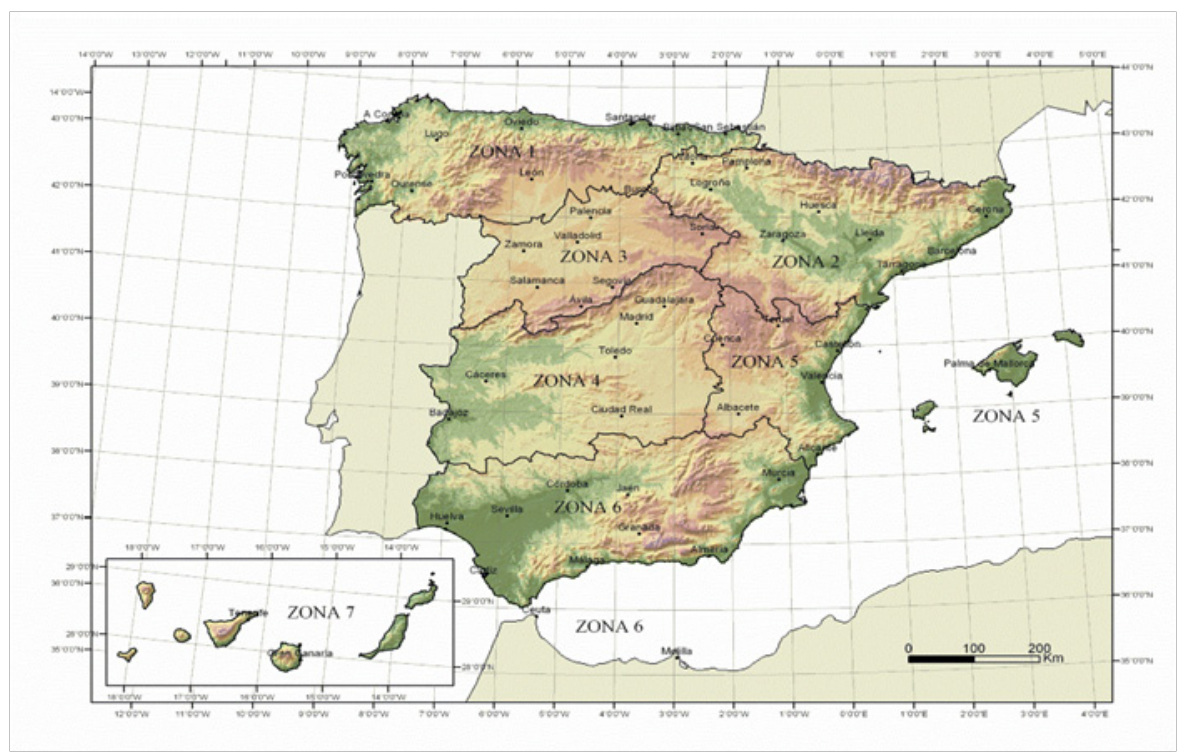

Figura 6.2 - Zonas geográficas de comportamiento homogéneo de los valores extremos en baja frecuencia de la carga de nieve sobre el terreno en función de la altitud sobre el nivel del mar.

A título de ejemplo, en la Figura 6.3 se representan los valores característicos de la carga de nieve sobre el terreno horizontal para las 190 estaciones consideradas en la Zona 4, en función de su altitud sobre el nivel del mar en metros, $A$, así como la función obtenida para el valor característico esperado de esta variable, $s_{4, k}(A)$, de acuerdo con la ecuación (6.26) y los valores de la Tabla 6.1 para las constantes. La mencionada dispersión de los valores característicos de la carga de nieve en las diferentes estaciones, relativa al valor característico esperado, se representa en la Figura 6.3 a través de unas funciones para los límites superior (L.S.) e inferior (L.I.), correspondientes al cuantil del 95\% (líneas continuas) y del 75\% (líneas discontinuas), respectivamente. Con el fin de cubrir estas dispersiones, las funciones empleadas a efectos normativos en el Código Técnico de la Edificación [CTE DB SE-AE 2006] para determinar el valor característico de la carga de nieve sobre el terreno horizontal, $s_{z, c o d e, k}(A)$, están basadas en el cuantil superior del 95\% (Tabla 6.1).

Tabla 6.1 - Constantes para la determinación de los valores característicos esperado y normalizado, $s_{z, k}$ y $s_{z, c o d e, k}$ respectivamente, de la carga de nieve sobre el terreno en función de la zona geográfica y la altitud del lugar, límite de aplicación de la ecuación (6.26), $A_{\max }$ y coeficiente de variación, CoV.

\begin{tabular}{|c|c|c|c|c|c|c|}
\hline \multirow{2}{*}{ Zona } & \multicolumn{2}{|c|}{$\boldsymbol{s}_{\boldsymbol{z}, \boldsymbol{k}}(\boldsymbol{A})\left[\mathbf{k N} / \mathbf{m}^{2}\right]$} & \multicolumn{2}{c|}{$\boldsymbol{s}_{\boldsymbol{z}, \text { code, } \boldsymbol{k}}(\boldsymbol{A})\left[\mathbf{k N} / \mathbf{m}^{2}\right]$} & \multirow{2}{*}{$\boldsymbol{A}_{\max }[\mathbf{m}]$} & \multirow{2}{*}{$\mathbf{C o V}[\boldsymbol{\%}]$} \\
\hline 1 & $\boldsymbol{X}_{\boldsymbol{z}}$ & $\boldsymbol{Y}_{\boldsymbol{z}}$ & $\boldsymbol{X}_{\boldsymbol{z}}$ & $\boldsymbol{Y}_{\boldsymbol{z}}$ & & \\
\hline 2 & 0,148 & 1,0016 & 0,336 & 1,0016 & 1600 & 72 \\
\hline 3 & 0,146 & 1,0014 & 0,368 & 1,0014 & 2200 & 91 \\
\hline 4 & 0,0459 & 1,0021 & 0,091 & 1,0021 & 1800 & 99 \\
\hline 5 & 0,0387 & 1,0022 & 0,138 & 1,0022 & 1600 & 68 \\
\hline 6 & 0,0777 & 1,0016 & 0,191 & 1,0016 & 1600 & 62 \\
\hline 7 & 0,0247 & 1,0026 & 0,089 & 1,0026 & 1800 & 128 \\
\hline
\end{tabular}




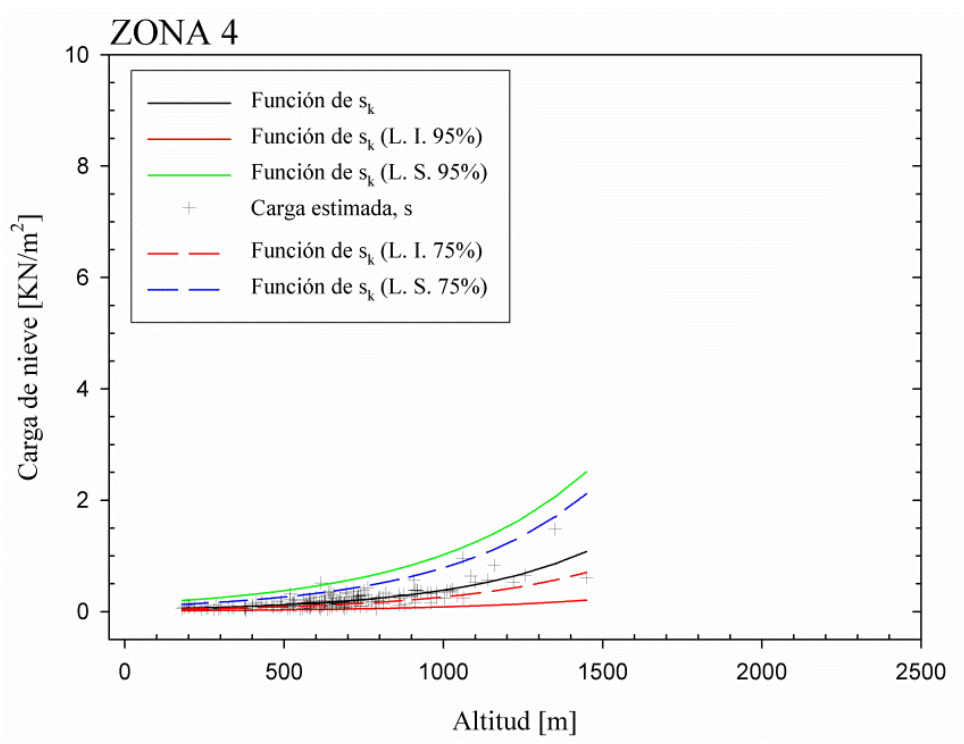

Figura 6.3 - Funciones correspondientes a la Zona 4 que rigen el comportamiento del valor característico de la carga de nieve sobre el terreno horizontal en función de la altitud sobre el nivel del mar.

\section{Modelo probabilista para la carga de nieve sobre el terreno horizontal}

\section{Requisitos para el modelo probabilista}

El objetivo del estudio realizado para la determinación de las precipitaciones de nieve consistió en la elaboración, a efectos normativos, de un modelo para la carga de nieve sobre el terreno horizontal [Morata 2004a]. Por este motivo, no se determinaron explícitamente los parámetros de las variables $S_{z}$ (carga de nieve sobre el terreno horizontal) y $\xi_{z}$ (coeficiente de incertidumbre asociado con el modelo para esta carga). Debido a que estas variables intervienen en la ecuación (6.25), el conocimiento de sus parámetros es imprescindible para la determinación de un modelo probabilista de la carga de nieve sobre una cubierta. El objetivo consiste por ello en la determinación de los valores para las constantes de la ecuación (6.26) que representen adecuadamente al valor medio y la desviación típica de la carga de nieve máxima sobre el terreno horizontal, en función de la zona geográfica y la altitud del lugar. Además, estas funciones deben establecerse en concordancia con el período de referencia considerado por las normas modernas para los requisitos de fiabilidad estructural. Según el Capítulo 3, para las estructuras de edificación tanto las reglas del Eurocódigo [EN 1990 2002] como las del Código Técnico de la Edificación [CTE DB SE 2006], normalmente están basadas en los índices de fiabilidad requeridos para un período de referencia de 50 años.

A efectos de la determinación de las constantes de la ecuación (6.26) para el valor medio y la desviación típica de la carga de nieve máxima sobre el terreno, se dispone, para cada una de las estaciones analizadas en el marco del citado estudio [Morata 2004a], de una base de datos con los valores de la precipitación máxima anual en forma de nieve, abarcando períodos temporales diferentes. Es a partir de estos datos que se había determinado el valor característico de la carga de nieve sobre el terreno horizontal en cada estación, $s_{k, \text { Gumbel }}$, y posteriormente, para cada zona, las funciones que rigen el comportamiento del valor característico de la carga de nieve sobre el terreno horizontal en función de la altitud sobre el nivel del mar (Figura 6.3). Evaluando los mismos datos de una determinada estación, se pueden establecer el valor medio, $\mu_{s, \max , 1}$, y la desviación típica, $\sigma_{s, \max , l}$, de la carga de nieve máxima anual sobre el terreno horizontal. A su vez, estos valores se pueden 
transformar a un período de referencia de 50 años, teniendo en cuenta que se ajustan a una función de distribución de los valores extremos de Tipo I [Gumbel 1958]. Para ello se utiliza la propiedad de la denominada función de distribución de Gumbel, según la que la desviación típica es independiente del período de referencia [Faber 2002]:

$$
\begin{array}{ll}
\sigma_{s, \max , n}= & \sigma_{s, \max , 1} \\
\sigma_{s, \max , 1} & : \text { desviación típica de la carga de nieve máxima anual sobre el terreno horizontal } \\
\sigma_{s, \max , n} & : \text { desviación típica de la carga de nieve máxima sobre el terreno horizontal para un período } \\
& \quad \text { de referencia de } n \text { años }
\end{array}
$$

Para la distribución de Gumbel también existe una relación sencilla para el valor medio en función del período de referencia [Gumbel 1958]:

$$
\mu_{s, \max , n}=\mu_{s, \max , 1}+\frac{\sqrt{6}}{\pi} \cdot \sigma_{s, \max , 1} \cdot \ln (n)
$$

$\mu_{s, \max , 1} \quad$ : valor medio de la carga de nieve máxima anual sobre el terreno horizontal

$\mu_{s, \max , n} \quad$ : valor medio de la carga de nieve máxima sobre el terreno horizontal para un período de referencia de $n$ años

\section{Inviernos sin nevadas}

Para las estaciones meteorológicas ubicadas en las zonas de la península ibérica donde se producen inviernos sin nevadas (Apartado 6.4.1), las series de los valores de la precipitación máxima anual en forma de nieve corresponden a una combinación de una distribución de valores extremos y de un cierto porcentaje de valores iguales a cero. Si el número de valores diferentes de cero resulta suficientemente grande, sólo éstos deberían tenerse en cuenta en el análisis estadístico [Corso, del 1995]. No obstante, esta manera de proceder no se ajusta a la práctica habitual en el campo de la meteorología donde siempre se usan todos los pasos temporales de una serie ya que para la evaluación de los períodos de retorno es necesario tener en cuenta también los años en los que no se produce el fenómeno estudiado.

Debido a que el objetivo del presente estudio consiste en la deducción de los riesgos para las personas y del nivel de fiabilidad requerido de acuerdo con la mejor práctica actual (Apartado 4.1), se estima la influencia de la muestra considerada en la evaluación estadística de los valores extremos sobre el índice de fiabilidad y la probabilidad de fallo de los elementos estructurales. A estos efectos, se seleccionan tres estaciones meteorológicas representativas, pertenecientes a diferentes zonas geográficas, respectivamente León "Escuela de capataces" (Zona 1), Zaragoza "Aeropuerto" (Zona 2) y Madrid "Puerta de Hierro" (Zona 4). Para cada una de ellas se establecen dos modelos probabilistas para la carga de nieve sobre el terreno horizontal (valor medio y desviación típica de la carga de nieve máxima para un período de referencia de 50 años, empleando una función de distribución de Gumbel), teniendo en cuenta todos los valores extremos en el primer modelo y sólo los valores diferentes de cero en el segundo. Siguiendo el procedimiento establecido en el Apartado 4.5, para un conjunto representativo de vigas de cubierta se establece la probabilidad de fallo implícitamente aceptada según la normativa en vigor, utilizando los dos modelos probabilistas para la carga de nieve. Las probabilidades de fallo obtenidas al emplear el modelo basado en los valores diferentes de cero se deben interpretar como siendo condicionales ya que dependen de que haya nevadas. Por este motivo, se deben multiplicar por la probabilidad de que se produzca una nevada en el lugar considerado, para poder comparar los resultados obtenidos al emplear este modelo con los correspondientes al modelo para la carga de nieve basado en la serie completa de los valores extremos. La probabilidad anual de que se produzca una nevada se puede estimar fácilmente, a partir del porcentaje de valores extremos diferentes de cero, mientras que para un período de referencia de 50 años se puede asumir que se 
produzcan nevadas en cada una de las tres estaciones consideradas, de acuerdo con los datos recopilados en el estudio de las precipitaciones de nieve [Morata 2004a].

Sin entrar en más detalles, los resultados obtenidos en el estudio comparativo sobre la influencia del modelo probabilista para la carga de nieve en la fiabilidad estructural de las vigas de cubierta, ponen de manifiesto que la fiabilidad es mayor si el modelo para la carga de nieve está basado en todos los valores extremos de la serie. No obstante, las diferencias entre los resultados obtenidos con ambos modelos resultan relativamente pequeñas, particularmente en cuanto a los parámetros más relevantes para la continuación del trabajo, el valor medio y el coeficiente de variación de la probabilidad de fallo. Estas diferencias, con una media para las tres estaciones analizadas del orden del $17 \%$ y $7 \%$, respectivamente, resultan reducidas en comparación con las dispersiones obtenidas en el análisis de la probabilidad de fallo admisible de un conjunto representativo de vigas de cubierta, por ejemplo de acero estructural, con un coeficiente de variación del orden del 96\% (Apartado 8.2). Por este motivo, y por coherencia con la práctica habitual en el campo de la meteorología donde se usan todos los valores de una serie [Morata 2004a], las funciones que representan al valor medio y la desviación típica de la carga de nieve máxima sobre el terreno horizontal, dependiendo de la zona geográfica y la altitud del lugar, se desarrollan sobre la base de la totalidad de los valores extremos registrados en las estaciones contempladas.

\section{Procedimiento}

La obtención de un modelo probabilista sencillo para la carga de nieve sobre el terreno horizontal, que sea válido para todo el país, se basa en las funciones para el valor medio y la desviación típica dependiendo de la altitud del lugar. Estas funciones, del tipo exponencial en analogía con la ecuación (6.26), se deben establecer para cada una de las zonas geográficas identificadas (Figura 6.2), teniendo en cuenta un período de referencia de 50 años. A continuación se resume el procedimiento adoptado para la deducción de estas funciones.

- En un primer paso se selecciona un conjunto representativo de estaciones termo-pluviométricas para cada zona geográfica, $z$. A estos efectos se eligen, en la medida de lo posible, las estaciones correspondientes a las capitales de provincia de cada zona. De esta manera, los modelos deducidos se basan automáticamente en los datos relevantes para el mayor número posible de edificios, ya que normalmente estas ciudades coinciden con las principales aglomeraciones de una zona.

- Tomando de la base de datos, establecida en el estudio de las precipitaciones de nieve [Morata 2004a], los valores de la precipitación máxima anual en forma de nieve, se establecen para cada estación, $i$, el valor medio, $\mu_{s, i, m a x, l}$, y la desviación típica, $\sigma_{s, i, \max , 1}$, de la carga de nieve máxima anual sobre el terreno horizontal. Mediante las ecuaciones (6.28) y (6.27), respectivamente, estos valores se transforman a un período de referencia de 50 años, obteniendo el valor medio, $\mu_{s, i, m a x, 50}$, y la desviación típica, $\sigma_{s, i, m a x, 50}$, de la carga de nieve máxima sobre el terreno horizontal de la estación, $i$, para el citado período.

- Agrupando las estaciones, $i$, según las zonas geográficas, $z$, definidas en la Figura 6.2, se ajusta para cada zona una función que relacione el valor medio de la carga de nieve máxima sobre el terreno horizontal para un período de referencia de 50 años con la altitud sobre el nivel del mar, $\mu_{s, z, \max , 50}(A)$. A estos efectos se emplea una función exponencial análoga a la ecuación (6.26), y se tiene en cuenta que dentro de cada zona el comportamiento de la carga de nieve sobre el terreno en función de la altitud es homogéneo, ya que es el criterio utilizado para la identificación de las zonas. En consecuencia, se mantienen sin cambio las constantes $Y_{z}$, obtenidas en el marco de la determinación de los modelos para el valor característico esperado de la carga de nieve sobre el terreno en función de la altitud y de la zona (Tabla 6.1), mediante un ajuste por el método de los mínimos cuadrados. Debido a que el ajuste de las constantes $Y_{z}$ se basa en un gran número de estaciones en cada zona, los valores obtenidos son fiables. Por todo ello, en el marco del presente 
análisis, sólo se deben determinar las constantes $X_{z, \mu s, \max , 50}$ mediante un ajuste por el método de los mínimos cuadrados, a partir de los datos obtenidos para las estaciones contempladas de cada zona. Formalmente, la relación a desarrollar se puede escribir en los siguientes términos:

$\mu_{s, z, \max , 50}(A)=X_{z, \mu s, \max , 50} \cdot Y_{z, \mu s, \max , 50}^{A} \cong X_{z, \mu s, \max , 50} \cdot Y_{z}^{A}$

$\mu_{s, z, \max , 50}$ : valor medio de la carga de nieve máxima sobre el terreno horizontal de la zona geográfica, $z$, en función de la altitud, $A$, para un período de referencia de 50 años

$X_{z, \mu s, \max , 50}:$ constante para la determinación de $\mu_{s, z, \max , 50}(A)$ en la zona $z$

$Y_{z, \mu s, \max , 50}:$ constante para la determinación de $\mu_{s, z, \max , 50}(A)$ en la zona $z$

- De manera análoga al valor medio esperado, $\mu_{s, z \max , 50}(A)$, se relaciona el valor medio más una desviación típica de la carga de nieve máxima sobre el terreno horizontal de la zona, $z$, con la altitud, $A$, para un período de referencia de 50 años, $\left(\mu_{s, z, \max , 50}(A)+\sigma_{s, z, \max , 50}(A)\right)$. Igual que en el caso de la ecuación (6.29), se emplea una función exponencial, asumiendo un comportamiento homogéneo de la carga de nieve dependiendo de la altitud dentro de cada zona y manteniendo sin variación las constantes $Y_{z}\left(Y_{z,(\mu+\sigma) s, \max , 50}=Y_{z}\right)$. El ajuste mediante el método de los mínimos

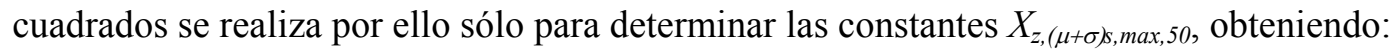

$\mu_{s, z, \max , 50}(A)+\sigma_{s, z, \max , 50}(A)=X_{z,(\mu+\sigma)_{s, \max , 50}} \cdot Y_{z,(\mu+\sigma) s, \max , 50}^{A} \cong X_{z,(\mu+\sigma) s, \max , 50} \cdot Y_{z}^{A}(6.30)$

$\sigma_{s, z, m a x, 50}$ : desviación típica de la carga de nieve máxima sobre el terreno horizontal de la zona geográfica, $z$, en función de la altitud, $A$, para un período de referencia de 50 años

$X_{z,(\mu+\sigma) s, \max , 50} \quad$ : constante para la determinación de $\left(\mu_{s, z, \max , 50}(A)+\sigma_{s, z, \max , 50}(A)\right)$ en la zona $z$

$Y_{z,(\mu+\sigma) s, \max , 50} \quad$ : constante para la determinación de $\left(\mu_{s, z, \max , 50}(A)+\sigma_{s, z, \max , 50}(A)\right)$ en la zona $z$

- A partir de las ecuaciones (6.29) para el valor medio esperado, y (6.30) para el mismo valor medio más una desviación típica de la carga de nieve máxima sobre el terreno horizontal, así como el valor característico normalizado de la carga de nieve sobre el terreno horizontal según la ecuación (6.26) y la Tabla 6.1, $s_{z, c o d e, k}(A)$, se determinan unas ecuaciones para los coeficientes de sesgo, $S_{z, s, \max , 50}(A)$, y de variación, $V_{z, s, \max , 50}(A)$, respectivamente, de la carga de nieve máxima sobre el terreno horizontal de la zona, $z$, en función de la altitud, $A$, para un período de referencia de 50 años:

$S_{z, s, \text { max }, 50}(A)=\frac{\mu_{s, z, \text { max }, 50}(A)}{S_{z, \text { code }, k}(A)} \cong \frac{X_{z, \mu s, \max , 50} \cdot Y_{z}^{A}}{X_{z, \text { code }, k} \cdot Y_{z}^{A}}=\frac{X_{z, \mu s, \max , 50}}{X_{z, \text { code }, k}}$

$s_{z, c o d e, k} \quad$ : valor característico normalizado de la carga de nieve sobre el terreno horizontal de la zona geográfica, $z$, en función de la altitud, $A$

$X_{z, c o d e, k} \quad$ : constante para la determinación de $s_{z, c o d e, k}$ en la zona $z$

$$
\begin{aligned}
& V_{z, s, \max , 50}(A)=\frac{\sigma_{s, z, \max , 50}(A)}{\mu_{s, z, \max , 50}(A)} \cong \frac{\left(\mu_{s, z, \max , 50}(A)+\sigma_{s, z, \max , 50}(A)\right)-\mu_{s, z, \max , 50}(A)}{\mu_{s_{z, \max , 50}}(A)}= \\
& =\frac{X_{z,(\mu+\sigma)_{s, \max , 50}-X_{z, \mu s, \max , 50}}}{X_{z, \mu s, \max , 50}}
\end{aligned}
$$

\section{Deducción de los modelos probabilistas}

De acuerdo con el procedimiento descrito en el párrafo anterior, se elige una estación por cada capital de provincia excepto en los casos de las provincias de Alicante (Zona 5) y Murcia (Zona 6), en las que las estaciones correspondientes a las capitales no registran un mínimo de tres valores extremos diferentes de cero. Por ello, se opta por sustituirlas por estaciones en las que se cumpla este requisito y que, simultáneamente, estén ubicadas en localidades con más de 50.000 habitantes (Alcoy y Lorca, 
respectivamente). Con esta medida, y según los criterios de selección mencionados, resulta un mínimo de tres (Zona 6) y un máximo de 8 (Zonas 2 y 3 ) estaciones representativas por cada zona geográfica (Figura 6.2). Como se menciona con anterioridad, no existen datos para el Archipiélago Canario (Zona 7).

Los datos obtenidos para las estaciones seleccionadas se utilizan para la determinación de los parámetros de la ecuación (6.29). Las constantes $Y_{z}$ se toman de la Tabla 6.1, mientras que las constantes $X_{z, \mu s, \max , 50}$ se determinan mediante un ajuste por el método de los mínimos cuadrados. Las constantes de la ecuación (6.30) se determinan de manera análoga a las de la ecuación (6.29). Los resultados numéricos de estos ajustes se encuentran en la Tabla 6.2.

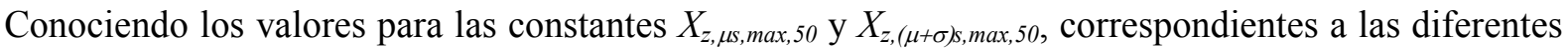
zonas geográficas, y tomando de la Tabla 6.1 los valores de la constante para la determinación del valor característico normalizado de la carga de nieve en las mismas zonas, $X_{z, \text { code }, k}$, los coeficientes de sesgo, $S_{z, s, \max , 50}$, y de variación, $V_{z, s, \max , 50}$, se obtienen mediante las ecuaciones (6.31) y (6.32), respectivamente. Los resultados para el coeficiente de sesgo, con un valor medio del orden de 0,29 (Tabla 6.2), indican que los modelos normalizados para la carga de nieve sobre el terreno horizontal son conservadores (Tabla 6.1). Se trata de una opción adoptada de manera deliberada en la elaboración del Código Técnico de la Edificación [CTE DB SE-AE 2006], con el fin de cubrir parcialmente las incertidumbres del modelo para la carga de nieve sobre el terreno horizontal, tal y como se menciona en párrafos anteriores. Efectivamente, con un valor medio de 0,28 para el coeficiente de variación, la dispersión de la carga de nieve máxima sobre el terreno horizontal para un período de referencia de 50 años es claramente superior, del orden del 30\%, a la observada en países con nevadas más frecuentes, por ejemplo en el centro de Europa [Holicky 2008].

Tabla 6.2 - Resultados del proceso de deducción de los modelos probabilistas para la carga de nieve sobre el terreno horizontal y de las incertidumbres asociadas.

\begin{tabular}{|c|c|c|c|c|c|}
\hline $\begin{array}{c}\text { Zona } \\
z\end{array}$ & $\begin{array}{l}\text { Constante } \\
X_{z, \mu s, \max , 50}\end{array}$ & $\begin{array}{l}\text { Constante } \\
X_{z,(\mu+\sigma) s, \max , 50}\end{array}$ & \begin{tabular}{|c|} 
Coeficiente de \\
sesgo \\
$S_{z, s, \max , 50}$ \\
\end{tabular} & $\begin{array}{c}\text { Coeficiente de } \\
\text { variación } \\
V_{z, s, \max , 50}\end{array}$ & \begin{tabular}{|c|} 
Incertidumbres \\
del modelo \\
$V_{\xi z}$
\end{tabular} \\
\hline 1 & 0,1180 & 0,1511 & 0,3512 & 0,2805 & 0,72 \\
\hline 2 & 0,1247 & 0,1595 & 0,3389 & 0,2791 & 0,91 \\
\hline 3 & 0,0232 & 0,0293 & 0,2549 & 0,2629 & 0,99 \\
\hline 4 & 0,0402 & 0,0518 & 0,2913 & 0,2886 & 0,68 \\
\hline 5 & 0,0592 & 0,0752 & 0,3099 & 0,2703 & 0,62 \\
\hline 6 & 0,0166 & 0,0217 & 0,1865 & 0,3072 & 1,28 \\
\hline 7 & \multicolumn{5}{|c|}{ No existen datos } \\
\hline
\end{tabular}

Si se comparan los resultados obtenidos para el valor medio esperado de la carga de nieve máxima sobre el terreno horizontal de la zona $z$, en función de la altitud, $A$, para un período de referencia de 50 años, $\mu_{s, z, \max , 50}(A)$, que se determina según la ecuación (6.29) utilizando la constante $X_{z, \mu s, \max , 50}$ (Tabla 6.2), con el valor esperado de la carga de nieve para un período de retorno de 50 años (valor característico esperado según la ecuación (6.26) y la Tabla 6.1), $s_{z, k}(A)$, se observa que muy aproximadamente son del mismo orden de magnitud dentro de cada una de las 6 zonas para las que existen datos, $\mu_{s, z, \max , 50}(A)=s_{z, k}(A)$. A título de ejemplo, la Figura 6.4 representa esta comparación para la Zona 4. Debido a que en el marco del estudio de las precipitaciones de nieve, anteriormente mencionado [Morata 2004a], se cuantifica la dispersión de los valores característicos de la carga de nieve sobre el terreno horizontal en las diferentes estaciones consideradas con respecto al valor 
característico esperado (Tabla 6.1), se dispone de información sobre las incertidumbres asociadas con el modelo para la carga de nieve sobre el terreno horizontal. A falta de un estudio más detallado, se adopta para el coeficiente de incertidumbre del modelo para la carga de nieve sobre el terreno horizontal de la zona $z, \xi_{z}$, un coeficiente de variación, $V_{\xi z}$, equivalente a las dispersiones determinadas en el mencionado estudio [Morata 2004a]. Estos coeficientes de variación están reflejados en la Tabla 6.2. Las mayores incertidumbres se asocian con al modelo correspondiente a la Zona 6 (Figura 6.2), lo que no resulta sorprendente ya que en gran parte de este territorio del sur de la península las nevadas son muy poco frecuentes.

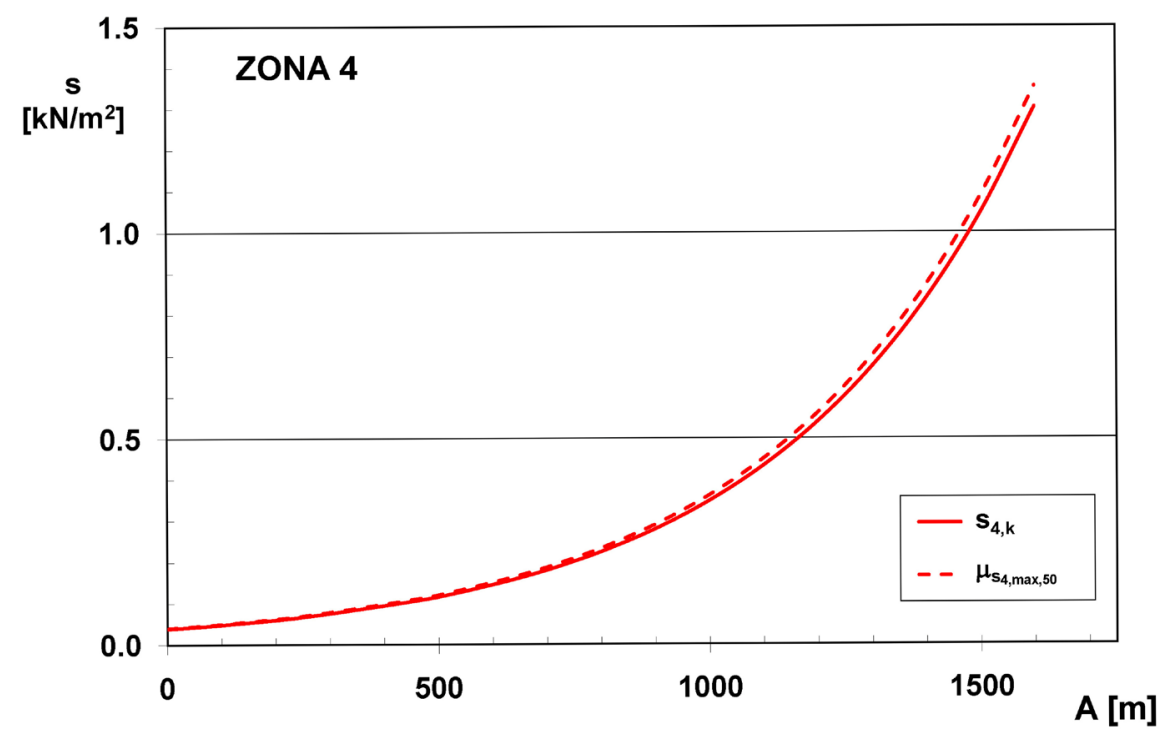

Figura 6.4 - Comparación de las funciones para $s_{z, k}(A)$ y $\mu_{s, z, \max , 50}(A)$, correspondientes a la Zona 4.

\section{Incertidumbres asociadas con el método}

En consonancia con los datos meteorológicos disponibles, la determinación de la carga de nieve sobre el terreno horizontal en las diferentes estaciones consideradas en el presente estudio está basada en un método indirecto de evaluación del equivalente en agua de la capa de nieve [Morata 2004a]. Este método implica cruzar los datos de las precipitaciones y de la temperatura ambiental para cada estación (Figura 6.1). Al proceder de esta manera, resulta verosímil que se sobreestime la carga de nieve en las estaciones situadas en lugares donde, aún produciéndose precipitaciones de nieve, ésta no siempre llega a cuajar sobre el terreno. Esta situación puede darse particularmente en lugares ubicados en bajas altitudes sobre el nivel del mar, muy especialmente en la parte sur de la península ibérica. Al contrario, en las zonas en las que la nieve de rachas sucesivas se puede acumular, por ejemplo en lugares montañosos, el método adoptado para la deducción de la carga de nieve en las diferentes estaciones puede conducir a una subestimación de ésta.

Según la ecuación (6.25), las incertidumbres descritas, inherentes al mencionado método indirecto para la determinación de la carga de nieve sobre el terreno horizontal, se tienen en cuenta a través del coeficiente $\xi_{s}$. Para poder cuantificar este coeficiente sería necesario disponer, al menos para algunas estaciones representativas, de valores determinados mediante un método directo de evaluación del equivalente en agua de la capa de nieve, además de los valores basados en el método indirecto del presente estudio. En ausencia de esta información, las incertidumbres asociadas con el método empleado para la determinación de la carga de nieve sobre el terreno horizontal se tienen en cuenta a través del coeficiente de variación $V_{\xi_{s}}=0,1$. En la mayoría de las estaciones no parece necesario asumir un coeficiente de variación mayor, ya que las hipótesis adoptadas en el marco del estudio [Morata 2004a] se ajustan a la climatología de muchas regiones, especialmente de aquéllas con el 
mayor número de edificios. Ese es particularmente el caso de la hipótesis relativa a la desaparición por fusión de la capa de nieve entre dos rachas sucesivas de precipitaciones de nieve. Aún así, el modelo probabilista adoptado para $\xi_{s}$ es subjetivo.

\section{Modelo probabilista para la carga de nieve sobre cubiertas}

A lo largo del presente Apartado 6.4.2 se justifican los parámetros de las variables que, según la ecuación (6.25), intervienen en el modelo para la carga de nieve sobre una cubierta, $q$. Los resultados obtenidos, considerando un período de referencia de 50 años, están resumidos en la Tabla 6.3. Según lo especificado en el Apartado 6.2.2, el coeficiente de sesgo es la ratio entre los valores medio y representativo de una variable, mientras que el coeficiente de variación, $\mathrm{CoV}$, es la ratio entre su desviación típica y su valor medio.

Tabla 6.3 - Modelos probabilistas para las variables que intervienen en el modelo para la carga de nieve sobre una cubierta.

\begin{tabular}{|c|c|c|c|}
\hline Variable & Notación & Sesgo & $\mathrm{CoV}$ \\
\hline Carga de nieve sobre el terreno horizontal & $s_{z}$ & \multicolumn{2}{|c|}{ Según Zona $z$ (Tabla 6.2) } \\
\hline Coeficiente de forma de la cubierta & $\mu_{i}$ & 1,0 & 0,15 \\
\hline Coeficiente de exposición & $C_{e}$ & \multicolumn{2}{|c|}{ Determinista } \\
\hline Coeficiente térmico & $C_{t}$ & \multicolumn{2}{|c|}{ Determinista } \\
\hline Incertidumbres del método para determinar $s_{z}$ & $\xi_{s}$ & 1,0 & 0,1 \\
\hline Incertidumbres del modelo para $s_{z}$ & $\xi_{z}$ & 1,0 & Seg. $z$ (Tabla 6.2) \\
\hline Incertidumbres del modelo para $q$ & $\xi_{q}$ & 1,0 & 0,1 \\
\hline
\end{tabular}

El valor medio de la carga de nieve máxima sobre una cubierta para un período de referencia de 50 años, $\mu_{q}$, se determina a partir de los valores medio de las variables que, según la ecuación (6.25), intervienen en la determinación de $q$ :

$\mu_{q}=\mu_{\mu i} \cdot \mu_{C e} \cdot \mu_{C t} \cdot \mu_{\xi q} \cdot \mu_{s, z, \max , 50}(A) \cdot \mu_{\xi s} \cdot \mu_{\xi z}$

Debido a que el valor medio esperado de la carga de nieve máxima sobre el terreno horizontal, $\mu_{s, z, \max , 50}(A)$, depende de la altitud del lugar, $A, \mu_{q}$ también depende de $A$. Por este motivo, una representación adimensional del valor medio, en términos del coeficiente de sesgo, $S_{q}$, resulta más práctica. Éste depende de la zona, $z$, y equivale al coeficiente de sesgo de la carga de nieve máxima sobre el terreno horizontal de la misma zona, para un período de referencia de 50 años, $S_{z, s, \max , 50}$, tal y como se puede deducir mediante unas transformaciones sencillas:

$S_{q}=\frac{\mu_{s, z, \max , 50}(A)}{S_{z, \text { code }, k}(A)}=\frac{X_{z, \mu s, \max , 50}}{X_{z, \text { code }, k}}=S_{z, s, \text { max }, 50}$

$S_{q} \quad:$ coeficiente de sesgo de la carga de nieve máxima sobre una cubierta para un período de referencia de 50 años

Los valores numéricos para $S_{z, s, \max , 50}$ correspondientes a las diferentes zonas geográficas están reflejados en la Tabla 6.2. Redondeándolos se obtienen los coeficientes de sesgo de la carga de nieve máxima sobre cubiertas para un período de referencia de 50 años (Tabla 6.4).

Teniendo en cuenta el carácter determinista asumido para los coeficientes térmico, $C_{t}$, y de exposición, $C_{e}$, el coeficiente de variación de la carga de nieve máxima sobre una cubierta para un período de referencia de 50 años, $V_{q}$, se determina según la siguiente ecuación: 


$$
\left(1+V_{q}^{2}\right)=\left(1+V_{\mu i}^{2}\right) \cdot\left(1+V_{\xi q}^{2}\right) \cdot\left(1+V_{z, s, \max , 50}^{2}\right) \cdot\left(1+V_{\xi s}^{2}\right) \cdot\left(1+V_{\xi z}^{2}\right)
$$

$V_{q} \quad$ : coeficiente de variación de la carga de nieve máxima sobre una cubierta para un período de referencia de 50 años

Utilizando los coeficientes de variación reflejados en la Tabla 6.3 para las variables que intervienen en la determinación de la carga de nieve sobre una cubierta, la ecuación (6.35) permite deducir un coeficiente de variación, $V_{q}$, para cada una de las zonas geográficas, $z$, para las que existen datos. Los resultados están reflejados en la Tabla 6.4.

A efectos prácticos interesa disponer de un único modelo probabilista para la carga de nieve sobre cubiertas que sea de aplicación en todas las zonas geográficas. Para ello se forma la media aritmética de los coeficientes de sesgo y de variación, respectivamente, obtenidos para las Zonas 1 a 5 . No se tienen en cuenta los valores de la Zona 6 ya que las nevadas son muy poco frecuentes y las cargas de nieve resultan en cualquier caso muy bajas (en altitudes por debajo de $A_{\max }$ ), por lo que se opta por emplear para la Zona 6 los parámetros $S_{q}$ y $V_{q}$ deducidos a partir de los datos de las zonas restantes. En cuanto a la función de distribución de los valores extremos de la carga de nieve sobre cubiertas, se puede asumir que sea del Tipo I [Gumbel 1958], igual que para la carga de nieve sobre el terreno.

Con todo lo anterior, se obtiene el siguiente modelo probabilista para la carga de nieve sobre cubiertas para un período de referencia de 50 años: $q=$ Gumbel $(0,31 ; 0,90)$. El valor del coeficiente de sesgo indica que los modelos normalizados para la carga de nieve sobre el terreno horizontal según el Código Técnico de la Edificación son conservadores [CTE DB SE-AE 2006], en concordancia con el objetivo arriba mencionado de cubrir parcialmente las incertidumbres asociadas con la carga de nieve sobre el terreno horizontal. En cuanto a la dispersión de esta carga, el coeficiente de variación obtenido permite concluir que es claramente superior, del orden del 30\% [Tanner 2011b], a la observada en países del centro de Europa con nevadas más frecuentes [Holicky 2008], en concordancia con los resultados obtenidos para la dispersión de la carga de nieve máxima sobre el terreno horizontal para el mismo período de referencia. A la misma conclusión conduce una comparación con el código modelo probabilista [JCSS 2001]. Utilizando los modelos probabilistas para las diferentes variables de las que depende la carga de nieve sobre una cubierta según este código, se obtiene un coeficiente de variación del orden de 0,73 [Faber 2002]. Este valor está asociado con un período de referencia de un año por lo que, traducido a un período de 50 años, sería menor. Debido a que los parámetros según el código modelo están basados en datos de regiones con nevadas más frecuentes, también esta diferencia con la dispersión obtenida en el presente estudio resulta verosímil.

Tabla 6.4-Modelos probabilistas correspondientes a la carga de nieve sobre cubiertas para un período de referencia de 50 años.

\begin{tabular}{|c|c|c|}
\hline $\begin{array}{c}\text { Zona } \\
\boldsymbol{z}\end{array}$ & $\begin{array}{c}\text { Sesgo } \\
\boldsymbol{S}_{q}\end{array}$ & $\begin{array}{c}\text { CoV } \\
\boldsymbol{V}_{q}\end{array}$ \\
\hline 1 & 0,35 & 0,84 \\
\hline 2 & 0,34 & 1,03 \\
\hline 3 & 0,25 & 1,10 \\
\hline 4 & 0,29 & 0,81 \\
\hline 5 & 0,31 & 0,74 \\
\hline 6 & 0,19 & 1,42 \\
\hline 7 & \multicolumn{2}{|c|}{ No existen datos } \\
\hline
\end{tabular}




\subsubsection{Verificación y ajuste de los parámetros}

\section{Introducción}

El modelo probabilista para la carga de nieve sobre cubiertas, deducido de la manera ilustrada en el apartado anterior, cumple con tres de los cuatro requisitos establecidos previamente (Apartado 6.2.2). Concretamente, este modelo:

- resulta apto para aplicaciones prácticas al caracterizar mediante una variable aleatoria las incertidumbres relevantes;

- representa las características físicas de la variable correspondiente;

- es consistente con el correspondiente modelo del código modelo probabilista [JCSS 2001].

Queda por comprobar si el modelo deducido también cumple con el cuarto requisito, es decir si representa el estado de incertidumbre asociado con las reglas de dimensionado de la normativa en vigor. A estos efectos se aplica el procedimiento establecido en el Apartado 4.5, determinando en primer lugar los valores de cálculo de las variables relevantes mediante el método FORM normalizado según las normas [ISO 2394 1998] y [EN 1990 2002] (Apartado 3.4), y los coeficientes parciales que relacionan estos valores de cálculo con los representativos de las mismas variables, definidos en las normas europeas y nacionales consideradas (Apartado 4.4), respectivamente [EN 1990 2002, EN 1991-1-3 2005] y [CTE DB SE 2006, CTE DB SE-AE 2006]. En el marco de las hipótesis adoptadas, correspondientes al método FORM normalizado, los coeficientes parciales obtenidos dependen de:

- el mecanismo de fallo considerado y la correspondiente función de estado límite (Apartado 5.4);

- el formato de los coeficientes parciales adoptado (Apartado 6.3.1);

- los valores representativos de las variables, establecidos en la normativa considerada;

- los modelos probabilistas identificados para estas variables (Apartado 6.4.2, para el caso de la carga de nieve sobre cubiertas).

A continuación, siguiendo el procedimiento del Apartado 4.5, estos coeficientes parciales se comparan con los correspondientes valores requeridos, según las normas analizadas. Esta comparación, así como el posible ajuste de los modelos probabilistas para optimizar la función objetivo (4.9), se ilustran en el marco del presente apartado para el caso de las vigas de cubierta solicitadas por momentos flectores inducidos por la carga de nieve. Concretamente, se determinan los valores de cálculo y los coeficientes parciales que tienen en cuenta las incertidumbres asociadas con las siguientes variables de las acciones y sus efectos:

$q \quad$ : carga de nieve sobre una cubierta;

$\xi_{E, M} \quad$ : coeficiente para las incertidumbres del modelo para el cálculo de los efectos de las acciones (momentos flectores).

En el marco de la aplicación del método FORM normalizado se consideran dominantes las variables de las acciones y la resistencia, respectivamente, con los coeficientes de variación máximos. En el caso de los momentos flectores debidos a la acción de la nieve sobre las vigas de cubierta, es decir en el lado de los efectos de las acciones, la carga de nieve constituye la variable dominante.

Cabe mencionar que de la misma manera se determinan los valores de cálculo y los coeficientes parciales para los momentos flectores debidos a las otras acciones consideradas en el presente estudio (peso propio, cargas permanentes, sobrecarga variable), los esfuerzos cortantes en las vigas y los esfuerzos axiles en los pilares debidos a todas las acciones (peso propio, cargas permanentes, sobrecarga variable, carga de nieve), así como para las resistencias correspondientes. Efectivamente, todas las variables que intervienen en las diferentes funciones de estado límite relacionadas con los mecanismos de fallo analizados contribuyen a la función objetivo, representada por la ecuación (4.9). En los Apartados 6.5 y 6.6 se ilustra el procedimiento también para otras variables, tal y como se 
adelanta en el Apartado 6.1. No obstante, resulta imposible representar de manera explícita la deducción de los parámetros de todas las variables que intervienen en las funciones de estado límite, establecidas en el Apartado 5.4.

\section{Valores de cálculo y coeficientes parciales}

Cargas de nieve

El modelo probabilista desarrollado en el Apartado 6.4.2 considera una función de distribución del Tipo I [Gumbel 1958] para los valores extremos de la carga de nieve sobre una cubierta. Aplicando el método FORM en analogía con lo establecido en el Eurocódigo [EN 1990 2002], para esta función de distribución el valor de cálculo de la carga de nieve se expresa en los siguientes términos:

$$
q_{F O R M, d}\left(\mu_{q} ; \sigma_{q}\right)=u-\frac{1}{\alpha} \cdot \ln \left(-\ln \phi\left(-\alpha_{E, s} \cdot \beta_{t}\right)\right)
$$

con

$$
\begin{aligned}
& u=\mu_{q}-\frac{0,577}{\alpha} \\
& \alpha=\frac{\pi}{\sigma_{q} \cdot \sqrt{6}}
\end{aligned}
$$

$\alpha_{E, s} \quad:$ factor de sensibilidad para la carga de nieve

$\mu_{q} \quad$ : valor medio de la carga de nieve máxima sobre una cubierta para un período de referencia de 50 años

$\sigma_{q} \quad:$ desviación típica de la carga de nieve máxima sobre una cubierta para un período de referencia de 50 años

Sustituyendo en la ecuación (6.36) los parámetros $u$ y $\alpha$, que caracterizan la función de distribución de valores extremos del Tipo I, por las expresiones (6.37) y (6.38) se obtiene, mediante unas transformaciones sencillas, la siguiente expresión para el valor de cálculo:

$$
q_{F O R M, d}\left(\mu_{q} ; \sigma_{q}\right)=\mu_{q}-\sigma_{q} \cdot \frac{\sqrt{6}}{\pi} \cdot\left(0,577+\ln \left(-\ln \phi\left(-\alpha_{E, s} \cdot \beta_{t}\right)\right)\right)
$$

De las ecuaciones (6.3), así como (6.5) a (6.7), se deduce que el coeficiente parcial para una determinada acción, que no tiene en cuenta las incertidumbres del modelo para la determinación de sus efectos, relaciona el valor de cálculo de esta acción con su valor característico. Por ello, el coeficiente parcial para la carga de nieve, $\gamma_{q, s}$, se puede expresar en función del valor característico normalizado de esta carga y del valor de cálculo correspondiente, anteriormente determinado mediante el método FORM. Además, sustituyendo $q_{F O R M, d}$ por la parte derecha de la ecuación (6.39), el coeficiente parcial $\gamma_{q, s}$ se expresa en función del modelo probabilista identificado para la carga de nieve:

$\gamma_{q, s}\left(\mu_{q} ; \sigma_{q}\right)=\frac{q_{\text {FORM }, d}}{q_{\text {code }, k}}=\frac{\mu_{q}}{q_{\text {code }, k}}-\frac{\sigma_{q}}{q_{\text {code }, k}} \cdot \frac{\sqrt{6}}{\pi} \cdot\left(0,577+\ln \left(-\ln \phi\left(-\alpha_{E, s} \cdot \beta_{t}\right)\right)\right)$

$q_{c o d e, k} \quad:$ valor característico normalizado de la carga de nieve sobre la cubierta

Con el fin de expresar el coeficiente parcial para la carga de nieve en función de los parámetros adimensionales de esta variable, se tiene en cuenta que el primer término de la ecuación (6.40) corresponde al coeficiente de sesgo de la carga de nieve máxima sobre una cubierta para un período de referencia de 50 años (Apartado 6.2.2): 


$$
S_{q}=\frac{\mu_{q}}{q_{\text {code }, k}}
$$

y que el coeficiente de variación de esta carga se puede expresar en función de este coeficiente de sesgo:

$$
V_{q}=\frac{\sigma_{q}}{q_{\text {code }, k}} \cdot \frac{1}{S_{q}}
$$

Mediante las ecuaciones (6.41) y (6.42), la anterior expresión (6.40) para el coeficiente parcial para la carga de nieve se transforma en:

$$
\gamma_{q, s}\left(S_{q} ; V_{q}\right)=S_{q} \cdot\left(1-V_{q} \cdot \frac{\sqrt{6}}{\pi} \cdot\left(0,577+\ln \left(-\ln \phi\left(-\alpha_{E, s} \cdot \beta_{t}\right)\right)\right)\right)
$$

Para los estados límite últimos, objeto del presente estudio, el Eurocódigo y, por extensión, el Código Técnico de la Edificación, respectivamente [EN 1990 2002] y [CTE DB SE 2006], definen un valor requerido del índice de fiabilidad para un período de referencia de 50 años de $\beta_{t}=3,8$ (Apartado 3.6.2). Las citadas normas para las bases de proyecto le asignan a la variable dominante de las acciones, en el presente caso la carga de nieve, el mismo valor normalizado para el factor de sensibilidad que, además, está en concordancia con el valor numérico establecido en la norma internacional [ISO 2394 1998]. De acuerdo con todos estos documentos se adopta para este factor un valor de $\alpha_{E, s}=-0,7$ (Apartado 3.4.2). Con estos valores normalizados y los parámetros previamente deducidos del modelo probabilista para la carga de nieve sobre una cubierta, $S_{q}=0,31$ y $V_{q}=0,90$, la ecuación (6.43) estriba en el siguiente valor numérico del coeficiente parcial para la carga de nieve:

$\gamma_{q, s}\left(S_{q} ; V_{q}\right)=1,388$

\section{Efectos de las cargas de nieve}

Para la variable que tiene en cuenta las incertidumbres del modelo empleado en el cálculo de los momentos flectores, $\xi_{E, M}$ (Apartado 5.4), en el presente trabajo se considera un modelo probabilista con una función de distribución lognormal (Apartado 6.7), en concordancia con el código modelo probabilista [JCSS 2001]. Si la dispersión de una variable con esta función de distribución es pequeña, con un coeficiente de variación por debajo del 25\%, su valor de cálculo se puede determinar de manera simplificada [ISO 2394 1998]. El Eurocódigo [EN 1990 2002] admite la misma simplificación (con un requisito ligeramente más restrictivo para el coeficiente de variación que se limita al 20\%) por lo que, según el método FORM normalizado (Apartado 3.4), el valor de cálculo de la variable del modelo para la determinación de los momentos flectores, $\xi_{E, M, F O R M, d}$, se obtiene a través de la ecuación:

$\xi_{E, M, F O R M, d}\left(\mu_{\xi E, M} ; \sigma_{\xi E, M}\right)=\mu_{\xi E, M} \cdot e^{-\alpha_{E, \xi} \cdot \beta_{t} \cdot\left(\sigma_{\xi E, M} / \mu_{\xi E, M}\right)}$

$\alpha_{E, \xi} \quad$ : factor de sensibilidad para la variable del modelo para la determinación de los efectos de las acciones

$\mu_{\xi E, M} \quad:$ valor medio de la variable del modelo para la determinación de los momentos flectores

$\sigma_{\xi E, M} \quad$ : desviación típica de la variable del modelo para la determinación de los momentos flectores

El coeficiente parcial, $\gamma_{S d, M}$ (Apartado 6.3.1), solo tiene en cuenta las incertidumbres asociadas con los modelos empleados en la determinación de los momentos flectores, ya que las incertidumbres del modelo de las acciones, particularmente la carga de nieve (Tabla 6.3), se tienen en cuenta a través del valor de cálculo de esta carga según la ecuación (6.39), estando cubiertas por el correspondiente 
coeficiente parcial, $\gamma_{q, s}$ (ecuación (6.43)). Consecuentemente, $\gamma_{S d, M}$ relaciona el valor de cálculo de la variable del modelo para la determinación de los momentos flectores, $\xi_{E, M, F O R M, d}$, con el valor característico o nominal de la misma variable, $\xi_{E, M, k}$ :

$$
\gamma_{S d, M}\left(\mu_{\xi E, M} ; \sigma_{\xi E, M}\right)=\frac{\xi_{E, M, F O R M, d}}{\xi_{E, M, k}}=\frac{\mu_{\xi E, M}}{\xi_{E, M, k}} \cdot e^{-\alpha_{E, \xi} \cdot \beta_{t} \cdot\left(\sigma_{\xi E, M} / \mu_{\xi E, M}\right)}
$$

El coeficiente de sesgo de la variable del modelo para la determinación de los momentos flectores, $S_{\xi E, M}$, se expresa a través de la ecuación (6.47):

$$
S_{\xi E, M}=\frac{\mu_{\xi E, M}}{\xi_{E, M, k}}
$$

El otro parámetro adimensional que caracteriza el modelo probabilista de la variable del modelo, $\xi_{E, M}$, el coeficiente de variación, $V_{\xi E, M}$, se obtiene a partir de la ecuación:

$$
V_{\xi E, M}=\frac{\sigma_{\xi E, M}}{\mu_{\xi E, M}}
$$

Sustituyendo las ecuaciones (6.47) y (6.48) en (6.46), el coeficiente parcial para los modelos empleados en la determinación de los momentos flectores se puede representar en función de los mencionados parámetros adimensionales del modelo probabilista de la variable $\xi_{E, M}$ :

$$
\gamma_{S d, M}\left(S_{\xi E, M} ; V_{\xi E, M}\right)=S_{\xi E, M} \cdot e^{-\alpha_{E, \xi} \cdot \beta_{t} \cdot V_{\xi E, M}}
$$

El coeficiente para las incertidumbres del modelo de cálculo de los momentos flectores, $\xi_{E, M}$, no constituye la variable dominante de las que intervienen en la determinación de los efectos de las acciones. Efectivamente, con una dispersión moderada, resulta que la variación de esta variable tiene una influencia muy reducida, en comparación con la de la variación de la carga de nieve, en la probabilidad de fallo de una viga de cubierta solicitada por momentos flectores inducidos por la nieve. La norma internacional [ISO 2394 1998] les asigna a las variables no dominantes de las acciones un valor normalizado para el factor de sensibilidad que corresponde al $40 \%$ del valor asignado a la variable dominante. El mismo valor numérico se encuentra también en el Eurocódigo [EN 1990 2002] y el Código Técnico de la Edificación [CTE DB SE 2006]. Consecuentemente es el valor que se adopta en el presente estudio para el factor de sensibilidad asociado con la variable $\xi_{E, M}$ : $\alpha_{E, \xi}=-0,28$ (Apartado 3.4.2). Con este valor normalizado, el valor arriba mencionado del índice de fiabilidad requerido para un período de referencia de 50 años, $\beta_{t}=3,8$ (Apartado 3.6.2), así como los coeficientes de sesgo y de variación identificados para la variable del modelo destinado a la determinación de los momentos flectores, recopilados en el Apartado $6.7\left(S_{\xi E, M}=1,0\right.$ y $\left.V_{\xi E, M}=0,1\right)$, se obtiene el siguiente valor numérico para el coeficiente parcial, $\gamma_{S d, M}$ :

$$
\gamma_{S d, M}\left(S_{\xi E, M} ; V_{\xi E, M}\right)=1,112
$$

\section{Optimización de los modelos}

\section{Generalidades}

De acuerdo con el procedimiento establecido en el Apartado 4.5, los coeficientes parciales obtenidos mediante el método FORM normalizado (ecuaciones (6.44) y (6.50)), asociados con los modelos probabilistas identificados para las variables que intervienen en la determinación de los momentos flectores inducidos por la carga de nieve en las vigas de cubierta, se comparan con los valores definidos en las normas analizadas para los correspondientes coeficientes parciales. Si la diferencia es pequeña, la contribución a la función objetivo (4.9) también lo es, y se puede deducir que los modelos 
probabilistas para las variables consideradas representan adecuadamente el estado de incertidumbre asociado con las reglas normalizadas. En caso contrario, los parámetros de estos modelos se deben variar, con el objetivo de minimizar la contribución a la función objetivo, pero sin que los modelos ajustados incumplan los otros requisitos establecidos en el Apartado 6.2.2.

De acuerdo con el formato adoptado para la verificación de la seguridad estructural (Apartado 6.3.1), la comparación se realiza a nivel de los efectos de las acciones (y de la resistencia correspondiente, tal y como se ilustra en los Apartados 6.5 y 6.6). Además, se debe tener en cuenta que los valores requeridos de los coeficientes parciales se inscriben en el formato de coeficientes parciales del Eurocódigo [EN 1990 2002] y del Código Técnico de la Edificación [CTE DB SE 2006], que es distinto al empleado en el presente estudio para la deducción de los modelos probabilistas. A continuación se presenta, para la carga de nieve sobre una cubierta, $q$, y la variable del modelo para la determinación de los momentos flectores, $\xi_{E, M}$, la comparación de los coeficientes parciales deducidos con los correspondientes valores requeridos y, en caso de revelarse necesario, el ajuste de los parámetros de los modelos probabilistas.

\section{Coeficiente parcial deducido}

Según el formato de los coeficientes parciales adoptado (Apartado 6.3.1), el coeficiente parcial para los efectos de la carga de nieve se desglosa en un coeficiente parcial para la acción, denominado $\gamma_{q, s}$ según la ecuación (6.40), y un coeficiente parcial para los modelos empleados en la determinación de los efectos de esta acción, en el presente caso los momentos flectores, $\gamma_{S d, M}$. De todas las variables que intervienen en la determinación de estos efectos en una viga de cubierta, la carga de nieve es la variable dominante, tal y como se menciona con anterioridad. Según la ecuación (6.5), en el caso de la acción variable dominante el coeficiente parcial para la sobrecarga se denomina $\gamma_{q, 1}$, que en el presente contexto equivale a $\gamma_{q, s}$ (ecuación (6.40)). Debido a que la carga de nieve es dominante, la variable del modelo para la determinación de los momentos flectores se debe considerar como no dominante. De acuerdo con los valores numéricos obtenidos con el método FORM normalizado, los modelos probabilistas deducidos para las variables relevantes en la determinación de los momentos flectores debidos a la carga de nieve, equivalen al siguiente coeficiente parcial:

$\gamma_{S d, M} \cdot \gamma_{q, 1}=\gamma_{S d, M} \cdot \gamma_{q, s}=1,112 \cdot 1,388=1,543$

\section{Valor requerido}

Las normas europea y española, respectivamente [EN 1990 2002] y [CTE DB SE 2006], establecen un formato en el que los coeficientes parciales para las acciones no se desglosan (ecuación (6.2)), contrariamente al formato establecido para el presente estudio. Ambas normas adoptan el mismo valor numérico para el coeficiente parcial para las acciones variables dominante, $\gamma_{Q, 1}$, y concomitante, $\gamma_{Q, i}$. Este constituye por tanto el valor requerido del coeficiente parcial para los efectos de la carga de nieve:

$\gamma_{Q, 1}=\gamma_{Q, i}=\gamma_{Q}=1,5$

\section{Contribución a la función objetivo}

La función objetivo (4.9), definida en el Apartado 4.5 para la verificación y, en su caso, el ajuste de los parámetros deducidos para los modelos probabilistas correspondientes a las variables que intervienen en un dimensionado estructural, introduce un coeficiente de ponderación para los diferentes mecanismos de fallo, $W_{Y, j}$. En el marco del presente estudio se les asigna la misma importancia relativa a todos los mecanismos de fallo, de todos los elementos estructurales, constituidos por cualquiera de los materiales considerados. Consecuentemente, el coeficiente de ponderación tiene un valor constante de $W_{Y, j}=1,0 \mathrm{y}$ los modelos probabilistas de las variables 
relevantes para la determinación de los momentos flectores inducidos por la carga de nieve en una viga de cubierta de cualquier material constitutivo, aportan la siguiente contribución a la función objetivo:

$\left(\gamma_{S d, M} \cdot \gamma_{q, s}-\gamma_{Q}\right)^{2}=(1,543-1,5)^{2}=0,001888$

Este resultado corresponde a una diferencia del 3\% entre los coeficientes parciales obtenidos mediante el método FORM normalizado y el correspondiente valor requerido según las normas consideradas. Siendo esta diferencia pequeña, se podrían aceptar como adecuados los modelos probabilistas para las variables consideradas $\left(q\right.$ y $\left.\xi_{E, M}\right)$. No obstante, existe un cierto margen para ajustar los parámetros de estos modelos, con el fin de minimizar la función objetivo.

\section{Ajuste de parámetros}

Como ya se menciona con anterioridad, información sobre los modelos probabilistas para las incertidumbres de los modelo empleados a efectos del cálculo de los momentos flectores en una viga de un pórtico, $\xi_{E, M}$, se encuentra en la literatura especializada, particularmente en el código modelo probabilista [JCSS 2001]. No se conoce evidencia alguna, ni teórica ni experimental, que permita justificar un ajuste del modelo adoptado en el presente estudio. Por este motivo, se mantienen sin cambio los parámetros de esta variable $\left(\xi_{E, M}=\mathrm{LN}(1,0 ; 0,1)\right)$, recopilados en el Apartado $6.7 \mathrm{y}$ mencionados anteriormente, en relación con la determinación del valor numérico para el coeficiente parcial, $\gamma_{S d, M}($ ecuación (6.50)).

El Apartado 6.4.2 incluye algunos comentarios relativos a los parámetros del modelo probabilista para la carga de nieve sobre una cubierta, deducidos para un período de referencia de 50 años. En particular, se mencionan los motivos por los que resulta un valor muy bajo para el coeficiente de sesgo, $S_{q}$. Si en la deducción de este modelo probabilista no se tuvieran en cuenta los datos correspondientes a los inviernos sin nevadas, resultaría un coeficiente de sesgo más elevado. Por este motivo, y debido a que el ajuste propuesto a continuación no conduce a un incumplimiento de los otros requisitos establecidos para los modelos probabilistas (Apartado 6.2.2), el coeficiente de sesgo se incrementa ligeramente (aproximadamente un $6 \%$ ) hasta un valor de $S_{q}=0,33$.

En el mismo Apartado 6.4.2 también se menciona que el coeficiente de variación de la carga de nieve máxima para un período de referencia de 50 años, $V_{q}$, resulta más elevado que para los países del centro y norte de Europa. En el caso de España, la elevada dispersión, y por tanto el coeficiente de variación obtenido, se explica en parte por el hecho de que en extensas zonas del país las nevadas son poco frecuentes, lo que se traduce en un número nada despreciable de inviernos sin nevadas. En las estaciones termo-pluviométricas analizadas en el estudio de sensibilidad de la fiabilidad estructural frente a la muestra considerada de valores extremos, mencionado en el Apartado 6.4.2, se observa una reducción máxima del coeficiente de variación del 10\% si en lugar de los datos de todos los inviernos solo se tienen en cuenta los inviernos con nevadas. Por todo lo anterior, se considera razonable una reducción del orden del $10 \%$ del coeficiente de variación, adoptando un valor de $V_{q}=0,81$. Este ajuste no afecta a los otros requisitos establecidos para los modelos probabilistas (Apartado 6.2.2).

Al adoptar el modelo probabilista para la carga de nieve sobre una cubierta (período de referencia: 50 años) con los parámetros ajustados según las anteriores consideraciones, $q=$ Gumbel $(0,33 ; 0,81)$, el método FORM normalizado (ecuación (6.43)) conduce a un coeficiente parcial de $\gamma_{q, s}\left(S_{q} ; V_{q}\right)=$ 1,3635. Debido a que no varía el coeficiente $\gamma_{S d, M}$, la diferencia entre los coeficientes parciales obtenidos mediante el método FORM normalizado y el correspondiente valor requerido según las normas analizadas ([EN 1990 2002] y [CTE DB SE 2006]) es del 1\%, por lo que los ajustes propuestos para los parámetros $S_{q}$ y $V_{q}$ resultan aceptables. A través de estos retoques, la contribución a la función objetivo para el ajuste de los modelos probabilistas de las variables relevantes a efectos 
de la determinación de los momentos flectores inducidos por la carga de nieve en una viga de cubierta, representada mediante la relación (6.53), se reduce en un $86 \%$ hasta un valor de:

$\left(\gamma_{S d, M} \cdot \gamma_{q, s}-\gamma_{Q}\right)^{2}=(1,112 \cdot 1,3635-1,5)^{2}=0,000263$

Consecuentemente, después de los ajustes descritos se consideran adecuados los modelos probabilistas para las citadas variables $\left(q\right.$ y $\left.\xi_{E, M}\right)$.

\subsection{LÍMITE ELÁSTICO DEL ACERO ESTRUCTURAL}

\subsubsection{Introducción}

\section{Modelado de la resistencia}

Se clasifica como una variable de resistencia cualquier variable aleatoria que esté relacionada con la capacidad del elemento o del sistema considerado para resistir las cargas y las influencias a las que esté sometido. La resistencia se debe entender como una característica inherente al elemento o sistema. En un modelo de resistencia intervienen normalmente variables relativas a [Schneider 1994, Schneider 1997]:

- las características geométricas;

- las características de los materiales;

- las incertidumbres del modelo.

En relación con el modelado probabilista de la resistencia, el aspecto más importante consiste en la representación de la variación aleatoria de las variables, tanto en el espacio como en el tiempo (Apartado 3.2). En analogía con las variables de las acciones y sus efectos (Apartado 6.4), una vez identificadas las características de un determinado mecanismo de resistencia, el establecimiento de un modelo probabilista consiste en:

- la definición detallada de las variables aleatorias empleadas para representar la resistencia y las incertidumbres asociadas;

- la selección de un tipo de distribución adecuado para la representación de las variables aleatorias;

- la asignación de los parámetros de las variables en consonancia con los tipos de distribución seleccionados.

Las propiedades de los modelos probabilistas para los distintos tipos de variables de resistencia pueden diferir considerablemente. Aún así, presentan algunos rasgos comunes, aplicables a efectos del modelado probabilista. A título de ejemplo, seguidamente se trata la deducción de un modelo probabilista para la resistencia de un determinado material, concretamente el límite elástico del acero estructural. Para comprobar si los modelos probabilistas deducidos para la resistencia de los materiales (por ejemplo: el límite elástico del acero) representan adecuadamente el estado de incertidumbre asociado con las reglas de dimensionado de la normativa en vigor, es necesario considerar simultáneamente los modelos probabilistas deducidos para las otras variables de resistencia. Eso en analogía con el caso de las variables de las acciones y sus efectos (ecuaciones (6.51) a (6.54)), debido a que el formato de coeficientes parciales del Eurocódigo [EN 1990 2002] y del Código Técnico de la Edificación [CTE DB SE 2006], es distinto al empleado en el presente estudio para la deducción de los modelos probabilistas (Apartado 6.3.1). Por este motivo, la comparación de los coeficientes parciales según el método FORM normalizado con los correspondientes valores requeridos, así como el ajuste de los parámetros en caso de revelarse necesario, de acuerdo con el procedimiento establecido en el Apartado 4.5, no se realizan en el marco del presente apartado, dedicado al límite elástico del acero estructural. Esta comparación se efectúa en el marco del Apartado 6.6, una vez identificados los parámetros de todas las variables que resultan 
relevantes para la resistencia de las vigas de acero estructural frente a momentos flectores, siempre según el ejemplo considerado a efectos ilustrativos. En este sentido, en el Apartado 6.6 también se mencionan algunos aspectos genéricos en relación con las incertidumbres geométricas y se aborda el modelado de las incertidumbres asociadas con los modelos de resistencia.

\section{Resistencia del material}

En términos generales, la descripción de cada propiedad de un material incluye un modelo matemático, por ejemplo un modelo elastoplástico o reológico, y una serie de variables aleatorias o campos aleatorios, por ejemplo un módulo de elasticidad o un coeficiente de fluencia. Relaciones funcionales entre las diferentes variables pueden formar parte del modelo del material. Un ejemplo sería la relación entre las resistencias del hormigón frente a compresión y tracción, respectivamente.

La respuesta de los materiales frente a las cargas estáticas o variables en el tiempo, incluidas las cargas dinámicas, resulta normalmente determinante a efectos del dimensionado estructural. No obstante, también la respuesta frente a las acciones e influencias físicas, químicas y biológicas puede ser relevante ya que éstas pueden afectar a las propiedades mecánicas de los materiales o su comportamiento.

Tanto los modelos como los valores numéricos para las variables se suelen deducir a partir de ensayos normalizados de laboratorio. Éstos deberían ser representativos para las condiciones en la obra, lo que incluye las condiciones de fabricación, exposición y puesta en carga. También deberían tener en cuenta las medidas de control de la fabricación, cubrir un período de tiempo suficientemente largo y ejecutarse con un número estadísticamente representativo. Incluso si se respetan todos estos condicionantes, los resultados de los ensayos de laboratorio normalmente no se pueden emplear directamente para describir las prestaciones de un determinado material en una estructura, debiendo convertirlos en función de las diferencias entre las condiciones de contorno de los ensayos y la estructura, respectivamente.

Las propiedades mecánicas más relevantes de un material suelen describirse sobre la base de un diagrama tensión - deformación unitaria, $\sigma-\varepsilon$. Como mínimo se debería determinar la resistencia del material y su módulo de elasticidad, tanto para tracción como para compresión. Otros parámetros importantes basados en el mismo diagrama son el límite elástico, el límite de proporcionalidad, o las deformaciones unitarias correspondientes a las tensiones máxima y de rotura, respectivamente. Esta última es función de mecanismos locales por lo que los valores obtenidos dependen fuertemente de la forma y las dimensiones de las probetas empleadas.

Además de las anteriores propiedades de un material, otras cantidades o efectos pueden ser relevantes, aunque normalmente no es necesario disponer de un modelo probabilista para todas ellas.

Por ejemplo [JCSS 2001]:

- estados de tensiones multiaxiales;

- duración y velocidad de aplicación de la carga;

- efectos térmicos;

- efectos de la humedad del ambiente;

- efectos de los defectos de fabricación o de los cambios bruscos de geometría;

- influencias químicas.

En muchos casos pueden existir correlaciones entre las diferentes propiedades de un material.

Por otro lado, las propiedades de un material están sometidas a una variación aleatoria en el espacio: el valor de una determinada propiedad, por ejemplo el límite elástico de un tipo específico de acero estructural, en un punto de una estructura es diferente al valor de la misma propiedad en otro punto de la misma, o de otra estructura (Apartado 3.2.1). Además de las variaciones espaciales, se deberían 
tener en cuenta las siguientes diferencias entre las propiedades determinadas experimentalmente sobre probetas de laboratorio y las correspondientes propiedades del material de una estructura real [JCSS 2001]:

- Las desviaciones sistemáticas que se puedan observar al comparar la propiedad deducida en los ensayos de laboratorio con la propiedad prevista, lo que apuntaría a un cierto sesgo en el modelo.

- Las desviaciones aleatorias entre la propiedad deducida en los ensayos y la prevista, lo que puede ser un indicio de una insuficiencia relacionada con las variables consideradas en el modelo.

- Las incertidumbres asociadas con la relación existente entre el material de una estructura y el material de las probetas de laboratorio.

- El efecto de las diferentes calidades de ejecución en la fabricación y la puesta en obra del material en las estructuras reales, que no suelen ser equivalentes a las de las probetas de laboratorio.

- Las incertidumbres asociadas con la variación de las propiedades de un material en función del tiempo y de las condiciones de exposición, que se puede acotar sobre la base de observaciones y mediciones en obras reales, o por medio de ensayos de laboratorio representativos.

\section{Estructuración del apartado}

En la literatura especializada existen modelos probabilistas para las propiedades del acero estructural, teniendo en cuenta las influencias arriba mencionadas. En particular, en el código modelo probabilista [JCSS 2001] se encuentran modelos de este tipo para la mayoría de las propiedades mecánicas mientras que el estudio escandinavo [SAKO 1999] se centra en la definición de un modelo probabilista para el límite elástico. También en el marco del presente estudio solo es necesario disponer de modelos probabilistas para el límite elástico del acero estructural en general y para el área de cortante, respectivamente $f_{y}$ y $f_{y w}$, ya que son las únicas variables de resistencia del material que intervienen en las funciones de estado límite establecidas para los elementos de acero (Apartado 5.4.2). Para el desarrollo de estos modelos se realizan las siguientes tareas, en concordancia con el procedimiento establecido en el Apartado 4.5:

- Partiendo de la información disponible en la literatura sobre las características de los aceros estructurales empleados en Europa, se identifican unos modelos probabilistas para las mencionadas variables, los límites elásticos $f_{y}$ y $f_{y w}$. Aunque el apartado no incluye ningún resumen explícito de los modelos correspondientes contenidos en los citados documentos de referencia [SAKO 1999, JCSS 2001], estos se usan a efectos comparativos (Apartado 6.5.2).

- Debido a que los resultados utilizados en la identificación de los modelos probabilistas para los dos límites elásticos se refieren a unos aceros empleados en el extranjero, se contrastan los parámetros con datos obtenidos sobre aceros destinados al mercado español. Esta comparación permite deducir unos modelos probabilistas que representan adecuadamente las características físicas de las variables correspondientes y que son compatibles con los modelos del código modelo probabilista, además de fáciles de usar (Apartado 6.5.2).

- El siguiente paso consiste en la determinación del valor de cálculo mediante el método FORM normalizado, así como del correspondiente coeficiente parcial para el límite elástico del acero estructural (Apartado 6.5.3). Debido a que para las acciones y sus efectos el procedimiento de verificación de los parámetros de los modelos probabilistas se ilustra para los momentos flectores inducidos por la carga de nieve en una viga de cubierta (Apartado 6.4.3), en el lado de la resistencia se considera el caso de la resistencia correspondiente.

- Por el motivo arriba mencionado, la comprobación del estado de incertidumbre representado por el modelo probabilista para el límite elástico y, en su caso, el ajuste de los parámetros correspondientes, se realiza en el Apartado 6.6.4, después de la identificación de los parámetros de todas las variables de resistencia necesarias para representar las incertidumbres asociadas con la resistencia de las vigas de acero frente a los mementos flectores. 


\subsubsection{Modelo}

\section{Identificación}

Para la identificación de un modelo probabilista para el límite elástico del acero estructural, $f_{y}$, se hace uso de los resultados obtenidos en un gran número de ensayos de tracción, realizados por la compañía de los ferrocarriles alemanes sobre probetas extraídas de perfiles laminados de acero S 235 [Dubas 1991]. Con un valor medio para el límite elástico de $267 \mathrm{~N} / \mathrm{mm}^{2}$ y una desviación típica de $16,66 \mathrm{~N} / \mathrm{mm}^{2}$, se deducen unos coeficientes de sesgo y variación de, respectivamente, $S_{f y}=1,136$ y $V_{f y}$ $=0,062$. Este coeficiente de sesgo supera en un $4 \%$ al valor máximo deducido según el código modelo probabilista [JCSS 2001]. No obstante, debido a que el empleo de perfiles laminados es habitual en las estructuras de edificación, se considera adecuado adoptar un valor de $S_{f y}=1,14$. En cuanto al coeficiente de variación, con un $6 \%$ se sitúa entre los valores adoptados en el estudio escandinavo [SAKO 1999] y el código modelo probabilista [JCSS 2001], respectivamente, por lo que también se considera apropiado, especialmente si se tiene en cuenta que el coeficiente de variación asumido en el segundo de estos dos documentos, [JCSS 2001], tiende a sobreestimar la dispersión [Faber 2002]. Con todo lo anterior, y suponiendo que el límite elástico del acero estructural se ajuste a una función de distribución lognormal, se identifica el siguiente modelo probabilista: $f_{y}=\operatorname{LN}(1,14$; $0,06)$.

Según el modelo establecido en el código modelo probabilista, [JCSS 2001], en perfiles laminados el valor medio del límite elástico del acero de las almas es aproximadamente un $5 \%$ superior al correspondiente valor del acero de las alas. Este incremento se puede tener en cuenta en la determinación de los modelos probabilistas para la resistencia de los elementos de acero frente a los esfuerzos cortantes. No obstante, a estos efectos también se debe considerar que en los perfiles laminados, cuyo empleo resulta habitual en las estructuras de edificación, la resistencia frente a los esfuerzos cortantes no suele ser determinante. Esta circunstancia puede cambiar si se emplean perfiles armados en lugar de los laminados, ya que en estos casos los espesores de chapa se adaptan a la capacidad portante requerida. Pero en los perfiles armados no se puede contar con un incremento del límite elástico del acero de las almas en comparación con el acero de las alas: en estos casos, el factor para la variación espacial tiene un valor de $\alpha=1,00$ [JCSS 2001]. Por todo lo anterior, para el límite elástico del acero de las almas o, en general, las áreas solicitadas por esfuerzos cortantes, $f_{y w}$, se adopta subjetivamente un coeficiente de sesgo que supera en un 2,5\% al coeficiente correspondiente para el acero de las alas, es decir de las áreas solicitadas por tensiones directas. En comparación con el modelo probabilista arriba mencionado, para el límite elástico del acero de las almas se mantienen sin cambios tanto el coeficiente de variación como la función de distribución. Con todo ello, el modelo probabilista identificado se escribe en los siguientes términos: $f_{y w}=\mathrm{LN}(1,17 ; 0,06)$.

\section{Resultados de ensayos de control de la fabricación}

Los modelos probabilistas para $f_{y}$ y $f_{y w}$, anteriormente identificados a partir de un gran número de ensayos de tracción efectuados sobre aceros destinados al mercado alemán, son compatibles con otros modelos reconocidos y válidos para diferentes mercados, como por ejemplo los modelos contenidos en el estudio escandinavo [SAKO 1999] y el código modelo probabilista [JCSS 2001]. A pesar de ello, resulta conveniente contrastar los modelos identificados con los datos experimentales obtenidos para los aceros estructurales destinados al mercado español. A estos efectos, a través de Calidad Siderúrgica, institución que promueve el desarrollo de políticas comunes de gestión de la calidad, normalización y certificación en la industria siderúrgica nacional, se solicitó la colaboración de las empresas del sector, pidiéndoles información sobre la resistencia del acero estructural de los productos que destinan al mercado nacional de la construcción. A esta petición contestaron cuatro empresas distinguidas con un certificado de calidad para sus productos siderúrgicos, particularmente los perfiles laminados de acero estructural. 
Tabla 6.5 - Evaluación de los resultados para el límite elástico, obtenidos en los ensayos de control de la fabricación de los aceros estructurales destinados al mercado español.

\begin{tabular}{|c|c|c|c|c|c|c|c|c|c|c|c|c|c|c|}
\hline 1 & 2 & 3 & 4 & 5 & 6 & 7 & 8 & 9 & 10 & 11 & 12 & 13 & 14 & 15 \\
\hline Tipo & $t$ & $f_{y k}$ & $F$ & $N$ & $\mu_{f y}$ & $\sigma_{f y}$ & $S_{f y}$ & $V_{f y}$ & \multicolumn{3}{|c|}{$\mu_{S, f y}$} & \multicolumn{3}{|c|}{$\mu_{V, f y}$} \\
\hline \multirow{7}{*}{ S 275} & \multirow{4}{*}{ a) } & \multirow{4}{*}{275} & 1 & 9518 & 336,9 & 13,39 & 1,225 & 0,04 & \multirow{4}{*}{$\begin{array}{l}1,182 \\
1,188\end{array}$} & \multirow{7}{*}{$\begin{array}{c}1,178 \\
1,19\end{array}$} & \multirow{12}{*}{$\begin{array}{l}1,164 \\
1,186\end{array}$} & & \multirow{7}{*}{$\begin{array}{l}0,037 \\
0,034\end{array}$} & \multirow{12}{*}{$\begin{array}{l}0,038 \\
0,035\end{array}$} \\
\hline & & & 2 & 22354 & 332,6 & 10,12 & 1,209 & 0,03 & & & & 0,036 & & \\
\hline & & & 3 & 743 & 317,3 & 11,98 & 1,154 & 0,038 & & & & 0,034 & & \\
\hline & & & 4 & 16034 & 313,1 & 11,11 & 1,139 & 0,036 & & & & & & \\
\hline & \multirow{3}{*}{ b) } & \multirow{3}{*}{265} & 2 & 6389 & 321,7 & 11,29 & 1,214 & 0,035 & \multirow{3}{*}{$\mid \begin{array}{l}1,174 \\
1,198\end{array}$} & & & \multirow{3}{*}{$\begin{array}{l}0,038 \\
0,035\end{array}$} & & \\
\hline & & & 3 & 875 & 304,8 & 14,95 & 1,15 & 0,049 & & & & & & \\
\hline & & & 4 & 1502 & 306,5 & 8,93 & 1,157 & 0,029 & & & & & & \\
\hline \multirow{5}{*}{ S 355} & \multirow{3}{*}{ a) } & \multirow{3}{*}{355} & 2 & 1450 & 413,5 & 13,08 & 1,165 & 0,032 & \multirow{3}{*}{$\begin{array}{l}1,139 \\
1,147\end{array}$} & \multirow{5}{*}{$\begin{array}{l}1,144 \\
1,144\end{array}$} & & \multirow{3}{*}{$\begin{array}{l}0,041 \\
0,038\end{array}$} & \multirow{5}{*}{$\begin{array}{c}0,039 \\
0,038\end{array}$} & \\
\hline & & & 3 & 359 & 398,4 & 19,1 & 1,122 & 0,048 & & & & & & \\
\hline & & & 4 & 1032 & 401,5 & 17,9 & 1,131 & 0,045 & & & & & & \\
\hline & \multirow{2}{*}{ b) } & \multirow{2}{*}{345} & 2 & 456 & 409,8 & 12,41 & 1,188 & 0,03 & \multirow{2}{*}{$\mid \begin{array}{l}1,152 \\
1,137\end{array}$} & & & \multirow{2}{*}{$\begin{array}{l}0,036 \\
0,038\end{array}$} & & \\
\hline & & & 3 & 1086 & 384,9 & 15,7 & 1,116 & 0,041 & & & & & & \\
\hline
\end{tabular}

1

2

3

4

$5 \quad$ : número de ensayos de control;

6 : valor medio del límite elástico del acero estructural en $\mathrm{N} / \mathrm{mm}^{2}$;

$7 \quad$ : desviación típica del límite elástico del acero estructural en N/mm²;

8 : coeficiente de sesgo del límite elástico del acero estructural;

$9 \quad$ : coeficiente de variación del límite elástico del acero estructural;

10-12 : valor medio del coeficiente de sesgo (en cursiva se indica el valor medio ponderado con el número de ensayos);

13 - 15 : valor medio del coeficiente de variación (en cursiva se indica el valor medio ponderado con el número de ensayos).

La información facilitada por estas empresas está basada en los ensayos de control de la fabricación de los aceros laminados de los tipos S 275 y S 355 [EN 1993-1-1 2005, CTE DB SE-A 2006, EAE 2011], tanto con espesores nominales inferiores a $16 \mathrm{~mm}$ como con espesores comprendidos en el intervalo entre $16 \mathrm{~mm}$ y $40 \mathrm{~mm}$. No incluye los datos correspondientes a los ensayos de tracción individuales, sino los parámetros estadísticos para el límite elástico del acero, obtenidos a partir de la totalidad de las coladas laminadas a lo largo del año 2008, por cada fábrica y para los productos considerados [CALSIDER 2009]. Los datos más relevantes para el presente estudio están recopilados en la Tabla 6.5. Se trata del valor medio, $\mu_{f y}$, y la desviación típica del límite elástico, $\sigma_{f y}$, para cada tipo de acero, en función del espesor nominal del producto así como de la fábrica que, por motivos de confidencialidad, está representada por medio de un número. También se representan el número de ensayos en los que se basan los mencionados parámetros estadísticos, así como el valor característico del límite elástico, $f_{y k}$, según el Código Técnico de la Edificación [CTE DB SE-A 2006]. Conviene 
destacar que esta norma considera una reducción del límite elástico del acero en productos con espesores nominales superiores a $16 \mathrm{~mm}$, mientras que otras normas, por ejemplo el Eurocódigo [EN 1993-1-1 2005] y la Instrucción [EAE 2011], contemplan una reducción de la resistencia del material sólo a partir de espesores nominales superiores a $40 \mathrm{~mm}$.

Partiendo de los parámetros para el límite elástico del acero estructural, facilitados por los fabricantes, se deducen los correspondientes coeficientes de sesgo, $S_{f y}$, y de variación, $V_{f y}$ (Tabla 6.5). El primero varía entre un valor mínimo de 1,116 y un máximo de 1,225. El coeficiente de variación, por otro lado, oscila entre un mínimo de 0,029 y un máximo de 0,049. A partir de los coeficientes de sesgo y de variación así obtenidos, también se pueden formar sus valores medio, $\mu_{S, f y}$ y $\mu_{V, f y}$, respectivamente. A estos efectos se agrupan en primer lugar los resultados correspondientes a un mismo tipo de acero y un determinado intervalo de espesores nominales del producto. Además se forman los valores medio agrupando los resultados de cada tipo de acero $\mathrm{y}$, finalmente, para la totalidad de los resultados disponibles. Para cada una de estas diferentes medias se indican dos valores numéricos, obtenidos respectivamente sin y con la ponderación de los datos de partida con el número de ensayos (Tabla 6.5).

Los valores medio del coeficiente de sesgo así obtenidos oscilan entre un mínimo de 1,137 (para productos de acero $\mathrm{S} 355$ con espesores nominales entre $16 \mathrm{~mm}$ y $40 \mathrm{~mm}$, ponderando los datos de partida con el número de ensayos) y un máximo de 1,198 (para productos de acero $\mathrm{S} 275$ con espesores nominales entre $16 \mathrm{~mm}$ y $40 \mathrm{~mm}$, ponderando los datos de partida con el número de ensayos). Para los valores medio del coeficiente de variación, los extremos se sitúan en 0,034 y 0,041, respectivamente. No obstante, los valores medio obtenidos para la totalidad de los resultados disponibles, sin ponderarlos con el número de ensayos, son los que mejor representan los parámetros estadísticos para el límite elástico de los aceros laminados con un certificado de calidad, empleados en la construcción en España. Suponiendo, como es habitual, que las variables de resistencia del material se ajusten a una función de distribución lognormal, el modelo probabilista para el límite elástico de estos aceros sería: $f_{y}=\mathrm{LN}(1,16 ; 0,04)$.

\section{Deducción}

En comparación con el modelo probabilista para el límite elástico basado en los ensayos de tracción realizados por la compañía de los ferrocarriles alemanes, el obtenido a partir de los ensayos de control de la fabricación de los aceros laminados con un certificado de calidad, destinados al mercado español, conduce a un valor medio mayor (102\%) y una dispersión menor (63\%). Para interpretar estos datos hay que tener en cuenta que los resultados obtenidos en ensayos de control de la fabricación sistemáticamente sobreestiman la resistencia del acero estructural [JCSS 2001]. Además, según se destaca en el estudio escandinavo [SAKO 1999], a los fabricantes les resultaría relativamente fácil reducir la resistencia media de los productos sin incumplir los requisitos de la normativa en vigor. Por estos motivos, parece prudente adoptar para el coeficiente de sesgo el valor identificado en primer lugar, y no el obtenido a partir de los ensayos de control.

Por otro lado, la dispersión de los resultados de los ensayos de control de cuatro fabricantes distinguidos con un certificado de calidad para sus productos siderúrgicos sin duda subestima la dispersión del límite elástico del material producido en el conjunto de fábricas del país, que incluye particularmente también aquéllas que no disponen de un certificado de calidad. Por ello, también en el caso del coeficiente de variación se debe adoptar el valor identificado a partir de los resultados obtenidos de manera independiente, en un gran número de ensayos de tracción. Como consecuencia, el modelo probabilista anteriormente identificado se considera representativo para el límite elástico del acero estructural empleado en el mercado nacional de la construcción: $f_{y}=\operatorname{LN}(1,14 ; 0,06)$. 
Finalmente, la información facilitada por los cuatro fabricantes de productos siderúrgicos no contiene datos específicos sobre la resistencia del acero de las almas en perfiles laminados. A falta de nuevas evidencias, mantienen su validez los argumentos empleados anteriormente en el marco de la identificación de un modelo probabilista para el límite elástico del acero de las áreas solicitadas por esfuerzos cortantes, $f_{y w}$. Y también la mantiene el propio modelo a emplear para la continuación de los trabajos: $f_{y w}=\mathrm{LN}(1,17 ; 0,06)$.

\subsubsection{Valor de cálculo y coeficiente parcial}

\section{Introducción}

Los modelos probabilistas para el límite elástico de los aceros estructurales empleados en España, deducidos en el apartado anterior, cumplen con los tres primeros de los cuatro requisitos establecidos en el Apartado 6.2.2. En analogía con el caso de los modelos probabilistas para la carga de nieve sobre cubiertas (Apartado 6.4.3), queda pendiente la comprobación del cumplimiento del cuarto requisito: la coincidencia con el estado de incertidumbre asociado con las reglas de dimensionado de la normativa en vigor.

A estos efectos se determinan los valores de cálculo de las variables consideradas mediante el método FORM normalizado [ISO 2394 1998, EN 1990 2002], así como los coeficientes parciales que los relacionan con los correspondientes valores representativos según las normas europeas y nacionales consideradas (Apartado 4.4), respectivamente [EN 1990 2002, EN 1993-1-1 2005] y [CTE DB SE 2006, EAE 2011], todo ello siguiendo el procedimiento definido en el Apartado 4.5. Por motivos de coherencia con las variables para las acciones y sus efectos, analizadas en el Apartado 6.4.3, se considera a título de ejemplo la resistencia frente a momentos flectores de las vigas de acero (Apartado 6.5.1). Es decir, se determina el coeficiente parcial para el límite elástico del acero estructural en vigas solicitadas por momentos flectores. Para este caso, el límite elástico es la variable de resistencia con el coeficiente de variación máximo (Apartado 6.7.2), por lo que se puede considerar como variable dominante en el marco de la aplicación del método FORM normalizado.

Por los motivos mencionados en el Apartado 6.5.1, la comparación del coeficiente parcial así determinado con el correspondiente valor requerido, así como el ajuste de los parámetros de los modelos probabilistas en caso de revelarse necesario optimizar la función objetivo (4.9), se realizan en el Apartado 6.6.4. Efectivamente, el formato de coeficientes parciales del Eurocódigo [EN 1993-11 2005] y de la Instrucción [EAE 2011], que es distinto al empleado en el presente estudio para la deducción de los modelos probabilistas (Apartado 6.3.2), requiere la identificación previa de los parámetros de todas las variables necesarias para representar las incertidumbres asociadas con la resistencia de las vigas de acero frente a mementos flectores:

$f_{y} \quad:$ límite elástico del acero estructural

$W_{p l} \quad$ : módulo plástico de la sección transversal

$\xi_{R, M} \quad$ : coeficiente para las incertidumbres del modelo de resistencia frente a momentos flectores.

\section{Límite elástico del acero estructural en vigas solicitadas por momentos flectores}

El modelo probabilista deducido para el límite elástico del acero estructural, $f_{y}$, se ajusta a una función de distribución lognormal (Apartado 6.5.2). Su dispersión es suficientemente pequeña (con un coeficiente de variación por debajo del $20 \%$ al $25 \%$ ) como para poder determinar el valor de cálculo, $f_{y, F O R M, d}$, mediante la formulación simplificada contenida en las normas internacionales [ISO 2394 1998, EN 1990 2002]:

$f_{y, F O R M, d}\left(\mu_{f y} ; \sigma_{f y}\right)=\mu_{f y} \cdot e^{-\alpha_{R, f y} \cdot \beta_{t} \cdot\left(\sigma_{f y} / \mu_{f y}\right)}$ 
$\begin{array}{ll}\alpha_{R, f y} & : \text { factor de sensibilidad para el límite elástico del acero estructural } \\ \mu_{f y} & : \text { valor medio del límite elástico del acero estructural } \\ \sigma_{f y} & : \text { desviación típica del límite elástico del acero estructural }\end{array}$

De acuerdo con el formato adoptado en el marco del presente estudio (Apartado 6.3.2), el coeficiente parcial para el límite elástico del acero estructural en elementos solicitados por momentos flectores, $\gamma_{m 0, M}$, tiene en cuenta la variación estadística de la resistencia del material. Este coeficiente se obtiene por ello a partir de los valores característico, $f_{y k}$ y de cálculo, $f_{y, F O R M, d}$, de esta variable:

$\gamma_{m 0, M}\left(\mu_{f y} ; \sigma_{f y}\right)=\frac{f_{y k}}{f_{y, F O R M, d}}=\frac{f_{y k}}{\mu_{f y}} \cdot e^{\alpha_{R, f y} \cdot \beta_{t} \cdot\left(\sigma_{f y} / \mu_{f y}\right)}$

Teniendo en cuenta la definición de los coeficientes de sesgo y de variación, respectivamente, de una variable básica (Apartado 6.2.2), el coeficiente parcial para el límite elástico del acero estructural se puede expresar en función de estos parámetros adimensionales:

$\gamma_{m 0, M}\left(S_{f y} ; V_{f y}\right)=\frac{1}{S_{f y}} \cdot e^{\alpha_{R, f y} \cdot \beta_{t} \cdot V_{f y}}$

$S_{f y} \quad$ : coeficiente de sesgo del límite elástico del acero estructural

$V_{f y} \quad$ : coeficiente de variación del límite elástico del acero estructural

Tal y como se menciona con anterioridad, en el caso considerado el límite elástico es la variable de resistencia dominante. Por ello, al correspondiente factor de sensibilidad se le puede asignar un valor de $\alpha_{R, f y}=0,8$ (Apartado 3.4.2), tanto según la norma internacional [ISO 2394, 1998] como el Eurocódigo y el Código Técnico de la Edificación [EN 1990 2002, CTE DB SE 2006]. Introduciendo en la ecuación (6.57) este valor normalizado para $\alpha_{R, f y}$, el valor del índice de fiabilidad requerido para un período de referencia de 50 años, $\beta_{t}=3,8$ (Apartado 3.6.2), así como los parámetros previamente deducidos del modelo probabilista para el límite elástico del acero estructural (Apartado 6.5.2), $S_{f y}=$ 1,14 y $V_{f y}=0,06$, se obtiene el siguiente valor numérico para el coeficiente parcial, $\gamma_{m 0, M}$ :

$\gamma_{m 0, M}\left(S_{f y} ; V_{f y}\right)=1,0527$

\subsection{INCERTIDUMBRES DE LOS MODELOS PARA LA RESISTENCIA DE LOS ELEMENTOS DE ACERO}

\subsubsection{Introducción}

\section{Contexto}

\section{Modelado de la resistencia}

El Apartado 6.5 contiene algunos aspectos genéricos en relación con el modelado de la resistencia de los elementos estructurales. De los tres tipos de variables (geométricas, características de los materiales, incertidumbres de los modelos), a título de ejemplo, se aborda la deducción de un modelo probabilista para el límite elástico del acero estructural y se explica que la comprobación de la concordancia de este modelo con el estado de incertidumbre asociado con las reglas de la normativa analizada requiere la consideración simultánea de los modelos probabilistas deducidos para las otras variables de resistencia que sean relevantes según el mecanismo de fallo y la correspondiente función de estado límite considerados. Por este motivo, a continuación no solamente se abordan las incertidumbres asociadas con los modelos de resistencia, tema principal del presente apartado, sino también se presentan algunas nociones sobre las incertidumbres geométricas, antes de proceder a la 
mencionada comprobación del estado de incertidumbre y, en su caso, el ajuste de los parámetros de los modelos probabilistas deducidos, según el procedimiento del Apartado 4.5.

\section{Incertidumbres geométricas}

Las propiedades geométricas de un elemento estructural o de una estructura se refieren a las dimensiones del sistema considerado. Ejemplos típicos son el canto de una sección transversal, el espesor de una chapa de acero, el recubrimiento de las armaduras en estructuras de hormigón, la rectitud de un elemento metálico o la excentricidad de la introducción de las cargas en pilares. También son propiedades geométricas los parámetros derivados de las dimensiones. Como ejemplos se pueden citar el área o el momento de inercia de una sección transversal.

El aspecto más relevante para el establecimiento de los modelos probabilistas de las dimensiones geométricas inciertas es su variabilidad espacial. Normalmente, su variabilidad en el tiempo no tiene importancia práctica. En el momento de la redacción de un proyecto, la geometría de la futura construcción resulta incierta. Los únicos medios disponibles para limitar las incertidumbres asociadas con la geometría son las especificaciones de proyecto y las tolerancias de ejecución establecidas. Sobre la base de estas especificaciones se pueden deducir unos modelos probabilistas apriorísticos para las propiedades geométricas [Faber 2002].

Durante la ejecución de la estructura, en el marco de las actividades del control de calidad, se determinan las dimensiones geométricas para comparar sus desviaciones de los valores nominales con las correspondientes tolerancias. Los valores medio suelen aproximarse a las dimensiones nominales, aunque pueden existir casos en los que aparezcan diferencias sistemáticas. Los valores absolutos de las desviaciones entre la geometría real y la nominal dependen fuertemente de las tolerancias establecidas. La desviación típica suele situarse en el mismo orden de magnitud de las tolerancias [Schneider 1994]. Por este motivo, las incertidumbres asociadas con la geometría tienden a tener una influencia decreciente en la medida en que aumenten las dimensiones de una estructura y de los elementos que la componen.

\section{Incertidumbres del modelo}

Cualquier fenómeno físico relacionado con un sistema técnico, por ejemplo una estructura, se puede describir mediante distintos modelos, alcanzando diferentes niveles de aproximación al comportamiento real, bajo la hipótesis de que éste sea conocido. Estas aproximaciones pueden variar entre una descripción puramente científico-matemática del fenómeno que gobierna el problema a resolver, y una descripción puramente empírica, basada en ensayos experimentales y en observaciones. En principio, para cualquiera de estos niveles de aproximación es posible establecer los correspondientes modelos probabilistas para las cargas, sus efectos y la capacidad del sistema para resistirlos. Las propiedades de estos modelos están afectadas por incertidumbres. Las denominadas incertidumbres de los modelos se mencionan con anterioridad en el marco del presente trabajo, por ejemplo en los Apartados 3.5, 6.3 y 6.4.

En la ingeniería en general, y ciertamente en la ingeniería estructural, los modelos empleados suelen pertenecer a un nivel intermedio entre los dos extremos arriba mencionados. Por este motivo, un análisis estructural mediante técnicas de fiabilidad utilizando modelos de este tipo, se basa en el conocimiento físico del problema a resolver, pero debido a diferentes simplificaciones inherentes a los modelos siempre será empírico hasta un cierto grado. Si se efectúan ensayos referidos a un determinado problema, esta situación se traduce en una falta de ajuste entre los resultados experimentales y los obtenidos mediante el correspondiente modelo. Es esta falta de ajuste que representa las incertidumbres del modelo, asociadas con el nivel de aproximación (al comportamiento real) de la formulación empleada para describir el problema físico. Por su relevancia, en un análisis 
de fiabilidad es imprescindible tener adecuadamente en cuenta las incertidumbres asociadas con los modelos.

\section{Determinación}

Las incertidumbres asociadas con un determinado modelo se pueden estimar por medio de experimentos, sobre todo en el caso de los modelos para la resistencia estructural. El coeficiente para las incertidumbres de un modelo de resistencia, $\xi_{R}$, se define como el factor con el que se debería multiplicar el valor de la capacidad portante de un elemento o sistema estructural, obtenido mediante un determinado modelo, $R_{t}$, para establecer la capacidad portante del sistema cuyo valor real, $R$, normalmente es desconocido:

$$
R=\xi_{R} \cdot R_{t}
$$

$$
\begin{array}{ll}
R & \text { : capacidad portante real de un elemento o sistema estructural } \\
R_{t} & \text { : capacidad portante teórica de un elemento o sistema estructural } \\
\xi_{R} & \text { : coeficiente para las incertidumbres del modelo de resistencia }
\end{array}
$$

A efectos de la determinación de los parámetros de esta variable, la capacidad portante obtenida en un ensayo representativo para un determinado elemento o sistema, $r_{e, i}$, se divide entre el valor correspondiente determinado mediante el modelo cuyas incertidumbres se procura determinar, $r_{t, i}$ :

$$
\xi_{R, i}=\frac{r_{e, i}}{r_{t, i}}
$$

$r_{e, i} \quad$ : capacidad portante real de un elemento o sistema estructural, obtenida experimentalmente sobre la probeta $i$

$r_{t, i} \quad$ : capacidad portante teórica de un elemento o sistema estructural, obtenida para la probeta $i$, empleando el modelo de resistencia analizado

$\xi_{R, i} \quad:$ ratio entre las capacidades portantes real y teórica para la probeta $i$

Para la determinación de los valores teóricos, $r_{t, i}$, se deben medir o controlar todas las variables básicas que intervienen en el modelo aplicado. En particular, se deben determinar las características geométricas y las propiedades de los materiales constitutivos de cada probeta $i$ ensayada. También se debe tener en cuenta la influencia de las condiciones de contorno del ensayo. De esta manera, la ratio establecido según la ecuación (6.60) se puede considerar como siendo de carácter intrínseco al modelo, aplicado a la probeta $i$. Eso a pesar de que en realidad existen incertidumbres adicionales, relacionadas con la determinación tanto de las variables básicas como del valor $r_{e, i}$ [Sykora 2014].

A partir de un número representativo de ensayos, se establece un histograma para la variable del modelo, $\xi_{R}$, que permite ajustar una función de distribución para la que se determina el valor medio y la desviación típica. En ausencia de un sesgo inherente al modelo, el valor medio de la variable se aproxima a $\mu_{\xi R}=1,0$. No obstante, debido a que los modelos de resistencia suelen ser conservadores, a menudo resulta $\mu_{\xi R}>1,0$. El valor numérico de la desviación típica, $\sigma_{\xi R}$, puede variar considerablemente, según el caso. Si el nivel de aproximación al comportamiento real es bueno, por ejemplo en los modelos de resistencia frente a momentos flectores de secciones de acero estructural o de hormigón armado, el coeficiente de variación puede ser del orden de 0,02 a 0,05 [Faber 2002]. Al contrario, en los modelos con un nivel de aproximación bajo, por ejemplo en los relativos a la resistencia de los elementos de hormigón armado frente a esfuerzos cortantes o frente al punzonamiento, el coeficiente de variación de la variable del modelo alcanza fácilmente valores entre 0,1 y 0,2 [Schneider 1994].

La variable del modelo de resistencia definida a través de la ecuación (6.59) se suele modelar mediante una función de distribución lognormal [Faber 2002]. Si la capacidad portante según el modelo empleado, $R_{t}$, también se describe mediante una distribución lognormal, el producto de las 
dos variables, la resistencia del elemento o del sistema estructural, $R$, se ajusta al mismo tipo de función de distribución.

\section{Estructuración del apartado}

Igual que para las variables de los modelos destinados a la determinación de los efectos de las acciones (Apartado 6.4.3), $\xi_{E}$, también para los coeficientes para las incertidumbres de los modelos de resistencia, $\xi_{R}$, se encuentran modelos probabilistas en la literatura especializada. Por ejemplo, el código modelo probabilista contiene modelos para estos coeficientes, asociados con los principales mecanismos de resistencia y materiales constitutivos de los elementos estructurales [JCSS 2001]. La reciente publicación [Sykora 2014], por otro lado, contiene información detallada sobre las incertidumbres asociadas con los modelos de resistencia para las estructuras de hormigón armado según el Eurocódigo [EN 1992-1-1 2004]. Este tipo de información, disponible en la literatura, se utiliza como base para la identificación de los modelos probabilistas para las variables de los modelos que intervienen en las funciones de estado límite establecidas en el Apartado 5.4. Aun así, en el marco del presente estudio se renuncia a incluir un resumen explícito de los modelos contenidos en publicaciones especializadas. En su lugar, se considera más pertinente justificar la verosimilitud de los modelos identificados.

Los modelos probabilistas para las incertidumbres de los modelos de resistencia de los elementos estructurales, normalmente, no están basados en datos experimentales adecuados ni suficientes en cuanto a su calidad y cantidad. Lo mismo también ocurre en relación con los modelos para los efectos de las acciones y sus incertidumbres [JCSS 2001]. Por este motivo suele ser necesario recurrir a estudios comparativos entre diferentes modelos para comprobar su verosimilitud. Estas comparaciones cobran especial valor cuando se basan en resultados experimentales. Y eso incluso cuando los elementos ensayados están fabricados de otros materiales constitutivos, como ocurre en el estudio desarrollado a continuación: si es posible demostrar una coincidencia entre los modelos subjetivamente identificados sobre la base de datos tomados de la literatura especializada y los deducidos a partir de unos ensayos representativos, la verosimilitud de los primeros aumenta de manera generalizada.

Teniendo en cuenta todo lo anterior, en este apartado se abordan los siguientes aspectos:

- A título de ejemplo, en el marco del presente estudio se considera de manera explícita la deducción de los modelos probabilistas para las variables que intervienen en la determinación de la resistencia de las vigas de acero frente a momentos flectores (Apartado 6.5.3). Consecuentemente, en el Apartado 6.6.2 se identifican los parámetros del modelo probabilista para la variable del modelo de resistencia de las vigas de acero frente a momentos flectores, $\xi_{R, M}$. A efectos informativos también se incluyen algunas observaciones sobre la identificación de los parámetros de los modelos probabilistas para las variables de los modelos de resistencia de los elementos de acero frente a esfuerzos cortantes y axiles, $\xi_{R, V}$ y $\xi_{R, N}$, respectivamente.

- La verosimilitud de los modelos identificados se comprueba a través de la determinación del modelo probabilista para la variable del modelo de resistencia de las vigas de otro material constitutivo, para las que se dispone de los resultados experimentales necesarios a efectos de la determinación de los parámetros $\mu_{\xi R}$ y $\sigma_{\xi \xi R}$ según el procedimiento arriba mencionado. Concretamente, se trata de dos campañas experimentales efectuadas sobre una serie de vigas de hormigón armado, deterioradas por la corrosión de las armaduras (Apartado 6.6.3).

- Como ya se menciona en el Apartado 6.5.1, la comprobación del estado de incertidumbre representado por los modelos probabilistas de las variables que intervienen en el modelo de resistencia de las vigas de acero frente a momentos flectores y, en su caso, el ajuste de los parámetros correspondientes, se realizan en el Apartado 6.6.4. 


\subsubsection{Identificación de parámetros}

\section{Modelo de resistencia frente a momentos flectores}

Los parámetros, reflejados en el código modelo probabilista en relación con la variable del modelo de resistencia de las vigas de acero, en realidad se refieren a los modelos para la capacidad resistente de estos elementos frente a solicitaciones por momentos flectores en presencia de esfuerzos axiles y esfuerzos cortantes [JCSS 2001]. Los valores indicados son 1,0 para la media y 0,05 para el coeficiente de variación. Por lo menos intuitivamente parece plausible que un modelo de resistencia para la flexión simple conduce a un mayor nivel de aproximación a la capacidad resistente real que un modelo de resistencia frente a la interacción de diferentes tipos de esfuerzos. Tanto es así que algunas publicaciones sugieren que las incertidumbres resultan despreciables en el caso de los modelos de resistencia plástica de las vigas laminadas de acero estructural, solicitadas por momentos flectores [Dubas 1991]. Debido a que no siempre es posible alcanzar el momento plástico, particularmente en las vigas armadas de chapas esbeltas de acero, y debido a que las incertidumbres asociadas con los modelos de resistencia que tienen en cuenta la abolladura de las zonas comprimidas de una sección con chapas esbeltas son mayores que las incertidumbres de los modelos para la resistencia plástica de una sección compacta, en la terminología del Eurocódigo [EN 1993-1-1 2005], parece prudente adoptar un coeficiente de variación intermedio entre los propuestos por [Dubas 1991] y [JCSS 2001], cercano a 0,0 y 0,05 , respectivamente. Con un valor de 0,02 este coeficiente de variación tendría un orden de magnitud comparable a la dispersión asumida en otras publicaciones especializadas para este tipo de modelos de resistencia [Faber 2002].

Con todo lo anterior, en el marco del presente estudio se adopta el siguiente modelo probabilista para las incertidumbres del modelo de resistencia de las vigas de acero estructural frente a momentos flectores: $\xi_{R, M}=\mathrm{LN}(1,0 ; 0,02)$.

\section{Modelo de resistencia frente a esfuerzos cortantes}

Para las incertidumbres del modelo de resistencia de las vigas de acero estructural frente a esfuerzos cortantes, $\xi_{R, V}$, el código modelo probabilista define un modelo con un valor medio de 1,0 y un coeficiente de variación de 0,05 [JCSS 2001]. Se trata de los mismos parámetros que este documento propone para los modelos relativos a la capacidad resistente de las vigas de acero frente a la interacción de momentos flectores con otros esfuerzos. Intuitivamente parece que el nivel de aproximación de un modelo para la resistencia de un elemento estructural a la capacidad resistente real debería ser mayor si la solicitación es un esfuerzo simple. Por ello parece razonable reducir en el presente caso el coeficiente de variación propuesto en el código modelo [JCSS 2001]. Por otro lado, la experiencia demuestra que el nivel de aproximación suele ser menor en el caso de los modelos de resistencia frente a los esfuerzos cortantes que en el caso de los modelos de resistencia frente a solicitaciones caracterizadas por tensiones directas. No existe motivo alguno para justificar que eso sea diferente en el caso de los modelos de resistencia frente a los esfuerzos cortantes para las vigas de acero, sobre todo si por la esbeltez del alma se pueden producir fenómenos de abolladura, con la subsiguiente formación de complejos mecanismos de resistencia post-crítica [EN 1993-1-1 2005]. Por todo ello se adopta en el presente estudio un modelo probabilista con un coeficiente de variación que duplica el adoptado para las incertidumbres de los modelos de resistencia frente a los momentos flectores: $\xi_{R, V}=\mathrm{LN}(1,0 ; 0,04)$.

\section{Modelo de resistencia frente a esfuerzos axiles}

El código modelo probabilista [JCSS 2001] no contiene información sobre las incertidumbres del modelo de resistencia de pilares de acero estructural frente a esfuerzos axiles de compresión. Debido a que en el caso de los pilares el presente estudio se centra en la resistencia de las secciones transversales, tal y como se justifica en el Apartado 5.3.1, y porque en pilares armados las chapas 
comprimidas en principio pueden estar afectadas por abolladuras, aunque este fenómeno de inestabilidad también queda excluido a través de las hipótesis adoptadas en el mismo apartado, subjetivamente se puede suponer que el nivel de aproximación entre los modelos para la resistencia frente a los esfuerzos axiles de compresión y la capacidad resistente real sea similar al asumido en el caso de los modelos de resistencia para la flexión simple. Por ello se adopta el siguiente modelo probabilista para las incertidumbres del modelo de resistencia de los pilares de acero estructural frente a los esfuerzos axiles de compresión: $\xi_{R, N}=\mathrm{LN}(1,0 ; 0,02)$.

\subsubsection{Estudio de verosimilitud}

\section{Estructuras de hormigón armado deterioradas por la corrosión}

\section{Efectos de la corrosión de las armaduras}

La corrosión del acero de las armaduras es considerada, generalmente, como el principal mecanismo de deterioro de las estructuras de hormigón armado [CONTECVET 2001]. Este mecanismo conlleva, en primer lugar, la reducción de la sección transversal de la armadura y la pérdida de ductilidad del material. Otra de las consecuencias es el efecto entalla, sobre todo si se trata de corrosión inducida por la penetración de cloruros, causando picaduras en el acero y, por tanto, unos cambios bruscos de la sección e irregularidades geométricas. Adicionalmente, la fisuración del recubrimiento de hormigón producida por la expansión de los productos de la corrosión puede tener un efecto adverso en la interacción entre el hormigón y el acero debido a la pérdida de adherencia entre estos dos materiales. En casos de estados avanzados de corrosión, la expansión de estos productos incluso puede causar el desprendimiento del hormigón. Por las razones anteriores, la corrosión del acero de las armaduras puede afectar al comportamiento de las estructuras de hormigón, tanto en el estado límite de servicio, como en el estado límite último.

\section{Capacidad portante}

En la literatura pueden encontrarse modelos simplificados que permiten estimar el comportamiento de vigas y pilares de hormigón con armaduras corroídas [CONTECVET 2001]. La capacidad portante de estos elementos puede determinarse de acuerdo a los principios básicos definidos en las normas para el dimensionado estructural, como el Eurocódigo [EN 1992-1-1 2004], convenientemente adaptados. En general, los modelos de resistencia pueden establecerse a partir del teorema estático de la teoría de la plasticidad [Muttoni 1997]. Para este fin, los efectos del deterioro en la resistencia y capacidad de deformación deben ser cuantificados y considerados a través de las propiedades actualizadas de la geometría y de los materiales [Tanner 2011a]. Puesto que en las estructuras existentes muchas características se pueden medir, la actualización de los parámetros de la geometría y de los materiales es factible incluso en el caso de elementos deteriorados.

Lo mismo no puede decirse sobre la adherencia entre las barras de armadura y el hormigón, y por consiguiente del mecanismo de transmisión de las tensiones longitudinales que puede verse afectado por la corrosión. Sin embargo, el conocimiento de la adherencia en estructuras deterioradas por la corrosión es esencial para la evaluación de la fiabilidad estructural puesto que un fallo en la transmisión de las fuerzas entre la armadura y el hormigón que la rodea lleva a un comportamiento potencialmente frágil de la estructura. En un intento por llenar la falta de conocimiento sobre la adherencia en las estructuras deterioradas por la corrosión, se llevó a cabo un estudio experimental y numérico sobre este tema [Prieto 2014]. El programa experimental y los resultados más importantes se describen en una publicación anterior [Prieto 2013], incluyendo la comparación con los resultados de algunas de las simulaciones numéricas realizadas.

Aunque se requieren estudios adicionales antes de disponer de un modelo práctico que permita determinar adecuadamente la adherencia de las barras de armadura corroídas, de acuerdo con lo 
anterior puede asumirse que toda la información relevante para determinar la capacidad portante de las estructuras de hormigón armado deterioradas por la corrosión está disponible o puede obtenerse: las propiedades de los materiales y las características geométricas, incluyendo las áreas residuales de las secciones de las armaduras y del hormigón, a partir de las correspondientes campañas de adquisición de datos en obra; la adherencia a partir de estudios como el citado [Prieto 2013, Prieto 2014]. La resistencia remanente a flexión de las vigas afectadas por la corrosión, por ejemplo, puede calcularse mediante la mencionada información actualizada, en combinación con los modelos para la resistencia como los descritos en las normas estructurales, por ejemplo el Eurocódigo [EN 1992-1-1 2004] o el código modelo [FIB 2013], adecuadamente adaptados y modificados. Una estimación para el límite superior de la resistencia remanente se obtiene considerando las secciones reducidas de las armaduras en los citados modelos para la resistencia a flexión. Los efectos de las concentraciones de tensiones debidas a los cambios geométricos por la corrosión de las armaduras deben considerarse cuando resulten relevantes, particularmente en los casos de la corrosión por picaduras, mientras que la posible fragilización del acero puede despreciarse en la mayoría de los elementos de hormigón armado. Además de estas modificaciones, si se producen desprendimientos se debe tener en cuenta el área de la sección residual del hormigón. Adicionalmente, aunque no se observen desprendimientos, debe considerarse que el recubrimiento de hormigón podría estar fisurado como resultado de la expansión de los productos de la corrosión. Se asume que los efectos de estas fisuras sobre la resistencia del hormigón sean equivalentes a los de las fisuras inducidas por unas deformaciones impuestas en sentido transversal a un campo de tensiones en una estructura de hormigón sana. En este caso, la resistencia plástica efectiva del hormigón, $f_{c e}$, puede determinarse, con suficiente precisión, en función de la deformación unitaria en sentido transversal, $\varepsilon_{l}$, y la resistencia característica a compresión, $f_{c k}$, determinada en probetas cilíndricas [Muttoni 2011]:

$$
\begin{aligned}
& f_{c e}=\frac{1}{0,8+170 \cdot \varepsilon_{1}} \cdot f_{c k} \leq f_{c k} \\
& f_{c e} \quad: \text { resistencia plástica efectiva del hormigón } \\
& \varepsilon_{l} \quad: \text { deformación unitaria en sentido transversal }
\end{aligned}
$$

Como las deformaciones unitarias inducidas por la corrosión son difíciles de cuantificar, la ecuación anterior no puede usarse directamente para determinar la resistencia efectiva del hormigón. El fenómeno del ablandamiento del hormigón debido a las fisuras inducidas por deformaciones impuestas debe tenerse en cuenta de manera indirecta. Nuevamente, se usa la analogía con las estructuras sanas en las que no se determinan directamente las deformaciones transversales en caso de emplear campos de tensiones rígido-plásticos: se adoptan valores aproximados para la resistencia efectiva del hormigón, dependiendo de los esfuerzos considerados y del ángulo entre las fisuras impuestas y la orientación del campo de compresión [Muttoni 2011]. La expansión de los productos de corrosión generalmente produce fisuras paralelas a las barras, por lo tanto paralelas al campo de compresión en el caso de flexión, lo que resulta en la siguiente resistencia efectiva del hormigón de recubrimiento [FIB 2013]:

$f_{c e}=k_{c p} \cdot \eta_{f c} \cdot f_{c k}$

$k_{c p} \quad:$ coeficiente para la determinación de la resistencia plástica del hormigón

$\eta_{f c} \quad:$ factor de corrección que tiene en cuenta el comportamiento frágil de los hormigones de alta resistencia

Para el coeficiente de reducción, $k_{c p}$, se adopta un valor de 0,75 [FIB 2013]. Por otro lado, $\eta_{f c}$ es un factor que tiene en cuenta el aumento de la fragilidad del hormigón con el incremento de la resistencia a compresión determinada en probetas cilíndricas [Muttoni 1997, Muttoni 2011, FIB 2013]: 
$\eta_{f c}=\left(\frac{30}{f_{c k}}\right)^{\frac{1}{3}} \leq 1,0$

Además de las anteriores consideraciones, se puede estimar un límite inferior para la resistencia remanente si se desprecia la contribución del recubrimiento de hormigón en la zona de compresión de la sección transversal analizada, asumiendo su desprendimiento hipotético como resultado de la expansión de los productos de corrosión. También en este caso, en los modelos de resistencia debe considerarse el área reducida de las secciones transversales de las barras de armadura.

De manera similar, la resistencia remanente frente a los esfuerzos cortantes se determina a partir de los modelos descritos en el código modelo [FIB 2013], adecuadamente adaptados y modificados, adoptando unas hipótesis equivalentes a las anteriores para la resistencia remanente a flexión, en combinación con el uso de la información actualizada sobre las propiedades de los materiales, la geometría y la adherencia. En las almas de las vigas, la armadura suele ser oblicua a la orientación del campo de compresión, en cuyo caso se utiliza un coeficiente de reducción $k_{c p}=0,55$ para determinar la resistencia efectiva del hormigón de acuerdo con la ecuación (6.62). En los pilares, por otra parte, las fisuras inducidas por la corrosión suelen ser paralelas a la dirección de la compresión, con lo que también en este caso puede asumirse un factor de reducción $k_{c p}=0,75$ para determinar la resistencia efectiva del hormigón de recubrimiento.

\section{Ensayos disponibles}

Para la deducción de los parámetros que caracterizan los coeficientes para las incertidumbres de los modelos de resistencia frente a momentos flectores y esfuerzos cortantes, respectivamente, de vigas de hormigón deterioradas por la corrosión de las armaduras, se dispone de los resultados de dos estudios [Rodríguez 1995, L’Hostis 2007]. A continuación se describen brevemente las dos campañas experimentales.

En el marco del segundo de los dos estudios mencionados [L'Hostis 2007], un proyecto de investigación a largo plazo, se fabricaron 40 vigas pretensadas, con armadura lisa, que se expusieron durante 40 años a un ambiente marino. Las vigas tenían una longitud de 2,5 $\mathrm{m}$ y una sección transversal de 0,2 $\mathrm{m} \times 0,2 \mathrm{~m}$. Para el pretensado se emplearon alambres de $7 \mathrm{~mm}$ de diámetro, embebidos en una vaina plástica de $12 \mathrm{~mm}$ de diámetro y anclados en los extremos de la viga. La armadura longitudinal y de cortante estaba constituida por barras lisas con un diámetro de $6 \mathrm{~mm}$. La ratio de armadura longitudinal variaba entre $0,71 \%$ y $0,85 \%$ mientras que para la armadura de cortante era constante, de $0,11 \%$. El acero de pretensar estaba protegido y no sufrió deterioro por corrosión, mientras que en la armadura longitudinal pasiva las pérdidas máximas de sección variaban entre el $18,1 \%$ y el $40,4 \%$ en la armadura de tracción, y alcanzaron hasta el $36,4 \%$ en la de compresión. Para determinar experimentalmente su capacidad portante, 6 de las vigas fueron sometidas a ensayos de flexión en 4 puntos. Todas las vigas ensayadas fallaron por flexión simple.

El primero de los dos estudios mencionados [Rodríguez 1995], formó parte de un proyecto de investigación más amplio sobre el período de servicio remanente de las estructuras de hormigón armado. Se fabricaron 41 vigas cuya longitud típica era de $2,3 \mathrm{~m}$, con secciones transversales de 0,2 $\mathrm{m}$ de canto y $0,15 \mathrm{~m}$ de ancho. Para las distintas vigas se utilizaron diferentes ratios de armadura longitudinal y transversal. En el caso de la armadura longitudinal esta ratio variaba entre el $0,5 \%$ y el $1,51 \%$, mientras que para la armadura de cortante lo hacía entre el $0,22 \%$ y el $0,44 \%$. De estas vigas, 31 se sometieron a un proceso de corrosión acelerada. Para determinar su capacidad portante, posteriormente estas vigas se llevaron hasta la rotura mediante ensayos de flexión en 4 puntos. 25 de las vigas ensayadas fallaron por flexión simple, de las cuales sólo 15 habían sido sometidas al proceso de corrosión acelerada. En ellas se obtuvieron pérdidas de sección en la armadura de tracción que 
variaban entre el $9,75 \%$ y el $26,4 \%$, mientras que en la de compresión alcanzaban valores hasta el $30,3 \%$. Las 10 vigas sanas restantes fallaron por flexión, aunque en el marco del presente trabajo no se analizan los resultados correspondientes.

En 12 de las vigas con armaduras corroídas, ensayadas en el mismo estudio [Rodríguez 1995], se observó un fallo por tracción en el alma inducida por los esfuerzos cortantes. Estas vigas mostraron pérdidas de sección en la armadura de tracción que variaban entre el 10,7\% y el 16,9\%. En la armadura de compresión alcanzaban un máximo del 25,2\%. En la armadura transversal de estas vigas las pérdidas de sección variaban entre el 21,4\% y el 37,6\%.

\section{Deducción de las incertidumbres de los modelos}

Partiendo de los resultados de las citadas campañas experimentales [Rodríguez 1995, L'Hostis 2007], se determinan los parámetros de los coeficientes para las incertidumbres de los modelos, anteriormente descritos, de resistencia frente a momentos flectores y esfuerzos cortantes de las vigas de hormigón armado afectadas por la corrosión, $\xi_{R, M, c o r r}$ y $\xi_{R, V, c o r r}$, respectivamente. Según las características de los elementos ensayados, se distingue entre vigas con armaduras lisas y corrugadas. Los parámetros de los diferentes coeficientes se deducen según las especificaciones del Apartado 6.6.1.

Para los posibles modos de fallo se determina la capacidad portante de cada una de las vigas estudiadas, utilizando los modelos de resistencia establecidos en el Eurocódigo [EN 1992-1-1 2004] y el código modelo [FIB 2013], respectivamente para flexión y cortante, adaptados según los criterios establecidos en el presente apartado, y comprobando además la ausencia de un fallo prematuro por una adherencia insuficiente entre armadura y hormigón. Para las dimensiones geométricas y las propiedades de los materiales se utilizan, a efectos de cálculo, los valores empíricos correspondientes a cada una de las vigas. En los casos en los que se desconocen estos datos, se emplean valores nominales para las dimensiones geométricas y valores medios para las características de los materiales, obtenidas para las vigas restantes de la misma serie.

La capacidad portante mínima obtenida para una determinada viga indica el modo de fallo teórico, además del valor de la resistencia teórica. El modo de fallo teórico debería coincidir con el observado en el ensayo correspondiente para poder tener en cuenta el caso en la evaluación estadística de los resultados. A continuación se establece, para cada una de las vigas analizadas, la ratio entre la capacidad portante determinada experimentalmente y la teórica, según la ecuación (6.60). Estas ratios se emplean, finalmente, para deducir los parámetros de las variables de los modelos para los límites superior e inferior de la resistencia frente a momentos flectores y esfuerzos cortantes, respectivamente, de las vigas de hormigón con armaduras (lisas o corrugadas) afectadas por la

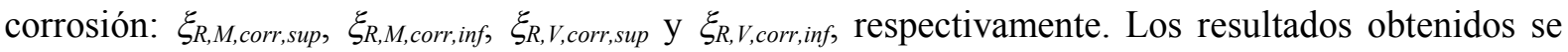
muestran en la Tabla 6.6, donde también se indica para cada caso el número de resultados utilizados a efectos de la deducción de los parámetros. La cuantificación de los parámetros se efectúa en términos de valores medio, $\mu_{\xi R}$, y coeficientes de variación, $V_{\xi R}$, mientras que para la función de distribución se asume que las variables de los modelos de resistencia se ajusten a una lognormal, como suele ser habitual (Apartado 6.6.1).

El valor medio de 1,29, obtenido para el límite inferior de las incertidumbres del modelo para vigas de hormigón armado con barras de acero corrugadas, $\xi_{R, M, c o r r, i n f}$, corresponde a una estimación conservadora de la resistencia. En cambio, la variable del modelo para el límite superior, $\xi_{R, M, c o r r, s u p}$, con un valor medio de 0,99 corresponde a una estimación ligeramente optimista de la capacidad resistente. El coeficiente de variación obtenido para las incertidumbres de ambos modelos es del orden de más del 10\%, indicando un nivel de precisión bajo en comparación con el coeficiente de variación para las incertidumbres del modelo de resistencia a flexión para vigas de hormigón sanas, 
deducido en un estudio previo [Tanner 2007b], o en comparación con el valor que puede encontrarse en la literatura [Schneider 1994].

Tabla 6.6 - Modelos probabilistas para las incertidumbres asociadas con los modelos de resistencia a flexión y cortante, adaptados del Eurocódigo [EN 1992-1-1 2004] y el código modelo [FIB 2013], respectivamente, para vigas de hormigón con armaduras corroídas.

\begin{tabular}{|c|c|c|c|c|c|c|c|}
\hline Modo de fallo & Tipo de barras & Límite & Notación & $\begin{array}{c}\mathbf{N}^{\mathbf{o}} \\
\text { ensayos }\end{array}$ & Tipo & $\mu_{\xi R}$ & $V_{\xi R}$ \\
\hline \multirow{4}{*}{ Flexión } & \multirow{2}{*}{ Lisas } & Superior & $\xi_{R, M, \text { corr }, \text { sup }}$ & 6 & \multirow{2}{*}{$\mathrm{LN}$} & 1,06 & 0,20 \\
\hline & & Inferior & $\xi_{R, M, \text { corr, inf }}$ & 6 & & 1,18 & 0,21 \\
\hline & \multirow{2}{*}{ Corrugadas } & Superior & $\xi_{R, M, \text { corr sup }}$ & 15 & \multirow{2}{*}{$\mathrm{LN}$} & 0,99 & 0,10 \\
\hline & & Inferior & $\xi_{R, M, c o r r, i n f}$ & 12 & & 1,29 & 0,14 \\
\hline \multirow{2}{*}{ Cortante } & \multirow{2}{*}{ Corrugadas } & Superior & $\xi_{R, V, \text { corr sup }}$ & 12 & \multirow{2}{*}{$\mathrm{LN}$} & 0,88 & 0,18 \\
\hline & & Inferior & $\xi_{R, V, \text { corr,inf }}$ & 12 & & 1,00 & 0,18 \\
\hline
\end{tabular}

El valor medio de 1,18 , obtenido para $\xi_{R, M, c o r r, i n f}$ en el caso de las vigas de hormigón armado con barras de acero lisas, significa que el modelo para el límite inferior es conservador, mientras que el modelo para el límite superior, con un valor medio de 1,06 para las incertidumbres del modelo, $\xi_{R, M, c o r r, s u p}$, ligeramente subestima la resistencia. El valor obtenido para el coeficiente de variación de las incertidumbres de ambos modelos para barras lisas, del orden de 0,2 , es moderadamente superior a los valores obtenidos para el caso de las barras corrugadas.

Para las 12 vigas que fallaron por cortante se calculan los valores de los límites superior e inferior de la resistencia teórica. En estos casos también se emplean los valores empíricos para las dimensiones y propiedades de los materiales constitutivos, conjuntamente con los modelos para la resistencia a cortante. Los resultados teóricos así obtenidos, junto con los valores de resistencia provenientes de los respectivos ensayos, se utilizan para deducir los parámetros de las variables para las incertidumbres $\xi_{R, V, c o r, \text { sup }}$ y $\xi_{R, V, c o r r, i n f}$, asociadas con los dos modelos, respectivamente para el límite superior e inferior de la resistencia a cortante de las vigas de hormigón armado con armaduras corroídas, de acuerdo con el nivel de aproximación II del código modelo [FIB 2013]. También estos resultados se encuentran en la Tabla 6.6.

El valor medio de 0,88, obtenido para las incertidumbres del modelo para el límite superior, $\xi_{R, V, c o r r, s u p}$, muestra un esviaje que no es conservador, sobreestimando la resistencia. Por otro lado, el modelo para el límite inferior, con un valor medio de 1,0 para las incertidumbres del modelo, $\xi_{R, V, c o r r, i n f}$, representa una buena estimación de la resistencia a cortante. El coeficiente de variación obtenido, del orden de 0,18 , indica un nivel de precisión bastante bajo comparado con los modelos de resistencia para vigas de hormigón armado sin corrosión [Tanner 2007b].

Es importante señalar que las incertidumbres de los modelos, recogidas en la Tabla 6.6, implícitamente cubren también algunas incertidumbres asociadas con ciertas desviaciones de la geometría y las propiedades de los materiales consideradas, puesto que no toda la información requerida sobre las vigas ensayadas está disponible en las publicaciones sobre los citados estudios experimentales [Rodríguez 1995, L'Hostis 2007]. En consecuencia, las incertidumbres asociadas con los modelos para la resistencia a flexión o cortante de las vigas con armaduras corroídas presumiblemente se están sobreestimando. Por esta razón, se requieren datos experimentales adicionales, por ejemplo para elementos deteriorados de hormigón armado de dimensiones mayores, o para elementos extraídos de estructuras existentes expuestas a condiciones reales de servicio y 
procesos de corrosión natural, con el fin de mejorar los modelos existentes para el cálculo de la resistencia de estructuras deterioradas por la corrosión [Tanner 2011a].

\section{Conclusiones}

A la vista de todo lo anterior, se puede concluir que las diferencias observadas entre los modelos probabilistas para las variables de los modelos de resistencia frente a momentos flectores y esfuerzos cortantes de las vigas de hormigón armado afectadas por la corrosión (Tabla 6.6), deducidos a partir de los resultados contenidos en dos estudios experimentales [Rodríguez 1995, L'Hostis 2007], tienen una explicación consistente. También la tienen las diferencias existentes entre estos modelos y los deducidos en un estudio anterior [Tanner 2007b], a partir de los datos disponibles en la literatura especializada, para las variables de los modelos de resistencia a flexión y cortante, respectivamente, de las vigas de hormigón sin deterioro. Según la argumentación expuesta en el Apartado 6.6.1, es por ello verosímil que también resulten adecuados los modelos probabilistas para las incertidumbres asociadas con los modelos de resistencia de los elementos estructurales de diferentes materiales constitutivos, que se deduzcan a partir de la información contenida en la literatura especializada o ciertas consideraciones teóricas, sin que exista la posibilidad de una comparación directa con datos experimentales. Es el caso, por ejemplo, de los modelos probabilistas para la variable de los modelos de resistencia de los elementos de acero, identificados en el Apartado 6.6.2.

\subsubsection{Verificación de los parámetros}

\section{Introducción}

Igual que los modelos probabilistas para las otras variables, también los correspondientes a los coeficientes para las incertidumbres de los modelos de resistencia deben cumplir los cuatro requisitos establecidos en el Apartado 6.2.2. Los modelos deducidos en el Apartado 6.6.2 para las incertidumbres de los modelos de resistencia de los elementos de acero cumplen tres de ellos, quedando pendiente la comprobación del estado de incertidumbre que representan en comparación con las reglas de dimensionado de la normativa en vigor. En apartados anteriores se explican los motivos por los que esta comparación no se puede efectuar de manera aislada para las variables de los modelos (Apartados 6.5.1, 6.5.3 y 6.6.1). También se explica que, debido al hecho de haber considerado (para ilustrar este proceso de verificación para las variables de las acciones y sus efectos) las vigas de cubierta solicitadas por momentos flectores inducidos por la carga de nieve (Apartado 6.4.3), en el presente contexto se analiza el caso de la resistencia correspondiente. La comprobación del estado de incertidumbre representado por los modelos probabilistas de las variables que intervienen en el modelo de resistencia de las vigas de acero frente a momentos flectores, se realiza según el procedimiento del Apartado 4.5.

\section{Valor de cálculo y coeficiente parcial}

\section{Generalidades}

De acuerdo con el formato adoptado para la determinación del valor de cálculo de la resistencia frente a momentos flectores de la sección de una viga de acero (Apartado 6.3.2), el coeficiente parcial para el modelo de resistencia, $\gamma_{R d, M}$, no solamente tiene en cuenta las incertidumbres asociadas con la variable del modelo, $\xi_{R, M}$, sino también las desviaciones en las dimensiones geométricas. Éstas están representadas, en el presente caso, por el módulo plástico de la sección, $W_{p l}$. Para la determinación del mencionado coeficiente parcial en función de los modelos probabilistas identificados para las citadas variables, se define una variable auxiliar, $M_{M}$, correspondiente al producto de ambas:

$$
M_{M}=\xi_{R, M} \cdot W_{p l}
$$

$M_{M} \quad$ : variable auxiliar 
Según el teorema del límite central, la función de distribución del producto de $n$ variables aleatorias independientes se aproxima, para un valor creciente de $n$, a la distribución lognormal, independientemente del tipo de función de distribución de las variables [Schneider 1994]. En el presente caso, $M_{M}$ es el producto de solo dos variables. Aún así, debido a que para una de ellas, $\xi_{R, M}$, se adopta un modelo probabilista con una función de distribución lognormal (Apartado 6.6.2), se asume que la variable auxiliar tenga una función de distribución del mismo tipo. Los parámetros de la variable auxiliar, $M_{M}$, se obtienen a partir de las siguientes ecuaciones:

$\mu_{M, M}=\mu_{\xi R, M} \cdot \mu_{W, p l}$

$V_{M, M} \cong \sqrt{V_{\xi R, M}^{2}+V_{W, p l}^{2}}=\sqrt{\left(\frac{\sigma_{\xi R, M}}{\mu_{\xi R, M}}\right)^{2}+\left(\frac{\sigma_{W, p l}}{\mu_{W, p l}}\right)^{2}}$

$V_{M, M} \quad:$ coeficiente de variación de la variable auxiliar

$V_{W, p l} \quad:$ coeficiente de variación del módulo plástico de la sección transversal

$V_{\xi R, M} \quad$ : coeficiente de variación de la variable del modelo de resistencia frente a momentos flectores

$\mu_{M, M} \quad$ : valor medio de la variable auxiliar

$\mu_{W, p l} \quad:$ valor medio del módulo plástico de la sección transversal

$\mu_{\xi R, M} \quad$ : valor medio de la variable del modelo de resistencia frente a momentos flectores

$\sigma_{W, p l} \quad:$ desviación típica del módulo plástico de la sección transversal

$\sigma_{\xi R, M} \quad:$ desviación típica de la variable del modelo de resistencia frente a momentos flectores

Estos parámetros se emplean a continuación a efectos de la determinación del valor de cálculo de la variable auxiliar según el método FORM normalizado (Apartado 3.4), $M_{M, F O R M, d}$. A su vez, este valor se utiliza finalmente para determinar el coeficiente parcial para el modelo de resistencia frente a momentos flectores, $\gamma_{R d, M}$.

Valor de cálculo

Debido a que el modelo probabilista de la variable auxiliar, $M_{M}$, se ajusta a una función de distribución lognormal con una dispersión pequeña, su valor de cálculo, $M_{M, F O R M, d}$, se obtiene mediante la siguiente formulación [ISO 2394 1998, EN 1990 2002]:

$M_{M, F O R M, d}\left(\mu_{M, M} ; V_{M, M}\right)=\mu_{M, M} \cdot e^{-\alpha_{R, M, M} \cdot \beta_{t} \cdot V_{M, M}}$

$\alpha_{R, M, M} \quad:$ factor de sensibilidad para la variable auxiliar

Al sustituir las ecuaciones (6.65) y (6.66) en la ecuación (6.67), el valor de cálculo $M_{M, F O R M, d}$ se puede expresar en función de los parámetros de los modelos probabilistas de las variables $\xi_{R, M}$ y $W_{p l}$ :

$M_{M, F O R M, d}\left(\mu_{\xi R, M} ; \sigma_{\xi R, M} ; \mu_{W, p l} ; \sigma_{W, p l}\right)=\mu_{\xi R, M} \cdot \mu_{W, p l} \cdot e^{-\alpha_{R, M, M} \cdot \beta_{i} \cdot \sqrt{\left(\frac{\sigma_{\xi R, M}}{\mu_{\xi R, M}}\right)^{2}+\left(\frac{\sigma_{W, p l}}{\mu_{W, p l}}\right)^{2}}}$

Coeficiente parcial para el modelo de resistencia frente a momentos flectores

El coeficiente parcial para el modelo de resistencia de las vigas de acero estructural frente a momentos flectores, $\gamma_{R d, M}$, relaciona el valor de cálculo de la variable auxiliar, $M_{M, F O R M, d}$, con el valor característico o nominal de la misma variable, $M_{M, k}$. Teniendo en cuenta la ecuación (6.68) para el valor de cálculo, así como la definición de la variable $M_{M}$ según la ecuación (6.64), el coeficiente parcial se puede expresar en función de los parámetros de los modelos probabilistas de las variables $\xi_{R, M}$ y $W_{p l}$ : 
$\gamma_{R d, M}\left(\mu_{\xi R, M} ; \sigma_{\xi R, M} ; \mu_{W, p l} ; \sigma_{W, p l}\right)=\frac{M_{M, k}}{M_{M, F O R M, d}}=\frac{\xi_{R, M, k}}{\mu_{\xi R, M}} \cdot \frac{W_{p l, k}}{\mu_{W, p l}} \cdot e^{\alpha_{R, M, M} \cdot \beta_{i} \cdot \sqrt{\left(\frac{\sigma_{\xi R, M}}{\mu_{\xi R, M}}\right)^{2}+\left(\frac{\sigma_{W, p l}}{\mu_{W, p l}}\right)^{2}}}$

$M_{M, k} \quad:$ valor característico de la variable auxiliar

$W_{p l, k} \quad$ : valor característico del módulo plástico de la sección transversal

$\xi_{R, M, k} \quad$ : valor característico de la variable del modelo de resistencia frente a momentos flectores

Teniendo en cuenta, además, la definición de los parámetros adimensionales que caracterizan el modelo probabilista de una variable (Apartado 6.2.2), la ecuación (6.69) se puede expresar en función de los coeficientes de sesgo y de variación de las variables $\xi_{R, M}$ y $W_{p l}$ :

$\gamma_{R d, M}\left(S_{\xi R, M} ; V_{\xi R, M} ; S_{W, p l} ; V_{W, p l}\right)=\frac{1}{S_{\xi R, M} \cdot S_{W, p l}} \cdot e^{\alpha_{R, M, M} \cdot \beta_{l} \cdot \sqrt{V_{\xi R, M}^{2}+V_{W, p l}^{2}}}$

$S_{W, p l} \quad:$ coeficiente de sesgo del módulo plástico de la sección transversal

$S_{\xi R, M} \quad$ : coeficiente de sesgo de la variable del modelo de resistencia frente a momentos flectores

Debido a que en el caso considerado, la resistencia de las vigas de acero estructural frente a momentos flectores, el límite elástico del material es la variable de resistencia dominante, tal y como se menciona en el Apartado 6.5.3, la variable $M_{M}$ es no dominante. Igual que en el caso de las variables no dominantes de las acciones, las normas [ISO 2394 1998, EN 1990 2002, CTE DB SE 2006] les asignan a las variables de resistencia no dominantes un factor de sensibilidad del $40 \%$ del factor correspondiente a la variable dominante (Apartado 3.4.2). Con este valor, $\alpha_{R, M, M}=0,32$, el índice de fiabilidad requerido para un período de referencia de 50 años, $\beta_{t}=3,8$ (Apartado 3.6.2), así como los parámetros identificados para los modelos probabilistas de la variable del modelo de resistencia de una viga de acero estructural frente a momentos flectores (Apartado 6.6.2), $S_{\xi R, M}=1,0 \mathrm{y}$ $V_{\xi R, M}=0,02$, y el módulo plástico de la sección transversal (Apartado 6.7.2), $S_{W, p l}=1,02$ y $V_{W, p l}=$ 0,02 , la ecuación (6.70) proporciona el siguiente valor numérico del coeficiente parcial para el modelo de resistencia de las vigas de acero frente a momentos flectores:

$\gamma_{R d, M}\left(S_{\xi R, M} ; V_{\xi R, M} ; S_{W, p l} ; V_{W, p l}\right)=1,0147$

\section{Modelos óptimos}

\section{Generalidades}

Siguiendo el procedimiento del Apartado 4.5, los coeficientes parciales obtenidos mediante el método FORM normalizado (ecuaciones (6.58) y (6.71)), asociados con los modelos probabilistas identificados para las variables que intervienen en la determinación de la resistencia de las vigas de acero frente a momentos flectores, se comparan con los valores definidos en las normas analizadas para los correspondientes coeficientes parciales. La diferencia resultante define la contribución a la función objetivo (4.9). Si es pequeña, se puede concluir que los modelos probabilistas para las variables consideradas representan adecuadamente el estado de incertidumbre asociado con las reglas normalizadas. Al contrario, si la diferencia no es despreciable, los parámetros de estos modelos requieren ajustes para minimizar la contribución a la función objetivo. Estos ajustes se deben realizar de forma que los modelos sigan cumpliendo los otros requisitos establecidos en el Apartado 6.2.2.

En la comparación de los coeficientes parciales deducidos con los correspondientes valores requeridos se debe tener en cuenta que estos últimos se inscriben en el formato de coeficientes parciales del Eurocódigo [EN 1993-1-1 2005] y de la Instrucción [EAE 2011], que es distinto al empleado en el presente estudio para la deducción de los modelos probabilistas. La existencia de esta diferencia se menciona con anterioridad, por ejemplo en los Apartados 6.3.1, 6.5.1 y 6.5.3. Partiendo de esta premisa, a continuación se procede a la comprobación del estado de incertidumbre 
representado por las variables que intervienen en el modelo de resistencia de las vigas de acero frente a los momentos flectores $\left(f_{y}, W_{p l}, \xi_{R, M}\right)$.

\section{Coeficiente parcial deducido}

Según el presente estudio (Apartado 6.3.2), para la determinación del valor de cálculo de la resistencia frente a momentos flectores de la sección transversal de una viga de acero estructural se emplean dos coeficientes parciales, respectivamente para el límite elástico del material, $\gamma_{m 0, M}, \mathrm{y}$ el modelo de resistencia, $\gamma_{R d, M}$, que también tiene en cuenta las imprecisiones geométricas. En la determinación de la resistencia frente a momentos flectores, el límite elástico es la variable dominante (Apartado 6.5.3), por lo que son variables no dominantes el módulo de la sección transversal de la viga y el coeficiente para las incertidumbres del modelo de resistencia. Los valores numéricos de los coeficientes parciales asociados con los modelos probabilistas para las citadas variables (Apartados 6.5.2, 6.6.2 y 6.7.2), obtenidos con el método FORM normalizado (Apartados 6.5.3 y 6.6.4), equivalen al siguiente coeficiente parcial para la resistencia:

$\gamma_{R d, M} \cdot \gamma_{m 0, M}=1,0147 \cdot 1,0527=1,0682$

\section{Valor requerido}

El formato de los coeficientes parciales empleado en la Instrucción [EAE 2011] no contempla el desglose del coeficiente parcial para la resistencia según la ecuación (6.9). En la citada norma, este coeficiente parcial para la resistencia de las secciones transversales, denominado $\gamma_{M 0}$, adopta el siguiente valor numérico:

$\gamma_{M 0}=1,05$

Se trata del valor objetivo con el que se deben comparar los coeficientes parciales asociados con los modelos probabilistas deducidos para las variables de resistencia.

\section{Contribución a la función objetivo}

Con los resultados obtenidos, y asumiendo un valor constante de $W_{Y, j}=1,0$ para el coeficiente de ponderación, tal y como se menciona en el Apartado 6.4.3, los modelos probabilistas de las variables relevantes para la determinación de la resistencia frente a momentos flectores de la sección de una viga de acero aportan la siguiente contribución a la función objetivo:

$\left(\gamma_{R d, M} \cdot \gamma_{m 0, M}-\gamma_{M 0}\right)^{2}=(1,0682-1,05)^{2}=0,000331$

La diferencia entre los coeficientes parciales obtenidos mediante el método FORM normalizado y el correspondiente valor objetivo según la Instrucción [EAE 2011] es del 1,7\%. Se trata de una desviación pequeña, por lo que no existe necesidad alguna de ajustar los parámetros de las variables de resistencia contempladas, ajuste para el que por otro lado no existiría ninguna justificación física, teniendo en cuenta los resultados obtenidos en la deducción de los modelos (Apartados 6.5 y 6.6.2). Por todo ello, resultan adecuados los modelos probabilistas deducidos para las variables de resistencia contempladas $\left(f_{y}, W_{p l}, \xi_{R, M}\right)$.

\subsection{RESUMEN DE LOS RESULTADOS OBTENIDOS}

\subsubsection{Introducción}

Siguiendo el procedimiento establecido en el Apartado 4.5, en el presente capítulo se muestra de manera explícita la deducción de los modelos probabilistas para tres variables representativas de, 
respectivamente, las acciones (carga de nieve), la resistencia (límite elástico del acero estructural) y las incertidumbres de los modelos (modelo de resistencia frente a momentos flectores de las vigas de acero). Esta deducción incluye la comprobación, para los momentos flectores inducidos por la carga de nieve en las vigas de cubierta y la resistencia correspondiente de las vigas de acero, si los modelos establecidos representan adecuadamente el estado de incertidumbre asociado con las reglas de la normativa en vigor. En caso contrario, el procedimiento también incluye el ajuste de los parámetros de los modelos para minimizar la función objetivo (4.9). Los modelos así deducidos cumplen con todos los requisitos establecidos en el Apartado 6.2.2.

De manera análoga, se deducen los modelos probabilistas para todas las variables que intervienen en las funciones de estado límite establecidas en el Apartado 5.4. Contrariamente a los ejemplos representados anteriormente, la identificación de los modelos probabilistas para las otras variables se basa en la literatura especializada y no requiere laboriosos desarrollos originales como en los casos de la carga de nieve y, en menor medida, el límite elástico del acero, así como las incertidumbres de los modelos de resistencia. Lo que es similar en todos los casos, es el proceso de comprobación del estado de incertidumbre y ajuste de los parámetros.

A continuación, se reflejan los modelos probabilistas obtenidos para todas las variables consideradas. A estos efectos se utiliza la representación adimensional establecida en el Apartado 6.2.2 y los resultados se resumen por grupos de variables, según intervienen en las funciones de estado límite para los elementos de, respectivamente, acero estructural (Apartado 6.7.2), hormigón armado (Apartado 6.7.3), mixtos de acero y hormigón (Apartado 6.7.4) y madera laminada encolada (Apartado 6.7.5). Dentro de cada apartado, se agrupan los modelos para las variables de las acciones y sus efectos por un lado, y las variables de resistencia por otro. Los modelos probabilistas deducidos para las cargas permanentes, sobrecarga, carga de nieve, así como las variables del modelo para la determinación de los efectos de las acciones, no dependen del material constitutivo de los elementos estructurales. Por este motivo, se reflejan solamente en el Apartado 6.7.2. Los únicos modelos probabilistas para las acciones y sus efectos que se representan en los Apartados 6.7.3 a 6.7.5 son por ello los relativos al peso propio de los respectivos elementos resistentes.

Finalmente, se recopila la contribución de los modelos probabilistas a la función objetivo (4.9), asumiendo un coeficiente de ponderación constante de $W_{Y, j}=1,0$. Esta hipótesis significa que se les asigna la misma importancia relativa a todos los mecanismos de fallo (Apartado 6.4.3). También estos resultados se analizan con un mayor grado de detalle para los modelos correspondientes a las variables que intervienen en las funciones de estado límite para los elementos de acero estructural (Apartado 6.7.2). Para las otras variables, los resultados obtenidos son equivalentes. Por este motivo, la información incluida en los Apartados 6.7.3 a 6.7.5 se limita en la práctica a la recopilación de la contribución de cada modelo probabilista a la función objetivo, sin análisis adicional. El Apartado 6.7.6 contiene una breve comparación de los resultados obtenidos en función de los materiales constitutivos considerados en el presente estudio.

\subsubsection{Estructuras de acero}

\section{Modelos probabilistas}

En la Tabla 6.7 se representan los modelos probabilistas, deducidos según el procedimiento del Apartado 4.5, para las variables que intervienen en las funciones de estado límite consideradas en el marco del presente estudio para las vigas y los pilares de acero estructural (Apartado 5.4.2). Estos modelos cumplen los cuatro requisitos establecidos en el Apartado 6.2.2. En particular, representan el estado de incertidumbre asociado con las reglas de la normativa española que está en vigor para el dimensionado de las estructuras de edificación, constituidas por elementos de acero: los Documentos Básicos para la Seguridad Estructural del Código Técnico de la Edificación, así como la Instrucción 
asociada, sobre las bases de proyecto [CTE DB SE 2006], las acciones [CTE DB SE-AE 2006] y la resistencia [EAE 2011].

En términos generales, las normas españolas citadas están basadas en las reglas de los Eurocódigos correspondientes, por lo que estos documentos son compatibles entre ellos. Eso también es así en relación con las tolerancias y el control de la ejecución, por lo que la aplicación correcta de los dos conjuntos de normas conduce a unos niveles de incertidumbres comparables. A efectos del presente estudio, la única diferencia consiste en el valor del coeficiente parcial para la resistencia de las secciones transversales: mientras que en la Instrucción [EAE 2011] se adopta un valor de $\gamma_{M 0}=1,05$ (ecuación (6.73)), el Eurocódigo recomienda un valor de $\gamma_{M_{0}}=1,0$ [EN 1993-1-1 2005]. No obstante, el Anejo Nacional del Eurocódigo relativo al proyecto de las estructuras de acero [AN/UNE-EN 1993-1-1 2013], establece el mismo valor para el coeficiente parcial que la Instrucción [EAE 2011], $\gamma_{M 0}=1,05$, y las mismas condiciones (relacionadas con las tolerancias de fabricación y montaje, el control de ejecución y la dispersión de la resistencia de los materiales [Tanner 2009]) bajo las que este valor puede ser reducido hasta $\gamma_{M 0}=1,0$. Por estas circunstancias, se puede concluir que los modelos de la Tabla 6.7 también representan el estado de incertidumbre asociado con las reglas de los Eurocódigos para el dimensionado de las estructuras metálicas de edificación [EN 1990 2002, EN 1991-1-1 2002, EN 1991-1-3 2003, EN 1993-1-1 2005], ya que éstos se deben aplicar conjuntamente con sus respectivos Anejos Nacionales.

Tabla 6.7 - Modelos probabilistas para las acciones y sus efectos, así como la resistencia de los elementos de acero estructural.

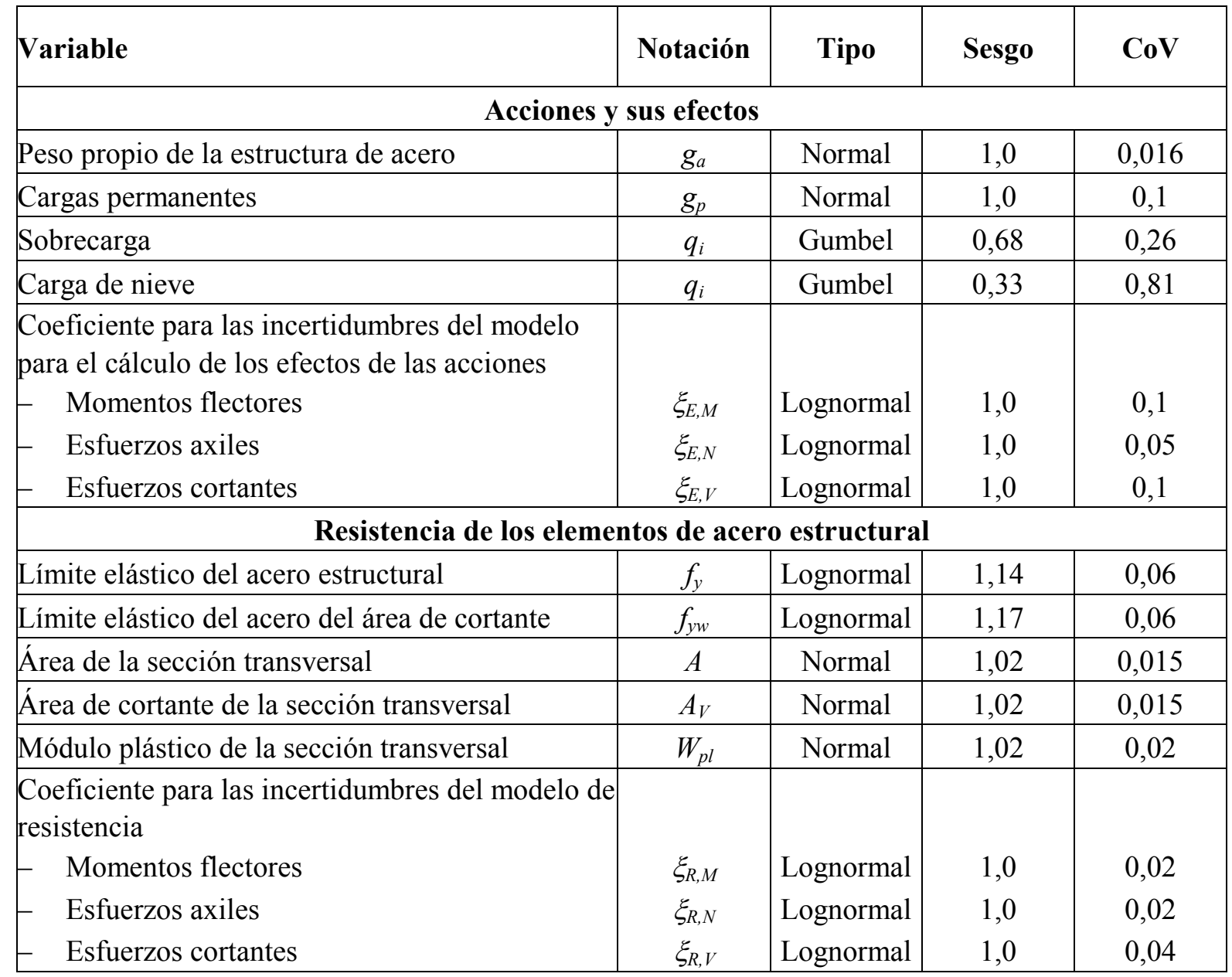




\section{Comprobación del estado de incertidumbre}

La Tabla 6.8 refleja la contribución de los modelos probabilistas de la Tabla 6.7 a la función objetivo (4.9). En este contexto conviene recordar que los parámetros de estos modelos ya recogen los resultados del proceso de ajuste de los parámetros, efectuado para optimizar la función objetivo e ilustrado en el Apartado 6.4.3 para la carga de nieve.

Los resultados obtenidos se agrupan según los mecanismos de fallo contemplados, respectivamente por flexión y esfuerzo cortante en vigas, así como esfuerzo axil de compresión en pilares. Dentro de cada uno de estos grupos de resultados se distingue entre los coeficientes parciales para las variables relacionadas con los efectos de las diferentes acciones, $E_{d}$, y la resistencia correspondiente, $R_{d}$. La tercera columna de la Tabla 6.8 representa los valores numéricos de los coeficientes parciales según el formato adoptado en el presente estudio, obtenidos mediante el método FORM normalizado y asociados con los parámetros ajustados de los modelos probabilistas, $\gamma_{Y, j}(\boldsymbol{\mu}, \boldsymbol{\sigma})$. En negrita se destaca para cada caso el valor numérico del coeficiente parcial que tiene en cuenta las incertidumbres asociadas con la variable dominante. En este contexto conviene recordar que, en principio, cualquier variable puede ser dominante (Apartado 3.4). El valor máximo de un determinado coeficiente parcial se obtiene en el caso de que resulte dominante alguna de las variables cuyas incertidumbres están cubiertas por este coeficiente. Los valores requeridos de los coeficientes parciales, $\gamma_{Y, t}$, según el formato empleado en las normas cuyo estado de incertidumbre se pretende aproximar, están representados en la cuarta columna. En las siguientes columnas se reflejan el coeficiente de ponderación que interviene en la función objetivo, $W_{Y, j}$, así como la contribución a esta función de los modelos probabilistas de las variables relevantes para la determinación de los efectos de las acciones y de la resistencia correspondiente (sexta columna $\left.\left(\gamma_{Y, j}(\mu, \sigma)-\gamma_{Y, t}\right)^{2}\right)$, tanto en términos absolutos como relativos (porcentaje de ${ }_{\min } W(\boldsymbol{\mu}, \boldsymbol{\sigma})$ ). Finalmente, la última columna recoge, para cada uno de los distintos mecanismos de fallo, la contribución de los modelos probabilistas de las variables relevantes para el dimensionado de los elementos estructurales a la función objetivo, $W_{j}(\mu, \sigma)$.

Los resultados de esta última columna ponen de manifiesto que los modelos de las variables que intervienen en el dimensionado frente a momentos flectores y esfuerzos cortantes, respectivamente, tienen una contribución a la función objetivo que es prácticamente idéntica, del orden del $16 \%$. La contribución de los modelos de las variables para la determinación de los esfuerzos axiles y la resistencia correspondiente es mucho más importante, superando los dos tercios del valor total de ${ }_{\min } W(\boldsymbol{\mu}, \sigma)=0,0636$. La mayor parte de esta contribución (el $56 \%$ de ${ }_{\min } W(\boldsymbol{\mu}, \sigma)$ ) se debe a los modelos probabilistas de las variables para la determinación de los esfuerzos axiles de compresión en los pilares, inducidos por el peso propio de la estructura metálica: los coeficientes parciales obtenidos mediante el método FORM normalizado se eleva a $\gamma_{S d, N} \cdot \gamma_{g, a}=1,1423 \cdot 1,017=1,16$, mientras que el correspondiente valor requerido es de $\gamma_{G}=1,35$, según las normas analizadas [EN 1990 2002, CTE DB SE 2006]. A pesar de esta desviación importante del objetivo, del orden del $14 \%$, no es aconsejable proceder a un ajuste de los parámetros de los modelos de las variables correspondientes. En primer lugar, estos modelos, reflejados en la Tabla 6.7, cumplen con tres de los cuatro requisitos establecidos para los modelos probabilistas (Apartado 6.2.2). Un ajuste en las proporciones necesarias para que los modelos representen al estado de incertidumbre asociado con las reglas normalizadas llevaría al incumplimiento de los otros requisitos. Por otro lado, las estructuras de acero son ligeras por lo que la contribución del peso propio a las solicitaciones es muy reducida, y por tanto también lo es su importancia relativa en el dimensionado estructural.

En el caso de los esfuerzos axiles inducidos por el peso propio de las estructuras de acero el problema no radica en que los modelos probabilistas deducidos (Tabla 6.7) representen inadecuadamente al estado de incertidumbre asociado con las reglas normalizadas. Al contrario, en la realidad estas incertidumbres son muy inferiores a las que corresponderían al coeficiente parcial para el peso propio 
según la normativa actual. Para el peso propio de las estructuras de acero, es este valor $\gamma_{G}=1,35$ que resulta muy conservador y por tanto inadecuado.

Tabla 6.8 - Contribución de los modelos probabilistas para las acciones, sus efectos y la resistencia de los elementos de acero estructural a la función objetivo.

\begin{tabular}{|c|c|c|c|c|c|c|}
\hline \multirow{2}{*}{$\begin{array}{c}\text { Mecanismo de } \\
\text { fallo }\end{array}$} & \multirow{2}{*}{$E_{d}, R_{d}$} & \multicolumn{2}{|c|}{ Coeficientes parciales } & \multicolumn{3}{|c|}{ Función objetivo } \\
\hline & & $\gamma_{Y, j}(\mu, \sigma)$ & $\gamma_{Y, t}$ & $W_{Y, j}$ & $\left(\gamma_{Y, j}-\gamma_{Y, t}\right)^{2}$ & $W_{j}(\mu, \sigma)$ \\
\hline Flexión & 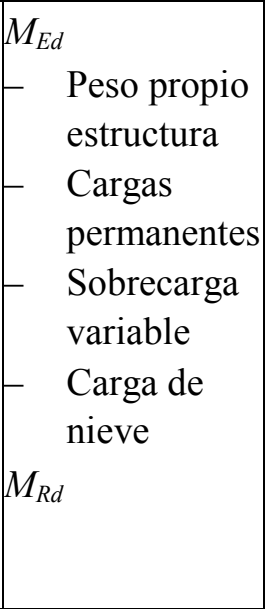 & $\begin{array}{c}\gamma_{S d, M} \cdot \gamma_{g, a} \\
\mathbf{1 , 3 0 4 7} \cdot 1,017 \\
\gamma_{S d, M} \cdot \gamma_{g, p} \\
\mathbf{1 , 3 0 4 7} \cdot 1,106 \\
\gamma_{S d, M} \cdot \gamma_{q, l} \\
1,112 \cdot \mathbf{1 , 3 6 3} \\
\gamma_{S d, M} \cdot \gamma_{q, s} \\
1,112 \cdot \mathbf{1 , 3 6 3 5} \\
\\
\gamma_{R d, M} \cdot \gamma_{m 0, M} \\
1,0147 \cdot \mathbf{1 , 0 5 2 7}\end{array}$ & $\begin{array}{c}\gamma_{G} \\
1,35 \\
\gamma_{G} \\
1,35 \\
\gamma_{Q} \\
1,5 \\
\gamma_{Q} \\
1,5 \\
\\
\gamma_{M 0} \\
1,05\end{array}$ & 1,0 & $\begin{array}{c}0,000533 \\
0,8 \% \\
0,00875 \\
13,7 \% \\
0,000245 \\
0,4 \% \\
0,000263 \\
0,4 \% \\
\\
0,000331 \\
0,5 \%\end{array}$ & $\begin{array}{c}0,010118 \\
15,9 \%\end{array}$ \\
\hline $\begin{array}{l}\text { Esfuerzo } \\
\text { cortante }\end{array}$ & \begin{tabular}{|ll}
$V_{E d}$ & \\
- & Peso propio \\
& estructura \\
& Cargas \\
& permanentes \\
- & Sobrecarga \\
& variable \\
& Carga de \\
& nieve \\
$V_{R d}$ &
\end{tabular} & $\begin{array}{c}\gamma_{S d, V} \cdot \gamma_{g, a} \\
\mathbf{1 , 3 0 4 7} \cdot 1,017 \\
\gamma_{S d, V} \cdot \gamma_{g, p} \\
\mathbf{1 , 3 0 4 7} \cdot 1,106 \\
\gamma_{S d, V} \cdot \gamma_{q, l} \\
1,112 \cdot \mathbf{1 , 3 6 3} \\
\gamma_{S d, V} \cdot \gamma_{q, s} \\
1,112 \cdot \mathbf{1 , 3 6 3 5} \\
\\
\gamma_{R d, V} \cdot \gamma_{m 0, V} \\
1,0327 \cdot \mathbf{1 , 0 2 5 7}\end{array}$ & $\begin{array}{c}\gamma_{G} \\
1,35 \\
\gamma_{G} \\
1,35 \\
\gamma_{Q} \\
1,5 \\
\gamma_{Q} \\
1,5 \\
\\
\gamma_{M 0} \\
1,05 \\
\end{array}$ & 1,0 & $\begin{array}{c}0,000533 \\
0,8 \% \\
0,00875 \\
13,7 \% \\
0,000245 \\
0,4 \% \\
0,000263 \\
0,4 \% \\
\\
0,000085 \\
0,1 \%\end{array}$ & $\begin{array}{c}0,009872 \\
15,5 \%\end{array}$ \\
\hline $\begin{array}{c}\text { Esfuerzo axil de } \\
\text { compresión }\end{array}$ & $\begin{array}{|ll|}N_{E d} & \\
- & \text { Peso propio } \\
& \text { estructura } \\
& \text { Cargas } \\
& \text { permanentes } \\
- & \text { Sobrecarga } \\
& \text { variable } \\
& \text { Carga de } \\
& \text { nieve } \\
N_{R d}\end{array}$ & $\begin{array}{c}\gamma_{S d, N} \cdot \gamma_{g, a} \\
\mathbf{1 , 1 4 2 3} \cdot 1,017 \\
\gamma_{S d, N} \cdot \gamma_{g, p} \\
1,055 \cdot \mathbf{1 , 2 6 6} \\
\gamma_{S d, N} \cdot \gamma_{q, l} \\
1,055 \cdot \mathbf{1 , 3 6 3} \\
\gamma_{S d, N} \cdot \gamma_{q, s} \\
1,055 \cdot \mathbf{1 , 3 6 3 5} \\
\\
\gamma_{R d, N} \cdot \gamma_{m 0, N} \\
1,0107 \cdot \mathbf{1 , 0 5 2 7}\end{array}$ & $\begin{array}{c}\gamma_{G} \\
1,35 \\
\gamma_{G} \\
1,35 \\
\gamma_{Q} \\
1,5 \\
\gamma_{Q} \\
1,5 \\
\\
\gamma_{M 0} \\
1,05\end{array}$ & 1,0 & $\begin{array}{c}0,03546 \\
55,7 \% \\
0,000219 \\
0,3 \% \\
0,003909 \\
6,1 \% \\
0,003844 \\
6,0 \% \\
\\
0,000194 \\
0,3 \%\end{array}$ & $\begin{array}{c}0,043627 \\
68,6 \%\end{array}$ \\
\hline & & & & & $\min W(\mu, \sigma)$ & \begin{tabular}{|c|}
0,063617 \\
$100 \%$
\end{tabular} \\
\hline
\end{tabular}




\subsubsection{Estructuras de hormigón armado}

\section{Modelos probabilistas}

La Tabla 6.9 refleja los modelos probabilistas para las variables que intervienen en las funciones de estado límite para los elementos de hormigón armado (Apartado 5.4.3). Los modelos, deducidos según el procedimiento del Apartado 4.5, cumplen los requisitos del Apartado 6.2.2. Eso implica que, asumiendo un control intenso de la ejecución según la Instrucción [EHE-08 2008], los modelos representan el estado de incertidumbre asociado con las reglas de las normas españolas para el dimensionado de los elementos de hormigón armado en las estructuras de edificación [CTE DB SE 2006, CTE DB SE-AE 2006, EHE-08 2008].

En términos generales, las reglas contenidas en las normas nacionales citadas son compatibles con los Eurocódigos correspondientes, ya que se basan en estos. También las tolerancias de ejecución son comparables y el nivel del control de la ejecución en las que se basan las reglas del Eurocódigo para el proyecto de las estructuras de hormigón [EN 1992-1-1 2004] es equiparable con el control intenso establecido en la Instrucción [EHE-08 2008]. Por estos motivos, los modelos de la Tabla 6.9 también representan el estado de incertidumbre asociado con las reglas de los Eurocódigos para el dimensionado de las estructuras de edificación de hormigón armado [EN 1990 2002, EN 1991-1-1 2002, EN 1991-1-3 2003, EN 1992-1-1 2004].

Tabla 6.9-Modelos probabilistas para las acciones y sus efectos, así como la resistencia de los elementos de hormigón armado.

\begin{tabular}{|c|c|c|c|c|}
\hline Variable & Notación & Tipo & Sesgo & $\mathrm{CoV}$ \\
\hline \multicolumn{5}{|c|}{$\begin{array}{l}\text { Acciones y sus efectos } \\
\text { es } g_{p}, q_{i}, \xi_{E, M}, \xi_{E, N}, \xi_{E, V} \text { están reflejados en la Tabla 6.7) }\end{array}$} \\
\hline Peso propio de la estructura de hormigón armado & $g_{c}$ & Normal & 1,0 & 0,04 \\
\hline \multicolumn{5}{|c|}{ Resistencia de los elementos de hormigón armado } \\
\hline Resistencia a compresión del hormigón & $f_{c}$ & Lognormal & 1,24 & 0,18 \\
\hline Factor de conversión de la resistencia $f_{c}$ & $\eta_{c}$ & \multicolumn{3}{|c|}{ Determinista } \\
\hline Límite elástico del acero de armar & $f_{s}$ & Lognormal & 1,12 & 0,053 \\
\hline Dimensiones de las secciones transversales & $a ; b_{A} ; b_{c}$ & Normal & 1,0 & 0,03 \\
\hline Canto útil de la sección transversal & $d$ & Normal & 1,0 & 0,04 \\
\hline Área de la sección del acero de armar & $A_{s} ; A_{s w}$ & Normal & 1,0 & 0,02 \\
\hline $\begin{array}{l}\text { Coeficiente para las incertidumbres del modelo de } \\
\text { resistencia }\end{array}$ & & & & \\
\hline - Momentos flectores & $\xi_{R, M}$ & Lognormal & 1,0 & 0,05 \\
\hline Esfuerzos axiles & $\xi_{R, N}$ & Lognormal & 1,0 & 0,05 \\
\hline - Tracción en el alma & $\xi_{R, V s}$ & Lognormal & 1,0 & 0,05 \\
\hline - Compresión oblicua en el alma & $\xi_{R, V c}$ & Lognormal & 1,4 & 0,25 \\
\hline
\end{tabular}

\section{Comprobación del estado de incertidumbre}

La contribución de los modelos probabilistas de la Tabla 6.9 a la función objetivo (4.9) se resume en la Tabla 6.10. Los parámetros de estos modelos están ajustados según el procedimiento del Apartado 4.5. La estructuración de la Tabla 6.10 es análoga a la de la Tabla 6.8, que se explica en el Apartado 6.7.2, referido a las variables relevantes para los elementos de acero. 
Tabla 6.10 - Contribución de los modelos probabilistas para las acciones, sus efectos y la resistencia de los elementos de hormigón armado a la función objetivo.

\begin{tabular}{|c|c|c|c|c|c|c|}
\hline \multirow{2}{*}{$\begin{array}{c}\text { Mecanismo de } \\
\text { fallo }\end{array}$} & \multirow{2}{*}{$E_{d}, R_{d}$} & \multicolumn{2}{|c|}{ Coeficientes parciales } & \multicolumn{3}{|c|}{ Función objetivo } \\
\hline & & $\gamma_{Y, j}(\mu, \sigma)$ & $\gamma_{Y, t}$ & $W_{Y, j}$ & $\left(\gamma_{Y, j}-\gamma_{Y, t}\right)^{2}$ & $W_{j}(\mu, \sigma)$ \\
\hline Flexión & 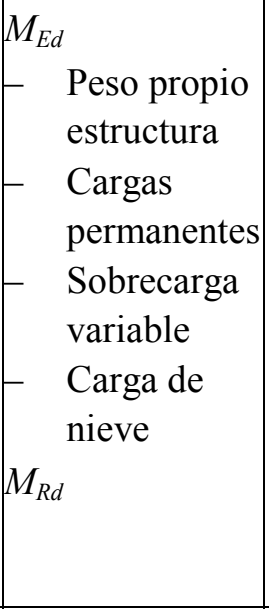 & $\begin{array}{c}\gamma_{S d, M} \cdot \gamma_{g, c} \\
\mathbf{1 , 3 0 4 7} \cdot 1,043 \\
\gamma_{S d, M} \cdot \gamma_{g, p} \\
\mathbf{1 , 3 0 4 7} \cdot 1,106 \\
\gamma_{S d, M} \cdot \gamma_{q, l} \\
1,112 \cdot \mathbf{1 , 3 6 3} \\
\gamma_{S d, M} \cdot \gamma_{q, s} \\
1,112 \cdot \mathbf{1 , 3 6 3 5} \\
\\
\gamma_{R d, M} \cdot \gamma_{s} \\
\mathbf{1 , 2 1 5} \cdot 0,957\end{array}$ & $\begin{array}{c}\gamma_{G} \\
1,35 \\
\gamma_{G} \\
1,35 \\
\gamma_{Q} \\
1,5 \\
\gamma_{Q} \\
1,5 \\
\\
\gamma_{S} \\
1,15\end{array}$ & 1,0 & $\begin{array}{c}0,000106 \\
0,2 \% \\
0,00875 \\
15,9 \% \\
0,000245 \\
0,4 \% \\
0,000263 \\
0,5 \% \\
0,00016 \\
0,3 \%\end{array}$ & $\begin{array}{c}0,009519 \\
17,3 \%\end{array}$ \\
\hline $\begin{array}{l}\text { Esfuerzo } \\
\text { cortante }\end{array}$ & 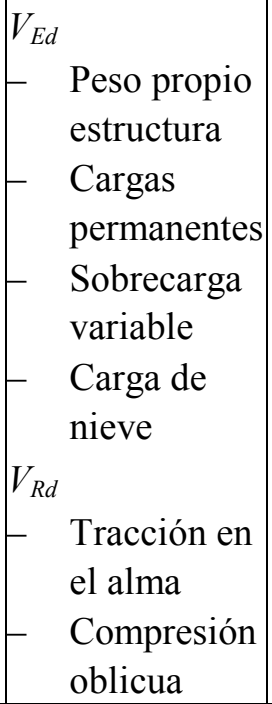 & $\begin{array}{c}\gamma_{S d, V} \cdot \gamma_{g, c} \\
\mathbf{1 , 3 0 4 7} \cdot 1,043 \\
\gamma_{S d, V} \cdot \gamma_{g, p} \\
\mathbf{1 , 3 0 4 7} \cdot 1,106 \\
\gamma_{S d, V} \cdot \gamma_{q, l} \\
1,112 \cdot \mathbf{1 , 3 6 3} \\
\gamma_{S d, V} \cdot \gamma_{q, s} \\
1,112 \cdot \mathbf{1 , 3 6 3 5} \\
\gamma_{R d, V s} \cdot \gamma_{s} \\
\mathbf{1 , 2 1 5} \cdot 0,957 \\
\gamma_{R d, V c} \cdot \gamma_{c} \\
\mathbf{1 , 5 4 6} \cdot 1,004\end{array}$ & $\begin{array}{c}\gamma_{G} \\
1,35 \\
\gamma_{G} \\
1,35 \\
\gamma_{Q} \\
1,5 \\
\gamma_{Q} \\
1,5 \\
\\
\gamma_{S} \\
1,15 \\
\gamma_{C} \\
1,5\end{array}$ & 1,0 & $\begin{array}{c}0,000106 \\
0,2 \% \\
0,00875 \\
15,9 \% \\
0,000245 \\
0,4 \% \\
0,000263 \\
0,5 \% \\
0,00016 \\
0,3 \% \\
0,002691 \\
4,9 \%\end{array}$ & $\begin{array}{c}0,01221 \\
22,2 \%\end{array}$ \\
\hline $\begin{array}{l}\text { Esfuerzo axil de } \\
\text { compresión }\end{array}$ & 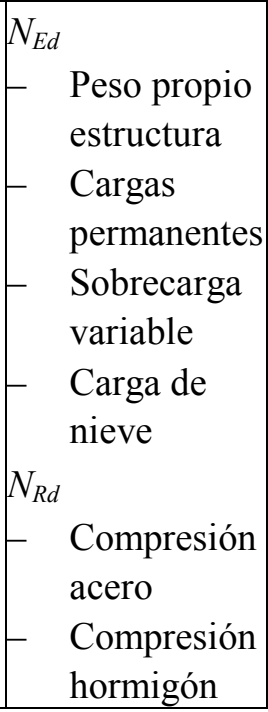 & $\begin{array}{c}\gamma_{S d, N} \cdot \gamma_{g, c} \\
\mathbf{1 , 1 4 2 3} \cdot 1,043 \\
\gamma_{S d, N} \cdot \gamma_{g, p} \\
1,055 \cdot \mathbf{1 , 2 6 6} \\
\gamma_{S d, N} \cdot \gamma_{q, l} \\
1,055 \cdot \mathbf{1 , 3 6 3} \\
\gamma_{S d, N} \cdot \gamma_{q, s} \\
1,055 \cdot \mathbf{1 , 3 6 3 5} \\
\\
\gamma_{R d, N} \cdot \gamma_{s} \\
1,077 \cdot \mathbf{1 , 0 6 4} \\
\gamma_{R d, N} \cdot \gamma_{c} \\
1,077 \cdot \mathbf{1 , 3 9}\end{array}$ & $\begin{array}{c}\gamma_{G} \\
1,35 \\
\gamma_{G} \\
1,35 \\
\gamma_{Q} \\
1,5 \\
\gamma_{Q} \\
1,5 \\
\\
\gamma_{S} \\
1,15 \\
\gamma_{C} \\
1,5 \\
\end{array}$ & 1,0 & $\begin{array}{c}0,02531 \\
46,0 \% \\
0,00022 \\
0,4 \% \\
0,003909 \\
7,1 \% \\
0,003844 \\
7,0 \% \\
0,000023 \\
--- \\
0,0000004 \\
---\end{array}$ & $\begin{array}{c}0,033306 \\
60,5 \%\end{array}$ \\
\hline & & & & & $\min W(\mu, \sigma)$ & $\begin{array}{c}0,05504 \\
100 \% \\
\end{array}$ \\
\hline
\end{tabular}


La única incongruencia contenida en la Tabla 6.10 se refiere al coeficiente parcial para la resistencia a compresión de la armadura en pilares, obtenido mediante el método FORM normalizado. Debido a que $\gamma_{R d, N}$ tiene en cuenta, entre otras, las incertidumbres asociadas con el área de la sección de hormigón (Apartado 6.3.3), se sobreestima el correspondiente coeficiente parcial deducido, $\gamma_{Y, j}$. No obstante, para las cuantías habituales de armadura, la contribución del acero a la resistencia a compresión de las secciones de los pilares suele ser reducida, por lo que la citada incongruencia no introduce ningún sesgo en los resultados del presente estudio.

\subsubsection{Estructuras mixtas de acero y hormigón}

\section{Modelos probabilistas}

La Tabla 6.11 contiene los modelos probabilistas, deducidos según el procedimiento del Apartado 4.5, para las variables de las funciones de estado límite relativas a los elementos mixtos de acero y hormigón (Apartado 5.4.4). En ausencia de una norma española para estructuras mixtas de edificación, el ajuste de los parámetros se realiza para que los modelos representen el estado de incertidumbre asociado con las reglas de los Eurocódigos para el dimensionado de este tipo de sistemas [EN 1990 2002, EN 1991-1-1 2002, EN 1991-1-3 2003, EN 1994-1-1 2004].

Tabla 6.11 - Modelos probabilistas para las acciones y sus efectos, así como la resistencia de los elementos mixtos de acero y hormigón.

\begin{tabular}{|c|c|c|c|c|}
\hline Variable & Notación & Tipo & Sesgo & $\mathrm{CoV}$ \\
\hline \multicolumn{5}{|c|}{$\begin{array}{c}\text { Acciones y sus efectos } \\
\text { (los modelos de las variables } g_{p}, q_{i}, \xi_{E, M}, \xi_{E, N}, \xi_{E, V} \text { están reflejados en la Tabla 6.7) }\end{array}$} \\
\hline Peso propio de los elementos de acero & $g_{a}$ & Normal & 1,0 & 0,016 \\
\hline Peso propio de los elementos de hormigón & $g_{c}$ & Normal & 1,0 & 0,04 \\
\hline \multicolumn{5}{|c|}{ Resistencia de los elementos mixtos de acero y hormigón } \\
\hline Límite elástico del acero estructural & $f_{y}$ & Lognormal & 1,14 & 0,06 \\
\hline Límite elástico del acero del área de cortante & $f_{y w}$ & Lognormal & 1,17 & 0,06 \\
\hline Límite elástico del acero de armar & $f_{s}$ & Lognormal & 1,12 & 0,053 \\
\hline Resistencia a compresión del hormigón & $f_{c}$ & Lognormal & 1,24 & 0,18 \\
\hline Factor de conversión de la resistencia $f_{c}$ & $\eta_{c}$ & \multicolumn{3}{|c|}{ Determinista } \\
\hline Canto de la sección de acero estructural & $h_{a}$ & Normal & 1,0 & 0,003 \\
\hline Canto de la losa superior de hormigón & $h_{c}$ & Normal & 1,0 & 0,03 \\
\hline Ancho eficaz de la losa de hormigón & $b_{e f f}$ & \multicolumn{3}{|c|}{ Determinista } \\
\hline Área de la sección de acero estructural & $A_{a}$ & Normal & 1,02 & 0,015 \\
\hline Área de cortante de la sección de acero estructural & $A_{V}$ & Normal & 1,02 & 0,015 \\
\hline Área de la sección del acero de armar & $A_{s}$ & Normal & 1,0 & 0,02 \\
\hline Área de la sección de hormigón del pilar mixto & $A_{c}$ & Normal & 1,0 & 0,004 \\
\hline $\begin{array}{l}\text { Coeficiente para las incertidumbres del modelo de } \\
\text { resistencia }\end{array}$ & & & & \\
\hline - Momentos flectores & $\xi_{R, M}$ & Lognormal & 1,0 & 0,02 \\
\hline Esfuerzos axiles & $\xi_{R, N}$ & Lognormal & 1,0 & 0,02 \\
\hline$-\quad$ Esfuerzos cortantes & $\xi_{R, V}$ & Lognormal & 1,0 & 0,04 \\
\hline
\end{tabular}


Teniendo en cuenta que las normas nacionales para el dimensionado de las estructuras constituidas por otros materiales están basadas en los Eurocódigos correspondientes, y que los niveles de incertidumbre asociados con ambos conjuntos de normas son comparables (Apartados 6.7.2, 6.7.3 y 6.7.5), el empleo de los modelos de la Tabla 6.11 conduce a resultados representativos en el marco del presente estudio. Los modelos de esta tabla, además de reflejar adecuadamente las incertidumbres asociadas con las reglas de las normas en vigor, también cumplen los otros requisitos establecidos en el Apartado 6.2.2.

\section{Comprobación del estado de incertidumbre}

En la Tabla 6.12 se refleja la contribución, a la función objetivo (4.9), de los modelos probabilistas para las variables que intervienen en las funciones de estado límite, consideradas en el marco del presente estudio para los elementos mixtos de acero y hormigón (Apartado 5.4.4). Los resultados representados están asociados con los modelos probabilistas de la Tabla 6.11. Por otro lado, la organización de esta Tabla 6.12 se explica en el Apartado 6.7.2, referente a las estructuras de acero.

Tabla 6.12 - Contribución de los modelos probabilistas para las acciones, sus efectos y la resistencia de los elementos mixtos de acero y hormigón a la función objetivo.

\begin{tabular}{|c|c|c|c|c|c|c|}
\hline \multirow{2}{*}{$\begin{array}{c}\text { Mecanismo de } \\
\text { fallo }\end{array}$} & \multirow{2}{*}{$E_{d}, R_{d}$} & \multicolumn{2}{|c|}{ Coeficientes parciales } & \multicolumn{3}{|c|}{ Función objetivo } \\
\hline & & $\gamma_{Y, j}(\mu, \sigma)$ & $\gamma_{Y, t}$ & $\boldsymbol{W}_{Y, j}$ & $\left(\gamma_{Y, j}-\gamma_{Y, t}\right)^{2}$ & $W_{j}(\mu, \sigma)$ \\
\hline Flexión & 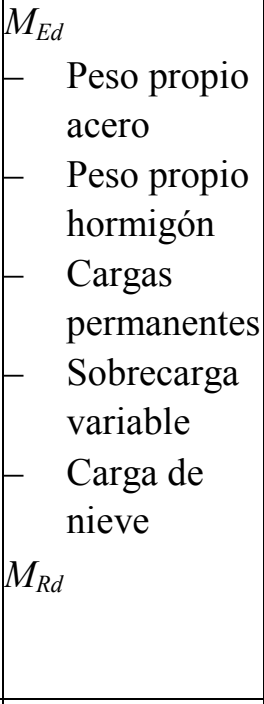 & $\begin{array}{c}\gamma_{S d, M} \cdot \gamma_{g, a} \\
\mathbf{1 , 3 0 4 7} \cdot 1,017 \\
\gamma_{S d, M} \cdot \gamma_{g, c} \\
\mathbf{1 , 3 0 4 7} \cdot 1,043 \\
\gamma_{S d, M} \cdot \gamma_{g, p} \\
\mathbf{1 , 3 0 4 7} \cdot 1,106 \\
\gamma_{S d, M} \cdot \gamma_{q, l} \\
1,112 \cdot \mathbf{1 , 3 6 3} \\
\gamma_{S d, M} \cdot \gamma_{q, s} \\
1,112 \cdot \mathbf{1 , 3 6 3 5} \\
\\
\gamma_{R d, M} \cdot \gamma_{a} \\
1,0121 \cdot \mathbf{1 , 0 5 2 7}\end{array}$ & $\begin{array}{c}\gamma_{G} \\
1,35 \\
\gamma_{G} \\
1,35 \\
\gamma_{G} \\
1,35 \\
\gamma_{Q} \\
1,5 \\
\gamma_{Q} \\
1,5 \\
\\
\gamma_{M 0} \\
1,05 \\
\end{array}$ & 1,0 & \begin{tabular}{|c}
0,000533 \\
$0,5 \%$ \\
0,000106 \\
$0,1 \%$ \\
0,00875 \\
$8,6 \%$ \\
0,000245 \\
$0,2 \%$ \\
0,000263 \\
$0,3 \%$ \\
\\
0,000238 \\
$0,2 \%$ \\
\end{tabular} & $\begin{array}{c}0,010135 \\
9,9 \%\end{array}$ \\
\hline $\begin{array}{l}\text { Esfuerzo } \\
\text { cortante }\end{array}$ & \begin{tabular}{|ll}
$V_{E d}$ & \\
- & Peso propio \\
& acero \\
- & Peso propio \\
& hormigón \\
- & Cargas \\
& permanentes \\
- & Sobrecarga \\
& variable \\
& Carga de \\
nieve & \\
$V_{R d}$
\end{tabular} & $\begin{array}{c}\gamma_{S d, V} \cdot \gamma_{g, a} \\
\mathbf{1 , 3 0 4 7} \cdot 1,017 \\
\gamma_{S d, V} \cdot \gamma_{g, c} \\
\mathbf{1 , 3 0 4 7} \cdot 1,043 \\
\gamma_{S d, V} \cdot \gamma_{g, p} \\
\mathbf{1 , 3 0 4 7} \cdot 1,106 \\
\gamma_{S d, V} \cdot \gamma_{q, l} \\
1,112 \cdot \mathbf{1 , 3 6 3} \\
\gamma_{S d, V} \cdot \gamma_{q, s} \\
1,112 \cdot \mathbf{1 , 3 6 3 5} \\
\\
\gamma_{R d, V} \cdot \gamma_{a} \\
1,0327 \cdot \mathbf{1 , 0 2 5 7}\end{array}$ & $\begin{array}{c}\gamma_{G} \\
1,35 \\
\gamma_{G} \\
1,35 \\
\gamma_{G} \\
1,35 \\
\gamma_{Q} \\
1,5 \\
\gamma_{Q} \\
1,5 \\
\\
\gamma_{M 0} \\
1,05\end{array}$ & 1,0 & $\begin{array}{c}0,000533 \\
0,5 \% \\
0,000106 \\
0,1 \% \\
0,00875 \\
8,6 \% \\
0,000245 \\
0,2 \% \\
0,000263 \\
0,3 \% \\
\\
0,000085 \\
0,1 \%\end{array}$ & $\begin{array}{c}0,009982 \\
9,8 \%\end{array}$ \\
\hline
\end{tabular}




\begin{tabular}{|c|c|c|c|c|c|c|}
\hline $\begin{array}{l}\text { Esfuerzo axil de } \\
\text { compresión }\end{array}$ & 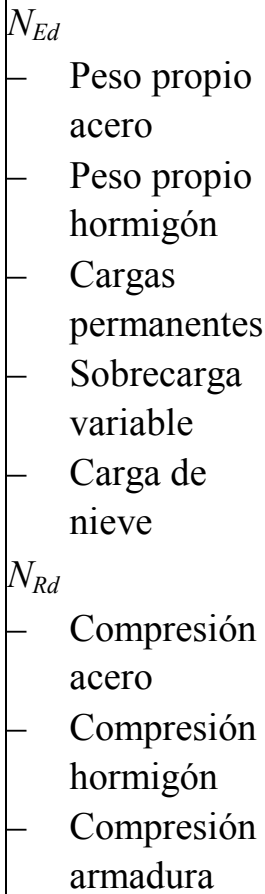 & $\begin{array}{c}\gamma_{S d, N} \cdot \gamma_{g, a} \\
\mathbf{1 , 1 4 2 3} \cdot 1,017 \\
\gamma_{S d, N} \cdot \gamma_{g, c} \\
\mathbf{1 , 1 4 2 3} \cdot 1,043 \\
\gamma_{S d, N} \cdot \gamma_{g, p} \\
1,055 \cdot \mathbf{1 , 2 6 6} \\
\gamma_{S d, N} \cdot \gamma_{q, l} \\
1,055 \cdot \mathbf{1 , 3 6 3} \\
\gamma_{S d, N} \cdot \gamma_{q, s} \\
1,055 \cdot \mathbf{1 , 3 6 3 5} \\
\gamma_{R d, N} \cdot \gamma_{a} \\
1,0199 \cdot \mathbf{1 , 0 5 2 7} \\
\gamma_{R d, N} \cdot \gamma_{c} \\
1,0199 \cdot \mathbf{1 , 3 9 4} \\
\gamma_{R d, N} \cdot \gamma_{s} \\
1,0199 \cdot \mathbf{1 , 0 4 9}\end{array}$ & $\begin{array}{c}\gamma_{G} \\
1,35 \\
\gamma_{G} \\
1,35 \\
\gamma_{G} \\
1,35 \\
\gamma_{Q} \\
1,5 \\
\gamma_{Q} \\
1,5 \\
\\
\gamma_{M 0} \\
1,05 \\
\gamma_{C} \\
1,5 \\
\gamma_{S} \\
1,15\end{array}$ & 1,0 & \begin{tabular}{|c}
0,03546 \\
$34,8 \%$ \\
0,02531 \\
$24,8 \%$ \\
0,000219 \\
$0,2 \%$ \\
0,003909 \\
$3,9 \%$ \\
0,003844 \\
$3,8 \%$ \\
\\
0,000559 \\
$0,5 \%$ \\
0,006125 \\
$6,0 \%$ \\
0,00642 \\
$6,3 \%$
\end{tabular} & $\begin{array}{c}0,081846 \\
80,3 \%\end{array}$ \\
\hline & & & & & $\min W(\mu, \sigma)$ & \begin{tabular}{|c|}
0,101963 \\
$100 \%$ \\
\end{tabular} \\
\hline
\end{tabular}

\subsubsection{Estructuras de madera laminada encolada}

\section{Modelos probabilistas}

Los modelos probabilistas para las variables que intervienen en las funciones de estado límite para los elementos de madera laminada encolada (Apartado 5.4.5) están resumidos en la Tabla 6.13. También estos modelos, igual que los resumidos en los Apartados 6.7.2 a 6.7.4, cumplen los requisitos del Apartado 6.2.2, entre ellos la representación del estado de incertidumbre asociado con las reglas de la normativa en vigor. Concretamente, se trata de las reglas para el dimensionado de los elementos de madera laminada encolada, integradas en el Código Técnico de la Edificación [CTE DB SE 2006, CTE DB SE-AE 2006, CTE DB SE-M 2006].

Las normas nacionales citadas están basadas en los Eurocódigos correspondientes, por lo que ambos conjuntos normativos son compatibles entre ellos. En lo relativo a las reglas empleadas en el marco del presente estudio, incluso son idénticos. Es por ello que los modelos de la Tabla 6.13 también representan el estado de incertidumbre asociado con las reglas de los Eurocódigos para el dimensionado de las estructuras de edificación de madera laminada encolada [EN 1990 2002, EN 1991-1-1 2002, EN 1991-1-3 2003, EN 1995-1-1 2004]. 
Tabla 6.13 - Modelos probabilistas para las acciones y sus efectos, así como la resistencia de los elementos de madera laminada encolada.

\begin{tabular}{|c|c|c|c|c|}
\hline Variable & Notación & Tipo & Sesgo & $\mathrm{CoV}$ \\
\hline \multicolumn{5}{|c|}{$\begin{array}{r}\text { Acciones y sus efectos } \\
\text { iables } g_{p}, q_{i}, \xi_{E, M}, \xi_{E, N}, \xi_{E, V} \text { esta }\end{array}$} \\
\hline Peso propio de la estructura de MLE & $g_{g}$ & Normal & 1,0 & 0,1 \\
\hline \multicolumn{5}{|c|}{ Resistencia de los elementos de madera laminada encolada } \\
\hline Resistencia a flexión de la MLE & $f_{m, g}$ & Lognormal & 1,6 & 0,21 \\
\hline Resistencia a compresión paralela a la fibra & $f_{c, 0, g}$ & Lognormal & 1,4 & 0,16 \\
\hline Resistencia a cortante de la MLE & $f_{v, g}$ & Lognormal & 1,45 & 0,18 \\
\hline Factor de modificación (clase de servicio) & $k_{\text {mod }}$ & \multicolumn{3}{|c|}{ Determinista } \\
\hline Factor de canto de la sección de madera & $k_{h}$ & \multicolumn{3}{|c|}{ Determinista } \\
\hline Área de la sección transversal & $A$ & Normal & 1,0 & 0,014 \\
\hline Módulo elástico de la sección transversal & $W_{e l}$ & Normal & 1,0 & 0,017 \\
\hline $\begin{array}{l}\text { Coeficiente para las incertidumbres del mod } \\
\text { resistencia }\end{array}$ & & & & \\
\hline - Momentos flectores & $\xi_{R, M}$ & Lognormal & 1,0 & 0,05 \\
\hline Esfuerzos axiles & $\xi_{R, N}$ & Lognormal & 1,0 & 0,05 \\
\hline Esfuerzos cortantes & $\xi_{R, V}$ & Lognormal & 1,0 & 0,05 \\
\hline
\end{tabular}

\section{Comprobación del estado de incertidumbre}

Los parámetros, ajustados según el procedimiento del Apartado 4.5 y resumidos en la Tabla 6.13, se utilizan para determinar la contribución de los modelos probabilistas para las acciones, sus efectos y la resistencia de los elementos de madera laminada encolada, a la función objetivo (4.9). Los resultados están reflejados en la Tabla 6.14, estructurada como la Tabla 6.8 (Apartado 6.7.2).

Tabla 6.14 - Contribución de los modelos probabilistas para las acciones, sus efectos y la resistencia de los elementos de madera laminada encolada a la función objetivo.

\begin{tabular}{|c|c|c|c|c|c|c|}
\hline \multirow{2}{*}{\begin{tabular}{|c|}
$\begin{array}{c}\text { Mecanismo de } \\
\text { fallo }\end{array}$ \\
\end{tabular}} & \multirow{2}{*}{$E_{d}, R_{d}$} & \multicolumn{2}{|c|}{ Coeficientes parciales } & \multicolumn{3}{|c|}{ Función objetivo } \\
\hline & & $\gamma_{Y, j}(\mu, \sigma)$ & $\gamma_{Y, t}$ & $W_{Y, j}$ & $\left(\gamma_{Y, j}-\gamma_{Y, t}\right)^{2}$ & $W_{j}(\mu, \sigma)$ \\
\hline Flexión & 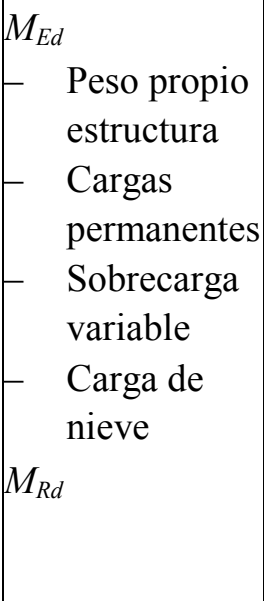 & $\begin{array}{c}\gamma_{S d, M} \cdot \gamma_{g, g} \\
\mathbf{1 , 3 0 4 7} \cdot 1,1074 \\
\gamma_{S d, M} \cdot \gamma_{g, p} \\
\mathbf{1 , 3 0 4 7} \cdot 1,106 \\
\gamma_{S d, M} \cdot \gamma_{q, l} \\
1,112 \cdot \mathbf{1 , 3 6 3} \\
\gamma_{S d, M} \cdot \gamma_{q, s} \\
1,112 \cdot \mathbf{1 , 3 6 3 5} \\
\\
\gamma_{R d, M} \cdot \gamma_{m} \\
1,0663 \cdot \mathbf{1 , 1 8 3 4}\end{array}$ & $\begin{array}{c}\gamma_{G} \\
1,35 \\
\gamma_{G} \\
1,35 \\
\gamma_{Q} \\
1,5 \\
\gamma_{Q} \\
1,5 \\
\\
\gamma_{M} \\
1,25\end{array}$ & 1,0 & $\begin{array}{c}0,00899 \\
19,9 \% \\
0,00875 \\
19,3 \% \\
0,000245 \\
0,5 \% \\
0,000263 \\
0,6 \% \\
\\
0,000141 \\
0,3 \%\end{array}$ & $\begin{array}{c}0,018389 \\
40,6 \%\end{array}$ \\
\hline
\end{tabular}




\begin{tabular}{|c|c|c|c|c|c|c|}
\hline $\begin{array}{l}\text { Esfuerzo } \\
\text { cortante }\end{array}$ & $\begin{array}{|ll|}V_{E d} & \\
- & \text { Peso propio } \\
& \text { estructura } \\
& \text { Cargas } \\
& \text { permanentes } \\
- & \text { Sobrecarga } \\
& \text { variable } \\
& \text { Carga de } \\
& \text { nieve } \\
V_{R d} & \end{array}$ & $\begin{array}{c}\gamma_{S d, V} \cdot \gamma_{g, g} \\
\mathbf{1 , 3 0 4 7} \cdot 1,1074 \\
\gamma_{S d, V} \cdot \gamma_{g, p} \\
\mathbf{1 , 3 0 4 7} \cdot 1,106 \\
\gamma_{S d, V} \cdot \gamma_{q, l} \\
1,112 \cdot \mathbf{1 , 3 6 3} \\
\gamma_{S d, V} \cdot \gamma_{q, s} \\
1,112 \cdot \mathbf{1 , 3 6 3 5} \\
\\
\gamma_{R d, V} \cdot \gamma_{m} \\
1,0651 \cdot \mathbf{1 , 1 9 2}\end{array}$ & $\begin{array}{c}\gamma_{G} \\
1,35 \\
\gamma_{G} \\
1,35 \\
\gamma_{Q} \\
1,5 \\
\gamma_{Q} \\
1,5 \\
\\
\gamma_{M} \\
1,25\end{array}$ & 1,0 & $\begin{array}{c}0,00899 \\
19,9 \% \\
0,00875 \\
19,3 \% \\
0,000245 \\
0,5 \% \\
0,000263 \\
0,6 \% \\
\\
0,000384 \\
0,8 \%\end{array}$ & $\begin{array}{c}0,018632 \\
41,1 \%\end{array}$ \\
\hline $\begin{array}{l}\text { Esfuerzo axil de } \\
\text { compresión }\end{array}$ & 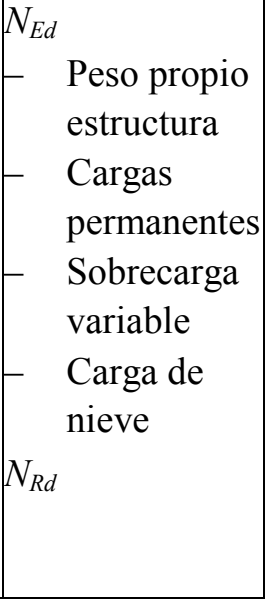 & $\begin{array}{c}\gamma_{S d, N} \cdot \gamma_{g, g} \\
1,0546 \cdot \mathbf{1 , 2 6 8 6} \\
\gamma_{S d, N} \cdot \gamma_{g, p} \\
1,055 \cdot \mathbf{1 , 2 6 6} \\
\gamma_{S d, N} \cdot \gamma_{q, l} \\
1,055 \cdot \mathbf{1 , 3 6 3} \\
\gamma_{S d, N} \cdot \gamma_{q, s} \\
1,055 \cdot \mathbf{1 , 3 6 3 5} \\
\\
\gamma_{R d, N} \cdot \gamma_{m} \\
1,0651 \cdot \mathbf{1 , 1 6 1 8}\end{array}$ & $\begin{array}{c}\gamma_{G} \\
1,35 \\
\gamma_{G} \\
1,35 \\
\gamma_{Q} \\
1,5 \\
\gamma_{Q} \\
1,5 \\
\\
\gamma_{M} \\
1,25 \\
\end{array}$ & 1,0 & $\begin{array}{c}0,000147 \\
0,3 \% \\
0,000219 \\
0,5 \% \\
0,003909 \\
8,6 \% \\
0,003844 \\
8,5 \% \\
\\
0,000158 \\
0,4 \% \\
\end{array}$ & $\begin{array}{c}0,008277 \\
18,3 \%\end{array}$ \\
\hline & & & & & $\min W(\mu, \sigma)$ & \begin{tabular}{|c|}
0,045298 \\
$100 \%$ \\
\end{tabular} \\
\hline
\end{tabular}

\subsubsection{Conclusiones}

El Apartado 6.7 contiene un resumen de los modelos probabilistas para todas las variables consideradas en el marco del presente estudio, deducidos de acuerdo con el procedimiento del Apartado 4.5 y agrupados según su utilización en las funciones de estado límite para los elementos de los diferentes materiales constitutivos: acero estructural (Apartado 6.7.2), hormigón armado (Apartado 6.7.3), mixtos (Apartado 6.7.4) y madera laminada encolada (Apartado 6.7.5), respectivamente. Los modelos cumplen los requisitos del Apartado 6.2.2, lo que implica que representan el estado de incertidumbre asociado con las reglas de la normativa que está en vigor para el proyecto de las estructuras de edificación, respectivamente el Código Técnico de la Edificación y el Eurocódigo que, a efectos de las estructuras analizadas, se pueden considerar como equivalentes.

El grado de ajuste de los modelos probabilistas al estado de incertidumbre implícito en las reglas normalizadas se cuantifica a través de su contribución a la función objetivo (4.9). El valor mínimo de esta función, ${ }_{\min } W(\boldsymbol{\mu}, \boldsymbol{\sigma})=0,266$, se obtiene sumando los valores $W_{j}(\boldsymbol{\mu}, \boldsymbol{\sigma})$ según las Tablas 6.8, 6.10, 6.12 y 6.14 , es decir, sumando la contribución de los modelos probabilistas de las variables relevantes para el dimensionado de los elementos estructurales para cada uno de los distintos materiales constitutivos y mecanismos de fallo considerados. Este resultado equivale a una desviación media del orden de 0,063 entre los coeficientes parciales obtenidos mediante el método FORM normalizado, $\gamma_{Y, j}(\mu, \sigma)$, y el correspondiente valor requerido según las normas consideradas, $\gamma_{Y, t}$. Teniendo en 
cuenta que el valor medio de los coeficientes parciales requeridos es 1,367 , la citada desviación media equivale al $4,6 \%$ de los correspondientes coeficientes parciales requeridos.

Al efectuar el mismo tipo de análisis de los resultados por separado para las variables que intervienen en el dimensionado de los elementos constituidos por los diferentes materiales, se obtienen valores muy similares. Las desviaciones medias entre los coeficientes parciales obtenidos mediante el método FORM normalizado y los correspondientes valores requeridos según las normas consideradas alcanzan, con respecto a estos últimos, el 4,8\% (acero estructural), 4,1\% (hormigón armado), 5,3\% (mixtos) y 4\% (madera laminada encolada). En este contexto se puede señalar que los valores medio de los coeficientes parciales requeridos también son similares: 1,35 para el dimensionado de los elementos de acero estructural; 1,385 para los de hormigón armado; 1,348 para los mixtos y 1,39 en el caso de los elementos de madera laminada encolada.

\subsection{OBSERVACIONES FINALES}

La cuantificación del estado de incertidumbre asociado con las reglas de las normas actuales para el dimensionado estructural es el objeto del presente capítulo. Este desarrollo es necesario debido a la coincidencia de dos circunstancias. Por un lado, según el enfoque del presente estudio (Capítulo 4), los riesgos aceptables para las personas dependen del nivel de fiabilidad y, por tanto, del nivel de incertidumbre asociado con las reglas normalizadas para el dimensionado estructural. Por otro lado, las normas que actualmente están en vigor no establecen explícitamente estas incertidumbres: no definen los modelos probabilistas para las variables relevantes a efectos del dimensionado estructural.

La deducción de los modelos probabilistas para estas variables, que a efectos del presente estudio son las que intervienen en las funciones de estado límite definidas en el Apartado 5.4, se realiza según el Paso 4 del procedimiento establecido en el Apartado 4.5. La estructuración del Capítulo 6 se ajusta a las diferentes tareas que es necesario abordar en este contexto.

En el Apartado 6.2 se definen las características requeridas para los modelos probabilistas para las acciones, sus efectos y la resistencia correspondiente de las estructuras:

- aptitud para aplicaciones prácticas;

- representación de las características físicas de la variable correspondiente;

- consistencia con los modelos del código modelo probabilista [JCSS 2001];

- representación del estado de incertidumbre asociado con las reglas de la normativa en vigor.

Para facilitar las aplicaciones prácticas de los modelos, se opta por representar las incertidumbres mediante variables aleatorias, $X_{i}$. Cada una de ellas está caracterizada por una determinada función de distribución estadística, así como los denominados parámetros de la distribución, concretamente su valor medio, $\mu_{x i}$, $\mathrm{l}$ la desviación típica, $\sigma_{x i}$. Además, el primero de estos parámetros se divide entre el valor representativo de la misma variable, definido en las normas cuyo estado de incertidumbre se está cuantificando, mientras que el segundo se divide entre el valor medio. De esta manera se obtiene una representación adimensional de cada variable, $X_{i}$, a través de sus coeficientes de sesgo y de variación, respectivamente: $X_{i}=$ Tipo $($ Sesgo; $\mathrm{CoV})$.

La representación del estado de incertidumbre asociado con las reglas de la normativa en vigor requiere comparar las incertidumbres correspondientes a los modelos probabilistas para las distintas variables básicas con las implícitamente cubiertas a través del método de los coeficientes parciales, empleado en estas normas. Para ello es preciso disponer de una representación consistente del formato de coeficientes parciales, utilizado en el conjunto de las normas analizadas. En el Apartado 6.3 se adopta un formato que facilita esta comparación ya que desglosa y particulariza los coeficientes parciales para las incertidumbres de los modelos en función de los efectos de las 
acciones considerados y la resistencia correspondiente. Este formato difiere del adoptado en los Eurocódigos y las normas españolas equivalentes, pero tiene la ventaja de permitir una mayor precisión en la deducción de los modelos probabilistas de las variables. Además, aunque diferente, el formato adoptado es compatible con el empleado para la verificación de la fiabilidad estructural según los mencionados conjuntos de normas.

La deducción de los modelos probabilistas para las variables que intervienen en las funciones de estado límite consideradas, se ilustra a través de tres ejemplos, para la carga de nieve (Apartado 6.4), el límite elástico del acero estructural (Apartado 6.5) y el modelo de resistencia frente a momentos flectores de las vigas de acero (Apartado 6.6), respectivamente. Una vez establecidos los requisitos para los modelos (Apartado 6.2), así como un formato de coeficientes parciales adecuado y consistente (Apartado 6.3), se llevan a cabo las siguientes tareas destinadas a la deducción de los modelos probabilistas:

- identificación de los parámetros de las variables;

- determinación, mediante el método FORM normalizado, de los valores de cálculo de las variables y de los correspondientes coeficientes parciales para los diferentes mecanismos de fallo;

- determinación de la contribución de los modelos probabilistas identificados a la función objetivo (4.9);

- ajuste de los parámetros de los modelos probabilistas para minimizar la función objetivo;

- verificación de los resultados.

Los ejemplos citados, para los que la deducción de los modelos probabilistas se muestra de manera explícita, cubren todo el abanico de diferentes variables: las relativas a las acciones, la resistencia y las imprecisiones de los modelos, respectivamente. Además, se trata de los modelos cuya identificación requiere los desarrollos originales más laboriosos para asegurar que representen las características físicas de las variables. Eso es especialmente el caso de la carga de nieve y, en menor medida, el límite elástico del acero así como las incertidumbres del modelo de resistencia frente a los momentos flectores. La deducción de los modelos probabilistas para las otras variables que intervienen en las funciones de estado límite establecidas en el Apartado 5.4 es análoga. La diferencia radica en que la deducción de los parámetros se basa en la literatura especializada, por lo que su identificación no requiere desarrollos específicos. A partir de esta tarea el procedimiento es idéntico al mostrado en detalle para las tres variables citadas. En particular, es el caso de todo el proceso de comprobación del estado de incertidumbre y ajuste de los parámetros.

Resulta imposible representar de manera explícita la deducción de los parámetros de todas las variables que intervienen en las funciones de estado límite consideradas (Apartado 5.4). Por este motivo, en el Apartado 6.7 se incluye un resumen de los resultados obtenidos en este proceso de deducción de los modelos probabilistas para las acciones, sus efectos y la resistencia de los elementos de acero estructural, hormigón armado, mixtos de acero y hormigón, así como madera laminada encolada. Todos los modelos cumplen los requisitos establecidos previamente (Apartado 6.2.2), lo que implica que representan el estado de incertidumbre asociado con las reglas de la normativa que está en vigor para el proyecto de las estructuras de edificación, el Código Técnico de la Edificación y el Eurocódigo, respectivamente. A efectos de las estructuras analizadas, estos dos conjuntos normativos son equivalentes.

El grado de ajuste de los modelos probabilistas al estado de incertidumbre implícito en las reglas de la mencionada normativa, se puede expresar en términos de la desviación entre los coeficientes parciales asociados con los modelos deducidos, obtenidos mediante el método FORM normalizado, y los correspondientes valores requeridos según las normas consideradas. La desviación media es inferior al 5\% del valor requerido de los coeficientes parciales. Además, debido a que no se observan dispersiones significativas en el grado de ajuste de los modelos probabilistas que intervienen en las 
funciones de estado límite para los elementos constituidos por los diferentes materiales considerados, se concluye que los modelos deducidos pueden ser usados a efectos de la continuación del estudio. Concretamente, son aptos para ser utilizados en la determinación del nivel de fiabilidad implícito en las normas analizadas y del nivel de riesgo asociado (Capítulo 8). 


\section{MODELOS DE CONSECUENCIAS}

\subsection{INTRODUCCIÓN}

Entre todas las posibles consecuencias adversas que puede tener un colapso estructural, los daños personales priman sobre las demás, particularmente cuando se producen víctimas mortales. Los riesgos para las personas son por ello dominantes en el campo de la ingeniería estructural (Apartados 1.1.4, 2.3), y el presente estudio se centra en ellos (Apartados 1.2, 1.3, 4.2). Por este motivo, se simplifica la representación de las consecuencias de los fallos estructurales, teniendo en cuenta únicamente la pérdida de vidas humanas.

El Eurocódigo [EN 1990 2002] distingue cualitativamente entre tres clases de consecuencias, asociadas con las correspondientes clases de fiabilidad que se ilustran en el Apartado 3.6.2 a través de diferentes tipos de edificios y obras de ingeniería (Tabla 3.6). La clase de consecuencias CC2 engloba los edificios destinados a un uso residencial o de oficinas, mientras que la clase CC3 se refiere a los edificios donde se pueden producir concentraciones de personas (Apartado 5.3). Según el presente estudio, los riesgos admisibles se fijan en los niveles de los riesgos aceptados implícitamente en la normativa en vigor (Apartado 4.1.2). Teniendo en cuenta este enfoque, es necesario que los modelos de consecuencias, cuyo desarrollo es objeto del presente capítulo, sean compatibles con la definición de las categorías de consecuencias contenida en las mismas normas. En particular, deben ser compatibles con la distinción entre las clases de consecuencias mencionadas, CC2 y CC3. Todo ello a pesar de que el Código Técnico de la Edificación [CTE DB SE 2006] no distingue entre diferentes clases de consecuencias y fiabilidad. Debido a que, en general, las reglas de la normativa nacional están basadas en los Eurocódigos correspondientes, la citada diferencia de aquella con respecto a estos no impide que las conclusiones del presente estudio se hagan extensivas al ámbito español.

Una mención aparte requiere la clase de consecuencias CC1. Engloba aquellos edificios en los que durante gran parte del tiempo no se encuentran personas, por ejemplo, edificios destinados a la agricultura, invernaderos o almacenes. Consecuentemente, si se produce el colapso de la estructura de un edificio de este tipo, se considera que la probabilidad de la presencia simultánea de personas resulta suficientemente pequeña como para poder asumir que normalmente conlleve solo pérdidas económicas. Bajo esta hipótesis, y debido a que únicamente se tienen en cuenta los daños personales, en el marco del presente estudio no es necesario establecer un modelo de consecuencias para la clase CC1.

Para la determinación de los modelos de consecuencias, se contemplan únicamente colapsos cuyo origen sean desviaciones desfavorables de los valores previstos para los efectos de las acciones e influencias o las resistencias correspondientes, relacionadas con las condiciones de uso normales de un edificio (Apartado 1.2). Es decir, colapsos que se producen a raíz de una situación persistente, en la terminología de las normas actuales [EN 1990 2002, CTE DB SE 2006]. Es razonable no considerar colapsos inducidos por acciones accidentales ya que, en estos casos, a menudo resulta imposible distinguir entre víctimas directas e indirectas. En un incendio, por ejemplo, la mayoría de las muertes se producen por intoxicación, no por el colapso de la estructura. Tampoco se contemplan los colapsos estructurales que se producen durante la fase de construcción de una obra debido a que, a efectos del presente estudio, estas situaciones transitorias no son comparables con las persistentes: el sistema estructural cambia de manera evolutiva; las personas expuestas suelen ser en su mayoría los operarios que ejecutan la obra, con unas características $y$, en caso de un accidente, un comportamiento diferentes a los de los usuarios de un edificio terminado; en muchos casos, los colapsos que se producen durante la construcción se deben a errores cometidos por las personas expuestas, es decir, los propios operarios; normalmente, también el número de personas expuestas es diferente. 
Bajo todas estas premisas, se definen las tareas destinadas al desarrollo de los modelos de consecuencias en términos del número esperado de víctimas mortales en caso de producirse un colapso estructural (Apartado 4.3). Estas tareas se describen en el presente capítulo, cuya estructuración se ajusta a ellas.

En primer lugar, se crea una base de datos relativa a colapsos reales de estructuras de edificación (Apartado 7.2). Se incluyen casos ocurridos en diferentes países occidentales, con sistemas constructivos homologables entre ellos. No obstante, mayoritariamente los casos analizados se han producido en España. La información correspondiente a estos colapsos constituye la base para la elaboración de los modelos de consecuencias.

Para muchos de los casos recopilados, las fuentes de información disponibles se limitan a diferentes medios de comunicación ya que no todos los países siguen la tradición anglosajona de publicar los informes de ingeniería forense [Tanner 2013b]. Además, en los medios generalistas estos accidentes suelen ser noticia en los primeros días después de su ocurrencia, cuando la información a menudo es confusa. Consecuentemente, los datos recopilados con frecuencia son escasos o poco fiables, conduciendo a lagunas en la base de datos original. Con el fin de rellenarlas, en la medida de lo posible, se emplea información complementaria extraída de diferentes fuentes, recurriendo particularmente a los datos disponibles en el Instituto Nacional de Estadística (Apartado 7.3). La base de datos así complementada se reduce finalmente a los casos con información suficientemente significativa.

Mediante una serie de pruebas y análisis estadísticos de estos datos, se deducen varios modelos matemáticos que permiten estimar el número de víctimas mortales en función de distintos parámetros relacionados con los edificios (Apartado 7.4). Finalmente, se seleccionan los más adecuados de estos modelos para las clases de consecuencias $\mathrm{CC} 2$ y CC3, respectivamente.

El capítulo se cierra con algunas observaciones finales (Apartado 7.5), destacando los aspectos más relevantes de cara a la continuación del trabajo.

\subsection{BASE DE DATOS SOBRE COLAPSOS ESTRUCTURALES}

\subsubsection{Información requerida}

Es conveniente recopilar toda la información disponible sobre cada una de las estructuras de edificación colapsadas, identificadas en una revisión de la literatura especializada y de los medios de comunicación generalistas. El interés de disponer no solamente de la información que pudiera resultar relevante para el tipo de modelos requeridos en el presente estudio reside en el hecho de que posibles trabajos futuros pudieran tener un alcance y unos objetivos distintos a los actuales: consideración de otras consecuencias adversas de los colapsos, además de las víctimas mortales (número de heridos, pérdidas económicas, etcétera); representación de las consecuencias en función de otros parámetros o características de los edificios, no considerados en el presente estudio (antigüedad, sistema constructivo, etcétera); análisis de las causas que están detrás de los motivos aparentes de los colapsos [Schneider 1994]; etcétera.

Los datos que se procura recopilar para cada una de las estructuras de edificación colapsadas, se pueden clasificar en una de las siguientes categorías:

- características del edificio;

- datos sobre el colapso;

- datos relativos a las consecuencias;

- información adicional. 
En los siguientes apartados se describen los distintos campos de la base de datos, correspondientes a las cuatro categorías. Para cada uno de ellos se resumen el tipo de la información requerida y, donde no resulte obvio, su utilidad. El formato de la base de datos se visualiza en la Figura 7.1, a través de un caso concreto. Un campo en blanco significa que las fuentes consultadas no contienen la información correspondiente.

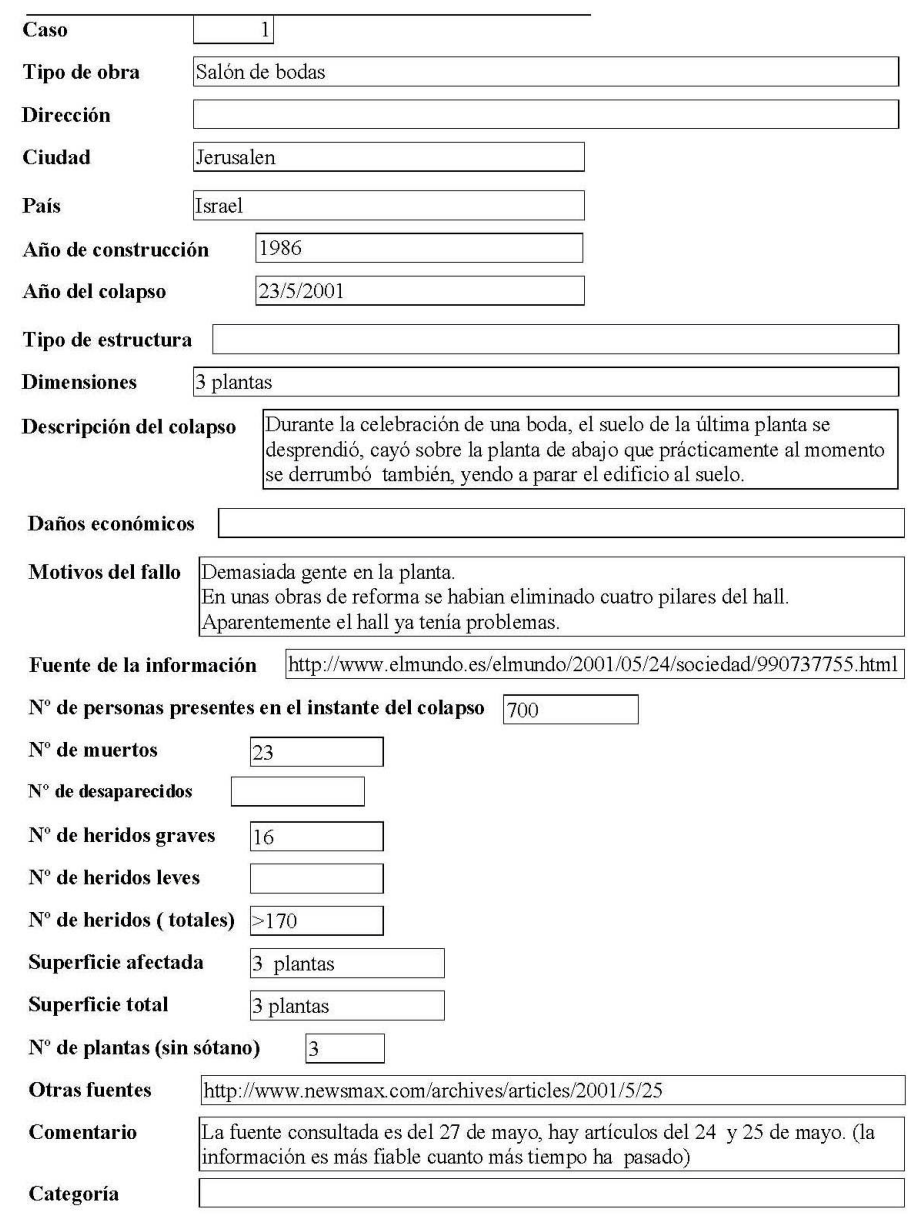

Figura 7.1 - Formato de la base de datos con la información recopilada para uno de los colapsos considerados.

\subsubsection{Edificio}

\section{Ubicación}

Para el caso de que sea conocida la ubicación del edificio colapsado, se introducen los campos que permiten reflejar su dirección, ciudad y país. Esta información puede contribuir a evitar contabilizaciones múltiples de un mismo caso, sobre la base de datos provenientes de diferentes fuentes.

\section{Categoría de uso}

El conocimiento del uso al que está destinado el edificio analizado resulta fundamental, puesto que de él depende el número de personas expuestas al sistema en el momento del colapso (Apartado 4.2.3). Para describir los diferentes usos se emplea el sistema de categorías de uso del Código Técnico de la Edificación [CTE DB SE-AE 2006]. 


\section{Año de la construcción}

En el marco del presente estudio no se tiene en cuenta la antigüedad de los edificios colapsados. No obstante, este dato podría proporcionar indicios sobre las soluciones constructivas empleadas, los materiales constitutivos implicados o las cargas consideradas en el dimensionado de la estructura. Esta información podría ser de interés para estudios futuros, motivo por el que se incluye un campo para el año de la construcción.

\section{Dimensiones y número de plantas o unidades}

En los campos previstos a estos efectos, se introduce toda la información disponible sobre las dimensiones del edificio analizado: altura, $H$; anchura, $B$, y longitud, $L$, de su base; superficie útil total, $A$. También es relevante el número de plantas, $n_{s}$, que en bastantes casos es el único indicio disponible sobre la envergadura de un edificio afectado por un colapso, especialmente si la fuente de información es un medio de comunicación generalista, como en el ejemplo reflejado en la Figura 7.1. Alternativamente, pueden aportar información útil, acerca del tamaño de un edificio, indicadores tales como el número de apartamentos, oficinas o habitaciones, este último en el caso de un hotel u hospital.

\section{Sistema estructural y materiales constitutivos}

Se incluye un campo que permite indicar la información disponible sobre el sistema estructural del edificio afectado por un colapso, incluidos los materiales constitutivos empleados. Este tipo de información no suele encontrarse en las noticias de los medios de comunicación generalistas, pero si en la literatura especializada. En el marco del presente estudio no se establecen diferentes modelos de consecuencias en función de los distintos sistemas estructurales o materiales constitutivos. No obstante, esta información podría ser de interés para estudios futuros.

\subsubsection{Colapso}

\section{Año del colapso}

La base de datos contiene un campo para introducir la fecha del colapso que suele ser conocida. En el marco del presente estudio se utiliza esta información básicamente a efectos de control, para evitar contabilizaciones múltiples de un mismo caso, sobre la base de datos provenientes de diferentes fuentes.

\section{Descripción y motivos del colapso}

La base de datos también contiene dos campos para una breve descripción del mecanismo del colapso y un resumen de sus causas, respectivamente. En los casos en los que la fuente de información es un informe de ingeniería forense o un artículo de una revista técnica especializada, normalmente tanto el mecanismo del colapso como sus causas pueden ser descritos con precisión. Al contrario, si la información proviene de los medios de comunicación generalistas, debe ser interpretada con cautela, ya que estas noticias suelen publicarse inmediatamente después de un accidente, mucho antes de que una investigación forense pueda aclarar sus causas.

\section{Superficie afectada por el colapso}

La superficie afectada por un colapso, $A_{c o l}$, no solamente incluye el área de influencia de un determinado elemento o conjunto de elementos en los que se produce una rotura, sino también el área de la planta o las plantas inferiores sobre las que impactan los elementos portantes que fallan y los no portantes apoyados en ellos. Se trata de un parámetro fundamental para el establecimiento de los modelos ya que, a menudo, se puede observar una cierta proporcionalidad entre esta superficie y los diferentes tipos de consecuencias adversas. Aunque las fuentes de información en la mayoría de los 
casos no contienen una indicación directa de la superficie afectada por el colapso, esta a veces se puede estimar a partir de otros parámetros:

- cuando el colapso de un edificio es total, suele mencionarse en las diferentes fuentes; en estos casos, $A_{c o l}$ corresponde muy aproximadamente a la superficie útil total, $A$;

- cuando el colapso no es total, en ocasiones se encuentra en la información disponible algún indicio sobre el porcentaje afectado del edificio, con lo que $A_{c o l}$ se puede estimar a través de la superficie útil total;

- algo similar ocurre en los casos en los que se encuentra información sobre el número de plantas colapsadas, $n_{c o l}$, o el número de unidades (apartamentos, oficinas, habitaciones) afectadas;

- también existe la posibilidad de efectuar una estimación del área afectada a partir de las fotografías disponibles, en combinación con otros parámetros tales como la superficie útil total, $A$, o el número de plantas, $n_{s}$.

La base de datos contiene un campo para introducir los datos conocidos en relación con el área afectada por un colapso.

\section{Número de personas presentes en el momento del colapso}

En algunos casos se conoce o se puede estimar el número de personas presentes en el edificio, en el momento del colapso. Conjuntamente con el número de víctimas mortales (Apartado 7.2.4), el número de personas presentes se puede usar para estimar la probabilidad condicional de que una persona muera en un colapso, denominada letalidad en el Apartado 4.2. Es de esperar que la dispersión para esta probabilidad condicional sea importante. Posiblemente podría ser más reducida si en lugar de las personas presentes en el edificio se contabilizaran solamente aquellas que se encuentren en la zona afectada por el colapso. No obstante, a su vez, este dato está afectado por grandes incertidumbres.

A pesar de estos inconvenientes, la base de datos contiene un campo que permite reflejar el número de personas presentes en el edificio en el momento del colapso, $N_{p}$. Aunque esta información no se utilice directamente en el presente estudio, podría resultar de interés para trabajos futuros.

\subsubsection{Consecuencias}

\section{Número de víctimas mortales}

En el marco del presente estudio resulta fundamental conocer el número de víctimas mortales, $N$, que se producen en cada uno de los colapsos analizados, por lo que la base de datos incluye el campo correspondiente. Por su trascendencia, es un dato que normalmente se refleja tanto en los medios de comunicación generalistas como en los informes de ingeniería forense y en los artículos especializados. No obstante, si la fuente de información es alguno de los medios generalistas, centrados normalmente en la inmediatez de las noticias, pueden producirse discrepancias entre el número publicado y el real. Posibles motivos para ello son el hecho de que las primeras noticias de un accidente normalmente son confusas, o que algunos heridos de gravedad pueden fallecer posteriormente. En cualquier caso, estas diferencias parecen de menor importancia teniendo en cuenta las incertidumbres asociadas con todos los parámetros.

\section{Número de heridos}

La base de datos contiene dos campos para reflejar el número de heridos graves y leves, respectivamente. Aunque en el presente estudio no se tienen en cuenta los heridos que se producen en un colapso estructural, la recopilación de estos datos puede ser importante para estudios futuros. 


\section{Número de desaparecidos}

Sobre todo en accidentes de gran envergadura puede haber personas, buscadas por sus familiares, que no se encuentren entre los heridos ni las víctimas mortales. En las estadísticas se clasifican como desaparecidos y en la base de datos se introduce el correspondiente campo, a pesar de que esta información tampoco se usa en el marco del presente estudio.

\section{Daños económicos}

En consonancia con el alcance del presente estudio, no se establecen modelos para las consecuencias económicas de los colapsos estructurales. No obstante, para los casos en los que se conozca este tipo de daño, la base de datos contiene un campo que permite reflejarlo, por su indudable interés para trabajos futuros. Sin embargo, es muy poco frecuente disponer de información fiable sobre los daños económicos, tanto directos como indirectos, asociados con un colapso estructural. En la mayoría de los casos, incluso los estudios de ingeniería forense contienen información de carácter descriptivo sobre las consecuencias de un colapso, sin mencionar los valores monetarios. La vía más prometedora, aunque también problemática por motivos de confidencialidad, para tener acceso a este tipo de información sería a través de las compañías aseguradoras.

Por otro lado, la base de datos no contiene campo alguno para reflejar los daños medioambientales causados por los colapsos estructurales. Si es difícil conseguir información fiable sobre los daños económicos, más difícil todavía resulta conseguir datos sobre los daños ecológicos. En cualquier caso, en comparación con los daños medioambientales inducidos por el colapso de determinadas instalaciones industriales, el potencial de daño asociado con el colapso de una estructura de edificación es relativamente limitado.

\subsubsection{Información adicional}

\section{Referencias}

En la mayoría de los casos, la información relativa a un determinado colapso estructural se extrae sobre todo de una determinada fuente principal. No obstante, siempre es aconsejable contrastar los datos recopilados con los contenidos en fuentes alternativas, si estas existen y se tiene acceso a ellas. Por este motivo, la base de datos contiene dos campos en los que se reflejan, respectivamente, la fuente de información principal y las otras fuentes consultadas en relación con un determinado colapso.

\section{Observaciones}

En este campo se comentan, en su caso, las hipótesis adoptadas o las estimaciones realizadas. Si existen, se reflejan las contradicciones entre las distintas fuentes de información consultadas. En general, se recopila toda la información que pudiera tener un cierto interés y que no esté reflejada en alguno de los campos anteriores.

\section{Utilidad}

En el último campo, finalmente, se valora la utilidad del caso estudiado. Este resulta poco útil a efectos del presente estudio, o incluso descartable, si se da alguna de las siguientes circunstancias:

- la información recopilada es poco fiable o contradictoria;

- falta de información esencial como por ejemplo el número de víctimas mortales o cualquier otro dato relevante que permita estimar el alcance del colapso;

- colapso en ausencia de personas;

- colapso en presencia de personas pero sin víctimas mortales. 


\subsubsection{Evaluación estadística de los datos}

\section{Casos inicialmente considerados}

La base de datos original contiene 301 colapsos de estructuras de edificación, ocurridos en diferentes países occidentales (Apartado 7.1). En una primera evaluación el número se reduce a 109, considerando parcialmente los criterios mencionados en el Apartado 7.2.5 sobre su utilidad, aunque sin excluir, a priori, los casos sin víctimas mortales o aquellos para los que se desconozca este dato, de cara a futuras investigaciones. La Tabla 7.1 refleja el reparto de los colapsos entre las diferentes categorías de uso, definidas en el Código Técnico de la Edificación [CTE DB SE-AE 2006]. La mayoría de ellos afectan a edificios de uso residencial (49 casos), así como edificios donde se pueden producir concentraciones de personas (40 casos). Los casos restantes se reparten entre edificios de oficinas (2), tiendas (5) y almacenes (5). Entre los edificios colapsados también se encuentran 5 aparcamientos de vehículos ligeros, mientras que en 3 casos resulta imposible determinar el uso específico.

Si se supone que los edificios destinados a almacén pertenezcan a la clase de consecuencias CC2, según la definición del Eurocódigo [EN 1990 2002], igual que los edificios colapsados cuyo uso se desconoce, algo menos de 2 de cada 3 casos (63\%) pertenecen a esta clase, con consecuencias esperadas medianas en caso de colapso (Apartado 3.6.2). Los casos restantes (37\%) pertenecen a la clase CC3, para la que las consecuencias esperadas son grandes.

Tabla 7.1 - Número de colapsos reales de estructuras de edificación, inicialmente considerados.

\begin{tabular}{|c|c|c|c|}
\hline Categoría & Uso específico & Clase & $\mathbf{N}^{\mathbf{0}}$ de casos \\
\hline A1 & Residencia & CC2 & 49 \\
\hline B & Oficina & CC2 & 2 \\
\hline C & Concentración de personas & CC3 & 40 \\
\hline D & Tienda & CC2 & 5 \\
\hline E1 & Almacén & CC1 a CC2 & 5 \\
\hline F & Aparcamiento & CC2 & 5 \\
\hline \multicolumn{2}{|l|}{ Uso sin especificar } & -- & 3 \\
\hline \multicolumn{2}{|l}{ Total } & & $\mathbf{1 0 9}$ \\
\hline
\end{tabular}

\section{Estadística descriptiva de los parámetros}

En el marco de la descripción de los diferentes campos de la base de datos sobre colapsos estructurales, se menciona cuáles de los parámetros resultan especialmente relevantes para la deducción de los modelos de consecuencias requeridos a efectos del presente estudio, así como los motivos para ello (Apartado 7.2.2 a 7.2.4). Se trata básicamente del número de víctimas mortales, $N$, así como de los parámetros descriptivos del colapso (en primer lugar, pero no exclusivamente, la superficie afectada por el colapso, $A_{c o l}$ ) que se presten para efectuar unos análisis estadísticos de regresión entre éstos y $N$. También son relevantes los parámetros que ayuden a completar los campos anteriores, así como la categoría de uso del edificio, para poder establecer modelos compatibles con la definición de las clases de consecuencias normalizadas (Apartado 7.1). En suma, los datos más relevantes engloban:

- categoría de uso [CTE DB SE-AE 2006];

- número de víctimas mortales en un colapso, $N$;

- número de personas presentes en el edificio en el momento del colapso, $N_{p}$; 
- superficie afectada por un colapso, $A_{\text {col }}$;

- superficie útil total de un edificio, $A$;

- número de plantas afectadas por un colapso, $n_{c o l}$;

- número de plantas de un edificio, sin planta baja ni cubierta, $n_{s}$.

La Tabla 7.2 contiene el número y el porcentaje de los 109 casos inicialmente considerados para los que la base de datos contiene información útil en relación con cada uno de los parámetros relevantes. Por los motivos arriba mencionados, los casos en los que se conoce el número de víctimas mortales no corresponden a la totalidad de los 109 registros, alcanzando el 87,2\%. El número de personas presentes en el edificio en el momento del colapso, $N_{p}$, se conoce en menos de la mitad de los casos $(43,1 \%)$. Aunque no sorprenda, resulta llamativa la escasez de los datos disponibles sobre la superficie útil total de los edificios, $A$, y la superficie afectada por un colapso, $A_{c o l}$, con porcentajes del $26,6 \%$ y $34,9 \%$, respectivamente. El mismo orden de magnitud $(27,5 \%)$ se obtiene también para el número de plantas afectadas por un colapso, $n_{c o l}$, mientras que se conoce en más de dos de cada tres casos $(71,6 \%)$ el número de plantas de un edificio, $n_{s}$.

Tabla 7.2 - Información disponible sobre los parámetros relevantes.

\begin{tabular}{|c|c|c|c|c|c|c|c|}
\hline Parámetro & Cat. & $\boldsymbol{N}$ & $\boldsymbol{N}_{\boldsymbol{p}}$ & $\boldsymbol{A}_{\text {col }}$ & $\boldsymbol{A}$ & $\boldsymbol{n}_{\text {col }}$ & $\boldsymbol{n}_{\boldsymbol{s}}$ \\
\hline Número de registros & 106 & 95 & 47 & 38 & 29 & 30 & 78 \\
\hline Porcentaje de registros & 97,2 & 87,2 & 43,1 & 34,9 & 26,6 & 27,5 & 71,6 \\
\hline
\end{tabular}

La Tabla 7.2 pone de manifiesto las esperadas lagunas en la información disponible, sobre todo en relación con los parámetros descriptivos de los colapsos. Se confirma por ello la necesidad arriba mencionada de utilizar información complementaria para completar la base de datos. Este aspecto se aborda en el Apartado 7.3.

Tabla 7.3 - Evaluación estadística de los datos originales para los edificios colapsados de uso residencial (categoría de uso A1, según [CTE DB SE-AE 2006]).

\begin{tabular}{|c|c|c|c|c|c|}
\hline Parámetro & $\boldsymbol{N}$ & $\boldsymbol{N}_{\boldsymbol{p}}$ & $\boldsymbol{A}_{\boldsymbol{c o l}}\left[\mathbf{m}^{2}\right]$ & $\boldsymbol{n}_{\text {col }}$ & $\boldsymbol{n}_{\boldsymbol{s}}$ \\
\hline Valor medio & 11,6 & 26,2 & 2.647 & 3,35 & 4,1 \\
\hline Desviación típica & 27 & 33,9 & 7.013 & 1,6 & 1,76 \\
\hline Coeficiente de variación & 2,33 & 1,29 & 2,65 & 0,48 & 0,43 \\
\hline Valor máximo & 137 & 121 & 20.000 & 6 & 11 \\
\hline Valor mínimo & 0 & 1 & 10 & 1 & 1 \\
\hline
\end{tabular}

Previamente, se evalúan estadísticamente los datos originales, obtenidos para los distintos parámetros. La evaluación se realiza por separado para los edificios colapsados pertenecientes a las categorías de uso A1 (residencia) y C (concentración de personas). Los resultados están reflejados en las Tablas 7.3 y 7.4, respectivamente. No por esperada resulta menos llamativa la gran dispersión de los datos recopilados, cuantificada mediante los correspondientes coeficientes de variación, particularmente para el número de víctimas mortales, $N$, y la superficie afectada por un colapso, $A_{c o l}$. A primera vista también sorprende que en el caso de los edificios colapsados de uso residencial el 
número máximo de víctimas mortales, $N$, supere al número máximo de personas presentes en el edificio en el momento del colapso, $N_{p}$ (Tabla 7.3). La explicación, sin embargo, es sencilla: ambos datos no pertenecen al mismo caso, por lo que no es posible establecer una comparación directa.

Tabla 7.4 - Evaluación estadística de los datos originales para los edificios colapsados de uso público con concentraciones de personas (categoría de uso C, según [CTE DB SE-AE 2006]).

\begin{tabular}{|c|c|c|c|c|c|c|}
\hline Parámetro & $\boldsymbol{N}$ & $\boldsymbol{N}_{\boldsymbol{p}}$ & $\boldsymbol{A}_{\boldsymbol{c o l}}\left[\mathbf{m}^{2}\right]$ & $\boldsymbol{A}\left[\mathbf{m}^{2}\right]$ & $\boldsymbol{n}_{\text {col }}$ & $\boldsymbol{n}_{\boldsymbol{s}}$ \\
\hline Valor medio & 13,2 & 284,3 & 1.594 & 7.523 & 1,44 & 1,71 \\
\hline Desviación típica & 30,6 & 529,2 & 2.735 & 12.458 & 0,73 & 0,76 \\
\hline Coeficiente de variación & 2,32 & 1,86 & 1,72 & 1,66 & 0,51 & 0,44 \\
\hline Valor máximo & 114 & 1.750 & 10.000 & 40.000 & 3 & 3 \\
\hline Valor mínimo & 0 & 1 & 20 & 150 & 1 & 1 \\
\hline
\end{tabular}

\subsection{DATOS COMPLEMENTARIOS}

\subsubsection{Generalidades}

El presente apartado está dedicado al aumento de la información relativa a los distintos campos de la base de datos, lo que resulta imprescindible según la evaluación estadística de los datos originales (Apartado 7.2.6). Prioritariamente, se procura complementar la información para los siguientes parámetros: número de personas presentes en el edificio en el momento del colapso, $N_{p}$, superficie afectada por un colapso, $A_{c o l}$, y superficie útil total de los edificios, $A$. Pero se pretende aumentar también la información de los otros campos que están poco cubiertos, según el resumen de la Tabla 7.2. En particular, se trata del número de plantas afectadas por un colapso, $n_{c o l}, \mathrm{y}$ el número de plantas de un edificio, $n_{s}$, ya que esta información puede ser útil para deducir, mediante estimaciones indirectas, datos válidos para la superficie afectada por un colapso, $A_{c o l}$, tal y como se esboza en el Apartado 7.2.3.

Para aumentar la información de los distintos campos, se usan datos sobre edificios similares a los investigados. En principio, los datos complementarios se pueden obtener externamente o internamente a la base de datos. En el marco del presente estudio, por ejemplo, a través de:

- la hipótesis de que la superficie útil total tenga un comportamiento homogéneo para los edificios de las categorías de uso B (oficina) y A1 (residencia), lo que permite obtener información complementaria de forma interna a la base;

- los datos del Instituto Nacional de Estadística, INE, que constituyen una fuente de información externa a la base de datos [INE]; permiten complementar, por ejemplo, los parámetros correspondientes a los edificios de la categoría de uso A1, particularmente el número de personas presentes en el momento del colapso, la superficie útil total y, de manera indirecta, también la superficie afectada por un colapso;

- la Orden del Ministerio de Educación y Ciencia, de 1991, por la que se regulan los requisitos que deben cumplir los proyectos de los centros de educación [MEC 1991]; se emplea como fuente de información externa a la base de datos para estimar la superficie útil total de estas obras; para ello se utilizan los mínimos establecidos en la citada Orden para la superficie útil, en función del nivel de educación y el número de unidades, información que se complementa con las estadísticas del propio Ministerio sobre las características de los centros. 


\subsubsection{Edificios residenciales}

\section{Superficies}

Para complementar los campos de la superficie útil total de los edificios, $A$, así como de la superficie afectada por un colapso, $A_{c o l}$, se hace uso de la información publicada por el Instituto Nacional de Estadística, INE. El censo de población y viviendas del año 2001 establece el número de viviendas en España, en función de la superficie útil de la misma y del número de plantas de un edificio [INE]. Esta información permite estimar la media de la superficie de una vivienda (superficie por unidad $\left[\mathrm{m}^{2} / \mathrm{ud}\right]$ ), valor que se representa en la segunda columna de la Tabla 7.5, en función del número de plantas de un edificio (primera columna). De las bases de datos del INE también se puede extraer el número de edificios en España, en función del número de viviendas y plantas del mismo. A su vez, esta información permite estimar la media del número de viviendas en función del número de plantas de un edificio (unidades por edificio [ud/ed]), datos que se reflejan en la tercera columna de la Tabla 7.5 .

Tabla 7.5 - Estimación de los parámetros de la superficie útil total de los edificios residenciales, $A$, en función del número de plantas, sin planta baja ni cubiertas, $n_{s}$, utilizando la información de las bases de datos del Instituto Nacional de Estadística [INE].

\begin{tabular}{|c|c|c|c|c|}
\hline $\mathbf{1}$ & $\mathbf{2}$ & $\mathbf{3}$ & $\mathbf{4}$ & $\mathbf{5}$ \\
\hline $\boldsymbol{n}_{\boldsymbol{s}}$ & {$\left[\mathbf{m}^{2} / \mathbf{u d}\right]$} & {$[\mathbf{u d} / \mathbf{e d}]$} & $\boldsymbol{\mu}_{A}\left[\mathbf{m}^{2} / \mathbf{e d}\right]$ & $\sigma_{A}\left[\mathbf{m}^{2} / \mathbf{e d}\right]$ \\
\hline 1 & 96,6 & 1,1 & 115,6 & 72,5 \\
\hline 2 & 102,7 & 1,2 & 139,3 & 131,3 \\
\hline 3 & 94,9 & 2,6 & 269,4 & 366,1 \\
\hline 4 & 81,8 & 7,6 & 679,5 & 569,0 \\
\hline 5 & 77,8 & 12,4 & $1.063,8$ & 732,7 \\
\hline 6 & 80,4 & 16,8 & $1.482,6$ & 907,0 \\
\hline 7 & 84,5 & 20,4 & $1.896,3$ & $1.089,7$ \\
\hline 8 & 87,3 & 24,8 & $2.378,0$ & $1.250,8$ \\
\hline 9 & 87,6 & 24,9 & $2.400,8$ & $1.170,3$ \\
\hline$\geq 10$ & 87,4 & 37,5 & $3.610,6$ & $1.633,64$ \\
\hline
\end{tabular}

En el siguiente paso se estima el valor medio de la superficie útil total por edificio, $\mu_{A}$, en función del número de plantas del mismo. Para ello se multiplican los valores de las columnas 2 y 3 de la Tabla 7.5 y el valor obtenido se aumenta en un $10 \%$, con el fin de tener en cuenta, de manera aproximada, las superficies comunes (que no se contabilizan con las superficies de las viviendas) de los edificios residenciales. Los resultados se reflejan en la cuarta columna de la tabla. La quinta columna, finalmente, refleja la desviación típica estimada de la superficie útil total por edificio, $\sigma_{A}$, en función del número de plantas del mismo. Las estimaciones obtenidas para la superficie útil total de los edificios, $A$, se pueden emplear para estimar también las superficies afectadas por los colapsos, $A_{c o l}$, por ejemplo a partir de los números de plantas colapsadas y totales, respectivamente, o de manera equivalente, a través del número de viviendas u otros parámetros. 


\section{Ocupación de la superficie de colapso}

El aumento de la información relativa al campo del número de personas presentes en el edificio en el momento del colapso, $N_{p}$, también se realiza a partir de la información publicada por el Instituto Nacional de Estadística, INE. Concretamente, se hace uso de una tabla que proporciona el número total de personas que viven en edificios de un determinado número de plantas [INE]. Este número se divide entre el número total de edificios con la misma cantidad de plantas, información que se encuentra en otra tabla del INE. Esta división permite estimar el valor medio del número de habitantes por edificio, en función del número de plantas del mismo. Si además se asume que todas estas personas se encuentren en el edificio en el momento de un colapso, se obtiene una estimación del parámetro $N_{p}$, en función del número de plantas, $n_{s}$, del edificio afectado por un colapso (Tabla 7.6). Debido a que los datos del INE se refieren a edificios de viviendas, se puede suponer que se trata de una estimación razonable si el colapso se produce por la noche cuando la mayoría de los habitantes se encuentran en su hogar. Al contrario, si el colapso de un edificio de viviendas se produce durante un día laborable, el valor esperado de personas presentes sería tendencialmente más bajo.

Tabla 7.6 - Estimación del número de personas presentes en el edificio en el momento del colapso, $N_{p}$, en función del número de plantas del mismo edificio, $n_{s}$.

\begin{tabular}{|c|c|c|c|c|c|c|c|c|c|c|}
\hline $\boldsymbol{n}_{\boldsymbol{s}}$ & 1 & 2 & 3 & 4 & 5 & 6 & 7 & 8 & 9 & $\geq 10$ \\
\hline $\boldsymbol{N}_{\boldsymbol{p}}$ & 1,8 & 2,5 & 4,6 & 14,4 & 23,4 & 29,7 & 37,8 & 51,1 & 55,1 & 80,5 \\
\hline
\end{tabular}

De manera análoga, se estima el valor medio del número de personas presentes en una vivienda, en el momento del colapso, $N_{p} / u d$, en función de su superficie, A/ud. Para ello se utilizan los datos del INE sobre el número de personas que residen en España en viviendas de un determinado tamaño, así como el número total de viviendas del mismo tamaño [INE]. Los resultados de esta estimación están reflejados en la Tabla 7.7 .

Tabla 7.7 - Estimación del número de personas presentes en una vivienda, $N_{p} / u d$, en función de su superficie, A/ud.

\begin{tabular}{|c|c|c|c|c|c|c|c|c|c|c|}
\hline $\begin{array}{c}A / \mathbf{u d} \\
{\left[\mathbf{m}^{2} / \mathbf{u d}\right]}\end{array}$ & $\leq 30$ & $31-45$ & $46-60$ & $61-75$ & $76-90$ & $\begin{array}{c}91- \\
105\end{array}$ & $\begin{array}{c}106- \\
120\end{array}$ & $\begin{array}{c}121- \\
150\end{array}$ & $\begin{array}{c}151- \\
180\end{array}$ & $>180$ \\
\hline $\boldsymbol{N}_{p} / \mathbf{u d}$ & 1,9 & 2,1 & 2,4 & 2,7 & 2,9 & 3,0 & 3,1 & 3,2 & 3,3 & 3,4 \\
\hline
\end{tabular}

Si se dispone de información sobre la superficie, $A_{c o l}$, el número de plantas, $n_{c o l}$, o el número de viviendas (unidades) afectadas por un colapso, obtenida de manera directa o mediante estimaciones indirectas, se pueden emplear las Tablas 7.6 y 7.7 para estimar el número de personas presentes en las zonas del colapso. Este número debe superar la suma de víctimas mortales y heridos del mismo colapso. Si eso no es el caso, la citada suma, de víctimas mortales y heridos, constituye un límite inferior para el número de personas expuestas. 


\subsubsection{Centros educativos}

\section{Superficies}

Para complementar los campos de la superficie útil total, $A$, así como de la superficie afectada por un colapso, $A_{c o l}$, en los edificios en los que se pueden producir concentraciones de personas, se procede de manera análoga al Apartado 7.3.2, dedicado a los edificios residenciales. En el presente caso, el análisis se realiza para los centros de educación y se hace uso de la información relevante, publicada por el Ministerio de Educación y Ciencia, MEC (Apartado 7.3.1). Los datos disponibles en las bases del Ministerio no siempre contienen toda la información sobre los diferentes niveles de educación ofrecidos en los distintos centros, particularmente cuando se trata de los centros de educación secundaria, con múltiples variantes según especialidades. Por ello, se analizan los centros de educación infantil y primaria, respectivamente, cuyo número correspondiente al curso 2001-02 se representa en la Tabla 7.8, en función del número de unidades por centro.

Tabla 7.8 - Número de centros educativos, en función del nivel de educación y el número de unidades por centro, correspondientes al curso 2001-02, según datos del MEC.

\begin{tabular}{|c|c|c|c|c|c|c|c|c|}
\hline Nivel de educación & \multicolumn{4}{|c|}{ Infantil } & \multicolumn{5}{c|}{ Primaria } \\
\hline Unidades por centro & $\mathbf{1 - 3}$ & $\mathbf{4 - 5}$ & $\mathbf{2 6}$ & Total & $\mathbf{1 - 6}$ & $\mathbf{7 - 1 2}$ & $\geq \mathbf{1 3}$ & Total \\
\hline Número de centros & 1.481 & 548 & 683 & 2.712 & 1.890 & 2.920 & 3.704 & 8.514 \\
\hline Porcentaje & 54,6 & 20,2 & 25,2 & 100 & 22,2 & 34,3 & 43,5 & 100 \\
\hline
\end{tabular}

Por otro lado, la Orden del MEC de 1991 por la que se regulan los requisitos que deben cumplir los proyectos de los centros de educación, citada en el Apartado 7.3.1 [MEC 1991], establece la superficie útil requerida para los centros, en función del número de unidades de educación infantil y primaria, respectivamente. Estos requisitos están resumidos en la Tabla 7.9.

Tabla 7.9 - Superficie útil requerida para los centros educativos, en función del nivel de educación y el número de unidades por centro, según la Orden [MEC 1991].

\begin{tabular}{|c|c|c|c|c|c|c|}
\hline Nivel de educación & \multicolumn{3}{|c|}{ Infantil } & \multicolumn{3}{c|}{ Primaria } \\
\hline Unidades por centro & $\mathbf{3}$ & $\mathbf{6}$ & $\mathbf{9}$ & $\mathbf{6}$ & $\mathbf{1 2}$ & $\mathbf{1 8}$ \\
\hline Superficie útil requerida $\left[\mathbf{m}^{2}\right]$ & 321 & 612 & 866 & 1.167 & 1.762 & 2.326 \\
\hline
\end{tabular}

Ponderando la superficie útil requerida de cada categoría de la Tabla 7.9 por el número de centros de la misma categoría de unidades según la Tabla 7.8, y utilizando los datos del MEC sobre los centros, se obtienen las estimaciones de la Tabla 7.10 para los parámetros de la superficie útil total, $A$, de los centros de educación infantil y primaria, respectivamente. Estas estimaciones, en combinación con los parámetros que describan el colapso de un centro educativo (por ejemplo, los números de plantas colapsadas y totales; etcétera), se pueden emplear para estimar la superficie afectada por este colapso, $A_{c o l}$. En los casos en los que se conozca el tipo de educación del centro en cuestión, se le asigna la superficie útil apropiada, tomando las escuelas especiales como infantiles ya que suelen ser similares en tamaño. En caso contrario, se supone que se trate de un centro de educación primaria. 
Tabla 7.10 - Estimación de los parámetros de la superficie útil total de los centros educativos, $A$, en función del nivel de educación, utilizando la información del MEC, así como la Orden [MEC 1991].

\begin{tabular}{|c|c|c|}
\hline Nivel de educación & Infantil & Primaria \\
\hline Valor medio, $\boldsymbol{\mu}_{\boldsymbol{A}}\left[\mathbf{m}^{2}\right]$ & 517 & 1.875 \\
\hline Desviación típica, $\boldsymbol{\sigma}_{\boldsymbol{A}}\left[\mathbf{m}^{2}\right]$ & 231 & 452 \\
\hline
\end{tabular}

\section{Ocupación de la superficie de colapso}

Para aumentar la información sobre el campo correspondiente al número de personas presentes en los centros educativos si el colapso se produce en horario de clase, $N_{p}$, se hace uso de las estadísticas del Ministerio de Educación y Ciencia, MEC, relativos al curso 2001-02. Según éstas, los valores medio de alumnos y profesores por unidad, en función del nivel de educación, son los representados en la Tabla 7.11.

Tabla 7.11 - Valor medio del número de alumnos y profesores por unidad, en función del nivel de educación del centro.

\begin{tabular}{|c|c|c|}
\hline Nivel de educación & Infantil & Primaria \\
\hline Alumnos/ud & 15,6 & 19,5 \\
\hline Profesores/ud & 1,4 & 1,5 \\
\hline
\end{tabular}

Además de alumnos y profesores, en cada centro suele estar presente personal no docente, sobre el que no se encuentra información en las fuentes consultadas del MEC. No obstante, aunque no sea representativa, a través de una encuesta $a d$ hoc entre el personal docente de varios centros, se estima un valor medio de 4 personas no docentes por centro: personal de administración, vigilancia y limpieza. Teniendo en cuenta esta estimación así como los valores medio para el número de alumnos y profesores (Tabla 7.11), después de una ponderación con el número de centros en función del nivel de educación y el número de unidades (Tabla 7.8), se obtienen el valor medio, $\mu_{N p}$, y la desviación típica, $\sigma_{N p}$, del número de personas presentes en el momento del colapso, si este se produce en horario de clase, en función del nivel de educación (Tabla 7.12).

Tabla 7.12 - Estimación del número de personas presentes en un centro educativo si el colapso se produce en horario de clase, $N_{p}$, en función del nivel de educación.

\begin{tabular}{|c|c|c|}
\hline Nivel de educación & Infantil & Primaria \\
\hline Valor medio, $\boldsymbol{\mu}_{N \boldsymbol{p}}$ & 92 & 282,8 \\
\hline Desviación típica, $\boldsymbol{\sigma}_{N \boldsymbol{p}}$ & 43,4 & 98,5 \\
\hline
\end{tabular}

Las Tablas 7.10 y 7.12 se pueden utilizar para estimar el número de personas presentes en las zonas de colapso de un centro de educación, si se dispone de información directa o indirecta (Apartado 7.2.3) sobre la superficie afectada, $A_{c o l}$. En ausencia de otros datos, las mismas tablas también se pueden emplear para estimar el número de personas expuestas en casos de colapsos estructurales de 
edificios pertenecientes a otras categorías de uso, distintos a los centros educativos, pero donde se pueden producir concentraciones de personas. Igual que en los edificios residenciales (Apartado 7.3.2), el número de personas así estimado debe superar la suma de víctimas mortales y heridos del mismo colapso. En caso contrario, se adopta esta suma como límite inferior para el número de personas expuestas.

\subsubsection{Base de datos complementada}

Utilizando información complementaria interna y externa a la base de datos original, según los apartados anteriores, se aumenta en la medida de lo posible la información relativa a los distintos campos, particularmente aquellos que están poco cubiertos (Apartado 7.3.1):

- número de personas presentes en el edificio en el momento del colapso, $N_{p}$;

- superficie afectada por un colapso, $A_{\text {col }}$;

- superficie útil total de un edificio, $A$;

- número de plantas afectadas por un colapso, $n_{c o l}$;

- número de plantas de un edificio, sin planta baja ni cubierta, $n_{s}$.

La Tabla 7.13 contiene la información disponible para los 109 casos inicialmente considerados (Apartado 7.2.6), una vez complementados los campos más relevantes. La primera columna contiene una numeración correlativa de los casos, mientras que la segunda refleja el número de registro en la base de datos original (Apartado 7.2). Los parámetros de las columnas restantes se explican con anterioridad, por ejemplo en relación con la Tabla 7.2.

Tabla 7.13 - Información complementada para los 109 colapsos considerados.

\begin{tabular}{|c|c|c|c|c|c|c|c|c|}
\hline$N^{o}$ & Registro & Cat. & $N$ & $N_{p}$ & $A_{c o l}\left[\mathrm{~m}^{2}\right]$ & $A\left[\mathrm{~m}^{2}\right]$ & $\boldsymbol{n}_{\text {col }}$ & $\boldsymbol{n}_{s}$ \\
\hline 1 & 1 & $\mathrm{C}$ & 23 & 700 & 2.100 & 2.100 & 3 & 3 \\
\hline 2 & 2 & A1 & 67 & 82 & 1.526 & 1.526 & 6 & 6 \\
\hline 3 & 3 & A1 & 3 & 13 & 655 & 1.092 & 3 & 5 \\
\hline 4 & 5 & A1 & 27 & 29 & 1.092 & 1.092 & 5 & 5 \\
\hline 5 & 6 & $\mathrm{C}$ & 2 & 32 & 1.875 & 1.875 & 2 & 2 \\
\hline 6 & 7 & D & 4 & 250 & 90 & 10.000 & --- & -- \\
\hline 7 & 12 & A1 & 4 & --- & 126 & 288 & --- & 3 \\
\hline 8 & 15 & A1 & 1 & 1 & 141 & 141 & 2 & 2 \\
\hline 9 & 16 & $\mathrm{C}$ & 6 & 25 & --- & --- & --- & --- \\
\hline 10 & 17 & A1 & 1 & 1 & 1.092 & 1.092 & 5 & 5 \\
\hline 11 & 19 & A1 & 3 & 16 & 751 & 751 & 4 & 4 \\
\hline 12 & 21 & $\mathrm{C}$ & 114 & 222 & 74 & 14.764 & 1 & 1 \\
\hline 13 & 28 & A1 & 1 & 33 & --- & 141 & --- & 2 \\
\hline 14 & 29 & $\mathrm{C}$ & 0 & 0 & 10.010 & 10.010 & --- & -- \\
\hline 15 & 34 & A1 & 2 & 7 & 400 & 1092 & --- & 5 \\
\hline
\end{tabular}




\begin{tabular}{|c|c|c|c|c|c|c|c|c|}
\hline$N^{o}$ & Registro & Cat. & $N$ & $N_{p}$ & $A_{c o l}\left[\mathrm{~m}^{2}\right]$ & $A\left[\mathrm{~m}^{2}\right]$ & $n_{\text {col }}$ & $n_{s}$ \\
\hline 16 & 39 & A1 & --- & 3 & --- & 288 & --- & 3 \\
\hline 17 & 40 & $\mathrm{D}$ & --- & --- & 36 & --- & --- & --- \\
\hline 18 & 59 & $\mathrm{C}$ & 98 & 300 & 900 & 1.500 & --- & 1 \\
\hline 19 & 62 & $\mathrm{~F}$ & 0 & --- & 1.722 & 1.722 & --- & 1 \\
\hline 20 & 63 & F & 0 & --- & --- & --- & --- & 1 \\
\hline 21 & 69 & $\mathrm{C}$ & 0 & --- & 206 & 206 & --- & 1 \\
\hline 22 & 71 & $\mathrm{C}$ & 0 & --- & 2.000 & 2.000 & --- & --- \\
\hline 23 & 72 & $\mathrm{C}$ & 0 & 283 & --- & 1.875 & --- & --- \\
\hline 24 & 73 & $\mathrm{C}$ & 0 & --- & 3.870 & 3.870 & --- & 1 \\
\hline 25 & 76 & E1 & 0 & --- & --- & --- & --- & --- \\
\hline 26 & 77 & E1 & 0 & --- & --- & 56.240 & --- & -- \\
\hline 27 & 79 & $\mathrm{C}$ & 0 & 5 & 1.170 & 4.800 & --- & --- \\
\hline 28 & 80 & $\mathrm{C}$ & -- & -- & 288 & 288 & -- & 1 \\
\hline 29 & 82 & $\mathrm{D}$ & -- & --- & 216 & -- & --- & 2 \\
\hline 30 & 83 & $\mathrm{~F}$ & 0 & --- & 54 & -- & -- & -- \\
\hline 31 & 84 & $\mathrm{C}$ & 0 & 0 & 4.745 & 6.643 & --- & 1 \\
\hline 32 & 85 & $\mathrm{C}$ & 2 & 12 & 1.000 & 12.000 & --- & --- \\
\hline 33 & 87 & $\mathrm{~F}$ & 0 & -- & --- & 2.530 & --- & -- \\
\hline 34 & 88 & $\mathrm{C}$ & --- & -- & 10.000 & 40.000 & --- & 1 \\
\hline 35 & 89 & $\mathrm{C}$ & 12 & -- & --- & -- & -- & 1 \\
\hline 36 & 94 & $\mathrm{C}$ & 4 & --- & 20 & 150 & --- & 1 \\
\hline 37 & 96 & $\mathrm{C}$ & -- & -- & --- & -- & --- & -- \\
\hline 38 & 97 & $\mathrm{C}$ & 0 & -- & --- & --- & --- & -- \\
\hline 39 & 99 & E1 & 7 & 100 & 4.500 & 4.500 & --- & 3 \\
\hline 40 & 100 & $\mathrm{C}$ & 0 & 0 & 1.500 & 1.500 & --- & 1 \\
\hline 41 & 101 & $\mathrm{C}$ & 0 & 2 & 150 & -- & --- & -- \\
\hline 42 & 111 & F & 0 & --- & -- & -- & --- & 3 \\
\hline 43 & 112 & $\mathrm{C}$ & 0 & 200 & -- & 1.200 & --- & -- \\
\hline 44 & 114 & A1 & 0 & 0 & 3.691 & 3.691 & --- & 10 \\
\hline 45 & 115 & E1 & 0 & --- & --- & --- & --- & 1 \\
\hline
\end{tabular}




\begin{tabular}{|c|c|c|c|c|c|c|c|c|}
\hline$N^{o}$ & Registro & Cat. & $N$ & $N_{p}$ & $A_{c o l}\left[\mathrm{~m}^{2}\right]$ & $A\left[\mathrm{~m}^{2}\right]$ & $n_{c o l}$ & $n_{s}$ \\
\hline 46 & 119 & A1 & 137 & 364 & 20.000 & 20.000 & --- & 5 \\
\hline 47 & 128 & $\mathrm{~A} 1$ & 0 & 0 & 751 & 751 & --- & 4 \\
\hline 48 & 132 & $\mathrm{C}$ & 0 & 30 & --- & --- & --- & --- \\
\hline 49 & 134 & $\mathrm{C}$ & 2 & 7 & 50 & --- & --- & -- \\
\hline 50 & 140 & A1 & 8 & 15 & 655 & 1.092 & 3 & 5 \\
\hline 51 & 141 & A1 & 1 & 10 & 437 & 1.092 & 2 & 5 \\
\hline 52 & 144 & $\mathrm{~A} 1$ & 1 & 3 & --- & 288 & --- & 3 \\
\hline 53 & 156 & A1 & 1 & --- & 10 & --- & --- & -- \\
\hline 54 & 162 & A1 & 0 & 1 & 70 & 141 & 1 & 2 \\
\hline 55 & 164 & $\mathrm{~A} 1$ & 2 & 70 & 376 & 751 & 2 & 4 \\
\hline 56 & 166 & A1 & 1 & 10 & 141 & 141 & 2 & 2 \\
\hline 57 & 168 & A1 & 2 & 5 & 225 & 1.092 & 5 & 5 \\
\hline 58 & 172 & A1 & 3 & -- & -- & 501 & --- & -- \\
\hline 59 & 173 & $\mathrm{C}$ & 2 & 92 & 517 & 517 & 2 & 2 \\
\hline 60 & 174 & $\mathrm{~A} 1$ & 10 & 16 & 376 & 751 & 2 & 4 \\
\hline 61 & 175 & A1 & 11 & 14 & 751 & 751 & 4 & 4 \\
\hline 62 & 176 & $\mathrm{C}$ & 10 & 27 & 1.875 & 1.875 & 2 & 2 \\
\hline 63 & 184 & $\mathrm{C}$ & 0 & --- & --- & 517 & --- & -- \\
\hline 64 & 197 & A1 & 5 & 50 & --- & 250 & --- & --- \\
\hline 65 & 204 & $\mathrm{C}$ & 1 & 1 & 491 & 491 & --- & 1 \\
\hline 66 & 205 & B & --- & --- & 141 & 3.641 & --- & 2 \\
\hline 67 & 206 & $\mathrm{~A} 1$ & 1 & 12 & 256 & 630 & --- & 5 \\
\hline 68 & 208 & A1 & 0 & 0 & 13 & 240 & --- & 2 \\
\hline 69 & 210 & $\mathrm{D}$ & --- & --- & 634 & 885 & --- & 1 \\
\hline 70 & 216 & $\mathrm{C}$ & 0 & --- & --- & --- & --- & 1 \\
\hline 71 & 217 & $\mathrm{C}$ & --- & -- & 1.824 & 1.824 & --- & 1 \\
\hline 72 & 220 & B & 0 & --- & --- & 116 & --- & 1 \\
\hline 73 & 228 & $\mathrm{~A} 1$ & 1 & -- & --- & 288 & --- & 3 \\
\hline 74 & 230 & $\mathrm{~A} 1$ & 1 & --- & --- & 288 & --- & 3 \\
\hline 75 & 233 & A1 & 22 & 87 & 1.092 & 1.092 & --- & 5 \\
\hline
\end{tabular}




\begin{tabular}{|c|c|c|c|c|c|c|c|c|}
\hline$N^{o}$ & Registro & Cat. & $N$ & $N_{p}$ & $A_{c o l}\left[\mathrm{~m}^{2}\right]$ & $A\left[\mathrm{~m}^{2}\right]$ & $\boldsymbol{n}_{\text {col }}$ & $n_{s}$ \\
\hline 76 & 235 & A1 & 2 & 2 & 116 & 116 & 1 & 1 \\
\hline 77 & 238 & A1 & 0 & 0 & --- & 141 & --- & 2 \\
\hline 78 & 239 & $\mathrm{~A} 1$ & 0 & 0 & --- & 288 & --- & 3 \\
\hline 79 & 243 & A1 & 2 & 24 & 1.092 & 1.092 & 5 & 5 \\
\hline 80 & 245 & A1 & 0 & --- & --- & 250 & --- & --- \\
\hline 81 & 246 & $\mathrm{~A} 1$ & 5 & --- & --- & 250 & --- & -- \\
\hline 82 & 247 & A1 & 3 & 35 & 751 & 751 & 4 & 4 \\
\hline 83 & 252 & $\mathrm{~A} 1$ & 2 & --- & --- & 288 & --- & 3 \\
\hline 84 & 256 & $\mathrm{~A} 1$ & 11 & 14 & 655 & 1.092 & 3 & 5 \\
\hline 85 & 263 & --- & 8 & 8 & --- & --- & --- & --- \\
\hline 86 & 266 & $\mathrm{~A} 1$ & 1 & 21 & 655 & 1.092 & 2 & 5 \\
\hline 87 & 270 & $\mathrm{~A} 1$ & 0 & 0 & 376 & 751 & --- & 4 \\
\hline 88 & 272 & A1 & 0 & 0 & -- & 141 & --- & 2 \\
\hline 89 & 278 & A1 & 92 & 121 & -- & 3.691 & --- & 11 \\
\hline 90 & 279 & $\mathrm{C}$ & 2 & 300 & 5.000 & 20.000 & --- & --- \\
\hline 91 & 280 & --- & 1 & 3 & 70 & --- & --- & 1 \\
\hline 92 & 283 & --- & 1 & 2 & --- & --- & --- & 2 \\
\hline 93 & 285 & $\mathrm{~A} 1$ & 12 & 52 & 75 & 288 & --- & 3 \\
\hline 94 & 288 & D & -- & -- & --- & --- & --- & 1 \\
\hline 95 & 290 & $\mathrm{C}$ & 2 & 7 & 800 & -- & --- & 3 \\
\hline 96 & 291 & E1 & 1 & --- & --- & -- & --- & -- \\
\hline 97 & 293 & $\mathrm{C}$ & 3 & 60 & -- & -- & --- & 1 \\
\hline 98 & 295 & $\mathrm{~A} 1$ & -- & 4 & 1.526 & 1.526 & 6 & 6 \\
\hline 99 & 296 & $\mathrm{C}$ & 3 & 40 & 160 & 500 & --- & 1 \\
\hline 100 & 297 & $\mathrm{C}$ & 0 & 11 & 400 & --- & --- & -- \\
\hline 101 & 298 & A1 & 0 & 2 & --- & 288 & -- & 3 \\
\hline 102 & 299 & $\mathrm{~A} 1$ & 0 & 2 & --- & 141 & --- & 2 \\
\hline 103 & 300 & $\mathrm{C}$ & 4 & 7 & 600 & -- & --- & 1 \\
\hline 104 & 301 & $\mathrm{C}$ & 0 & 0 & 2 & -- & --- & 1 \\
\hline 105 & 302 & $\mathrm{C}$ & 0 & 0 & 84 & 1.875 & --- & --- \\
\hline
\end{tabular}




\begin{tabular}{|c|c|c|c|c|c|c|c|c|}
\hline $\boldsymbol{N}^{\boldsymbol{o}}$ & Registro & $\boldsymbol{C a t .}$ & $\boldsymbol{N}$ & $\boldsymbol{N}_{\boldsymbol{p}}$ & $\boldsymbol{A}_{\boldsymbol{c o l}}\left[\mathbf{m}^{2}\right]$ & $\boldsymbol{A}\left[\mathbf{m}^{2}\right]$ & $\boldsymbol{n}_{\text {col }}$ & $\boldsymbol{n}_{\boldsymbol{s}}$ \\
\hline 106 & 303 & $\mathrm{~A} 1$ & 7 & 9 & 80 & 250 & --- & --- \\
\hline 107 & 304 & $\mathrm{C}$ & 0 & 0 & --- & -- & --- & 1 \\
\hline 108 & 305 & $\mathrm{C}$ & 1 & 35 & --- & 1.875 & --- & -- \\
\hline 109 & 306 & $\mathrm{~A} 1$ & 1 & 2 & 288 & 288 & 3 & 3 \\
\hline
\end{tabular}

En la tabla anterior llama la atención la aparición de valores coincidentes en un cierto número de casos, sobre todo para los parámetros $A_{c o l}$ (superficie afectada por un colapso) y $A$ (superficie útil total de un edificio). Estas coincidencias se deben a la estimación de los datos según las consideraciones e hipótesis de los Apartados 7.3.1 a 7.3.3, por lo que no son casuales ni se deben a errores. La determinación del número y el porcentaje de los 109 colapsos considerados, con la información complementada mediante las citadas estimaciones, para los que la base contiene datos útiles sobre los parámetros más relevantes, conduce a los resultados reflejados en la Tabla 7.14. También se indica la variación de la cobertura de los distintos campos, en comparación con la información disponible antes de complementarla (Tabla 7.2). Los casos en los que se conoce el número de víctimas mortales aumentan ligeramente, sin alcanzar la totalidad, básicamente por haber podido descartar que se hayan producido víctimas mortales en algunos de los colapsos. El aumento de la información es más significativo en relación con los campos del número de personas presentes en el edificio en el momento del colapso, $N_{p}$, la superficie afectada por un colapso, $A_{c o l}$, así como la superficie útil total de un edificio, $A$. Los aumentos de la información correspondiente a estos tres parámetros son del $24,8 \%, 29,3 \%$ y $48,6 \%$, respectivamente. Por otro lado, se mantiene constante la información relativa al número de plantas de un edificio, $n_{s}$, mientras que se reduce la relativa al número de plantas afectadas por un colapso, $n_{c o l}$. Esta reducción $(-3,6 \%)$ se debe al hecho de haber descartado algunos casos con datos inverosímiles.

Tabla 7.14 - Información disponible sobre los parámetros relevantes de los 109 casos, una vez complementados los campos.

\begin{tabular}{|c|c|c|c|c|c|c|c|}
\hline Parámetro & $\boldsymbol{C a t}$. & $\boldsymbol{N}$ & $\boldsymbol{N}_{\boldsymbol{p}}$ & $\boldsymbol{A}_{\text {col }}$ & $\boldsymbol{A}$ & $\boldsymbol{n}_{\text {col }}$ & $\boldsymbol{n}_{\boldsymbol{s}}$ \\
\hline Número de registros & 106 & 98 & 74 & 70 & 82 & 26 & 78 \\
\hline Porcentaje de registros & 97,2 & 89,9 & 67,9 & 64,2 & 75,2 & 23,9 & 71,6 \\
\hline Variación [\%] & 0 & $+2,7$ & $+24,8$ & $+29,3$ & $+48,6$ & $-3,6$ & 0 \\
\hline
\end{tabular}

\subsection{ANÁLISIS DE REGRESIÓN}

\subsubsection{Criterios}

En el marco del presente apartado se busca deducir, sobre la base empírica de los datos recopilados y complementados de colapsos estructurales (Tabla 7.13), unos modelos matemáticos que permitan estimar de manera sencilla el número esperado de víctimas mortales, $N$, causadas por un colapso estructural, en función de alguno o algunos de los parámetros descriptivos del edificio correspondiente o del colapso. A tales efectos, se realizan unos análisis estadísticos de regresión para 
relacionar estos parámetros con $N$. Como parámetro descriptivo parece prestarse, en primer lugar, la superficie afectada por el colapso, $A_{c o l}$ (Apartado 7.2.6).

Un conjunto de pares de datos se puede representar, normalmente, a través de distintos modelos de regresión. Para la elección del modelo más adecuado existen diferentes criterios bien conocidos, destinados a la determinación de la calidad del ajuste:

- coeficiente de determinación;

- coeficiente de correlación;

- residuos estudentizados;

- valores de influencia;

- significancia estadística.

La mayoría de los paquetes estadísticos comerciales, como el empleado en este estudio [Portilla 2001], permiten comparar distintos modelos de regresión, ajustados a los pares de los datos de una muestra. En el marco del presente trabajo se utiliza el criterio de la significancia estadística de los modelos y sus parámetros, para valorar la calidad de los posibles ajustes y, finalmente, seleccionar el modelo de regresión más adecuado. La significancia estadística establece la diferencia entre el modelo planteado y la nube de puntos, o conjunto de pares de datos. Se expresa en términos de la probabilidad, $P$, de tomar la decisión de rechazar la hipótesis nula, cuando ésta es verdadera. En la práctica son comunes unos niveles de significancia del orden de 0,$05 ; 0,01$ y 0,001 . Si se exige por ejemplo un nivel mínimo del 5\%, un modelo de regresión resulta estadísticamente significante si el valor $P$ asociado es igual o inferior a 0,05 . Al contrario, si es mayor, no debe rechazarse que el modelo escogido se aleje del real.

\subsubsection{Resultados}

\section{Generalidades}

Los análisis estadísticos de regresión se realizan por separado para los casos pertenecientes a las clases de consecuencias $\mathrm{CC} 2$ y CC3, respectivamente (Tabla 7.1). El número de víctimas mortales en un colapso, $N$, se transforma en variable $Y$, y el parámetro descriptivo del edificio o colapso correspondiente, en variable $X$. En el marco del presente capítulo se renuncia a repasar los análisis efectuados para los posibles modelos de regresión y las comparaciones realizadas entre ellos, representando directamente los modelos finalmente obtenidos, con la superficie afectada por el colapso, $A_{\text {col }}$, como parámetro descriptivo.

\section{Clase de consecuencias CC2}

A efectos del presente estudio, pertenecen a la clase de consecuencias CC2 los edificios de uso residencial (categoría A1 según [CTE DB SE-AE 2006]), oficinas (B), tiendas (D), almacenes (E1), aparcamientos (F), y también aquellos para los que resulta imposible determinar el uso específico (Apartado 7.2.6). Por la combinación de las siguientes circunstancias, está justificado considerar todos estos casos conjuntamente para la deducción del modelo de consecuencias correspondiente a la clase CC2: la gran mayoría de los casos pertenecen a la categoría de uso A1 (Tabla 7.1); los edificios de oficinas (categoría B) son comparables a los de uso residencial, también en cuanto a su ocupación; $\mathrm{y}$, finalmente, los análisis efectuados ponen de manifiesto que los casos que aportan las categorías restantes (D, E1, F, uso sin especificar) apenas producen cambios en el modelo deducido.

En la Figura 7.2 se representan los pares de datos $N-A_{c o l}$ para la totalidad de los 30 casos útiles, pertenecientes a la clase de consecuencias CC2: aquellos para los que se conozcan simultáneamente ambos parámetros, $N$ y $A_{c o l}$, con valores superiores a cero (Tabla 7.13). En verde se representan los colapsos cuyos datos originales están complementados según las especificaciones del Apartado 7.3. Los puntos rojos reflejan los casos restantes (datos originales). El análisis del conjunto de estos datos 
permite establecer el siguiente modelo de consecuencias para el número esperado de víctimas mortales, $N$, en función de la superficie afectada por el colapso, $A_{c o l}$, de una estructura de edificación de la clase de consecuencias CC2:

$$
N=0,27 \cdot\left(A_{c o l}\right)^{0,5}-1 \geq 0
$$

La ecuación (7.1) también se representa en la Figura 7.2. La dispersión de los datos empíricos con respecto al modelo deducido es importante. No obstante, este modelo resulta estadísticamente significante, con un valor de $P=0,002$.

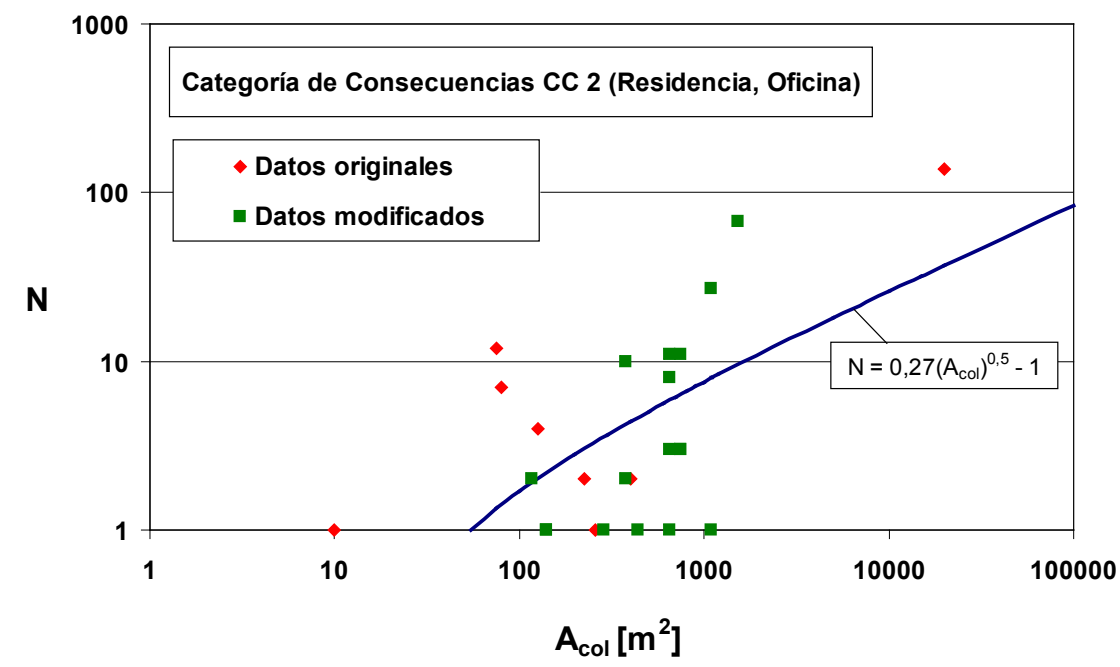

Figura 7.2 - Número de víctimas mortales, $N$, en función de la superficie afectada por el colapso, $A_{\text {col }}$, para los casos pertenecientes a la categoría de consecuencias CC2, y modelo de consecuencias deducido.

\section{Clase de consecuencias $\mathrm{CC} 3$}

De todos los colapsos de edificios pertenecientes a la clase de consecuencias CC3, cuya información recopilada y complementada está resumida en la Tabla 7.13, únicamente en 14 casos se conocen simultáneamente los dos parámetros, $N$ y $A_{c o l}$, y sus valores son superiores a cero. Sobre la base de estos datos se establece un modelo de consecuencias análogo al obtenido para la clase de consecuencias CC2. Este modelo permite determinar, para el colapso de un edificio donde se pueden producir concentraciones de personas (CC3), el número esperado de víctimas mortales, $N$, en función de la superficie afectada, $A_{c o l}$ :

$$
N=0,59 \cdot\left(A_{c o l}\right)^{0,56}-1 \geq 0
$$

La dispersión de los datos empíricos es incluso mayor que en el caso del modelo para la clase CC2. Desde un punto de vista estadístico, el modelo deducido para la clase de consecuencias CC3 no es significante $(P=0,4)$. A pesar de ello, la ecuación (7.2) obtenida se utiliza para la continuación del estudio. Eso por los siguientes motivos:

- frente a otros posibles modelos cuya significancia estadística sería mejor, por ejemplo determinando el número esperado de víctimas en función del número de personas presentes en el edificio en el momento del colapso $\left(N-N_{p}\right)$, se opta por la ecuación (7.2) debido a la similitud del modelo con el obtenido para la clase $\mathrm{CC} 2$, tal y como se aprecia en la Figura 7.3; 
- los modelos de consecuencias deducidos se emplean para determinar los riesgos asociados con las estructuras de edificación (Capítulo 4) que, a su vez, se utilizan a efectos comparativos;

- debido a lo anterior, no se requiere una excesiva precisión en la estimación de las consecuencias de un colapso estructural.

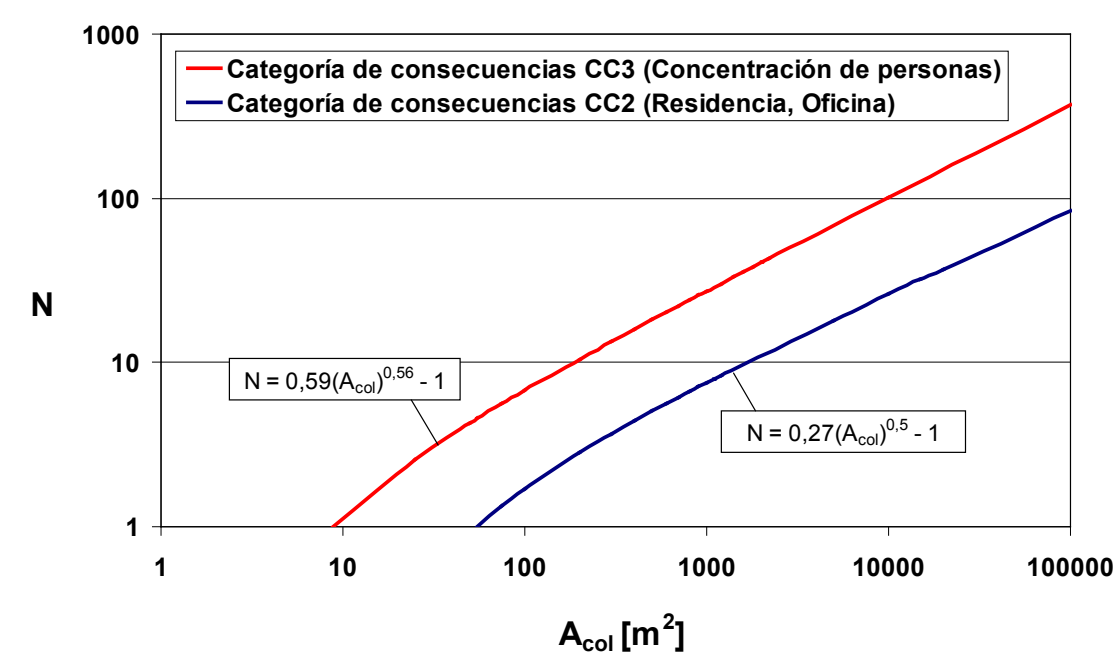

Figura 7.3 - Modelos de consecuencias para determinar el número esperado de víctimas mortales, $N$, en función de la superficie afectada por el colapso, $A_{c o}$, de una estructura de edificación perteneciente a las clases de consecuencias CC2 y CC3, respectivamente.

\subsection{OBSERVACIONES FINALES}

Según el enfoque del presente estudio (Capítulo 4), se requieren unos modelos para estimar las consecuencias de los colapsos estructurales en términos de la pérdida de vidas humanas. El desarrollo de estos modelos corresponde al Paso 5 del procedimiento establecido en el Apartado 4.5 y es objeto del presente capítulo. Debido a que los riesgos admisibles se fijan en los niveles implícitamente aceptados en la normativa en vigor, es necesario asegurar la compatibilidad de los modelos con la definición de las clases de consecuencias según la normativa considerada. El Eurocódigo [EN 1990 2002] define tres clases para las consecuencias. Por la combinación de dos circunstancias no se necesita ningún modelo para la primera de estas clases, $\mathrm{CC} 1$ : por un lado, engloba edificios en los que normalmente no se encuentran personas y, por otro lado, en el presente estudio no se tienen en cuenta otras pérdidas que no sean las de vidas humanas. Por todo ello, se desarrollan modelos para las clases de consecuencia CC2 (edificios residenciales y de oficinas) y CC3 (edificios con posibles concentraciones de personas), respectivamente, cubriendo los colapsos asociados con las denominadas situaciones persistentes [EN 1990 2002, CTE DB SE 2006]. En concordancia con el alcance del estudio (Apartado 1.2), para el desarrollo de los modelos no se consideran los colapsos estructurales inducidos por acciones accidentales, ni los que se producen durante la fase de construcción de una obra.

Para la elaboración de los modelos de consecuencias se crea una base de datos con información sobre colapsos reales de estructuras de edificación (Apartado 7.2). La base original contiene 301 colapsos ocurridos en diferentes países con sistemas constructivos homologables entre ellos, aunque la mayoría de los casos proviene de España. Para cada uno de ellos, se recopila toda la información disponible sobre las características del edificio, el colapso y sus consecuencias, consultando tanto 
investigaciones de ingeniería forense como publicaciones especializadas y diversos medios de comunicación generalistas. A efectos del presente estudio, los siguientes datos resultan especialmente importantes:

- categoría de uso;

- número de víctimas mortales en un colapso, $N$;

- número de personas presentes en el edificio en el momento del colapso, $N_{p}$;

- superficie afectada por un colapso, $A_{\text {col }}$;

- superficie útil total de un edificio, $A$;

- número de plantas afectadas por un colapso, $n_{c o l}$;

- número de plantas de un edificio, sin planta baja ni cubierta, $n_{s}$.

Mediante una valoración de la utilidad de la información recopilada se reduce la base original a $\mathbf{1 0 9}$ casos, de los que el $63 \%$ corresponden a edificios de la clase de consecuencias CC2 y el $37 \%$ restante a la clase CC3. A pesar del mencionado control de calidad, en muchos casos la información disponible es escasa, sobre todo si esta se extrae de las noticias contenidas en los medios de comunicación generalistas. Las mayores lagunas se presentan en relación con los parámetros descriptivos de los colapsos.

Con el fin de aumentar la información relativa a los distintos campos se emplean datos complementarios, tanto internos como externos a la base, para estimar de manera indirecta algunos de los parámetros relevantes (Apartado 7.3). Se utilizan por ejemplo los datos del Instituto Nacional de Estadística, INE, como fuente de información externa para describir diferentes parámetros relativos a los edificios residenciales, tales como la superficie útil en función del número de plantas o el número de usuarios por unidad de superficie. A su vez, estos parámetros permiten estimar otros, de manera indirecta, por ejemplo el número de personas presentes en el momento de un colapso, $N_{p}$, la superficie útil total del edificio correspondiente, $A$, o la superficie afectada por el mismo colapso, $A_{c o l}$. Estas estimaciones se hacen extensivas a todos los edificios pertenecientes a la clase de consecuencias CC2 y se utilizan para complementar los campos correspondientes de la base de datos. De manera análoga, se emplean fuentes de información del Ministerio de Educación y Ciencia, MEC, para aumentar los datos relativos a los centros educativos y, por extensión, los otros edificios pertenecientes a la clase de consecuencias CC3. Mediante este tipo de información complementaria se logra cubrir mejor algunos de los campos relevantes de los 109 colapsos. A título de ejemplo, para los parámetros $N_{p}, A_{c o l}$ y $A$, los aumentos alcanzan el $24,8 \%, 29,3 \%$ y $48,6 \%$, respectivamente.

Utilizando la información complementada para los 109 colapsos considerados se realiza una serie de análisis estadísticos de regresión para relacionar los diferentes parámetros relativos a los edificios y los colapsos con el número esperado de víctimas mortales, $N$. Los mejores resultados se obtienen al caracterizar los colapsos mediante la superficie afectada, $A_{c o l}$. Existen 30 casos pertenecientes a la clase de consecuencias $\mathrm{CC} 2$ con un mínimo de una víctima mortal y para los que se conocen simultáneamente ambos parámetros, $N$ y $A_{c o l}$. Para la clase de consecuencias CC3 el número de casos que cumplen estos requisitos es de 14. A través del análisis de estos datos se establecen los modelos matemáticos para las consecuencias en términos del número esperado de víctimas mortales, $N$, en función de la superficie afectada por el colapso, $A_{c o l}$, de una estructura de edificación (Apartado 7.4). Los modelos para las estructuras de edificación pertenecientes a las clases de consecuencia CC2 y CC3 están representados por las ecuaciones (7.1) y (7.2), respectivamente. A pesar de la gran dispersión de los datos empíricos con respecto a los modelos deducidos, el obtenido para clase CC2 es estadísticamente significante. Aunque no ocurre lo mismo con el modelo correspondiente a la clase $\mathrm{CC} 3$, existen razones de peso para adoptarlo en vista de la continuación del estudio. Por todo ello, los modelos deducidos son aptos para estimar las consecuencias de un colapso parcial o total de un determinado edificio y se emplean en el marco del Capítulo 8 para inferir el nivel aceptable de los riesgos para las personas, asociados con las estructuras de edificación. 


\section{CRITERIOS DE ACEPTACIÓN}

\subsection{INTRODUCCIÓN}

El desarrollo de herramientas destinadas a la aplicación práctica de los métodos de análisis de riesgo, tanto al dimensionado estructural como a la evaluación de las estructuras existentes en el campo de la edificación (Apartado 1.3), implica necesariamente la determinación de las prestaciones requeridas para estos sistemas. Éstas se pueden cuantificar en términos de las probabilidades de fallo admisibles o, lo que es equivalente, los niveles de fiabilidad requeridos, así como los riesgos aceptables para las personas. De acuerdo con la metodología establecida en el Capítulo 4, las prestaciones requeridas corresponden a los niveles aceptados para, respectivamente, las probabilidades de fallo y los riesgos para las personas según la mejor práctica actual (Best Current Practice, $B C P$ ), que a su vez equivalen al nivel de fiabilidad implícito a la normativa que está en vigor y al nivel de riesgo asociado. La inferencia de estos requisitos de seguridad estructural corresponde al Paso 6 del procedimiento establecido en el Apartado 4.5:

- Todos los elementos estructurales de todas las estructuras de edificación seleccionadas (Apartado 5.3) se dimensionan de manera estricta, de acuerdo con las reglas de la normativa que está en vigor, respectivamente los Eurocódigos y el Código Técnico de la Edificación. Ambos conjuntos normativos son equivalentes en el marco del dimensionado de las estructuras analizadas (Capítulo 6). A efectos de la verificación de la seguridad estructural se emplea el formato de los coeficientes parciales establecido en el Apartado 6.3, compatible con las reglas de los citados conjuntos normativos.

- Cálculo de la probabilidad de ocurrencia de cada escenario relevante, lo que equivale a la determinación de la probabilidad de fallo para cada uno de los mecanismos considerados (Apartado 5.4), en todos los elementos dimensionados de manera estricta. A su vez, estas probabilidades se expresan también en términos de los índices de fiabilidad correspondientes. Para tener en cuenta el nivel de incertidumbre asociado con las reglas de las normas empleadas en el dimensionado estructural se utilizan los modelos probabilistas deducidos en el Capítulo 6 para todas las variables que intervienen en las funciones de estado límite (Apartado 5.4), asociadas con los distintos mecanismos de fallo.

- Determinación del número esperado de víctimas mortales para cada escenario, en función de la categoría de uso del edificio y la clase de consecuencias asociada, así como la superficie afectada por el colapso. Para ello se emplean los modelos de consecuencias deducidos en el Capítulo 7, teniendo en cuenta la hipótesis del Apartado 5.2.1 sobre la ausencia de fallos en cadena después de la rotura de un determinado elemento estructural.

- Sobre la base de la probabilidad de ocurrencia y de las consecuencias esperadas para cada escenario, se determinan los perfiles de riesgo (Apartado 4.3) para las estructuras de cada uno de los edificios analizados.

- Análisis, evaluación estadística e interpretación de los resultados obtenidos para los conjuntos de los elementos y sistemas estructurales, respectivamente.

Todas estas tareas se abordan en el presente capítulo que se estructura de la manera resumida a continuación.

La determinación del nivel de fiabilidad implícitamente requerido según la normativa en vigor es objeto del Apartado 8.2. Incluye unas consideraciones de carácter general, tanto sobre el dimensionado estricto de los elementos estructurales seleccionados a estos efectos como el cálculo de las probabilidades de fallo e índices de fiabilidad correspondientes. Los resultados obtenidos se evalúan por separado para los elementos constituidos por los diferentes materiales considerados, distinguiendo también entre vigas de cubierta y planta, respectivamente, así como pilares. 
El Apartado 8.3 está dedicado a la inferencia del nivel aceptable de los riesgos para las personas, asociados con las estructuras de edificación. En este caso, el análisis se realiza conjuntamente para todas las estructuras seleccionadas, sin separación según materiales constitutivos, distinguiendo únicamente entre sistemas estructurales de edificios pertenecientes a las clases de consecuencias CC2 y CC3. Los criterios de aceptación de los riesgos para las personas así obtenidos se traducen a probabilidades de fallo aceptables e índices de fiabilidad requeridos para los estados límite últimos, proponiendo diferentes requisitos para el dimensionado de elementos estructurales de nueva construcción y la evaluación de estructuras existentes, respectivamente.

Las conclusiones del presente capítulo se encuentran en el Apartado 8.4.

\subsection{NIVEL DE FIABILIDAD REQUERIDO}

\subsubsection{Generalidades}

\section{Dimensionado estricto}

De acuerdo con la práctica profesional predominante en el país, el dimensionado de las estructuras de edificación se realiza según las reglas establecidas en los Documentos Básicos relativos a la Seguridad Estructural del Código Técnico de la Edificación, así como las Instrucciones asociadas, sobre las bases de proyecto [CTE DB SE 2006], las acciones [CTE DB SE-AE 2006] y la resistencia de los elementos constituidos por, respectivamente, acero estructural [EAE 2011], hormigón armado [EHE-08 2008], o madera laminada encolada [CTE DB SE-M 2006]. Estas normas forman un conjunto consistente desde el punto de vista del tratamiento de las incertidumbres relativas a las variables relevantes (Apartado 4.4 y Capítulo 6). Por este motivo, el citado conjunto se usa en el presente estudio para el dimensionado estricto de los elementos que constituyen las estructuras consideradas de acero, hormigón armado y madera laminada encolada.

En el Capítulo 6 también se pone de manifiesto que, a efectos del dimensionado de las estructuras analizadas en este estudio, los documentos del Código Técnico de la Edificación son equivalentes a los correspondientes Eurocódigos relativos a las bases de proyecto [EN 1990 2002], las acciones [EN 1991-1-1 2002, EN 1991-1-3 2003] y la resistencia [EN 1992-1-1 2004, EN 1993-1-1 2005, EN 19951-1 2004]. Por este motivo, el dimensionado estricto de los elementos y las estructuras de acero, hormigón armado y madera laminada encolada, en principio, se podría realizar indistintamente según cualquiera de los dos conjuntos normativos, conduciendo a unos resultados idénticos si para los distintos parámetros relativos a la geometría, el uso, las acciones y los materiales se adoptan los mismos valores numéricos establecidos en el Apartado 5.3. Esta circunstancia es relevante en relación con las estructuras mixtas de acero y hormigón. En ausencia de una norma nacional para la resistencia de estos elementos, en el campo de la edificación, su dimensionado estricto se realiza según las reglas de los Eurocódigos [EN 1990 2002, EN 1991-1-1 2002, EN 1991-1-3 2003, EN 1994-1-1 2004], conduciendo a resultados comparables, en términos de las probabilidades de fallo y los riesgos asociados, a los obtenidos para los elementos y las estructuras de los otros materiales.

La selección de los conjuntos representativos de las estructuras y los elementos que las constituyen, objeto de análisis y por tanto de un dimensionado estricto en el sentido del Apartado 4.4, se realiza en el marco del Capítulo 5. En el mismo capítulo también se establecen las hipótesis relativas a los aspectos conceptuales para las estructuras y los elementos que condicionan los mecanismos de fallo relevantes y, consecuentemente, influyen en el dimensionado. Los valores de cálculo de los efectos de las acciones e influencias, $E_{d}$, y de las resistencias correspondientes, $R_{d}$, cuya determinación es necesaria para verificar la condición del dimensionado estricto, $E_{d}=R_{d}$, se establecen según el formato de los coeficientes parciales definido en el Apartado 6.3. Este formato es simultáneamente 
compatible con las reglas de los dos conjuntos normativos empleados: los documentos del Código Técnico de la Edificación y los Eurocódigos.

El dimensionado estricto se realiza teniendo en cuenta la combinación y disposición relevantes de las acciones consideradas según el Apartado 5.2.1 (cargas permanentes, sobrecargas en función de la categoría de uso, carga de nieve en función del clima regional), para cada mecanismo de fallo de cada uno de los elementos estudiados. Este dimensionado implica un cálculo iterativo debido a la interacción entre las dimensiones finales de las secciones transversales de vigas y pilares y su peso propio. El dimensionado estricto de los elementos considerados se realiza de manera automática, utilizando un programa de ordenador desarrollado específicamente para este fin e implementado en la herramienta de software matemático MATLAB ${ }^{\circledR}$.

\section{Análisis de fiabilidad}

Existen diferentes métodos de análisis de la fiabilidad estructural, numéricos o analíticos (Capítulo 3). Para analizar los elementos estructurales representativos, seleccionados en el marco del Apartado 5.3 y dimensionados de manera estricta según las especificaciones anteriores, se emplea el método conocido por sus siglas en inglés, FOSM (First Order Second Moment Method). Este método permite caracterizar numéricamente la fiabilidad de un elemento estructural en términos de su índice de fiabilidad para el que, a su vez, existe una relación directa con la probabilidad de fallo, asociada con un determinado período de referencia.

El estudio está basado en las funciones de estado límite, representadas en el Apartado 5.4, para las vigas de planta y de cubierta así como los pilares de, respectivamente, acero, hormigón armado, mixtos de acero y hormigón y madera laminada encolada. Para las variables que intervienen en estas funciones se utilizan los modelos probabilistas deducidos en el marco del Capítulo 6 y resumidos en el Apartado 6.7. Los cálculos probabilistas se efectúan con un programa de ordenador [VaP 3.0 2010] que trata las variables de acuerdo con los principios de la publicación [Hasofer 1974] y permite calcular índices de fiabilidad según el método FOSM, así como las correspondientes probabilidades de fallo. Este programa se dota, específicamente para este trabajo, con un pre- y un postprocesador que permiten la lectura y el tratamiento automáticos de los resultados obtenidos en el dimensionado estricto de los 118.946 elementos estructurales diferentes que forman el conjunto representativo resumido en la Tabla 5.6. Solo a través de una automatización es posible obtener y gestionar los 122.350 resultados correspondientes a los diferentes mecanismos de fallo de todos los elementos estructurales seleccionados.

\section{Representación de los resultados}

Los resultados obtenidos en este estudio se representan gráficamente, en términos del índice de fiabilidad, $\beta$, y la probabilidad de fallo, $p_{f}$, en función de la ratio entre los valores característicos de los efectos de las acciones variables y totales, $v$. De manera genérica, esta ratio queda reflejada a través de la ecuación (8.1):

$$
v=\frac{E_{k, Q}}{E_{k, G+Q}}
$$

$E_{k, G+Q} \quad$ : valor característico de los efectos de las acciones permanentes y variables

$E_{k, Q} \quad:$ valor característico de los efectos de las acciones variables

Frente a otras posibles representaciones de los resultados, en función de otros parámetros, se opta por reflejarlos en función de la ratio $v$ por la combinación de los siguientes motivos:

- La dependencia del índice de fiabilidad, y de la probabilidad de fallo, de parámetros distintos a las cargas permanentes y variables, tales como por ejemplo la luz de las vigas o la resistencia de los materiales, es reducida. 
- La representación de los resultados en función de un parámetro generalizable para todos los elementos estructurales analizados, facilita su interpretación comparativa.

Los resultados obtenidos para las 944 vigas de cubierta, 1.770 vigas de planta y 116.232 pilares (Tabla 5.6), se reflejan por separado, según:

- los materiales constitutivos (Apartados 8.2.2 a 8.2.5);

- el tipo de elemento estructural (vigas de cubierta, vigas de planta, pilares);

- en el caso de las vigas se distingue, además, entre los resultados obtenidos para los distintos mecanismos de fallo (flexión, cortante).

Los índices de fiabilidad y las probabilidades de fallo indicados se refieren a todo el período de servicio de las estructuras consideradas. Para este período se admiten 50 años. Todo ello está en concordancia tanto con la práctica habitual [EN 1990 2002, CTE DB SE 2006], como con las características de los modelos probabilistas deducidos en el Capítulo 6.

\section{Evaluación de los resultados}

Para los distintos tipos de elementos estructurales, constituidos por un determinado material, se deducen los siguientes valores numéricos para el índice de fiabilidad, $\beta$, y la correspondiente probabilidad de fallo, $p_{f}$, para un período de referencia de 50 años:

- valor medio $\left(\mu_{\beta}, \mu_{p f}\right)$;

- desviación típica $\left(\sigma_{\beta}, \sigma_{p f}\right)$;

- coeficiente de variación $\left(v_{\beta}, v_{p f}\right)$;

- fiabilidad máxima $\left(\beta_{\max }, p_{f, \min }\right)$;

- fiabilidad mínima $\left(\beta_{\min ,}, p_{f, \max }\right)$.

Esta evaluación se efectúa tanto por separado para cada mecanismo de fallo de un determinado tipo de elementos, constituidos por un material específico, como para la totalidad de los resultados correspondientes a los diferentes elementos estructurales (vigas de cubierta, vigas de planta, pilares) del mismo material.

Suponiendo que los resultados obtenidos para los índices de fiabilidad de los elementos analizados obedezcan a una determinada distribución, por ejemplo la normal, se puede estimar un determinado cuantil de la variable $\beta$, por ejemplo el del $5 \%$. De acuerdo con la terminología empleada en la mayoría de las normas estructurales modernas, tales como los Eurocódigos y el Código Técnico de la Edificación [EN 1990 2002, CTE DB SE 2006], en cierto modo se trataría de un valor característico del índice de fiabilidad, $\beta_{k}$, para un período de referencia de 50 años. Este valor se puede interpretar en el sentido de que, para el tipo de elementos considerados, constituidos por un determinado material y dimensionados de manera estricta según las reglas de la normativa aplicada, en el 5\% de los casos el índice de fiabilidad es inferior a $\beta_{k}$. Los denominados valores característicos del índice de fiabilidad se prestan para una interpretación comparativa de los resultados del estudio.

Los resultados de la evaluación anteriormente mencionada de los valores numéricos del índice $\beta$ y la probabilidad de fallo, $p_{f}$, no solamente se utilizan para realizar comparaciones internas al estudio, por ejemplo entre diferentes materiales y tipos de elementos. También se comparan con otros trabajos de investigación, concretamente un estudio nórdico sobre las posibles modificaciones de los coeficientes parciales en los Eurocódigos [SAKO 1999]. En este contexto, el Joint Nordic Group for Structural Matters, dependiente de la agencia encargada de la armonización de los reglamentos de los países nórdicos en el campo de la edificación, NKB, evaluó la fiabilidad de una serie de elementos estructurales dimensionados según las denominadas prenormas europeas que existían en aquel momento para las bases de proyecto [ENV 1991-1 1994], las acciones [ENV 1991-2-1 1995, ENV 1991-2-3 1995] y la resistencia de los elementos estructurales constituidos por diferentes materiales [ENV 1992-1-1 1991, ENV 1993-1-1 1992, ENV 1995-1-1 1993]. Estas prenormas (versión ENV de 
los Eurocódigos) han sido sustituidos posteriormente por las correspondientes normas europeas (versión EN) que están actualmente en vigor. Para los casos analizados en el documento nórdico [SAKO 1999], las reglas de ambas generaciones de los Eurocódigos son equivalentes. Debido a que, en lo referente al dimensionado de los elementos analizados en el presente estudio, los Eurocódigos actuales también son equivalentes al Código Técnico de la Edificación, tal y como se menciona con anterioridad, los resultados del estudio nórdico se pueden utilizar a efectos comparativos con los del presente trabajo.

El alcance del estudio nórdico se limitó a vigas y pilares isostáticos de tres materiales: hormigón armado, acero estructural y madera laminada encolada [SAKO 1999]. De acuerdo con la información disponible, para cada uno de estos materiales se dimensionaron, de manera estricta según las prenormas arriba mencionadas, 6 vigas con una luz constante de $12 \mathrm{~m}$, así como 6 pilares. Como única acción variable parece haberse considerado la carga de nieve, por lo que se puede suponer que se analizaron, respectivamente, vigas de cubierta y pilares de la última planta de un edificio. Para los elementos así dimensionados se determinaron los índices de fiabilidad para un período de referencia de un año. En el informe [SAKO 1999], los resultados así obtenidos están representados de manera gráfica, aunque no numérica.

A pesar de la compatibilidad de los conjuntos normativos analizados, respectivamente en el estudio nórdico y el presente trabajo, no se pueden comparar directamente los valores deducidos para los niveles de fiabilidad requeridos implícitamente. Para ello es necesario, en primer lugar, referir los índices de fiabilidad de ambos estudios al mismo período de tiempo, transformando los del estudio nórdico, obtenidos para un período de referencia de un año, a un período de 50 años, correspondiente al adoptado en el presente estudio. Además, a efectos de la comparación del nivel de fiabilidad de los pilares, del presente estudio se deben extraer los resultados correspondientes a la última planta de los edificios considerados. Es decir, en concordancia con las hipótesis del estudio nórdico, solo se tienen en cuenta los pilares expuestos a situaciones con la carga de nieve como única acción variable.

La interpretación de los resultados obtenidos en el presente trabajo, incluida su comparación con los del estudio nórdico, se realiza de manera detallada para los elementos de acero estructural (Apartado 8.2.2) y de hormigón armado (Apartado 8.2.3). Para no sobrecargar el capítulo, solo se incluye una representación resumida de los resultados para los elementos mixtos de acero y hormigón (Apartado 8.2.4) y los de madera laminada encolada (Apartado 8.2.5). El Apartado 8.2.6, finalmente, contiene algunas comparaciones de los resultados obtenidos para los elementos estructurales constituidos por diferentes materiales.

\subsubsection{Elementos de acero}

\section{Resultados}

\section{Vigas de cubierta}

Los índices de fiabilidad, $\beta$, obtenidos para las vigas de cubierta de acero estructural, dimensionadas de manera estricta según las reglas de las normas estructurales españolas, equivalentes a las europeas (Apartado 8.2.1), están afectados por una dispersión que no se puede despreciar, pero que se sitúa dentro de unos límites esperables (Figura 8.1a). En ambos mecanismos de rotura considerados (los inducidos por momentos flectores y esfuerzos cortantes, respectivamente), el nivel máximo de fiabilidad se observa para valores de la ratio entre los efectos característicos de las acciones variables y totales, $v$, del orden de 0,2. El nivel de fiabilidad disminuye tanto para valores inferiores como superiores de la ratio $v$, definida en la ecuación (8.1). Los valores mínimos del índice de fiabilidad se obtienen para los casos en los que la acción variable (carga de nieve) predomina sobre las cargas permanentes, para valores de $v$ del orden de 0,75 . La dispersión de los resultados es prácticamente 
idéntica para la rotura por flexión y por cortante, con coeficientes de variación del 8,4\% y 8,6\%, respectivamente. Los valores medio de los índices de fiabilidad son del mismo orden de magnitud para los dos mecanismos de fallo analizados, con un valor medio máximo de 3,95 para la rotura por cortante de la sección de apoyo, y un valor medio mínimo de 3,87 para la rotura por flexión de la sección del centro del vano.

$\beta$

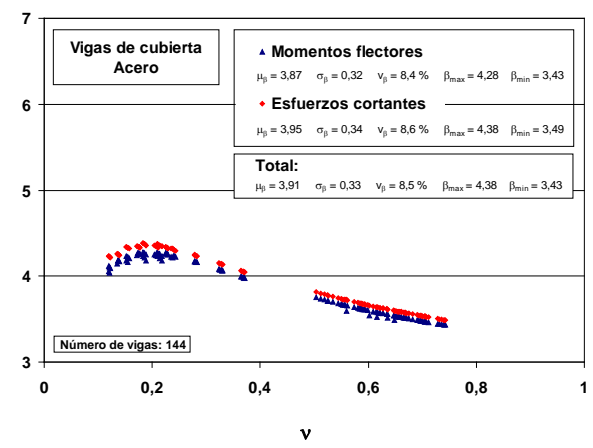

a)

$\beta$

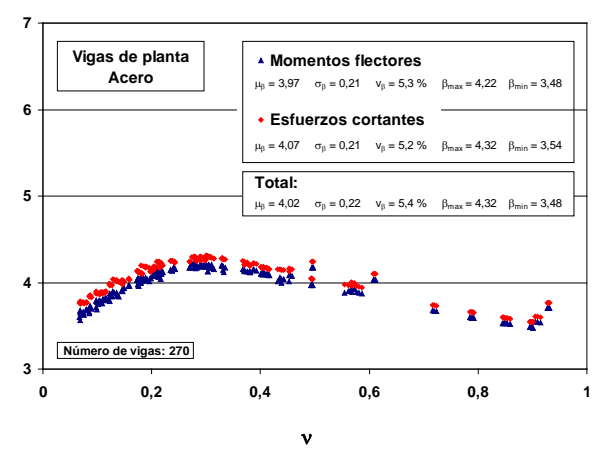

c)

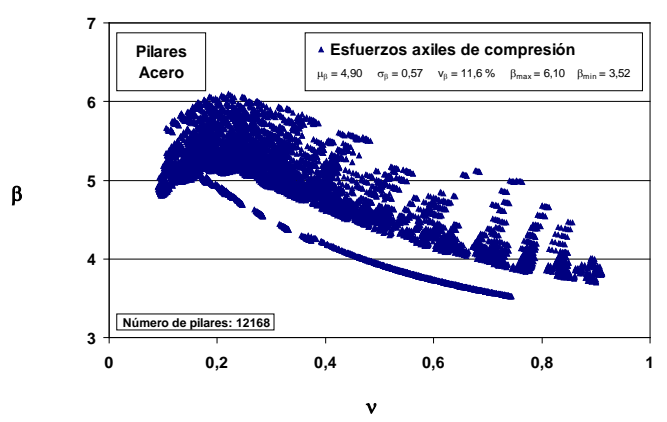

e)

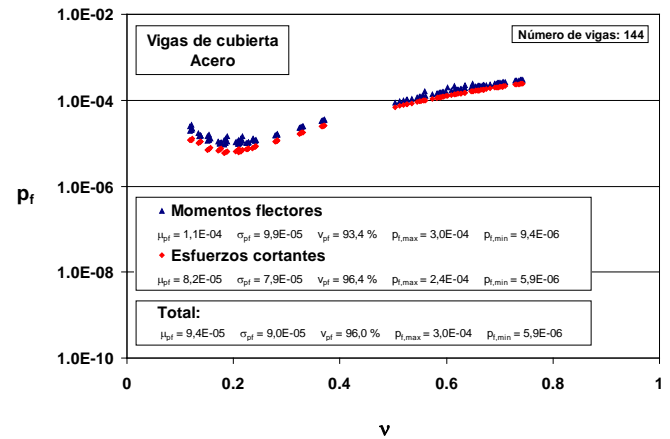

b)

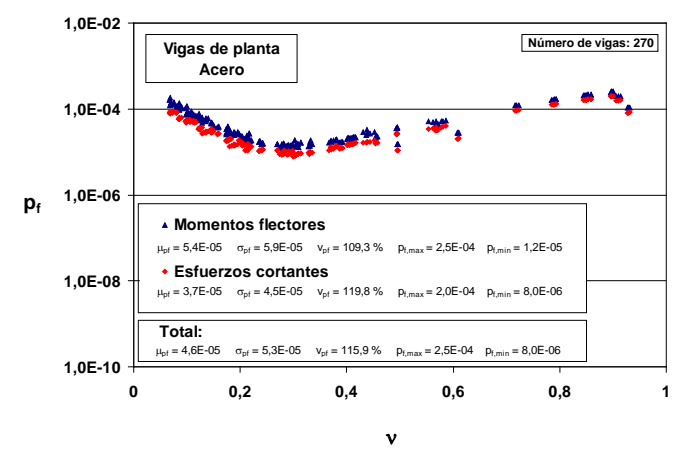

d)

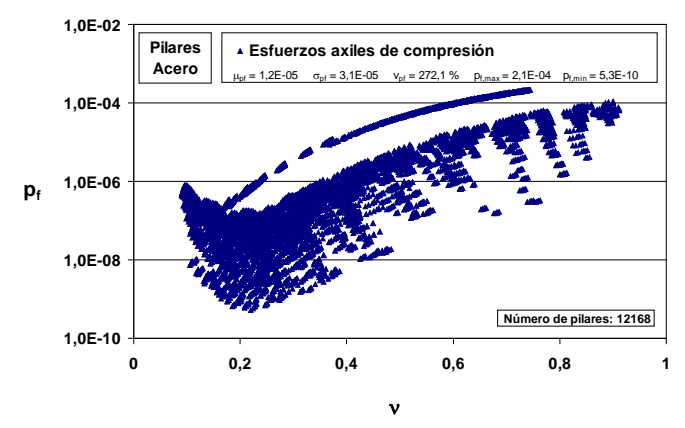

f)

Figura $8.1-a), c), e$ ) Índice de fiabilidad, $\beta, y b$ ), d), f) probabilidad de fallo, $p_{f}$, para un período de referencia de 50 años, en función de la ratio entre los valores característicos de los efectos de las acciones variables y totales, $v$, para los mecanismos de fallo de cada uno de los elementos de acero estructural analizados: a), b) 144 vigas de cubierta; c), d) 270 vigas de planta; e), f) 12.168 pilares.

La evaluación estadística de la totalidad de los resultados obtenidos para los dos mecanismos de fallo de cada una de las 144 vigas de cubierta conduce a un valor medio del índice de fiabilidad de 3,91. 
Este valor es ligeramente superior al valor nominal del índice de fiabilidad requerido para todo el período de servicio que según los Eurocódigos [EN 1990 2002], y por extensión también el Código Técnico de la Edificación [CTE DB SE 2006], se eleva a 3,8 para la clase de fiabilidad RC2 (Apartado 3.6.2). Teniendo en cuenta que para la deducción de los modelos probabilistas que reflejan el estado de incertidumbre correspondiente a la fase de dimensionado de las estructuras se emplea el método FORM normalizado (Apartado 4.5 y Capítulo 6), cuyas hipótesis suelen ser conservadoras al emplear valores normalizados para los factores de sensibilidad (Tabla 3.2), la diferencia entre el valor medio obtenido y el valor nominal requerido para el índice de fiabilidad sería tendencialmente mayor si para la deducción de los modelos probabilistas se adoptaran unos factores de sensibilidad calculados. En cualquier caso, en la interpretación de los resultados no se debe obviar que para ratios $v$ superiores a 0,5 la mayoría de los índices de fiabilidad obtenidos están por debajo del valor requerido.

Por otro lado, con unos valores mínimo y máximo del índice de fiabilidad de, respectivamente, $\beta_{\min }=$ 3,43 para la rotura por flexión de una de las vigas y $\beta_{\max }=4,38$ para la rotura por cortante de otra, así como con un coeficiente de variación para todos los resultados del 8,5\%, la dispersión parece sorprendentemente pequeña. Esta conclusión, aparentemente favorable a la luz de los problemas relacionados con los criterios de aceptación de los riesgos en relación con las reglas de dimensionado de las normas actuales (Apartado 1.1.2), cambia radicalmente al representar los mismos resultados en términos de la probabilidad de fallo, $p_{f}$, en lugar del índice de fiabilidad (Figura 8.1b). Según el mecanismo de rotura analizado, el coeficiente de variación de los resultados, $v_{p f}$, alcanza valores que oscilan entre el 93,4\% (rotura por flexión) y el 96,4\% (rotura por cortante). Para la totalidad de los resultados correspondientes a las vigas de cubierta, el coeficiente de variación se sitúa en el 96\%. Estas importantes dispersiones observadas se manifiestan por ejemplo en que en el caso de la probabilidad de fallo por flexión de las vigas de cubierta analizadas, el valor máximo es 32 veces superior al valor mínimo. Teniendo en cuenta la totalidad de los 288 resultados, este factor se eleva hasta 51.

\section{Vigas de planta}

La Figura 8.1c) pone de manifiesto que en el caso de las vigas de planta de acero estructural la variación de los índices de fiabilidad en función de las condiciones de carga, expresadas en términos de la ratio entre los valores característicos de los efectos de las acciones variables y totales, $v$, es del mismo orden de magnitud que la observada para las vigas de cubierta. En este caso, el nivel máximo de fiabilidad para ambos mecanismos de rotura analizados se alcanza para valores de la ratio $v$ del orden de 0,3. Los valores mínimos del índice de fiabilidad se obtienen para los casos en los que las acciones variables predominan sobre las cargas permanentes, para valores de $v$ del orden de 0,9 . La dispersión de los resultados es menor que en el caso de las vigas de cubierta, con coeficientes de variación del 5,3\% y del 5,2\% para la rotura por flexión y cortante, respectivamente. El valor medio mínimo del índice de fiabilidad se obtiene para el mecanismo de fallo por flexión de la sección de centro de vano $(3,97)$, y el valor medio máximo para la rotura por cortante de la sección de apoyo $(4,07)$.

La evaluación conjunta de todos los 540 resultados estriba en un valor medio del índice de fiabilidad de 4,02 con un coeficiente de variación del 5,4\%. El valor medio es superior al valor nominal del índice de fiabilidad para estados límite últimos, referido a todo el período de servicio, requerido para la clase de fiabilidad RC2 según las normas empleadas, los Eurocódigos [EN 1990 2002] y, por extensión, el Código Técnico de la Edificación [CTE DB SE 2006]: $\beta=3,8$ (Tabla 3.6). Igual que en el caso de las vigas de cubierta, esta diferencia sería tendencialmente mayor si, para la deducción de los modelos probabilistas que representan el estado de incertidumbre correspondiente a la fase de dimensionado de las estructuras (Apartado 4.5 y Capítulo 6), se emplearan valores calculados para los 
factores de sensibilidad en lugar de los normalizados. Aún así, es importante tener en cuenta que para ratios $v$ superiores a 0,7 la mayoría de los índices de fiabilidad obtenidos están por debajo del valor requerido.

También en analogía con las vigas de cubierta, al representar los resultados para las vigas de planta en términos de la probabilidad de fallo, su variación se dispara. Por ejemplo en el caso de la probabilidad de fallo por flexión, el valor máximo es 21 veces superior al valor mínimo. En consonancia con esta observación, para la probabilidad de fallo por flexión de las 270 vigas de planta se determina un coeficiente de variación del 109,3\%. Para la totalidad de los 540 resultados correspondientes a las vigas de planta, el valor máximo de la probabilidad de fallo es 31 veces superior al valor mínimo y el coeficiente de variación se eleva al 115,9\%. Estos valores apuntan a una dispersión que es del mismo orden de magnitud que el obtenido para las vigas de cubierta, mientras que el valor medio de la probabilidad de fallo para la totalidad de los resultados es del orden de la mitad, según las Figuras 8.1b) y 8.1d), respectivamente.

\section{Pilares}

Los índices de fiabilidad, $\beta$, obtenidos para los pilares de acero estructural, dimensionados de manera estricta según las reglas de las normas analizadas (Apartado 8.2.1), alcanzan su nivel máximo para valores de la ratio entre los efectos característicos de las acciones variables y totales, $v$, del orden de 0,2 (Figura 8.1e). Los valores mínimos del índice de fiabilidad se observan para los casos en los que la nieve constituye la acción variable dominante, con valores de $v$ del orden de 0,75 . El índice de fiabilidad máximo $(6,1)$ es sensiblemente superior a los valores correspondientes obtenidos para las vigas de cubierta y de planta, mientras que el índice de fiabilidad mínimo $(3,52)$ es del mismo orden de magnitud como en el caso de las vigas. Consecuentemente, el valor medio del índice de fiabilidad $(4,9)$, obtenido para la totalidad de los 12.168 pilares de acero analizados, supera los valores medio correspondientes a las vigas de cubierta y de planta, respectivamente. Con un coeficiente de variación del 11,6\%, la dispersión también es mayor que en el caso de las vigas.

En términos de la probabilidad de fallo, $p_{f}$, la dispersión observada para los pilares supera incluso a la obtenida para las vigas (Figura 8.1f): con 272\%, el coeficiente de variación alcanza 2,3 veces el valor obtenido para las vigas de planta y 2,8 veces el de las vigas de cubierta. Esta dispersión se traduce en un valor máximo de la probabilidad de fallo por compresión que corresponde a 4 x $10^{5}$ veces el valor mínimo.

\section{Evaluación}

\section{Interpretación de los resultados}

En la Tabla 8.1 se recapitulan los valores medio, $\mu_{\beta}$, y los coeficientes de variación, $v_{\beta}$, del índice de fiabilidad, $\beta$, para la totalidad de los resultados obtenidos, respectivamente para las vigas de cubierta y planta, así como los pilares, todos ellos constituidos por acero estructural. El valor medio máximo del índice de fiabilidad se obtiene para los pilares. Los valores medio del índice de fiabilidad de las vigas de cubierta y de planta son del mismo orden de magnitud, pero sensiblemente inferiores al anterior. A efectos de la cuantificación de la diferencia resulta más ilustrativo emplear las probabilidades de fallo. De acuerdo con los resultados reflejados en la Tabla 8.1, el valor medio de la probabilidad de fallo de los pilares es aproximadamente 8 veces inferior al valor medio obtenido para las vigas de cubierta.

Tal y como se comenta con anterioridad, en términos del índice de fiabilidad la dispersión de los resultados aparentemente es pequeña, con coeficientes de variación del orden del 12\% para los pilares y menores aún para las vigas. Que estas dispersiones no son despreciables se pone de manifiesto al analizar los coeficientes de variación para los resultados obtenidos en términos de las probabilidades 
de fallo: para las vigas de acero estructural el coeficiente de variación se sitúa en torno a los $100 \%$ mientras que en el caso de los pilares casi triplica este valor. Teniendo en cuenta las dificultades relacionadas con los criterios de aceptación de los riesgos en las normas (Apartado 1.1.2), cuyo nivel de fiabilidad implícito se determina en el marco del presente trabajo, la dispersión de los resultados obtenidos no debe sorprender.

Tabla 8.1 - Evaluación estadística de los índices de fiabilidad, $\beta$, y de las probabilidades de fallo, $p_{f}$, para un período de referencia de 50 años, de los elementos de acero estructural, dimensionados de manera estricta según las reglas de las normas españolas, equivalentes a las europeas.

\begin{tabular}{|l|c|c|c|c|c|c|c|c|}
\hline Elementos & $\mathbf{N}^{\mathbf{o}}$ elementos & $\begin{array}{c}\text { Mecanismos } \\
\text { de fallo }\end{array}$ & $\mathbf{N}^{\mathbf{o}}$ resultados & \multicolumn{3}{|c|}{$\boldsymbol{\beta}$} & \multicolumn{2}{|c|}{$\boldsymbol{p}_{\boldsymbol{f}}$} \\
\hline V. cubierta & 144 & 2 & 288 & 3,91 & 0,085 & 3,36 & 9,4 & 0,96 \\
\hline Vigas planta & 270 & 2 & 540 & 4,02 & 0,054 & 3,65 & 4,6 & 1,16 \\
\hline Pilares & 12.168 & 1 & 12.168 & 4,9 & 0,116 & 3,96 & 1,2 & 2,72 \\
\hline
\end{tabular}

Con los resultados obtenidos para las vigas de cubierta, se deduce un valor característico del índice de fiabilidad, para un período de referencia de 50 años, de $\beta_{k}=3,36$ (Tabla 8.1). Según la definición de $\beta_{k}$ en el Apartado 8.2.1, este resultado significa que para el 5\% de las vigas de cubierta de acero estructural, dimensionadas de manera estricta según las normas españolas o europeas que están en vigor (Apartado 8.2.1), el índice de fiabilidad es inferior a 3,36. De manera análoga, se puede estimar que para aproximadamente el 37\% de las mismas vigas resulta un índice de fiabilidad inferior al valor requerido, para elementos de la clase de fiabilidad RC2 y un período de referencia de 50 años, de $\beta_{t 50}$ = 3,8 (Tabla 3.6). Para las vigas de planta los resultados son ligeramente diferentes, con un valor característico del índice de fiabilidad de 3,65 y el 15,9\% de estos elementos dimensionados de manera estricta que no cumplen el requisito de fiabilidad estructural. Mientras que para las vigas de acero estructural el valor característico del índice de fiabilidad está por debajo del valor requerido para un período de referencia de 50 años $\left(\beta_{t 50}=3,8\right.$ para la clase RC2), para los pilares se sitúa ligeramente por encima de este requisito, con $\beta_{k}=3,96$. En concordancia con este resultado, el porcentaje de pilares dimensionados de manera estricta que no cumplen el requisito de fiabilidad es pequeño, del orden del 2,7\%.

\section{Comparación con otros resultados}

La Figura 8.2 contiene la comparación de los resultados obtenidos en el presente trabajo con los del estudio nórdico [SAKO 1999], según lo especificado en el Apartado 8.2.1. A pesar de la selección de resultados equivalentes de los dos estudios, así como de su transformación al mismo período de referencia, la comparación se debe efectuar con la máxima cautela. Eso por una serie de razones:

- En primer lugar, en el estudio [SAKO 1999] se emplean modelos probabilistas con funciones de distribución realistas para las diferentes variables o, en otras palabras, modelos que representan las características físicas de las variables. Consecuentemente, estos modelos no cumplen con todos los requisitos para los modelos probabilistas empleados en el presente estudio (Apartado 6.2.2). En particular, al no haberlos deducido según un procedimiento similar al establecido en el Apartado 4.5, los modelos probabilistas empleados en el estudio nórdico no necesariamente representan el estado de incertidumbre asociado a las reglas de los Eurocódigos.

- Al tratarse de modelos realistas, los empleados en el estudio [SAKO 1999] representan las características de las acciones y sus efectos, así como las resistencias de los elementos estructurales para su ámbito de aplicación: los países nórdicos. Por este motivo, estos modelos posiblemente no resulten totalmente representativos de la situación en otras zonas geográficas, 
por ejemplo España, donde pueden existir considerables diferencias en cuanto a las acciones e influencias relevantes, los métodos de construcción, la calidad de ejecución o los procedimientos para asegurarla, etcétera.

- De acuerdo con la información disponible, en el estudio nórdico [SAKO 1999] se determinan los índices de fiabilidad sin tener en cuenta las incertidumbres de los modelos para el cálculo de los efectos de las acciones. Eso en contraste con el presente estudio.

- El estudio [SAKO 1999] incluye casos con una ratio entre cargas variables y totales de, respectivamente, $v=0$ (situaciones sin acciones variables) y $v=1$ (estructuras sin peso propio ni cargas permanentes). Dado el reducido número de resultados, los índices de fiabilidad obtenidos para estos casos poco realistas pueden distorsionar considerablemente el conjunto de resultados, particularmente su dispersión.

- La deducción de los índices de fiabilidad obtenidos en el estudio nórdico a partir de un gráfico, a efectos de su posterior transformación a un período de referencia de 50 años, constituye una fuente de incertidumbre adicional.

$\beta$

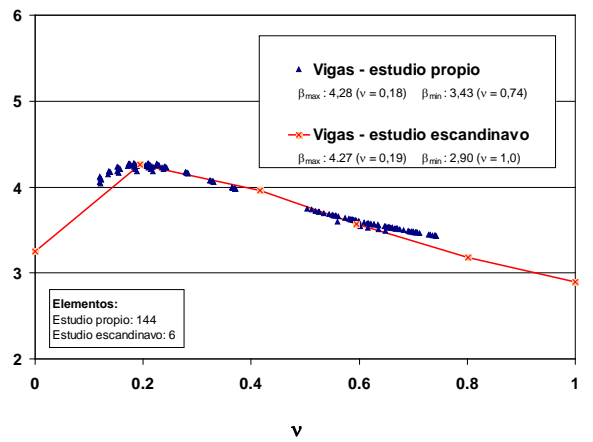

a)

b)

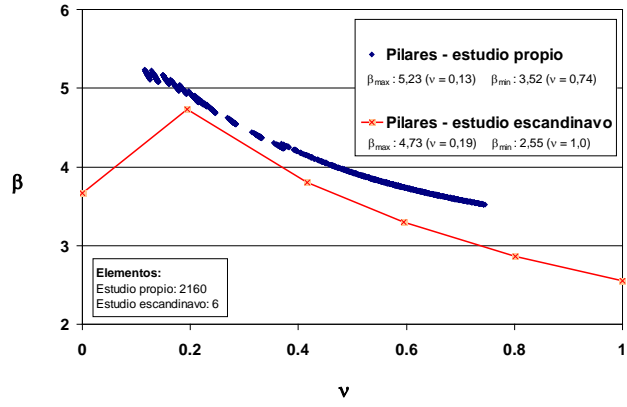

Figura 8.2 - Comparación de los resultados obtenidos en el presente trabajo, para los elementos de acero estructural, con los del estudio nórdico [SAKO 1999], en términos del índice de fiabilidad, $\beta$, para un período de referencia de 50 años, en función de la ratio $v$ : a) para el mecanismo de fallo por

flexión de las vigas de cubierta; b) para el mecanismo de fallo por compresión de los pilares expuestos a situaciones con la carga de nieve como única acción variable.

La comparación de los resultados obtenidos en los dos estudios pone de manifiesto, en primer lugar, una cierta similitud en el aspecto de la relación entre el índice de fiabilidad, $\beta$, y la ratio $v$. Sobre todo en el caso de las vigas de cubierta (Figura 8.2a), la coincidencia de los resultados es sorprendente dadas las diferencias inherentes en ambos estudios. El nivel máximo de fiabilidad se observa para valores de $v$ del orden de 0,2 . La fiabilidad disminuye en la medida en que la ratio $v$ se aleja de este valor, aunque la reducción es mayor para los casos en los que la carga de nieve tiene una mayor relevancia ( $v$ creciente). Debido a que el estudio nórdico incluye casos con $v=0$ y $v=1$, los valores mínimos obtenidos para los índices de fiabilidad son considerablemente inferiores a los obtenidos en el presente estudio. En el caso de los pilares de la última planta (Figura 8.2b), la coincidencia es buena para los resultados correspondientes a valores realistas de la ratio $v$, comprendidos en el intervalo entre $v=0,2$ y $v=0,7$, aproximadamente, siendo los valores obtenidos en el estudio nórdico algo inferiores. Tanto para las vigas de cubierta como para los pilares de la última planta, los valores medio de los índices de fiabilidad según el presente estudio superan los valores medio según el estudio nórdico. Por otro lado, la dispersión de los resultados es mayor en el estudio nórdico, lo que se refleja en los coeficientes de variación para los índices de fiabilidad, $v_{\beta}$ (Tabla 8.2). De no haber considerado, en el estudio nórdico, los casos extremos para $v=0$ y $v=1$, los valores medio y los 
coeficientes de variación serían del mismo orden de magnitud en los dos estudios, sobre todo para las vigas de cubierta.

Tabla 8.2 - Comparación del nivel de fiabilidad requerido para un período de referencia de 50 años, obtenido en el presente estudio y el estudio nórdico [SAKO 1999], respectivamente, para elementos de acero estructural.

\begin{tabular}{|l|c|c|c|c|c|c|}
\hline \multirow{2}{*}{$\begin{array}{l}\text { Elementos estructurales; } \\
\text { mecanismo de fallo }\end{array}$} & \multicolumn{3}{|c|}{ Estudio actual } & \multicolumn{3}{c|}{ Estudio nórdico } \\
$\mathbf{N}^{\mathbf{0}}$ de & $\boldsymbol{\mu}_{\boldsymbol{\beta}}$ & $\boldsymbol{v}_{\boldsymbol{\beta}}$ & $\begin{array}{c}\mathbf{N}^{\mathbf{0}} \text { de } \\
\text { resultados }\end{array}$ & $\boldsymbol{\mu}_{\boldsymbol{\beta}}$ & $\boldsymbol{v}_{\boldsymbol{\beta}}$ \\
\hline $\begin{array}{l}\text { Vigas de cubierta; flexión en el } \\
\text { centro del vano }\end{array}$ & 144 & 3,87 & 0,084 & 6 & 3,52 & 0,146 \\
\hline $\begin{array}{l}\text { Pilares de última planta; } \\
\text { compresión simple }\end{array}$ & 2.160 & 4,31 & 0,132 & 6 & 3,48 & 0,222 \\
\hline
\end{tabular}

Debido a las dificultades relacionadas con los criterios de aceptación de los riesgos en las normas actuales (Apartado 1.1.2), no sería razonable esperar que los índices de fiabilidad de los elementos dimensionados de manera estricta según estas mismas normas se encuentren dentro de unos límites muy estrechos. Si además se tienen en cuenta las importantes diferencias entre campo de aplicación, alcance e hipótesis adoptadas para la realización de los dos estudios objeto de comparación, los resultados obtenidos parecen convincentes. Efectivamente, el orden de magnitud del nivel de fiabilidad requerido implícitamente por dos conjuntos normativos consistentes en sí y compatibles entre ellos, resulta comparable. A esta conclusión hay que añadir que en ambos estudios se observa una dependencia similar entre la fiabilidad estructural y las características de las cargas, expresadas a través de la ratio $v$ según la ecuación (8.1).

\section{Conclusiones}

Los índices de fiabilidad, $\beta$, obtenidos para las vigas, tanto de cubierta como de planta, fabricadas de acero estructural y dimensionadas de manera estricta según las reglas de las normas españolas que están en vigor, equivalentes a las europeas (Apartado 8.2.1), están afectados por una dispersión que se sitúa dentro de unos límites esperables. Con un valor medio del índice de fiabilidad, $\mu_{\beta}$, referido a todo el período de servicio de la estructura, de 3,9 y 4,0 para los dos conjuntos analizados de vigas de cubierta y planta, el coeficiente de variación, $v_{\beta}$, se sitúa en un $8,5 \%$ y $5,4 \%$, respectivamente. Para los pilares de acero estructural, dimensionados de manera análoga a las vigas, el valor medio del índice de fiabilidad referido a todo el período de servicio, $\mu_{\beta}=4,9$, resulta sensiblemente superior a los anteriores, y con un coeficiente de variación de $v_{\beta}=0,116$ la dispersión también es mayor que en el caso de las vigas. Esta última observación puede parecer sorprendente si se tiene en cuenta que por cada pilar se considera un único mecanismo de fallo, mientras que por cada viga se analizan dos mecanismos distintos. No obstante, el número de elementos analizados es muy superior en el caso de los pilares, lo que aumenta la dispersión de los resultados. Tanto para las vigas como para los pilares, el valor medio del índice de fiabilidad es superior al valor requerido por muchas normas actuales para todo el período de servicio, fijado en 3,8 para estados límite últimos en elementos pertenecientes a la clase de fiabilidad RC2 [EN 1990 2002]. Por otro lado, la dispersión de los resultados se explica, entre otros motivos como por ejemplo la variabilidad natural, por el hecho de que los requisitos de seguridad estructural en las normas actuales no son totalmente consistentes (Apartado 1.1.2). Por ejemplo, según los resultados del presente trabajo se estima que el índice de fiabilidad de aproximadamente el $37 \%$ de las vigas de cubierta dimensionadas de manera estricta según las normas españolas o europeas estaría por debajo del valor requerido nominalmente por las mismas normas. El 
16\% de las vigas de planta dimensionadas de manera estricta están en la misma situación, mientras que en el caso de los pilares esta proporción es significativamente menor al no alcanzar el 3\%.

A pesar de las diferencias observadas en el nivel de fiabilidad correspondiente a los distintos mecanismos de fallo de los elementos analizados que cumplen estrictamente los criterios de seguridad estructural según las normas empleadas, y a pesar de la dispersión de los resultados obtenidos para cada uno de estos mecanismos considerados por separado, los resultados parecen coherentes. Además, la comparación con un estudio realizado en los países nórdicos pone de manifiesto que los resultados obtenidos en ambos trabajos de investigación son comparables. Aunque el alcance del estudio nórdico sea menor que el del presente trabajo, y a pesar de la existencia de importantes diferencias entre ambos, esta comparación incrementa la confianza en los análisis y resultados de la presente investigación.

La dispersión de los requisitos de seguridad estructural implícitos en las reglas actuales es muy superior si estos se consideran en términos de las probabilidades de fallo. A título de ejemplo, para la totalidad de los 12.996 resultados obtenidos en el presente estudio para los elementos de acero estructural, se comparan los valores máximo $\left(p_{f, \max }=3 \times 10^{-4}\right)$ y mínimo $\left(p_{f, \min }=5,3 \times 10^{-10}\right)$ de la probabilidad de fallo. La primera, correspondiente a la rotura por flexión de una viga de cubierta, es aproximadamente 5,6 x $10^{5}$ veces superior a la segunda que se observa para el fallo por compresión de un pilar.

Teniendo en cuenta que todos los elementos analizados, incluidos los dos para los que se obtienen los valores extremos mencionados, cumplen estrictamente los criterios de seguridad estructural de acuerdo con el conjunto de normas empleadas en su dimensionado, las importantes dispersiones observadas ponen claramente de manifiesto los problemas relacionados con los actuales requisitos de seguridad estructural (Apartado 1.1.2). Por este motivo, y por su sensibilidad frente a un cambio de las hipótesis de partida, los resultados obtenidos en un análisis de fiabilidad estructural requieren una interpretación extremadamente cautelosa. Así, la definición de un criterio de aceptación de la seguridad estructural, basado en la fiabilidad implícita en un conjunto consistente de normas, no se puede disociar de las hipótesis adoptadas para la determinación de esta fiabilidad, particularmente en cuanto a los modelos probabilistas para las diferentes variables.

\subsubsection{Elementos de hormigón armado}

\section{Resultados}

Los índices de fiabilidad, $\beta$, y las probabilidades de fallo, $p_{f}$, obtenidos para los elementos de hormigón armado, seleccionados en el marco del Apartado 5.3.2 y dimensionados de manera estricta según las reglas de las normas estructurales españolas, equivalentes a las europeas (Apartado 8.2.1), están reflejados en la Figura 8.3. Los resultados están basados en un período de referencia de 50 años y se representan de manera análoga a los obtenidos para los elementos representativos de acero estructural (Figura 8.1), en función de la ratio entre los valores característicos de los efectos de las acciones variables y totales, v. Las Figuras 8.3a) y 8.3b) reflejan los resultados para los tres mecanismos de rotura considerados (Apartado 5.4.3) en cada una de las 240 vigas de cubierta analizadas, respectivamente en términos de los índices de fiabilidad, $\beta$, y las correspondientes probabilidades de fallo, $p_{f}$. De manera análoga, las Figuras $8.3 c$ ) y 8.3d) contienen los resultados para las 450 vigas de planta analizadas, también en términos de $\beta$ y $p_{f}$. Finalmente, las Figuras 8.3e) y 8.3f) reflejan los resultados obtenidos para el mecanismo de rotura considerado para cada uno de los 22.320 pilares analizados.

La descripción de los resultados sería análoga a la realizada en el Apartado 8.2.2 para los elementos de acero. Además, los parámetros obtenidos para los índices de fiabilidad y las probabilidades de 
fallo están reflejados en las Figuras 8.3a) a 8.3f). Por ello se renuncia a este análisis descriptivo de los resultados obtenidos para los elementos de hormigón armado, procediendo directamente a su evaluación.

$\beta$

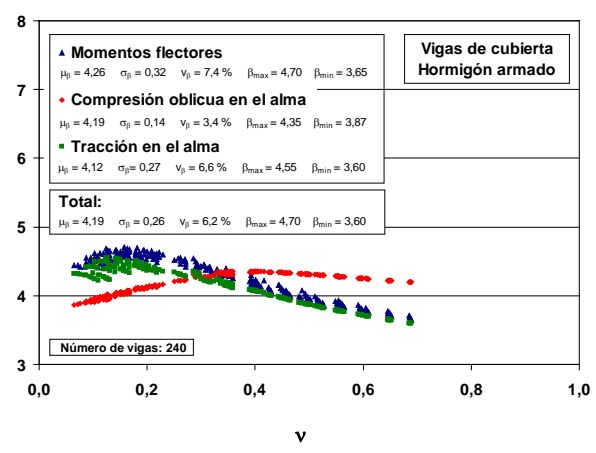

a)

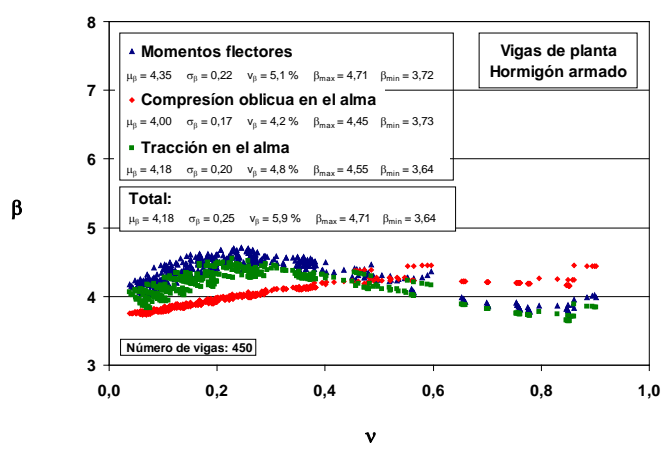

c)

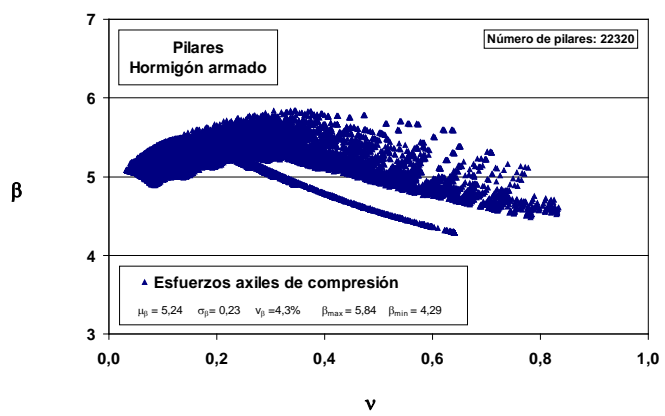

e)

Figura $8.3-a), c), e)$ Índice de fiabilidad, $\beta, y$ b), d), f) probabilidad de fallo, $p_{f}$, para un período de referencia de 50 años, en función de la ratio entre los valores característicos de los efectos de las acciones variables y totales, $v$, para los mecanismos de fallo de cada uno de los elementos de hormigón armado analizados: a), b) 240 vigas de cubierta; c), d) 450 vigas de planta; e), f) 22.320 pilares.

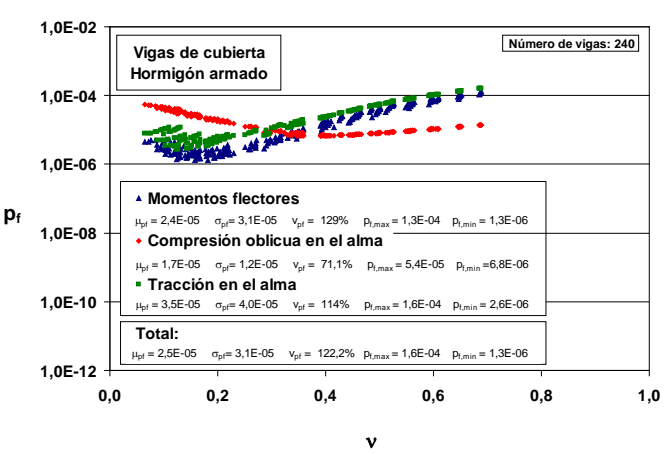

b)

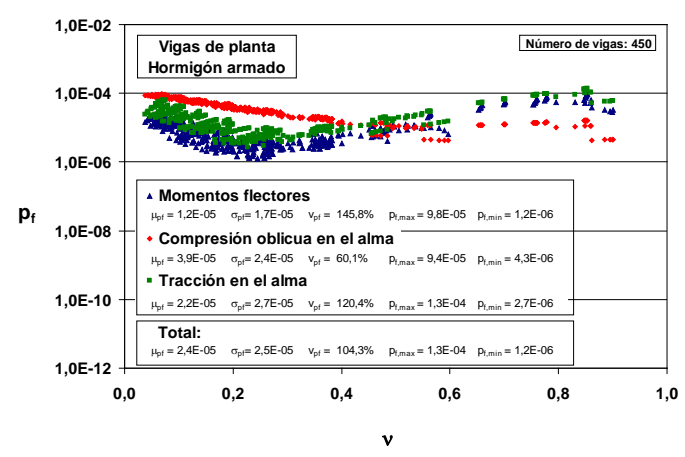

d)

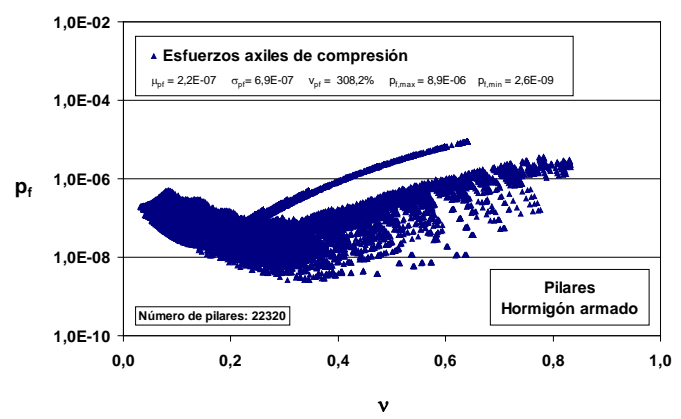

f) 


\section{Evaluación}

Interpretación de los resultados

La interpretación de los resultados obtenidos para los elementos de hormigón armado es análoga a la llevada a cabo para los elementos de acero estructural (Apartado 8.2.2). La Tabla 8.3 representa, para todos los resultados obtenidos para las vigas de cubierta, las vigas de planta y los pilares, respectivamente, los valores medio, $\mu_{\beta}$, y los coeficientes de variación, $v_{\beta}$, del índice de fiabilidad, $\beta$. El valor medio máximo del índice de fiabilidad se obtiene para los pilares. Los valores medio del índice de fiabilidad de las vigas de cubierta y de planta son prácticamente idénticos, pero sensiblemente inferiores al valor correspondiente para los pilares. A efectos de la cuantificación de la diferencia resulta más ilustrativo emplear las probabilidades de fallo. De acuerdo con los resultados reflejados en la Tabla 8.3, el valor medio de la probabilidad de fallo de los pilares es aproximadamente 110 veces inferior al valor medio de la probabilidad de fallo de las vigas.

También en el caso de los elementos de hormigón armado, la dispersión de los resultados aparentemente es pequeña en términos del índice de fiabilidad. Los coeficientes de variación son del orden del 6\% para las vigas y de algo más del 4\% para los pilares. Que estas dispersiones no son despreciables se pone de manifiesto al analizarlas considerando los resultados en términos de las probabilidades de fallo. Para las vigas de hormigón armado el coeficiente de variación supera el $100 \%$ mientras que en el caso de los pilares incluso triplica este valor. A la vista de las dificultades relacionadas con los criterios de aceptación de los riesgos en las normas actuales (Apartado 1.1.2), la dispersión de los resultados no debe sorprender, igual que en el caso de los resultados relativos a los elementos de acero estructural (Tabla 8.1).

Tabla 8.3 - Evaluación estadística de los índices de fiabilidad, $\beta$, y de las probabilidades de fallo, $p_{f}$, para un período de referencia de 50 años, de los elementos de hormigón armado, dimensionados de manera estricta según las reglas de las normas españolas, equivalentes a las europeas.

\begin{tabular}{|c|c|c|c|c|c|c|c|c|}
\hline \multirow{2}{*}{ Elementos } & \multirow{2}{*}{$\mathrm{N}^{\mathrm{o}}$ elementos } & \multirow{2}{*}{$\begin{array}{c}\text { Mecanismos } \\
\text { de fallo }\end{array}$} & \multirow{2}{*}{$\mathbf{N}^{0}$ resultados } & \multicolumn{3}{|c|}{$\beta$} & \multicolumn{2}{|c|}{$p_{f}$} \\
\hline & & & & $\mu_{\beta}$ & $v_{\beta}$ & $\beta_{k}$ & $\mu_{p f}\left[10^{-5}\right]$ & $v_{p f}$ \\
\hline V. cubierta & 240 & 3 & 720 & 4,19 & 0,062 & 3,76 & 2,5 & 1,22 \\
\hline Vigas planta & 450 & 3 & 1.350 & 4,18 & 0,059 & 3,77 & 2,4 & 1,04 \\
\hline Pilares & 22.320 & 1 & 22.320 & 5,24 & 0,043 & 4,86 & 0,022 & 3,08 \\
\hline
\end{tabular}

Con los resultados obtenidos para las vigas de cubierta, se deduce un valor característico del índice de fiabilidad, para un período de referencia de 50 años, de $\beta_{k}=3,76$ (Tabla 8.3). De manera análoga, se puede estimar que para aproximadamente el 6,7\% de las mismas vigas resulta un índice de fiabilidad inferior al valor requerido según las normas europeas [EN 1990 2002] (y por extensión, según las españolas), para elementos de la clase de fiabilidad RC2 y un período de referencia de 50 años, de $\beta_{t 50}=3,8$ (Tabla 3.6). Para las vigas de planta los resultados son prácticamente idénticos, con un valor característico del índice de fiabilidad de 3,77 y el 6,4\% de estas vigas dimensionadas de manera estricta que no cumplen el requisito nominal de fiabilidad estructural. Mientras que para las vigas de hormigón armado el valor característico del índice de fiabilidad equivale aproximadamente al valor requerido para un período de referencia de 50 años $\left(\beta_{t 50}=3,8\right.$ para la clase RC2), para los pilares se sitúa muy por encima de este requisito, en $\beta_{k}=4,86$. En concordancia con este resultado, el porcentaje de pilares dimensionados de manera estricta que no cumplen el requisito de fiabilidad resulta marginal. 


\section{Comparación con otros resultados}

La Figura 8.4 compara los resultados obtenidos en el presente trabajo para los elementos de hormigón armado con los del estudio nórdico [SAKO 1999], según lo especificado en el Apartado 8.2.1. Esta comparación se efectúa para resultados equivalentes de ambos estudios, previa transformación al mismo período de referencia. Aun así, por los motivos mencionados en el Apartado 8.2.2, las conclusiones que se extraigan de esta comparación se deben interpretar con cautela.

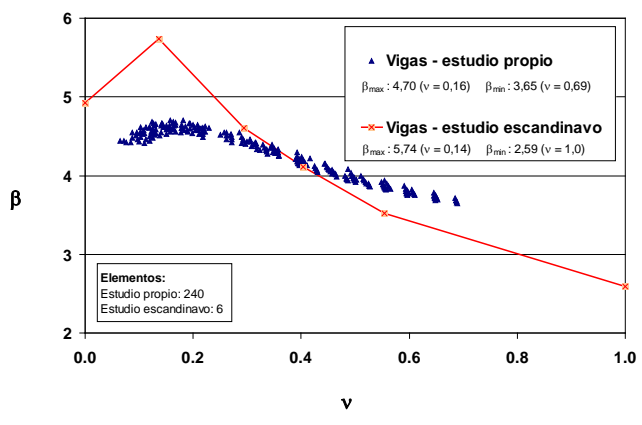

a)

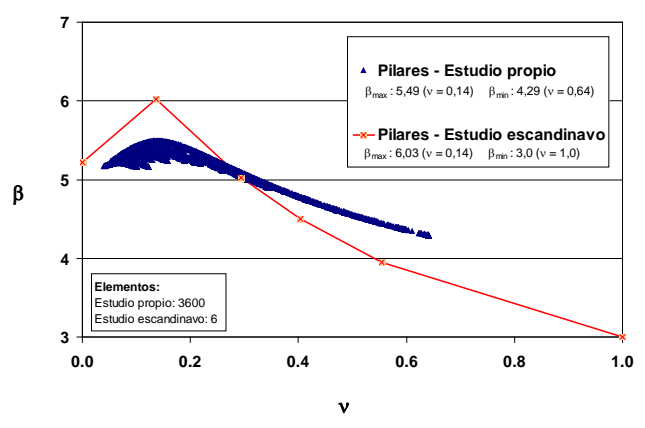

b)

Figura 8.4 - Comparación de los resultados obtenidos en el presente trabajo, para los elementos de hormigón armado, con los del estudio nórdico [SAKO 1999], en términos del índice de fiabilidad, $\beta$, para un período de referencia de 50 años, en función de la ratio $v$ : a) para el mecanismo de fallo por

flexión de las vigas de cubierta; b) para el mecanismo de fallo por compresión de los pilares expuestos a situaciones con la carga de nieve como única acción variable.

Aunque en menor medida que en el caso de los elementos de acero estructural (Figura 8.2), la comparación de los resultados obtenidos en los dos estudios muestra una similitud en el aspecto de la relación entre el índice de fiabilidad, $\beta$, y la ratio $v$. Tanto en el caso de las vigas de cubierta (Figura 8.4a) como de los pilares de la última planta (Figura 8.4b), el nivel máximo de fiabilidad se observa para valores de $v$ del orden de 0,15. La fiabilidad disminuye tanto para valores menores como mayores de $v$. La reducción es más acusada para valores crecientes de $v$, es decir, en la medida en la que aumenta la importancia relativa de la carga de nieve. Debido a que el estudio nórdico incluye casos con $v=1$, los valores mínimos obtenidos para los índices de fiabilidad son considerablemente inferiores a los obtenidos en el presente trabajo. Por otro lado, tanto para las vigas de cubierta como para los pilares de la última planta, los índices de fiabilidad máximos obtenidos en el estudio nórdico superan los valores máximos de este estudio. La dispersión de los resultados es por ello superior en el estudio nórdico, lo que se refleja en los coeficientes de variación para los índices de fiabilidad, $v_{\beta}$ (Tabla 8.4). Estos coeficientes se podrían reducir considerablemente en el estudio nórdico si se consideraran únicamente los casos correspondientes a valores realistas para la ratio $v$. De esta manera, los coeficientes de variación se aproximarían algo más a los obtenidos en el presente estudio: $7,4 \%$ para las vigas de cubierta y $6 \%$ para los pilares de última planta. Para el mecanismo de fallo por flexión de las vigas de cubierta, los valores medio del índice de fiabilidad, $\mu_{\beta}$, son prácticamente idénticos en ambos estudios (Tabla 8.4). Por otro lado, en el caso de los pilares la diferencia entre los valores medio del índice de fiabilidad no es despreciable, con $\mu_{\beta}=5,12$ obtenido en el presente estudio frente a $\mu_{\beta}=4,62$ en el estudio nórdico [SAKO 1999].

Igual que en el caso de los elementos de acero estructural (Apartado 8.2.2), no se puede esperar que los índices de fiabilidad de los elementos de hormigón armado, dimensionados de manera estricta según un conjunto consistente de normas, estén dentro de unos límites estrechos. Consecuentemente, 
tampoco es de esperar que los resultados obtenidos para diferentes conjuntos normativos, aunque consistentes en sí y compatibles entre ellos, sean idénticos o casi idénticos. Si además se tienen en cuenta las diferencias entre el presente estudio y el nórdico en cuanto a campo de aplicación, alcance e hipótesis, se puede concluir que la comparación arroja unos resultados satisfactorios, tanto desde un punto de vista cualitativo como cuantitativo.

Tabla 8.4 - Comparación del nivel de fiabilidad requerido para un período de referencia de 50 años, obtenido en el presente estudio y el estudio nórdico [SAKO 1999], respectivamente, para elementos de hormigón armado.

\begin{tabular}{|l|c|c|c|c|c|c|}
\hline \multirow{2}{*}{$\begin{array}{l}\text { Elementos estructurales; } \\
\text { mecanismo de fallo }\end{array}$} & \multicolumn{3}{|c|}{ Estudio actual } & \multicolumn{3}{c|}{ Estudio nórdico } \\
$\mathbf{N}^{\mathbf{0}}$ de & $\boldsymbol{\mu}_{\boldsymbol{\beta}}$ & $\boldsymbol{v}_{\boldsymbol{\beta}}$ & $\begin{array}{c}\mathbf{N}^{\mathbf{0}} \mathbf{d e} \\
\text { resultados }\end{array}$ & $\boldsymbol{\mu}_{\boldsymbol{\beta}}$ & $\boldsymbol{v}_{\boldsymbol{\beta}}$ \\
\hline $\begin{array}{l}\text { Vigas de cubierta; flexión en el } \\
\text { centro del vano }\end{array}$ & 240 & 4,26 & 0,074 & 6 & 4,25 & 0,26 \\
\hline $\begin{array}{l}\text { Pilares de última planta; } \\
\text { compresión simple }\end{array}$ & 3.600 & 5,12 & 0,06 & 6 & 4,62 & 0,23 \\
\hline
\end{tabular}

\section{Conclusiones}

La determinación del nivel de fiabilidad implícitamente aceptado para los elementos de hormigón armado, según las normativas española y europea que están en vigor, conduce a unas conclusiones equivalentes a las obtenidas para los elementos de acero estructural (Apartado 8.2.2). Los índices de fiabilidad, $\beta$, determinados para las vigas de hormigón armado, dimensionadas de manera estricta según las reglas de las normas mencionadas (Apartado 8.2.1), arrojan un valor medio, $\mu_{\beta}$, referido a todo el período de servicio de la estructura, de 4,18 para los dos conjuntos analizados de vigas de cubierta y planta. El coeficiente de variación, $v_{\beta}$, se sitúa en un $6 \%$, aproximadamente. Para los pilares de hormigón armado, dimensionados de manera análoga a las vigas, el valor medio del índice de fiabilidad referido a todo el período de servicio resulta claramente superior $\left(\mu_{\beta}=5,24\right)$, mientras que con un coeficiente de variación del 4,3\% la dispersión es menor que en el caso de las vigas. Esta observación parece verosímil si se tiene en cuenta que por cada pilar se considera un único mecanismo de fallo, mientras que por cada viga se analizan tres mecanismos distintos, incluida la rotura por compresión oblicua en el alma, cuyo modelo de resistencia está afectado por importantes incertidumbres (Apartado 6.7.3), con la correspondiente repercusión en la fiabilidad. Tanto para las vigas como para los pilares, el valor medio del índice de fiabilidad es superior al valor requerido por las normas consideradas para todo el período de servicio, fijado en 3,8 para estados límite últimos en los elementos pertenecientes a la clase de fiabilidad RC2 [EN 1990 2002]. La dispersión de los resultados se debe, entre otros motivos, a las dificultades relacionadas con los criterios de aceptación de los riesgos en las normas actuales (Apartado 1.1.2). En este contexto, se estima que el índice de fiabilidad de aproximadamente el 6,5\% de las vigas dimensionadas de manera estricta según las normas españolas o europeas estaría por debajo del valor requerido nominalmente por las mismas normas. En el caso de los pilares, esta proporción resulta despreciable.

Igual que en el caso de los elementos de acero estructural, los resultados obtenidos para el nivel de fiabilidad correspondiente a los distintos mecanismos de fallo de los elementos de hormigón armado que cumplen estrictamente los criterios de seguridad estructural según las normas empleadas, parecen coherentes. Además, la comparación con un estudio realizado en los países nórdicos pone de manifiesto que los resultados de ambos trabajos de investigación son semejantes. 
Si los requisitos de seguridad estructural implícitos en las reglas actuales se consideran en términos de las probabilidades de fallo, la dispersión es muy superior. Los 24.390 resultados obtenidos en el presente estudio para los elementos de hormigón armado engloban un valor máximo de la probabilidad de fallo de $p_{f, \max }=1,6 \times 10^{-4}$, obtenido para la rotura por tracción en el alma de una de las vigas de cubierta, y un valor mínimo de $p_{f, \min }=2,6 \times 10^{-9}$, correspondiente a la rotura por compresión de uno de los pilares. La ratio entre ambos valores es del orden de 6,15 x $10^{4}$. En relación con estas dispersiones, cabe recordar que todos los elementos analizados, incluidos los dos para los que se obtienen los valores extremos mencionados, cumplen estrictamente los criterios de seguridad estructural de acuerdo con el conjunto de normas empleadas en su dimensionado. Por este motivo, los resultados obtenidos en un análisis de fiabilidad estructural requieren una interpretación extremadamente cautelosa. Eso también afecta a la hipotética definición de un criterio de aceptación de la seguridad estructural, basado en la fiabilidad implícita en un conjunto consistente de normas, tal y como se explica en el Apartado 8.2.2.

\subsubsection{Elementos mixtos de acero y hormigón}

Los índices de fiabilidad, $\beta$, y las probabilidades de fallo, $p_{f}$, obtenidos para los elementos mixtos de acero y hormigón, seleccionados en el marco del Apartado 5.3.3 y dimensionados de manera estricta según las reglas de las normas estructurales europeas (Apartado 8.2.1), están reflejados en la Figura 8.5. Los resultados están basados en un período de referencia de 50 años y se representan en función de la ratio entre los valores característicos de los efectos de las acciones variables y totales, $v$. Las Figuras 8.5a) y 8.5b) reflejan los resultados para los dos mecanismos de rotura considerados (Apartado 5.4.4) en cada una de las 480 vigas de cubierta analizadas, respectivamente en términos de los índices de fiabilidad, $\beta$, y las correspondientes probabilidades de fallo, $p_{f}$. De manera análoga, las Figuras 8.5c) y 8.5d) contienen los resultados para las 900 vigas de planta analizadas, también en términos de $\beta$ y $p_{f}$. Finalmente, las Figuras 8.5e) y 8.5f) reflejan los resultados obtenidos para el mecanismo de rotura considerado para cada uno de los 76.464 pilares analizados.

Con el fin de no sobrecargar el capítulo, se renuncia a una descripción y evaluación detalladas de los resultados. En cualquier caso, la descripción sería análoga a la realizada en el Apartado 8.2.2 para los elementos de acero estructural. En cuanto a la evaluación de los resultados, los parámetros obtenidos para los índices de fiabilidad y las probabilidades de fallo están reflejados en las Figuras 8.5a) a 8.5f). Una comparación con el estudio nórdico [SAKO 1999] no es posible, ya que éste no abarca los elementos mixtos de acero y hormigón. 


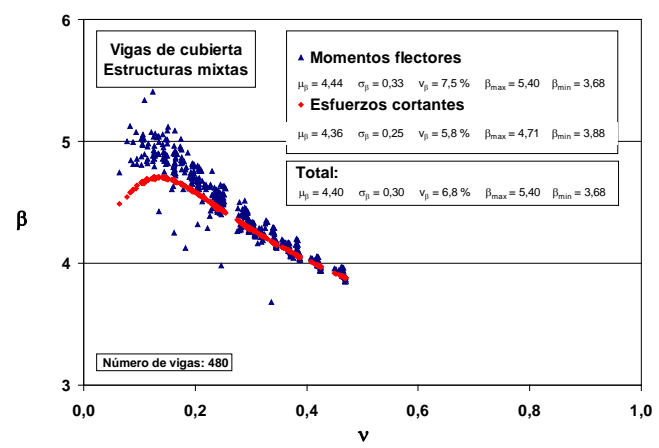

a)

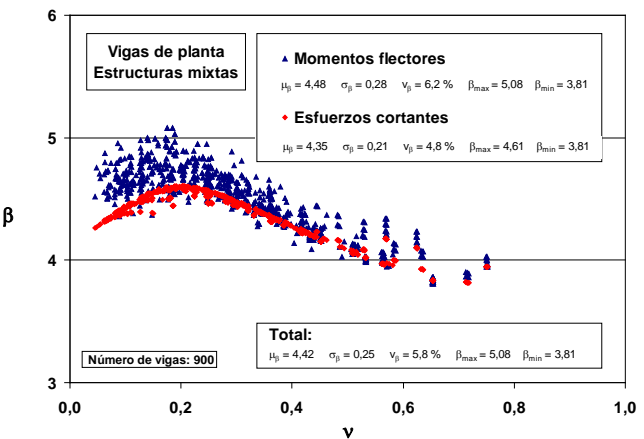

c)

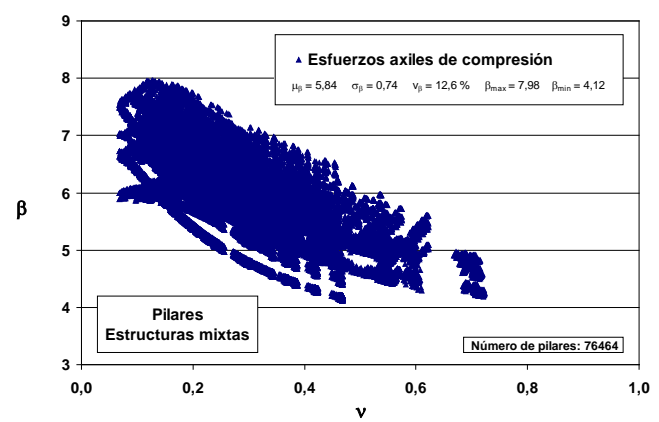

e)

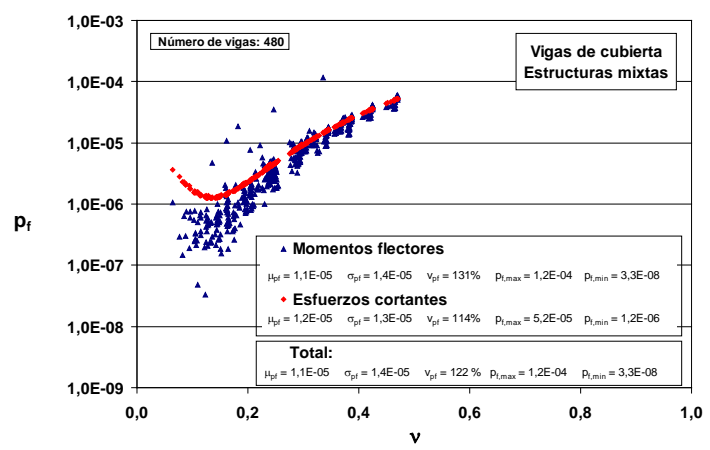

b)

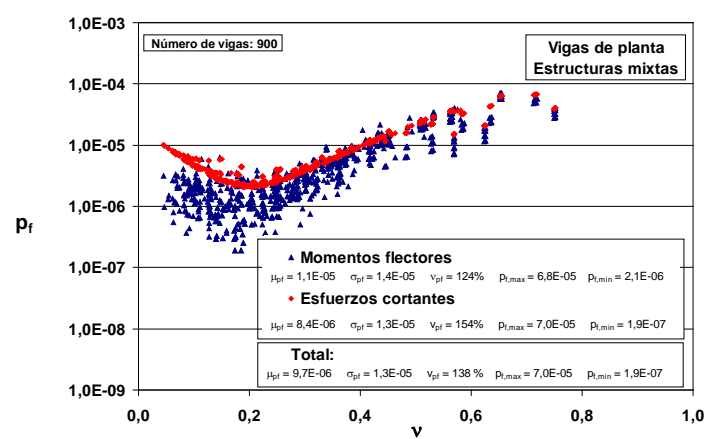

d)

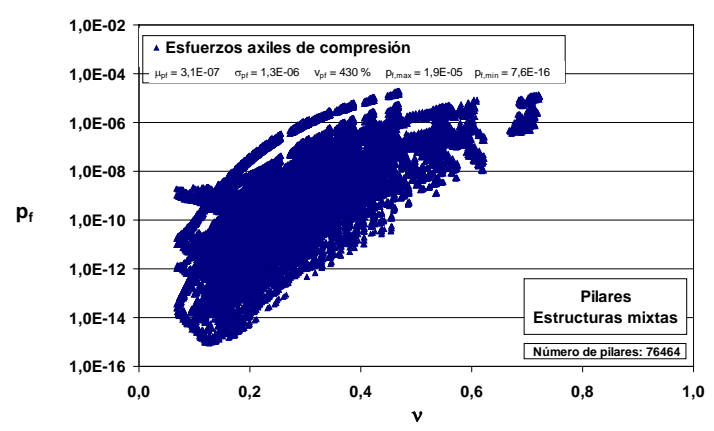

f)

Figura $8.5-a), c)$, e) Índice de fiabilidad, $\beta, y b$ ), d), f) probabilidad de fallo, $p_{f}$, para un período de referencia de 50 años, en función de la ratio entre los valores característicos de los efectos de las acciones variables y totales, $v$, para los mecanismos de fallo de cada uno de los elementos mixtos de acero y hormigón analizados: a), b) 480 vigas de cubierta; c), d) 900 vigas de planta; e), f) 76.464 pilares.

\subsubsection{Elementos de madera laminada encolada}

Los índices de fiabilidad, $\beta$, y las probabilidades de fallo, $p_{f}$, obtenidos para los elementos de madera laminada encolada, seleccionados en el marco del Apartado 5.3.4 y dimensionados de manera estricta según las reglas de las normas estructurales españolas, equivalentes a las europeas (Apartado 8.2.1), 
están reflejados en la Figura 8.6. Los resultados están basados en un período de referencia de 50 años y se representan de manera análoga a los obtenidos para los elementos representativos de los otros materiales constitutivos, contemplados en este estudio (Figuras 8.1, 8.3 y 8.5), en función de la ratio $v$. Las Figuras 8.6a) y 8.6b) reflejan los resultados para los dos mecanismos de rotura considerados (Apartado 5.4.5) en cada una de las 80 vigas de cubierta analizadas, respectivamente en términos de $\beta$ y $p_{f}$. Las Figuras 8.6c) y 8.6d) contienen los resultados para las 150 vigas de planta y las Figuras 8.6e) y 8.6f) los correspondientes a los 5.280 pilares analizados.

$\beta$

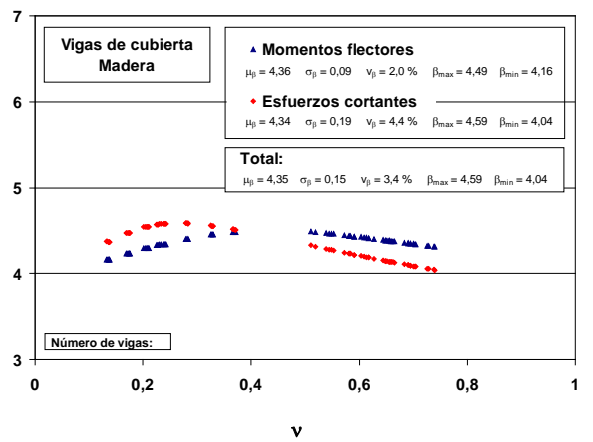

a)

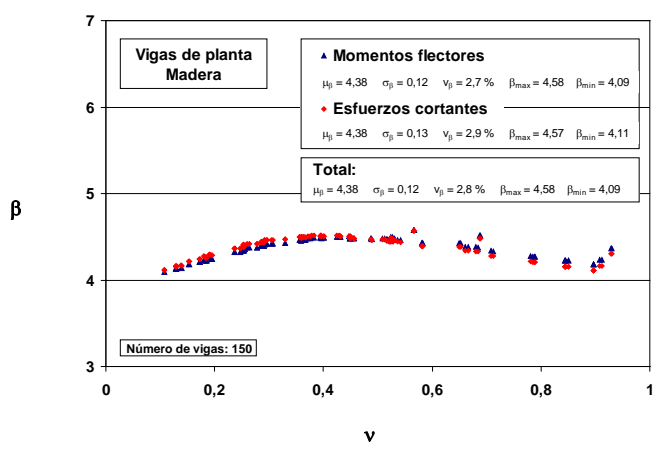

c)

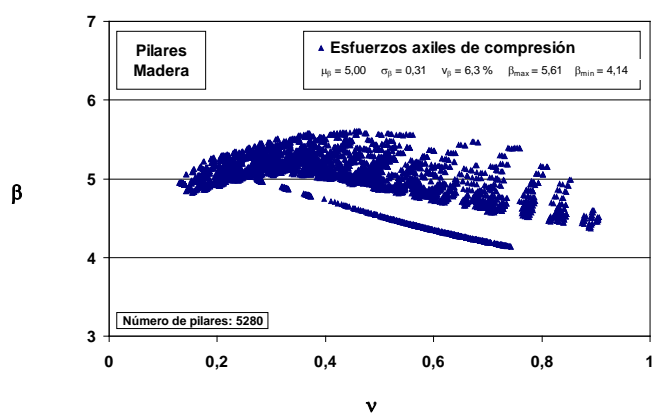

e)

Figura 8.6 - a), c), e) Índice de fiabilidad, $\beta, y$ b), d), f) probabilidad de fallo, $p_{f}$, para un período de referencia de 50 años, en función de la ratio entre los valores característicos de los efectos de las acciones variables y totales, $v$, para los mecanismos de fallo de cada uno de los elementos de madera laminada encolada analizados: a), b) 80 vigas de cubierta; c), d) 150 vigas de planta; e), f) 5.280 pilares.

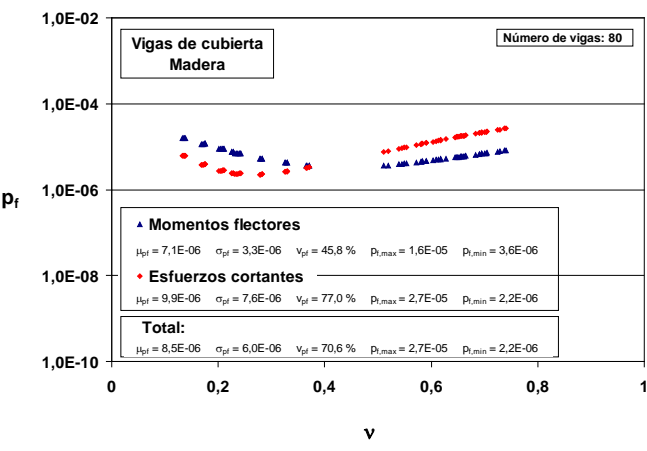

b)

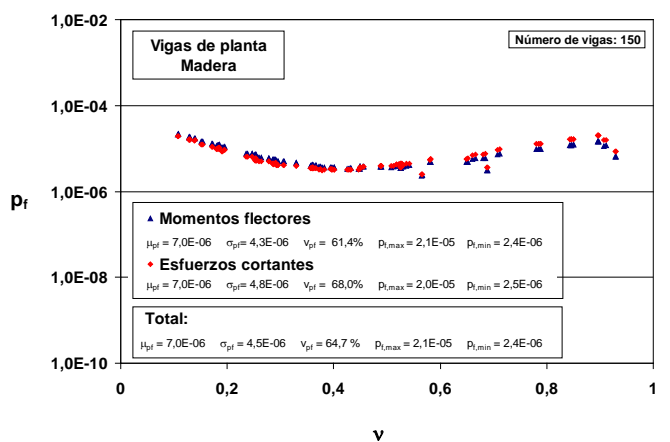

d)

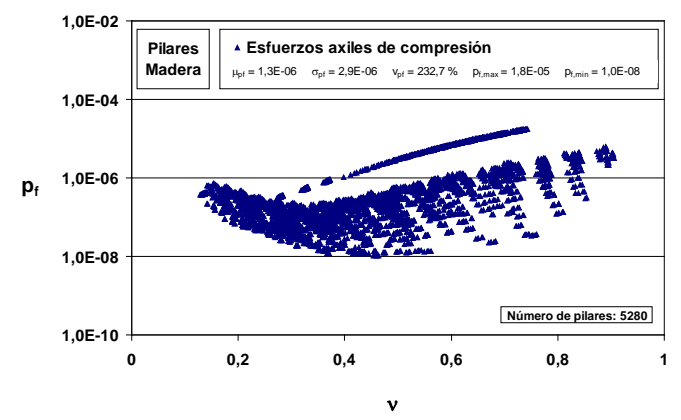

f) 


\subsubsection{Observaciones finales}

Siguiendo el procedimiento establecido en el Apartado 4.5, en el presente apartado se investiga el nivel de fiabilidad estructural implícitamente requerido según las normativas española y europea que están en vigor y que son equivalentes a efectos del presente estudio (Apartado 8.2.1). Los resultados, en términos de los índices de fiabilidad, $\beta$, y las correspondientes probabilidades de fallo, $p_{f}$, están basados en un período de referencia de 50 años y se representan y evalúan por separado para los mecanismos de fallo representativos de los elementos constituidos por los diferentes materiales considerados en este estudio (Apartados 8.2.2 a 8.2.5).

La Tabla 8.5 recoge los valores medio, $\mu_{p f}$, de la probabilidad de fallo, $p_{f}$, implícitamente aceptada según la mejor práctica actual (Apartado 8.1), para los elementos estructurales de los diferentes materiales de construcción. Los resultados ponen de manifiesto que, para todos los materiales, el valor medio de esta probabilidad de fallo para las vigas, $\mu_{p f \text {,Viga, }}$, supera perceptiblemente al valor medio correspondiente para los pilares, $\mu_{p f, \text { Pilar }}$. La ratio $\mu_{p f \text {,Viga }} / \mu_{p f, \text { Pilar }}$ oscila entre 5 para los elementos de acero estructural y 111 para los elementos de hormigón armado. Además, se aprecia que para los elementos de acero estructural, tanto las vigas como los pilares, el valor medio de la probabilidad de fallo implícitamente aceptada supera al valor medio correspondiente para los elementos de los otros materiales constitutivos, en algunos casos por más de un orden de magnitud. El valor medio mínimo para las vigas corresponde a las de madera laminada encolada, mientras que en el caso de los pilares el valor medio mínimo se obtiene para el hormigón armado.

Si en lugar de la probabilidad de fallo, $p_{f}$, se evalúan los índices de fiabilidad, $\beta$, se puede observar que los valores medio, $\mu_{\beta}$, correspondientes a los valores medio $\mu_{p f}$ de la Tabla 8.5 , superan el valor nominal del índice de fiabilidad, referido a todo el período de servicio y requerido por la normativa europea (y por extensión también por la española, aunque ésta no distingue entre diferentes clases de fiabilidad [CTE DB SE 2006]) para los estados límite últimos en elementos pertenecientes a la clase de fiabilidad RC2 [EN 1990 2002]: ( $\beta_{t 50}=3,8$. No obstante, teniendo en cuenta la dispersión de los resultados, se debe mencionar que para una determinada fracción, no siempre despreciable, de los elementos estudiados, se obtiene un índice de fiabilidad inferior al citado valor requerido, tal y como se muestra de manera explícita en el Apartado 8.2.2 para los elementos de acero estructural y en el Apartado 8.2.3 para los de hormigón armado [Tanner 2007b].

Tabla 8.5 - Valores medio, $\mu_{p f}$, y coeficientes de variación, $v_{p f}$, de la probabilidad de fallo, $p_{f}$, implícitamente aceptada para un período de referencia de 50 años, según la normativa en vigor.

\begin{tabular}{|l|c|c|c|c|c|}
\hline \multirow{2}{*}{$\begin{array}{l}\text { Material constitutivo de los } \\
\text { elementos estructurales }\end{array}$} & \multicolumn{3}{|c|}{ Valores medio } & \multicolumn{2}{c|}{ Coeficientes de variación } \\
& $\mu_{p f, \text { Viga }}\left[\mathbf{1 0}^{-5}\right]$ & $\mu_{p f, \text { Pilar }}\left[\mathbf{1 0}^{-5}\right]$ & $\mu_{p f, \text { Viga }} \boldsymbol{\mu}_{p f, \text { Pilar }}$ & $\boldsymbol{v}_{\boldsymbol{p f} \text {,Viga }}$ & $\boldsymbol{v}_{\boldsymbol{p f} \text {,Pilar }}$ \\
\hline Acero estructural & 6,2 & 1,2 & 5 & 1,15 & 2,72 \\
\hline Hormigón armado & 2,5 & 0,022 & 111 & 1,11 & 3,08 \\
\hline Mixto de acero y hormigón & 1,0 & 0,031 & 33 & 1,32 & 4,3 \\
\hline Madera laminada encolada & 0,75 & 0,13 & 5,8 & 0,68 & 2,33 \\
\hline
\end{tabular}

El orden de magnitud de los coeficientes de variación para las probabilidades de fallo obtenidas, $v_{p f}$, indica dispersiones importantes de los resultados. Mientras que para las vigas $v_{p f \text {,viga }}$ oscila entre el $68 \%$ (vigas de madera laminada encolada) y el 132\% (vigas mixtas), el coeficiente de variación se dispara para los pilares, en el caso de los mixtos hasta un valor de $v_{p f, \text { Pilar }}=430 \%$. Las dispersiones de los resultados son considerablemente menos llamativas si se evalúan en términos de los índices de 
fiabilidad, $\beta$, en lugar de las probabilidades de fallo, $p_{f}$ (Apartados 8.2.2 a 8.2.5). No obstante, la probabilidad de fallo es el parámetro determinante a efectos del presente estudio ya que interviene en la cuantificación de los riesgos. Teniendo en cuenta que todos los elementos analizados cumplen estrictamente los criterios de seguridad estructural, de acuerdo con el conjunto de normas empleadas en su dimensionado, tanto las dispersiones observadas en términos de los coeficientes de variación para las probabilidades de fallo implícitamente aceptadas, $v_{p f}$, como las diferencias arriba mencionadas de los valores medio de estas probabilidades, $\mu_{p}$, ilustran claramente las dificultades relacionadas con los requisitos de fiabilidad estructural, tal y como se menciona en el Apartado 1.1.2.

La mejora de los requisitos actuales, objetivo del presente trabajo (Apartado 1.3), no consiste simplemente en una reducción de la dispersión de las probabilidades implícitamente aceptadas por las normas estructurales, o en obtener un nivel de fiabilidad más uniforme para diferentes tipos de elementos y materiales constitutivos. Efectivamente, considerar solamente la frecuencia de ocurrencia de los colapsos estructurales en términos de su probabilidad de fallo, no conduce a resultados satisfactorios. Por todo ello, se trata de desarrollar unos requisitos racionales de seguridad estructural, basados en los riesgos para las personas.

\subsection{RIESGOS ADMISIBLES PARA LAS PERSONAS}

\subsubsection{Generalidades}

El procedimiento a seguir para la determinación del nivel aceptable de los riesgos para las personas, asociados con las estructuras de edificación, queda establecido a través de los Apartados 4.4 y 4.5 (Paso 6), mientras que en el Apartado 8.1 se detallan algunos aspectos adicionales. Este procedimiento incluye el dimensionado estricto de todos los elementos de los 19.008 sistemas estructurales seleccionados (Apartado 5.3), de los que 10.872 corresponden a edificios pertenecientes a la clase de consecuencias CC2 y 8.136 a la clase CC3. El dimensionado estricto se realiza de manera automática, en analogía con el de los elementos analizados para la deducción del nivel de fiabilidad implícito en la normativa en vigor, según las especificaciones del Apartado 8.2.1. La determinación de la probabilidad de fallo para cada mecanismo representativo, en todos los elementos estrictos de todas las estructuras, también se realiza de forma automática según lo establecido en el mismo Apartado 8.2.1. De acuerdo con la definición adoptada en el Apartado 4.2.2, cada una de estas probabilidades de fallo corresponde a la probabilidad de ocurrencia, $p_{j}$, del correspondiente escenario de riesgo, $j$. Las consecuencias asociadas a cada uno de estos escenarios, en términos del número esperado de víctimas mortales, $N_{j}$, se determinan mediante los modelos del Apartado 7.4.2, en función de la clase de consecuencias que a su vez depende de la categoría de uso del edificio, así como la superficie afectada por el colapso, $A_{c o l, j}$. Para la determinación de ésta, se asume que la rotura de un determinado pilar o viga no conduzca a un fallo en cadena de otros elementos (Apartado 5.2.1).

Sobre la base de la probabilidad de ocurrencia, $p_{j}$, y el número esperado de víctimas mortales, $N_{j}$, para cada escenario, $j$, se determinan los perfiles de riesgo (Apartado 4.3) para las estructuras de todos los edificios analizados. La Figura 8.7 representa, a título de ejemplo, las envolventes inferior y superior de los perfiles de riesgo obtenidos para las estructuras de todos los edificios analizados con elementos de acero: 2.256 de la clase de consecuencias CC2 y 1.680 de la clase CC3 (Apartado 5.3.1). Los perfiles de riesgo, y por tanto sus envolventes, se representan en términos de la probabilidad de fallo acumulada, $P_{f}$, para un período de referencia de 50 años, y del número esperado de víctimas, $N$, distinguiendo entre las estructuras de los edificios pertenecientes a las clases de consecuencias CC2 y CC3, respectivamente. En consonancia con la ecuación (4.8), mediante integración de cada perfil, se obtiene el riesgo colectivo para las personas, $R$, asociado con la estructura analizada. 


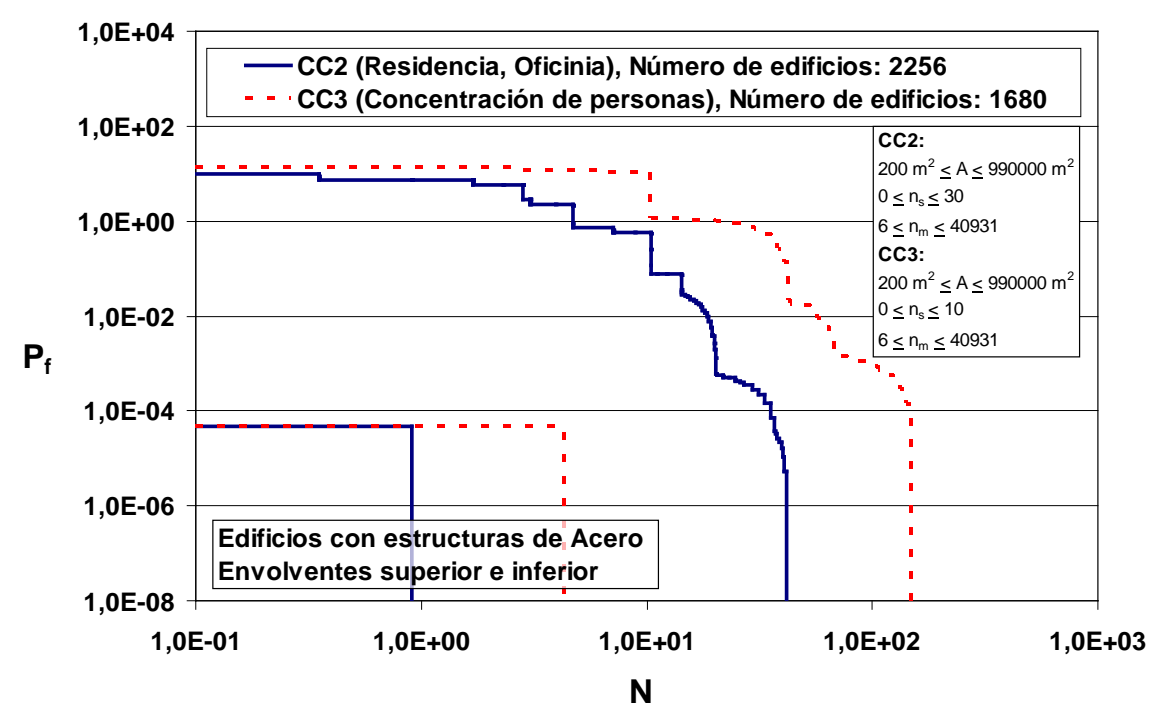

Figura 8.7 - Envolventes inferiores y superiores de los perfiles de riesgo, referidos a un período de 50 años, para las estructuras de todos los edificios analizados con elementos de acero: 2.256 edificios de la clase de consecuencias CC2 y 1.680 de la clase CC3.

\subsubsection{Riesgos nominales}

\section{Representación de los resultados}

El riesgo colectivo para las personas, $R$, asociado con la estructura de un determinado edificio y obtenido según lo especificado en el apartado anterior, se puede representar en función de la superficie útil total, $A$, del mismo edificio. La Figura 8.8 representa el mencionado riesgo, $R$, en función de $A$, para las estructuras de todos los edificios analizados. El período de referencia es de 50 años y se distingue entre los edificios pertenecientes a las clases de consecuencias CC2 y CC3, respectivamente. La Figura 8.8a) contiene los 10.872 resultados correspondientes a la clase CC2, mientras que los 8.136 resultados relativos la clase CC3 están reflejados en la Figura 8.8b).

Para los pares de datos $R-A$ se efectúan unos análisis estadísticos de regresión, asumiendo una distribución lognormal de la variable $R$. Los resultados de estos análisis se representan también en las Figuras 8.8a) y b), en términos del valor medio del riesgo colectivo para las personas, $R_{m}$, en función de la superficie, $A$, y de los valores correspondientes a los cuantiles del $5 \%$ y del $95 \%, R_{k, 5}$ y $R_{k, 95}$, respectivamente. Estos modelos estadísticos permiten apreciar particularmente bien las diferencias entre ambas clases de consecuencias. Se manifiestan básicamente en un mayor número esperado de víctimas mortales para un edificio de la clase CC3, en comparación con uno de la clase CC2 que tenga la misma superficie. Aparte de este resultado esperado y razonable, se pone de manifiesto la existencia de varios efectos de escala: los riesgos asociados con las estructuras dimensionadas de manera estricta según la normativa en vigor crecen con el número de diferentes mecanismos de fallo, el número de elementos estructurales, el número de combinaciones de acciones e influencias que puedan conducir a un fallo estructural, y con la superficie útil del edificio. Este último es el más relevante de todos los efectos de escala mencionados ya que engloba a varios de los restantes.

Las anteriores observaciones conducen a la conclusión de que no es posible definir, de manera absoluta, un nivel aceptable de los riesgos colectivos para las personas. En cambio, el criterio de aceptación se podría expresar en términos del valor esperado del riesgo colectivo, o de un determinado cuantil de los resultados obtenidos, en función de la superficie útil total del edificio (Figura 8.8). De cara a la continuación del estudio, es importante recordar que debido a que todos los 
elementos de todas las estructuras analizadas cumplen, exactamente, los requisitos de seguridad estructural según la normativa que está en vigor (Apartado 4.4), los riesgos asociados a cada una de ellas resultan aceptables por definición. En particular, eso significa que también son aceptables los riesgos colectivos para las personas correspondientes a un cuantil superior de los resultados obtenidos, por ejemplo $R_{k, 95}$ (Figura 8.8).

a)

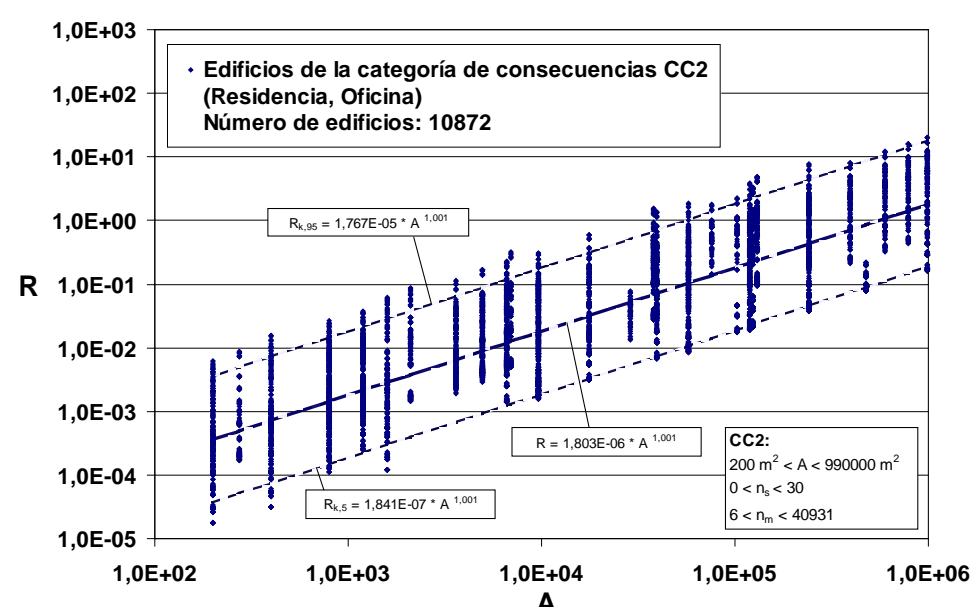

b)

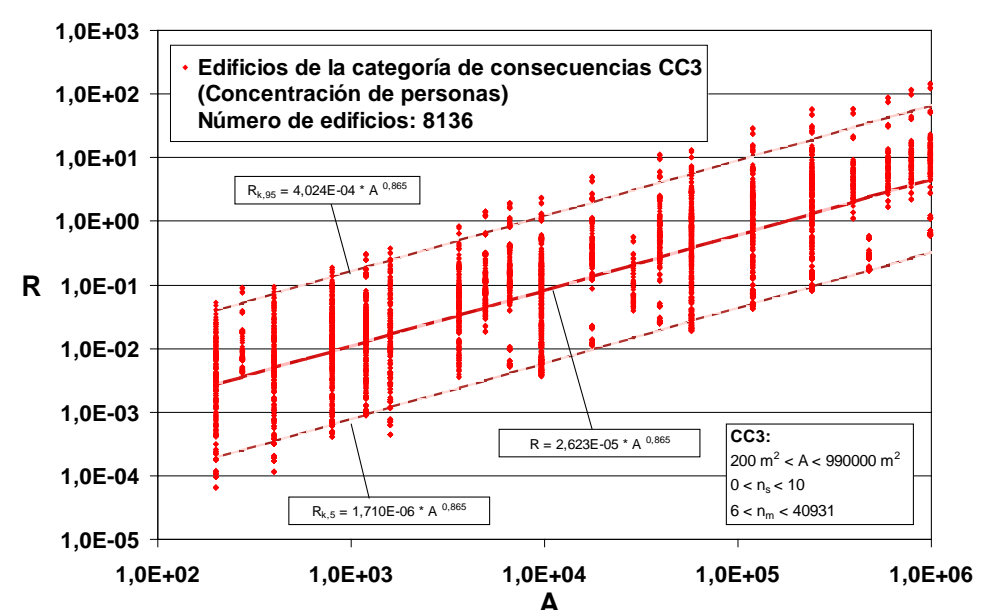

Figura 8.8 - Riesgo colectivo para las personas, $R$, referido a un período de 50 años y representado en función de la superficie útil total del edificio, $A$, para todas las estructuras analizadas: a) 10.872 resultados correspondientes a la clase de consecuencias CC2; b) 8.136 resultados correspondientes a la clase CC3.

\section{Normalización de los resultados}

Los efectos de escala se pueden eliminar parcialmente a través de una normalización de los resultados. Por ejemplo, la normalización del riesgo colectivo para las personas, asociado con un determinado edificio y referido al período de tiempo considerado, $R$, con la superficie útil del mismo edificio, $A$, conduce a un valor medio del riesgo por unidad de superficie y tiempo, para la disposición relevante de las cargas en cada escenario. Esta representación es equivalente a la que se emplea a menudo en obras lineales, tales como los sistemas de transporte para los que los riesgos se suelen expresar en función de una unidad de tiempo y longitud (por ejemplo: número de muertos anuales por kilómetro de autopista). 
La Figura 8.9 representa el riesgo colectivo para las personas, $R$, normalizado con la superficie útil total, $A$, en función de esta misma superficie, $A$. Igual que en la Figura 8.8, cada punto representa el resultado para la estructura de uno de los edificios analizados. El período de referencia es de 50 años, y se distingue entre edificios pertenecientes a las categorías de consecuencias CC2 y CC3, respectivamente: los 10.872 resultados correspondientes a la clase CC2 se reflejan en la Figura 8.9a), mientras que los 8.136 resultados relativos a la clase CC3 están representados en la Figura 8.9b). También para los riesgos normalizados se observa una importante dispersión de los resultados obtenidos para las estructuras analizadas. No obstante, a través de la normalización con la superficie útil de los edificios, se elimina el más importante de los efectos de escala anteriormente enumerados en el contexto de los riesgos colectivos. La dispersión observada de los resultados se debe a la dependencia de los riesgos, $R$, de los otros parámetros mencionados (el número de diferentes mecanismos de fallo, el número de elementos estructurales, el número de combinaciones de acciones e influencias) y pone de manifiesto, una vez más, la calibración incompleta, según criterios totalmente racionales, de las reglas de dimensionado estructural según las normas actuales.

a)

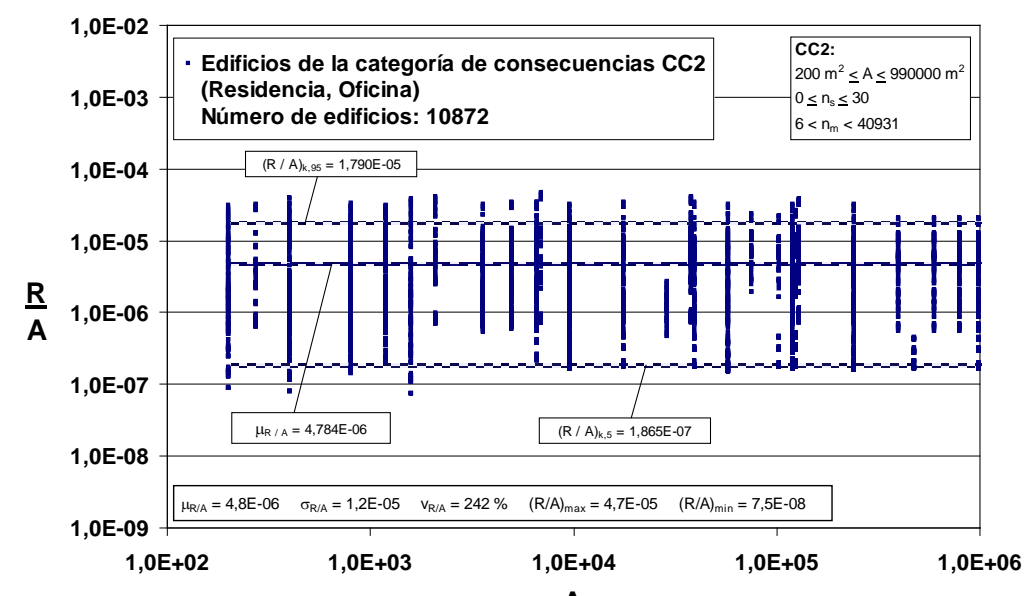

A

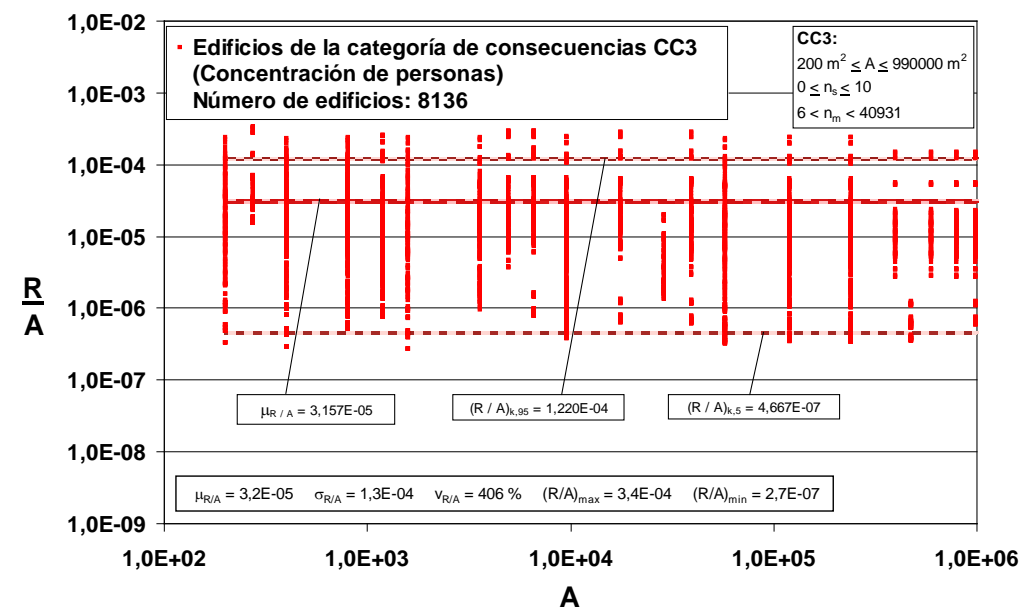

b)

Figura 8.9 - Riesgo colectivo para las personas, $R$, referido a un período de 50 años y normalizado con la superficie útil total del edificio, $A$, en función de A, para todas las estructuras analizadas: a) 10.872 resultados correspondientes a la clase de consecuencias CC2; b) 8.136 resultados correspondientes a la clase CC3.

Asumiendo una distribución lognormal de la variable $R / A$ se efectúa un análisis estadístico de los riesgos normalizados. Los resultados obtenidos se reflejan en las Figuras 8.9a) y b), en términos de 
los valores medio, $(R / A)_{m}$, y de los cuantiles del 5\% y del 95\%, $(R / A)_{k, 5}$ y $(R / A)_{k, 95}$, respectivamente, y se resumen en la Tabla 8.6. Por los motivos mencionados en relación con la interpretación de los riesgos colectivos (Figura 8.8), se podría adoptar como nivel aceptable de los riesgos normalizados el valor esperado o un determinado cuantil de los resultados obtenidos. En otras palabras, un cuantil superior como por ejemplo $(R / A)_{k, 95}$ podría considerarse como límite de aceptación.

Por otro lado, a efectos de la normalización del riesgo colectivo para las personas asociado con un edificio, $R$, también es conveniente utilizar otros parámetros, particularmente el número total de escenarios relevantes para la estructura del mismo edificio, $n_{s c}$. Según el significado del término escenario en el marco del presente trabajo (Apartado 4.2.2), esta normalización resulta en un valor medio del riesgo por mecanismo de fallo y unidad de tiempo, para la disposición relevante de las cargas en cada caso. La Figura 8.10 representa los resultados de la normalización de $R$ con $n_{s c}$, en función de este mismo número de escenarios, $n_{s c}$, para todas las estructuras analizadas. El período de referencia es de 50 años y se distingue entre los resultados correspondientes a las categorías de consecuencias CC2 (Figura 8.10a) y CC3 (Figura 8.10b), respectivamente.

a)

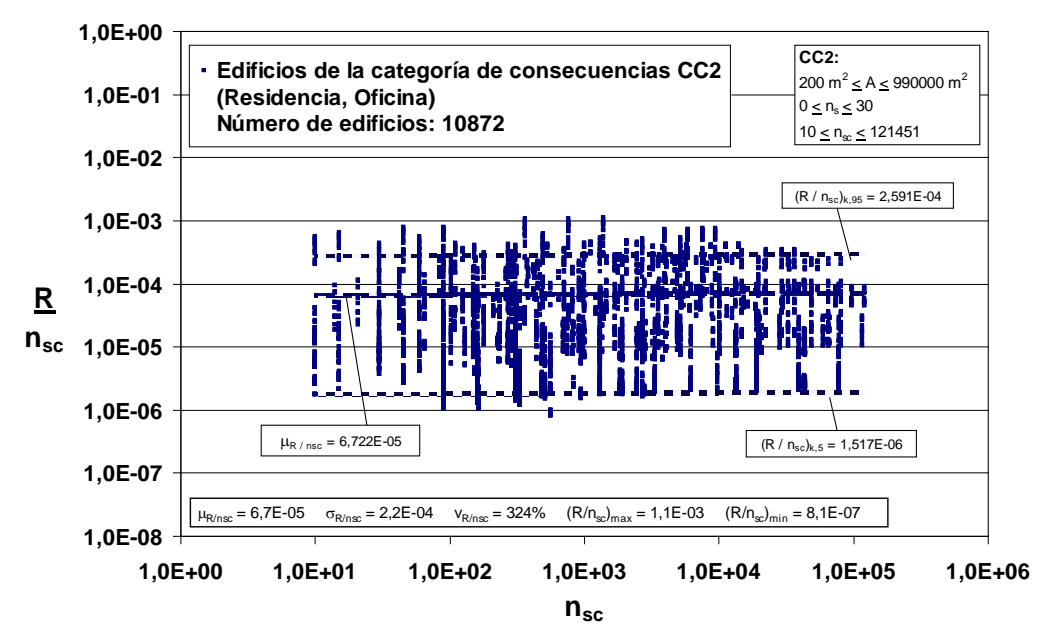

b)

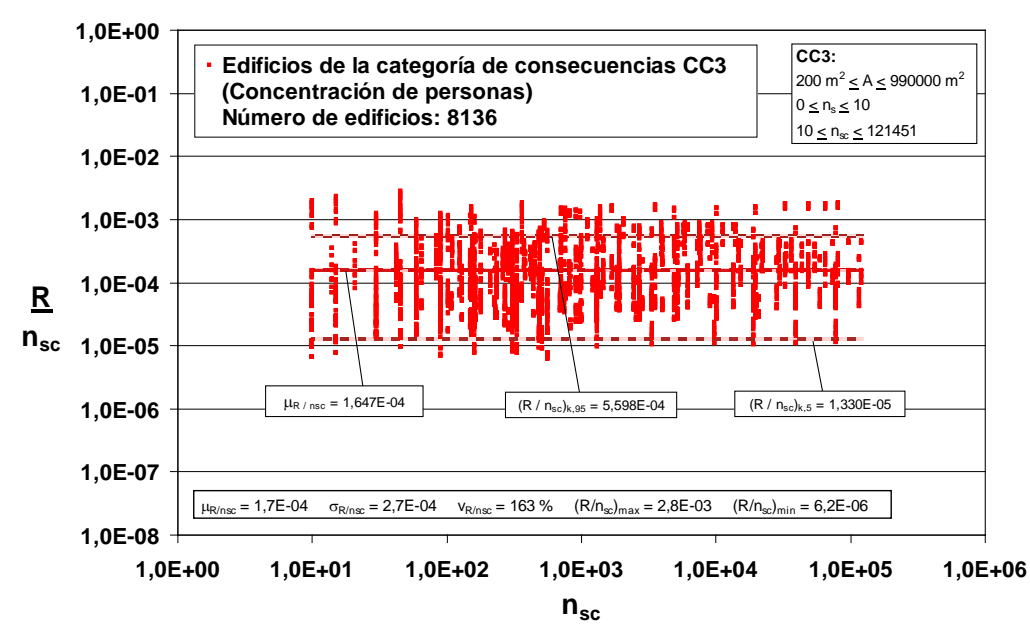

Figura 8.10 - Riesgo colectivo para las personas, $R$, referido a un período de 50 años y normalizado con el número total de escenarios relevantes para la estructura del edificio, $n_{\mathrm{sc}}$, en función de $n_{\mathrm{sc}}$, para todas las estructuras analizadas: a) 10.872 resultados correspondientes a la clase de consecuencias CC2; b) 8.136 resultados correspondientes a la clase CC3. 
La representación gráfica de los resultados pone de manifiesto que el valor medio de la variable $R / n_{s c}$ no varía con el número de escenarios, $n_{\text {sc }}$. No sorprende que esta normalización tampoco conduzca a una mayor reducción de la dispersión de los resultados obtenidos para las estructuras analizadas. Para cuantificarla, se asume una distribución lognormal de la variable $R / n_{s c}$ y se efectúa un análisis estadístico de los resultados, obteniendo los valores medio, $\left(R / n_{s c}\right)_{m}$, y de los cuantiles del $5 \%$ y del $95 \%,\left(R / n_{s c}\right)_{k, 5}$ y $\left(R / n_{s c}\right)_{k, 95}$, que se reflejan en las Figuras $\left.8.10 \mathrm{a}\right)$ y $\left.8.10 \mathrm{~b}\right)$, respectivamente para las clases de consecuencias CC2 y CC3. Finalmente, también en analogía con la interpretación de los resultados anteriores (Figuras 8.8 y 8.9), cabe destacar que se podrían considerar como aceptables los riesgos normalizados con el número de escenarios correspondientes al valor esperado o un determinado cuantil de los resultados obtenidos. A título de ejemplo, el cuantil superior del 95\%, $\left(R / n_{s c}\right)_{k, 95}$, podría adoptarse como límite de aceptación.

\subsubsection{Criterios de aceptación de los riesgos individuales}

\section{Riesgos para las personas}

Los resultados representados en la Figura 8.9 se pueden emplear a efectos de la definición de los criterios de aceptación para el riesgo mortal individual. Este gráfico representa el número de víctimas mortales por unidad de superficie útil para un período de referencia de 50 años que resultaría aceptable según la mejor práctica actual. Debido a que el número de personas por unidad de superficie útil del edificio es una función del tipo de uso del mismo edificio, se puede considerar que, hasta un cierto punto, esta unidad de superficie relaciona el riesgo colectivo con el individual. Como se explica en el apartado anterior, el criterio de aceptación podría expresarse en términos del valor medio o de un determinado cuantil del número de víctimas por unidad de superficie útil del edificio (por ejemplo, $(R / A)_{m},(R / A)_{k, 5}$ ó $\left.(R / A)_{k, 95}\right)$. Mientras que estos valores se refieren a un período de 50 años, uno de un año resulta más conveniente a efectos prácticos. La ecuación (8.2) proporciona unos resultados suficientemente aproximados para la transformación. Estos resultados se reflejan en la Tabla 8.6 para las clases de consecuencias CC2 y CC3, en términos de los valores medio así como los cuantiles del 5\% y 95\%, respectivamente:

$(R / A)_{1 y} \cong \frac{(R / A)_{50 y}}{50}$

$(R / A)_{n y} \quad$ : riesgo colectivo para las personas, normalizado con la superficie útil total de los edificios, para un período de referencia de $n$ años

El riesgo anual de que un determinado usuario de un edificio pierda su vida debido a un colapso estructural se puede estimar relacionando el riesgo normalizado, $(R / A)_{1 y}$, con la tasa de ocupación del edificio, es decir, el número de personas por unidad de superficie, $A$, que depende de la categoría de uso. Para edificios residenciales, por ejemplo, la superficie útil disponible, $A$, por persona, $i$, correspondiente al valor inverso de la tasa de ocupación, se estima a partir de la información del Instituto Nacional de Estadística [INE], obteniendo un valor medio de $A_{i, m}=30 \mathrm{~m}^{2} /$ persona. Este resultado se emplea en el presente estudio para los edificios de la clase de consecuencias CC2. Para los edificios de la clase CC3, tales como los que engloban salones de actos, teatros, cines o tribunas, la superficie útil disponible por persona se sitúa en un rango estimado de 0,5 a $2 \mathrm{~m}^{2}$. En otros tipos de edificios de esta clase de consecuencias, por ejemplo en hospitales o estaciones, la superficie disponible por persona puede ser muy superior. A efectos del presente estudio se adopta un valor medio de $A_{i, m}=3 \mathrm{~m}^{2} /$ persona.

Multiplicando las anteriores estimaciones de la superficie disponible por persona, $A_{i, m}$, por el riesgo normalizado, $(R / A)_{1 y}$, se obtiene el riesgo individual por año. Si a estos efectos se emplean los valores 
admisibles para el riesgo normalizado según la Tabla 8.6, se pueden deducir los valores admisibles para el riesgo individual medio por año, $r_{I R, a d m}$, que se reflejan en la misma tabla:

$r_{I R, a d m} \cong(R / A)_{1 y} \cdot A_{i, m}$

$A_{i, m} \quad$ : valor medio de la superficie útil disponible por persona

Tabla 8.6 - Valores medio $\left(X_{m}\right)$ y de los cuantiles del 5\% $\left(X_{k, 5}\right)$ y del 95\% $\left(X_{k, 95}\right)$ de, respectivamente, el riesgo colectivo para las personas, normalizado con la superficie útil total de los edificios, para períodos de referencia de 50 años, $(R / A)_{50 y}, y 1$ año, $(R / A)_{1 y}$; el valor admisible para el riesgo individual medio por año, $r_{I R, a d m}$; el valor objetivo de la probabilidad de fallo anual asociada con el riesgo individual medio, $p_{f t, I R}$; el valor requerido del índice de fiabilidad asociado con el riesgo individual medio por año, $\beta_{t, I R}$.

\begin{tabular}{|c|c|c|c|c|c|c|c|c|c|c|}
\hline Clase & \multicolumn{5}{|c|}{$\mathrm{CC2}$} & \multicolumn{5}{|c|}{ CC3 } \\
\hline$n$ años [y] & 50 & \multicolumn{4}{|c|}{1} & 50 & \multicolumn{4}{|c|}{1} \\
\hline Criterio & $\begin{array}{r}\left.(\mathrm{R} / \mathrm{A})_{50 y}\right] \\
{\left[\mathrm{c} /\left(\mathrm{m}^{2}\right.\right.}\end{array}$ & \begin{tabular}{|l|}
$\mid(R / A)_{1 y}$ \\
$\left.\left.{ }^{2} \cdot n y\right)\right]$
\end{tabular} & $\begin{array}{c}r_{I R, a d m} \\
{\left[\mathrm{y}^{-1}\right]}\end{array}$ & $\begin{array}{c}p_{f t, I R} \\
{\left[10^{-6}\right]}\end{array}$ & $\begin{array}{c}\beta_{t, I R} \\
{[-]}\end{array}$ & $\begin{array}{r}(R / A)_{50 y} \\
{\left[C /\left(\mathbf{m}^{2}\right.\right.}\end{array}$ & $\begin{array}{l}(R / A)_{1 y} \\
\cdot n y)]\end{array}$ & $\begin{array}{c}r_{I R, a d m} \\
{\left[\mathrm{y}^{-1}\right]}\end{array}$ & $\begin{array}{c}p_{f t, I R} \\
{\left[10^{-6}\right]}\end{array}$ & $\begin{array}{c}\beta_{t, I R} \\
{[-]}\end{array}$ \\
\hline$X_{k, 5}$ & $2 \cdot 10^{-7}$ & $4 \cdot 10^{-9}$ & $1 \cdot 10^{-7}$ & 2 & 4,6 & $5 \cdot 10^{-7}$ & $9 \cdot 10^{-9}$ & $3 \cdot 10^{-8}$ & 0,1 & 5,1 \\
\hline$X_{m}$ & $5 \cdot 10^{-6}$ & $1 \cdot 10^{-7}$ & $3 \cdot 10^{-6}$ & 60 & 3,9 & $3 \cdot 10^{-5}$ & $6 \cdot 10^{-7}$ & $2 \cdot 10^{-6}$ & 9 & 4,3 \\
\hline$X_{k, 95}$ & $2 \cdot 10^{-5}$ & $4 \cdot 10^{-7}$ & $1 \cdot 10^{-5}$ & 200 & 3,6 & $1 \cdot 10^{-4}$ & $2 \cdot 10^{-6}$ & $7 \cdot 10^{-6}$ & 40 & 4 \\
\hline
\end{tabular}

Según los resultados del presente estudio, el valor esperado para el límite de aceptación del riesgo individual medio es del orden de $10^{-6}$ por año, para ambas clases de consecuencias, CC2 y CC3. Por otro lado, el cuantil del $95 \%$ de $r_{I R, a d m}$ se aproxima a valores del orden de $10^{-5}$ por año. Estos resultados son consistentes con los criterios de aceptación para el riesgo individual medio asociado con los colapsos estructurales, establecidos en la literatura especializada. Según un consenso generalizado, para este riesgo se suelen admitir valores en el intervalo de $10^{-6}$ a $10^{-5}$ por año. A efectos de recordatorio (Apartado 2.3.2), según la norma internacional sobre fiabilidad estructural [ISO 2394 1998] el valor admisible es del orden de $10^{-6}$ por año, mientras que la norma suiza sobre la evaluación de las estructuras existentes [SIA 269 2011] establece un límite de aceptación de $10^{-5}$ por año. Las recomendaciones holandesas relativas a las actividades industriales en general distinguen entre requisitos para los sistemas de nueva construcción y existentes, estableciendo unos límites de aceptación, $r_{I R, a d m}$, de $10^{-6}$ y $10^{-5}$ por año, respectivamente [Vrijling 2005]. Otros autores holandeses adoptan este último valor para la determinación de los índices de fiabilidad requeridos para la evaluación de las estructuras existentes [Steenbergen 2010], alineándose con la citada norma suiza destinada a los mismos fines [SIA 269 2011]. Unos desarrollos similares en la República Checa [Sykora 2013], mientras tanto, están basados en un valor $r_{I R, a d m}=10^{-6}$ por año, en concordancia con la norma internacional [ISO 2394 1998].

\section{Niveles de fiabilidad}

Cabe destacar la buena coincidencia entre los riesgos individuales para las personas implícitamente aceptados según la mejor práctica actual, determinados en este estudio, y los criterios de aceptación definidos en las normas y recomendaciones anteriormente citadas, a menudo basados en simples comparaciones con los valores frecuentistas para los riesgos mortales asociados con otras actividades de la vida diaria (Apartado 2.3.2). Esta concordancia sustenta la validez del presente estudio como base racional para la adopción de decisiones sobre la seguridad estructural. Por ejemplo, las probabilidades de fallo objetivo, deducidas a partir de los riesgos admisibles aquí obtenidos, podrían 
usarse para una calibración consistente de los coeficientes parciales a emplear en los análisis tradicionales de ingeniería para el dimensionado o la evaluación estructural. Estas probabilidades de fallo objetivo, $p_{f t, I R}$, basadas en los valores admisibles para el riesgo individual, $r_{I R, a d m}$, se obtienen a partir de la relación (2.6), interpretada en términos de ecuación. La probabilidad mortal condicional, $p_{c \mid f}$, que interviene a estos efectos, se podría estimar a partir de un análisis estadístico de la base de datos sobre colapsos estructurales, establecida para deducir los modelos de consecuencias empleados en el presente estudio (Capítulo 7). No obstante, las estimaciones resultantes de este análisis deben interpretarse con cautela ya que los coeficientes de variación, del orden del 100\%, denotan unas incertidumbres significativas en la determinación de la probabilidad condicional, $p_{c \mid f}$. Una estimación más verosímil requiere por tanto unos análisis adicionales, tal y como apuntan también otros autores [Sykora 2013, Steenbergen 2015]. Es por ello que, a efectos de la continuación del trabajo, se adoptan para la probabilidad condicional, $p_{c \mid \text {, }}$ las estimaciones disponibles en la literatura y citadas en la publicación anteriormente mencionada [Steenbergen 2015]: 0,05 para los edificios de la clase de consecuencias CC2 y 0,2 para la clase CC3.

Introduciendo los anteriores valores de $p_{c \mid f}$, en la parte derecha de la relación (2.6), conjuntamente con los valores de $r_{I R, a d m}$ reflejados en la Tabla 8.6, resultan las probabilidades de fallo objetivo, basadas en el riesgo individual admisible, $p_{f t, I R}$. Los resultados obtenidos están resumidos en la misma tabla, donde se recogen también los correspondientes valores requeridos del índice de fiabilidad asociado con el riesgo individual medio, $\beta_{t, I R}$. Estos últimos valores se determinan a partir de $p_{f t, I R}$ mediante la inversa de la función de distribución normal estándar.

Aunque probablemente se trate de una simple casualidad, es interesante observar que los valores del índice $\beta_{t, I R}$ correspondientes al cuantil del $5 \%$ para el valor admisible del riesgo individual medio por año para las clases de consecuencias CC2 y CC3, respectivamente $\beta_{t, I R}=4,6$ y $\beta_{t, I R}=5,1$ (Tabla 8.6), son casi idénticos a los índices de fiabilidad requeridos en el Eurocódigo [EN 1990 2002] para los estados límite últimos y el mismo período de referencia de 1 año: respectivamente $\beta_{t 1}=4,7$ y $\beta_{t 1}=5,2$ (Tabla 3.6). De la Tabla 8.6 se deduce que estos índices de fiabilidad corresponden a un valor admisible para el riesgo individual medio de $r_{I R, a d m}=10^{-7}$ por año, como máximo, mientras que los límites de aceptación suelen situarse uno o dos órdenes de magnitud por encima de este valor, tal y como se menciona con anterioridad. Por todo ello, unos índices de fiabilidad requeridos, asociados con un riesgo individual medio del orden de $10^{-6}$ a $10^{-5}$ por año, pueden considerarse como un requisito razonable para la seguridad estructural, aunque se podría hacer una distinción entre el dimensionado de estructuras nuevas y la evaluación de las existentes, en consonancia con las recomendaciones holandesas anteriormente mencionadas [Vrijling 2005] y otras propuestas similares. Este aspecto se retoma brevemente en el Apartado 8.3.5.

\subsubsection{Criterios de aceptación de los riesgos colectivos}

\section{Generalidades}

Es frecuente y generalmente aceptado el empleo de los diagramas frecuencia - consecuencias para cuantificar los riesgos colectivos para las personas. Estos diagramas, o curvas $F$-n, se describen en el Apartado 2.3.3 donde también se incluye la correspondiente definición matemática del criterio de aceptación de los riesgos. Además, se identifican, y se resumen en el Apartado 2.4, los problemas relacionados con este tipo de criterios de aceptación que están disponibles en la literatura especializada:

- los criterios de aceptación no suelen estar asociados con un sistema de referencia claramente definido;

- la aversión de la sociedad frente a los riesgos dificulta una definición racional de los límites de aceptación; 
- la ausencia de modelos fiables para estimar el número de víctimas de los colapsos estructurales;

- la relación desconocida entre los criterios de aceptación y las incertidumbres asociadas con las variables que intervienen en los análisis.

Estos problemas se pueden obviar empleando como criterio de aceptación los riesgos nominales obtenidos en el presente estudio (Figura 8.8): el sistema de referencia se introduce a través de la superficie útil total, $A$; los riesgos aceptables obtenidos corresponden a la mejor práctica actual que cambiaría rápidamente si los resultados que conlleva suscitaran aversión social (Apartado 4.1.2); para la deducción de los criterios de aceptación se estima el número de víctimas de los colapsos mediante el modelo empírico deducido en el Capítulo 7; finalmente, las incertidumbres asociadas con las variables están establecidas en el Capítulo 6.

Por otro lado, la representación de los riesgos nominales según la Figura 8.8 es específica del presente estudio y no tiene el carácter universal que se les asigna a los diagramas $F-n$. Además, los resultados se refieren exclusivamente a las estructuras de edificación. Por estos motivos, los riesgos nominales de la Figura 8.8 no se pueden comparar directamente con los riesgos asociados con otros sistemas o actividades. Este inconveniente se puede resolver utilizando los resultados obtenidos en el presente estudio para deducir unos criterios de aceptación del riesgo colectivo en términos de la condición (2.7) que define las curvas frecuencia - consecuencias. A estos efectos, se adopta un valor constante de $\alpha=2$ para la pendiente de las curvas, respetando el criterio dominante en la literatura especializada [ISO 2394 1998, CIB 259 2001, Vrijling 2005]. Con esta hipótesis, únicamente queda por determinar la frecuencia anual admisible para los colapsos estructurales con una o más víctimas mortales, $F(1)$. En términos generales, este parámetro debe ser consistente con el sistema de referencia al que se le aplica el criterio de aceptación, ya que refleja el efecto escala (Apartado 2.3.3). Además, para evitar decisiones poco racionales, los criterios de aceptación también deben ser consistentes con el número esperado de víctimas mortales, $E(N)$, asociado con el sistema y el período de referencia considerados [Kroon 2008]. Para un determinado criterio de aceptación en términos de un diagrama $F-n, E(N)$ equivale al área por debajo de la curva frecuencia - consecuencias y se obtiene a partir de la ecuación (8.4), siendo $F(n)$ la frecuencia según lo establecido en el Apartado 2.3.3:

$$
E(N)=\int F(n) \cdot d n
$$

Para los diagramas F-n con valores $\alpha>1$, la ecuación (8.5) constituye una solución aproximada de la integral (8.4) [CIB 259 2001], permitiendo una determinación suficientemente precisa del número esperado de víctimas mortales:

$$
E(N) \cong F(1) \cdot \frac{\alpha}{\alpha-1}
$$

Por otro lado, la Figura 8.8 representa los riesgos aceptables para las personas, $R$, en función de la superficie útil total, $A$, para un período de referencia de 50 años. El riesgo admisible para un determinado sistema, representado por $A$, se puede expresar en términos del correspondiente valor medio, $R_{m}$, o de un determinado cuantil, por ejemplo $R_{k, 5}$ ó $R_{k, 95}$ (Apartado 8.3.2). Igual que en el caso de los riesgos individuales (Apartado 8.3.3), resulta más práctico traducir estos valores a un período de referencia de un año:

$$
R_{1 y} \cong \frac{R_{50 y}}{50}
$$

$R_{n y} \quad$ : riesgo colectivo para las personas, asociado con el sistema analizado, para un período de referencia de $n$ años 
El riesgo colectivo $R_{1 y}$ representa el número admisible de víctimas mortales por año, asociado con el sistema de referencia considerado, caracterizado a su vez por medio de la superficie útil total, $A$. $R_{1 y}(A)$ también puede expresarse en términos de su valor medio, en función de la superficie, o de un determinado cuantil, por ejemplo del $5 \%$ y del $95 \%$. El riesgo colectivo $R_{1 y}(A)$ equivale al número esperado de víctimas mortales, $E(N)$, asociado con el sistema y el período de referencia considerados. La sustitución de la ecuación (8.6) en la ecuación (8.5) permite establecer la relación entre los diagramas F-n (Apartado 2.3.3) y los resultados obtenidos en el presente estudio para los riesgos admisibles (Apartado 8.3.2):

$$
R_{1 y}(A) \cong F(1) \cdot \frac{\alpha}{\alpha-1}
$$

La ecuación (8.7) permite determinar la frecuencia anual admisible para los colapsos estructurales con una o más víctimas mortales, $F(1)$, en función de la superficie útil total, $A$. Conocidos los valores de $F(1)$ así como $\alpha$, el criterio de aceptación de los riesgos colectivos queda establecido a través de la condición (2.7), para el sistema de referencia considerado, representado a través de la superficie útil total, $A$. El procedimiento adoptado para la determinación de $F(1)$ permite asegurar una consistencia completa entre los criterios de aceptación de los riesgos colectivos e individuales (Apartado 8.3.3), ya que ambos están basados en los riesgos nominales obtenidos según la mejor práctica actual (Apartado 8.3.2).

\section{Riesgos para las personas}

Para un conjunto de sistemas de referencia, constituidos por estructuras de edificios pertenecientes a la clase de consecuencias CC2 y caracterizados mediante la superficie útil total, $A$, la Figura 8.11 representa los diagramas $F-n$ obtenidos según el anterior procedimiento. Estos diagramas corresponden a los criterios de aceptación de los riesgos colectivos para un período de referencia de un año. En el caso de la Figura 8.11a), están basados en el valor medio del riesgo anual para las personas según la mejor práctica actual, $R_{m, 1 y}$, mientras que los de la Figura $8.11 \mathrm{~b}$ ) se refieren al cuantil del $95 \%$ del riesgo anual, $R_{k, 95,1 y}$. En principio, se podría adoptar cualquiera de los dos conjuntos de diagramas $F$ - $n$ como criterio de aceptación, dependiendo de si se considera como nivel aceptable el valor esperado o un cuantil superior de los riesgos nominales obtenidos en el presente estudio (Apartado 8.3.2). Todo ello en analogía con los criterios de aceptación de los riesgos individuales (Apartado 8.3.3). La selección del nivel aceptable de los riesgos se vuelve a abordar muy brevemente en el Apartado 8.3.5.

El efecto escala relacionado con la superficie útil total de los edificios, $A$, particularmente visible en la Figura 8.8, también se manifiesta en el presente contexto, a través de unas frecuencias acumuladas, $F(N \geq n)$, que crecen con las dimensiones del sistema de referencia, caracterizadas a su vez en términos de $A$. Si los criterios de aceptación de los riesgos colectivos relacionados con las estructuras de edificación se definen a nivel nacional, el sistema de referencia está constituido por todas las estructuras del país, dimensionadas según un determinado conjunto de normas. En este contexto parece razonable asumir que el intervalo de renovación de las normas estructurales sea de aproximadamente 10 años. Considerando, además, la década entre 1999 y 2008, que incluye los años del boom inmobiliario en España, la construcción de edificios pertenecientes a la clase de consecuencias CC2 alcanza en promedio una superficie útil total de $A=8,15 \times 10^{7} \mathrm{~m}^{2}$ por año, según datos del Ministerio de Fomento [MFOM 2008]. Para este sistema de referencia, el valor medio de las víctimas mortales por año que resulta aceptable, $R_{m, 1 y}$, es de aproximadamente 3 . La correspondiente frecuencia, $F(1)$, alcanza un valor de 1,47. Este resultado se debe interpretar en el sentido de que a nivel nacional es aceptable que se produzcan cada año entre uno y dos colapsos estructurales con una o más víctimas mortales [Tanner 2015]. El diagrama F-n correspondiente a las anteriores hipótesis está representado por la curva superior de la Figura 8.11a). Si se admite un riesgo anual para las 
personas correspondiente al cuantil del $95 \%, R_{k, 95,1 y}$, las frecuencias de los eventos con $n$ o más víctimas mortales que resultan aceptables en el mismo período de tiempo, $F(N \geq n)$, superan a las anteriores en aproximadamente un orden de magnitud, tal y como se desprende de la Figura 8.11b).

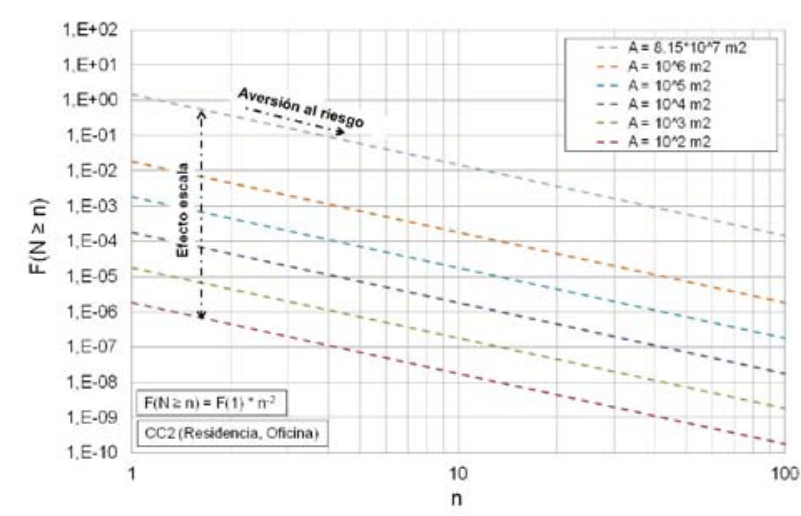

a)

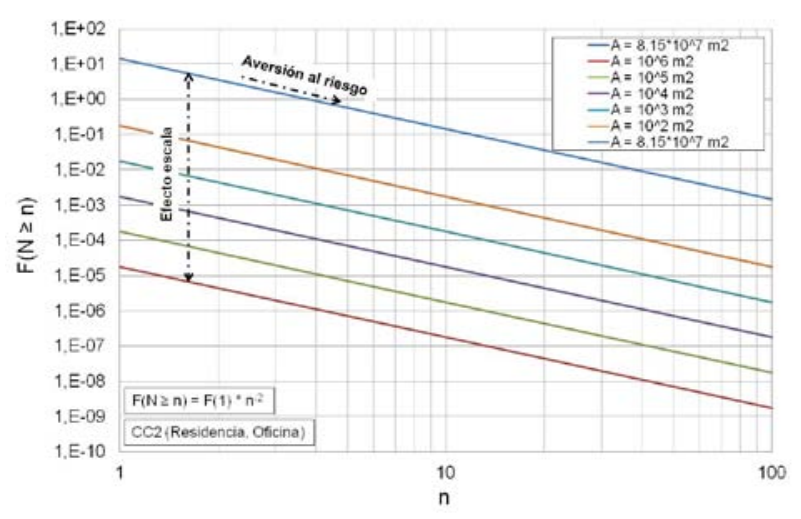

b)

Figura 8.11 - Criterios de aceptación de los riesgos anuales para estructuras de edificios de la clase de consecuencias CC2 con diferentes valores de la superficie útil total, A: a) diagramas F-n basados en el valor medio del riesgo colectivo por año, $\left.R_{m, 1 y} ; b\right)$ diagramas $F-n$ basados en el cuantil del $95 \%, R_{k, 95,1 y}$.

La Figura 8.11 representa los criterios de aceptación de los riesgos anuales también para otros sistemas de referencia constituidos por estructuras de edificios de la clase CC2, variando la superficie útil total, $A$, entre $10^{2} \mathrm{~m}^{2}$ y $10^{6} \mathrm{~m}^{2}$. A título de ejemplo, un bloque de viviendas puede tener una superficie útil del orden de $10^{3} \mathrm{~m}^{2}$, mientras que la de una gran urbanización puede superar los $10^{5}$ $\mathrm{m}^{2}$. De manera análoga, la Figura 8.12 refleja los criterios de aceptación para las estructuras de los edificios de la clase de consecuencias CC3. En este caso se desconoce la superficie media construida anualmente a nivel nacional. No obstante, cabe destacar que las frecuencias aceptables de los colapsos con víctimas mortales, $F(N \geq n)$, superan a las obtenidas para CC2, lo que es consecuencia directa del hecho de que los riesgos nominales implícitamente aceptados son mayores para las estructuras de los edificios de la clase CC3 que para la clase CC2 (Apartado 8.3.2).

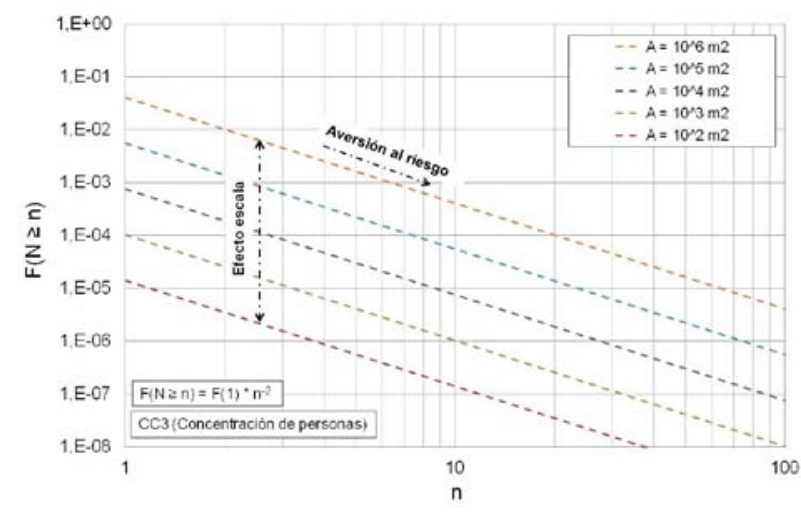

a)

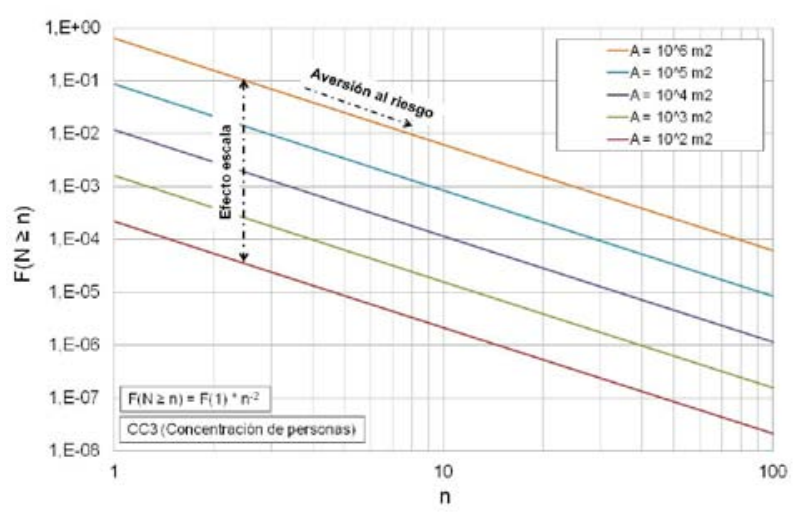

b)

Figura 8.12 - Criterios de aceptación de los riesgos anuales para estructuras de edificios de la clase de consecuencias CC3 con diferentes valores de la superficie útil total, A: a) diagramas F-n basados en el valor medio del riesgo colectivo por año, $\left.R_{m, 1 y} ; b\right)$ diagramas $F-n$ basados en el cuantil del $95 \%, R_{k, 95,1 y}$. 


\section{Niveles de fiabilidad}

Con el fin de deducir las probabilidades de fallo objetivo, basadas en los riesgos colectivos admisibles, $p_{f t, S R}$, se interpreta la relación (2.8) en términos de ecuación. Según la práctica actual, estas probabilidades se refieren a los mecanismos de fallo de los elementos estructurales. Para la determinación de la frecuencia $F(1)$, que interviene en la citada ecuación, es por ello necesario reducir el sistema de referencia del nivel de las estructuras al nivel de los elementos estructurales individuales que las constituyen, considerando los escenarios de riesgo relevantes que, según la definición adoptada en el presente trabajo (Apartado 4.2.2), corresponden a los mecanismos de fallo de estos elementos para las condiciones contempladas. Para ello se pueden emplear los resultados de la Figura 8.10 que representa el número de víctimas mortales por escenario que, para un período de referencia de 50 años, resultaría aceptable según la mejor práctica actual. El límite de aceptación se puede fijar en el nivel del valor medio, $\left(R / n_{s c}\right)_{m}$, o de un determinado cuantil, por ejemplo $\left(R / n_{s c}\right)_{k, 5}$ ó $\left(R / n_{s c}\right)_{k, 95}$ (Apartado 8.3.2). También en este caso, los valores se convierten por motivos prácticos a un período de referencia de un año:

$\left(R / n_{s c}\right)_{1 y} \cong \frac{\left(R / n_{s c}\right)_{50 y}}{50}$

$\left(R / n_{s c}\right)_{n y}$ : riesgo colectivo para las personas, normalizado con el número total de escenarios relevantes para la estructura del edificio, para un período de referencia de $n$ años

La frecuencia anual, aceptable según la mejor práctica actual, de las roturas de elementos estructurales que conllevan una o más víctimas mortales, $F(1)$, se obtiene mediante la ecuación (8.5). En analogía con lo especificado anteriormente, a estos efectos se sustituye $E(N)$ por el riesgo normalizado medio, $\left(R / n_{s c}\right)_{m, 1 y}$, o el correspondiente a un cuantil del $95 \%,\left(R / n_{s c}\right)_{k, 95,1 y}$, según el caso. Asumiendo nuevamente $\alpha=2$, se obtienen los diagramas $F-n$ normalizados que representan las frecuencias aceptables, $F(N \geq n)$, para la rotura, con consecuencias fatales, de los elementos constitutivos de las estructuras de edificación. Los diagramas obtenidos están reflejados en la Figura 8.13 .

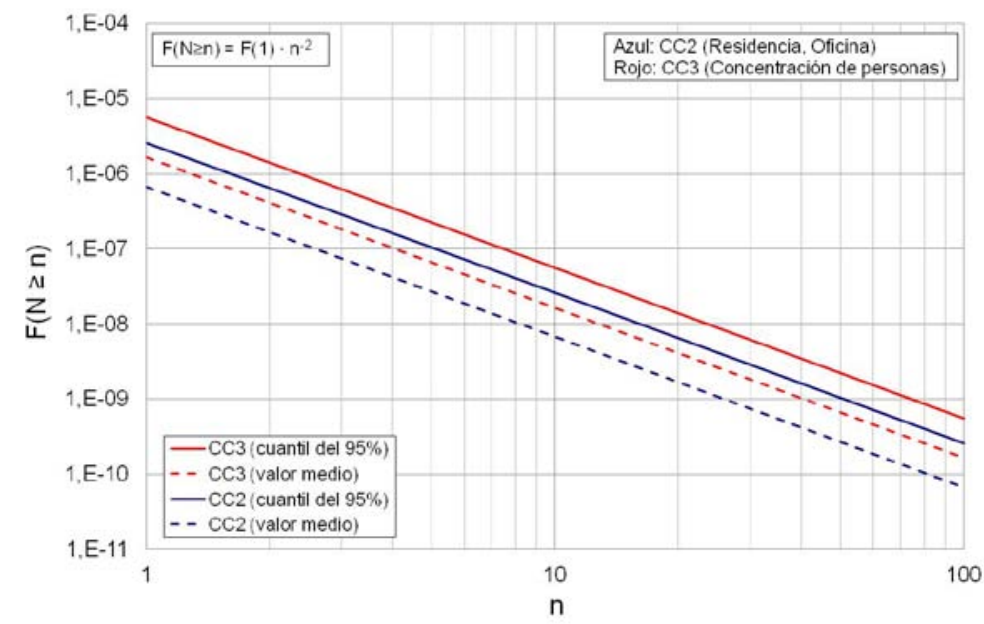

Figura 8.13 - Criterios de aceptación de los riesgos anuales para los elementos constitutivos de las estructuras de edificios de las clases de consecuencias CC2 y CC3, basados en el riesgo normalizado medio, $\left(R / n_{s c}\right)_{m, 1 y}$, y el correspondiente a un cuantil del $95 \%,\left(R / n_{s c}\right)_{k, 95,1 y}$.

Las frecuencias aceptables de los colapsos con víctimas mortales, $F(N \geq n)$, resultan mayores para los elementos pertenecientes a las estructuras de los edificios de la clase CC3, en comparación con los de la clase CC2. La diferencia se debe al hecho de que los riesgos nominales implícitamente aceptados 
son mayores para las estructuras de los edificios de la clase CC3 que para la clase CC2 (Apartado 8.3.2). En ambas categorías las frecuencias aceptables, $F(N \geq n)$, son naturalmente mayores si están basadas en el cuantil del $95 \%$ del riesgo normalizado, $\left(R / n_{s c}\right)_{k, 95,1 y}$, que si se adopta el valor medio, $\left(R / n_{s c}\right)_{m, 1 y}$. También cabe destacar que las frecuencias $F(1)$ basadas en $\left(R / n_{s c}\right)_{m, 1 y}$ se aproximan a valores del orden de $10^{-6}$ por año, mientras que las frecuencias basadas en el cuantil del $95 \%$, $\left(R / n_{s c}\right)_{k, 95,1 y}$, convergen con $10^{-5}$ por año. Estos resultados son consistentes con los obtenidos para el riesgo individual, $r_{I R, a d m}$ (Apartado 8.3.3), lo que no es sorprendente ya que en ambos casos se utilizan los mismos datos de partida: los riesgos nominales obtenidos según la mejor práctica actual (Apartado 8.3.2).

Finalmente, para la determinación de las probabilidades de fallo objetivo, basadas en el riesgo colectivo admisible, $p_{f t, S R}$, se necesita conocer la probabilidad condicional de que el colapso de un determinado elemento produzca $N \geq n$ víctimas mortales, $p_{N \mid f}$. A falta de datos específicos al respecto, se sustituye $p_{N \mid f}$ por la probabilidad condicional de fallecimiento de una persona, dado el colapso, $p_{c \mid f}$ (Apartado 8.3.3), lo que es una hipótesis conservadora. Introduciendo en la parte derecha de la condición (2.8) los valores adoptados para esta probabilidad condicional, respectivamente para las clases CC2 y CC3, conjuntamente con los pertinentes valores para $F(1)$ y $\alpha$, se obtienen las probabilidades de fallo objetivo, $p_{f t, S R}$, en función de la clase de consecuencias y el número de víctimas mortales, $n$. No obstante, es más conveniente representar los requisitos de fiabilidad estructural en función de la superficie afectada por el colapso del elemento considerado, $A_{c o l}$, tal y como apuntan también otros autores [Sykora 2013, Steenbergen 2015]. A través de los modelos de consecuencias para las clases CC2 y CC3, representados respectivamente en las ecuaciones (7.1) y (7.2), el número de víctimas, $n$, se convierte en la superficie, $A_{c o l}$. Finalmente, mediante la inversa de la función de distribución normal estándar, las probabilidades de fallo objetivo, $p_{f t, S R}$, se transforman en valores requeridos del índice de fiabilidad asociados con el riesgo colectivo, $\beta_{t, S R}$, que a su vez se representan en función de la superficie $A_{\text {col }}$ (Figura 8.14).

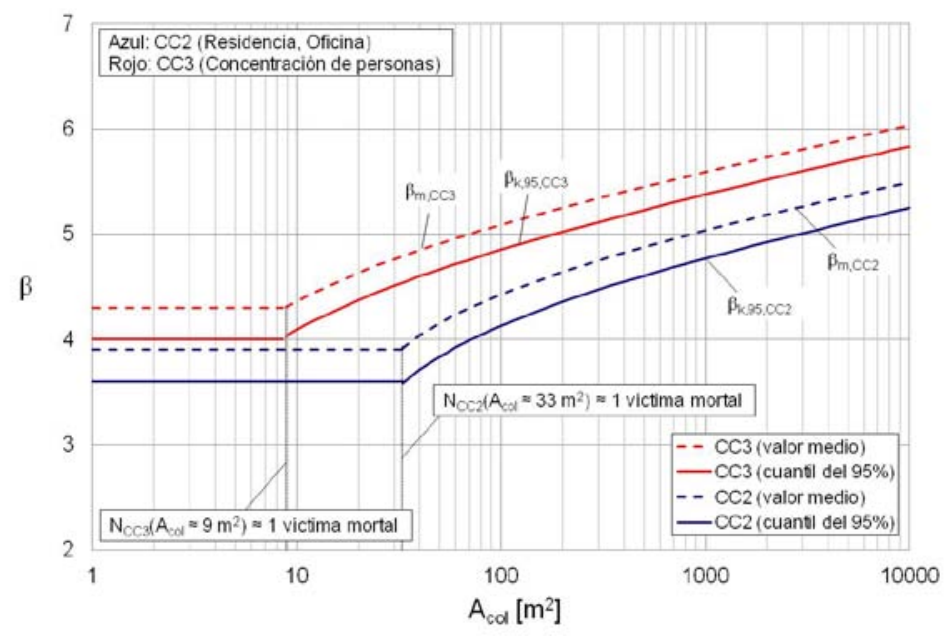

Figura 8.14 - Índice de fiabilidad requerido para un período de referencia de un año, $\beta_{t 1}$, en función de la superficie afectada por el colapso, $A_{\text {col }}$, para los elementos constitutivos de las estructuras de edificios de las clases de consecuencias CC2 y CC3, basado en el valor esperado del riesgo asociado con la mejor práctica actual y el correspondiente a un cuantil del 95\%.

Para un período de referencia de un año, la Figura 8.14 representa los diagramas $\beta_{t, S R}-A_{c o l}$ que son consistentes con el riesgo normalizado medio asociado con la mejor práctica actual, $\left(R / n_{s c}\right)_{m, 1 y}$, y el correspondiente a un cuantil del $95 \%,\left(R / n_{s c}\right)_{k, 95,1 y}$, tanto para los elementos constitutivos de las estructuras de edificios de la clase de consecuencias CC2 como de la clase CC3. A pesar de que las 
frecuencias aceptables de los colapsos con víctimas mortales, $F(N \geq n)$, son mayores para los elementos de la clase CC3 que para los de la clase CC2 (Figura 8.13), los requisitos de fiabilidad estructural en términos de $\beta_{t, S R}$ son más restrictivos para los primeros. Este resultado se debe a la anterior hipótesis de que la probabilidad condicional $p_{N \mid f}$ sea mayor para la clase de consecuencias CC3 que para la clase CC2.

Los diagramas $\beta_{t, S R^{-}} A_{c o l}$ se interceptan con unas líneas horizontales que representan los respectivos índices de fiabilidad asociados con el riesgo individual, $\beta_{t, I R}$, resumidos en la Tabla 8.6. Según los resultados obtenidos, los requisitos de fiabilidad estructural asociados con el riesgo individual son determinantes si la superficie afectada por el colapso del elemento considerado está por debajo de los $33 \mathrm{~m}^{2}$ en el caso de la clase CC2, mientras que este límite se sitúa en $9 \mathrm{~m}^{2}$ para los elementos de la clase CC3. Teniendo en cuenta los modelos de consecuencias (Apartado 7.4.2), empleados para establecer la relación entre $n$ y $A_{c o l}$, se constata que, en el caso de un colapso afectando a superficies de estas dimensiones, el número esperado de víctimas mortales sería muy aproximadamente uno. Los puntos de transición entre los requisitos de fiabilidad estructural basados en los riesgos individual y colectivo, respectivamente, parecen por ello verosímiles.

\subsubsection{Observaciones finales}

Los resultados obtenidos en el presente apartado sobre los riesgos aceptables para las personas, asociados con las estructuras de edificación, parecen plausibles. Eso a pesar de que las frecuencias, las probabilidades y los riesgos establecidos deben considerarse en primer lugar como valores nominales, tal y como se menciona con anterioridad. No obstante, guardan relación con la realidad debido a que las estructuras analizadas son realistas (Apartado 5.3), los modelos que intervienen en los cálculos de las probabilidades de fallo representan las características físicas de las variables correspondientes (Capítulo 6) y se emplean modelos empíricos para las consecuencias, basados en datos de colapsos reales (Capítulo 7). El orden de magnitud de los valores deducidos para los riesgos aceptables, asociados con la mejor práctica actual, es por ello significativo y los resultados pueden emplearse para definir unos requisitos para la seguridad estructural, basados en los riesgos para las personas. Aunque la consideración de las cuestiones económicas está fuera del alcance del presente trabajo (Apartado 1.2), un aspecto a tener en cuenta en este contexto es el hecho de que un incremento de los requisitos de fiabilidad estructural implica menores costes en la fase de dimensionado de las estructuras nuevas que en estructuras existentes [Steenbergen 2010]. Es por ello razonable aceptar unos riesgos mayores para la evaluación de las estructuras existentes que para el dimensionado de las de nueva construcción.

De acuerdo con las anteriores consideraciones y dado que, según las hipótesis del presente trabajo, son aceptables los riesgos individuales y colectivos correspondientes a un cuantil superior, por ejemplo del 95\%, de los riesgos asociados con la mejor práctica actual, se propone adoptar estos valores característicos superiores como criterio de aceptación de los riesgos para las personas en relación con las estructuras existentes. Los correspondientes valores admisibles para los riesgos individual (Tabla 8.6) y colectivos (Figuras 8.11b) y 8.12b), así como las líneas continuas en la Figura 8.13) pueden por ello adoptarse como criterios de aceptación en una evaluación estructural mediante métodos explícitos de análisis de riesgo. Los correspondientes valores requeridos del índice de fiabilidad, representados por las líneas continuas en la Figura 8.14, pueden usarse como criterio de aceptación para la evaluación de las estructuras existentes mediante métodos más convencionales (Capítulo 3).

Por otro lado, con el fin de cubrir las inevitables dispersiones en los procesos de dimensionado y construcción, como criterio de aceptación para las estructuras nuevas deberían adoptarse los valores medio de los riesgos individual y colectivos, asociados con la mejor práctica actual (Tabla 8.6; 
Figuras 8.11a) y 8.12a), así como las líneas discontinuas en la Figura 8.13). Los valores requeridos del índice de fiabilidad, asociados con estos riesgos aceptables y representados a través de las líneas discontinuas de la Figura 8.14, pueden emplearse para la calibración de los coeficientes parciales para el dimensionado de las estructuras de nueva construcción. En este contexto cabe recordar que, según los resultados del presente estudio, el valor esperado del riesgo individual medio, asociado con la mejor práctica actual en el campo de las estructuras de edificación, es del orden de $10^{-6}$ por año, mientras que el valor del cuantil superior del $95 \%$ es de aproximadamente $10^{-5}$ por año (Apartado 8.3.3). Consecuentemente, según las anteriores consideraciones, para las estructuras existentes se aceptaría un riesgo individual que supera en un orden de magnitud al correspondiente valor objetivo para las estructuras de nueva construcción. Para los criterios de aceptación de los riesgos colectivos, la diferencia también es de un orden de magnitud (Apartado 8.3.4).

\subsection{CONCLUSIONES}

El presente capítulo está dedicado al establecimiento de unos requisitos de seguridad estructural racionales que, de acuerdo con el enfoque del presente estudio (Capítulo 4) y en consonancia con la nueva edición de la norma internacional sobre la fiabilidad estructural [ISO/FDIS 2394 2014], se deducen a partir de las prestaciones requeridas según la mejor práctica actual (Best Current Practice, BCP). A su vez, estas prestaciones se obtienen mediante la inferencia del nivel de fiabilidad implícito a la normativa que está en vigor o, más adecuadamente, del nivel de riesgo asociado, según el Paso 6 del procedimiento definido en el Apartado 4.5.

En el Apartado 8.2 se determina el nivel de fiabilidad implícitamente requerido por el Código Técnico de la Edificación y el Eurocódigo, que son equivalentes a efectos del presente estudio. Los resultados se representan en términos de los índices de fiabilidad, $\beta$, y las correspondientes probabilidades de fallo, $p_{f}$, para un período de referencia de 50 años, por separado para los mecanismos de fallo representativos de los elementos constituidos por los diferentes materiales considerados en este estudio: acero estructural, hormigón armado, mixtos de acero y hormigón, así como madera laminada encolada.

Los resultados obtenidos en el presente trabajo se comparan con los de un estudio nórdico [SAKO 1999], una de las escasas investigaciones relacionadas. Esta comparación se realiza con cautela, teniendo debidamente en cuenta las diferencias entre ambos estudios en cuanto a contexto, campo de aplicación, alcance e hipótesis (Apartado 8.2.1). A pesar de estas importantes diferencias, los resultados son comparables, tanto cualitativamente como cuantitativamente (Apartados 8.2.2 y 8.2.3), lo que pese a todas las reservas contribuye a la plausibilidad del enfoque y las hipótesis adoptados en el marco de este estudio, así como de los resultados obtenidos. Estos ponen de manifiesto la existencia de grandes diferencias entre los valores medio de la probabilidad de fallo implícitamente aceptada o, lo que es equivalente, los índices de fiabilidad requeridos, dependiendo del material constitutivo de la estructura, el tipo de elemento estructural y el mecanismo de fallo (Apartado 8.2.6). Además, para un mecanismo de fallo específico de un tipo de elemento constituido por un material determinado, los resultados reflejan unas dispersiones muy importantes en el nivel de fiabilidad implícitamente requerido. Como consecuencia, para una cierta fracción de los elementos estudiados, este nivel está por debajo del índice de fiabilidad nominalmente exigido por la normativa que está en vigor. Por ejemplo, en el caso de las vigas de cubierta fabricadas de acero estructural, esta fracción alcanza el 37\%. Para otros tipos de elementos y materiales, aunque menor, el correspondiente porcentaje tampoco es despreciable.

Evidentemente, no es de esperar que los índices de fiabilidad o las correspondientes probabilidades de fallo de los elementos estructurales dimensionados de manera estricta según un conjunto 
consistente de normas, es decir, el nivel de fiabilidad implícitamente requerido por estas normas, estén dentro de unos límites estrechos. No obstante, tanto las dispersiones del nivel de fiabilidad requerido, cuantificadas en términos de los coeficientes de variación para las probabilidades de fallo implícitamente aceptadas, $v_{p f}$, como las diferencias de los valores medio de estas probabilidades, $\mu_{p f}$, en función del material, tipo de elemento y mecanismo de fallo (Tabla 8.5), ponen de manifiesto los problemas asociados con los requisitos de fiabilidad estructural de las normas que están actualmente en vigor (Apartado 1.1.2). Para mejorar esta situación, no es suficiente con considerar únicamente la frecuencia de ocurrencia de los colapsos estructurales, en términos de probabilidades de fallo o índices de fiabilidad. También se deben tener en cuenta las consecuencias esperadas, por ejemplo para las personas como en el marco de este estudio, en caso de producirse estos colapsos.

La inferencia del nivel aceptable de los riesgos para las personas según la mejor práctica actual es objeto del Apartado 8.3. Siguiendo el procedimiento establecido (Apartado 4.5) y utilizando los diferentes modelos determinados en los Capítulos 4, 6 y 7, se determinan los riesgos nominales asociados con los 19.008 sistemas estructurales previamente seleccionados (Apartado 5.3), correspondientes a edificios de las clases de consecuencias CC2 (10.872) y CC3 (8.136). A partir de estos resultados se deducen unos valores admisibles de los riesgos anuales para las personas, respectivamente a nivel individual y colectivo, distinguiendo entre estructuras de edificios de las dos clases de consecuencias consideradas, pero no entre estructuras de distintos materiales constitutivos. Por el contrario, se establecen diferentes criterios de aceptación para la evaluación de las estructuras existentes y el dimensionado de las de nueva construcción, respectivamente. Esta diferenciación es razonable debido a que la reducción de los riesgos asociados con las estructuras existentes presenta a menudo más dificultades que en estructuras de nueva construcción, con unos costes de las medidas necesarias que pueden resultar desproporcionados en relación con las mejoras alcanzadas.

Para las estructuras existentes se propone un nivel aceptable del riesgo individual de $10^{-5}$ por año, mientras que para el dimensionado de las estructuras de nueva construcción se recomienda un valor objetivo de $10^{-6}$ por año. Según los resultados obtenidos en este estudio, los dos límites corresponden, respectivamente, al cuantil superior del 95\% y al valor esperado del riesgo individual medio, asociado con la mejor práctica actual (Apartado 8.3.3). De manera equivalente, los criterios de aceptación para los riesgos colectivos, representados en términos de diagramas frecuencia - consecuencias, $F-n$, también se diversifican, en función de si se usan para evaluar o dimensionar, con una diferencia de un orden de magnitud (Apartado 8.3.4). Los diagramas F-n se establecen para diferentes sistemas de referencia, abarcando desde la totalidad de las estructuras de edificación construidas, a nivel nacional, según las reglas establecidas en un determinado conjunto de normas, hasta elementos individuales de estas estructuras.

Los criterios de aceptación de los riesgos para las personas, deducidos en el presente trabajo, se pueden emplear a efectos de comprobaciones de las prestaciones estructurales mediante métodos explícitos de análisis de riesgo. Adicionalmente, estos requisitos se transforman en probabilidades de fallo admisibles y, lo que es equivalente, índices de fiabilidad requeridos. Estos dependen de la superficie afectada por el posible colapso del elemento analizado y la clase de consecuencias del edificio correspondiente, distinguiendo también entre requisitos para el dimensionado de estructuras nuevas y la evaluación de las existentes (Figura 8.14). Los índices de fiabilidad así obtenidos constituyen una base racional para una calibración de los valores de cálculo de las variables que intervienen en un análisis estructural, o de los coeficientes parciales asociados que se emplean en la práctica diaria conjuntamente con los valores característicos de las variables (Capítulo 3). En este contexto cabe mencionar que tanto los criterios de aceptación de los riesgos para las personas, a nivel individual y colectivo (Figuras 8.11b) y 8.12b), como los índices de fiabilidad requeridos (líneas continuas en la Figura 8.14), deducidos en el presente trabajo y publicados en la literatura 
especializada [Tanner 2015], están recogidos en el documento europeo sobre la evaluación de las estructuras existentes [JRC 2015]. Este documento constituye algo como un germen de un futuro Eurocódigo sobre la materia que se va a desarrollar durante los próximos años. 


\section{OBSERVACIONES FINALES}

\subsection{INTRODUCCIÓN}

El proyecto y la explotación de los sistemas técnicos en general, y de las estructuras de ingeniería civil en particular, siempre implican la consideración de los aspectos de seguridad. Según la práctica actual, en los proyectos de ingeniería estructural este tema se aborda de manera implícita, enfoque que no permite justificar que los riesgos inherentes a una determinada estructura se mantengan por debajo de un determinado umbral de aceptación. Las normas para el proyecto de las estructuras de nueva construcción que están en vigor, normalmente ni siquiera establecen este umbral de los riesgos aceptados. También escasean criterios consistentes para la evaluación de la fiabilidad de las estructuras existentes. Por otro lado, los riesgos asociados con las estructuras de ingeniería civil, dimensionadas según las reglas de las normas actuales, están afectados por dispersiones importantes.

Debido a la importancia de estas insuficiencias y lagunas en los reglamentos actuales, el objetivo de esta tesis doctoral consiste en el desarrollo de unos métodos, modelos y requisitos que constituyan una base racional para la adopción de decisiones en relación con la fiabilidad de las estructuras, y que faciliten no solamente el dimensionado estructural basado en prestaciones, sino también la evaluación de las estructuras existentes. A pesar de que, según los principios de la nueva edición de la norma internacional sobre la fiabilidad estructural [ISO/FDIS 2394 2014], estrictamente no es necesario definir un nivel aceptable de los riesgos para las personas, en la opinión de los científicos sociales contactados en una encuesta $a d h o c$, no es razonable pensar que los usuarios y el público en general aceptarían unas frecuencias anuales de colapsos estructurales mayores que las asociadas con la mejor práctica actual (Best Current Practice, BCP). Ni siquiera disponiendo de una base racional, como pueden ser unos requisitos de seguridad estructural correspondientes al valor óptimo del costo equivalente para evitar una víctima mortal, ICAF (Apartado 2.3.5), la sociedad aceptaría un aumento de la frecuencia de los colapsos. En efecto, la citada norma [ISO/FDIS 2394 2014], que se orienta en los principios de los análisis coste - beneficio del tipo de $I C A F$, establece que una actividad aceptable según estos principios, también debería ser evaluada respecto al nivel asociado de los riesgos para las personas. La implementación práctica de los métodos basados en el ICAF utilizando el índice de calidad de vida (Life Quality Index, LQI) requiere por ello la especificación de unos valores aceptables de los riesgos para las personas. El presente trabajo aborda precisamente esta temática, lo que es necesario y oportuno ya que las normas existentes sobre fiabilidad estructural, incluida la más reciente [ISO/FDIS 2394 2014], no contienen información consistente al respecto.

Teniendo en cuenta que en un contexto técnico el término riesgo se refiere a una previsión matemática de las consecuencias de un evento no deseado, se identifican los siguientes temas de estudio para alcanzar el objetivo del trabajo:

- Métodos de análisis de riesgo explícitos e implícitos: examen de los principios básicos de los métodos explícitos de análisis de riesgo y de su relación con el tratamiento implícito de los aspectos de seguridad y fiabilidad en la ingeniería estructural.

- Metodología e hipótesis: definición de un procedimiento adecuado para el análisis de los riesgos asociados con las estructuras, vinculando los dos tipos de métodos, explícitos e implícitos, que actualmente están disponibles en un contexto técnico.

- Incertidumbres: desarrollo de modelos probabilistas, aptos para aplicaciones prácticas, en relación con las variables que intervienen en un análisis estructural.

- Consecuencias: desarrollo de modelos matemáticos, aptos para aplicaciones prácticas, para las consecuencias de los fallos estructurales.

- Requisitos: determinación de las prestaciones requeridas de las estructuras de ingeniería. 
Los estudios se realizan para estructuras de edificación, constituidas por elementos de acero estructural, hormigón armado, mixtos de acero y hormigón, así como madera laminada encolada, expuestas a las denominadas situaciones persistentes [EN 1990 2002, CTE DB SE 2006]. Otras limitaciones del alcance del trabajo se refieren a los eventos no deseados ya que se consideran únicamente los posibles colapsos de las estructuras, parciales o totales, sin tener en cuenta otros tipos de fallos, tales como comportamientos inadecuados en servicio o problemas de durabilidad. Esta limitación, a su vez, es consistente con la representación de las consecuencias de estos eventos, a través de la pérdida de vidas humanas. No se consideran otras consecuencias adversas de los colapsos, por ejemplo pérdidas económicas o daños medioambientales, debido a que el presente trabajo se centra, por los motivos arriba mencionados, en los riesgos para las personas que son dominantes en ingeniería civil, tanto por razones éticas como legales.

Este capítulo final de la tesis cubre los siguientes aspectos:

- metodología adoptada para el desarrollo del trabajo y resultados obtenidos (Apartado 9.2);

- resumen de las conclusiones más relevantes (Apartado 9.3);

- propuestas para trabajos futuros (Apartado 9.4).

\subsection{DESARROLLOS Y RESULTADOS}

\section{Enfoque}

Los resultados de un análisis de riesgo se deben comparar con un requisito de seguridad, en vista de la adopción de una decisión sobre la aceptación del sistema analizado. En este contexto, se puede asumir que en la ingeniería estructural el nivel de los riesgos asociados con la mejor práctica actual (Best Current Practice, $B C P$ ) resulte aceptable y, además, se aproxime a un óptimo. Eso por la combinación de las siguientes circunstancias (Apartado 4.1.2):

- La práctica cambiaría rápidamente si los fallos estructurales fueran demasiado frecuentes [Schneider 1997].

- Aunque en teoría cabe la posibilidad de que se pudiera elevar el nivel de los riesgos, sería difícil cambiar la práctica actual relajando el nivel de exigencia para las estructuras, ya que estas se suelen optimizar en el marco de las normas empleadas y, además, su dimensionado a menudo no está gobernado por los requisitos de seguridad estructural sino por criterios de aptitud al servicio o de tipo constructivo.

Según lo anterior, los riesgos aceptables se pueden fijar en los niveles aceptados de acuerdo con la mejor práctica actual, que queda reflejada en la normativa que está en vigor. Los riesgos aceptables dependen por ello del nivel de fiabilidad requerido implícitamente por estas normas, que a su vez depende del nivel de incertidumbre asociado con las reglas normalizadas.

La primera dificultad que se plantea en relación con este enfoque, aparentemente sencillo, reside en el hecho de que los comités de normalización no suelen establecer explícitamente los modelos probabilistas para todas las variables en los que se basan las reglas de los reglamentos para el dimensionado de las estructuras. El estado de incertidumbre asociado con las normas en vigor es por ello desconocido $\mathrm{y}$, por tanto, se desconocen las incertidumbres asociadas con las estructuras dimensionadas de acuerdo con estos documentos. Además, tampoco se conoce la relación entre estas incertidumbres y los riesgos admisibles según la misma normativa. A todo ello se suman las dudas, arriba mencionadas (Apartado 9.1), sobre cuál debe ser el nivel aceptable de los riesgos.

Los temas que se deben estudiar para conseguir el objetivo de este trabajo, identificados en el Apartado 1.3 y resumidos en el Apartado 9.1, son consecuencia directa de las dificultades asociadas con el enfoque adoptado para el estudio. Naturalmente, también están condicionados por el alcance 
establecido para el estudio (definido en el Apartado 1.2 y resumido en el Apartado 9.1). En el presente apartado se resumen los resultados obtenidos en relación con los diferentes temas estudiados:

- análisis de riesgo explícito e implícito (Capítulos 2 y 3);

- metodología e hipótesis (Capítulos 4 y 5);

- incertidumbres (Capítulo 6);

- consecuencias (Capítulo 7);

- requisitos (Capítulo 8).

\section{Análisis de riesgo explícito e implícito}

Los principios básicos de los métodos explícitos de análisis y gestión de los riesgos tecnológicos y naturales se presentan en el Capítulo 2. Una de las exigencias más importantes a las que deben responder estos métodos es la necesidad de tratar de manera racional lo que algunos autores denominan el dilema "cero multiplicado por infinito" (Apartado 2.1), al abordar el problema de los eventos muy poco frecuentes, en combinación con valores elevados para el daño esperado, en caso de producirse. Resulta crucial, en este contexto, la determinación de los niveles aceptables de los riesgos, respectivamente desde el punto de vista de las personas, en términos económicos, o mediante indicadores sociales. Siendo los riesgos para las personas dominantes en ingeniería civil, en el marco del presente trabajo se considera únicamente el primero de estos requisitos, en concordancia con el objetivo y el alcance establecidos. Finalmente, es importante señalar que en las decisiones sobre la aceptación de los riesgos para las personas se deben tener en cuenta los puntos de vista de, respectivamente, los individuos y la sociedad en su conjunto.

El Capítulo 3 se centra en los métodos más habituales que se emplean en el campo de la ingeniería civil para asegurar que los riesgos asociados con los sistemas estructurales se mantengan en unos niveles considerados como aceptables. Estos métodos se denominan implícitos ya que, contrariamente a los del Capítulo 2, no permiten cuantificar explícitamente los riesgos asociados con un determinado sistema. No obstante, igual que los explícitos, los métodos implícitos también deben considerar las incertidumbres asociadas con los parámetros que intervienen en los análisis estructurales. En el capítulo se presentan diferentes posibilidades para el tratamiento de estas incertidumbres, particularmente el más extendido en la práctica actual, el denominado método de los coeficientes parciales.

Los Capítulos 2 y 3 no se limitan a una revisión de la literatura especializada sobre los principios generalmente aplicables al análisis y la gestión de los riesgos tecnológicos y naturales por un lado, así como el tratamiento de los problemas de seguridad y fiabilidad en la ingeniería estructural, por otro lado. También se explora la posibilidad de la aplicación de los métodos explícitos al tratamiento de los riesgos en el campo de la ingeniería estructural. Además, se establece la relación entre los dos tipos de métodos, explícitos e implícitos, y se identifican los aspectos que en la actualidad no están resueltos de manera satisfactoria. Estos estudios conducen a las siguientes conclusiones principales, relevantes para la continuación del trabajo:

- La relación entre los métodos implícitos y explícitos se puede establecer a través de las probabilidades de fallo estructural, o los correspondientes índices de fiabilidad, que a su vez están relacionados con los riesgos para las personas.

- Los riesgos para las personas dependen de la probabilidad de fallo estructural en un período de tiempo establecido y la probabilidad condicional de que, dado el colapso, se produzcan unas consecuencias de un determinado alcance: en el caso del riesgo individual, esta probabilidad condicional se refiere al fallecimiento de una persona presente en el área de colapso y, si se consideran los riesgos colectivos, a que se produzca un determinado número de víctimas mortales. De manera inversa, si se conocen estas probabilidades condicionales, así como los 
riesgos admisibles para las personas, se pueden deducir las probabilidades de fallo admisibles y los correspondientes índices de fiabilidad requeridos.

- En términos generales, las probabilidades de fallo admisibles disminuyen en la medida en la que aumentan las consecuencias esperadas de un posible colapso estructural o, lo que es equivalente, el nivel requerido de la fiabilidad estructural crece con el alcance previsible de las consecuencias.

- No existen modelos fiables para estimar las consecuencias, en términos del número de víctimas, de los colapsos estructurales. Por tanto, tampoco existen estimaciones satisfactorias de la probabilidad condicional de que, dado el colapso, se produzca un determinado daño. Debido a que estas probabilidades condicionales influyen directamente en las probabilidades de fallo admisibles, los requisitos de seguridad estructural están afectados por grandes incertidumbres.

- Los valores admisibles para la probabilidad de fallo estructural que se encuentran en la literatura especializada, basadas en los niveles de aceptación de los riesgos para las personas, son valores nominales y se desconoce su relación con las incertidumbres asociadas con las variables que intervienen en un análisis estructural.

- Los criterios de aceptación de los riesgos colectivos para las personas, contenidos en normas y recomendaciones internacionales, no están asociados con un sistema de referencia claramente establecido, lo que puede distorsionar las decisiones sobre la aceptación de una determinada estructura.

- Además, la aversión de la sociedad frente a los riesgos depende de parámetros subjetivos, entre otros, lo que dificulta aún más la definición de unos criterios de aceptación racionales para los riesgos colectivos asociados con una estructura o un conjunto de estructuras.

- En la práctica habitual de la ingeniería estructural, los aspectos de seguridad y fiabilidad se suelen tratar a nivel de los elementos estructurales considerados aisladamente. Los análisis de riesgo, al contrario, se pueden efectuar para cualquier sistema. Esta diferencia se debe tener en cuenta en la determinación de las prestaciones requeridas de las estructuras de ingeniería, sobre la base de los riesgos para las personas.

\section{Metodología e hipótesis}

En los Apartados 4.2 y 4.3 se establece un modelo matemático que permite cuantificar los riesgos individuales y colectivos para las personas, asociados con las estructuras de edificación. Este modelo se caracteriza por su sencillez y constituye una particularización, para las estructuras de edificación, de los métodos explícitos para el análisis de los riesgos tecnológicos y naturales, presentados en el Capítulo 2, estableciendo además un vínculo con los métodos de fiabilidad estructural, resumidos en el Capítulo 3, que tratan los riesgos de manera implícita. El modelo relaciona por tanto ambos tipos de métodos, explícitos e implícitos, un rasgo imprescindible en el marco del presente trabajo. En concordancia con este modelo matemático, en el Capítulo 4 también se elabora el procedimiento a seguir para el desarrollo de las herramientas prácticas destinadas al tratamiento explícito de los riesgos para las personas, asociados con las estructuras de edificación, particularmente para la deducción de los correspondientes criterios de aceptación (Apartado 4.4).

Los aspectos más relevantes en relación con ambos, el modelo matemático y el procedimiento para los desarrollos prácticos, se pueden resumir de la siguiente manera:

- En el marco del presente estudio se denomina escenario de riesgo cualquier mecanismo de fallo de un elemento estructural, con unas propiedades establecidas y para una determinada combinación y disposición de las acciones e influencias, que tenga el potencial de conducir a un colapso parcial o total de la estructura a la que pertenece.

- Para una determinada estructura, el riesgo mortal individual se cuantifica en términos de las probabilidades de ocurrencia de los relevantes escenarios de riesgo y la letalidad de cada uno de estos escenarios para una persona. De manera análoga, el riesgo colectivo se cuantifica teniendo en cuenta que diferentes personas suelen estar expuestas simultáneamente a la misma estructura. 
- La probabilidad de ocurrencia de un determinado escenario de riesgo, en un período de tiempo establecido, se puede cuantificar a través de la probabilidad de fallo de un elemento estructural, para la combinación de acciones e influencias y el mecanismo de fallo contemplados.

- La letalidad de un escenario de riesgo para una persona equivale a la probabilidad condicional de que esta persona muera en el caso de que se produzca el escenario. Sumando la letalidad para cada una de las personas que puedan estar expuestas al sistema en el momento del colapso, se obtienen las consecuencias del escenario en términos del número esperado de víctimas mortales. Por tanto, existe un vínculo entre los riesgos individual y colectivo, asociados con una estructura.

- Los denominados perfiles de riesgo facilitan una representación práctica de los riesgos para las personas, asociados con una determinada estructura de edificación. Para ello se determinan las probabilidades de ocurrencia y las consecuencias de cada uno de los escenarios de riesgo, relevantes en relación con la estructura analizada, y se representan en un diagrama probabilidad de fallo acumulada - consecuencias, por orden decreciente de las consecuencias. A estos efectos se supone independencia estadística entre los distintos escenarios.

- Cada estructura tiene un perfil de riesgo específico, cuya integración proporciona el riesgo colectivo para las personas, asociado con esta estructura.

- Es aceptable el riesgo relacionado con una estructura si ésta se ajusta exactamente a los requisitos de seguridad estructural, definidos en un conjunto consistente de normas actuales. Consecuentemente, según el enfoque adoptado en el presente estudio, los criterios de aceptación para los riesgos individuales y colectivos, asociados con las estructuras de edificación, se infieren a partir de los riesgos inherentes a las estructuras dimensionadas estrictamente según los requisitos de la normativa en vigor. Efectivamente, tal y como se menciona con anterioridad, las estructuras con estas características representan la mejor práctica actual y los riesgos asociados son aceptables y próximos al nivel óptimo.

- Las claves del procedimiento para los desarrollos prácticos en el marco de este trabajo residen en los siguientes aspectos:

- dimensionado estricto, según las normas actuales, de todos los elementos estructurales de un conjunto representativo de edificios;

- determinación de las probabilidades de fallo (colapso) de estos elementos, utilizando unos modelos probabilistas para las variables relevantes que reflejen las incertidumbres asociadas con las reglas de las normas empleadas;

- previsión verosímil de las consecuencias de los correspondientes colapsos;

- estas probabilidades de fallo y consecuencias esperadas se utilizan para el establecimiento de los perfiles de riesgo de cada una de las estructuras seleccionadas, por lo que los riesgos asociados representan la mejor práctica actual y de los resultados pueden extraerse los criterios de aceptación requeridos.

El procedimiento detallado para la elaboración de las pretendidas herramientas prácticas se define al hilo de la anterior línea argumental (Apartado 4.5). La continuación del trabajo se desarrolla siguiendo los pasos de este procedimiento y los capítulos restantes de esta tesis se estructuran en consecuencia. Así, el Capítulo 5 está destinado al establecimiento de las bases necesarias para la elaboración de estas herramientas (Pasos 1 a 3 del mencionado procedimiento):

- definición del alcance del estudio en cuanto a las características de las estructuras y los tipos de fallo;

- selección de un conjunto representativo de edificios, estructuras y elementos estructurales;

- identificación de los mecanismos de fallo más representativos y formulación de las correspondientes funciones de estado límite.

De las tareas llevadas a cabo en el marco de este capítulo, se pueden destacar los resultados y conclusiones que se resumen a continuación: 
- Se demuestra que la consideración de elementos estructurales hiperestáticos con un comportamiento dúctil conduciría a una subestimación del nivel aceptable de los riesgos (Apartado 5.2.2). Por este motivo, se estudian estructuras constituidas por vigas y pilares isostáticos, hipótesis que también está justificada por tratarse de una elección realista a la vista de la práctica habitual.

- La intraslacionalidad de las estructuras se puede asegurar mediante medidas conceptuales sencillas. Por ello se puede asumir que, en concordancia con la mejor práctica actual, se adopten este tipo de medidas. Consecuentemente, corresponde a una hipótesis realista estudiar sistemas intraslacionales (Apartado 5.2.1).

- Para evitar los posibles mecanismos de inestabilidad en las vigas y los pilares de los diferentes materiales constitutivos, se pueden adoptar medidas de carácter conceptual y puesta en obra sencilla (Apartado 5.3). Por este motivo se asume que, según la mejor práctica actual, los mecanismos de inestabilidad estén impedidos. Otro motivo para no considerar explícitamente estos mecanismos es la ausencia de indicios de que pudieran alterar los resultados del estudio (Apartado 5.4.1).

- Partiendo de las anteriores consideraciones, a efectos de la determinación de los conjuntos representativos de los sistemas y elementos estructurales, respectivamente, dentro de unos límites suficientemente amplios que permitan cubrir la gran mayoría de los casos prácticos, se seleccionan valores realistas para los parámetros más relevantes que determinan las características de las estructuras (Apartado 5.3):

- geometría del edificio (proporciones; longitud; anchura; altura; número de plantas; luz de las vigas; separación de los pórticos);

- acciones (cargas permanentes, con la excepción del peso propio que resulta del dimensionado estricto de las estructuras; sobrecargas; cargas de nieve);

- material constitutivo (acero estructural; hormigón armado; mixto de acero y hormigón; madera laminada encolada) y su tipo (caracterizado por su resistencia).

- La combinación de los valores numéricos seleccionados para cada uno de los parámetros objeto de variación conduce a los conjuntos representativos de 118.946 diferentes elementos estructurales (944 vigas de cubierta; 1.770 vigas de planta; 116.232 pilares) y 19.008 estructuras de otros tantos edificios (10.872 edificios pertenecientes a la clase de consecuencias CC2 según la definición del Eurocódigo [EN 1990 2002]; 8.136 de la clase CC3). La Tabla 5.6 refleja el reparto entre los diferentes materiales constitutivos considerados, tanto para los elementos como los sistemas estructurales. El conjunto de los edificios y sus estructuras, seleccionados para el posterior análisis, engloban casos dentro de los siguientes límites:

- las superficies útiles de los edificios oscilan entre $200 \mathrm{~m}^{2}$ y $990.000 \mathrm{~m}^{2}$, siendo este último valor el equivalente a la superficie construida de una gran urbanización o de un rascacielos del tipo de las Torres Gemelas de New York;

- sin contar la planta baja ni la cubierta, los edificios de la clase CC2 tienen un máximo de 30 plantas (10 para los edificios con estructuras de madera laminada encolada), mientras que para la clase CC3 se consideran edificios con un máximo de 10 plantas (5 para las estructuras de madera);

- el número de elementos estructurales por sistema varía entre un mínimo de 6 (4 pilares y 2 vigas principales, en las que se apoyan los elementos secundarios de la cubierta cuyos posibles mecanismos de fallo no se tienen en cuenta para la determinación, en el marco del presente estudio, de los riesgos asociados con las estructuras) y un máximo de 40.931 .

- Los mecanismos de colapso más representativos para las vigas y los pilares de las estructuras seleccionadas se deben al fallo de las secciones transversales más solicitadas por momentos flectores, esfuerzos cortantes y esfuerzos axiles de compresión, respectivamente. Las 
correspondientes funciones de estado límite se establecen teniendo en cuenta las reglas de los respectivos Eurocódigos para las bases de proyecto, las acciones y la resistencia de los elementos estructurales constituidos por los diferentes materiales (Apartado 5.4). Para los mecanismos de fallo considerados y las hipótesis adoptadas, las normas españolas equivalentes a los Eurocódigos conducen a las mismas funciones de estado límite.

\section{Incertidumbres}

En el Capítulo 6 se aborda la cuantificación de las incertidumbres asociadas con las reglas para el dimensionado estructural, reflejadas en las normas actuales. Se deduce un modelo probabilista para cada una de las variables que intervienen en las funciones de estado límite establecidas en el Apartado 5.4, en términos de una determinada función de distribución estadística, así como sus coeficientes de sesgo y variación. La deducción de los modelos probabilistas, según el Paso 4 del procedimiento definido en el Apartado 4.5, se realiza de manera detallada para las cargas de nieve (Apartado 6.4), el límite elástico del acero estructural (Apartado 6.5), así como el coeficiente para las incertidumbres del modelo de resistencia frente a momentos flectores de las vigas de acero (Apartado 6.6). Se trata de variables que requieren unos desarrollos específicos para que los modelos correspondientes representen sus características físicas. Los modelos para las otras variables, relativas a las acciones, la resistencia y las imprecisiones de los modelos, se deducen a partir de la información disponible en la literatura especializada, comprobando el estado de incertidumbre y ajustando los parámetros según el mismo procedimiento (Apartado 4.5).

La deducción de los modelos probabilistas para todas las variables consideradas en el presente estudio permite extraer las siguientes conclusiones:

- al representar las incertidumbres mediante variables aleatorias, los modelos son aptos para aplicaciones prácticas;

- los modelos probabilistas deducidos representan las características físicas de las variables correspondientes: los parámetros de las variables investigadas detalladamente en el marco del presente estudio se obtienen a partir de registros meteorológicos o ensayos de laboratorio, mientras que los de las variables restantes se desarrollan básicamente a partir de la información contenida en el código modelo probabilista [JCSS 2001], que a su vez está contrastada empíricamente;

- para el campo de aplicación del presente estudio respecto a las características (geometría; acciones; materiales constitutivos) de las estructuras consideradas, los modelos probabilistas deducidos son consistentes con los establecidos en el código modelo probabilista [JCSS 2001], particularmente aquellos cuyos parámetros se obtienen a partir de la información del citado código, pero también los desarrollados específicamente en el marco de este trabajo;

- la desviación media entre los coeficientes parciales asociados con los modelos deducidos y los correspondientes valores requeridos según las normas consideradas, es inferior al 5\% de estos últimos; además, los resultados obtenidos ponen de manifiesto que el grado de ajuste de los modelos al estado de incertidumbre asociado con las reglas normalizadas no depende del material constitutivo de los elementos estructurales.

Según estas conclusiones, los modelos probabilistas deducidos cumplen todos los requisitos establecidos previamente (Apartado 6.2.2). Eso implica que representan adecuadamente el estado de incertidumbre asociado con las reglas de la normativa que está en vigor para el proyecto de las estructuras de edificación: el Código Técnico de la Edificación y el Eurocódigo, respectivamente, conjuntos normativos que son equivalentes a efectos de las estructuras analizadas en este estudio. Consecuentemente, los modelos deducidos no solamente son aptos para aplicaciones prácticas, sino también pueden ser usados a efectos de la continuación del presente trabajo. 


\section{Consecuencias}

El modelado de las consecuencias esperadas de los colapsos estructurales, en términos de la pérdida de vidas humanas, es el objeto del Capítulo 7 (Paso 5 del procedimiento del Apartado 4.5). Los desarrollos son empíricos al basarse en la recopilación de todos los datos disponibles sobre colapsos reales de estructuras de edificación (Apartado 7.2), ocurridos en países occidentales con sistemas constructivos comparables, excluyendo los fallos inducidos por acciones accidentales y los acontecidos durante la construcción de una obra, en concordancia con el alcance del estudio (Apartado 1.2). Los casos se dividen según la pertenencia de los edificios correspondientes a las clases de consecuencias $\mathrm{CC} 2$, que incluye por ejemplo los edificios residenciales o de oficinas, y CC3, en los que se pueden producir concentraciones de personas [EN 1990 2002]. En la recopilación no se incluyen colapsos de edificios pertenecientes a la clase de consecuencias $\mathrm{CC} 1$ ya que engloba obras en las que normalmente no se encuentran personas, por lo que están fuera del alcance del presente estudio en el que únicamente se tienen en cuenta las pérdidas de vidas humanas (Apartados 1.1.4 y 1.2).

A través de un riguroso control de calidad, la base de datos original se reduce de 301 colapsos a 109 casos con información útil, de los que el $63 \%$ corresponde a edificios de la clase de consecuencias CC2 y el 37\% a la clase CC 3 . Mediante datos complementarios, tanto internos como externos a la base, se estiman de manera indirecta algunos de los parámetros relativos a los edificios y los colapsos sobre los que la información inicialmente disponible resulta escasa (Apartado 7.3). De esta manera, se obtienen unos aumentos considerables de la información. A título de ejemplo, en los campos del número de personas presentes en el edificio en el momento del colapso, la superficie afectada por el colapso y la superficie útil total del edificio, los aumentos alcanzan el 24,8\%, 29,3\% y 48,6\%, respectivamente (Apartado 7.3.4).

Mediante una serie de análisis estadísticos de regresión que se efectúan sobre la base de la información complementada de los 109 casos útiles, con el fin de relacionar los diferentes parámetros que caracterizan los edificios y los colapsos, respectivamente, con el número de víctimas mortales, se obtienen los siguientes resultados y conclusiones (Apartado 7.4):

- el mejor ajuste para los modelos empíricos se obtiene representando los accidentes mediante la superficie afectada por el colapso;

- la base de datos complementada contiene 30 casos pertenecientes a la clase de consecuencias CC2, con un mínimo de un muerto, para los que se conocen simultáneamente ambos parámetros, el número de víctimas y la superficie afectada por el colapso, mientras que para la clase de consecuencias CC3 son 14 los casos que cumplen estos requisitos (Tabla 7.13);

- mediante un análisis estadístico de regresión de estos datos se obtienen los modelos matemáticos para las consecuencias, en términos del número esperado de víctimas mortales, en función de la superficie afectada por el colapso, respectivamente para las estructuras de los edificios pertenecientes a las clases de consecuencias CC2 y CC3 (Apartado 7.4.2);

- el modelo deducido para la clase CC2 es estadísticamente significante, a pesar de la gran dispersión de los datos empíricos, por lo que es apto para estimar las consecuencias de un colapso parcial o total de un determinado edificio y se emplea en la continuación del estudio para inferir el nivel aceptable de los riesgos para las personas;

- aun sin ser estadísticamente significante, el modelo obtenido para la clase CC3 también se utiliza para la continuación del trabajo, tanto por su similitud con el modelo para la clase CC2, como por el hecho de que la estimación de las consecuencias de los colapsos no requiere una precisión excesiva, ya que los resultados del estudio se utilizan básicamente a efectos comparativos;

- mientras que la información recopilada sobre accidentes permite deducir unos modelos adecuados para estimar las consecuencias de un colapso estructural para las personas desde un punto de vista colectivo, por la dispersión de los datos no ocurre lo mismo para la probabilidad mortal 
condicional, por lo que a estos efectos se adoptan las estimaciones disponibles en la literatura especializada (Apartado 8.3.3).

\section{Requisitos}

La determinación de los requisitos de seguridad para las estructuras de edificación, respectivamente de nueva construcción y existentes, es objeto del Capítulo 8 del presente trabajo. Las prestaciones requeridas para los elementos constitutivos de las estructuras, o para los sistemas en su conjunto, se pueden cuantificar por medio de las probabilidades de fallo admisibles o, lo que es equivalente, los niveles de fiabilidad requeridos (Apartado 8.2), así como los riesgos aceptables para las personas (Apartado 8.3). El procedimiento adoptado para la inferencia de estos requisitos corresponde a uno de los desarrollos originales, realizados en el marco del presente trabajo, y se expone en varios apartados, con distintos propósitos y grados de detalle:

- establecimiento de las tareas genéricas a realizar para la deducción de los criterios de aceptación (Apartado 4.4);

- definición del procedimiento detallado para la determinación de estos requisitos (Paso 6 según el Apartado 4.5);

- descripción de la relación de las diferentes tareas en las que se divide este procedimiento con las hipótesis y modelos desarrollados a lo largo de los Capítulos 4 a 7 (Apartado 8.1);

- finalmente, en el marco del presente apartado, se resumen los aspectos clave del procedimiento (Apartado 9.2).

El nivel de fiabilidad implícitamente requerido según la mejor práctica actual, reflejada en las normas que están en vigor, concretamente el Eurocódigo y el Código Técnico de la Edificación, equivalentes a efectos del presente estudio, se determina en términos de las probabilidades de fallo, $p_{f}$, y los correspondientes índices de fiabilidad, $\beta$, para un período de referencia de 50 años. Los resultados se representan por separado para los relevantes mecanismos de fallo de los elementos constituidos por los diferentes materiales considerados. Los análisis efectuados conducen a las siguientes observaciones:

- la existencia de una similitud cualitativa y cuantitativa de los resultados con los obtenidos en una de las escasas investigaciones comparables (Apartados 8.2.2 y 8.2.3), lo que contribuye a la plausibilidad del enfoque y las hipótesis del presente estudio, a pesar de las importantes diferencias entre ambos trabajos en cuanto a contexto, campo de aplicación, alcance e hipótesis;

- la existencia de grandes diferencias entre los valores medio de la probabilidad de fallo implícitamente aceptada, o los índices de fiabilidad requeridos, dependiendo del material constitutivo de la estructura, el tipo de elemento estructural y el mecanismo de fallo considerados (Apartado 8.2.6);

- los resultados reflejan unas dispersiones muy importantes en el nivel de fiabilidad implícitamente requerido, incluso si se consideran los valores para un único mecanismo de fallo de un tipo de elemento específico, constituido por uno de los materiales estudiados (Apartados 8.2.2 a 8.2.5);

- para una cierta fracción de los elementos analizados, hasta un $37 \%$ en el caso de las vigas de cubierta fabricadas de acero estructural, el nivel de fiabilidad implícitamente requerido por la normativa en vigor está por debajo del valor nominalmente exigido por la misma normativa (Apartados 8.2.2 y 8.2.3);

- las dispersiones del nivel de fiabilidad requerido y las diferencias en sus valores medio, en función del material, tipo de elemento y mecanismo de fallo, ilustran los problemas asociados con los requisitos de fiabilidad estructural de las normas que están actualmente en vigor y que motivan el presente estudio (Apartados 1.1.2 y 9.1).

Para mejorar los actuales requisitos de seguridad estructural, se establece el nivel aceptable de los riesgos para las personas, según la mejor práctica actual en el campo de las estructuras de 
edificación, reflejada en el Eurocódigo y el Código Técnico de la Edificación. Distinguiendo entre sistemas estructurales de edificios pertenecientes a las clases de consecuencias $\mathrm{CC} 2$ y CC3, pero sin separarlos según los materiales constitutivos de sus elementos resistentes, los riesgos inherentes a todas las estructuras analizadas en el estudio (Apartado 5.3) y dimensionadas de manera estricta (Apartado 8.3.1), se interpretan primero y se transforman después en probabilidades de fallo admisibles e índices de fiabilidad requeridos para los estados límite últimos. Los resultados principales de los análisis efectuados en el marco del Apartado 8.3 se pueden resumir de la siguiente manera:

- Los riesgos para las personas, deducidos según el procedimiento del Apartado 4.5, deben interpretarse como valores nominales, aunque guarden una cierta relación con la realidad debido a que las estructuras analizadas son realistas, los modelos probabilistas para las diferentes variables representan sus características físicas y los modelos de consecuencias son empíricos (Apartado 8.3.5).

- Son aceptables los riesgos asociados con las estructuras de edificación analizadas, representados en las Figuras 8.8 a 8.10. En particular, también son aceptables los riesgos para las personas correspondientes a un cuantil superior de estos resultados (Apartado 8.3.2).

- En relación con las estructuras de nueva construcción se propone adoptar, como criterio de aceptación, el valor esperado de los riesgos para las personas, asociados con la mejor práctica actual. Para las estructuras existentes es razonable aceptar el cuantil superior del $95 \%$ de estos riesgos (Apartado 8.3.5).

- La aceptación de unos riesgos mayores para la evaluación de las estructuras existentes, en comparación con los requisitos para el dimensionado de las estructuras de nueva construcción, se justifica por los siguientes motivos (Apartado 8.3.5):

- la reducción de los riesgos asociados con las estructuras existentes implica normalmente mayores dificultades que en estructuras de nueva construcción, con unas medidas necesarias cuyo coste puede resultar desproporcionado en relación con las mejoras alcanzadas;

- con el fin de cubrir las inevitables dispersiones asociadas con los procesos de dimensionado y construcción, a efectos de la calibración de las normas para estructuras nuevas, los requisitos de seguridad deberían ser más restrictivos que los mínimos aceptables.

- Para el riesgo individual, se deduce un límite de aceptación de $10^{-6}$ por año en el contexto del dimensionado de las estructuras de nueva construcción, y de $10^{-5}$ por año para la evaluación de las existentes (Apartados 8.3.3 y 8.3.5).

- Los criterios de aceptación para los riesgos colectivos, en términos de diagramas frecuencia consecuencias para un período de referencia de un año, dependen de (Figuras 8.11 y 8.12, así como Apartado 8.3.5):

- la clase de consecuencias de los edificios, respectivamente CC2 y CC3;

- el sistema de referencia, abarcando desde la totalidad de las estructuras de edificación construidas a nivel nacional, hasta elementos individuales de estas estructuras; según los análisis efectuados (Apartado 8.3.4), una frecuencia esperada del orden de uno a dos colapsos anuales con víctimas mortales, resultaría aceptable en un país como España;

- el empleo de los requisitos para, respectivamente, el dimensionado o la evaluación estructural, siendo la diferencia también en este caso de un orden de magnitud, con riesgos aceptables mayores en el contexto de la evaluación de las estructuras existentes.

- Los requisitos de fiabilidad para los elementos estructurales, deducidos a partir del nivel aceptable de los riesgos para las personas según la mejor práctica actual, expresados en términos de las probabilidades de fallo admisibles para un período de referencia de un año, o los correspondientes índices de fiabilidad requeridos (Figura 8.14), dependen de:

- la clase de consecuencias del edificio cuya estructura se analiza, respectivamente CC2 y CC3; 
- la superficie afectada por el posible colapso del elemento analizado;

- el empleo de los requisitos para, respectivamente, el dimensionado o la evaluación estructural.

- Los índices de fiabilidad requeridos, basados en los valores esperados de los riesgos admisibles y, por tanto, relevantes para el dimensionado de las estructuras de nueva construcción, están por debajo de los requisitos de fiabilidad definidos en el Eurocódigo (Tabla 3.6) para elementos cuyo colapso afectaría superficies inferiores a $254 \mathrm{~m}^{2}$ en edificios de la clase CC2 e inferiores a $159 \mathrm{~m}^{2}$ en edificios de la clase CC 3 . Para superficies mayores, los requisitos para estructuras nuevas, obtenidos en este trabajo, resultan más restrictivos que los del Eurocódigo.

\subsection{CONCLUSIONES}

\section{Generalidades}

En la ingeniería estructural, siempre es necesario abordar los aspectos de seguridad. En este contexto y en relación con las estructuras de edificación se lleva a cabo la presente tesis, con el objetivo de desarrollar métodos, modelos y requisitos que contribuyan a la adopción de decisiones racionales, sobre eventos muy poco frecuentes que, en caso de ocurrencia, pueden producir daños importantes. En este apartado se recopilan las conclusiones principales de la tesis, que se refieren tanto a la situación actual en el mencionado campo de trabajo, como a la evaluación de los riesgos para las personas según los desarrollos realizados. También se resumen las ventajas de los métodos explícitos para la evaluación y la gestión de los riesgos asociados con las estructuras, frente a los enfoques tradicionales, basados en un tratamiento implícito (Apartado 1.1.3), y se destacan las aportaciones originales de esta tesis.

\section{Situación actual}

- Las probabilidades de fallo admisibles, establecidas en las normas estructurales que están en vigor, son valores nominales con una relación desconocida, tanto con los riesgos para las personas, inducidos por las estructuras de ingeniería civil, como las incertidumbres asociadas con las variables que intervienen en un análisis estructural.

- Las normas actuales para el dimensionado estructural implican unos requisitos de fiabilidad cuyo valor medio y dispersión varían de manera importante, en función del material constitutivo, tipo de elemento, mecanismo de fallo y otros parámetros.

- Para una determinada fracción de los elementos estructurales que, según el caso, puede ser considerable, el nivel de fiabilidad implícitamente requerido por las normas actuales está por debajo del valor nominal de la fiabilidad estructural, exigido por la misma normativa.

- Según un enfoque más reciente, basado en criterios económicos y utilizando el denominado índice de calidad de vida, $L Q I$, el nivel de fiabilidad requerido se puede determinar de manera racional, en función del valor óptimo del costo equivalente para evitar una víctima mortal, ICAF.

- La sociedad no aceptaría un aumento de las frecuencias anuales de colapsos estructurales, en comparación con las asociadas con la mejor práctica actual. Consecuentemente, la aplicación práctica de los requisitos de fiabilidad estructural basados en el ICAF debe complementarse con una evaluación de los riesgos para las personas, lo que a su vez requiere el establecimiento de unos niveles aceptables para estos riesgos.

- El nivel de fiabilidad requerido para una estructura o un elemento estructural aumenta con el número esperado de víctimas causadas por el posible colapso del sistema analizado. 


\section{Evaluación de los riesgos para las personas}

- El modelo desarrollado en esta tesis para cuantificar los riesgos para las personas, asociados con las estructuras de edificación, es compatible con los métodos explícitos para el análisis y la gestión de los riesgos, de carácter general, que se emplean en diferentes campos tecnológicos, y establece un vínculo entre éstos y los métodos habituales de la ingeniería estructural que tratan los riesgos de manera implícita.

- La relación entre los métodos explícitos e implícitos queda establecida a través de, por un lado, los riesgos para las personas y, por otro, una función de las probabilidades de fallo estructural y las probabilidades condicionales de que, dado el fallo, se produzca un determinado daño. Consecuentemente, también están relacionados los niveles aceptables de los riesgos y las probabilidades de fallo admisibles, o los correspondientes índices de fiabilidad requeridos.

- Es posible representar, mediante variables aleatorias que son aptas para aplicaciones prácticas, las incertidumbres asociadas con los parámetros que intervienen en el dimensionado de las estructuras de edificación. Los modelos probabilistas desarrollados en la tesis para las acciones, sus efectos y las correspondientes resistencias, representan las características físicas de los distintos parámetros $\mathrm{y}$, simultáneamente, son compatibles con las normas para el dimensionado estructural al cuantificar su nivel de incertidumbres con una desviación inferior al 5\%.

- Los análisis estadísticos de regresión, efectuados con diferentes parámetros descriptivos de colapsos reales ocurridos en estructuras de edificación, ponen de manifiesto que el número esperado de víctimas mortales depende de la superficie afectada por el colapso, así como la categoría de uso del edificio. Los modelos de consecuencias obtenidos en el presente trabajo se basan en estas relaciones.

- Los riesgos para las personas, determinados mediante los modelos desarrollados en esta tesis, deben interpretarse como valores nominales. No obstante, tienen una cierta relación, no investigada en el trabajo, con los riesgos reales ya que los modelos probabilistas para las variables representan sus características físicas y los modelos de consecuencias son empíricos.

- Los riesgos asociados con la mejor práctica actual en la ingeniería estructural son a la vez aceptables y próximos al nivel óptimo.

- La diferencia en el estado de la información sobre las estructuras nuevas y existentes, respectivamente, en combinación con el hecho de que en estas últimas la reducción del nivel de los riesgos puede tener un coste desproporcionado, justifican la aceptación de mayores riesgos en estructuras existentes que en las de nueva construcción, adoptando como requisito para aquéllas el cuantil superior del 95\% y, para éstas, el valor esperado de los riesgos para las personas, asociados con la mejor práctica actual.

- El nivel aceptable de los riesgos individuales, asociados con las estructuras existentes y de nueva construcción es de, respectivamente, $10^{-5}$ y $10^{-6}$ por año. Estos valores están uno y dos órdenes de magnitud por debajo de la tasa mortal individual debida a los accidentes en general, que se sitúa aproximadamente en $10^{-4}$ por año.

- Para un determinado período de referencia, el nivel aceptable de los riesgos colectivos depende de la clase de consecuencias de los edificios y del sistema de referencia considerados. Para un país como España, asumiendo un volumen anual de construcción similar al del boom inmobiliario del primer lustro del siglo, el nivel aceptable equivale a una frecuencia esperada de uno a dos colapsos con víctimas mortales por año. También para los riesgos colectivos, el nivel aceptable para las estructuras existentes supera en un orden de magnitud al criterio de aceptación para las estructuras nuevas.

\section{Ventajas}

Siguiendo un procedimiento genérico para la gestión de los riesgos (Figura 2.1), los modelos y requisitos desarrollados en la tesis se pueden emplear para la comprobación, mediante métodos 
explícitos, de las prestaciones relacionadas con la seguridad de las estructuras de edificación. A estos efectos, se debe tener en cuenta que los requisitos, deducidos en la tesis como base de decisión para la aceptación o el rechazo de las soluciones analizadas, no son valores absolutos. Efectivamente, estos requisitos están interrelacionados con las incertidumbres, asociadas con las variables que intervienen en la determinación de las prestaciones de las estructuras, adoptadas para su determinación. En función del método y formato de verificación empleados, los criterios de aceptación se expresan en términos de los riesgos admisibles para las personas, probabilidades de fallo admisibles o índices de fiabilidad requeridos.

El empleo de los métodos explícitos para la evaluación y la gestión de los riesgos asociados con las estructuras conlleva una serie de ventajas frente a los enfoques tradicionales, basados en un tratamiento implícito (Apartado 1.1.3):

- reducción de los riesgos residuales;

- mayor racionalidad en la aceptación o el rechazo de soluciones, lo que tiene efectos beneficiosos en numerosas actividades en las que se deben adoptar decisiones de este tipo, por ejemplo:

- calibración de los modelos empleados en el marco de los métodos implícitos de verificación de la seguridad estructural;

- optimización de soluciones;

- justificación de soluciones innovadoras;

- evaluación de la fiabilidad de las estructuras existentes;

- evaluación de las causas y de la fiabilidad de estructuras colapsadas, en el contexto de investigaciones de ingeniería forense.

- cuantificación de la influencia de diferentes medidas de mitigación de los riesgos;

- facilidad de comunicación entre expertos y el público.

\section{Aportaciones originales}

El presente trabajo incluye una serie de desarrollos novedosos e innovadores. Están relacionados con los temas, identificados en el Apartado 1.3 y resumidos en el Apartado 9.1, cuyo estudio es necesario para alcanzar el objetivo de la tesis. Las aportaciones originales se explican detalladamente a lo largo del estudio, vinculándolas de manera adecuada con el estado actual de la técnica, y se resumen en el Apartado 9.2. Por este motivo, a continuación se procede únicamente a la enumeración de las novedades más relevantes:

- La originalidad del modelo desarrollado para cuantificar los riesgos para las personas (Apartados 4.2 y 4.3), reside en el vínculo que establece entre los métodos explícitos para el análisis y la gestión de los riesgos tecnológicos y naturales, de carácter general (Capítulo 2), y los implícitos que se emplean para tratar los riesgos asociados con las estructuras de ingeniería civil (Capítulo $3)$.

- También resulta novedoso, y esencial para el estudio, el procedimiento establecido para el desarrollo de las herramientas prácticas (Apartados 4.4 y 4.5), incluida la inferencia de los criterios de aceptación de los riesgos, que permitan tratar de manera explícita los riesgos para las personas.

- Aunque el análisis de la fiabilidad de sistemas no sea novedoso, las consideraciones genéricas sobre la influencia del sistema estático de un tipo de elemento estructural y de su comportamiento en la fiabilidad, relacionada con la mejor práctica actual, contienen aspectos originales. Las conclusiones extraídas de estas consideraciones resultan esenciales para la adopción de las hipótesis necesarias a efectos de la determinación del nivel aceptable de los riesgos (Capítulo 5).

- La deducción del nivel de las incertidumbres asociadas con los parámetros que intervienen en el dimensionado de las estructuras de edificación es una aportación original (Capítulo 6), que 
resulta esencial en el marco de la inferencia de los riesgos admisibles según la mejor práctica actual.

- La obtención de los modelos probabilistas para las cargas de nieve (Apartado 6.4), el límite elástico del acero estructural (Apartado 6.5), así como el coeficiente para las incertidumbres de un determinado modelo de resistencia (Apartado 6.6), requiere una serie de desarrollos específicos. En el primer caso, constituyen aportaciones originales tanto el método indirecto empleado para la determinación de la carga de nieve a partir de los datos meteorológicos disponibles, como el tratamiento de la influencia de los inviernos sin nevadas. En el caso del límite elástico, la aportación reside en el simple hecho de deducir los modelos probabilistas a partir de resultados experimentales obtenidos sobre aceros destinados al mercado nacional. Finalmente, la cuantificación de las incertidumbres de los modelos de resistencia implica abordar un tema poco tratado en la literatura especializada.

- Los modelos de consecuencias obtenidos en el presente trabajo también cubren una laguna en la literatura especializada (Capítulo 7).

- La determinación del nivel de fiabilidad implícitamente requerido según la normativa que está en vigor, efectuada en el marco de esta tesis (Apartado 8.2), se distingue de los trabajos de otros investigadores, principalmente en los siguientes aspectos: el alcance del estudio y, sobre todo, el establecimiento de la relación entre los requisitos de fiabilidad y el nivel de las incertidumbres asociadas con los parámetros que intervienen en el dimensionado estructural.

- Es novedosa la determinación de los niveles aceptables de los riesgos para las personas, asociados con las estructuras de nueva construcción y existentes, respectivamente, en función de la clase de consecuencias de los edificios, así como el sistema de referencia considerado (Apartado 8.3). También lo es la transformación de estos requisitos en índices de fiabilidad requeridos.

\subsection{TRABAJOS FUTUROS}

\section{Generalidades}

Por la variedad y complejidad de los temas a tratar en el marco del desarrollo de unas herramientas prácticas para el análisis de los riesgos asociados con las estructuras de ingeniería civil, en una tesis no es posible analizar todos los aspectos relevantes que sería deseable tener en cuenta. Por este motivo, el alcance de esta tesis está limitado (Apartados 1.2 y 9.1) y existen campos para trabajos futuros que complementarían el presente estudio. A continuación, se señalan los temas que se deberían abordar con mayor urgencia.

\section{Situaciones accidentales}

El presente trabajo se centra en las estructuras de edificación expuestas a las situaciones persistentes. Es necesario estudiar también la exposición de las estructuras a las situaciones accidentales, ya que contribuyen a los riesgos inducidos por estos sistemas. Es por ello importante cuantificar los riesgos para las personas, asociados con la mejor práctica actual en cuanto al tratamiento de las situaciones accidentales. Los resultados se deberán interpretar conjuntamente con los obtenidos en esta tesis.

\section{Criterios económicos}

Por la importancia de los riesgos para las personas, en el presente trabajo los requisitos de seguridad estructural se establecen exclusivamente sobre esta base. Adicionalmente, el nivel de fiabilidad requerido también se debe determinar teniendo en cuenta criterios económicos. A estos efectos, se debería utilizar el enfoque basado en el denominado índice de calidad de vida, LQI, e interpretar los resultados teniendo en cuenta los del presente estudio. 


\section{Modelos de consecuencias}

Para poder establecer unos niveles aceptables de los riesgos, basados en criterios económicos, es necesario disponer de los correspondientes modelos de consecuencias. Es por ello necesario desarrollar unos modelos que permitan estimar todas las consecuencias adversas de los colapsos estructurales, incluyendo daños medioambientales y pérdidas económicas, directas e indirectas, además de los daños personales. En cuanto a éstos, los modelos desarrollados en esta tesis se deberían refinar y completar con una estimación verosímil de la probabilidad mortal condicional para las personas que estén presentes en el área de colapso de una estructura.

\section{Riesgos reales}

Aunque los modelos desarrollados en la tesis estén relacionados con la realidad, los riesgos que se deducen al aplicarlos a casos prácticos deben, a priori, interpretarse como nominales. Se debería investigar la relación entre éstos y los riesgos reales, asociados con las estructuras, para comprender las posibles diferencias. Una explicación verosímil facilitaría la comparación con los riesgos asociados con otras tecnologías o actividades, y contribuiría a la adopción de decisiones más racionales sobre su aceptación. A estos efectos sería necesario investigar explícitamente los riesgos, nominales y reales, asociados con los detalles constructivos cuyo fallo está en el origen de un número importante de colapsos estructurales, debiéndose a menudo a una concepción, análisis o ejecución deficiente.

\section{Puentes}

Se deberían desarrollar unas herramientas prácticas para el análisis de los riesgos asociados con otros tipos de estructuras de ingeniería civil, particularmente los puentes. Igual que en el caso de las estructuras de edificación, además de los riesgos para las personas, también se deberían investigar los aspectos económicos. Finalmente, los estudios deberían incluir una comparación de los riesgos admisibles que se deduzcan con los reales, para facilitar comparaciones con otros sistemas y actividades, entre los que destacan las estructuras de edificación.

\section{Aspectos legales}

En comparación con los métodos implícitos del tratamiento de los riesgos, de carácter prescriptivo, los métodos explícitos que, siguiendo una tendencia reciente, también se podrían denominar métodos prestacionales, le brindan al técnico que los aplique un mayor grado de libertad en el momento de adoptar una determinada solución, o de justificar que ésta cumpla con los requisitos de seguridad (Apartados 1.1.3 y 9.3). Los métodos explícitos contribuyen a fomentar y justificar desarrollos innovadores, u optimizar determinadas soluciones. Por otro lado, un mayor grado de libertad normalmente también implica más responsabilidad ya que, por lo menos aparentemente, el técnico que aplique un documento normativo con reglas prescriptivas delega una parte de su responsabilidad en los comités de redacción de estas normas o en los organismos de normalización. Es por ello que en un trabajo previo se estudiaron, desde un punto de vista doctrinal y jurisprudencial, así como en términos comparativos con la práctica habitual, los efectos de la aplicación de los métodos explícitos de análisis de riesgo sobre la responsabilidad penal de los técnicos [Jiménez Losada 2005].

Debido a la falta de antecedentes resulta extremadamente difícil predecir de forma indubitada qué ocurriría si se cambiaran las normas prescriptivas actuales por otras que permitieran el empleo de los métodos explícitos de análisis de riesgo al dimensionado de las estructuras de nueva construcción o a la evaluación de las existentes. A pesar de esta dificultad intrínseca de la temática, el estudio citado deduce de las características de la sociedad actual, de las tendencias del derecho penal moderno, de la teoría general del derecho, y de los casos sentenciados hasta la fecha, que es más que probable que el aumento o no de condenas a los técnicos de la construcción no va a depender del tipo de normativa, 
ya sea prescriptiva o prestacional. En cualquier caso, sería interesante actualizar y ampliar este estudio a la luz de los últimos cambios legislativos y las sentencias más recientes. Igualmente, se debería realizar un estudio equivalente, centrado en el derecho civil. 


\section{REFERENCIAS}

[AN/UNE-EN 1993-1-1 2013] AN/UNE-EN 1993-1-1:2013, Anejo Nacional - Eurocode 3: Proyecto de estructuras de acero. Parte 1-1: Reglas generales y reglas para edificios, Asociación Española de Normalización y Certificación, AENOR, Madrid, 2013.

[AS/NZS 4360 1999] Australian / New Zealand Standard AS/NZS 4360, Risk management, 1999, ISBN $073372647 \mathrm{X}$.

[Bailey 1996] Bailey, S. F., Basic principles and load models for the structural safety evaluation of existing bridges, Thesis $\mathrm{n}^{\circ}$ 1467, Swiss Federal Institute of Technology, Lausanne, 1996.

[Basler 1961] Basler, E., Untersuchungen über den Sicherheitsbegriff von Bauwerken, Schweizer Archiv für angewandte Wissenschaft und Technik, 4, 1961.

[BUWAL 1991a] StFV, Handbuch I zur Störfallverordnung, Bundesamt für Umwelt, Wald und Landschaft (BUWAL), Bern, 1991.

[BUWAL 1991b] StFV, Handbuch III zur Störfallverordnung, Bundesamt für Umwelt, Wald und Landschaft (BUWAL), Bern, 1991.

[CALSIDER 2009] Calidad Siderúrgica, Valores estadísticos para el límite elástico, Comunicación privada, CALSIDER, Madrid, 2009, http://www.calsider.es.

[CAN/CSA Q634 1991] CAN/CSA-Q634-91, Risk analysis requirements and guidelines, 1991.

[CIB 259 2001] CIB Publication 259, Risk assessment and risk communication in civil engineering, Editors: Vrouwenvelder, T., Holicky, M., Tanner, P., Lovegrove, R. and Canisius, G., International Council for Research and Innovation in Building and Construction, CIB, $\mathrm{n}^{\circ} 259$, 62 pages, Rotterdam, 2001, ISBN 90-6363-026-3.

[CONTECVET 2001] CONTECVET, A validated user's manual for assessing the residual service life of concrete structures, EC Innovation Program IN30902I, 2001.

[Cornell 1969] Cornell, A. C., A probability based structural code, ACI Journal, Vol. 66, No. 12, 1969.

[Corso, del 1995] Corso, del, R., Gränzer, M., Gulvanessian, H., Raoul, J., Sandvik, R., Sanpaolesi, L. and Steifel, U., New european code for snow loads - Background document, Proceedings of the Department of Civil Engineering, $n^{\circ}$ 264, University of Pisa, Pisa, 1995.

[CTE DB SE 2006] CTE DB SE, Código técnico de la edificación - Documento básico: Seguridad estructural, Ministerio de Fomento, Madrid, 2006.

[CTE DB SE-AE 2006] CTE DB SE-AE, Código técnico de la edificación - Documento básico: Seguridad estructural - Acciones en la edificación, Ministerio de Fomento, Madrid, 2006.

[CTE DB SE-A 2006] CTE DB SE-A, Código Técnico de la Edificación - Documento básico: Seguridad estructural - Acero, Ministerio de Fomento, Madrid, 2006.

[CTE DB SE-M 2006] CTE DB SE-M, Código técnico de la edificación - Documento básico: Seguridad estructural - Madera, Ministerio de Fomento, Madrid, 2006.

[Diamantidis 2007] Diamantidis, D. and Bazzurro, P., Target safety criteria for existing structures, Special Workshop on Risk Acceptance and Risk Communication, ASCE - JCSS - John A. 
Blume Earthquake Engineering Center, Stanford University, Stanford, 2007, http://www.ripid.ethz.ch.

[Diamantidis 2012] Diamantidis, D., Holicky, M., Vrouwenvelder, T., Tanner, P., Croce, P., Toprak, S., et al., Innovative methods for the assessment of existing structures, CTU Prague (publisher), 148 pages, Prague, 2012, ISBN 978-80-01-05115-3.

[Ditlevsen 1977] Ditlevsen, O., Structural reliability and the invariance problem, Solid Mechanics Division, Report No 22, University of Waterloo, Ontario, Canada, 1973.

[Ditlevsen 1980] Ditlevsen, O., Formal and real structural safety - The influence of gross errors, IABSE Periodica, Proceedings P-36/80, International Association for Bridge and Structural Engineering, Zürich, 1980.

[Ditlevsen 1989] Ditlevsen, O., Proposal for a code for the direct use of reliability methods in structural design, Working document for the Joint Committee on Structural Safety, International Association for Bridge and Structural Engineering, Zürich, 1989.

[Dubas 1991] Dubas, P., Der Baustoff Stahl. Autographieblatt Grundlagen des Stahlbaus, Institut für Baustatik und Konstruktion, IBK, Eidgenössische Technische Hochschule Zürich, ETHZ, Zürich, 1991.

[EAE 2011] EAE, Instrucción de acero estructural, Ministerio de Fomento, Madrid, 2011, ISBN 978-84-498-0904-0.

[EHE-08 2008] EHE-08, Instrucción de hormigón estructural, Ministerio de Fomento, Madrid, 2008, ISBN 978-84-498-0825-8.

[Eldukair 1991] Eldukair, Z. A. and Ayyub, B. M., Analysis of recent U.S. structural and construction failures, Journal of Performance of Constructed Facilities, Vol. 5, No 1, pp. 5773, 1991.

[Ellingwood 1999] Ellingwood, B. R., Probability-based structural design: Prospect for acceptable risk bases, Applications of Statistics and Probability in Civil Engineering, ICASP 8, pp. 1118, A.A. Balkema, Rotterdam, 1999.

[EN 1990 2002] EN 1990:2002, Eurocode - Basis of structural design, European Committee for Standardization, CEN, Brussels, 2002.

[EN 1991-1-1 2002] EN 1991-1-1:2002, Eurocode 1: Actions on structures. Part 1-1: General actions - Densities, self-weight, imposed loads for buildings, European Committee for Standardization, CEN, Brussels, 2002.

[EN 1991-1-3 2003] EN 1991-1-3:2003, Eurocode 1: Actions on structures. Part 1-3: General actions - Snow loads, European Committee for Standardization, CEN, Brussels, 2003.

[EN 1992-1-1 2004] EN 1992-1-1:2004, Eurocode 2: Design of concrete structures. Part 1-1: General rules and rules for buildings, European Committee for Standardization, CEN, Brussels, 2004.

[EN 1993-1-1 2005] EN 1993-1-1:2005, Eurocode 3: Design of steel structures. Part 1-1: General rules and rules for buildings, European Committee for Standardization, CEN, Brussels, 2005.

[EN 1994-1-1 2004] EN 1994-1-1:2004, Eurocode 4: Design of composite steel and concrete structures. Part 1-1: General rules and rules for buildings, European Committee for Standardization, CEN, Brussels, 2004. 
[EN 1995-1-1 2004] EN 1995-1-1:2004, Eurocode 5: Design of timber structures. Part 1-1: General rules and rules for buildings, European Committee for Standardization, CEN, Brussels, 2004.

[ENV 1991-1 1994] ENV 1991-1, Basis of design and actions on structures - Part 1: Basis of design, European Committee for Standardization, CEN, Brussels, 1994.

[ENV 1991-2-1 1995] ENV 1991-2-1, Basis of design and actions on structures - Part 2 - 1: Actions on structures, densities, self-weight and imposed loads on buildings, European Committee for Standardization, CEN, Brussels, 1995.

[ENV 1991-2-3 1995] ENV 1991-2-3, Basis of design and actions on structures - Part 2 - 3: Snow loads, European Committee for Standardization, CEN, Brussels, 1995.

[ENV 1992-1-1 1991] ENV 1992-1-1, Design of concrete structures - General rules and rules for buildings, European Committee for Standardization, CEN, Brussels, 1991.

[ENV 1993-1-1 1992] ENV 1993-1-1, Design of steel structures - General rules and rules for buildings, European Committee for Standardization, CEN, Brussels, 1992.

[ENV 1995-1-1 1993] ENV 1995-1-1, Design of timber structures - General rules and rules for buildings, European Committee for Standardization, CEN, Brussels, 1993.

[Faber 2002] Faber, M. H., Lecture notes on risk and safety in civil engineering, Swiss Federal Institute of Technology, ETH, Zürich, 2002.

[Faber 2012] Faber, M. H., Lind, N., Nathwani, J., Thomas, P. and Vrouwenvelder, T., A common rationale for health and life safety management, Organisation for Economic Co-operation and Development, OECD, Public Governance and Territorial Development Directorate, Public Governance Committee, Paris, 2012.

[Ferry-Borges 1971] Ferry-Borges, J. and Castanheta, M., Structural safety, Laboratorio Nacional de Engenharia Civil, Lisboa, 1971.

[FIB 2013] FIB, Model Code for Concrete Structures 2010, Fédération Internationale du Béton, fib, Lausanne, Verlag Ernst \& Sohn, Berlin, 2013, ISBN 978-3-433-03061-5.

[Freudenthal 1947] Freudenthal, A. M., The safety of structures, Transactions of the ASCE, Vol. 112, 1947.

[Gumbel 1958] Gumbel, E.J., Statistics of extremes, Columbia University Press, 1958, 375 pages.

[Hambly 1994] Hambly, E. C. and Hambly, E. A., Risk evaluation and realism, Proceedings Institute of Civil Engineers, Civil Engineering 102, Paper 10324, 1994.

[Hasofer 1974] Hasofer, A. M. and Lind, N. C., Exact and invariant second moment code format, Journal of the Engineering Mechanics Division, ASCE, Vol. 100, No 1, pp. 111-121, 1974.

[Hingorani 2011] Hingorani, R. y Tanner, P., Nivel de fiabilidad implícito de pilares de hormigón armado sometidos a la interacción de esfuerzos axiles y momentos flectores, V Congreso de ACHE, Barcelona, 2011, ISBN 978-84-89670-73-0.

[Holicky 2008] Holicky, M. and Sykora, M., Safety of lightweight steel roofs exposed to snow loads, Eurosteel 2008, ECCS, Brussels, 2008, ISBN 92-0147-000-90.

[IAP-11 2012] IAP-11, Instrucción sobre las acciones a considerar en el proyecto de puentes de carretera, Ministerio de Fomento, Madrid, 2012, ISBN 9788449809156.

[INE] Instituto Nacional de Estadística, INE, Madrid, http://www.ine.es. 
[ISO 2394 1998] ISO 2394:1998, General principles on reliability for structures, International Organization for Standardization, ISO, Geneva, 1998.

[ISO/FDIS 2394 2014] ISO/FDIS 2394:2014, General principles on reliability for structures, Fourth edition, International Organization for Standardization, ISO, Geneva, 2014.

[ISO 13824 2009] ISO 13824:2009, Bases for design of structures - General principles on risk assessment of systems involving structures, International Organization for Standardization, ISO, Geneva, 2009.

[JCSS 2000] JCSS, Probabilistic assessment of existing structures, Editor: Diamantidis, D., A publication by The Joint Committee on Structural Safety, RILEM Publications S. A. R. L., 162 pages, Cachan, 2000, ISBN 2-912143-24-1.

[JCSS 2001] JCSS, Probabilistic Model Code, Joint Committee on Structural Safety, 2001.

[JCSS 2008] JCSS, Risk assessment in engineering - Principles, system representation and risk criteria, Joint Committee on Structural Safety, 2008.

[Jiménez Losada 2005] Jiménez Losada, E., Análisis de riesgos aplicado a las estructuras de edificación. Estudio de las consecuencias en el ámbito jurídico, Proyecto FOM-741, Ministerio de Fomento, Madrid, 2005.

[JRC 2015] Joint Research Centre, JRC Science and Policy Report - New European technical rules for the assessment and retrofitting of existing structures, European Commission, Joint Research Centre, Institute for the Protection and Security of the Citizen, JRC, Ispra, 2015, ISBN 978-92-79-46022-7 (Print), 978-92-79-46023-4 (PDF), ISSN 1018-5593 (Print), 18319424 (Online), doi: 10.2788/052881.

[Kroon 2008] Kroon, I. B. and Maes, M. A., Theoretical framework for risk assessment and evaluation, Background documents on risk assessment in engineering, Joint Committee on Structural Safety, JCSS, Zürich, 2008, www.jcss.ethz.ch.

[L’Hostis 2007] L’Hostis, V., Benchmark des poutres de la Rance, Revue européenne de génie civil, Volume 11, No. 1-2, Paris, 2007, ISBN 978-2-7462-1676-1.

[Matousek 1976] Matousek, M. und Schneider, J., Untersuchungen zur Struktur des Sicherheitsproblems bei Bauwerken, Institut für Baustatik und Konstruktion der ETH Zürich, Bericht No 59, ETH Zürich, 1976.

[Mayer 1926] Mayer, M., Die Sicherheit der Bauwerke und ihre Berechnung nach Grenzkräften anstatt nach zulässigen Spannungen, Verlag von J. Springer, Berlin, 1926.

[MEC 1991] Ministerio de Educación y Ciencia, Orden de 4 de noviembre de 1991, por la que se aprueban los programas de necesidades para la redacción de los proyectos de construcción de centros de educación infantil, educación primaria, educación infantil y primaría, educación secundaria obligatoria y educación secundaria completa, Boletín Oficial del Estado, BOE 271, Madrid, 1991.

[MFOM 2008] Ministerio de Fomento, MFOM, Madrid, 2008, www.fomento.es.

[Melchers 1987] Melchers, R. E., Structural reliability - Analysis and prediction, Ellis Horwood Series in Civil Engineering, Ellis Horwood Ltd., Chichester, 1987, ISBN 0-85312-930-4.

[Morata 2004a] Morata, A., Tanner, P. y Almarza, C., Evaluación de extremos meteorológicos aplicados al Código Técnico de la Edificación, Dirección General del Instituto Nacional de 
Meteorología, Ministerio de Medio Ambiente, Nota técnica, Madrid, 2004, ISBN 84-8320273-5, 43 páginas.

[Morata 2004b] Morata, A., Tanner, P., Luna, Y. y Almarza, C., Sobrecarga de nieve máxima sobre una superficie horizontal: Diferencias regionales en España, El clima, entre el mar y la montaña, Santander, 2004, ISBN 84-8102-384-1, pp. 85-94.

[Muttoni 1997] Muttoni, A., Schwartz, J. and Thürlimann, B., Design of concrete structures with stress fields, Birkhäuser Verlag, Berlin, 1997, ISBN 3-7643-5491-7.

[Muttoni 2011] Muttoni, A., Fernández Ruiz, M. et Kostic, N., Champs de contraintes et méthode des bielles-et-tirants, Laboratoire de construction en béton, IBETON-ENAC, École Polytechnique Fédérale de Lausanne, EPFL, Lausanne, 2011, ISBN 978-2-8399-0829-0.

[Nathwani 1997] Nathwani, J. S., Lind, N. C., Randey, M. D., Affordable safety by choice: the life quality method, Institute for Risk Research, University of Waterloo, Waterloo, Canada, 1997.

[ONU 1948] DUDH, Declaración Universal de Derechos Humanos, Organización de las Naciones Unidas (ONU), Paris, 1948, www.un.org/es/documents/udhr.

[Portilla 2001] Portilla, M., et al., Manual práctico del paquete estadístico SPSS9 para Windows, Universidad Pública de Navarra, 2001, ISBN 9-788495-075703.

[Prieto 2013] Prieto, M., Tanner, P., Andrade, C. and Fernández, M., Experimental and numerical study of bond response in structural concrete with corroded steel bars, IABSE Conference on Assessment, upgrading and refurbishment of infrastructures, Rotterdam, 2013, ISBN 978-385748-123-9.

[Prieto 2014] Prieto, M., Estudio de la adherencia de armaduras corroídas y su influencia en la capacidad resistente de elementos de hormigón armado, Tesis Doctoral, Universidad Politécnica de Madrid, Madrid, 2014.

[Rackwitz 1977] Rackwitz, R., First order reliability theories and stochastic models, ICOSSAR 77, Proceedings, TU München, 1977.

[Rackwitz 1999] Rackwitz, R., Optimization - The basis of code making and reliability verification, Structural Safety, Elsevier Science Ltd., 1999.

[Rackwitz 2002] Rackwitz, R. and Streicher, H., Optimization and target reliabilities, Workshop on reliability based code calibration, Joint Committee on Structural Safety, JCSS, Zürich, 2002, http://www.jcss.ethz.ch.

[Rackwitz 2006] Rackwitz, R., Zuverlässigkeit und Lasten im konstruktiven Ingenieurbau - Teil 1: Zuverlässigkeitstheoretische Grundlagen, Technische Universität München, 2006.

[Reid 2002] Reid, S. G., Acceptable risk criteria, Progress in Structural Engineering and Materials, Vol. 2, pp. 254-262, John Wiley and Sons, 2002.

[Rodríguez 1995] Rodríguez, J., Ortega, L. M. and Casal, J., Relation between corrosion and load bearing capacity on concrete beams, Brite Euram Project BREU-CT-0591, 1995.

[SAKO 1999] SAKO Joint Nordic Group for Structural Matters, Basis of design of structures Proposals for modification of partial safety factors in Eurocodes, Nordic Committee on Building Regulations (NKB) and Nordic Standardization in the Construction Field (INSTAB), NKB Committee and Work Reports 1999:01 E, Oslo, 1999, ISBN 91-7147-547-8. 
[Schneider 1994] Schneider, J., Sicherheit und Zuverlässigkeit im Bauwesen - Grundwissen für Ingenieure, Verlag der Fachvereine AG, Zürich und Teubner Verlag, Stuttgart, 1994, ISBN 3519-05040-4 (Teubner).

[Schneider 1997] Schneider, J., Introduction to safety and reliability of structures, Structural Engineering Documents, $\mathrm{N}^{\circ}$ 5, International Association for Bridge and Structural Engineering, IABSE, Zürich, 1997.

[SIA 269 2011] SIA 269, Grundlagen zur Erhaltung von Tragwerken, Schweizerischer Ingenieurund Architektenverein, SIA, Zürich, 2011.

[Steenbergen 2010] Steenbergen, R. D. J. M. and Vrouwenvelder, A. C. W. M., Safety philosophy for existing structures and partial factors for traffic loads on bridges, Heron 55, № 2, 2010.

[Steenbergen 2015] Steenbergen, R. D. J. M., Sykora, M., Diamantidis, D., Holicky, M. and Vrouwenvelder, A. C. W. M., Economic and human safety reliability levels for existing structures, Structural Concrete, Vol. 16, Issue 3, pp. 323-332, 2015, doi: 10.1002/suco.201500022.

[Sykora 2013] Sykora, M. and Holicky, M., Target reliability levels for the assessment of existing structures, Vocational Training in Assessment of Existing Structures, Project N ${ }^{\circ}$ CZ/11/LLPLdV/TOI/134005, 2013, http://www.leonardo.cvut.cz/download/target-reliabilities_2.pdf.

[Sykora 2014] Sykora, M., Holicky, M., Prieto, M. and Tanner, P., Uncertainties in resistance models for sound and corrosion-damaged RC structures according to EN 1992-1-1, Materials and structures, Vol. 48, Issue 10, pp. 3415-3430, 2015, ISSN 1359-5997 (Print), 1871-6873 (Online), 2014, doi: 10.1617/s11527-014-0409-1.

[Tanner 1999] Tanner, P., Análisis de riesgos y planificación de medidas, Hormigón y Acero, $\mathrm{n}^{\circ}$ 210, pp. 109-124, Madrid, 1999, ISSN: 0439-5689.

[Tanner 2001] Tanner, P. and Gutiérrez, J. P., Reliability-based expertise for the establishment of public liabilities, Safety, risk and reliability - Trends in Engineering, International Association for Bridge and Structural Engineering, Zürich, 2001, ISBN 3-85748-102-4.

[Tanner 2002] Tanner, P., Structural behaviour and code calibration. Composite bridges, Workshop on reliability based code calibration, JCSS, Joint Committee on Structural Safety, ETH Zürich, 2002, http://www.jcss.ethz.ch.

[Tanner 2005] Tanner, P., La adopción de decisiones en ingeniería. Un proceso no tan racional, III Congreso de ACHE, Comunicaciones, vol. 3, Madrid, 2005, ISBN 84-89670-53-6.

[Tanner 2006] Tanner, P., Safety and reliability in structural engineering. Implicit vs. explicit approaches, Concrete Solutions 2006, $2^{\text {nd }}$ International Conference on Concrete Repair, Saint Malo, 2006, ISBN 1-86081-915-X, pp. 767 - 774.

[Tanner 2007a] Tanner, P. and Arteaga, A., Structural safety requirements based on notional risks associated with current practice, Special Workshop on Risk Acceptance and Risk Communication, ASCE - JCSS - John A. Blume Earthquake Engineering Center, Stanford University, Stanford, 2007, http://www.ripid.ethz.ch.

[Tanner 2007b] Tanner, P., Lara, C. y Hingorani, R., Seguridad estructural. Una lucha con incertidumbres, Hormigón y Acero, nº 245, Madrid, 2007, ISSN: 0439-5689.

[Tanner 2008] Tanner, P., Development of risk acceptance criteria for the design of steel structures, Eurosteel 2008, ECCS, Brussels, 2008, ISBN 92-0147-000-90. 
[Tanner 2009] Tanner, P., Instrucción de Estructuras de Acero, EAE. Deducción de un requisito cuantitativo para la reducción del coeficiente parcial para la resistencia a un valor de $\gamma_{M 0}=$ 1,0”, Estudio realizado por encargo de la Secretaría General Técnica del Ministerio de Fomento, IETcc-CSIC, Madrid, 2009.

[Tanner 2010] Tanner, P. and Hingorani, R., Development of risk-based requirements for structural safety, Joint IABSE - fib conference on codes in structural engineering, International Association for Bridge and Structural Engineering, Zürich, 2010, ISBN 978-953-7621-05-6.

[Tanner 2011a] Tanner, P., Lara, C. and Prieto, M., Semi-probabilistic models for the assessment of existing concrete structures, Applications of Statistics and Probability in Civil Engineering, ICASP 11, pp. 1039-1047, Taylor \& Francis Group, London, 2011, ISBN 978-0-415-66986-3.

[Tanner 2011b] Tanner, P., Lara, C. y Morata, A., Modelado de fenómenos meteorológicos extremos a efectos del análisis estructural, V Congreso de ACHE, Comunicaciones, Madrid, 2011, ISBN 978-84-89670-73-0.

[Tanner 2013a] Tanner, P. and Hingorani, R., Collapse of the River Verde viaduct scaffolding system, IABSE Workshop on Safety, failures and robustness of large structures, Workshop report, pp. 162-169, International Association for Bridge and Structural Engineering, Zürich, 2013, ISBN 978-3-85748-130-7, http://dx.doi.org/10.2749/222137813807018890.

[Tanner 2013b] Tanner, P., Bellod, J. L., Sanz, D. and Hingorani, R., Lessons from incidents attributable to the uncertainties in bridge launching illustrated by a case study, Civil Engineering and Environmental Systems, Vol. 30, No. 2, pp. 146-161, 2013, doi: 10.1080/10286608.2012.733376.

[Tanner 2015] Tanner, P. and Hingorani, R., Acceptable risks to persons associated with building structures, Structural Concrete, Vol. 16, Issue 3, pp. 314-322, 2015, doi: 10.1002/suco.201500012.

[Thoft-Christensen 1982] Thoft-Christensen, P. and Baker, M., Structural reliability and its applications, Springer Verlag, Berlin, 1982.

[Torroja 1957] Torroja, E. y Páez, A., La determinación del coeficiente de seguridad de las distintas obras, Instituto de la construcción y del cemento, Madrid, 1957.

[Turkstra 1972] Turkstra, C. J., Theory of structural design decisions, Solid Mechanics Division, Study $N^{\circ}$ 2, University of Waterloo, Ontario, Canada, 1972.

[VaP 3.0 2010] VaP 3.0, Variables Processor - User Manual, PSP, Feldkirchen (Austria), 2010.

[Vrijling 2005] Vrijling, J. K., van Gelder, P. H. A. J. M. and Ouwerkerk, S. J., Criteria for acceptable risk in the Netherlands, Infrastructure Risk Management Processes, pp. 143-157, 2005, doi: 10.1061/9780784408155.ch05.

[Vrouwenvelder 2011] Vrouwenvelder, T. and Scholten, N., Assessment criteria for existing structures, Structural Engineering International, Vol. 21, International Association for Bridge and Structural Engineering, Zürich, 2011. 